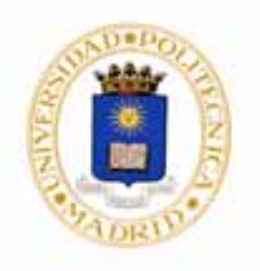

Universidad Politécnica de Madrid

Escuela Técnica Superior de Ingeniería y Sistemas de Telecomunicación

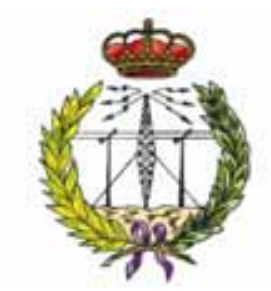

\title{
VALIDACIÓN DE HP UV-LED PARA LA DETECCIÓN EN CONTINUO DE CONTAMINANTES EN AGUAS CONTINENTALES MEDIANTE FLUORESCENCIA
}

\section{Tesis Doctoral}

Francisco José Arqués Orobón

Ingeniero Electrónico

2016 

Departamento de Teoría de la Señal y Comunicaciones

Departamento de Electrónica Física

Escuela Técnica Superior de Ingeniería y Sistemas de Telecomunicación

Universidad Politécnica de Madrid
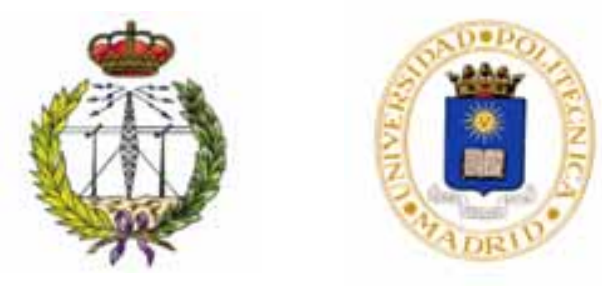

\title{
Validación de HP UV-LED para la detección en continuo de contaminantes en aguas continentales mediante fluorescencia
}

\author{
Francisco José Arqués Orobón \\ Ingeniero Electrónico
}

\author{
Directores: \\ Vicente González Posadas \\ Doctor Ingeniero de Telecomunicación \\ Neftalí Núñez Mendoza \\ Doctor por la Universidad Politécnica de Madrid
}



Tesis doctoral: Validación de HP UV-LED para la detección en continuo de contaminantes en aguas continentales mediante fluorescencia.
Autor:
F. José Arqués Orobón
Directores: Prof. Dr. Vicente González Posadas
Prof. Dr. Neftalí Núñez Mendoza

El Tribunal nombrado por el Mgfco. y Exmo. Sr. Rector de la Universidad Politécnica de Madrid, el día de de , para juzgar la Tesis arriba indicada, compuesto por los siguientes doctores:

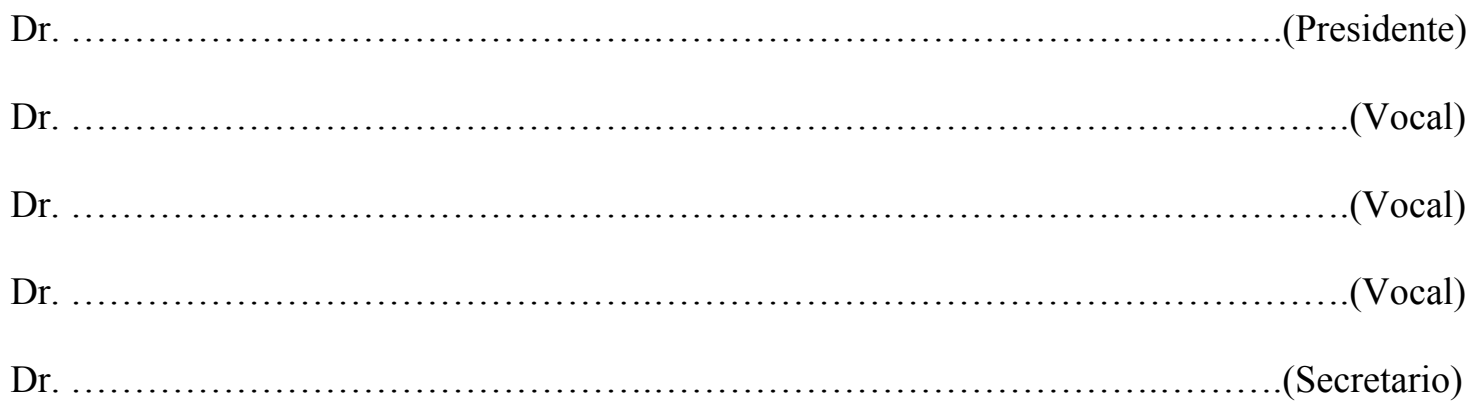

Realizado el acto de lectura y defensa de la Tesis día ............ de de en acuerda otorgarle la calificación de:

El Presidente:

El Secretario:

Los Vocales: 

"Nunca podrá cruzar el océano a menos que tenga el coraje de perder de vista la costa."

Cristóbal Colón 



\section{Índice}

1 Introducción y objetivos de la tesis......................................................................................... 1

1.1 Evolución de los LEDs en el rango ultravioleta.................................................................. 3

1.2 Objetivos de la Tesis ................................................................................................................ 4

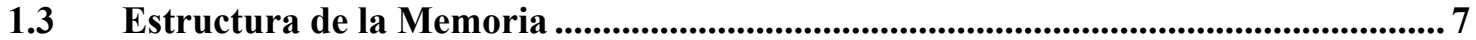

2 Estado del Arte en control de calidad del agua y detección de contaminantes..............9

2.1 El control de calidad el agua mediante estaciones automáticas ................................9

2.2 Estaciones Automáticas de Alerta en España ...................................................10

2.2.1 Descripción de los trabajos de mantenimiento de estaciones automáticas.................. 11

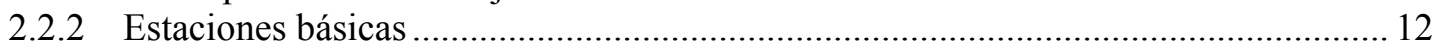

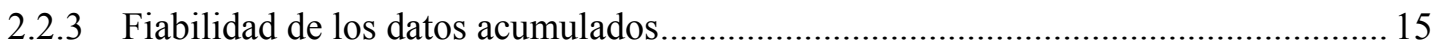

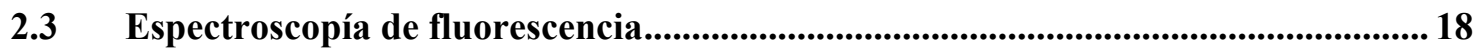

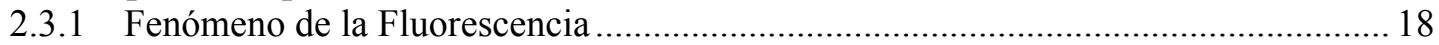

2.4 Los hidrocarburos como contaminantes........................................................................ 21

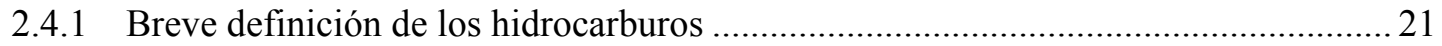

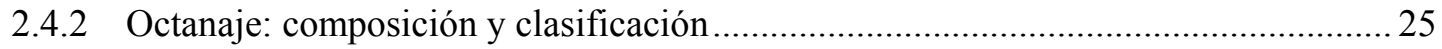

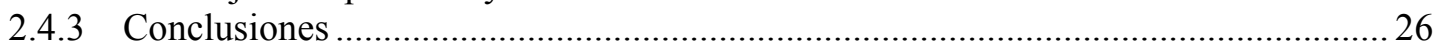

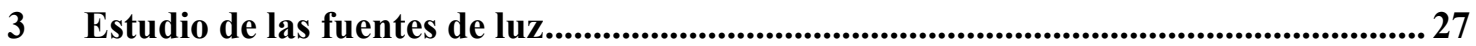

3.1 Fuentes de luz en espectroscopía de fluorescencia ..................................................... 27

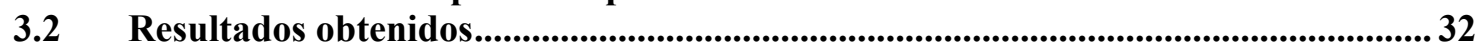

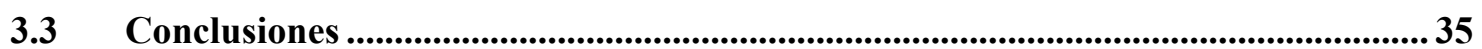

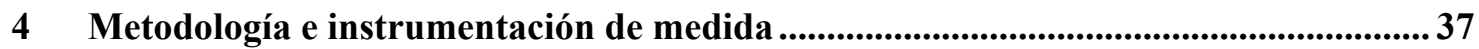

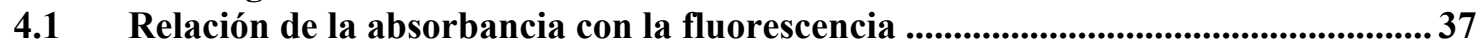

4.2 Instrumentación convencional en espectroscopía .................................................... 41

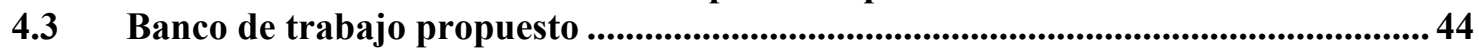

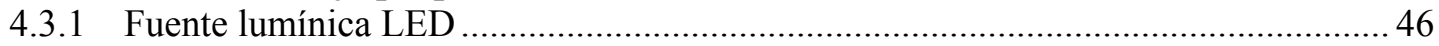

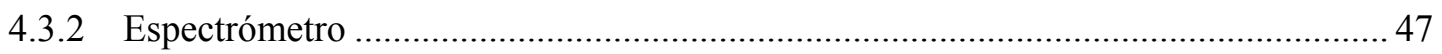

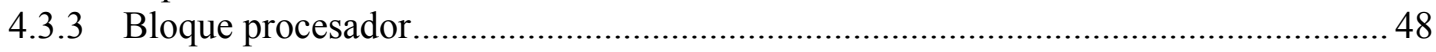

5 Análisis del espectro de fluorescencia de los hidrocarburos .....................................51

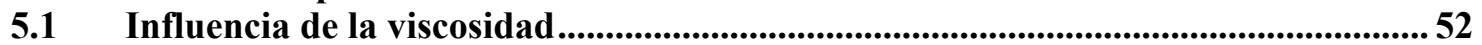

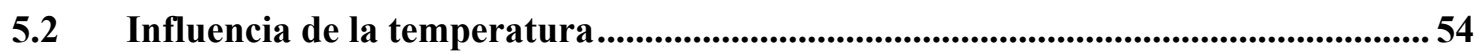

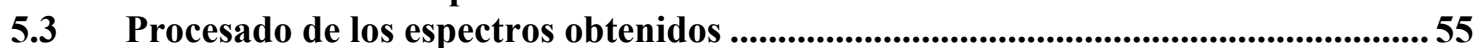

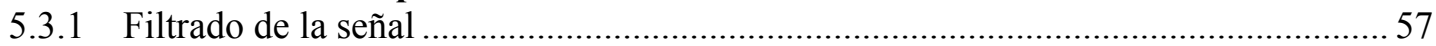

5.3.2 Descomposición de las respuestas en funciones gaussianas y su análisis................... 61

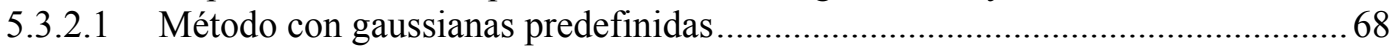

5.3.2.2 Método de ajuste de gaussianas mediante iteraciones........................................ 70

$5.4 \quad$ Estudio de la fluorescencia en función de la corriente LED. ................................... 85

5.5 Obtención de plantillas de los hidrocarburos ..............................................................95

5.5.1 Método de obtención de huellas particulares de cada compuesto ..............................96

5.5.2 Método de obtención de huellas común para todos los compuestos............................ 98

5.5.3 Método de obtención de huellas con lorentzianas.................................................... 100

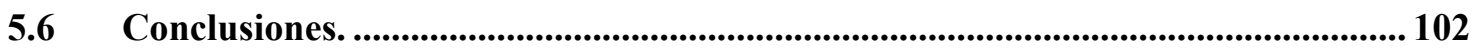


6 Análisis funcional a largo plazo de los LEDs...................................................................... 105

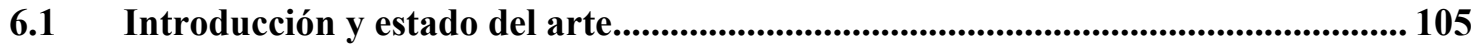

6.2 Bases teóricas de la fiabilidad y los ensayos de vida acelerada ................................. 107

6.3 Metodología, planificación e instrumentación de ensayos........................................... 116

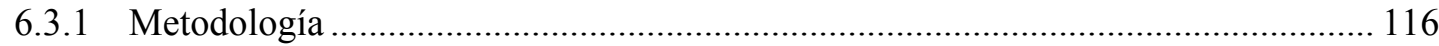

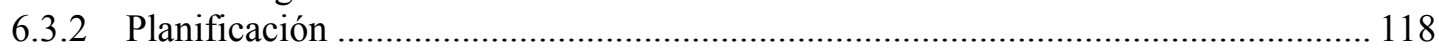

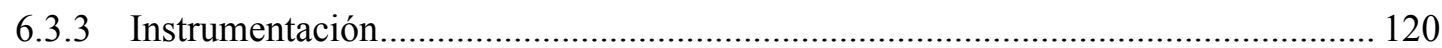

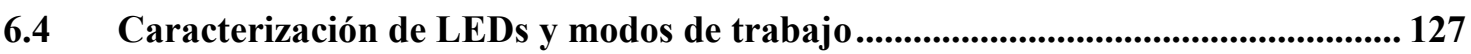

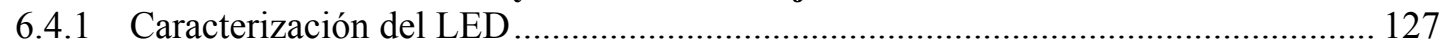

6.4.2 Caracterización del LED en convección natural: temperatura .................................. 133

6.4.3 Caracterización del LED en convección natural: potencia óptica............................. 134

6.4.4 Caracterización del LED en convección natural: circuito térmico ........................... 137

6.4.5 Caracterización del LED en convección forzada: temperatura y potencia óptica.... 138

6.5 Resultados de los ensayos acelerados ............................................................................. 141

6.6 Evaluación de parámetros de fiabilidad a $25^{\circ} \mathrm{C}$ : esperanza de vida (MTTF) ...... 148

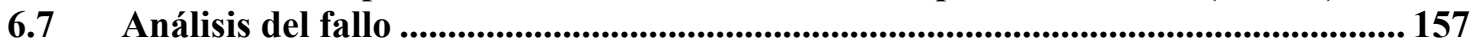

6.7.1 Identificación de fallos por degradación del encapsulado ........................................ 159

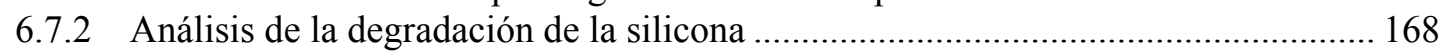

6.7.3 Análisis de la degradación del semiconductor ..................................................... 175

6.8 Discusión y conclusiones.................................................................................................... 178

7 Comunicación con Metamateriales ............................................................................... 183

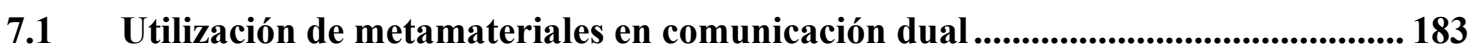

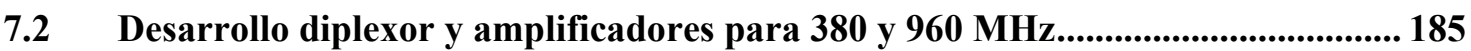

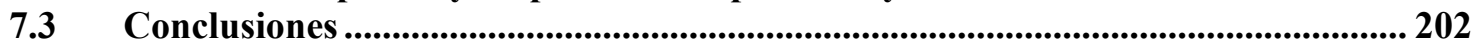

8 Conclusiones y trabajos futuros........................................................................................ 203

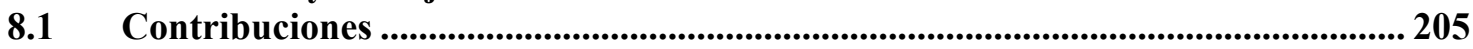

8.2 Trabajos futuros...................................................................................................................... 207

8.3 Publicaciones y contribuciones a congresos................................................................... 208

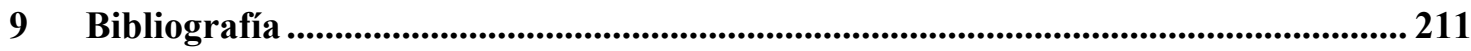

10 Anexo: Estudio de la fiabilidad de los datos en sistemas automáticos ........................ 221

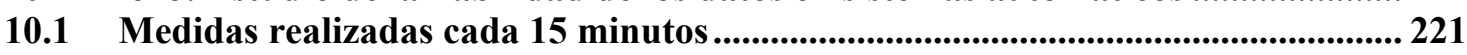

10.1.1 Medida de temperatura: 1 muestra cada 15 minutos................................................ 222

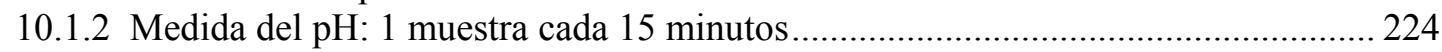

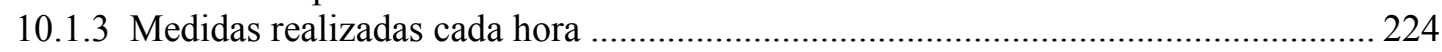

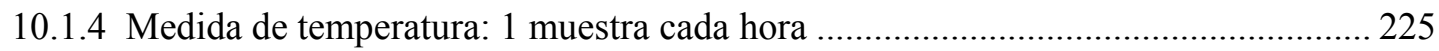

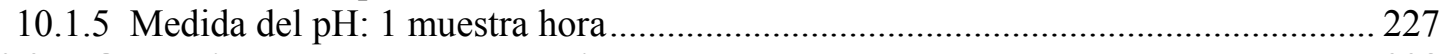

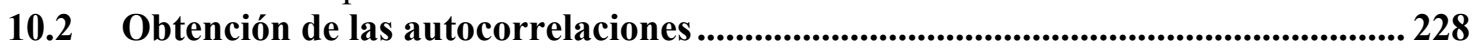

11 Anexo: Espectros de Fluorescencia obtenidos................................................................... 231

12 Anexo: Ajuste de gaussianas obtenido con los programas Origin y Fytik................ 235 


\section{Lista de figuras}

Figura 1-1: Distribución de energía espectral de LEDs UV, diferente de la de las lámparas de mercurio. Fuente: LEDs Magazine. 11 marzo 2014 .......................................................... 3

Figura 1-2: Longitudes de onda de emisión de Lámparas de gas Hg (a) y UV-LED (b).

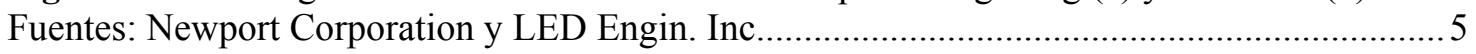

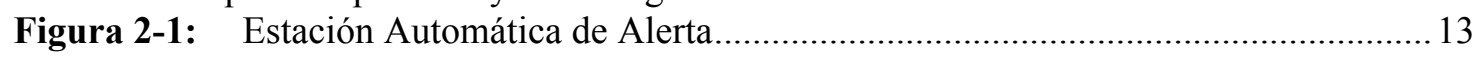

Figura 2-2: Esquema de una Estación Automática de Alerta. ............................................ 14

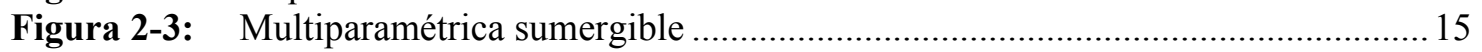

Figura 2-4: Vista del panel con sensores. Arriba bloque procesador, en el centro línea de

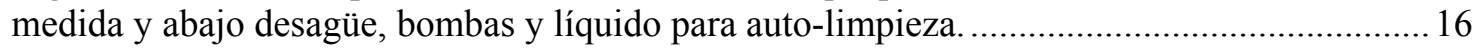

Figura 2-5: Fluorescencia de gasóleo C producida por LED ultravioleta de $365 \mathrm{~nm}$............. 21

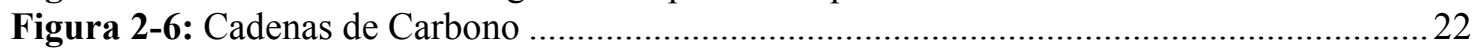

Figura 2-7: Obtención de Hidrocarburos por método de destilación ......................................23

Figura 2-8: Algunas de las cadenas Carbono-Hidrógeno derivados del petróleo........................23

Figura 3-1: Dispositivo desarrollado para la detección de crudo en agua marina. ................27

Figura 3-2: Fuentes de luz utilizadas en instrumentación de laboratorio................................29

Figura 3-3: Bombilla de gas de mercurio a $365 \mathrm{~nm}$ con casquillo E46 utilizada para el

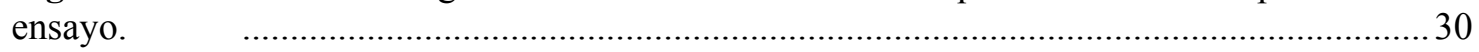

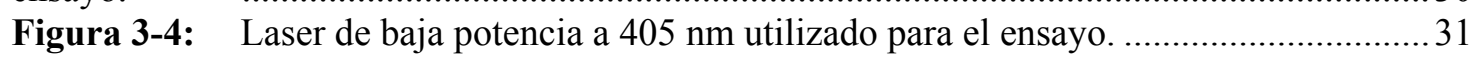

Figura 3-5: LED a $365 \mathrm{~nm}$ utilizado para el ensayo ............................................................. 31

Figura 3-6: Preparación de los recipientes contenedores de las muestras de hidrocarburos. 32

Figura 3-7: Distintos hidrocarburos en recipientes con agua destilada................................. 33

Figura 4-1: $\quad$ Espectrofotómetro Merck SpectroQuant ${ }^{\circledR}$ Pharo .............................................. 38

Figura 4-2: Absorbancia de Diesel A: Respuesta en amplio ancho de banda (a) y detalle de las longitudes de onda relevantes (b). La línea roja indica la longitud de onda de la fuente..... 38

Figura 4-3: $\quad$ Espectrómetro Perkin Elmer ${ }^{\circledR}$ Lambda 25 utilizado en las medidas de

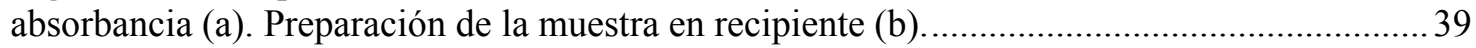

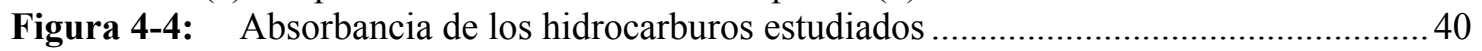

Figura 4-5: Comparativa Absorbancia vs. Fluorescencia de distintos hidrocarburos ............ 41

Figura 4-6: Instrumentación para detección de Hidrocarburos: (a) ICP. (b) FID ...................42

Figura 4-7: Diagrama de Bloques de un espectrofotómetro de doble haz clásico .................. 43

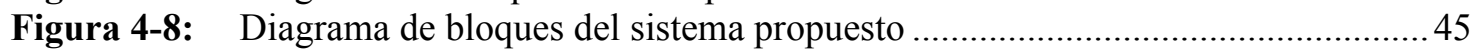

Figura 4-9: LEDs utilizados en los ensayos: (a) Tipo A y (b) Tipo B ....................................46

Figura 4-10: Conexionado LEDs utilizados en los ensayos: (a) Tipo A y (b) Tipo B ........ 47

Figura 4-11: Espectrómetros utilizados en medidas y desarrollo. ................................................. 48

Figura 4-12: Imagen del programa desarrollado para los ensayos...........................................5 50

Figura 5-1: Medidas de viscosidad de los gasóleos estudiados ...............................................53

Figura 5-2: Medidas de viscosidad de aceites motor. Fuente: Wildman International SRL.

http://www.widman.biz/boletines/95.html ............................................................................5

Figura 5-3: Resultados de fluorescencias a diferentes temperaturas con fuente LED a 365nm.

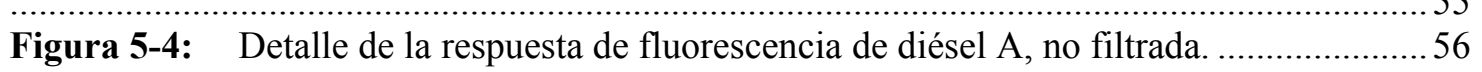

Figura 5-5: Señal original con picos (negro) y señal filtrada mediante filtrado mediana..... 58

Figura 5-6: Respuesta de diésel A (negro) y filtrada con filtrado mediana. ...........................58 
Figura 5-7: Detalle de la fluorescencia producida por gasoil tipo A, filtrado mediante

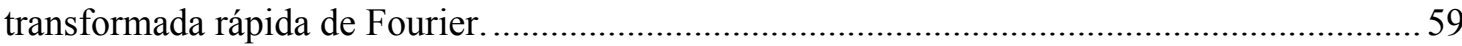

Figura 5-8: Detalle de la fluorescencia producida por gasoil tipo A, filtrado mediante filtro

Savitzky-Golay.

Figura 5-9: Comparativa de filtrado de la fluorescencia producida por gasoil tipo A........... 61

Figura 5-10: Representación del ajuste de un punto del espectro como suma de gaussianas

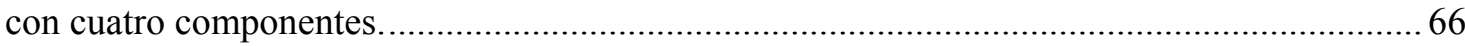

Figura 5-11: Gaussianas a prueba para modelar la respuesta del gasóleo A con 0.65A............69

Figura 5-12: Ajuste manual a 4 componentes para gasoil A@0.65A.......................................69

Figura 5-13: Picos obtenidos por el método de máximos locales (ventana de 2 puntos) para

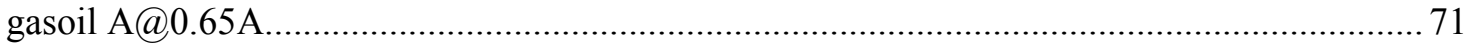

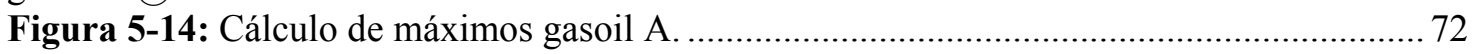

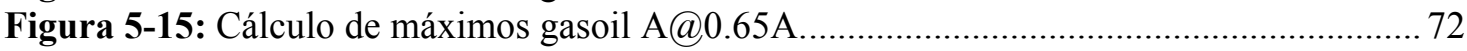

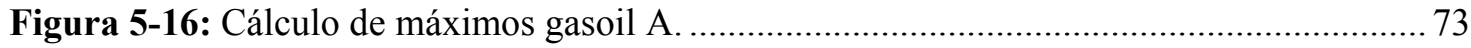

Figura 5-17: Cálculo de máximos gasolina98 @0.65A................................................................ 73

Figura 5-18: Cálculo de máximos gasolina 98 ...................................................................... 74

Figura 5-19: Cálculo de máximos gasoil A por el método de la derivada segunda sin post-

filtrado (a) y con post-filtrado (b). ................................................................................... 75

Figura 5-20: Cálculo de máximos por el método de la derivada segunda para el gasoil tipo A.

Figura 5-21: Cálculo de máximos por el método de la derivada segunda para el gasolina 95. 76

Figura 5-22: Ajuste con gaussianas del espectro de gasoil A con cftool de Matlab. ............... 77

Figura 5-23: Comparativa de ajuste con 4 y 6 gaussianas del espectro de gasoil A con cftool de

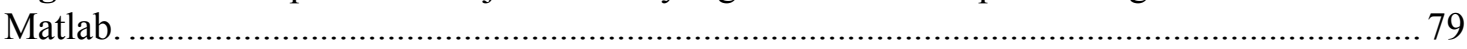

Figura 5-24: Comparativa del error del ajuste con 4 y 8 gaussianas del espectro de gasoil A

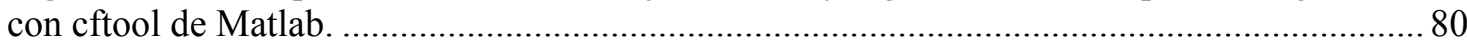

Figura 5-25: Ajuste mediante gaussianas con el programa Fityk ......................................... 83

Figura 5-26: Espectros emitidos por gasóleo A con iluminación de LED de 365nm con

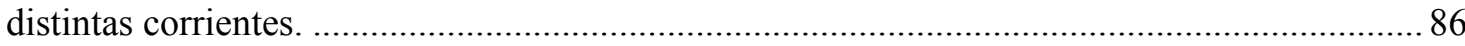

Figura 5-27: Espectros emitidos por gasóleo A con iluminación de LED de 365nm con

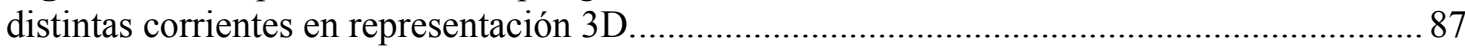

Figura 5-28: Descomposición en gaussianas del espectro emitido por gasóleo A con $650 \mathrm{~mA}$

Figura 5-29: Espectros emitidos por gasóleo A plus con iluminación de LED de 365nm con

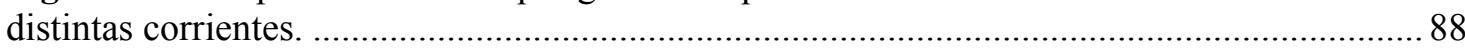

Figura 5-30: Espectros emitidos por gasóleo A+ con iluminación de LED de 365nm con

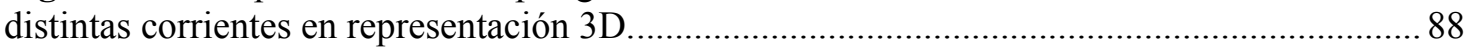

Figura 5-31: Descomposición en gaussianas para el espectro emitido con $650 \mathrm{~mA}$ para gasóleo

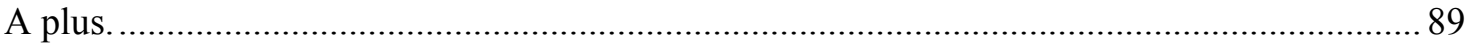

Figura 5-32: Espectros emitidos por gasóleo B con iluminación de LED de 365nm con

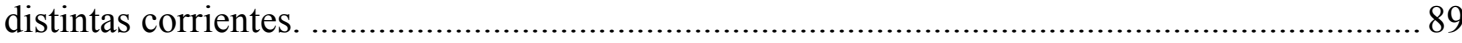

Figura 5-33: Espectros emitidos por gasóleo B con iluminación de LED de 365nm con

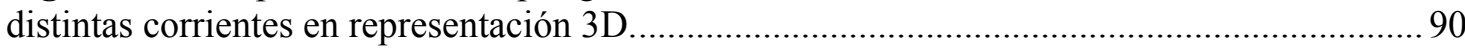
Figura 5-34: Descomposición en gaussianas para el espectro emitido con $650 \mathrm{~mA}$ para gasóleo

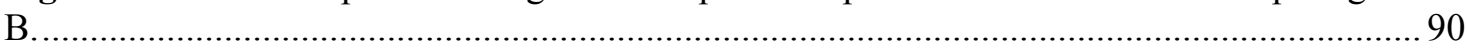

Figura 5-35: Espectros emitidos por gasóleo C con iluminación de LED de 365nm con

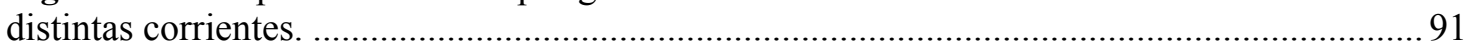

Figura 5-36: Espectros emitidos por gasóleo C con iluminación de LED de 365nm con

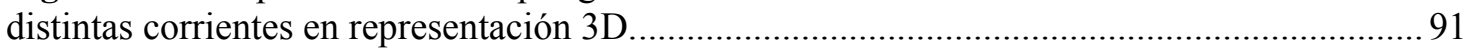
Figura 5-37: Descomposición en gaussianas para el espectro emitido con $650 \mathrm{~mA}$ para gasóleo

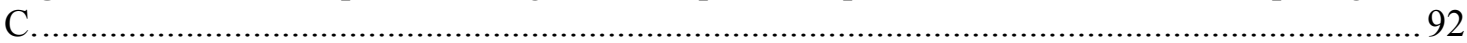

Figura 5-38: Espectros emitidos por gasolina 95 con iluminación de LED de 365nm con

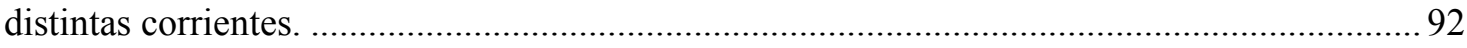


Figura 5-39: Espectros emitidos por gasolina 95 con iluminación de LED de 365nm con distintas corrientes en representación 3D......

Figura 5-40: Descomposición en gaussianas para el espectro emitido con $650 \mathrm{~mA}$ para gasolina 95 .

Figura 5-41: Espectros emitidos por gasolina 98 con iluminación de LED de 365nm con distintas corrientes...

Figura 5-42: Espectros emitidos por gasolina 98 con iluminación de LED de 365nm con distintas corrientes en representación 3D.

Figura 5-43: Descomposición en gaussianas para el espectro emitido con $650 \mathrm{~mA}$ para gasolina 98.

Figura 5-44: Plantilla de diagrama caja-bigotes obtenida para identificación de Diésel A......96

Figura 5-45: Plantilla de diagrama caja-bigotes obtenida para identificación de Diésel A con los demás hidrocarburos superpuestos

Figura 5-46: Plantilla de diagrama caja-bigotes obtenida para identificación de gasolina 95 con los demás hidrocarburos superpuestos...

Figura 5-47: Plantilla a partir de la cual se obtienen los ajustes con gaussianas con los demás

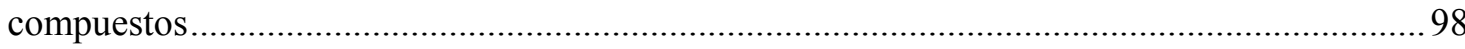

Figura 5-48: Plantilla de diagrama caja-bigotes obtenida para identificación de Gasóleo A con

los demás hidrocarburos superpuestos....

Figura 5-49: Plantilla de diagrama caja-bigotes obtenida para identificación de Gasolina 95

con los demás hidrocarburos superpuestos

Figura 5-50: Comparativa de las funciones gaussiana y lorentziana. Fuente:

http://ppenteado.net/idl/pp_lib/doc/pp_lorentz_from_fwhm.html.

Figura 5-51: Plantilla de diagrama caja-bigotes con plantilla común para identificación de Gasóleo A con los demás hidrocarburos superpuestos .

Figura 5-52: Plantilla de diagrama caja-bigotes con plantilla común para identificación de Gasolina 95 con los demás hidrocarburos superpuestos

Figura 6-1: Evolución de la tasa de fallos de los dispositivos semiconductores. Tomada y traducida de [O'Con12].

Figura 6-2: Gráficas de la función densidad, fiabilidad, y tasa instantánea de fallos de la

función de Weibull. Tomada de la Figura 5.3.1 del [MHDBK98].....

Figura 6-3: Flujograma del plan de ensayos acelerados en temperatura. ................................ 119

Figura 6-4: Flujograma del análisis de resultados de los ensayos acelerados. ........................ 120

Figura 6-5: LEDs dentro de la caja preparados para el ensayo............................................. 121

Figura 6-6: Circuito de 8 LEDs ensayados en una de las estufas antes de cerrar la caja........ 122

Figura 6-7: Instrumentación de ensayos acelerados en el centro, dos estufas a ambos lados, y

una tercera estufa en la parte inferior izquierda.

Figura 6-8: Estructura de la instrumentación.

Figura 6-9: Estructura de la instrumentación para la medida de la temperatura de la unión del LED durante los dos modos de trabajo, y para caracterización de curva I-V.

Figura 6-10: Sistema de instrumentación segundo midiendo la curva I-V de un LED, también

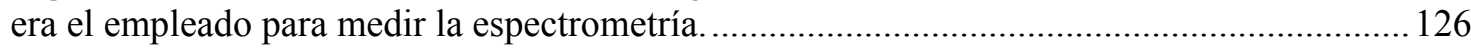

Figura 6-11: Sistema de medida de potencia óptica del LED, a la distancia real de uso, $8 \mathrm{~cm}$.

Figura 6-12: Curvas I-V de los LEDs tipo A y B.

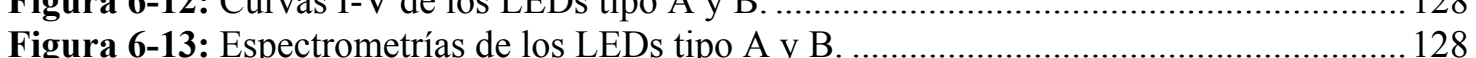

Figura 6-14: Foto real del LED, incluye circuito MCPCB, y el LED montado sobre el

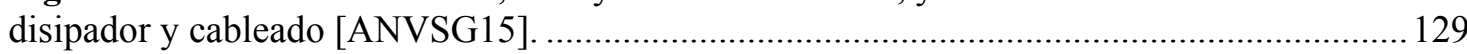

Figura 6-15: Encapsulado del LED con circuito MCPCB y disipador [ANVSG15].............. 130

Figura 6-16: Evolución desde el encendido de la temperatura del LED tipo B en continua, y en

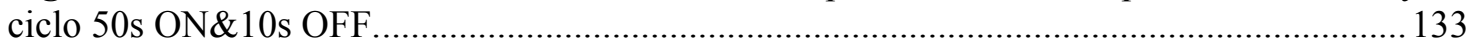

Figura 6-17: Evolución desde el encendido de la temperatura del LED tipo A en continua, y de

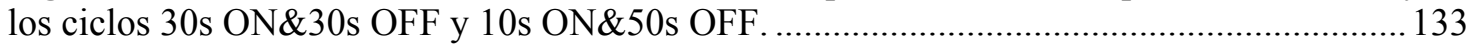

Figura 6-18: Evolución desde el encendido de la temperatura del LED tipo A en continua, y de los ciclos 30s ON\&30s OFF y 10s ON\&50s OFF. [ANVSG15] .......................................... 134 
Figura 6-19: Evolución desde el encendido de la potencia óptica emitida del LED tipo A en continua, y de los ciclos 30 s ON\&30s OFF y 10 s ON\&50s OFF.

Figura 6-20: Evolución desde el encendido de la potencia óptica emitida del LED tipo B en continua, y de los ciclos 30s ON\&30s OFF y 10s ON\&50s OFF. [ANVSG15] ..................... 135 Figura 6-21: Detalle de evolución en funcionamiento estable de la potencia óptica emitida del LED tipo A en continua, y de los ciclos 30s ON\&30s OFF y 10s ON\&50s OFF..... 135 Figura 6-22: Detalle de evolución en funcionamiento estable de la potencia óptica emitida del LED tipo B en continua, y de los ciclos 30s ON\&30s OFF y 10s ON\&50s OFF. [ANVSG15]

Figura 6-23: Temperatura en la unión experimental (línea discontinua) y simulación PSPICE (línea continua) para la condición de trabajo 30s ON\& 30s OFF en LED tipo B. [ANVSG15]

Figura 6-24: Evolución de la temperatura del LED tipo A en continua, y de los ciclos 30s ON\&30s OFF y 10 s ON\&50s OFF. C. forzada.

Figura 6-25: Evolución de la potencia óptica emitida del LED tipo A en continua, y de los ciclos 30 s ON\&30s OFF y 10 s ON\&50s OFF. C. forzada.

Figura 6-26: Detalle de evolución en funcionamiento estable de la potencia óptica emitida del LED tipo A en continua, y de los ciclos 30s ON\&30s OFF y 10s ON\&50s OFF.C. forzada. 140 Figura 6-27: Espectro de un LED funcionando en modo cíclico en diferentes estados del ensayo de vida acelerado a $90^{\circ} \mathrm{C}$

Figura 6-28: Evolución de la potencia óptica relativa de los LEDs tipo A sometidos a ensayo de vida acelerada a $60^{\circ} \mathrm{C}$. La letra final de la caja de títulos es $\mathrm{C}$ para la condición de trabajo continuo y CL para la condición de trabajo cíclico.

Figura 6-29: Evolución de la potencia óptica relativa de los LEDs tipo B sometidos a ensayo de vida acelerada a $60^{\circ} \mathrm{C}$. La letra final de la caja de títulos es $\mathrm{C}$ para la condición de trabajo continuo y CL para la condición de trabajo cíclico.

Figura 6-30: Evolución de la potencia óptica relativa media de los LEDs tipo A sometidos a ensayos de vida acelerada. La letra final de la caja de títulos es $\mathrm{C}$ para la condición de trabajo continuo y CL para la condición de trabajo cíclico.

Figura 6-31: Evolución de la potencia óptica relativa media de los LEDs tipo B sometidos a ensayos de vida acelerada.

Figura 6-32: Gráfica de Weibull $\mathrm{F}(\mathrm{t})$ a $25^{\circ} \mathrm{C}$, probabilidad de fallo en función del tiempo de LEDs A. A la izquierda modo de trabajo continuo y a la derecha modo de trabajo cíclico. Los puntos son los instantes de fallo en cada temperatura de ensayo extrapolado mediante Arrhenius. (C significa funcionamiento continuo y CL funcionamiento cíclico)..................... 151 Figura 6-33: Función de vida respecto al estrés en temperatura, para LEDs tipo A ............... 153 Figura 6-34: Gráfica de Weibull $\mathrm{F}(\mathrm{t})$ a $25^{\circ} \mathrm{C}$, probabilidad de fallo en función del tiempo de LEDs B. A la izquierda modo de trabajo continuo y a la derecha modo de trabajo cíclico. Los puntos son los instantes de fallo en cada temperatura de ensayo extrapolado mediante Arrhenius. (C significa funconamiento continuo y $\mathrm{CL}$ funcionamiento cíclico).

Figura 6-35: Función de vida respecto al estrés en temperatura, para LEDs tipo B. (C significa funcionamiento continuo y CL funcionamiento cíclico)......................................................... 156

Figura 6-36: LED tipo A antes y al final del ensayo acelerado............................................. 160

Figura 6-37: LED tipo $B$ antes y al final del ensayo acelerado........................................... 160

Figura 6-38: Potencia de salida normalizada para los LEDs tipo B a $60^{\circ} \mathrm{C}$, y el "instante" de detección de la grieta en la silicona. (C significa funcionamiento continuo y CL

funcionamiento cíclico).

Figura 6-39: Detección del agrietamiento de la silicona para cada temperatura de ensayo, ambas condiciones de trabajo, y ambos tipos de LED.

Figura 6-40: Evolución de la degradación y de la curva I-V en los LEDs tipo A ensayados a $60{ }^{\circ} \mathrm{C}$, la $\mathrm{C}$ final del título significa trabajo continuo, y la CL trabajo cíclico.

Figura 6-41: Situación del encapsulado de los LEDs tipo A ensayados a $60^{\circ} \mathrm{C}$, al finalizar el ensayo 4020 horas.

Figura 6-42: Evolución de la curva I-V en los LEDs tipo B ensayados a $60{ }^{\circ} \mathrm{C}$, donde la $\mathrm{C}$

final del título significa trabajo continuo, y la CL trabajo cíclico. 
Figura 6-43: Situación del encapsulado de los LEDs tipo A ensayados a $60{ }^{\circ} \mathrm{C}$, al finalizar el ensayo 4020 horas.

Figura 6-44: $60^{\circ} \mathrm{C}$ en continua, parte superior LED tipo A, parte inferior LED tipo B de [ANVSG15].

Figura 6-45: Análisis térmico estático mediante $\mathrm{FEM}$ del UV-LED a $\mathrm{Ta}=25^{\circ} \mathrm{C}$, convección

natural, y funcionamiento continuo a $600 \mathrm{~mA}$. [ANVSG15]

Figura 6-46: Resultado del análisis de estrés estático mediante von Misses, para la silicona que

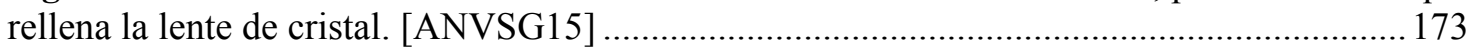
Figura 6-47: Tomada de [YSCQ+07], evolución de la curva I-V en un ensayo acelerado en temperatura de leds violeta (InGaN/GaN).

Figura 6-48: Tomada de [MK09], explicación de las zonas de la curva I-V, sobre los resultados de un ensayo acelerado.

Figura 6-49: Tomada de [MLPR+02], explicación de las zonas de la curva I-V, sobre los resultados de un ensayo acelerado.

Figura 7-1: Clasificación de los distintos tipos de materiales de acuerdo con los valores de permitividad y permeabilidad

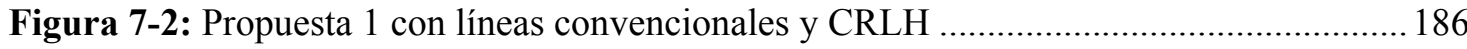

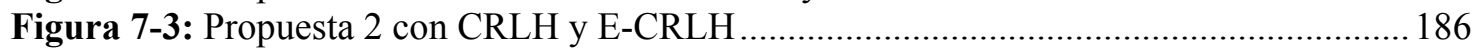

Figura 7-4: Circuito donde se introducen las líneas convencionales y las metalíneas............. 188

Figura 7-5: Resultados (potencia de salida, PAE y S11) del circuito optimizado implementado

con líneas convencionales y metalíneas CRLH, a $380 \mathrm{MHz}$. 189

Figura 7-6: Resultados (potencia de salida, PAE y S11) del circuito optimizado implementado

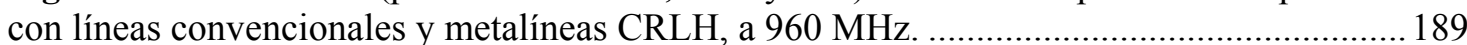

Figura 7-7: Circuito resultante implementado con líneas CRLH y E-CRLH ......................... 190

Figura 7-8: Potencia de salida, rendimiento y reflexión a $380 \mathrm{MHz} . . . \ldots \ldots \ldots \ldots \ldots \ldots \ldots \ldots \ldots \ldots \ldots . . . . . . . . . . . . . . . . .191$

Figura 7-9: Potencia de salida, rendimiento y reflexión a $960 \mathrm{MHz}$..................................... 191

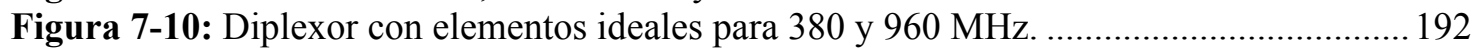

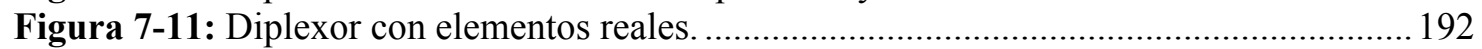

Figura 7-12: Resultados de la simulación del diplexor con elementos reales para 380 y 960

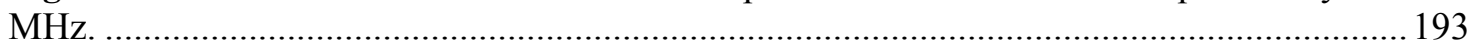

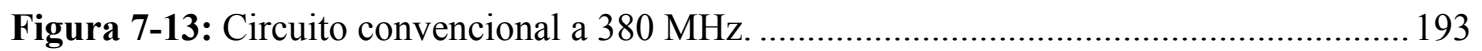

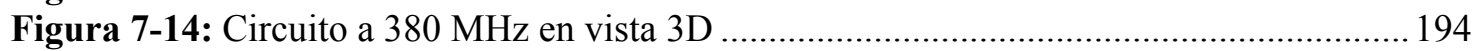

Figura 7-15: Resultados comparativos del amplificador de 380MHz ideal y real..................... 194

Figura 7-16: Circuito para el análisis de potencia del amplificador. ....................................... 195

Figura 7-17: Estudio comparativo de potencias del circuito ideal y real a $380 \mathrm{MHz}$.............. 195

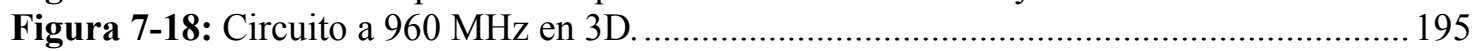

Figura 7-19: Resultados comparativos del amplificador de $960 \mathrm{Mhz}$ ideal y real................... 196

Figura 7-20: Estudio comparativo de potencias del circuito ideal y real a $960 \mathrm{MHz}$............. 196

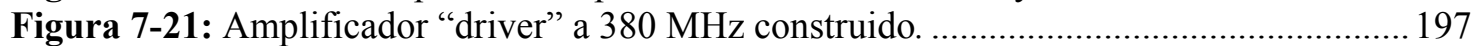

Figura 7-22: Resultados comparativos del amplificador "driver" a $380 \mathrm{MHz}$ construido. .... 197

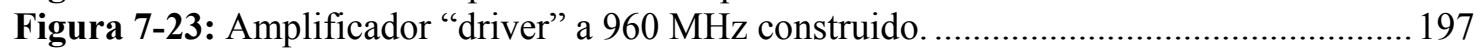

Figura 7-24: Resultados comparativos del amplificador "driver" a $960 \mathrm{MHz}$ construido. .... 198

Figura 7-25: Diagrama de bloques driver+Potencia, detalle del circuito de potencia y circuito

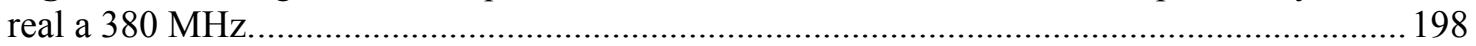

Figura 7-26: Resultados comparativos del amplificador driver+Potencia a $380 \mathrm{MHz}$............ 199

Figura 7-27: Amplificador driver+Potencia a $380 \mathrm{MHz}$ construido..................................... 199

Figura 7-28: Diagrama de bloques driver+Potencia, detalle del circuito de potencia y circuito

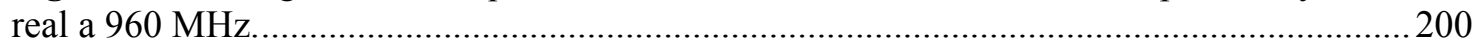

Figura 7-29: Resultados comparativos del amplificador driver+Potencia a $960 \mathrm{MHz}$............200

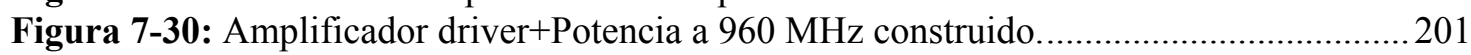

Figura 7-31: Diagrama de bloques y circuito físico con dos diplexores y dos amplificadores.

Figura 7-32: Resultados comparativos del amplificador dual completo para una frecuencia de

$380 \mathrm{MHz}$. 
Figura 7-33: Resultados comparativos del amplificador dual completo para una frecuencia de

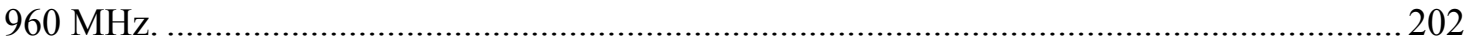

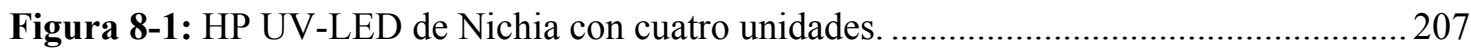

Figura 10-1: Evolución de los parámetros con medidas tomadas cada 15 minutos...........221

Figura 10-2: Datos de temperatura tomados cada 15 minutos en 12 días..........................222

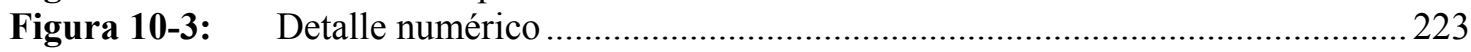

Figura 10-4: Detalle del pico sobre la muestra de 15 minutos de temperatura..................223

Figura 10-5: Detalle de la tabla de las medidas de temperaturas de 15 minutos donde se

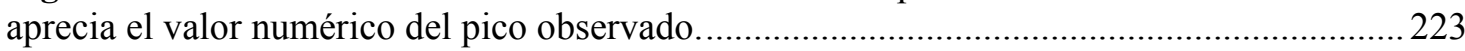

Figura 10-6: $\quad$ Datos de $\mathrm{pH}$ tomados cada 15 minutos en 12 días........................................224

Figura 10-7: Evolución de los parámetros con medidas tomadas cada hora. ......................225

Figura 10-8: Datos de temperatura tomados cada hora en 42 días ..................................226

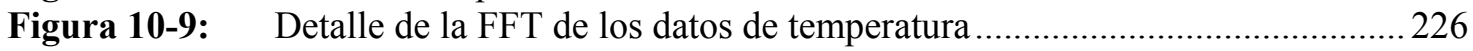

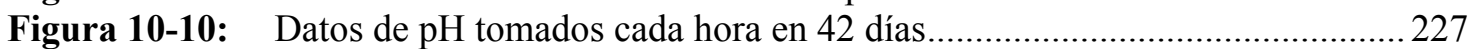

Figura 10-11: Autocorrelación de la temperatura para medidas quinceminutales................228

Figura 10-12: Autocorrelación del $\mathrm{pH}$ para medidas quinceminutales................................229 


\section{Lista de tablas}

Tabla I.- Fluorescencias producidas por diversos hidrocarburos comerciales al ser irradiados con luz UV de varias fuentes.

Tabla II Resultados de ajuste con gaussianas del espectro de Gasoil A por medio de cftool de Matlab.

Tabla III Resultados de ajuste con gaussianas del espectro de Gasoil A+ por medio de cftool de Matlab.

Tabla IV Resultados de ajuste con gaussianas del espectro de Gasoil B por medio de cftool de

Matlab.

Tabla V Resultados de ajuste con gaussianas del espectro de Gasoil C por medio de cftool de Matlab.

Tabla VI Resultados de ajuste con gaussianas del espectro de Gasolina 95 por medio de cftool de Matlab.

Tabla VII Resultados de ajuste con gaussianas del espectro de Gasolina 98 por medio de cftool de Matlab.

Tabla VIII Resultados de ajuste con gaussianas del espectro de Gasoil A con Tifyk..........83 Tabla IX Resultados de ajuste con gaussianas del espectro de Gasoil A+ por medio de Tifyk.

Tabla X $\quad$ Resultados de ajuste con gaussianas del espectro de Gasoil B por medio de Tifyk.

Tabla XI Resultados de ajuste con gaussianas del espectro de Gasoil C por medio de Tifyk. . 84

Tabla XII Resultados de ajuste con gaussianas del espectro de Gasolina 95 por medio de Tifyk.

Tabla XIII Resultados de ajuste con gaussianas del espectro de Gasolina 98 por medio de

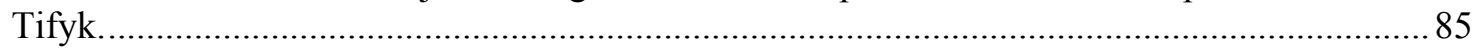

Tabla XIV Relación entre medida de cuentas del espectrómetro y potencia óptica del LED a 8

$\mathrm{cm}$ de distancia.

Tabla XV Instante estimado de fallo a cada temperatura durante el ensayo para los LEDs

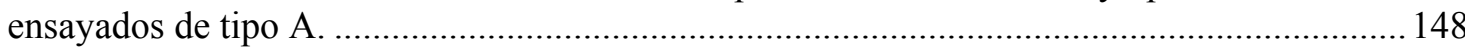

Tabla XVI Instante estimado de fallo a cada temperatura durante el ensayo para los LEDs ensayados de tipo B.

Tabla XVII Parámetros de la función defiabilidad F(t) para LEDs tipo A a temperatura ambiente de $25^{\circ} \mathrm{C}(298 \mathrm{k})$

Tabla XVIII Parámetros de la función defiabilidad $\mathrm{F}(\mathrm{t})$ para LEDs tipo $\mathrm{B}$ a temperatura ambiente de $25^{\circ} \mathrm{C}(298 \mathrm{k})$

Tabla XIX Parámetros térmicos y mecánicos de la zona superior del encapsulado. [ANVSG15]

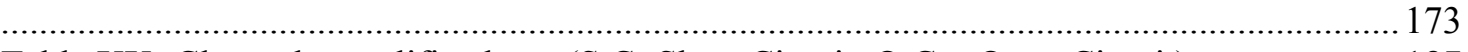

Tabla XX.-Clases de amplificadores (S.C=Short Circuit, O.C.= Open Circuit)........................ 187

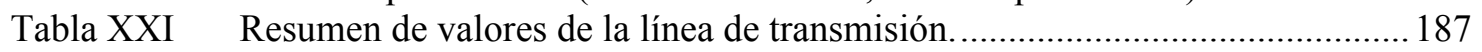

Tabla XXII Resumen de valores de la línea de transmisión de entrada CRLH.......................188

Tabla XXIII Resumen de valores de la línea de transmisión de salida E-CRLH. ................... 190 


\section{Índice de ecuaciones}

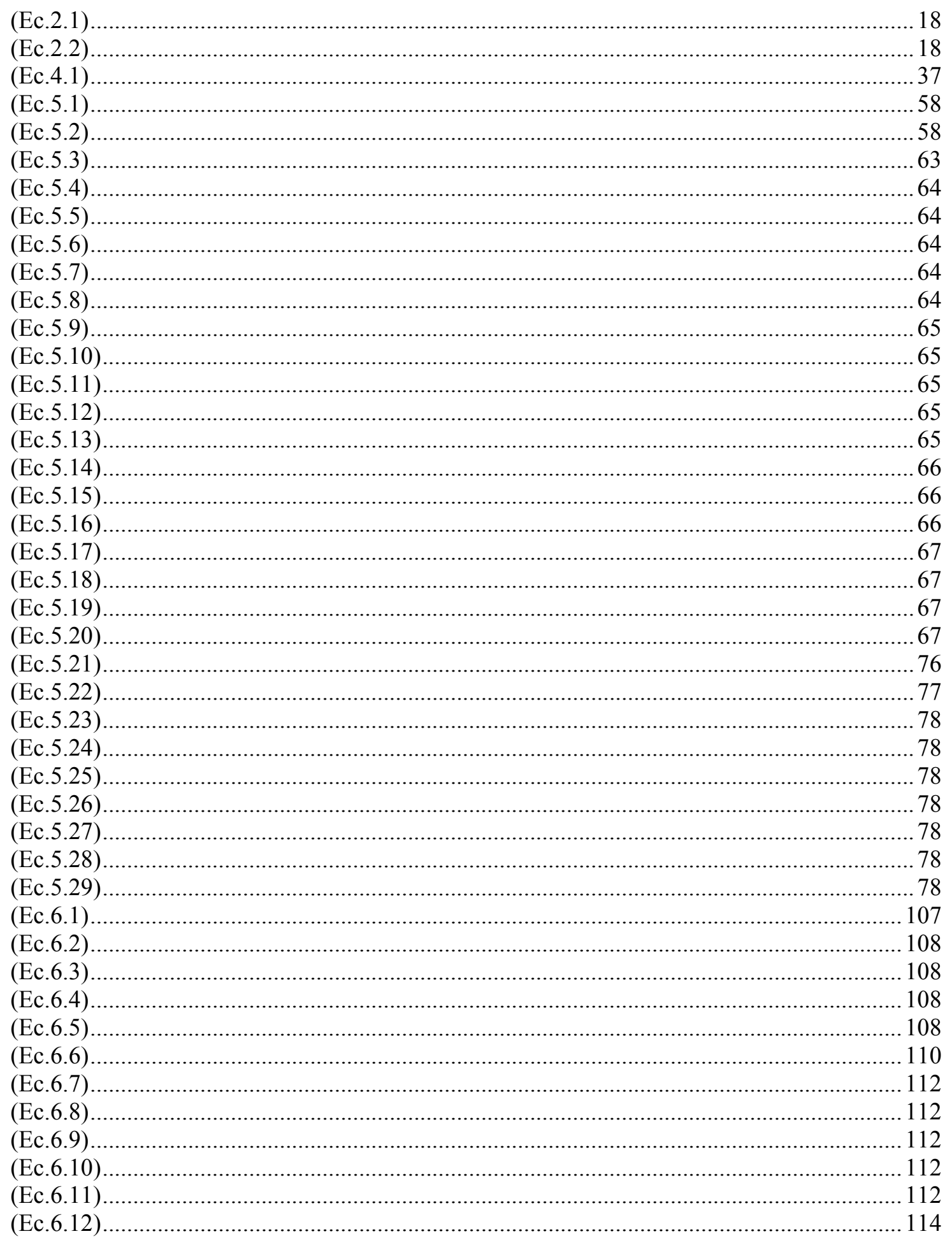


(Ec.6.13).

114

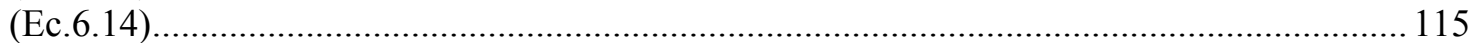

(Ec.7.1). 


\section{Agradecimientos}

Esta sección es opcional, en ella el autor agradece a las personas o instituciones que colaboraron en la realización del trabajo. Si se incluye esta sección, deben aparecer los nombres completos, los cargos y su aporte al trabajo.

Francisco Sánz Pérez, Jefe de Proyecto del Laboratorio de Combustibles y Petroquímica. 


\section{Resumen}

La preservación del medio ambiente, el avance en las técnicas para que el impacto de la actividad humana sobre la fauna y flora sea lo menor posible, hacen que se deban monitorizar los diversos indicadores de calidad. El presente estudio viene motivado debido a que actualmente existen sistemas de medida y control en continuo de la calidad de las aguas, al margen de los estudios de laboratorio por toma de muestras, a través de los cuales se obtienen indicadores de calidad. El desarrollo tecnológico en analizadores en continuo para la medida de fósforo, amonio, DBO y otros, hacen que cada vez se consiga un control más exhaustivo de la calidad en tiempo real. Sin embargo, la detección temprana de contaminantes que no deben encontrarse presentes en el agua, hacen que el desarrollo de sensores de detección de estos contaminantes sea de gran utilidad. A este respecto, las técnicas mediante fluorescencia presentan enormes ventajas, ya que no existe contacto directo con la muestra, reduciéndose el desgaste y alargando el tiempo entre mantenimientos, como se ha comprobado en numerosos desarrollos con tecnología láser. Para la producir fluorescencia, tradicionalmente se vienen utilizando en el laboratorio principalmente lámparas de gas y monocromadores. Los nuevos LED de alta potencia en el espectro ultravioleta son una alternativa muy interesante que además puede ser aplicada en los mencionados sistemas de medición en continuo. En este trabajo se realiza un estudio de viabilidad de estos dispositivos como fuentes de excitación para la producción de fluorescencia tomando como contaminantes los hidrocarburos. El funcionamiento en estaciones en continuo hace que se tenga que realizar además ensayos de vida acelerados, así como estudios de modos de trabajo. Al respecto de la fluorescencia producida, se estudia la influencia de factores que pueden afectar a las medidas, tales como la temperatura. El estudio del espectro y su análisis para la identificación del contaminante es otro de los puntos desarrollados en este trabajo. Por último, y dado que la monitorización se realiza en modo continuo, es necesario un sistema de comunicaciones compacto y fiable: en este apartado se analizan los metamateriales como solución tecnológica, ya que se adapta perfectamente a la filosofía de estas estaciones de medición. 


\begin{abstract}
Currently the monitoring of quality indicators is a need to preserve the environment and minimize the impact of human activity on the fauna and flora. Currently there are measuring systems and continuous monitoring of water quality, regardless of sampling laboratory studies, through which quality indicators are obtained. Technological development in continuous analyzers for the measurement of phosphorus, ammonia, BOD and others increasingly make a more comprehensive real-time quality control is achieved. However, early detection of contaminants that should not be present in the water, make the development of sensors for detecting these contaminants is very useful. In this regard, fluorescence techniques have huge advantages, since there is no direct contact with the sample, reducing wear and extending the time between maintenance, as has been demonstrated in numerous developments in laser technology. To produce fluoresce, traditionally are being used mainly gas lamps and monochromators at the laboratory. The new high-power LEDs in the ultraviolet spectrum are a very interesting alternative that can also be applied in the above continuous measurement systems. In this paper a viability study of these devices as excitation sources to produce fluorescence using hydrocarbon as contaminants is performed. The stations in continuous operation makes it necessary to also perform accelerated life tests and studies operating modes. In regard to the fluorescence produced, the influence of factors that may affect the measurements, such as temperature is studied. The study of the spectrum and analysis to identify the contaminant is another of the points developed in this work. Finally, since the monitoring is carried out in continuous mode, a compact and reliable communication is necessary: in this section metamaterials as a technological solution is analyzed since it fits perfectly with the philosophy of these measuring stations.
\end{abstract}

Keywords: UV-LED, Sensors, Fluorescence, Fluoro-sensing, Spectroscopy. Reliability, Acceletrated Life Test. 


\section{Glosario}

ALT: $\quad$ Accelerated Life Test. Ensayo de Vida Acelerado.

ARQM: $\quad$ Automatic river quality monitoring. Control automático de calidad en ríos.

CCC: $\quad$ Centro de Control de la Cuenca

CH: Confederación Hidrográfica

CPC: $\quad$ Centro Principal de Control

CRT: $\quad$ Catodic Ray Tube. Tubo de Rayos Catódicos.

DGCA: $\quad$ Dirección General de Calidad de las Aguas

EAA: $\quad$ Estación Automática de Alerta.

EL: $\quad$ Electroluminiscence, Electroluminiscencia.

FWHM: $\quad$ Full Width at half maximun. Anchura a media altura.

Gap: $\quad$ Anchura de la Banda Prohibida.

HB: $\quad$ High Bright. Alto Brillo.

HVPE: $\quad$ Hydride vapour phase epitaxy. Epitaxia en fase vapor con hidruros.

ICA: $\quad$ red Integral de Control de Calidad del Agua

I-V: $\quad$ Current Intensity - Voltage. Corriente - Tensión.

LD: $\quad$ Laser Diode. Diodo Láser.

LED: $\quad$ Light Emitting Diode. Diodo Electroluminiscente.

L-I: $\quad$ Lumniscence - Intensity. Luminiscencia - Corriente.

ML: $\quad$ Monolayer. Monocapa.

MOCVD: $\quad$ Metalorganic Vapour Deposition. Deposición Química Metal-Orgánica en Fase Vapor.

MTBE: $\quad$ Metil Tert-Butil Éter. 
PL: $\quad$ Photoluminiscence. Fotoluminiscencia.

QMS: $\quad$ Quadrupole Mass Spectrometry. Espectroscopía de Masas.

SAVCA: $\quad$ Subdirección de Análisis y Vigilancia de la Calidad de las Aguas

SAICA: $\quad$ Sistema Automático de Información de Calidad de las Aguas.

SGTCCA: $\quad$ Subdirección General de Tratamiento y Control de Calidad de las Aguas

UV: $\quad$ Ultraviolet. Ultravioleta.

VSAT: $\quad$ Very Small Aperture Terminal. Terminal de muy pequeña apertura. 



\section{Introducción y objetivos de la tesis}

El agua es uno de los recursos más importantes para la vida en la Tierra. La población crece y tiene como consecuencia el aumento de infraestructuras, industrias, agricultura intensiva, plantas de tratamiento de residuos de diversa procedencia y aumento de la contaminación en suelo, aire y agua.

En la década de los 90 se han desarrollado varios proyectos piloto con el fin de realizar tareas de medición de parámetros en continuo y control de la calidad de las aguas continentales en varios países. El proyecto SAICA [Leo98] ha sido pionero en Europa y realizado en España, consistente en el desarrollo e instalación de estaciones automáticas de medición en continuo. Este proyecto ha sido financiado en un $80 \%$ por la Unión Europea, y su objetivo es el desarrollo de estaciones automáticas que funcionen las 24 horas, en modo autónomo, proporcionando datos de calidad del agua, y transmitiendo estos datos en tiempo real.

El desarrollo, así como el comportamiento y los resultados obtenidos han sido seguidos de cerca por diversos organismos públicos y privados tanto de Europa como de otros países. En un principio se desarrolló electrónica a medida para la construcción de automatismos de propósito concreto, dado que las características de los computadores de entonces no cumplían con los requisitos necesarios. Además, se utilizaban componentes de series militares con el fin de asegurar la fiabilidad de los mismos en un entorno donde las condiciones de humedad y temperatura resultan más extremas. Todos los componentes de este tipo de estaciones han evolucionado con el paso del tiempo, mejorando en fiabilidad y prestaciones, siguiendo las directrices que se marcaron al inicio. Durante la última década, la medición de otros parámetros que aportasen más variables para observar la evolución, controlar y vigilar la calidad de las aguas, se han visto reflejadas en nuevos analizadores específicos para la medición de amonio, fósforo, etc. Estos elementos se encuentran presentes en mayor o menor medida, y resulta de gran ayuda su medición. Sin embargo, existen otro tipo de sustancias que no deben encontrarse nunca presentes en el agua de ríos y embalses, como son los detergentes, determinados tipos de ácidos, y otros elementos procedentes de la industria, por citar algunos ejemplos. La detección de este tipo de contaminantes se realiza mediante campañas en la que se toman muestras que son analizadas con posterioridad, por lo que resulta muy útil la detección en continuo mediante un sistema que sea sencillo, económico y fiable. Conscientes de esta necesidad, varios fabricantes 
trabajan es esta línea de desarrollo sacando al mercado diversos productos para este fin. En particular, los hidrocarburos son productos que debido a accidentes o negligencias pueden contaminar el entorno, causando un enorme daño tanto a la fauna como a la flora, en especial cuando se trata del medio acuático, ya que se extiende de forma rápida. Por tanto se trata de sustancias muy contaminantes cuta detección es básicamente visual gracias bien a las labores de vigilancia del personal destinado a este efecto o bien por avisos de personas. Para confirmar el hecho, es necesaria la toma de muestra por parte de las autoridades competentes y realizar el posterior análisis. En todo caso cuanto antes se tomen las acciones correctoras, menor será el daño causado.

El fenómeno de la fluorescencia es ampliamente conocido desde hace décadas, y su utilización en la identificación de sustancias también. Una de las grandes ventajas de la fluorescencia es que puede producirse sin contacto directo con la sustancia, evitando el deterioro de los sensores, como en el caso de los de oxígeno, conductividad o $\mathrm{pH}$. Gracias al avance en tecnología y en química ha sido posible el desarrollo de fuentes luminosas en un amplio margen de frecuencias, destacando los láseres, obteniéndose potencias y frecuencias muy elevadas. Al igual que en las mencionadas aguas continentales, similares casos de contaminación pueden darse en el medio marino, donde el transporte de fuel se realiza en grandes cantidades existiendo riesgo de vertido: dado que muchos derivados del petróleo fluorecen significativamente cuando son excitados con la frecuencia e intensidad correcta, numerosos desarrollos han aprovechado este hecho para realizar estudios y sistemas adaptados a cubrir superficies de gran tamaño por medio de sistemas basados láser [CCK+88] [BF03] [BICR03] [RBH+09].

Recientemente se han desarrollado LEDs de alta potencia en frecuencias del ultravioleta, favoreciendo la investigación en sistemas portátiles para medidas in-situ [KW11] [CSH12] así como otros procedimientos específicos para la detección de determinadas sustancias que se encuentran en el agua y que resultan de interés, como son la presencia de algas, herbicidas, etc [IE11] [LBW13].

En esta tesis se plantea progresar en esta línea a partir del estado del arte actual, con la integración de sistemas espectrométricos en estaciones de medición (tanto en fijas con infraestructura propia como en las más modernas plataformas compactas portátiles) para detectar de forma continua y en tiempo real, la posible contaminación producida por alguno de los compuestos cuya firma se ha introducido previamente en una base de datos contando con los HB UV-LEDs como fuente lumínica. Dado que la filosofía de estas estaciones es la monitorización en continuo, los diversos elementos que las componen se ven sometidos a un régimen de funcionamiento intenso que obliga a un estudio previo que analice la viabilidad de su uso en este tipo de entornos. 


\subsection{Evolución de los LEDs en el rango ultravioleta}

Desde que en 1907 fuese fabricado el primer LED al hacer pasar una corriente a través de un contacto formado por un electrodo metálico y una capa de carburo de Silicio, estos dispositivos han evolucionado enormemente tanto en el rango de frecuencias como de potencia. A partir de la invención del LED rojo ( $\sim 625 \mathrm{~nm})$ por Holonyak en 1962 ya medida que se fueron entendiendo los mecanismos mediante los cuales se produce la electroluminiscencia (EL), la fabricación de uniones p-n con distintos Gap hizo que entre los años sesenta y setenta comenzase la producción a gran escala apareciendo rápidamente el LED en colores verdes ( 530nm ), naranjas $(\sim 610 \mathrm{~nm})$ y amarillos $(\sim 590 \mathrm{~nm})$. Con la aparición de los semiconductores III-V, como los basados en GaAs de emisión en el infrarrojo se fabricaron LEDs y diodos láser (LD) en una carrera llevada a cabo por distintos grupos (General Electric, RCA, IBM y MIT) [XXXXXXXX]. Esto hizo que su utilización fuese cada vez mayor, y que cada vez tuviesen más usos. Sin embargo, las longitudes de onda de las tonalidades azules resultaron difíciles de implementar, necesarias para la fabricación, entre otras cosas, de pantallas planas y mayores que las convencionales de tubo (CRT) y sistemas de discos con almacenamiento de alta densidad (Blue Ray y HD-DVD). Finalmente en los años noventa se obtuvieron LEDs azules y los primeros en ultravioleta cercano, pero de muy baja potencia y eficiencia (relación potencia óptica/potencia eléctrica).

Los UV-LEDs (emiten en longitudes de onda de $400 \mathrm{~nm}$ o menores) están llamados a ser los sustitutos de las fuentes tradicionales de luz ultravioleta (como las lámparas de mercurio) [MKN14] [Ven15]. En los primeros años del siglo XXI Nitride Semiconductors Co. junto con la Universidad de Tokushima inicia el desarrollo de LEDs a frecuencias ultravioleta, siendo la evolución de estos dispositivos constante.

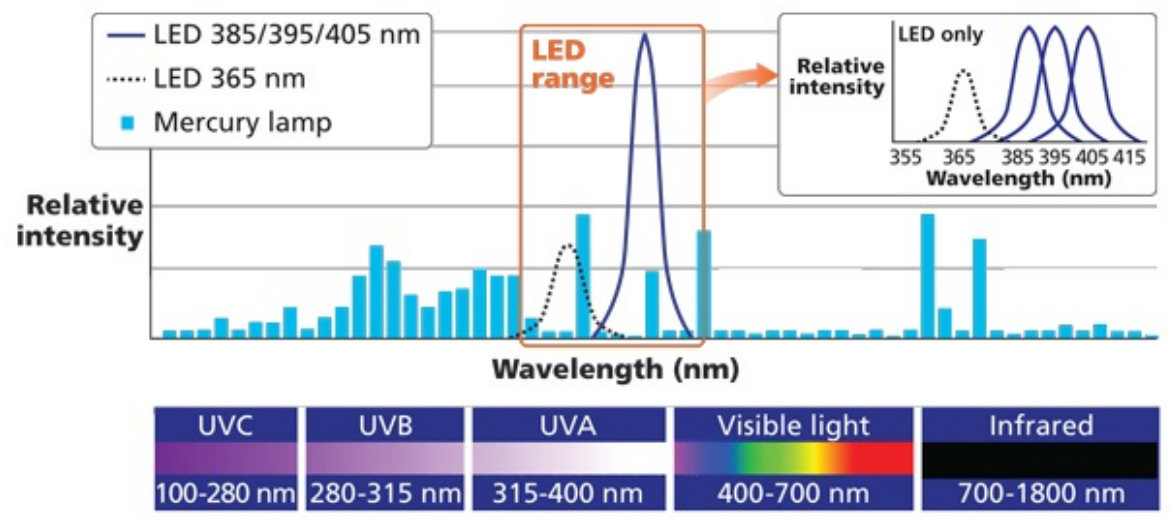

Figura 1-1: Distribución de energía espectral de LEDs UV, diferente de la de las lámparas de mercurio. Fuente: LEDs Magazine. 11 marzo 2014. 
Dentro de estos UV-LEDs existe una clasificación en función del rango de longitudes de onda: los "near-ultraviolet light-emitting diodes" (NUV-LEDs) emiten entre 300 y $400 \mathrm{~nm}$, mientras que los "deep- ultraviolet light-emitting diodes" emiten entre los 200 y $300 \mathrm{~nm}$. Los UV-LEDs son serios candidatos a ser aplicados en sustitución de lámparas UV, fuentes luminosas y displays; fuentes de luz de alta resolución para microscopios; fuentes de luz para excitación química, secado de resinas, medicina y biotecnología; fuente de luz para uso sanitario en desinfección y esterilización. El uso como fuente de luz para espectroscopía es una de las ramas más interesantes, ya que unido a su reducido tamaño pueden acelerar el proceso que se lleve a cabo, dado que los LEDs no precisan de tiempo de caldeo como las lámparas de gas. En particular, los NUV-LED han evolucionado en su fabricación a nivel de crecimiento cristalográfico, procesamiento de los materiales semiconductores del chip así como en el encapsulado, alcanzando mejoras notables en todos estos aspectos. Cuanto menor es la longitud de onda, la evolución es más lenta debido a que la complejidad de los materiales aumenta. Existen desarrollos para longitudes de onda entre 210 y $280 \mathrm{~nm}$ realizados con compuestos III$\mathrm{N}$ con altos contenidos de Al pero por el momento emiten con muy baja potencia, tienen un muy bajo tiempo de vida y su coste es muy elevado dado que la tecnología es aún algo inmadura. Los dispositivos así construidos presentan potencias varios órdenes de magnitud inferiores [RLw] a los de longitudes de onda mayores en las que existen desarrollos más eficientes con estos mismos compuestos: dentro de este espectro se encuentran las longitudes de onda de 405, 385 y $365 \mathrm{~nm}$, siendo esta última objeto del presente estudio. Los semiconductores de InAlGaN con Gap directo resultan más eficientes que los de Gap indirecto y cubren el espectro desde el infrarrojo hasta el ultravioleta [YC05]. Tras muchos desarrollos fallidos a lo largo de años de investigación, los LED basados en GaN se fabrican depositando capas de cristal de GaN sobre una base de zafiro $\left(\mathrm{Al}_{2} \mathrm{O}_{3}\right)$ mediante MOCVD (metalorganic vapour deposition). El GaN sobre zafiro adquiere el dopaje tipo $n$, y el GaN dopado con $\mathrm{Mg}$ adquiere conductividad tipo $p$. La principal dificultad en este procedimiento consiste en hacer crecer capas cristalinas de alta calidad, ya que las constantes del zafiro y el GaN son diferentes. Nichia Corp. demostró que mediante tratamientos térmicos [NSM91] se puede activar el Mg. Técnicas con procesos en hornos a altas temperaturas facilitan este proceso, y aunque su coste en principio era elevado, este ha decrecido gracias a la producción en masa: para los primeros ensayos realizados en el presente estudio los LEDs solicitados costaron un $400 \%$ más que las últimas unidades adquiridas. Aun así, sigue siendo necesario aumentar la eficiencia y la potencia óptica, dado que aumentaría la vida útil y los usos de estos

\subsection{Objetivos de la Tesis}

En este estudio se pretenden llevar a cabo varios objetivos que aportan relevantes novedades en el área de la espectrometría de contaminantes. 
En primer lugar se plantea el desarrollo de un sistema de detección e identificación de contaminantes sin contacto, en funcionamiento continuo y en tiempo real. Para validar este método se ha elegido analizar los hidrocarburos, ya que son uno de los contaminantes que más afectan y que pueden encontrarse en accidentes o vertidos en las aguas continentales, pero el método puede extenderse a otros compuestos y longitudes de onda.

En segundo lugar, se determinará la viabilidad del uso de LEDs como fuentes de luz ultravioleta para excitar los compuestos y que éstos produzcan fluorescencia de forma que sean sustitutos de las fuentes luminosas tradicionales (lámparas de diversos gases principalmente). Para este fin se han realizado mediciones de la fluorescencia producida con varios tipos de hidrocarburos. A diferencia de las fuentes tradicionales que por lo general emiten en un ancho de banda extenso y con marcados picos de intensidades diferentes, siendo por lo tanto necesario el uso de un monocromador para fijar la frecuencia emitida [L06], los LEDs emiten en un estrecho margen de frecuencias, si bien no emiten con tanta potencia luminosa como las mencionadas lámparas. Además como es sabido, estos dispositivos resultan mucho más livianos, y no necesitan tiempo de caldeo para comenzar a funcionar correctamente. Por otro lado, se debe verificar que los espectros emitidos por las sustancias excitadas con luz procedente de UV-LEDs fluorecen al igual que lo hacen con las fuentes tradicionales. Como el espectro de fluorescencia depende, entre otros factores, de la fuente de excitación, es necesario obtener la huella de cada compuesto con los LEDs con los que posteriormente se realiza la detección, obteniendo así una primitiva base de datos definida para estos dispositivos.

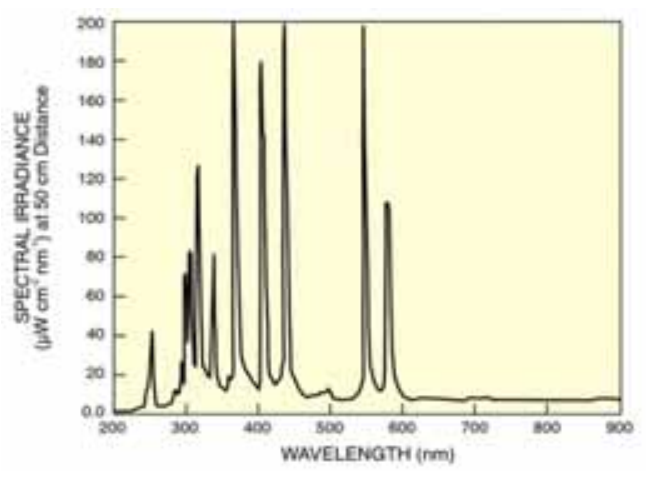

(a)

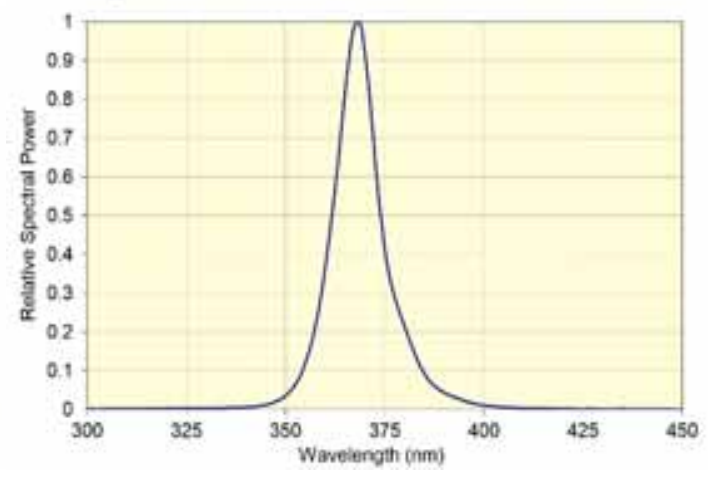

(b)

Figura 1-2: Longitudes de onda de emisión de Lámparas de gas Hg (a) y UV-LED (b). Fuentes: Newport Corporation y LED Engin. Inc.

Un tercer objetivo es determinar la fiabilidad de estos dispositivos, y probar si su degradación a largo plazo podría impedir la detección de los contaminantes, dado que se pretende sean usados para la detección en continuo, y estarían ubicados en las estaciones automáticas de 
alerta. Es por tanto necesario determinar la vida útil de los mismos, para prever su reposición antes de que la degradación de luz pueda afectar a la calidad de las medidas, evitando la identificación de contaminantes. Como casi todos los dispositivos semiconductores, los LEDs tienen presumiblemente alta fiabilidad, pero también como es común, al tratarse de dispositivos de alta potencia que dicha fiabilidad se reduzca considerablemente debido al fuerte estrés por temperatura y corriente. Por ello se han probado en los ensayos de vida dos tipos de funcionamiento compatibles con la detección en continuo continua: se propone el funcionamiento en modo continuo y en modo cíclico, con ciclos de 30 segundos encendido y 30 apagado. A priori no es evidente cuál de estos modos es el más favorable para la vida de los LEDs ya que cada uno presenta ventajas e inconvenientes que se tratarán más adelante. Los estudios realizados en este sentido para esta tesis resultan de interés para este y otros fines debido a que previamente no se ha realizado trabajo específico de fiabilidad de HB UV-LEDs en este área de sensado dando lugar a publicaciones en las que se reflejan parte de los resultados obtenidos.

Para llevar a cabo estos objetivos se han realizado diversos test de vida acelerados (ALT) con el fin de determinar la evolución de la intensidad luminosa a lo largo del tiempo.

Una parte final de la tesis se dedica al estudio de metamaterias, por dos motivos: en primer lugar, debido a que se trata de una prometedora tecnología con numerosas aplicaciones [CSH12], entre las que se encuentra el desarrollo de sensores para la medida de la permitividad, siendo el origen de la presente tesis dado que se pensó en el desarrollo de sensores de hidrocarburos basados en metamateriales. Para llegar a este objetivo se comenzó por el estudio en el área de comunicaciones, ya que permitían realizar circuitos de comunicaciones móviles muy útiles en las estaciones automáticas, sirviendo además para adquirir experiencia y poder avanzar en su uso como sensores. Se han obtenido resultados positivos en el diseño y construcción de amplificadores de clase $\mathrm{E}$ y diplexores a frecuencias de uso en comunicaciones móviles, que han dado lugar a las publicaciones detalladas más adelante. Mientras se trabajaba en este campo, surgieron los primeros UV LED de alta potencia y los microespectrómetros, como alternativa a los sistemas de espectrometría clásicos. Se optó entonces por avanzar en esta línea de trabajo, y aunque varios fabricantes radicados en Japón mostraban resultados, resultó muy difícil y costoso adquirir muestras para su estudio. Otros grupos de investigación realizan avances en el uso de UV LEDs, pero en líneas diferentes. 


\subsection{Estructura de la Memoria}

Al objeto de poder cubrir los objetivos marcados en el apartado anterior y con los resultados experimentales obtenidos, se ha dividido esta tesis en las siguientes partes:

En el segundo capítulo se trata el estado del arte de varios de los temas que sirven de soporte para el desarrollo de esta tesis: el control de calidad de las aguas y los métodos utilizados, así como las estaciones de medición en continuo como herramienta, la espectroscopía de fluorescencia como sistema de medición y detección, y los hidrocarburos como ejemplo de elemento contaminante válido para el sistema propuesto.

En el tercer capítulo se comparan diferentes alternativas de fuentes luminosas para producir fluorescencia, y la influencia de ciertos factores de las mismas como la intensidad y la longitud de onda sobre los resultados espectrométricos obtenidos.

En el cuarto capítulo se detalla la metodología utilizada para la obtención de los resultados presentados en los capítulos posteriores.

En el quinto capítulo se trata el análisis de los UV-LED como elemento de iluminación en el sistema de espectrofluorimetría para la detección del contaminante, así como los procedimientos de filtrado de señal Savitzky-Goley, análisis de la señal medida fitting con gausianas o lorenzianas, y detección del material contaminante, superposición de la descomposición de la medida con cada una de las gausianas de la base de datos y superposición sobre el diagrama de bigotes. También se trata la fiabilidad de LEDs, instrumentación, caracterización del LED, espectrometría, potencia luminosa, curva I-V típica, plan de ensayos a tres temperaturas y los dos tipos de condiciones de trabajo, así como los resultados fiabilidad curvas de Weibull y cálculo de la fiabilidad. Por último se realiza un análisis de fallos, evolución de curvas I-V degradación del encapsulado y de los LEDs y medidas de temperatura con simulaciones.

En el capítulo sexto se analizan los espectros obtenidos con los LEDs, teniendo en cuenta las particularidades propias de los hidrocarburos, cuyas propiedades pueden verse afectadas por factores como temperatura, etc.

El capítulo siete muestra el estudio realizado con metamateriales, con el fin de realizar un diseño de circuito de comunicaciones aptos para sistemas compactos y fiables.

Se concluye con una serie de conclusiones generales y planteamiento de trabajos futuros para continuar con la línea de investigación. 



\section{Estado del Arte en control de calidad del agua y detección de contaminantes.}

\subsection{El control de calidad el agua mediante estaciones automáticas}

A efectos de control de calidad de las aguas los ríos se encuentran divididos por tramos cada uno de los cuales debe cumplir unos criterios de calidad que vienen marcados por la legislación. La calidad viene dada por la medición de diversos parámetros, así como la concentración de varios elementos. Estas mediciones deben realizarse de acuerdo a la normativa, que indica el método. A este respecto, existen laboratorios acreditados que reciben la muestra en un plazo y en unas condiciones de almacenamiento, transporte y temperatura adecuadas. Sin embargo, la periodicidad con la que se realiza la toma de muestras, así como la aparición de vertidos puntuales, hace necesaria la vigilancia mediante otros métodos: en muchos puntos se ha aumentado la frecuencia de toma de muestras en función de la ubicación del punto, de la época del año, etc. Existen estudios precedentes [SR08] [G91], y desarrollos conocidos con las siglas ARQM (Automatic river quality monitoring) con mayor o menor complejidad [EWH97] [YJD08] en diversos países, desde la simple recogida de muestras para su posterior análisis, hasta sistemas de medición más completos. En este sentido se desarrolló el proyecto SAICA, al objeto de implementar estaciones automáticas de muestreo periódico, con envío de datos en tiempo real. Estas estaciones en un principio realizaban medidas de calidad, de manera que se pudiese tener un indicador de la evolución de los parámetros de calidad. Otro aspecto importante muy a tener en cuenta, es el referido a los vertidos puntuales de mayor o menor duración y de muy diversa procedencia. Este aspecto es el que se refiere a la vigilancia: esta labor la realizan los guardas fluviales, pero dada las limitaciones obvias de este cometido (tanto físicas como temporales) se pensó en hacer extensiva la funcionalidad de las estaciones automáticas, de manera que sirviesen también como indicadores de alerta temprana. De esta forma, en una labor conjunta se pueden realizar tareas de medición, control y vigilancia de los ríos. No obstante, todas estas medidas continúan siendo insuficientes, dado que existen ciertos contaminantes que no son controlados de forma directa ni mediante las estaciones automáticas ni mediante los análisis periódicos. Esta inquietud es compartida y puesta de manifiesto desde la U.E. y se han hecho grandes avances 
tecnológicos en esta dirección; así, en los últimos años se han ido desarrollando métodos de medida en continuo de compuestos que no deben superar una concentración en el agua. Paralelamente se realizan campañas de detección mediante recogida de muestras, como es el caso de los detergentes, ya que estos compuestos son especialmente dañinos en el periodo estival en el que flora, fauna y cultivos se encuentran en su apogeo y existe una más elevada temperatura y menor cantidad de caudal. Queda mucho trabajo por delante a este respecto, ya que se busca la detección en continuo de forma rápida y económica de pesticidas, detergentes, fungicidas y un largo etcétera. La amplia variedad y procedencia de estos contaminantes hace difícil su identificación, pero gracias a los avances en el almacenamiento y procesado de datos este horizonte es cada vez más cercano.

\subsection{Estaciones Automáticas de Alerta en España}

La entonces Subdirección de Análisis y Vigilancia de la Calidad de las Aguas perteneciente a la Dirección General de Calidad de las Aguas (DGCA), diseñó y puso en marcha el proyecto SAICA (Sistema Automático de Información de Calidad de las Aguas) que, además de otras actuaciones, integró las redes de control existentes en una única Red Integral de Control de Calidad del Agua (Red ICA), adaptada a las necesidades y exigencias de la legislación en vigor. El proyecto SAICA incorpora en cada Cuenca Hidrográfica una serie de Estaciones Automáticas de Alerta (EAA), que se encargan de realizar mediciones y muestras periódicas de la Calidad de las Aguas de una forma automática. La información recogida en cada EAA es entonces enviada en tiempo real a su respectivo Centro de Control de Cuenca, (CCC), localizado en la Confederación Hidrográfica $(\mathrm{CH})$, a través de comunicación satélite VSAT.

Los datos de la calidad de las aguas concentrados en cada CCC permiten alertar y proteger zonas de especial interés y constituye una herramienta básica de ayuda a la guardería fluvial y de gestión para las acciones de vigilancia, control, autorización y sanción de los vertidos en cada $\mathrm{CH}$.

La Subdirección General de Gestión Integrada del Dominio Público Hidráulico tiene en servicio el SAICA, que implica la integración de las redes de control en una única red integral adaptada a las necesidades y exigencias de la legislación en vigor.

El sistema SAICA incorpora además una red de Estaciones Automáticas de Alerta que realiza mediciones de forma automática y continua de la calidad de las aguas y se encuentran en emplazamientos estratégicos para el control de vertidos o de vigilancia de zonas que requieren especial protección. En el ámbito de la Confederación Hidrográfica del Tajo con la que se ha colaborado para la obtención de varios resultados presentados en esta tesis, esta red está constituida por veintitrés (23) Estaciones Automáticas. 
La información registrada por cada EAA se envía cada 15 minutos, a través de la red de comunicación vía satélite VSAT, al centro de proceso donde se almacena, procesa y gestiona. La explotación y mantenimiento del centro de proceso de cuenca requiere una gestión eficaz tanto de las comunicaciones como de los datos recibidos. De la misma forma, la explotación y mantenimiento de las EAA requiere una adecuada gestión de los medios, una supervisión de los elementos que la componen, y una continua evolución en nuevas tecnologías para hacer cada vez más fiables los sensores y analizadores, así como ampliar el número de factores a analizar.

\subsubsection{Descripción de los trabajos de mantenimiento de estaciones automáticas}

La descripción de los trabajos y tareas a realizar, se exponen de forma detallada en el Pliego de Prescripciones Técnicas, necesario para un proyecto de éstas características, dándose aquí un resumen de los mismos:

a) Realización del Mantenimiento preventivo en cada Estación Automática de Alerta, sobre todos los elementos que en ella existan, tanto en infraestructura como en elementos de captación y preparación de la muestra, en equipos de análisis y en elementos de control, almacenamiento de datos y de transmisión, incluyendo herramientas informáticas de software y hardware.

b) Realización del Mantenimiento correctivo en cada EAA, sobre cualquier elemento, equipo e instalación que presente un funcionamiento defectuoso y no cumpla la funcionalidad que se le haya asignado.

c) Abastecimiento de los consumibles necesarios para el funcionamiento de cada equipo parte de la instalación, que se prescriban, así como de los servicios adscritos a las estaciones.

d) Recogida en los tomamuestras automáticos de las muestras correspondientes a determinadas alarmas y su entrega en el laboratorio de la Comisaría de Aguas de la Cuenca Hidrográfica o en el Laboratorio que se designe.

e) Desarrollo de los trabajos de aseguramiento de la calidad correspondientes a cada una de las estaciones, e intercalibración que determine la garantía de calidad de la medida de los analizadores.

f) Sustitución de piezas, elementos o partes de las instalaciones y/o equipos que impidan el funcionamiento previsto que se les ha asignado.

g) Puesta a disposición de la realización del contrato de los medios humanos y materiales que se suponen suficientes para desarrollar estas prestaciones en el ámbito del mismo.

h) Generación de la documentación adecuada y suficiente para informar de los trabajos realizados, del estado de las instalaciones y de las incidencias acaecidas. 
Es por tanto finalidad de estos trabajos garantizar en todo momento una disponibilidad en el Centro de Control de los parámetros obtenidos por los elementos instalados en las EAA, consiguiendo el perfecto funcionamiento de cada parte o elemento de la instalación, y/o subsanando averías en los plazos establecidos. Para ello las estaciones deberán estar dotadas de sensores lo suficientemente fiables y robustos para minimizar los fallos así como su mantenimiento, siguiendo la filosofía de estaciones automáticas. Los métodos de detección y/o análisis por medio de la fluorescencia presentan una alternativa fiable que encaja en las necesidades de las estaciones, ampliando el abanico de posibilidades de éstas sin suponer un sobrecoste importante, gracias a los nuevos dispositivos disponibles.

\subsubsection{Estaciones básicas}

$\mathrm{Al}$ objeto de cubrir los requisitos mencionados en el apartado anterior, las estaciones deben estar ubicadas de acuerdo con puntos estratégicos donde se puedan medir apropiadamente los parámetros para los que ha sido diseñada. Así por ejemplo, existen puntos donde bien por construcciones naturales o artificiales, el agua aumenta su concentración de oxígeno disuelto (azudes y otros), sufriendo a las pocas decenas de metros una bajada importante, dependiendo de la calidad de la zona. De la misma forma, en alusión a este mismo parámetro, en zonas donde el agua tiene poco movimiento, la proliferación de algas genera una falsa medida de calidad, ya que durante las horas de sol las algas expulsan oxígeno; durante la noche el fenómeno es el contrario. Por ello, la medida en continuo representa una gran ventaja en el tratamiento de datos, dado que este y otros parámetros manifiestan diversos ciclos de acuerdo a las horas del día y las épocas del año.

a) Ubicaciones

Para definir la ubicación para cada EAA, se efectúa un estudio sobre el terreno, con los siguientes criterios:

- Cumplir el objetivo de control para el que está prevista la EAA.

- Las estaciones se sitúan lo más cercana posible al cauce o vertido a controlar, minimizándose la altura manométrica de bombeo, para alterar lo menos posible las características del agua a analizar y reducir la potencia de bombeo.

- Las estaciones se sitúan en puntos con fácil acceso y disponibilidad de energía eléctrica, con el fin de reducir los costes de instalación y la necesidad de ocupación de terrenos. 
- Los terrenos deben ser de dominio público o en su defecto donde se estime que no se causan daños a la propiedad y por tanto no es de esperar oposición a la implantación de la estación.

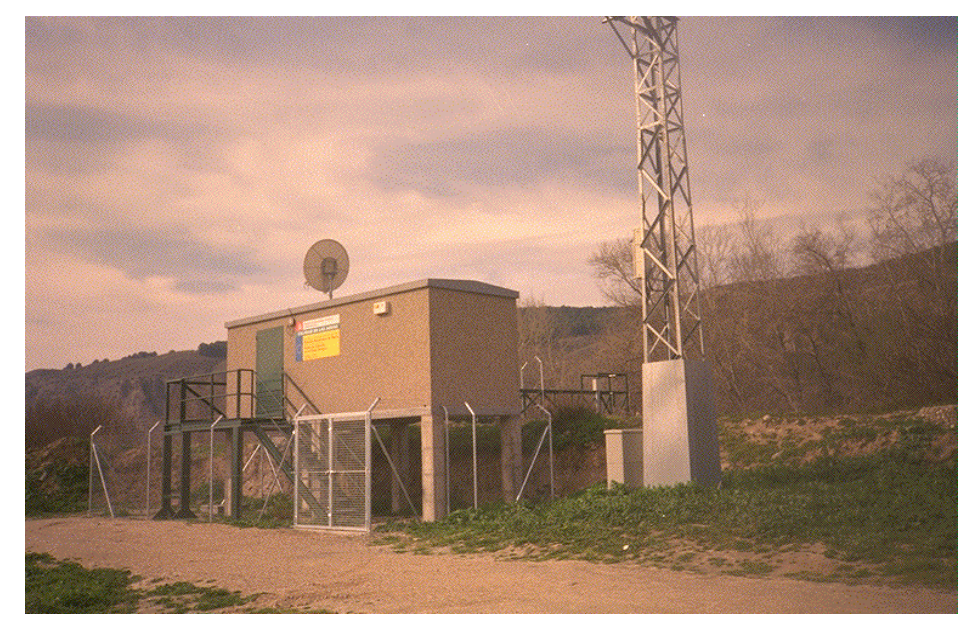

Figura 2-1: Estación Automática de Alerta

b) Analizadores y Sensores

- Todas las estaciones, disponen de los siguientes analizadores y sensores para la vigilancia de la calidad de las aguas, encontrándose todos ellos en correcto estado de funcionamiento:

- Multiparamétrica con sondas para $\mathrm{pH}$, conductividad, temperatura y oxígeno disuelto, instaladas en el interior de la estación.

- Sonda de nivel, piezorresistiva o por ultrasonido, según las características de cada ubicación.

- Turbidímetro, inmerso en el cauce o instalado en el interior de la estación, según las características de cada ubicación.

- Sensores y central de alarmas para el control de: intrusismo, inundación y temperatura interior de la estación.

c) Equipamiento Básico

Las estaciones, disponen del siguiente equipamiento básico:

- Caseta prefabricada (Figura 2-1).

- Captación de agua.

- Bomba sumergida para la captación del agua a analizar

- Sistema de acondicionamiento de muestras.

- Tomamuestras automático. 
- Acometida eléctrica, en Media o Baja Tensión, según las características de cada ubicación.

- Red de Baja Tensión 380/220 V, alumbrado y red de puesta a tierra.

- Sistema de alimentación ininterrumpida (SAI).

- Red de aire comprimido.

- Sistema de adquisición de datos, red de conexiones de señales.

- Al menos un sistema de comunicaciones VSAT.

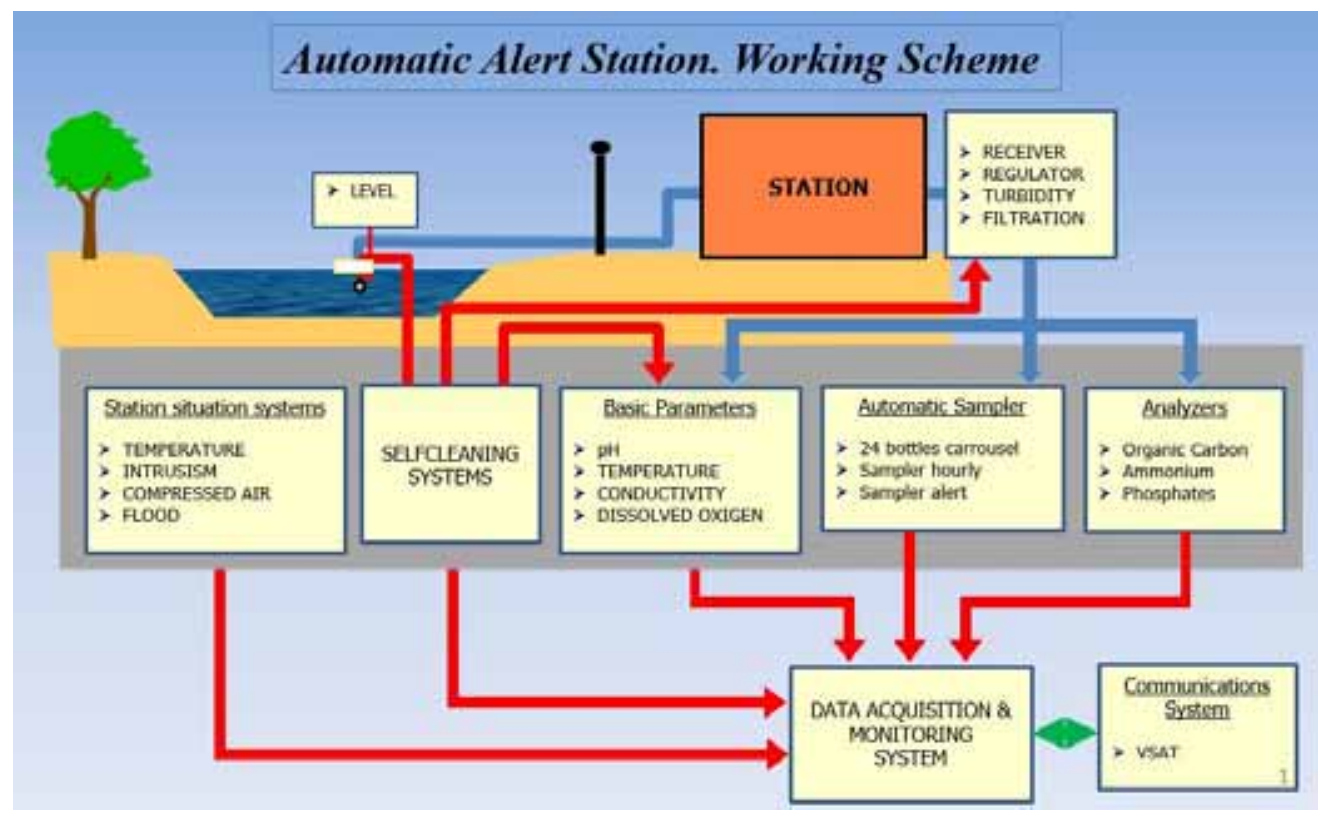

Figura 2-2: $\quad$ Esquema de una Estación Automática de Alerta.

En la Figura 2-2 se muestra un esquema del conexionado de los distintos elementos de una estación automática. Parámetros como la turbidez deben ser medidos previamente al objeto de que no se vean alterados. La tendencia en la evolución de las estaciones de acuerdo a los sensores, electrónica y procesadores, es la integración de estos medidores en un elemento más manejable y portátil, en el que se midan los parámetros de forma directa (Figura 2-3). De esta manera, se podrán tener en función de las necesidades un conjunto de posibilidades de medición. Para ello se hace necesario el integrar ciertos componentes así como reducir el tamaño y aumentar la fiabilidad de otros. A este respecto, uno de los elementos más importantes son los encargados de las comunicaciones, y para ello existen diversas propuestas de mejora, en función de las necesidades y ubicación de las estaciones. Del mismo modo, las estaciones pueden evolucionar hacia varios tipos, según necesidad: sumergibles, flotantes y fijas pudiendo en los dos primeros casos prescindir de las casetas prefabricadas, reduciendo costes. 


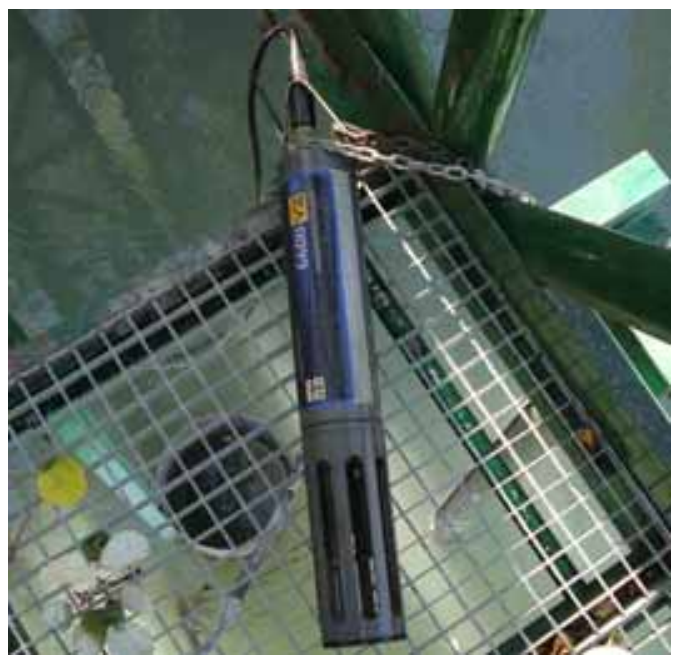

Figura 2-3: Multiparamétrica sumergible

\subsubsection{Fiabilidad de los datos acumulados}

En este apartado se trata de dar un breve análisis de la validez de los datos realizados en mediciones en continuo, dado el amplio conocimiento adquirido a lo largo de varios años de experiencia ininterrumpida. Esta información puede utilizarse para dos fines fundamentales: en primer lugar para, de acuerdo a los problemas encontrados en los sensores y analizadores existentes (caídas de tensión y rearmes, fallos por temperatura, frecuencias de mantenimiento, etc.), extrapolar y tener en cuenta estos aspectos en el desarrollo hardware y software de nuevos analizadores y/o detectores. En segundo lugar, valorar los errores y derivas analizados, de forma que, en caso de utilizar alguno de los parámetros analizados (como puede ser la temperatura y el pH que afectan a la fluorescencia), se tengan en cuenta a la hora de implementar márgenes de error y cálculos de fiabilidad.

En las estaciones fijas, el agua es pre-filtrada por un sistema de centrifugado (hidrociclón), de manera que las partículas pesadas como la grava, son eliminadas sin que se alteren las características del agua que se miden posteriormente. El agua pasa entonces por una línea de medida donde se encuentran los cuatro sensores que miden temperatura, $\mathrm{pH}$, oxígeno disuelto y conductividad (Figura 2-4). En algunas estaciones existe otra línea de medida donde el agua no es pre-filtrada, pasando por conducciones adecuadas. 


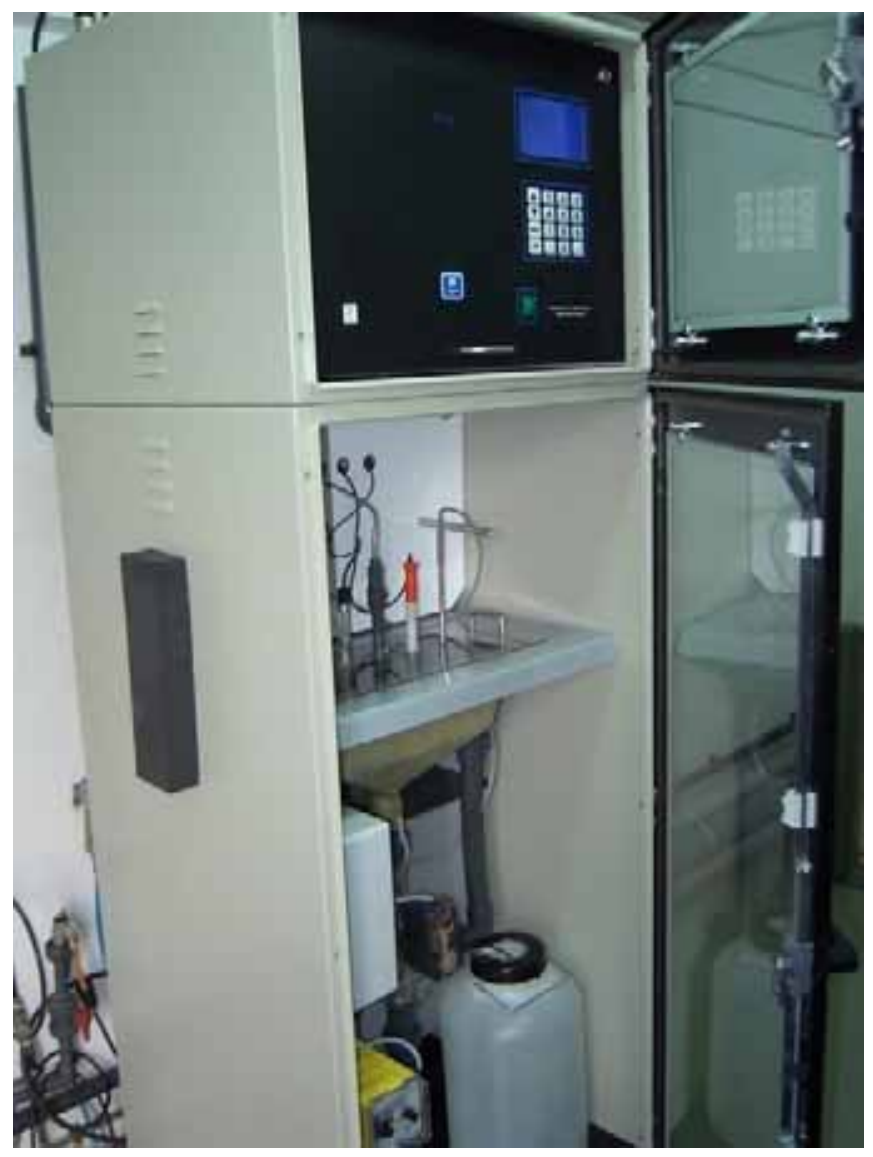

Figura 2-4: Vista del panel con sensores. Arriba bloque procesador, en el centro línea de medida y abajo desagüe, bombas y líquido para auto-limpieza.

La estación está dotada de un equipo receptor de la medida encargado de almacenar los datos. Estos datos son trasladados a un PC que se encarga de procesar estos datos convenientemente. El equipo multiparamétrico incorpora tres salidas de señalización mediante relés:

- Una salida para la activación de un sistema externo de autolimpieza de las sondas, característica que hace a este equipo adecuado para una operación automática e ininterrumpida sin atención del operador, siendo sólo necesario intervenciones de mantenimiento periódicas y programadas.

- Una salida para la información de que alguna señal está en fuera del rango de valores establecidos.

- Una salida para la generación de una señal de toma de muestra por alarma. Esta señal, configurable por el usuario, puede generar una orden a un equipo de toma de muestras, con un número de maniobras programable e intervalo entre tomas también programable. 
El equipo está regulado por un sistema electrónico estando previsto el funcionamiento local, remoto y la comunicación con los equipos de la misma gama (funcionamiento en red). Básicamente el equipo electrónico se compone de microprocesador, del conjunto de periféricos necesarios para la lectura de datos analógicos, generación de señales de salidas e interfaces con el operador (teclado y pantalla) y de los módulos de acondicionamiento de las señales:

- Al módulo de acondicionamiento le llegan las señales eléctricas proporcionadas por las sondas de medida (normalmente 4 a $20 \mathrm{~mA}$ ), las cuales son transformadas (mediante amplificación, filtrado, o cualquier otra operación que sea conveniente) para que el microprocesador las pueda interpretar correctamente.

- El microprocesador capta las señales analógicas proporcionadas por el módulo de acondicionamiento, calcula el valor físico asociado a cada valor analógico, almacena los valores históricos de cada parámetro medido, y genera alarmas en función de estos valores.

Mediante el teclado y la pantalla es posible visualizar los valores instantáneos de los distintos parámetros. Además es posible realizar la configuración de los valores de alarma de cada una de las medidas, así como el calibrado de cada uno de los sensores.

Las sondas que se incorporen pueden elegirse entre un amplio abanico de las existentes en el mercado, en función de las características de la muestra, de preferencias o de cualquier otra consideración que el usuario estime importante.

Para cada una de las sondas el equipo dispone de salidas configurables que permiten transmitir las medidas ya procesadas a equipos de automatización y control.

En el Anexo: Estudio de la fiabilidad de los datos en sistemas automáticos, se muestra un breve análisis donde se pone de manifiesto la necesidad de la calibración, tanto automática como manual, y el efecto de deriva que sufren las medidas. A la vista de los resultados obtenidos mostrados en dicho apéndice, se observa que para realizar un estudio más profundo se haría necesario el conocer con mayor exactitud las características de los sensores, de forma que se puedan analizar, aparte de las oscilaciones propias de las medidas, la interpretación de los diferentes tipos de ruidos. Se propone el realizar un estudio a muy alta frecuencia para identificar el ruido "Flicker".

Por otro lado, la detección tan aparentemente clara del período de calibración, indica la importancia de este, y una mejora en las medidas, de forma que se eviten las derivas de los sensores, deberían manifestarse en una disminución de la potencia de estas. En definitiva, el análisis de la FFTs es un reflejo claro no sólo de los ciclos naturales que en este caso existen, y que cualquier alteración irregular se debería detectar, sino también de los fenómenos no deseados, siendo por tanto una herramienta muy útil para el análisis de los datos con este origen. 
Sería interesante realizar los estudios conducentes a identificar el ruido térmico en este tipo de montajes, ya que casi con total seguridad aparecerá. Por último, sería también interesante analizar las FFTs y autocorrelaciones de las señales ideales para obtener pautas de comportamiento predecibles, para poder identificar fallos en el sistema, de manera automática. Se propone asimismo el extender las FFTs a medidas completas por meses, de forma que dependiendo de la época del año así se tengan modelos predictivos.

$\mathrm{A} 1$ respecto de la afección del ruido a la hora de detectar e identificar contaminantes, no resulta tan trascendente como en el caso de los parámetros mostrados con anterioridad dado que la respuesta espectral analizada en cada caso puede ser filtrada. La deriva observada debida a las calibraciones resulta una derivada algo más compleja más allá del presente estudio, toda vez que en principio no tiene que observarse descalibración con el método propuesto. No obstante, y como se verá más adelante, un ajuste más preciso en la detección de contaminantes requiere la intervención de los parámetros como temperatura y $\mathrm{pH}$ y por tanto su inexactitud repercute indirectamente en la detección. Es interesante por tanto extender el estudio de sensores sin contacto a estas medidas, a fin de minimizar falsos positivos.

\subsection{Espectroscopía de fluorescencia}

\subsubsection{Fenómeno de la Fluorescencia}

La luminiscencia es el conjunto de fenómenos producidos en ciertas sustancias que se caracterizan por emitir radiación durante un tiempo, como consecuencia de la acción de un agente externo, que puede ser un campo eléctrico, una reacción química o radiación incidente. El fenómeno de la incandescencia (emisión de radiación visible como consecuencia de la temperatura que adquiere un cuerpo) tiene otro origen y por tanto no debe confundirse con los fenómenos de luminiscencia. La fotoluminiscencia ocurre cuando una substancia es excitada por medio de radiación electromagnética, pasando a un estado electrónico excitado. Esta absorción de energía posteriormente puede ser disipada de dos maneras diferentes una en forma de calor, por medio de colisiones entre átomos o moléculas cercanas, tal y como ocurre en la espectrofotometría de absorción.

$$
X+h \cdot v \rightarrow X^{*} \rightarrow X+h o t
$$

Y la segunda manera, en cambio, pierde una parte de esa energía absorbida en forma de calor, y el resto es emitida en forma de radiación electromagnética en una longitud de onda distinta a la de la fuente.

$$
X+h \cdot v \rightarrow X+h o t+h \cdot v^{\prime}
$$


La duración de la emisión depende de la substancia, del tipo de luminiscencia y del agente externo. El agente externo puede ser reacción química, campo eléctrico o radiación. Dependiendo entonces de estas variables, el fenómeno luminiscente toma distintos nombres, como quimioluminiscencia, sonoluminiscencia, triboluminiscencia, fosforescencia, fluorescencia, etc.

Se define fotoluminiscencia al proceso de emisión de radiación como consecuencia de la desactivación de una determinada molécula. Tal y como se ha indicado anteriormente, también se puede dar el caso de que la energía de excitación sea de otro tipo, no lumínica, originando entonces otras luminiscencias como la quimio-luminiscencia, donde la energía de excitación proviene de una reacción química, o si ésta se da en un ser vivo, recibe el nombre de bioluminiscencia. En este último caso, existen desarrollos en este sentido para la detección de cianobacterias entendiéndolas como agentes contaminantes. A su vez, las micro-algas también presentan clara bio-luminiscencia, y actualmente también se controla su densidad en aguas no circulantes (embalses y lagos).

En el trabajo aquí presentado se estudia la fluorescencia, fenómeno que no debe confundirse con la fosforescencia: ambos fenómenos son similares, pero normalmente la fosforescencia es de mayor duración. A las substancias que tienen fosforescencia se las denomina fósforos, no porque tengan en su composición química el elemento químico fósforo $(\mathrm{P})$, sino debido a que el término fósforo proviene del griego y significa "portador de luz". En algunos casos una pequeña variación en la composición de la substancia luminiscente hace que el fenómeno varíe su duración desde microsegundos hasta horas. El agente externo utilizado en los desarrollos aquí expuestos será radiación electromagnética del espectro ultravioleta cercano. Tanto en fluorescencia como en fosforescencia la longitud de onda de la radiación emitida por la substancia es mayor que la de la fuente de excitación. Esto es debido a que cuando la molécula absorbe un fotón, éste transfiere su energía a la molécula produciendo una variación en su estado fundamental cambiando la ocupación de los orbitales moleculares. La molécula se dice entonces que se encuentra en un estado excitado que es inestable respecto del estado fundamental, y una de las formas de perder la energía de excitación es caer a niveles más bajos. En función de la caída, se emitirá un fotón cuya energía está de acuerdo con la ley de Plank, y por tanto su frecuencia será mayor cuanto mayor sea el salto energético. El salto puede darse en uno o varios saltos, siendo en este segundo caso cuando se emiten varios fotones de menor energía. Esta emisión se produce después de la absorción, siendo el intervalo de tiempo de unos 10ns. Este espectro emitido con longitudes de onda mayores se denomina desplazamiento de Stokes. Si, como en el caso de los experimentos desarrollados en esta tesis, la fuente de luz de excitación se encuentra en el espectro del ultravioleta, la fluorescencia producida se dará en el espectro visible. Puede darse el caso que los fotones emitidos sean de la misma longitud de onda que los de la 
radiación absorbida: este caso se conoce como fluorescencia de resonancia. Sin embargo, es más común que la radiación emitida sea de una mayor longitud de onda que la absorbida. Esta diferencia hacia mayores longitudes de onda se denomina desplazamiento de Stokes. En el trabajo aquí presentado, tal y como se observa en los espectros de emisión de las substancias estudiadas, las longitudes de onda del espectro de emisión son claramente mayores. El estudio de otro tipo de substancias a detectar hace en cualquier caso necesario el estudio de las mismas bajo diferentes condiciones, dado que éstas pueden hacer que se modifique el espectro de emisión.

Algunas substancias son intrínsecamente fluorescentes, es decir, que presentan este fenómeno siempre, a diferencia de otras que sólo lo hacen cuando la substancia se encuentra ligeramente contaminada con otros elementos denominados activadores, como por ejemplo los iones de los metales de transición. Al contrario que estos, existen otras substancias llamadas venenos que al mezclarlas con una que sea fluorescente, impide su fluorescencia. El hierro es conocido por presentar esta propiedad. Es importante por tanto, determinar cuidadosamente la elección de los compuestos que pueden ser detectados mediante el procedimiento aquí presentado, ya que si es susceptible de ser contaminado con substancias que intensifican o impiden su fluorescencia, la detección de los mismos puede verse comprometida. Por ello, la determinación de la intensidad lumínica de la fuente de radiación es muy importante, puesto que la intensidad de la radiación emitida por fluorescencia es proporcional a la intensidad de la radiación incidente. Dado que este estudio se ha realizado dentro de la cuenca del Tajo, no existen aguas en las que se encuentre el hierro en cantidades a tener en cuenta, pero esto no significa que no sea necesario el estudio previo de las características del agua realizado en laboratorio.

Los hidrocarburos presentan ciertas propiedades que facilitan esta labor, entre las que cabe destacar su menor densidad que el agua, de forma que no se mezclan. En las medidas realizadas, para provocar la excitación se han utilizado fuentes de luz ultravioleta en el entorno de los $365 \mathrm{~nm}$, que es una longitud de onda a la cual fluorecen, entre otros, los compuestos aromáticos y heterocíclicos aromáticos con anillos fusionados, los compuestos con dobles enlaces conjugados múltiples, los compuestos policíclicos, las purinas, los nucleósidos y los polienos conjugados. Cada una de ellas debe quedar caracterizada por su espectro de emisión. En éste, se observa la energía que emiten las moléculas como consecuencia del proceso previo de excitación y absorción, siendo éste último, característico de cada substancia. 


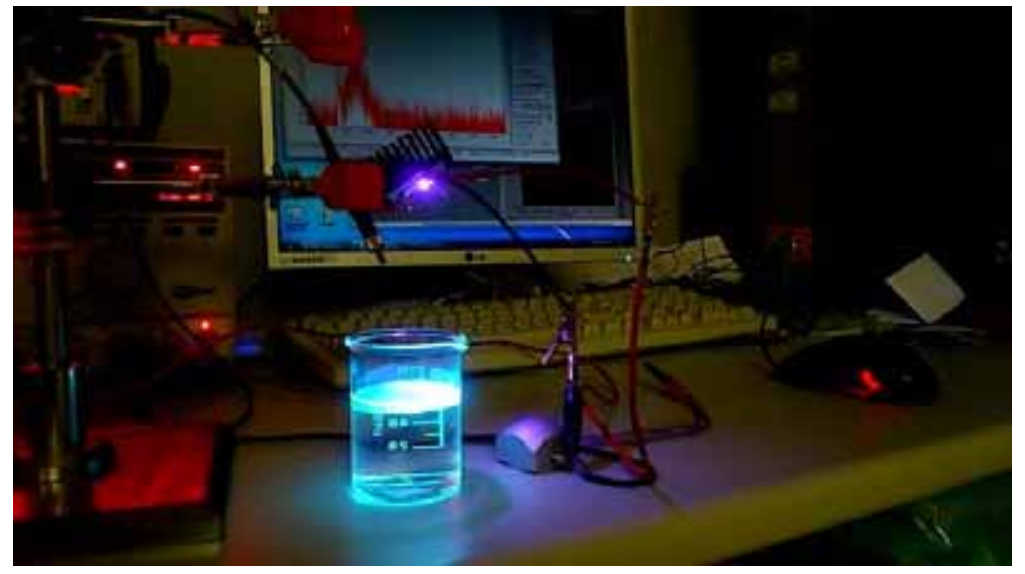

Figura 2-5: Fluorescencia de gasóleo C producida por LED ultravioleta de 365nm

Estudios previos en este sentido han sido realizados para la detección de vertidos en medio marino [EGV08] [JLG08] [GVS+06], pero, cómo se ha apuntado anteriormente para largas distancias y necesitando el empleo de una fuente de luz muy potente a fin de poder obtener resultados [LFL05] [BF03] operativos. En cambio, apenas hay desarrollos de este tipo para la medida en tiempo real en aguas continentales, principalmente ríos y embalses, para los hidrocarburos. Los hechos, sin embargo, demuestran que periódicamente se producen episodios de contaminación también en aguas continentales, con resultados desastrosos. Para que un proyecto de estas características fuese viable su implantación verdadera y de manera general, debería ser posible su realización mediante una técnica sencilla, económica, fiable y que permitiese control en tiempo real.

\subsection{Los hidrocarburos como contaminantes.}

\subsubsection{Breve definición de los hidrocarburos}

Los hidrocarburos constituyen los elementos esenciales del petróleo, son compuestos orgánicos que contienen carbono e hidrógeno en sus moléculas. Se dividen en varias familias químicas dependiendo de la estructura que presentan las cadenas moleculares Carbono-Carbono. Pueden presentar enlaces simples, dobles y triples (Figura 2-6). El átomo de carbono presenta cuatro electrones libres para compartir en los compuestos orgánicos pudiendo formar cuatro enlaces covalentes con otros átomos de carbono, o como en el caso de compuestos más complejos, con otro elemento como oxígeno, nitrógeno, azufre, etc. 


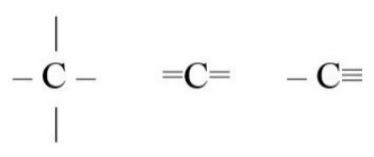

Figura 2-6: Cadenas de Carbono

El petróleo es un líquido natural oleaginoso e inflamable cuyo color puede variar desde el negro hasta casi incoloro. Se encuentra en el interior de la tierra, aflorando en ocasiones a la superficie de forma natural, y consiste básicamente en una mezcla de hidrocarburos. Está originado por restos de plantas y animales sometidos a altas presiones y temperaturas ayudado por bacterias anaerobias. Se encuentra normalmente lejos de la superficie en los anticlinales, en casi todas las rocas sedimentarias inalteradas. Los productos refinados derivados del petróleo pueden dividirse en tres grandes grupos:

- Gases Ligeros: como el gas butano y el gas propano.

- Intermedios: gasolina, aceite lubricante, gas-oil, naftas.

- Pesados: fuelóleos y asfaltos.

Pueden presentar enlaces simples, dobles y triples. Hay diferentes clases según esos enlaces:

- Hidrocarburos alifáticos saturados o alcanos: se unen en cadenas abiertas, lineales que pueden tener ramificaciones. Las parafinas presentan cadenas lineales.

- Isoparafinas: presentan cadenas ramificadas.

- Hidrocarburos alifáticos insaturados, Olefinas o Alquenos: presentan dobles uniones entre los átomos de carbono. No están presentes en el petróleo crudo o los productos de destilación directa, pero sí aparecen en productos de refino.

- Hidrocarburos aromáticos: son hidrocarburos cíclicos poli-insaturados, están presentes en una gran proporción en los crudos del petróleo. Los más sencillos contribuyen a aumentar el número de octanos de las gasolinas. $\mathrm{Y}$ se forman cuando los ciclos de carbono presentan dobles uniones alternas (anillo bencénico). Su efecto cancerígeno y liposolubilidad implican que los derivados del petróleo representen un riesgo para la salud humana y el equilibrio ecológico.

Además de hidrocarburos, el crudo contiene compuestos de azufre, de nitrógeno y de oxígeno. El contenido en azufre está relacionado con la calidad del crudo. 
Los procesos de refino se pueden clasificar por orden de realización en destilación, conversión y tratamiento (Figura 2-7). En la destilación se separan debido al calor los distintos componentes del crudo en la torre de fraccionamiento. Las fracciones más ligeras ascienden hasta la parte superior de la torre a medida que descendemos encontramos los productos más pesados (Figura 2-8). En la conversión se realizan operaciones químicas mediante catalizadores o calor se rompen las moléculas. Antes de su comercialización se someten a tratamiento para eliminar compuestos no deseados como los derivados del azufre.

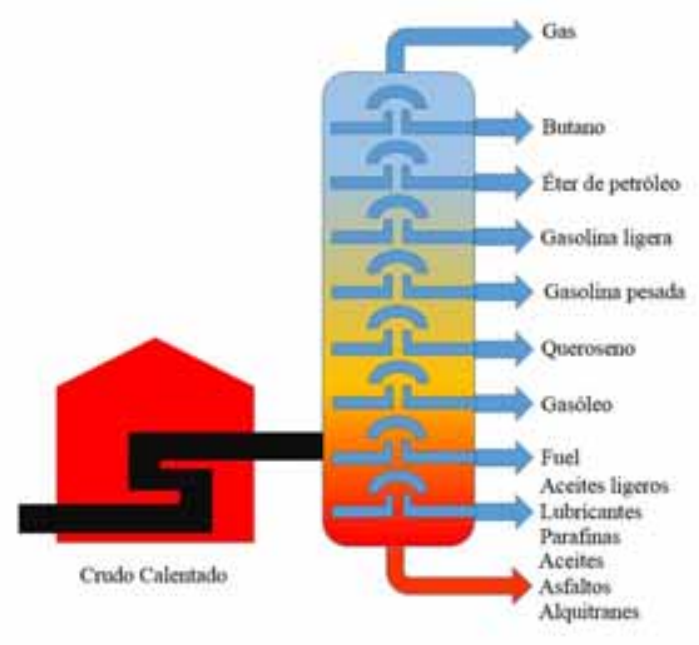

Figura 2-7: Obtención de Hidrocarburos por método de destilación

Dependiendo del número de átomos de carbono presentes, los hidrocarburos varían en viscosidad. El espectro característico del material está relacionado con la densidad de la muestra, siendo ésta es menor cuanto mayor es la relación atómica H/C. A partir de estos datos y de otros elementos que le son añadidos para fijar la velocidad de combustión, cada compuesto presenta un espectro característico.

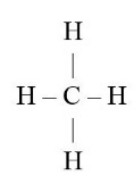

METANO

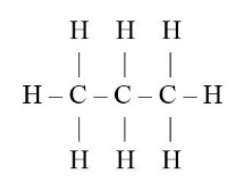

PROPANO

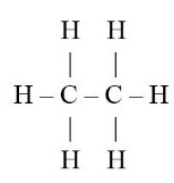

ETANO

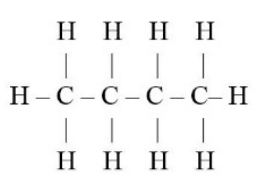

BUTANO

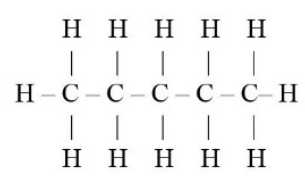

PENTANO

Figura 2-8: Algunas de las cadenas Carbono-Hidrógeno derivados del petróleo

Según los fabricantes, incluyen en las fichas de estos derivados la forma y potencial contaminante: 
Persistencia y degradabilidad: Liberado en el medio ambiente los componentes más ligeros tenderán a evaporarse y foto-oxidarse por reacción con los radicales hidroxilos, el resto de los componentes más pesados también pueden estar sujetos a fotooxidación pero lo normal es que sean absorbidos por el suelo o sedimentos. Liberado en el agua flota y se separa y aunque es muy poco soluble en agua, los componentes más solubles podrán disolverse y dispersarse. En suelos y sedimentos, bajo condiciones aeróbicas, la mayoría de los componentes del gasóleo están sujetos a procesos de biodegradación, siendo en condiciones anaerobias más persistente. Posee un DBO de $8 \%$ en cinco días.

Movilidad/bioacumulación: Los log Kr* de los componentes del gasóleo sugieren su bioacumulación, pero los datos de literatura demuestran que esos organismos testados son capaces de metabolizar los hidrocarburos del gasóleo.

Efecto sobre el medio ambiente/ecotoxicidad: Tóxico para los organismos acuáticos, puede provocar a largo plazo efectos negativos en el medio ambiente acuático.

Son por tanto elementos que no deben encontrarse presentes en agua de lagos y ríos, y por tanto su detección precoz resulta muy conveniente. Dentro de estos derivados del petróleo, los elementos más comunes que pueden encontrarse en aguas continentales, bien por accidente o bien por negligencia son los siguientes:

\section{Gasolina:}

La gasolina es una mezcla compleja de hidrocarburos con un número de átomos de carbono entre 5 y 9 por molécula. Sus principales componentes son hidrocarburos parafínicos, nafténicos y aromáticos procedentes del proceso de refino del crudo. Además puede haber presencia de benceno. Es un líquido ligeramente soluble y de color amarillo claro pálido, a veces está teñido de verde.

\section{Gasóleo A:}

El gasóleo es utilizado en los motores de tipo diesel, es decir motores con encendido por compresión. Los principales componentes son hidrocarburos olefínicos, saturados y aromáticos provenientes de la destilación del petróleo. Puede contener hidrocarburos policíclicos aromáticos. Contiene entre 15 y 18 moléculas de carbono, es líquido de color pajizo claro. Es más pesado y aceitoso que la gasolina.

Aceite:

Los aceites minerales se obtienen de la destilación del petróleo bruto aplicando procesos de refinación. En cambio los aceites sintéticos se obtienen por reacciones químicas (esteres e hidrocarburos de síntesis). Los lubricantes tienen entre 20 y átomos de carbono. 
El aceite de parafina (lubrificante) está formado por los hidrocarburos líquidos más densos, pero debe contener la menor cantidad posible de parafina, de la que se priva por refrigeración. Es de color amarillo, pardo o negro y muy espeso.

Vemos que a medida que aumenta el número de átomos de carbono por molécula disminuye la intensidad de la fluorescencia y en consecuencia aumenta el ruido.

Fuelóleos:

Son combustibles residuales, se trata del residuo que queda cuando se somete al crudo a destilación atmosférica. Su composición en hidrocarburos depende de las que tuviera el crudo original. Contiene más de 20 átomos de carbono por molécula y es de color negro. Dos de los más comunes son:

IFO 380 (Intermedian Fuel Oil) es un fuel pesado, el mismo que se transportaba en el Prestige. Contiene hidrocarburos saturados, aromáticos, resinas y asfaltenos.

Fuelóleo 1BIA: Es un fuel comercializado en España, con un Bajo Índice de Azufre (BIA). Por lo demás es similar a cualquier otro tipo de fuel.

\subsubsection{Octanaje: composición y clasificación}

En el caso de las gasolinas, es necesario hablar del octanaje, ya que para el control de éste se introducen aditivos que hacen que varíe su composición y por tanto el espectro obtenido. El octanaje, también llamado número de octanos es una medida de calidad y capacidad antidetonante de las gasolinas. La gasolina entra en el pistón junto con el aire en el proceso de admisión, siendo posteriormente comprimida. En este proceso la gasolina no puede explosionar, ya que el quemado prematuro (preignición) hace que el cigüeñal se extienda sin completar el ciclo, perdiendo eficiencia el motor. De la misma forma, la explosión, cuando se produce correctamente, debe empujar el pistón de una forma constante y continua. Un alto número de octanos producen una combustión más suave, liberándose la mayor cantidad de energía, reduciendo también los residuos. Antiguamente se utilizaba el tetrametil plomo $\left(\left(\mathrm{Pb}\left(\mathrm{CH}_{3}\right)_{4}\right)\right.$ como aditivo antidetonante, pero tenía el inconveniente de liberar a la atmósfera partículas de plomo que por supuesto generaban perjuicios en la salud pública, razón por la cual se tuvo que pensar en sustitutos menos nocivos. Por otro lado, la aparición de vehículos con catalizador hacen incompatible la presencia del plomo, ya que los catalizadores (fabricados con una rejilla de platino, óxidos de metales de transición o rodio) con los que se pretende reducir en más de un $80 \%$ las emisiones de monóxido de carbono, hidrocarburos y óxidos de carbono se obstruyen con el plomo.

Como elementos sustitutivos del plomo se han ido introduciendo aditivos oxigenados que favorecen la combustión más completa de los hidrocarburos de la gasolina. El más empleado ha sido el metil tert-butil éter (MTBE), seguido del etano el metanol, el tert-butil alcohol y otros. 
Concretamente, el MTBE está ampliamente extendido y se ha añadido con diferentes porcentajes en distintos países, variando desde menos de un $0.5 \%$ en el Reino Unido hasta más del 7\% VOL. en Finlandia. Por otro lado, la cantidad de oxígeno puede influir también en la fluorescencia, ya que éste tiende a desactivar cualquier estado excitado, en función de cómo se encuentre asociado.

Pero lo que en principio se ideó como un elemento para reducir la contaminación atmosférica, supone un problema ambiental para los recursos hídricos, ya que se trata de un compuesto orgánico volátil muy soluble en el agua y de lenta degradación.

Este y otros elementos añadidos a las gasolinas en distintas composiciones y proporciones, hacen que las huellas espectrales que presenten sean diferentes, por lo que se hace necesario la obtención de patrones de los distintas sustancias potencialmente peligrosas, generando una base de datos lo más completa y ampliable posible.

\subsubsection{Conclusiones}

Los derivados refinados del petróleo, y en particular los hidrocarburos destinados a la automoción, son ampliamente utilizados en nuestra sociedad actual, y a diferencia de otros subproductos del petróleo, su reparto geográfico se encuentra extensamente distribuido con disparidad tanto en cantidad como en concentración, por lo que se multiplica la posibilidad de accidentes, pudiendo perjudicar la tierra, el aire o las aguas. Los accidentes donde grandes tanques de combustible explosionan, dan como resultado humos tóxicos que se desplazan en función de las corrientes. Las medidas de seguridad que se aplican a este tipo de almacenamientos son muy restrictivas debido al daño material y contra las personas que se ocasiona con este tipo de situaciones, alertándose rápidamente a los cuerpos de seguridad de forma que se minimicen los daños. Sin embargo, existen otro tipo de accidentes con cantidades sustancialmente menores (debido a la distribución antes mencionada) cuya alerta se produce mucho después de ocasionado o incluso pasa desapercibido. En el medio acuático, este tipo de vertidos resultan enormemente perjudiciales, por lo que los hidrocarburos como contaminantes son un objetivo muy interesante en la detección aquí propuesta. Además, presentan fluorescencia con relativa facilidad, por lo que son un candidato ideal en el desarrollo propuesto. Sinn embargo, la diferencia en la formulación de cada fabricante, hace que sea conveniente el estudio particular de cada compuesto. 


\section{Estudio de las fuentes de luz}

\subsection{Fuentes de luz en espectroscopía de fluorescencia}

Para que se produzca el fenómeno de la fluorescencia, es necesario que la sustancia a detectar emita en una longitud de onda superior a la de la fuente lumínica con la que se irradia, el ultravioleta cercano [L06] [EGV08]. La fuente lumínica es por tanto el componente más importante a la hora de realizar el sistema. Por ello, para conseguir los objetivos planteados en esta tesis se realizaron diversas colaboraciones con el Departamento de Tecnología Fotónica y Bioingeniería de la U.P.M., ya que han desarrollado un sistema basado en láser [EGV08] con el objetivo de detectar fuel en aguas marinas a largas distancias (Figura 3-1). El montaje se basa en la medición del tiempo de decaimiento de la fluorescencia producida, y se compone fundamentalmente en tres componentes principales:

- Láser de nitrógeno de $337 \mathrm{~nm}$.

- Fotomultiplicador

- Sistema de procesado con una muy alta frecuencia de muestreo.

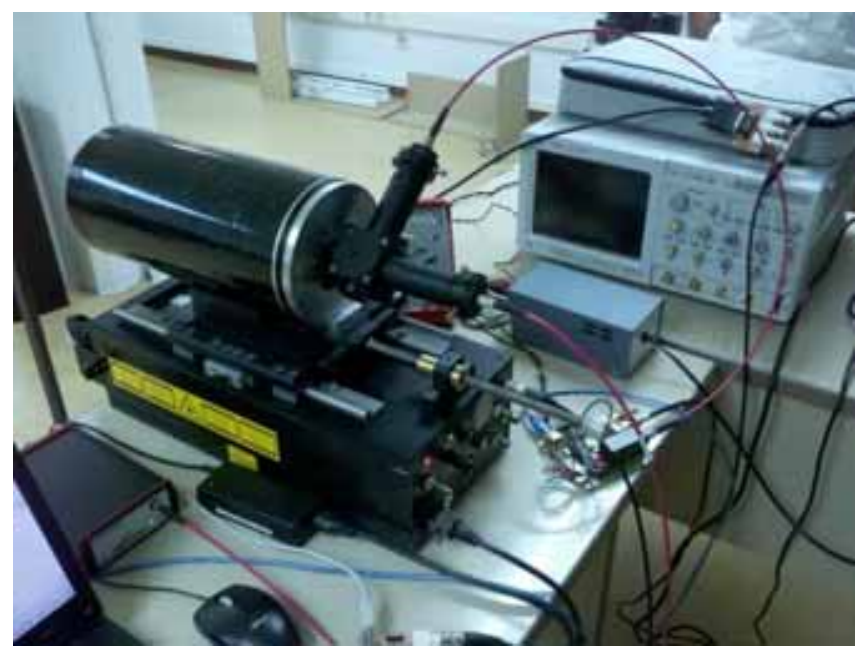

Figura 3-1: $\quad$ Dispositivo desarrollado para la detección de crudo en agua marina.

El dispositivo desarrollado ha obtenido resultados satisfactorios, permitiendo unas capacidades operativas día/noche detectando incluso contaminantes sumergidos, espesores y 
concentraciones. Gracias a la elevada potencia que ofrece un sistema laser, es posible la elaboración de mapas de contaminación. Con la experiencia de primera mano, en el presente estudio no se hacen necesarios muchos de los requisitos del sistema de detección en aguas marinas, por lo que se hace fundamental la correcta elección de la fuente de excitación.

Existen muchas fuentes de luz ultravioleta. Éstas deben presentar una potencia lumínica suficiente para excitar el compuesto, siendo además estable durante el período de tiempo en el que se realiza la medida. Una breve descripción de algunas de ellas servirá para una mejor comprensión de la elección de la misma para un sistema como el presentado. Se requiere una fuente fiable y robusta, capaz de funcionar 24 horas/día, de coste y tamaño reducido. A cambio, no es necesario que presente exactamente una luz completamente monocromática, admitiendo una cierta anchura en el espectro de emisión. Se describen a continuación cuatro de las más utilizadas en laboratorio.

- Lámparas de descarga: se trata de una ampolla de vidrio o cuarzo en cuyo interior se encuentra una mezcla de gases. Al aplicar una tensión entre sus extremos el gas es ionizado, conduciendo una corriente eléctrica que hace que el gas emita en longitudes de onda propias del compuesto. Dado que se requiere un adaptador para fijar el voltaje requerido, y que es necesario a su vez un monocromador para eliminar las líneas espectrales no deseadas, este tipo de fuentes no se adapta a las necesidades requeridas para el equipo presentado, si bien si son utilizadas en laboratorio.

- Lámparas de media y alta presión: Similares a los fluorescentes, tienen en su interior presiones más altas. Necesitan un período de calentamiento hasta que la presión interior del mercurio alcanza el régimen de funcionamiento. Dado su bajo coste en comparación con las otras aquí presentadas, es una de las opciones sometidas a estudio.

- Tubos de luz negra: emite en ultravioleta de la banda A, y algo en el espectro visible, por lo que puede superponerse con el espectro de emisión. Se diferencia de los anteriores en que el vidrio del que está fabricado es de un color violáceo oscuro llamado cristal de Wood, que impide el paso de casi toda la radiación visible por encima de los $400 \mathrm{~nm}$. El tubo contiene un fósforo que absorbe la radiación de $365 \mathrm{~nm}$ (típica del mercurio) y emite entre 350 y $370 \mathrm{~nm}$. Para emitir en $365 \mathrm{~nm}$ se emplea silicato de Bario dopado con plomo. Este tipo de tubos ha sido ensayado en otros medidores en continuo en estaciones automáticas, como en el caso de los analizadores de demanda biológica de oxígeno (BOD). Aunque los hay de tamaño reducido y la emisión es correcta a 
las necesidades del proyecto tanto en intensidad como en frecuencia, presentan un desgaste notable, y los repuestos son muy específicos debido la forma del tubo y tipo de casquillo, no se encuentran siempre disponibles.

- Lámparas de mercurio tipo lápiz: se mencionan en este apartado este tipo de lámparas por ser bastante utilizadas en numerosas aplicaciones como cromatografía, absorción atómica, microlitografía, mineralogía, etc. Básicamente son tubos de baja presión con los electrodos en un extremo. Al aplicar radiofrecuencia emiten rayas de mercurio, sobre todo en $253.7 \mathrm{~nm}$, por lo que se emplean como fuente de calibración espectral. Sin embargo, para su utilización en la medida en continuo, y en una longitud de onda única, ocurre lo mismo que con las lámparas de descarga.

A diferencia de los trabajos mencionados anteriormente donde se proponen fuentes lumínicas láser [LFL05] [BF03] [RBH+09], que normalmente emiten dentro del ultravioleta cercano usando láseres de nitrógeno a $337 \mathrm{~nm}$, presentan ventajas como la elevada potencia de emisión, permitiendo hacer medidas a distancias largas y obteniendo muy buenos resultados, aquí se busca una fuente lumínica que permita, en primer lugar el desarrollo de patrones de los contaminantes comunes para distancias cortas. Para ello la fuente debe emitir en unas longitudes de onda similares al láser anteriormente citado, asegurando así buenos resultados. Al mismo tiempo, al no necesitar rangos de distancia tan grandes, la potencia requerida es menor. Transmitir alrededor de los 350nm asegura buenos resultados [5], existiendo bombillas comerciales que presentan una intensidad lumínica suficiente y a coste reducido.
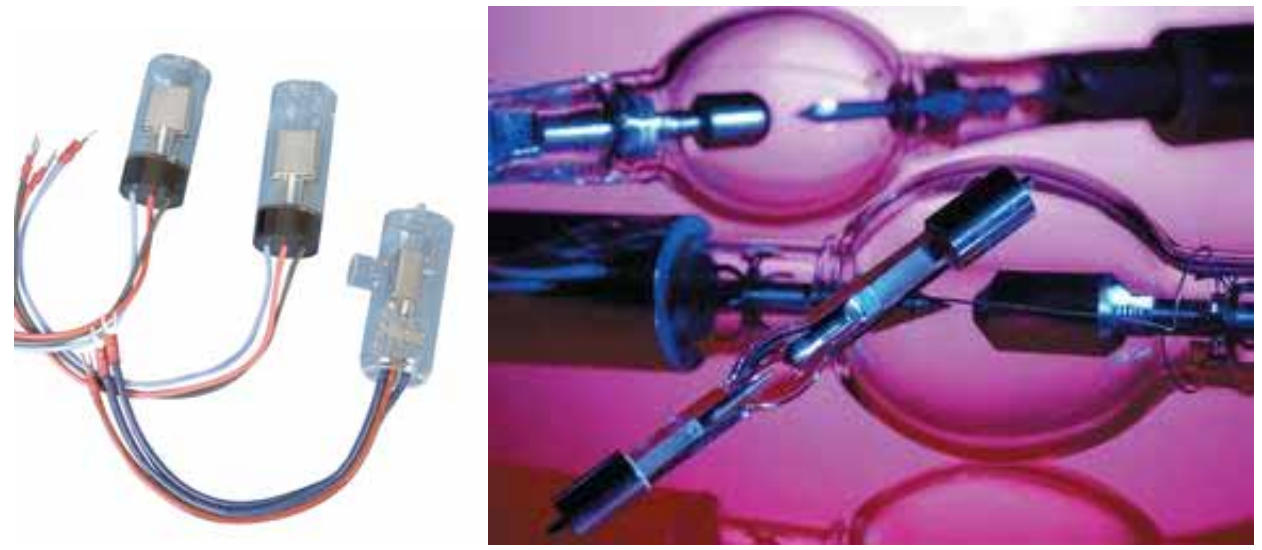

Figura 3-2: Fuentes de luz utilizadas en instrumentación de laboratorio.

Dado que se requiere una fuente económica y robusta, examinado el mercado se analizan tres elementos que pueden resultar adecuados para este fin:

- Bombilla de luz en el ultravioleta cercano, a $365 \mathrm{~nm}$ (Figura 3-3). Este dispositivos es bastante económico comparado con otras fuentes, pero presenta diversas restricciones como la 
imposibilidad de realizar medidas de tiempo de decaimiento, en el caso de ser necesario, dado que no permite la iluminación estroboscópica. Existen sistemas mecánicos de obstrucción de luz que resultan aptos para entornos de laboratorio, pero inviables en estaciones de funcionamiento continuo donde se tiene que reducir el número de componentes mecánicos. Sin embargo, como elemento de comparación dado que emite en un rango relativamente ancho con respecto a las otras dos fuentes presentadas, resulta interesante su estudio.

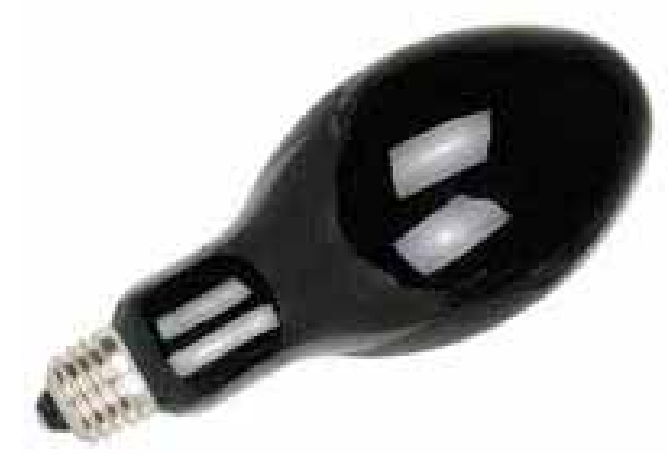

Figura 3-3: Bombilla de gas de mercurio a $365 \mathrm{~nm}$ con casquillo E46 utilizada para el ensayo.

Este tipo de emisores presentan otras dos particularidades que conviene tener en cuenta: han de calentarse suficientemente antes de emitir con la intensidad y longitud de onda nominales $\mathrm{y}$, al cabo de un determinado tiempo de funcionamiento, se autodesconectan por exceso de temperatura hasta que se vuelven a enfriar. Como hecho adicional, cabe destacar que, al elevar su temperatura pueden calentar la muestra a analizar, por lo que ha de tenerse en cuenta este efecto a la hora de analizar los resultados puesto que la fluorescencia es dependiente de la temperatura. Por ello, en los ensayos realizados se controló repetidamente las temperaturas de las muestras, usándose un termómetro sin contacto. Éste, a pesar de no ser el único factor que afecta a la fluorescencia, es el que se ha tenido más en cuenta, ya que al aumentar la temperatura disminuye la emisión. Otros factores que habrán de tenerse en cuenta en ensayos posteriores serán la naturaleza del compuesto a nivel de viscosidad (a mayor viscosidad, mayor fluorescencia), nivel de acidez ( $\mathrm{pH}$ ) o presencia de oxígeno. Todos estos factores tendrán mayor influencia y variabilidad cuando se analicen las muestras en el medio natural, y no en el laboratorio.

- Otra fuente utilizada en este análisis es un diodo laser de baja potencia ( $5 \mathrm{~mW})$, que emite en 405nm (Figura 3-4). En principio parece una opción muy conveniente, puesto que a pesar de tener baja potencia, la emisión lumínica se encuentra muy concentrada, teniendo un consumo muy bajo y teniendo un coste bajo. La elevada direccionalidad puede solventarse confinando el paso de agua o realizando un barrido espacial, pero esto conllevaría al problema presentado para la fuente de luz anterior, ya que se debería incluir un sistema mecánico. Por otro lado, el tiempo 
de encendido es muy reducido, y la longitud de onda mayor sirve en este estudio para validar el método, ya que en principio, el espectro de emisión es independiente de la longitud de onda de la fuente de excitación siempre que ésta sea menor que la de este espectro de emisión.

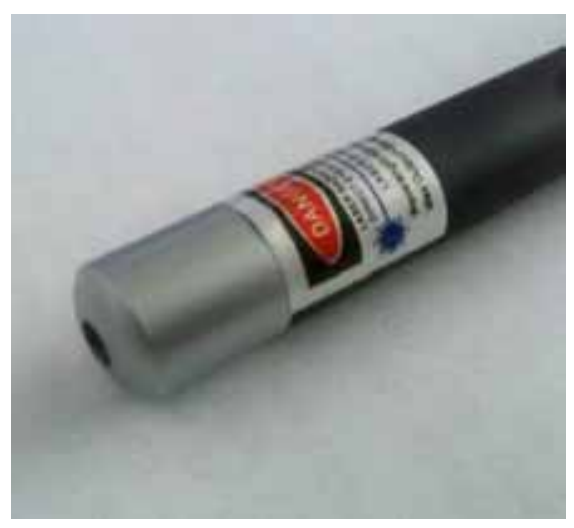

Figura 3-4: Laser de baja potencia a $405 \mathrm{~nm}$ utilizado para el ensayo.

- $\quad$ Por último, se realizaron medidas con un UV-LED que emite en el entorno de los $365 \mathrm{~nm}$ (Figura 3-5). Este LED es uno de los que primero aparecieron a frecuencias ultravioleta con potencias más elevadas que las existentes, de forma que ya no se trata de un LED de señalización, sino de iluminación. Tanto el costo como la dificultad para conseguir estos dispositivos resultaron elevados cuando se realizaron las medidas aquí reflejadas. Posteriormente, para los estudios presentados más adelante en esta tesis, fueron utilizados otros de mayor potencia ya que salieron al mercado con relativa celeridad.

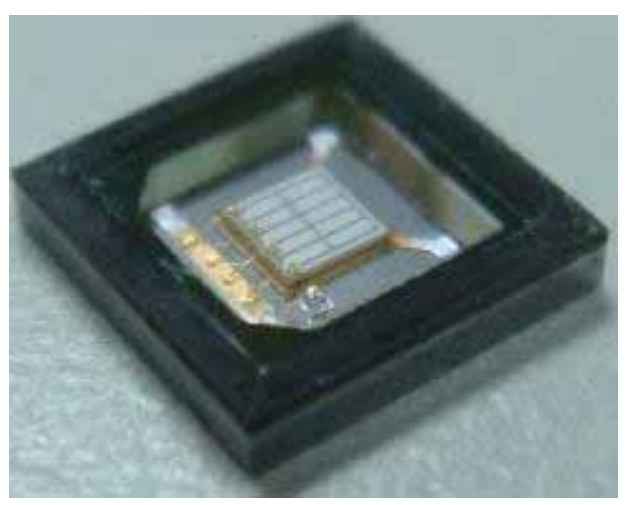

Figura 3-5: $\quad$ LED a $365 \mathrm{~nm}$ utilizado para el ensayo

Las ventajas de este dispositivo son obvias, ya que éste tiene un tiempo de respuesta muy pequeño, permite modular la corriente de alimentación mediante un driver controlado por pulsos (PWM). Además, la luz emitida no se encuentra tan concentrada como en el caso del láser, abarcando una mayor área. 


\subsection{Resultados obtenidos}

Se procedió a realizar mediciones en el laboratorio con diferentes hidrocarburos que pueden estar presentes en las aguas continentales. En este estudio se muestran las fluorescencias producidas por combustible diésel, gasolina y aceite lubricante de coche. Se ha mantenido la misma escala en las gráficas con excepción de los obtenidos con el láser, donde las escalas son diferentes. Las medidas se realizaron con un vaso de precipitados Pyrex con agua destilada y con una lámina de diferentes tipos de hidrocarburos, obteniendo patrones de referencia iniciales para detectar contaminantes. Las muestras fueron conservadas a baja temperatura en recipientes de cristal de laboratorio (Figura 3-6) previamente lavados y secados de forma que no hubiese sustancias que alterasen las medidas. Con el fin de intentar obtener una respuesta estandarizada, hubo un espesor de deposición uniforme de $1 \mathrm{~mm}$ y una distancia fija de $8 \mathrm{~cm}$ entre el agua y la fuente de luz.

En este estudio se han analizado dos tipos de gasolina con diferentes índices de octano, dos tipos comunes de diésel (que tienen diferentes aditivos, que pueden ocasionar cambios en la respuesta espectral) presentes en las estaciones de servicio, y el diésel B para vehículos agrícolas y otros usos tales como calderas de calefacción. Adicionalmente se introdujeron muestras de aceite de motor, ya que también es probable que aparezca en el medio ambiente acuático, siendo altamente contaminante. Aunque en este primer estudio es más importante la respuesta fluorimétrica, estos resultados pueden ser útiles para la identificación exacta de los contaminantes en los futuros desarrollos por lo que el procesamiento posterior será más elaborado.

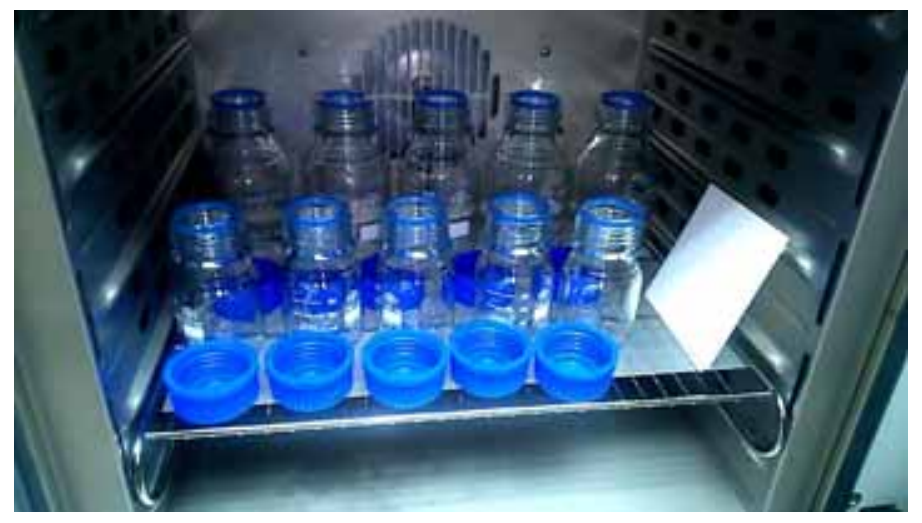

Figura 3-6: Preparación de los recipientes contenedores de las muestras de hidrocarburos.

En los espectros obtenidos con la bombilla es claramente visible el efecto de calentamiento se mencionó anteriormente, en forma de pico romo a bajas frecuencias. Aunque este efecto es irrelevante, se muestra al estar dentro del rango de longitudes de onda representadas.

A este respecto los otros resultados, las respuestas espectrales aparecen presentar marcas muy distintas en cada uno de los compuestos, aunque es necesario el procesamiento de los 
mismos. Más resultados ambiguos se obtienen con la fuente de láser, por lo que deben estudiar más a fondo con este dispositivo. Con el $365 \mathrm{~nm}$ fuentes de luz son espectros similares, propios para cada contaminante. Al igual que ocurre en lo espectros de absorción, algunos presentan picos muy definidos, y otros en cambio muestran curvas muy suaves como en todos los casos estudiados.

En las respuestas obtenidas mostradas en la Tabla I se incluye un amplio margen de longitudes de onda del receptor (espectrómetro) con el fin de comprobar el nivel de ruido así como corroborar la no presencia de falsas respuestas provenientes de fuentes ajenas o de fallos del propio espectrómetro, permitiendo además verificar que todos los compuestos en estudio fluorecen con relativa facilidad cuando se utiliza una excitación de $365 \mathrm{~nm}$, siendo claramente diferenciada con la muestra no contaminada (solo agua). En el caso del aceite, aunque menos volátil, ha mostrado también una respuesta fácil de obtener y similar a la de los otros hidrocarburos estudiados como se muestra en la Tabla $\mathbf{I}$.

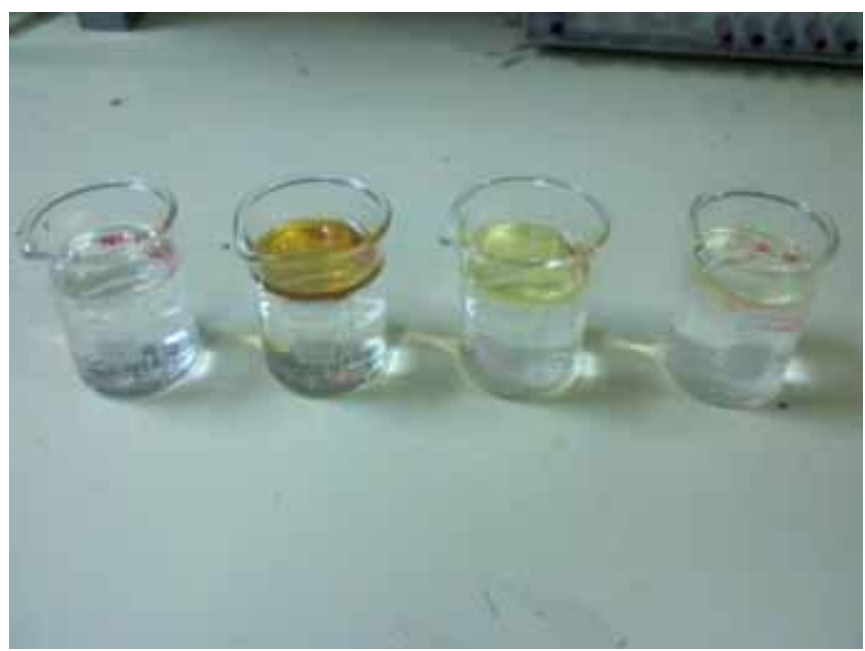

Figura 3-7: Distintos hidrocarburos en recipientes con agua destilada. 


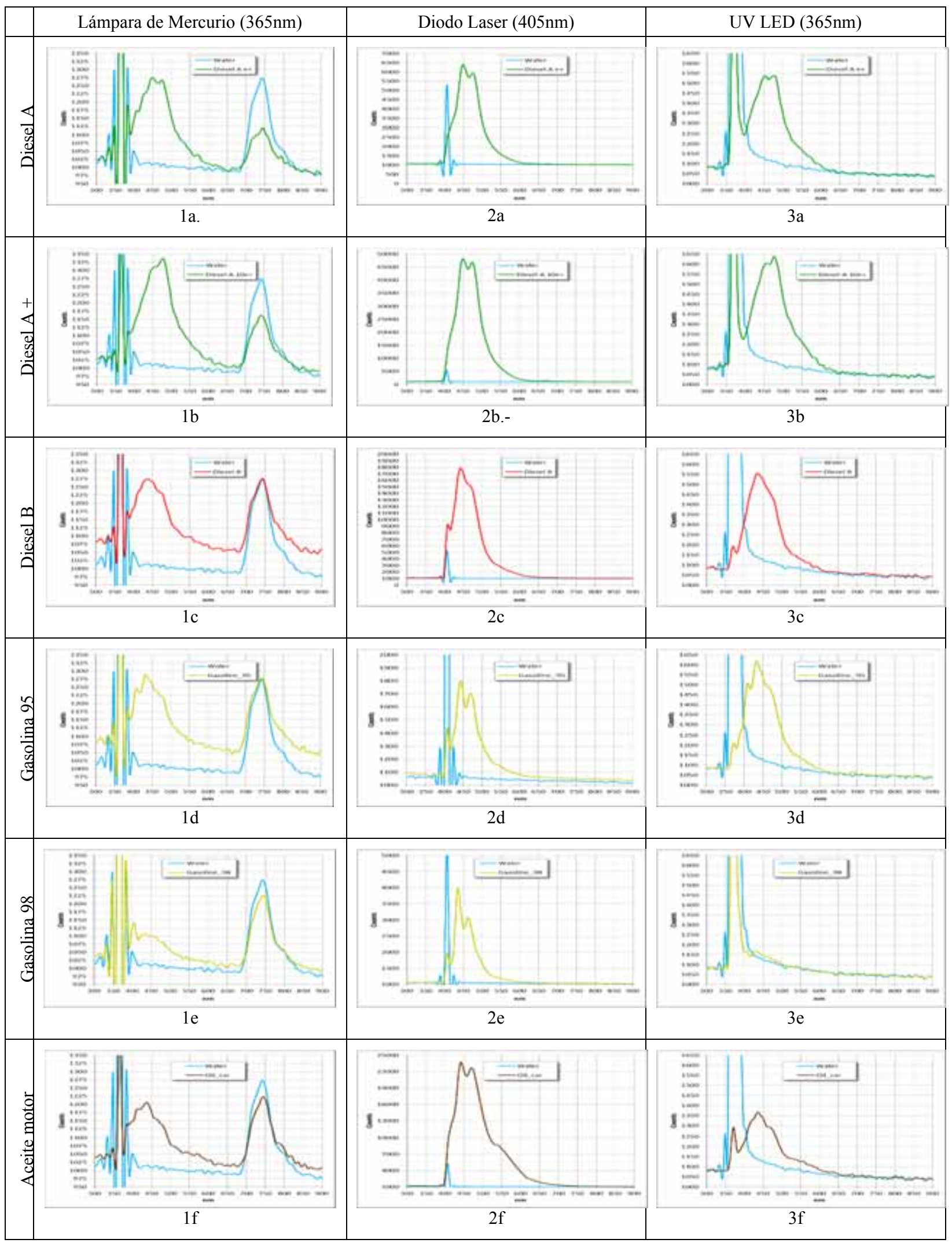

Tabla I.- Fluorescencias producidas por diversos hidrocarburos comerciales al ser irradiados con luz UV de varias fuentes. 


\subsection{Conclusiones}

Por medio de fuentes de luz de bajo coste se puede obtener fluorescencia de diferentes compuestos, cuyos espectros pueden medirse por medio de los nuevos espectrómetros de tamaño muy reducido y gran precisión. Dentro de las fuentes de luz estudiadas, el LED se presenta como el más conveniente por el reducido tamaño y consumo, así como rápida respuesta. El diodo laser en principio parece una alternativa más adecuada, pero la respuesta obtenida es altamente dependiente de los ángulos tanto del emisor como del receptor, y en el caso de un sistema en continuo donde el agua es circulante, esta circunstancia se daría en numerosas ocasiones debido a las oscilaciones de la lámina del líquido. Esto provoca resultados "todo-nada" o respuestas que saturan el receptor.

Por otro lado, aunque los espectros obtenidos deben ser independientes de la longitud de onda emitida, siempre y cuando ésta se encuentre por debajo de un valor umbral se observan diferencias entre las respuestas obtenidas con 365 y $405 \mathrm{~nm}$. Esto puede ser debido a la cercanía de esta longitud de onda umbral con las fuentes estudiadas, y por otro lado, a que la respuesta es proporcional a la potencia luminosa con la que se irradia la muestra, siendo claramente mayor con el diodo laser ya que la emisión se encuentra más concentrada.

Por tanto, en vista de los resultados obtenidos, el desarrollo de un sistema de control para detectar la presencia de hidrocarburos en aguas interiores es posible, al menos en una primera aproximación, siendo la medición y el uso de materiales y componentes mucho más barato que los sistemas utilizados para las aguas marinas. El banco de pruebas montado a estos efectos donde podríamos variar los ángulos de incidencia y reflexión, así como las distancias y las fuentes de luz, han sido eficaces para llevar a cabo las medidas presentadas. Una parte muy importante es la sección relativa a la adquisición y procesamiento de datos. Es posible un procesamiento simple que se puede hacer con el software y los dispositivos que no consumen mucha energía y no hay muchos recursos de hardware. 



\section{Metodología e instrumentación de medida}

En el capítulo anterior se evidenció que la firma de cada hidrocarburo era muy similar cuando se empleaban fuentes de luz de fundamentalmente monócromaticas de la misma longitud de onda. Una vez dado el primer paso, para demostrar la funcionalidad de los UV LEDs en la detección de los hidrocarburos había que medir e implementar procedimientos que permitiesen una detección adecuada, con las condiciones ambientales que exigíamos en el sistema propuesto, la medida sin contacto de agua fluente con hidrocarburo mezclado o en la superficie, la detección en tiempo real, y continua durante un periodo prolongado de tiempo.

En este capítulo se presenta una propuesta de un sistema de medida donde se puedan poner en funcionamiento conjunto elementos novedosos que ofrecen la posibilidad de conformar un modo robusto y fiable para conseguir los objetivos propuestos, en comparación con los sistemas de laboratorio que son bastante complejos y voluminosos a cambio de una gran precisión. Previamente se realiza un estudio acerca de la viabilidad de la utilización de la longitud de onda de $365 \mathrm{~nm}$ propuesta a la vista de la disponibilidad en el mercado por medio de la absorbancia de los compuestos estudiados.

\subsection{Relación de la absorbancia con la fluorescencia}

La espectroscopía de absorción del compuesto se obtiene empleando un espectrofotómetro que mide la luz reflejada, (R) y transmitida (T) en función de la longitud de onda v. Ésta puede calcularse fácilmente a partir de estas medidas, ya que:

$$
A(v)+T(v)+R(v)=1
$$

Por tanto, en los métodos cuantitativos como el que se realiza en laboratorio, se realizan dos medidas de potencia radiante.

Es conveniente que el compuesto a analizar absorba la luz de la longitud de onda con la que se pretende que fluorezca, y aunque esto no garantiza que ésta se produzca, la medida de la absorbancia indica el rango de longitudes de onda que no pasan a través del compuesto y por lo tanto son absorbidas por ella, siendo posteriormente su energía liberada como calor, vibración o 
por emisión de fotón en la misma y/u otra frecuencia. Esto es particularmente útil en el análisis de sustancias con alta transparencia, como es el caso que se estudia.

Con el fin de corroborar los datos obtenidos, las medidas se realizaron primeramente con un espectrofotómetro Merck SpectroQuant ${ }^{\circledR}$ Pharo (Figura 4-1). Esta primera medida se realizó con diésel y se repitió tres veces para evitar errores, obteniéndose los resultados que se muestran

\section{en Figura 4-2.}

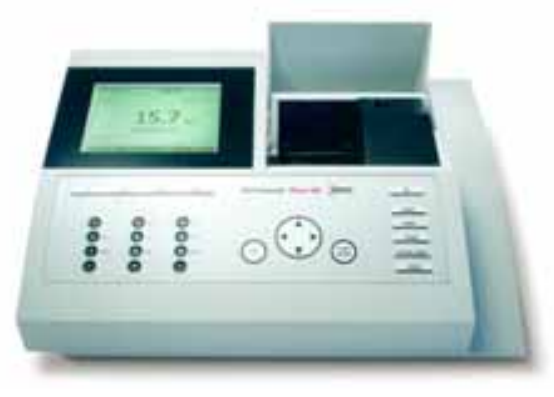

Figura 4-1: $\quad$ Espectrofotómetro Merck SpectroQuant ${ }^{\circledR}$ Pharo

En estos resultados se observa alta absorbancia en el rango de 350 a $370 \mathrm{~nm}$, coincidiendo con la longitud de onda emitida por los LED estudiados, por lo que la emisión alrededor de 350 $\mathrm{nm}$ resulta conveniente para obtener buenos resultados [GVS+06].

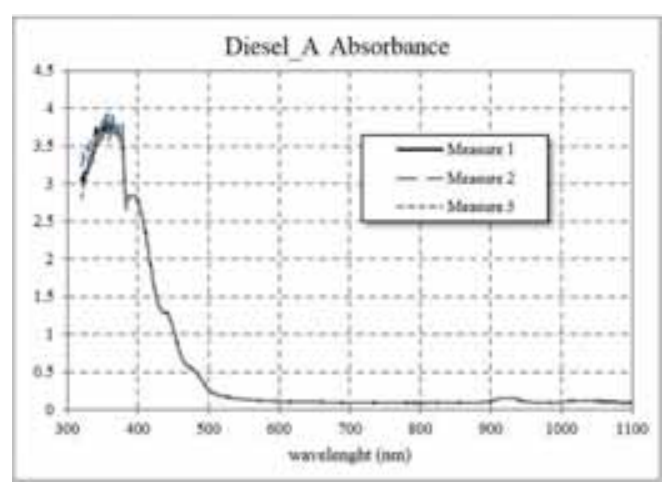

(a)

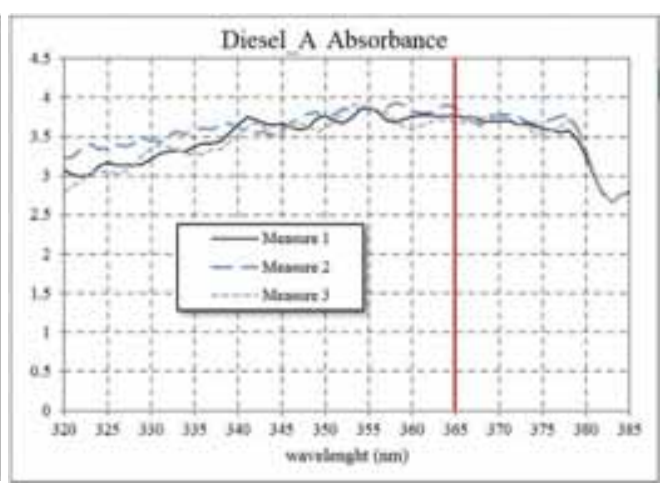

(b)

Figura 4-2: $\quad$ Absorbancia de Diesel A: Respuesta en amplio ancho de banda (a) y detalle de las longitudes de onda relevantes (b). La línea roja indica la longitud de onda de la fuente.

Posteriormente se repitieron estas medidas con varios tipos de hidrocarburos y con un espectrofotómetro más precio (PerkinElmer Lambda 25), obteniendo máxima absorbancia en un rango de longitudes de onda donde se encuentran los $365 \mathrm{~nm}$ a los que emiten los UV-LED estudiados, con la excepción de la gasolina de 95 y 98 octanos en la que la absorbancia a esta 
longitud de onda es mucho más baja. Por lo tanto, puede determinarse si para probar compuestos, hay una relación directa entre la energía absorbida y la generación de fluorescencia. Es decir, es posible determinar si la energía proporcionada por los fotones cuando son absorbidos por el compuesto causa un cambio de nivel en sus electrones a niveles más altos, y si esta energía se emite como luz de frecuencia más baja (fluorescencia) o como vibración (calor).

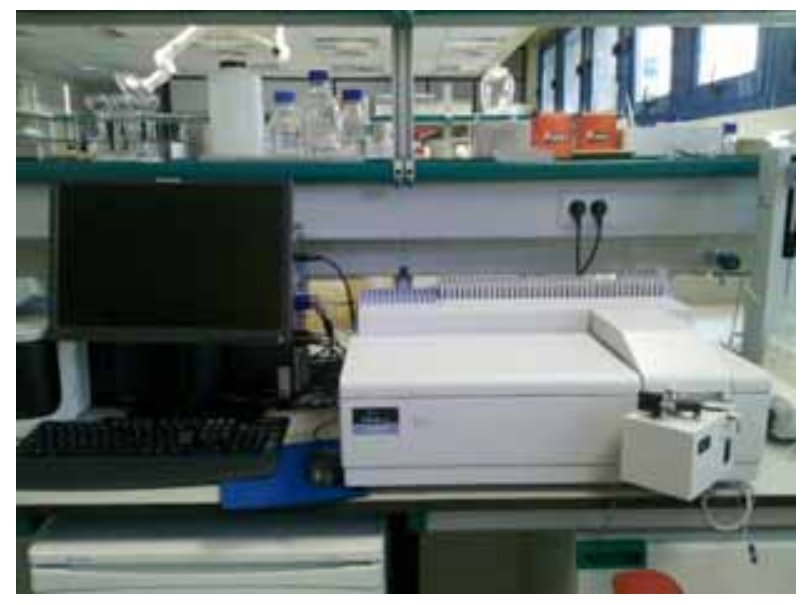

(a)

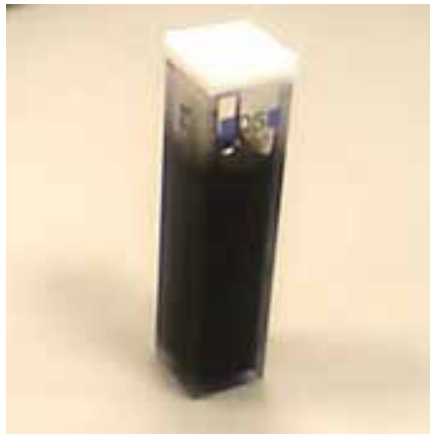

(b)

Figura 4-3: $\quad$ Espectrómetro Perkin Elmer ${ }^{\circledR}$ Lambda 25 utilizado en las medidas de absorbancia (a). Preparación de la muestra en recipiente (b).

Cabe destacar en los resultados obtenidos con el espectrómetro Lambda 25 la presencia de un alto nivel de ruido por debajo de los $330 \mathrm{~nm}$, que si bien no resulta trascendente para el presente estudio, es necesario indicar. En el resto de longitudes de onda las medidas coinciden con las realizadas con la instrumentación anterior, pero con este segundo la salida de datos tiene una mayor precisión ya que almacena un mayor número de registros.

Las muestras deben ser preparadas en un recipiente de un material en el que la luz del espectro de la radiación a estudiar atraviese con las menores pérdidas Figura 4-5(b), que puede ser de cuadro o sílice fundida. De la misma forma, en el manejo de los recipientes debe tenerse especial cuidado ya que huellas dactilares, polvo u otros materiales alteran la medición. La correcta limpieza de los recipientes para la realización de cada medida por tanto es indispensable. 


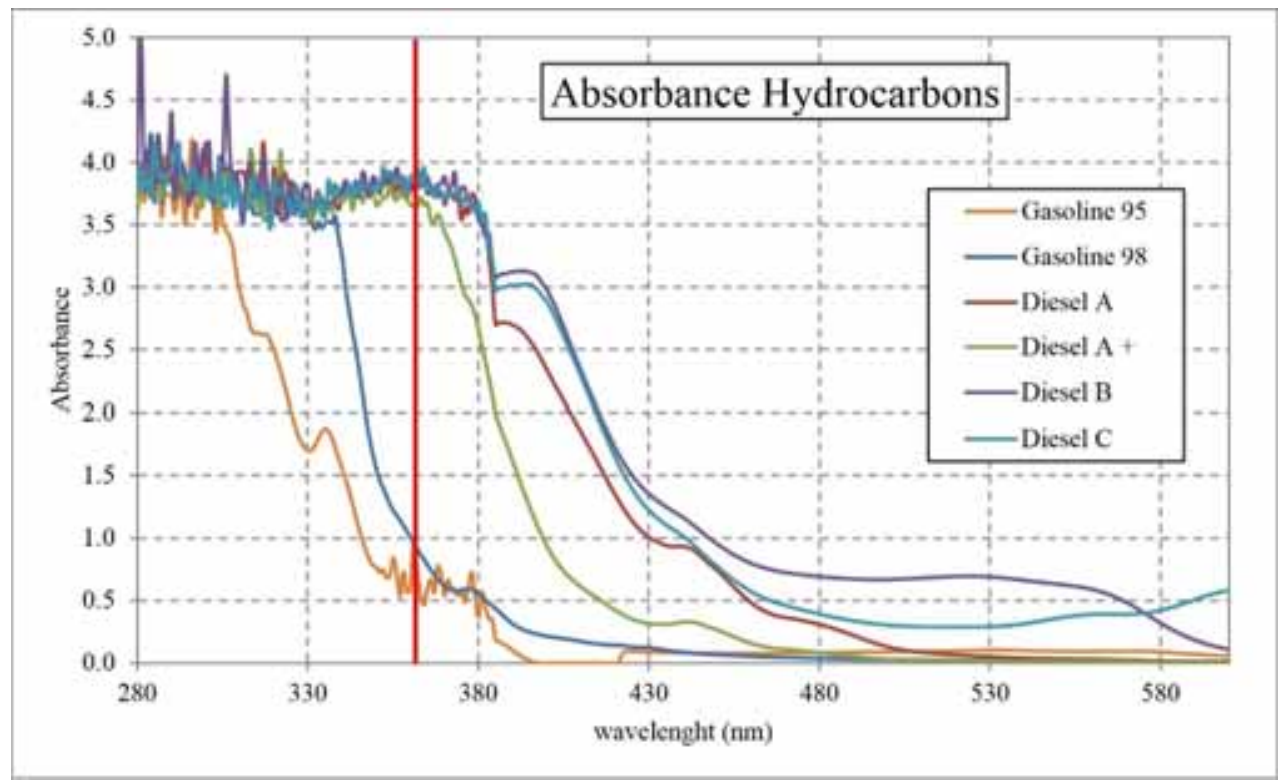

Figura 4-4: Absorbancia de los hidrocarburos estudiados

Aunque todas las medidas presentadas son realizadas tomando como longitud de onda de excitación los $365 \mathrm{~nm}$, cuando la tecnología se encuentre desarrollada para longitudes de onda menores, resultará interesante un estudio con éstas, dado que pueden existir estados energéticos mayores que pueden ser alcanzados a la vista de los resultados de absorción obtenidos.

En la Figura 4-5 se muestran los resultados comparando la absorbancia con la fluorescencia producida. Con el fin de que sirvan de referencia, se representan valores normalizados. Los valores absolutos representativos pueden consultarse en el apartado 10 (Anexo). En el caso de los cuatro gasóleos la zona de alta absorbancia contiene la longitud de onda de excitación. Sin embargo, en el caso de las gasolinas, ambas se encuentran en una zona de baja de absorbancia, y se obtienen más bajas fluorescencias. Para el caso de la gasolina 98 la respuesta tiene una potencia lumínica menor dentro del rango de longitudes de onda a la que han respondido el resto de hidrocarburos, siendo prácticamente la mitad que para la gasolina 95. La respuesta a la misma longitud de onda que la de la excitación, se debe a dos efectos: en primer lugar a la re-emisión de los fotones absorbidos, llamada "resonancia de fluorescencia", y aunque es característica de la fluorescencia atómica, se observa también en la fluorescencia molecular y en segundo lugar a la reflexión. Este segundo efecto se ha calibrado variando el ángulo del receptor, de manera que se debe observar una potencia lumínica mucho mayor en el mismo ángulo que el de la fuente de excitación de producirse solamente reflexión. Sin embargo, los resultados mostraron una emisión notable a la misma longitud de onda en todos ángulos, por lo que existe un acusado efecto de la llamada resonancia de fluorescencia. 


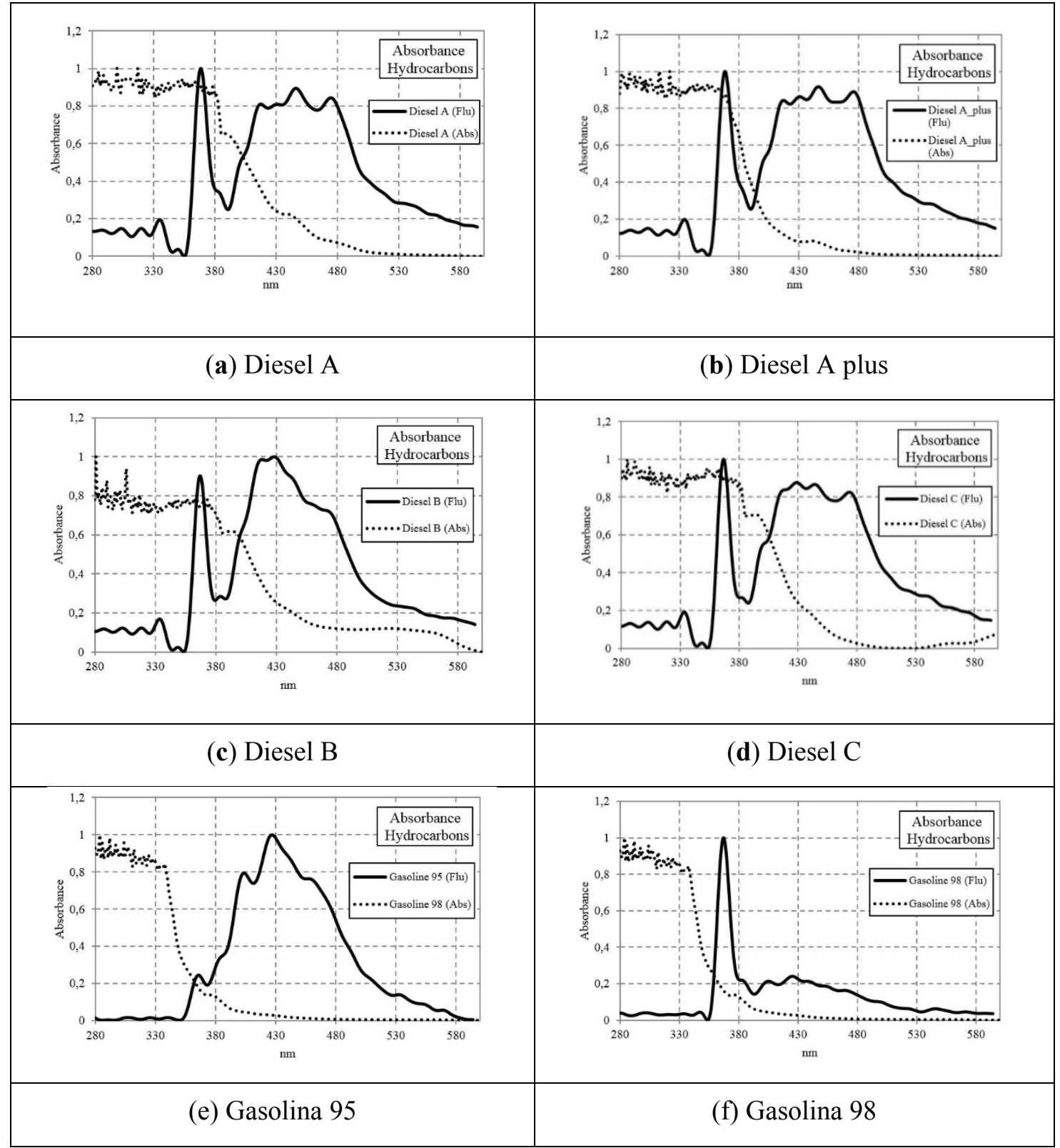

Figura 4-5: $\quad$ Comparativa Absorbancia vs. Fluorescencia de distintos hidrocarburos

\subsection{Instrumentación convencional en espectroscopía}

Los sistemas existentes para la medición en continuo de los parámetros de calidad de agua proporcionan valores en tiempo real de oxígeno, $\mathrm{pH}$, conductividad, temperatura, etc. Analizadores más sofisticados se han desarrollado para medir (en modo continuo) de nitrógeno, amonio, fosfatos, etc. Estos métodos pueden en algunos casos, identificar el detrimento de la calidad del agua o bien la contaminación de la misma de forma indirecta. El exceso de amonio o de nitrógeno, por citar algunos ejemplos, son detectados mediante esta técnica, revelando una mala depuración o el vertido de fertilizantes. Sin embargo, para la detección de contaminantes 
concretos, es necesario tomar la muestra de agua y transportarla bajo unas condiciones normalizadas, a un laboratorio donde identificar el tipo de contaminación. Es por tanto muy interesante desarrollar sistemas para la detección temprana de sustancias específicas que no deben estar presentes en el agua. En este sentido hoy en día se están realizando muchos esfuerzos para desarrollar la siguiente generación de medidores en continuo. Todos estos sistemas siempre serán complementarios de los análisis de las muestras se efectuarán en los laboratorios certificados donde las medidas allí realizadas son más completas y exhaustivas, siguiendo un esquema de trazabilidad que hace que además puedan servir como prueba para una posible sanción. Un ejemplo de ello es la medición de sólidos totales, metales (mercurio, cromo, plomo...) y no metales (boro, sulfato...). ICP (Inducted Coupled Plasma) espectrometría óptica y de masas se utilizan para medir los metales presentes en el agua (Figura 4-6a). En cuanto a la medición de hidrocarburos, cromatografía de gases con dispositivos con FID (Flame Ionization Detection) es ampliamente utilizado en el laboratorio (Figura 4-6b).

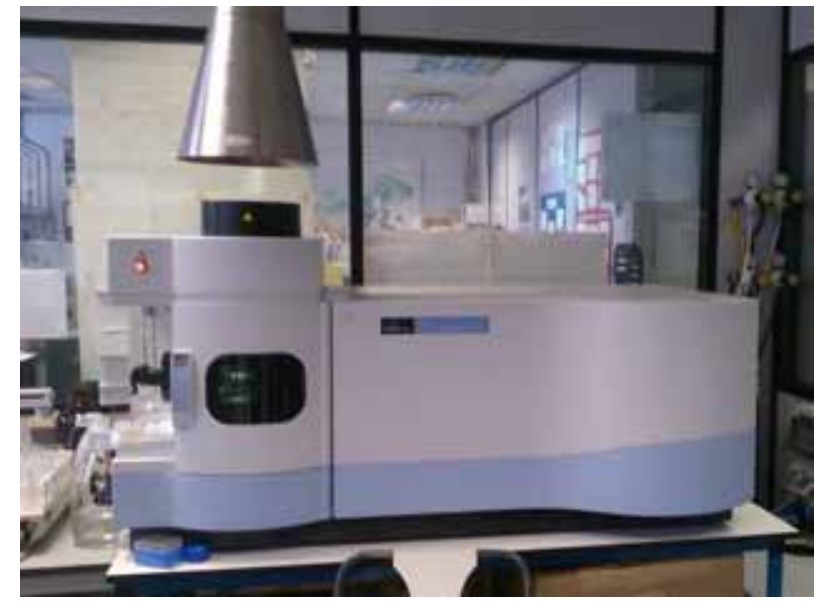

(a)

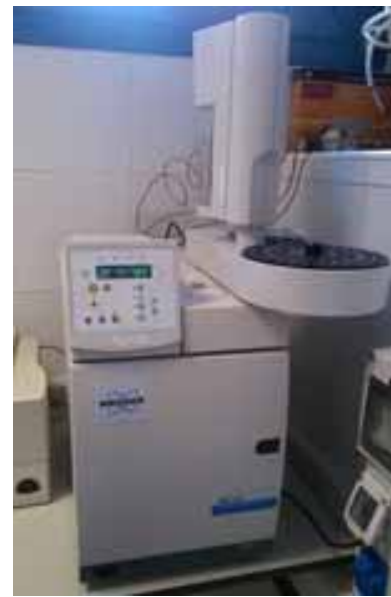

(b)

Figura 4-6: Instrumentación para detección de Hidrocarburos: (a) ICP. (b) FID

La espectroscopia de fluorescencia es un método conocido desde hace décadas, que ha sido ampliamente desarrollado en los últimos años con las nuevas tecnologías, haciendo posible identificar sustancias mezcladas con agua [HBM+09] [CAH13] [NTC+14]. Este método analítico se basa en la fluorescencia molecular, que como ya se ha indicado anteriormente se trata de un tipo de luminiscencia en la que las moléculas emiten fotones cuando los electrones pasan de estados excitados a estados más estables, por lo tanto, se requiere una fuente de radiación $[\mathrm{VVG}+10]$. En particular, los hidrocarburos son compuestos volátiles que responden 
claramente con fluorescencia cuando son excitados con una fuente de luz de una determinada gama de frecuencias, por lo general la gama ultravioleta, debido a su alta energía de la radiación.

En la figura Figura 4-7 se representa el esquema un espectrofotómetro utilizado como instrumentación clásica de laboratorio. La muestra a analizar se compara con un patrón de forma que se busca la coincidencia de los espectros obtenidos.

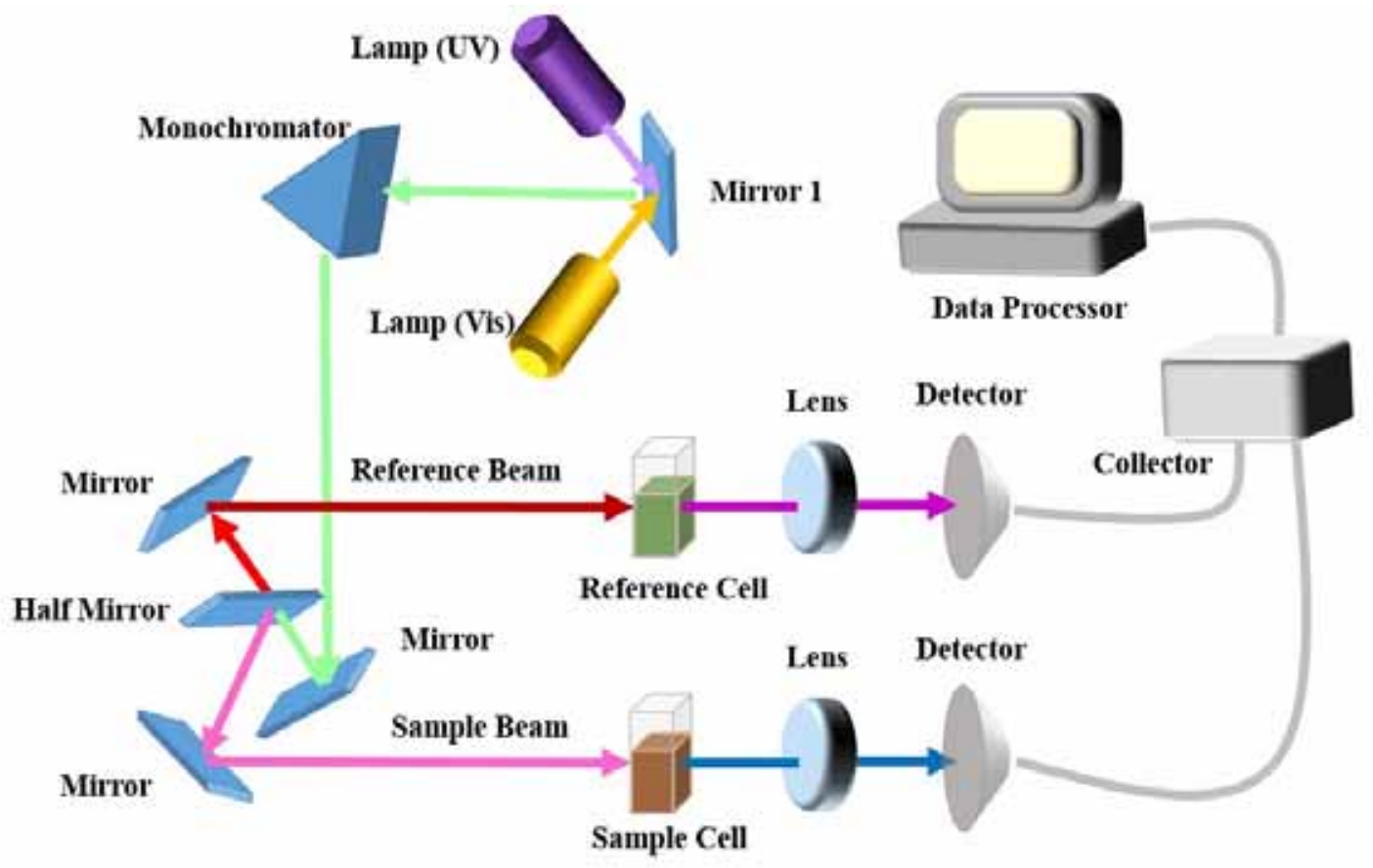

Figura 4-7: Diagrama de Bloques de un espectrofotómetro de doble haz clásico

Tal y como se observa en la figura, el proceso de identificación se basa en la emisión de una luz proveniente de una o más fuentes de forma que se cubra el espectro deseado. La luz generada pasa a través de un monocromador, de manera que se obtenga un haz en una única longitud de onda. La luz monocromática pasa a través de la muestra y del patrón (contenidas en celdas especiales de vidrio óptico o cuarzo), obteniéndose el espectro de transmisión de ambos. Se repite el proceso cambiando el monocromador a otra longitud de onda hasta cubrir el espectro deseado. Los datos obtenidos son comparados en base a diversos criterios, en función de los cuales se deduce la coincidencia o no de ambos.

Actualmente este tipo de instrumentación ha sufrido muchos cambios, ya que el uso de procesadores más complejos, así como la inclusión de resultados en bases de datos ha hecho que se mejore el procedimiento original, que obligaba a disponer de muestras conservadas convenientemente, reponiéndolas periódicamente debido a la degradación de éstas. Sin embargo, en las medidas de laboratorio se hace necesario preparar la muestra a analizar en un recipiente de cristal de cuarzo, ya que el aparato de medida tiene en cuenta las pérdidas por reflexión en las 
interfaces, reduciendo el error a las pérdidas por dispersión en el compuesto. Teniendo en cuenta que se producen reflexiones en las interfaces aire/cristal y cristal/compuesto, normalmente se realiza una medida de calibración en ausencia de sustancia o con disolvente, en caso de ser utilizado. Este proceso pone de manifiesto la complejidad del método, de muy difícil implementación en la realización de un sistema de medidas en continuo. La eliminación de interfaces hace mucho más factible el desarrollo de un sistema de estas características, ya que no se requiere una medida cuantitativa de precisión como en el caso del laboratorio.

\subsection{Banco de trabajo propuesto}

De la misma forma, durante los últimos años ha habido avances importantes en varias áreas tecnológicas, cuya integración permite el desarrollo de un sistema de espectroscopía de fluorescencia moderna aplicada en la detección e identificación de sustancias específicas, utilizando un equipo portátil o fijo con la identificación en tiempo real 24/7. Con el fin de aprovechar todos estos avances en las diferentes áreas tecnológicas se requieren equipos multidisciplinares que cubran los diferentes conocimientos. Un equipo que tenga en cuenta todos estos requisitos deberá cumplir ciertas características, como son:

Autónomo. El ordenador con alta capacidad de procesamiento software, varios métodos de $\mathrm{E} / \mathrm{S}$ y conectores (USB - Bluetooth - HDMI), de comunicación a distancia, etc. permite bajo costo con altas capacidades. El desarrollo de la aplicación específica puede llevarse a cabo con un procesador integrado y software comercial.

Flexible. El sistema ha sido diseñado principalmente para la detección e identificación de hidrocarburos que presentan alta de fluorescencia, pero la evolución puede aumentar o cambiar el reconocimiento de patrones por software. Cambiar o agregar nuevas fuentes de luz sólo es necesario si el alcance en la detección de contaminantes a identificar no responde adecuadamente mediante fluorescencia a la misma longitud de onda.

Fiable. Este tipo de equipo no utiliza partes mecánicas en movimiento. Debido a que el sistema sea un sistema de baja potencia electrónica que presenta una alta fiabilidad. Este equipo tiene un bajo poder que contribuye a la mejora de la fiabilidad. Los autores han trabajado en la mejora de la fiabilidad de uno de los elementos más críticos, los UV-LED.

Seguro: Si se produce la contaminación del agua se envía un aviso con un sistema de comunicación a distancia y redundante en tiempo real. Los autores han trabajado en un sistema de comunicación redundante específico. 
De coste reducido: La instrumentación propuesta sustituye a los elementos básicos del equipo de laboratorio complejo de fluorescencia, por elementos menos complejos gracias a las mejoras de las tecnologías y los nuevos métodos físicos para abordar el problema.

En un primer hito se tiene como objetivo detectar hidrocarburos que se pueden encontrar en las aguas continentales. Por lo tanto, la demostración de la instrumentación se realiza sobre estas sustancias, pero es extensible a otras sustancias mezcladas con agua y se puede aplicar a estaciones fijas automáticas, portátiles, boyas o vehículos subacuáticos autónomos, etc.

Teniendo en cuenta las características anteriormente mencionadas, se propone un banco de trabajo en el que se además se pueda estudiar la fiabilidad de cada una de las partes, la durabilidad así como el correcto funcionamiento del conjunto.

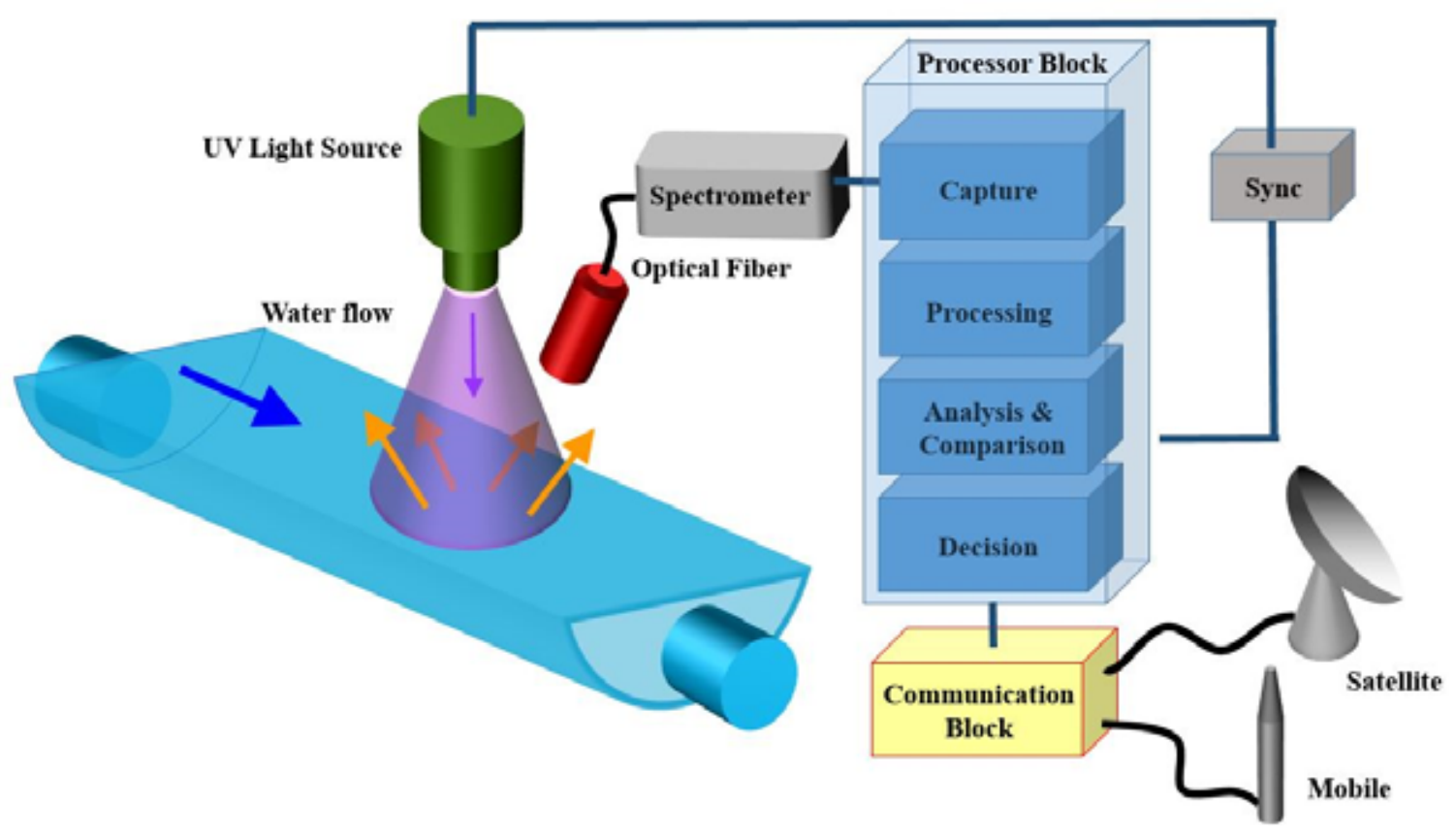

Figura 4-8: Diagrama de bloques del sistema propuesto

Tal y como se muestra en el esquema, el sistema se basa en la respuesta fluorométrica de la muestra circulante a través de un canal. Los sistemas de medición en continuo plantean el problema de la degradación de la medida por efecto de la acumulación de sedimentos en los sensores. Esto obliga a realizar autolimpiezas periódicas que en muchos casos no son suficientes, teniendo que realizar labores de mantenimiento manuales. La toma de datos sin contacto se presenta como una alternativa muy eficiente, pero se tienen que tener en cuenta factores importantes como la intensidad lumínica suficiente, disipación de calor y otros, como se indica más adelante. En los siguientes apartados se analizan las partes más importantes del diagrama. 


\subsubsection{Fuente lumínica LED}

Para la realización de los ensayos aquí presentados se han tomado dos tipos de LEDs comerciales de $3 \mathrm{~W}$, dado que son los de mayor potencia en el momento de realizar el estudio, si bien sí existen matrices de LED que ofrecen valores más elevados al combinar varias unidades de menor potencia.

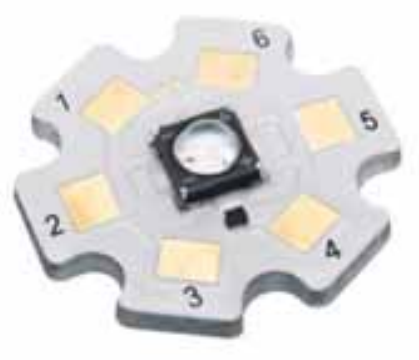

(a)

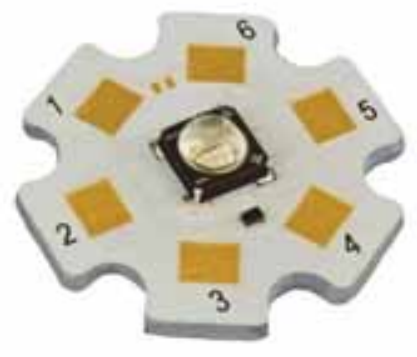

(b)

Figura 4-9: LEDs utilizados en los ensayos: (a) Tipo A y (b) Tipo B

Sin embargo la ventaja del estudio individual del dispositivo, hizo más conveniente el tratar con los primeros. Se tomaron por tanto dos modelos de reciente comercialización, ambos de características similares: $3 \mathrm{~W}$ de potencia, máxima potencia de emisión lumínica a una longitud de onda de $365 \mathrm{~nm}$, y $700 \mathrm{~mA}$ de corriente máxima nominal. Ambos tipos emiten en principio aproximadamente la misma potencia luminosa, existiendo diferencias entre ellos tanto en el chip como en el conexionado y presumiblemente en la silicona de la lente.

Aunque el mercado ahora mismo es muy cambiante dado que la evolución de estos dispositivos es muy rápida, ofreciendo cada vez mejores prestaciones, se han tomado para el estudio dos modelos del mismo fabricante, ya que de esta forma la comparativa resulta más interesante al diferir básicamente en la fabricación del chip y en el conexionado. El modelo A salió al mercado unos meses antes que el modelo $\mathrm{B}$, presentando el primero un conexionado en línea, frente al conexionado en cuadrícula que tiene el modelo posterior. En la Figura 4-10 se muestra en forma esquemática y el resultado real construido donde se puede apreciar esta diferencia. 

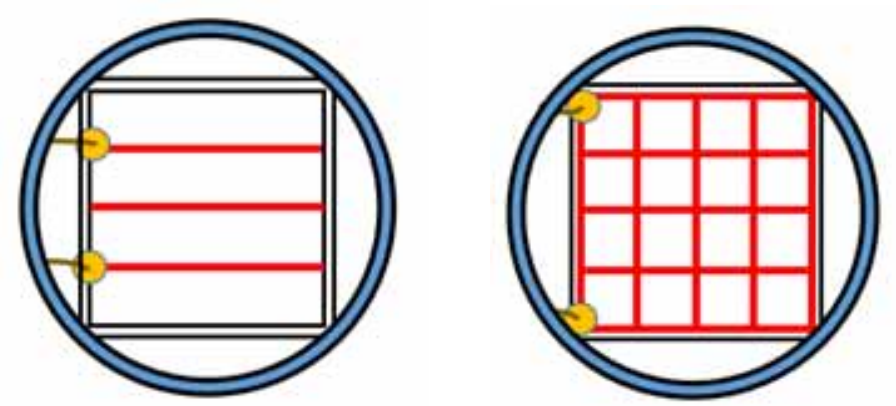

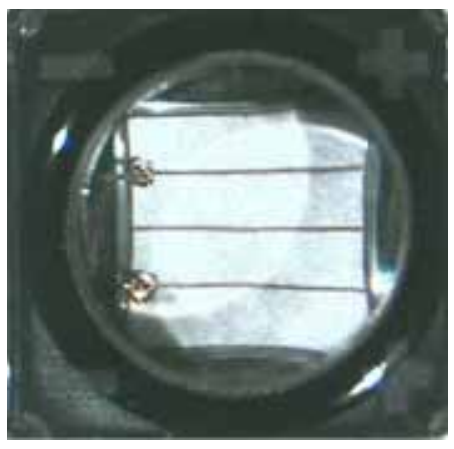

(a)

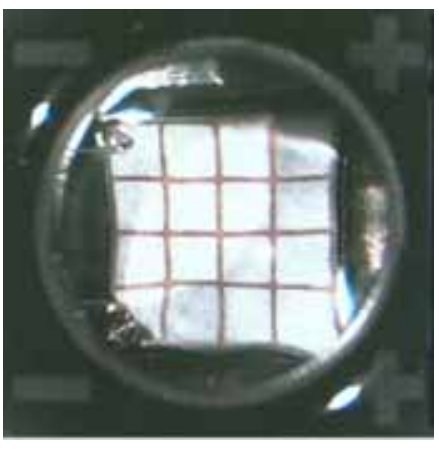

(b)

Figura 4-10: Conexionado LEDs utilizados en los ensayos: (a) Tipo A y (b) Tipo B

Este cambio en la construcción se debe a que las zonas más próximas al punto de contacto con la alimentación, al tratarse de un LED de alta potencia, adquieren una temperatura significativamente mayor que las que se encuentran alejadas, ofreciendo un gradiente de temperaturas acusado que provoca la fractura de la silicona. Al establecer un entramado más uniforme por toda la superficie del diodo, se puede prever que la distribución de temperaturas será más uniforme, evitando la rotura temprana de la silicona y aumentando la vida útil del LED.

\subsubsection{Espectrómetro}

Para este trabajo se han utilizado dos micro-espectrómetros, ambos con características similares (Figura 4-11). El espectrómetro Mightex ${ }^{\circledR}$ se ha utilizado para desarrollar pruebas de vida acelerada, y el espectrómetro de Avantes ${ }^{\circledR}$ se ha utilizado para las mediciones de fluorescencia de laboratorio y de campo. Ambos espectrómetros tienen el software propietario de la medición. En el caso de las mediciones de laboratorio y de campo realizadas con el espectrómetro de Avantes ${ }^{\circledR}$ para identificar la huella de hidrocarburos se ha desarrollado un programa Matlab ${ }^{\circledR}$, siendo necesario adquirir las librerías adicionales que proporciona el fabricante, tanto para plataformas Linux como Windows. 
Para detectar las longitudes de onda emitidas, ambos espectrómetros tienen un detector CCD con 2.048 pixel y rejilla que va desde $200 \mathrm{~nm}$ a $1400 \mathrm{~nm}$. La resolución del espectrómetro de Avantes ${ }^{\circledR}$ es $0,6 \mathrm{~nm}$ con una abertura 50 micras. Este tipo de espectrómetro tiene pequeño tamaño, alta precisión, conectividad directa a través de USB y que puede ser controlado por programa El efecto de la fluorescencia se produce en longitudes de onda superiores a las de la fuente, $y$ es deseable aislar el sensor de la fuente para evitar el acoplamiento entre ambos: para ello deben situarse en una posición en la que se reciba la mayor cantidad de potencia óptica debida a la fluorescencia como sea posible y no la emisión de la fuente de excitación. Del mismo modo, tiene gran importancia la fibra óptica utilizada para recoger la luz de la muestra bajo prueba y para llevarla guiada al espectrómetro. La fibra óptica tiene que ser lo bastante gruesa para permitir que la luz sea suficiente, pero a medida que aumenta el diámetro se vuelve más frágil. Se determinó como solución de compromiso que la fibra de 600 micras era la más adecuada. No se hace necesario colimar la luz para recoger más superficie debido a la corta distancia a la que se realiza la toma de datos, observando además en las pruebas realizadas que las pérdidas por cambio de medio (donde se produce reflexión y absorción) superan a las ganancias obtenidas..

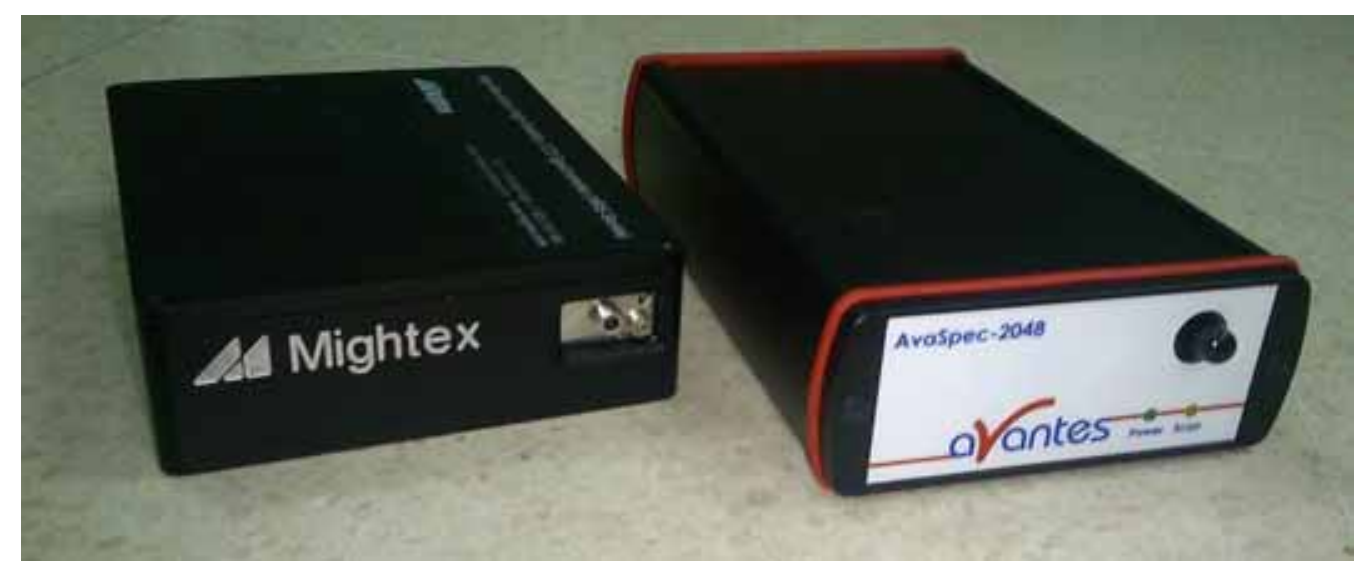

Figura 4-11: Espectrómetros utilizados en medidas y desarrollo.

\subsubsection{Bloque procesador}

El bloque procesador debe ser un procesador de reducido tamaño, ya que en principio no se requiere una gran potencia de procesado, teniendo además que estar provisto de la suficiente conectividad. En este sentido se puede pensar en miniPCs tipo Small From Factor (SFF), con las que se garantiza el correcto funcionamiento de sistemas basados normalmente en Linux. Los sistemas basados en placa única o Single-Board Computer (SBC) resultan muy útiles y están en 
constante evolución. Actualmente existe una numerosa oferta en este sentido. Raspberry Pi ${ }^{\circledR}$ presenta actualmente placas con las que se puede trabajar tanto en Linux como en Windows. AMD Gizmo es un sistema potente y compacto que trabaja también tanto en Linux como en Windows, pero presenta la desventaja de incorporar ventilación forzada en la disipación, y en sistemas de campo esto resulta un elemento que aumenta la posibilidad de fallo. En todo caso, en general resultan lo suficientemente potentes para realizar los procesos requeridos como son:

- Captura y almacenamiento de las medidas obtenidas sincronizadamente con el espectrómetro (señal y ruido).

- Procesado de los datos adquiridos: eliminación de ruido, obtención de promedio, filtrado, normalización, etc.

- Análisis de los datos procesados (ver capítulo 5) por medio de uno o varios algoritmos.

- Decisor: en base a los resultados proporcionados a partir del análisis, se decide el tipo de compuesto detectado por medio de algoritmos de comparación rápidos [BMK97] a partir de los patrones almacenados.

En este sentido, se ha trabajado con varios programas independientes que pueden ser unificados en una plataforma común. Para ello, Matlab® ${ }^{\circledR}$ resulta de gran utilidad, ya que a la facilidad de las librerías antes mencionadas, se une la existencia de numerosas "toolboxes" donde quedan implementados algoritmos matemáticos utilizados en el desarrollo.

Además los programas desarrollados pueden ser compilados para diversas plataformas, de manera que no es necesario que el programa Matlab ${ }^{\circledR}$ se encuentre instalado. La compatibilidad con el lenguaje $\mathrm{C}$ es otra de las ventajas por las que se ha elegido esta plataforma de desarrollo. 


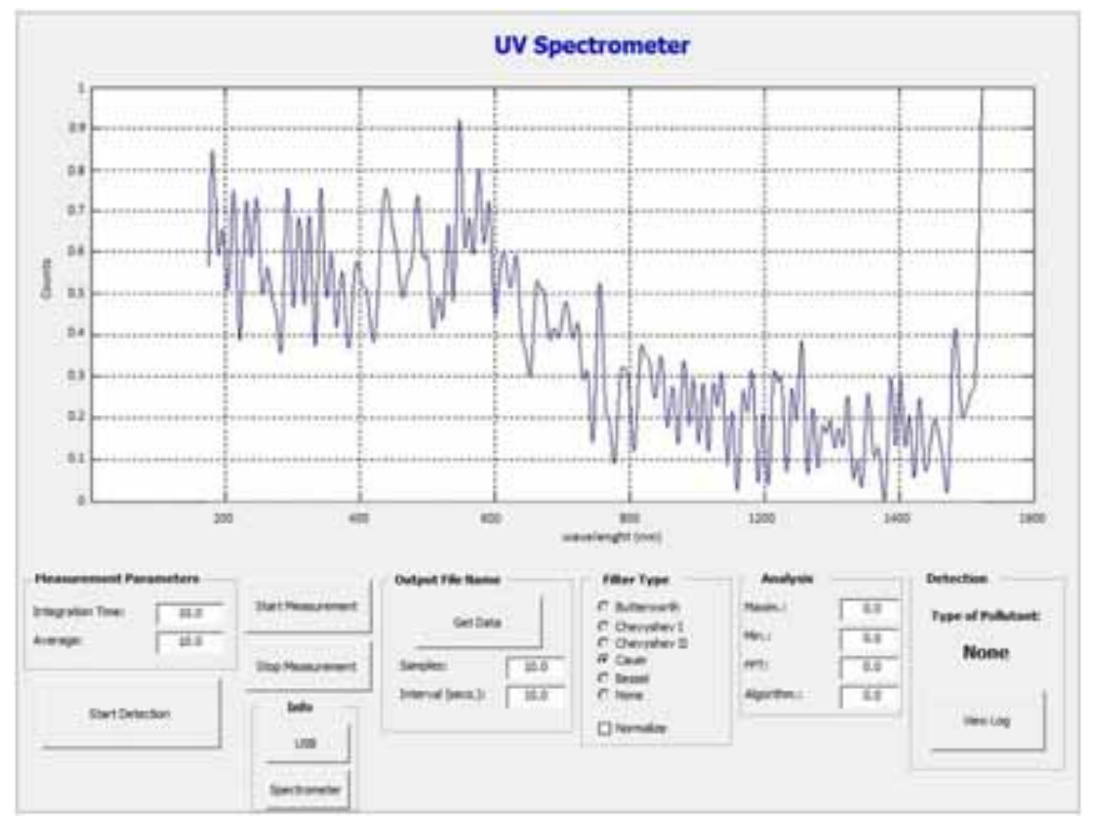

Figura 4-12: Imagen del programa desarrollado para los ensayos.

En la Figura 4-12 se muestra la pantalla del programa de adquisición de datos desarrollado para las pruebas de laboratorio y obtención de patrones. En el desarrollo final la representación del espectro capturado en tiempo real no es necesaria, si se requiere ahorro de procesado. Tal y como se explica posteriormente, la mayor carga de procesador se encuentra en el bloque decisor, ya que se realiza además del tratamiento de datos, la comparación. 


\title{
$5 \quad$ Análisis del espectro de fluorescencia de los hidrocarburos
}

Existen varios factores que afectan a la fluorescencia. Sin embargo es necesario cuantificar el impacto de cada uno de los factores, de manera que esta cuantificación pueda verse reflejada en el software de identificación de contaminantes. Para ello es necesario por tanto medir estos factores con otros sensores, como por ejemplo la temperatura o el oxígeno disuelto, para el caso de los hidrocarburos. La temperatura puede hacer decrecer entre un 1 y un $5 \%$ por grado centígrado incrementado. Esto es debido a que el aumento de la temperatura incrementa la frecuencia de colisiones entre las moléculas, incrementando la probabilidad de desactivación como energía no radiante. De la misma forma, una menor viscosidad influye en el fenómeno de la fluorescencia decrementando este efecto.

$\mathrm{El} \mathrm{pH}$ es otro de los factores que puede reflejar sus efectos en la fluorescencia, pero en el caso de los hidrocarburos esta variación es muy pequeña, por lo que en los estudios aquí presentados no se ha tenido en consideración, si bien es necesario señalar que se han realizado medidas de contraste para verificar este hecho.

Se tomarán seis hidrocarburos comunes en Europa, de forma que sean la base sobre la que poder realizar la comparativa. Los compuestos estudiados son los siguientes:

\author{
Gasoil tipo A. \\ Gasoil tipo A con aditivos extras (en adelante $\mathrm{A}+$ ). \\ Gasoil tipo B. \\ Gasoil tipo C. \\ Gasolina de 95 octanos. \\ Gasolina de 98 octanos.
}




\subsection{Influencia de la viscosidad}

Para el caso particular de los compuestos aquí estudiados, los hidrocarburos, existe una relación directa entre estos dos factores que se han tenido en consideración, dado que la temperatura influye en la viscosidad. Por lo tanto se han realizado medidas de viscosidad a diferentes temperaturas de los diferentes compuestos estudiados, puesto que los valores ofrecidos por el fabricante en las fichas de sus productos no especificaban en todos los casos las condiciones en las que daba el valor indicado. Los datos del fabricante son:

Diesel A: Viscosidad 2 - $4.5 \mathrm{cSt}$ a $40^{\circ} \mathrm{C}$ (ASTMD-445)

Diesel A plus: Viscosidad: $\left(40{ }^{\circ} \mathrm{C}\right) 2-4.5 \mathrm{cSt}$ (ASTM D-445)

Diesel B: Viscosidad 2 - 4.5 cSt a $40^{\circ} \mathrm{C}$ (ASTMD-445)

Diesel C: Viscosidad 7 cSt.a $40{ }^{\circ} \mathrm{C}$ (ASTM D-445)

Gasolina 95: Viscosidad $<1 \mathrm{cSt}$ a $38^{\circ} \mathrm{C}$ (ASTMD-445)

Gasolina 98: Viscosidad $<1 \mathrm{cSt}$ a $38^{\circ} \mathrm{C}$ (ASTMD-445)

Por ello, y dado que esta variable podría tener una influencia remarcable en los resultados obtenidos, y en las medidas de campo pueden encontrarse variaciones de temperatura notables, se decidió realizar estas medidas en un laboratorio homologado. Las medidas se realizaron en el Laboratorio de Combustibles y Petroquímica, que es una infraestructura científica y tecnológica creada por la UPM en colaboración con la Fundación Gómez Pardo adscrita a la Escuela Superior Técnica de Ingenieros de Minas y Energía, que viene prestando servicios a la industria desde el año 1991.

Las medidas son de viscosidad dinámica, que se obtiene como cociente de la viscosidad dinámica (o absoluta) y la densidad. La unidad en el SI es el $\left(\mathrm{m}^{2} / \mathrm{s}\right)$. La unidad física de la viscosidad cinemática en el sistema CGS es el stoke (abreviado $\mathrm{S}$ o St), cuyo nombre proviene del físico irlandés George Gabriel Stokes (1819-1903). A veces se expresa en términos de centistokes ( $\mathrm{cS}$ o $\mathrm{cSt}$ ), siendo $1 \mathrm{cSt}=10^{-6} \mathrm{~m}^{2} / \mathrm{s}^{1}$. Se optó por medir tres de los gasóleos estudiados, de forma que fuesen representativos. En la Figura 5-1(a) se muestran los resultados obtenidos comparados con el de aceite de motor sin usar, con el fin de referenciar la baja viscosidad que presentan estos compuestos. 


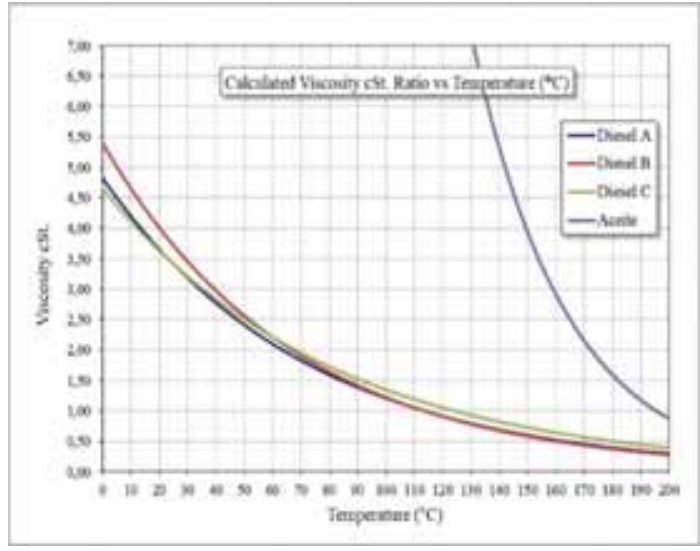

(a)

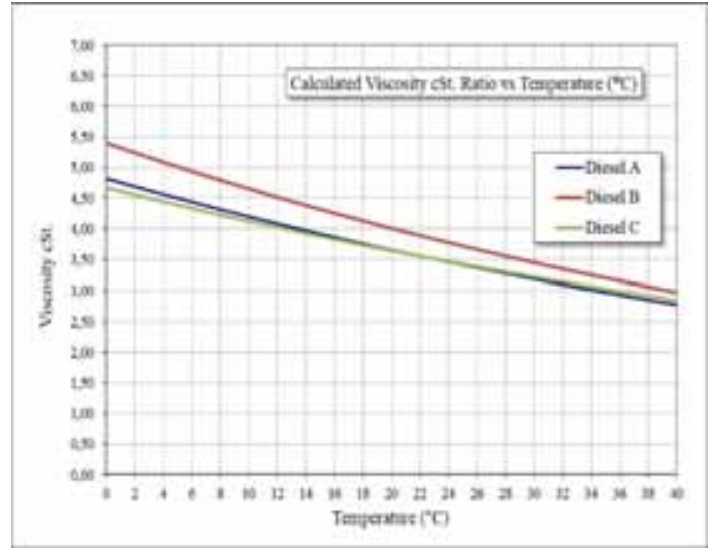

(b)

Figura 5-1: Medidas de viscosidad de los gasóleos estudiados

Como se muestra en la Figura 5-2, se han realizado algunas medidas para los tres tipos de gasóleo, observando que no hay gran diferencia entre ellos. Para el rango de temperatura que se pueden encontrar en el agua, se muestra en detalle en la Figura 5-1(b) en el que existe una variación entre 3 y $5 \mathrm{cSt}$. Los datos de viscosidad proporcionados por el fabricante se refieren a una temperatura de 40 grados centígrados y no coinciden exactamente con los medidos en el laboratorio. Se puede prever que hay una variación de este parámetro debido al deterioro hidrocarburos al entrar en contacto con el aire debido a su volatilidad. En general, los hidrocarburos presentan variaciones poco significativas de viscosidad, sobre todo si los comparamos con otros compuestos como el aceite del motor (que trabajan a temperaturas elevadas), o aceites de transmisión (que trabajan a temperaturas más bajas) en las que podemos encontrar variaciones a $0^{\circ} \mathrm{C}$ desde $5000 \mathrm{cSt}$ del SE $25 \mathrm{~W}-60$ hasta $300 \mathrm{cSt}$ del SAE $0 \mathrm{~W}-20$, siempre muy superiores a las de los hidrocarburos (Figura 5-2). 

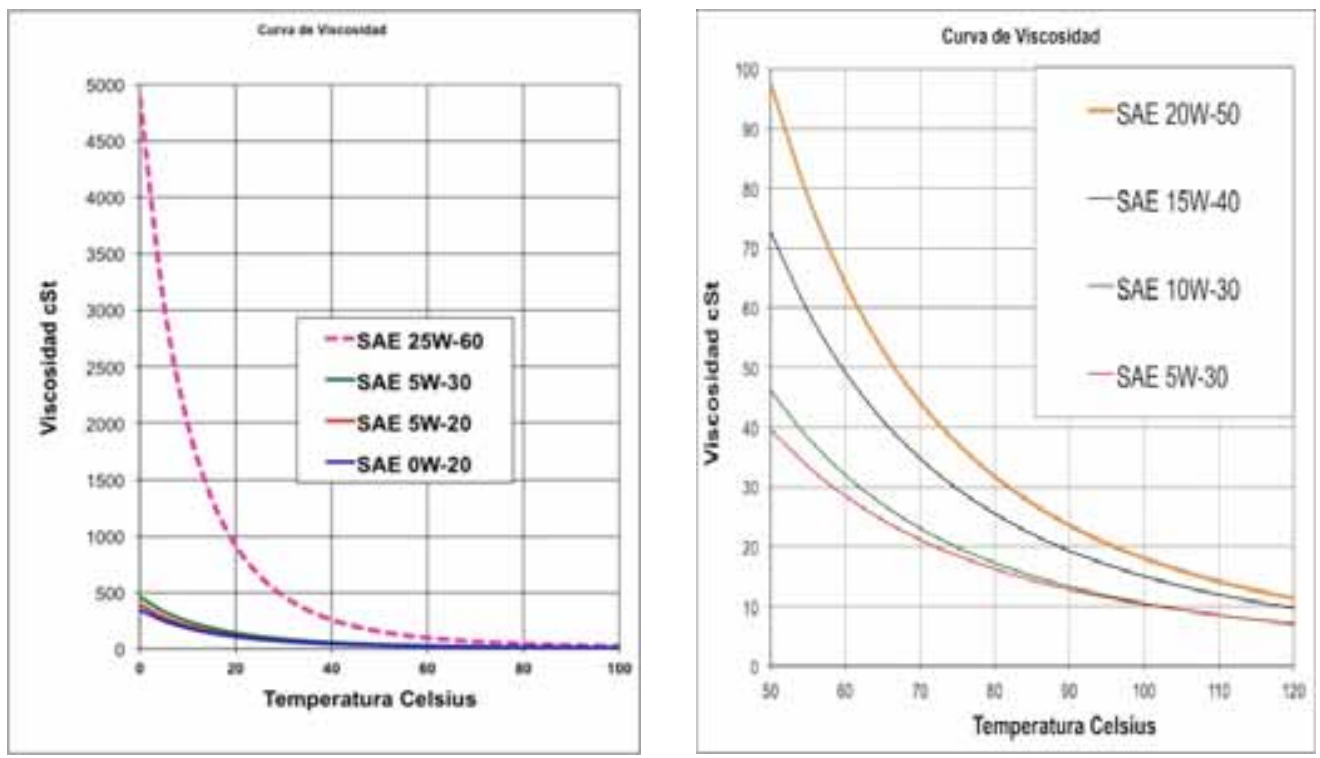

Figura 5-2: Medidas de viscosidad de aceites motor. Fuente: Wildman International SRL. http://www.widman.biz/boletines/95.html

\subsection{Influencia de la temperatura}

Para corroborar los resultados presentados, se hicieron algunas medidas de fluorescencia utilizando como fuente de luz UV-LED. Las medidas se realizan en las mismas condiciones a diferentes temperaturas de manera que se hará manifiesta si la potencia óptica de fluorescencia es diferente.

Las temperaturas seleccionadas son 5, 21 y 35 grados centígrados, ya que estos valores de temperatura son que se pueden encontrar en las medidas de campo. Ha habido hornos de laboratorio y frigoríficos utilizados para fijar la temperatura en la que ponemos los contenedores, el agua destilada y los hidrocarburos. Cada respuesta representa el promedio de siete medidas realizadas con un intervalo de 0,5 segundos.

En la Figura 5-3 se muestran a modo de ejemplo cuatro hidrocarburos representativos. El pico de la izquierda representa los aproximadamente $365 \mathrm{~nm}$ de emisión del UV-LED. Como se puede observar en los resultados, a temperaturas más bajas se obtiene una potencia óptica de la fluorescencia mayor (mayor número de cuentas), pero las diferencias son muy poco significativas como para tener en consideración en el software de identificación, tal y como se demuestra en capítulos posteriores. 


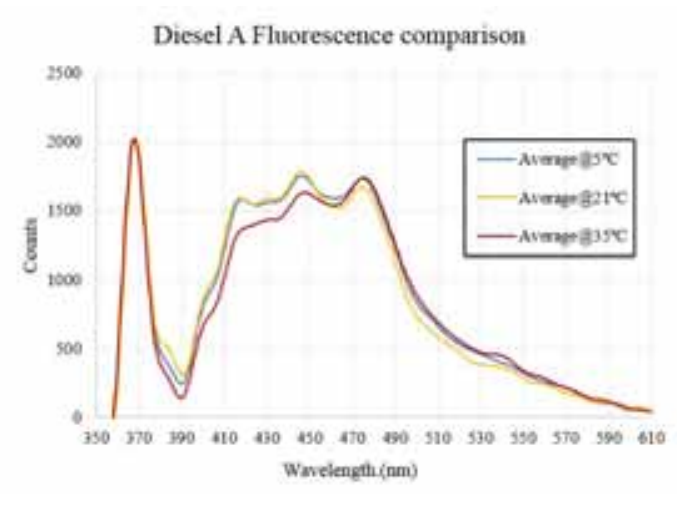

(a) Diésel A

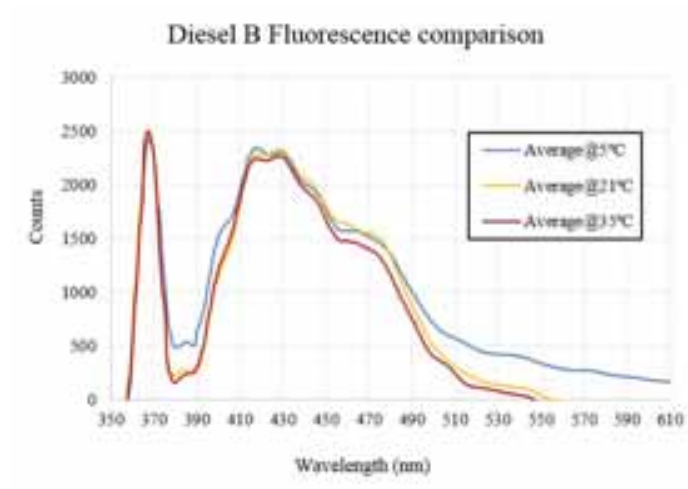

(c) Diésel B

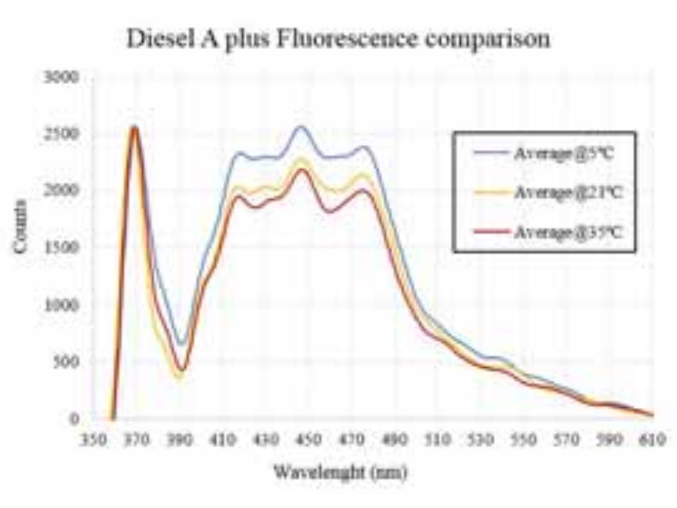

(b) Diésel A plus

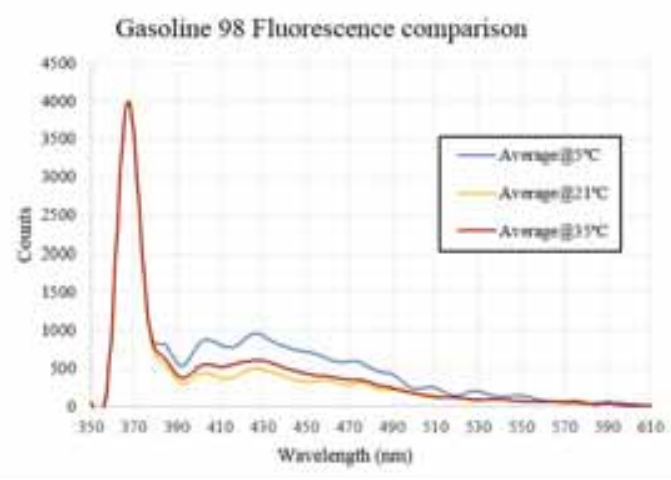

(d) Gasolina 98 octanos

Figura 5-3: Resultados de fluorescencias a diferentes temperaturas con fuente LED a $365 \mathrm{~nm}$.

Sin embargo, cabe destacar algunos detalles:

En el caso de diésel A, la respuesta a 35 grados Celsius es diferente de las otras temperaturas más bajas debido a que el pico de fluorescencia a $425 \mathrm{~nm}$ es muy tenue. Esto puede representar un problema en la identificación si resulta imprescindible la comparativa de las alturas de los picos, en la diferenciación con el diésel A con aditivos, con el que presenta una gran similitud.

En el caso de diésel A plus (con aditivos), la diferencia de la potencia óptica a baja temperatura es mucho más grande que en el resto hidrocarburos. Dado que en teoría estos añadidos son la única diferencia de este compuesto con el diésel A, es probable que la diferencia se deba a éstos. Este factor es importante en la detección de compuestos de diferentes marcas donde las proporciones y los aditivos cambiarán de forma acusada.

\subsection{Procesado de los espectros obtenidos}

Con el fin de obtener medidas fiables de la respuesta del espectro de fluorescencia a partir de irradiar la muestra con luz ultravioleta de $365 \mathrm{~nm}$, para lo que se varía la corriente inyectada al LED con el fin de controlar la potencia lumínica emitida. De esta manera se puede discernir 
si es posible a partir del espectro recibido determinar si existe un hidrocarburo e identificarlo. El desgaste del LED a lo largo del tiempo, hará que cada vez emita menos potencia lumínica, de manera que a partir de un momento dado, no emitirá la suficiente potencia como para provocar fluorescencia mesurable con la que identificar el compuesto.

El proceso de reconocimiento del contaminante debe ser sencillo, pero a la vez fiable, de manera que existe un compromiso entre el tiempo y potencia del procesado y la fiabilidad del resultado. Aunque en el laboratorio se pueden hacer análisis con procesadores muy potentes, es necesario pensar que la instrumentación de campo no estará dotada de procesadores con la misma capacidad, dado que se trata de desarrollar en el futuro un sistema lo más compacto posible. El filtrado se realiza tras la obtención de los datos calculados como la media de las medidas realizadas, pero posteriormente quedan análisis que requieren mayor tiempo de proceso. Estos análisis básicamente se basan en distinguir máximos y mínimos, así como su distancia tanto en abscisas como en ordenadas, por lo que un buen filtrado facilita enormemente esta tarea, evitando errores. En el otro lado, en el afán de hacer desaparecer el ruido, un filtrado excesivo o incorrecto puede eliminar puntos que pueden resultar útiles en la identificación.

El desarrollo de captación de espectros se realiza con MatLab ${ }^{\mathrm{TM}}$, dado que está dotado de gran flexibilidad, el fabricante de los espectrómetros provee librerías para los desarrollos, y una vez desarrollado el programa se puede generar un ejecutable compacto sin tener que instalar el paquete completo en la instrumentación final, donde las limitaciones de memoria y procesador son mayores. Los filtros mencionados posteriormente son proporcionados por la "Signal Processing Toolbox" de MatLab ${ }^{\mathrm{TM}}$, de forma que no es necesario realizar análisis adicionales.

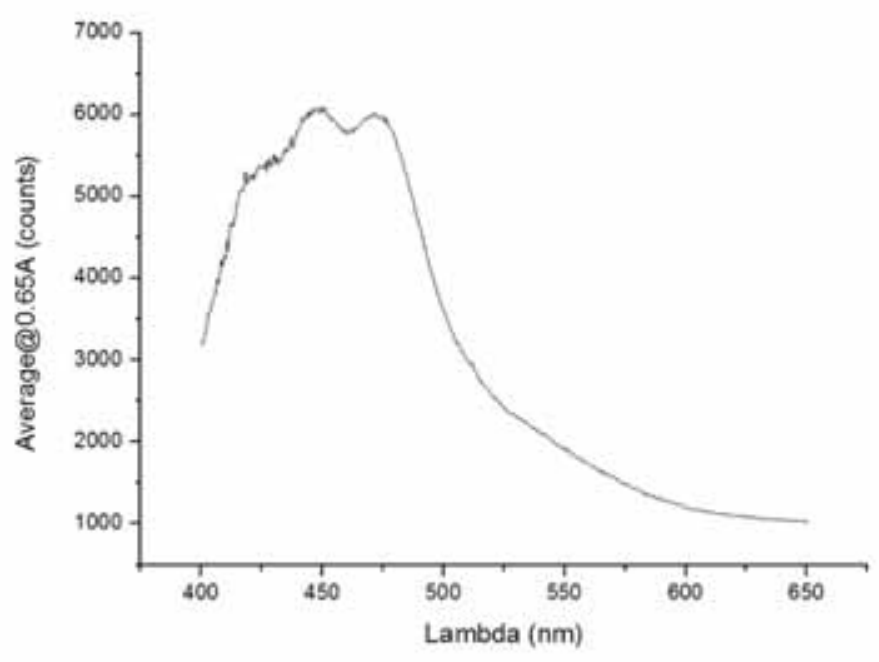

Figura 5-4: Detalle de la respuesta de fluorescencia de diésel A, no filtrada.

Por tanto, el proceso a seguir para la obtención de los patrones es:

- Realización de medidas espectrométricas en intervalos cortos. 
- Cálculo del promedio de las medidas realizadas.

- Suavizado del promedio para eliminación del ruido.

- Substracción de la referencia-suelo introducida por el espectrómetro. Re-escalado.

- Identificación de picos significativos.

- Descomposición de la función en base a los picos como suma de gaussianas o lorentzianas.

En el proceso anterior, en algunos casos no se ha incluido la normalización de la señal, al objeto de poder realizar comparativas entre la fluorescencia producida para las diversas intensidades de corriente y los distintos compuestos. En el desarrollo final y con el fin de trabajar con valores acotados es conveniente normalizar, dado los resultados de máximos y mínimos son idénticos.

\subsubsection{Filtrado de la señal}

Tipos de filtro

Con el objeto de que queden manifestados con claridad máximos y mínimo (en esencia, eliminación de ruido), se realiza el denominado "smoothing" o suavizado de la señal. Este proceso se realiza comúnmente en las señales definidas en el tiempo, pero es posible aplicarlo a respuestas como las obtenidas con el espectrómetro (definidas en frecuencia), abstrayendo la naturaleza del eje horizontal. Existen varios métodos de smoothing que funcionan de manera diferente dependiendo de la naturaleza de la señal y el ruido que contenga. Cada tipo de filtrado realza o atenúa con mayor o menor énfasis diferentes aspectos.

Dentro de los diversos filtros que pueden ser utilizados para eliminar el ruido, cabe distinguir tres básicos que pueden ser utilizados en el filtrado de las respuestas obtenidas con el espectrómetro:

- Filtrado de media y filtrado mediana.

- Filtrado mediante FFT

- Filtrado mediante filtro Savitzky-Golay.

Los filtrados porcentuales son utilizado para las señales donde el ruido aparece como picos localizados; el filtrado percentil 50\% (o filtrado mediana) puede ser la mejor opción de filtrado en muchos casos. Este método reemplaza el valor de la señal en cada punto por el valor de la mediana de un grupo de puntos circundantes. 
Un filtrado de media se encuadra dentro de los filtros lineales. Así, para un filtro de media de una dimensión de longitud $N=2 k+1$, la salida para un instante $i$, queda definida como:

$$
y[m]=\frac{1}{2 k+1} \sum_{j=-k}^{k} x[m+j]
$$

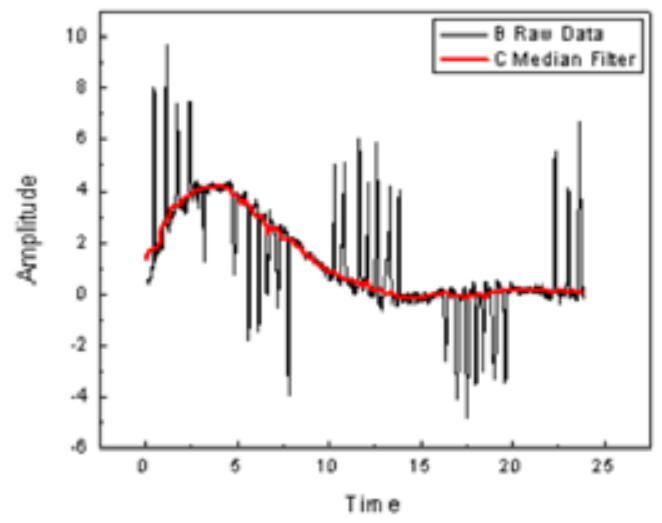

Figura 5-5: Señal original con picos (negro) y señal filtrada mediante filtrado mediana.

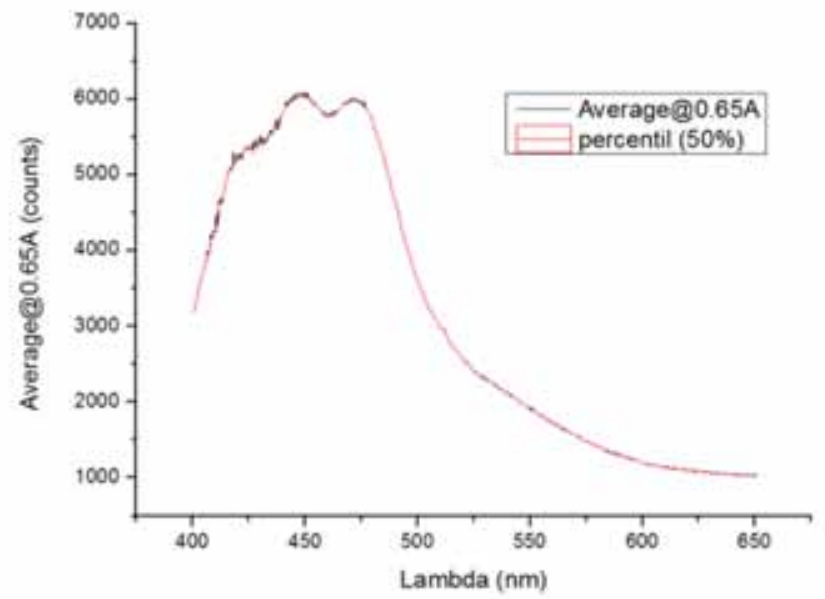

Figura 5-6: Respuesta de diésel A (negro) y filtrada con filtrado mediana.

El filtrado mediante la transformada rápida de Fourier FFT), se lleva a cabo mediante la eliminación de componentes de Fourier con frecuencias más altas que una frecuencia de corte dada por:

$$
f_{\text {corte }}=\frac{1}{n \Delta t}
$$

Donde $n$ es el número de puntos de datos en estudio, y $\Delta t$ es el tiempo (o en general el eje de abscisas) de separación entre dos puntos adyacentes. Los valores más elevados de $n$ dan 
como resultado frecuencias de corte menores y por tanto un mayor grado de suavizado. La función utilizada para recortar las componentes de alta frecuencia es una parábola con un máximo de 1 a frecuencia cero, cayendo a cero en la frecuencia de corte definida $f_{\text {corte }}$.

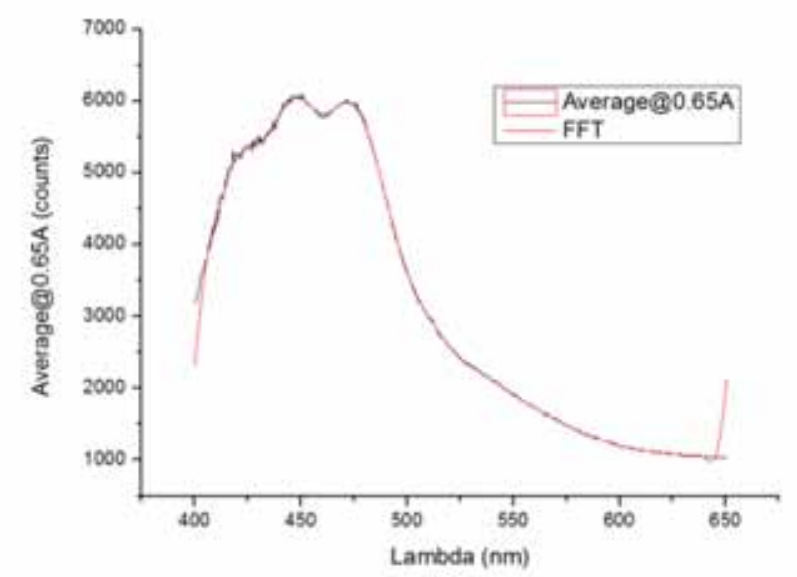

Figura 5-7: Detalle de la fluorescencia producida por gasoil tipo A, filtrado mediante transformada rápida de Fourier.

El filtrado Savitzky-Golay es muy utilizado en el tratamiento de datos experimentales, si bien no tiene una gran difusión en el entorno de las telecomunicaciones donde el procesado de señal y el tratamiento de datos difieren dado el origen de éstos. El método fue propuesto en 1964 por Savistsky y Golay basado en una aproximación polinómica mediante un criterio de mínimos cuadrados [SG64] [S11]. El artículo donde Savitzky y Golay propusieron un método de suavizado de datos basado en el cálculo de una regresión polinomial local (de grado k), con al menos $\mathrm{k}+1$ puntos equiespaciados, para determinar el nuevo valor de cada punto es uno de los más citados de la revista Analytical Chemistry [RZN00]. En el artículo mostraron que ajustando un polinomio a un conjunto de muestras de entrada para luego evaluar el polinomio resultante en un solo punto dentro del intervalo de aproximación es equivalente a una convolución discreta con una respuesta de impulso fija. Los filtros de paso bajo obtenidos por este método son ampliamente conocidos (en algunos sectores) como filtros Savitzky-Golay. 


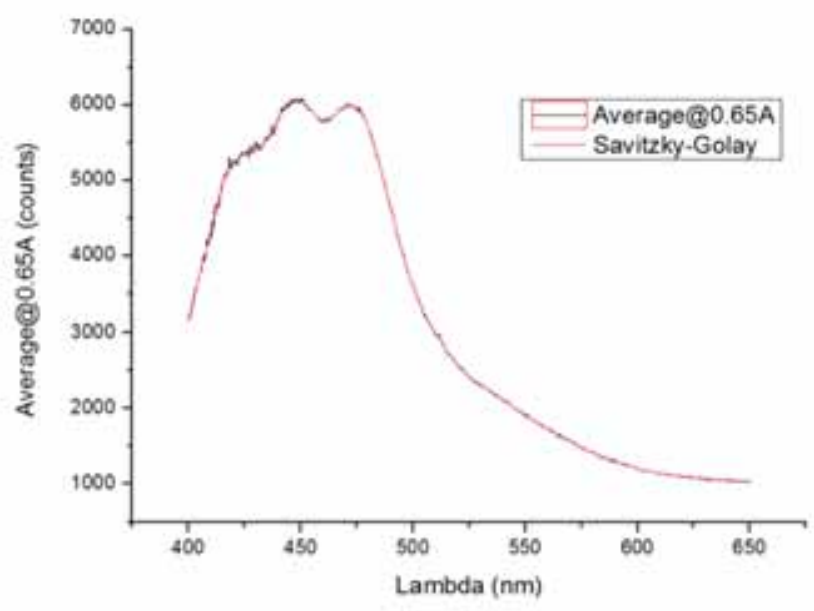

Figura 5-8: Detalle de la fluorescencia producida por gasoil tipo A, filtrado mediante filtro Savitzky-Golay.

Al realizar una regresión polinómica local alrededor de cada punto y crear una nueva pero suavizando el valor para cada punto de datos, se obtiene un resultado que es en esencia más fiel a la señal original que el método del promedio adyacente, ya que éste tiende a preservar las características de los datos tales como la altura del pico así como su anchura, que pueden ser ignoradas si se usan otros métodos. Para aumentar la suavidad del resultado, se puede aumentar el tamaño de la ventana o el número de puntos de datos utilizados en cada regresión local. Por muy grande que sea el tamaño de la ventana, realizando el promedio adyacente la señal resultante puede diferir demasiado de la de la señal de entrada, mientras que Savitzky-Golay todavía puede conservar el perfil general.

En esencia, y tal como se muestra en la Figura 5-9 puede observarse que aparentemente no existen grandes diferencias con los tres métodos de filtrado propuestos para los espectros obtenidos en laboratorio, cuando se filtra con una ventana de 10 puntos en todos los casos. Sin embargo, como se verá en los apartados posteriores, cuando la potencia lumínica disminuye, el tipo de filtrado empleado tiene mucha mayor relevancia. De la misma forma, como la fluorescencia producida es proporcional a la concentración del elemento que la genera, para bajas concentraciones en las que el espectro es más débil, el filtrado empleado es por tanto más relevante. A la hora de procesar los datos, en el paso posterior donde se trata de identificar el compuesto, es fundamental que el filtrado sea lo más adaptado el método de reconocimiento. En el filtrado percentil permanece algo de ruido, por lo que la descomposición posterior de la señal para su identificación será más compleja, elevando el tiempo de procesado y aumentando el error. 


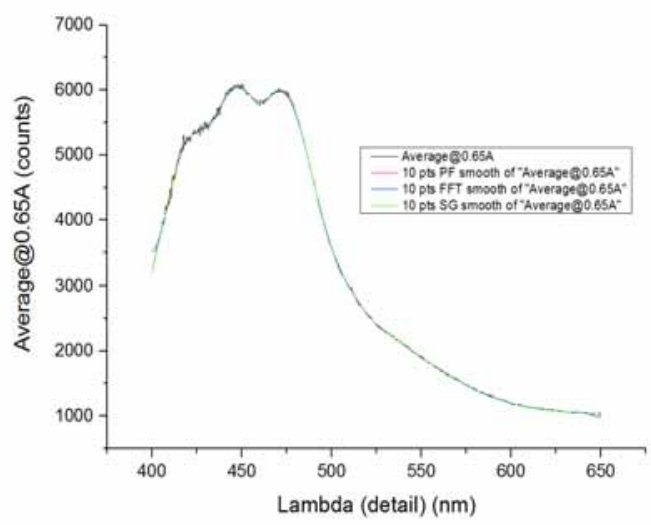

(a)

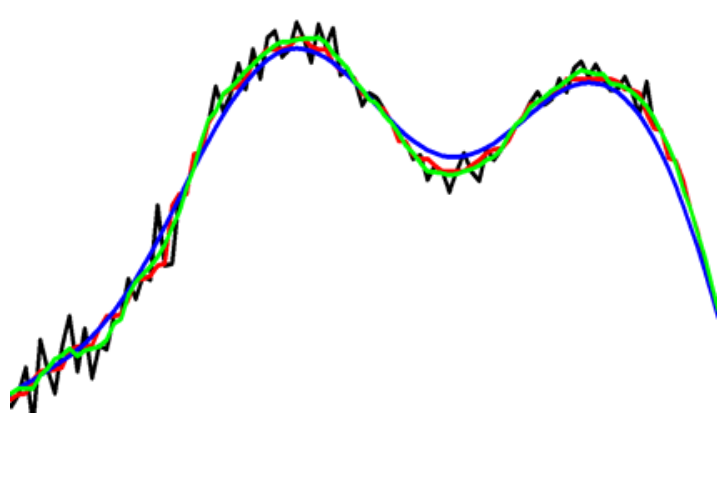

(b)

Figura 5-9: Comparativa de filtrado de la fluorescencia producida por gasoil tipo A

En el filtrado por FFT el suavizado es muy acusado, pudiéndose perder información, y dada la similitud en la respuesta producida por algunos compuestos, aumenta la probabilidad de error.

El filtrado Savitzky-Golay es por tanto el más adecuado para este tipo de aplicaciones. No en vano es ampliamente utilizado en aplicaciones de quimiometría o espectrometría de masas, donde se realizan procesos similares al aquí presentado. Además este filtrado puede considerarse como una media móvil generalizada. Se pueden derivar los coeficientes del filtro mediante la realización de un ajuste lineal ponderado de mínimos cuadrados utilizando un polinomio de un grado determinado: por esta razón, un filtro Savitzky Golay (también se llama un filtro de suavizado polinómico digital o filtro de suavizado de mínimos cuadrados). Es necesario tener en cuenta que un polinomio de grado más alto hace que sea posible lograr un alto nivel de suavizado sin atenuación de las funciones de datos. El método de filtrado Savitzky-Golay se utiliza a menudo con datos de frecuencia o con datos espectroscópicos (picos). Para los datos de frecuencia, el método es eficaz en la preservación de las componentes de alta frecuencia de la señal. Para los datos espectroscópicos, el método es eficaz en la preservación de los picos tanto en la longitud de onda como en el ancho de éstos. En comparación, el filtro de media móvil tiende a filtrar una porción significativa del contenido de alta frecuencia de la señal, preservando los picos a bajas frecuencias.

\subsubsection{Descomposición de las respuestas en funciones gaussianas y su análisis}

El empleo de un modelo matemático para la representación de respuestas de resultados experimentales [WAT+13] $[\mathrm{CAG}+14]$ resulta muy útil cuando se utilizan únicamente los parámetros de funciones conocidas. Las ventajas más obvia de utilizar estos parámetros en lugar 
de los datos originales es la reducción de bytes necesarios en el almacenamiento y la significativa reducción en tiempo de computación cuando estos datos son tratados. Existen muchos métodos matemáticos para utilizar en el análisis de datos en función del perfil de datos a tratar: principal components analysis $(\mathrm{PCA})[\mathrm{H} 08 \mathrm{w}]$, principal components regression $(\mathrm{PCR})[\mathrm{CLM}+01]$ partial least regression (PLS) $[\mathrm{PDC}+06]$ y redes neuronales artificiales.

Goshtasby y O’Neill propusieron en un artículo publicado en 1994 [GO94] que, dada una secuencia de datos individuales uniformemente espaciados, es posible aproximar los datos a una suma de funciones gaussianas con una precisión predeterminada.

Al objeto de verificar si para diferentes potencias lumínicas la fluorescencia producida es tal que permite la identificación del compuesto en base a la comparación con el espectro generado en condiciones óptimas, la descomposición en gaussianas de dicho espectro es una técnica que resulta muy útil debido a que el almacenamiento de los datos es relativamente sencillo, ya que basta con almacenar la longitud de onda, anchura y factor multiplicador de cada una de las componentes. La suma de todas las componentes establecerá una función-resultado que al ser comparada con la original, se podrá obtener el error para cada punto.

En análisis químico se asume que la propiedad de interés de una muestra (ya sea concentración, viscosidad, número de octano, etc.) se encuentra relacionado con la técnica utilizada para analizar dicha muestra. En el caso de la detección e identificación, se compara el valor proporcionado por la técnica (fluorescencia) con valores previamente medidos. También es posible, en análisis cuantitativo, calcular un modelo matemático univariante que permita predecir una propiedad de interés a partir de una medida instrumental. A partir de este concepto, se puede desarrollar un modelo de calibración o comparación multivariable, para observar y comparar propiedades de interés de múltiples medidas instrumentales. Esta técnica permite cuantificar a partir de medidas no selectivas (es decir, en presencia de interferencias comunes en las medidas de campo), y es especialmente útil en el análisis de medidas espectrométricas. En el caso aquí presentado, este método es útil tanto para cuantificar la concentración del elemento que produce la fluorescencia, como para determinar, como es el objeto de este estudio, la fluorescencia producida en función de la potencia lumínica incidente, ya que, como se verá más adelante, presenta un comportamiento lineal hasta la corriente nominal.

Con la calibración multivariable se pueden cuantificar la propiedad de interés (fluorescencia), utilizando respuestas intrumentales no selectivas, como es el espectro de las muestras analizadas. El tipo de modelo multivariable más común es el lineal, donde la respuesta fluorométrica de la muestra viene dada por la respuesta de cada gaussiana en cada longitud de onda multiplicada por un coeficiente y sumando, donde las gaussianas, para otros compuestos, representarían las respuestas proporcionales de cada uno de los elementos que componen la mezcla. Los hidrocarburos son cadenas de carbono e hidrógenos más o menos largas y los 
elementos añadidos dependen de cada fabricante, por lo que el objeto de esta descomposición no pretende identificar componentes que lo conforman, sino utilizar la técnica para identificar espectros conocidos y almacenados. La realización de un ajuste del espectro con gaussianas, desde un punto de vista puramente matemático resulta una herramienta de identificación válida. En sucesivos estudios de campo donde sea posible la presencia de otros elementos que presenten claros marcadores a frecuencias concretas se deberán añadir al modelo de manera sencilla de forma que sea identificable la mezcla.

Para ello se proponen dos métodos basados en el modelo básico de regresión lineal (MBRL) definidos para la matriz obtenida a partir de los valores de la fluorescencia producida por cada compuesto. En uno de los métodos las funciones gaussianas de entrada son predefinidas, siendo valores fijos resultado de las medidas experimentales. El segundo método calcula $\mathrm{N}$ componentes gaussianas suficientes para ajustarse a la respuesta original.

Los datos de entrada de los que se dispone son los obtenidos experimentalmente en condiciones de laboratorio. El objetivo es, a partir de los datos obtenidos con la corriente nominal, general un modelo válido con el que se pueda verificar la potencia lumínica a partir de la cual el LED, por degradación, ya no es válido.

Con la regresión lineal simple es posible analizar la influencia de una variable explicativa $\mathrm{X}$ sobre una variable dependiente $\mathrm{Y}$. En el caso estudiado, los datos de entrada (Y) son los espectros de fluorescencia producidos por un LED cuya potencia varía con la corriente emitida. Por tanto, para cada corriente, se obtiene una tabla en la que cada una de las longitudes de onda se corresponde con una medida (en número de cuentas o "counts") proporcional a la potencia lumínica recibida. El espectrómetro cubre desde aproximadamente los 175 hasta los $1325 \mathrm{~nm}$. Sin embargo, tal y como se observa en la Tabla I, los datos relevantes para el análisis de los hidrocarburos estudiados están circunscritos entre los 400 y los $650 \mathrm{~nm}$. Por tanto, y al objeto de hacer más sencillo el cálculo, los análisis se concentran en estas frecuencias. En todo caso, es necesario el uso de la regresión lineal múltiple ya que intervienen más de una variable: una por cada longitud de onda. A partir de estos datos, se pueden obtener los coeficientes multiplicadores de las gaussianas que resulten suficientes para definir el espectro.

Por tanto, en base a lo anterior, para cada longitud de onda se define:

$$
y_{i}=\beta_{1}+\beta_{2} x_{2 i}+\beta_{3} x_{3 i}+\ldots \ldots . .+\beta_{k} x_{k i}+U_{i}
$$

Donde

$y_{i} \quad$ Medida normalizada del espectrómetro en la longitud de onda $i$. 
$x_{k i}$ Valor de la función respuesta $\mathrm{k}$ en la longitud de onda $i$

$\beta_{k}$ Factor multiplicador que cuantifica $k$.

Para resolver los factores multiplicadores, existen diversos métodos, en los que se pretende encontrar la combinación de $\beta 1, \beta 2, \ldots \ldots \beta \mathrm{k}$ que minimice los errores del modelo. De esta forma, la función en base a los factores calculados siempre tendrá un error, ya que la función calculada vendrá definida en cada punto por:

$$
\hat{y}_{i}=\hat{\beta}_{1}+\hat{\beta}_{2} x_{2 i}+\hat{\beta}_{3} x_{3 i}+\ldots \ldots . .+\hat{\beta}_{k} x_{k i}
$$

Siendo el error o residuo que el modelo comete en la estimación de cada valor:

$$
e_{i}=y_{i}-\hat{y}_{i}=y_{i}-\left(\hat{\beta}_{1}+\hat{\beta}_{2} x_{2 i}+\hat{\beta}_{3} x_{3 i}+\ldots \ldots . .+\hat{\beta}_{k} x_{k i}\right)
$$

El estimador de Mínimos Cuadrados Ordinarios (MCO) es uno de os métodos para resolver y obtener los valores de los factores multiplicadores. Para ello se propone utilizar aquella combinación de parámetros que minimice la suma al cuadrado de todos los errores cometidos para las " $n$ " observaciones realizadas.

$$
\hat{\beta}_{M C O} \rightarrow \min (S)=\min \sum_{i=1}^{n}\left(e_{i}\right)^{2}
$$

Por medio de la derivación no matricial de la expresión de los estimadores MCO es posible realizar el cálculo. Siendo la expresión a minimizar:

$$
(S)=\sum_{i=1}^{n}\left(e_{i}\right)^{2}=\sum_{i=1}^{n}\left(y_{i}-\hat{\beta}_{1}-\hat{\beta}_{2} x_{2 i}-\hat{\beta}_{3} x_{3 i}-\ldots \ldots . . \hat{\beta}_{k} x_{k i}\right)^{2}
$$

Donde, para obtener los valores de cada uno de los " $\mathrm{k}$ " parámetros que minimizan esta expresión es necesario derivar con respecto a cada uno de ellos e igualar a cero, obteniendo " $\mathrm{k}$ " expresiones del tipo:

$$
\frac{\partial(S)}{\partial \hat{\beta}_{j}}=2 \sum_{i=1}^{n}\left(y_{i}-\hat{\beta}_{1}-\hat{\beta}_{2} x_{2 i}-\hat{\beta}_{3} x_{3 i}-\ldots \ldots . . . \hat{\beta}_{k} x_{k i}\right)^{2} \cdot\left(-x_{j i}\right)=0
$$


A estas ecuaciones se las denomina "ecuaciones normales", y forman un sistema donde las incógnitas son los parámetros $\hat{\beta}_{j}$. Una a una, las ecuaciones normales para cada parámetro son:

$$
\begin{aligned}
& \sum_{i=1}^{n} y_{i} x_{1 i}=\hat{\beta} \sum_{i=1}^{n} x_{1 i} x_{1 i}+\hat{\beta}_{2} \sum_{i=1}^{n} x_{2 i} x_{1 i}+\hat{\beta}_{3} \sum_{i=1}^{n} x_{3 i} x_{1 i}+\ldots \ldots . .+\hat{\beta}_{k} \sum_{i=1}^{n} x_{k i} x_{1 i} \\
& \sum_{i=1}^{n} y_{i} x_{2 i}=\hat{\beta}_{1} \sum_{i=1}^{n} x_{1 i} x_{2 i}+\hat{\beta}_{2} \sum_{i=1}^{n} x_{2 i} x_{2 i}+\hat{\beta}_{3} \sum_{i=1}^{n} x_{3 i} x_{2 i}+\ldots \ldots . .+\hat{\beta}_{k} \sum_{i=1}^{n} x_{k i} x_{2 i} \\
& \sum_{i=1}^{n} y_{i} x_{3 i}=\hat{\beta}_{1} \sum_{i=1}^{n} x_{1 i} x_{3 i}+\hat{\beta}_{2} \sum_{i=1}^{n} x_{2 i} x_{3 i}+\hat{\beta}_{3} \sum_{i=1}^{n} x_{3 i} x_{3 i}+\ldots \ldots . .+\hat{\beta}_{k} \sum_{i=1}^{n} x_{k i} x_{3 i} \\
& \vdots \quad=\quad \vdots+\vdots+\ldots+\ldots+\ldots \\
& \sum_{i=1}^{n} y_{i} x_{k i}=\hat{\beta}_{1} \sum_{i=1}^{n} x_{1 i} x_{k i}+\hat{\beta}_{2} \sum_{i=1}^{n} x_{2 i} x_{k i}+\hat{\beta}_{3} \sum_{i=1}^{n} x_{3 i} x_{k i}+\ldots \ldots \ldots+\hat{\beta}_{k} \sum_{i=1}^{n} x_{k i} x_{k i}
\end{aligned}
$$

Que puede ser representado matricialmente como:

$$
X^{\prime} Y=X^{\prime} X \hat{\beta}
$$

De aquí se puede despejar la expresión matricial del vector de parámetros estimados $\hat{\beta}$

$$
\begin{aligned}
X^{\prime} Y=X^{\prime} X \hat{\beta} & \Rightarrow\left(X^{\prime} X\right)^{-1} X^{\prime} Y=\left(X^{\prime} X\right)^{-1} X^{\prime} X \hat{\beta} \Rightarrow \\
& \Rightarrow \hat{\beta}=\left(X^{\prime} X\right)^{-1} X^{\prime} Y
\end{aligned}
$$

Se puede reescribir lo anterior, particularizado para la fluorescencia medida en "cuentas" proporcionales a la potencia lumínica como:

$$
A=G \cdot C
$$

Donde A es la matriz de las medidas obtenidas por el espectrómetro, $\mathrm{G}$ es la matriz rectangular de donde w son las longitudes de onda sobre las que se ha obtenido datos (432 en el rango de longitudes de onda indicado), y n el número de gaussianas en el que se descompone el espectro. C es la matriz de los factores multiplicadores. Las $\mathrm{n}$ funciones de $\mathrm{G}$ son en este caso gaussianas normalizadas, cada una centrada en una longitud de onda, y con un ancho 
determinado. Así en la longitud de onda w, si la respuesta fluorométrica medida es Aw, se puede descomponer en una suma de la contribución de cada una de las funciones gaussianas en esa w:

$$
\hat{A}_{w}=g_{1, w} \cdot c_{1}+g_{2, w} \cdot c_{2}+\ldots .+g_{n, w} \cdot c_{n}
$$

Donde cada una de las $n$ componentes gaussianas responde a una función:

$$
g_{n}(w)=e^{-\frac{\left(w-w_{c}\right)^{2}}{2 \sigma^{2}}}
$$

Con centro en $w_{c}$ y ancho en función de la varianza $\sigma^{2}$ entendida en este caso como parámetro. En la Figura 5-10 se ilustra a modo de ejemplo, para una de las medidas del espectro, su descomposición en gaussianas tomando cuatro componentes. Partiendo de las cuatro gaussianas normalizadas. Cada una de las funciones gaussianas queda ponderada por el factor $c$, de manera que la suma tenga el error mínimo con respecto al valor original.

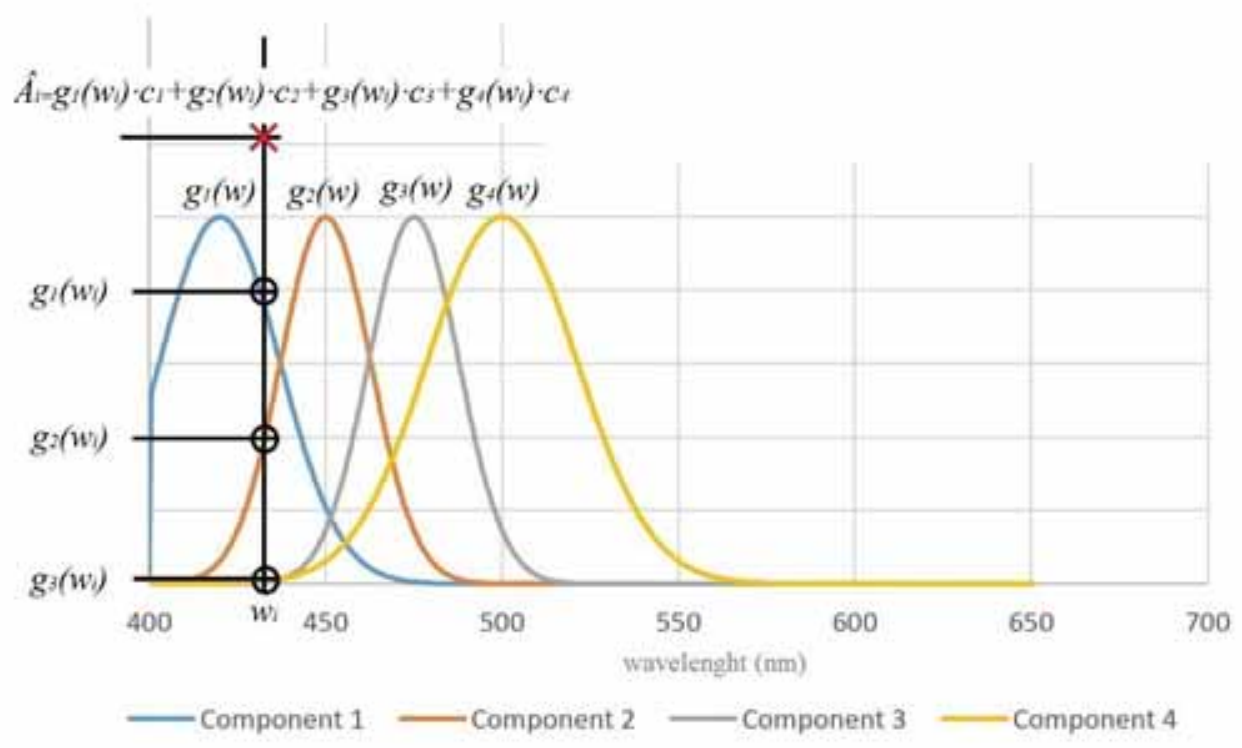

Figura 5-10: Representación del ajuste de un punto del espectro como suma de gaussianas con cuatro componentes.

Donde el error cometido con respecto a la señal original del espectrómetro vendrá dado por la diferencia, de manera que para una longitud de onda $w$ dada:

$$
A_{w}=\hat{A}_{w}+u_{w}
$$


Representado en forma de matriz:

$$
A=\left[\begin{array}{c}
A_{1} \\
A_{2} \\
\ldots \\
A_{w}
\end{array}\right] \quad G=\left[\begin{array}{cccc}
g_{11} & g_{21} & \ldots & g_{n 1} \\
g_{12} & g_{22} & \ldots & g_{n 2} \\
\ldots & \ldots & \ldots & \ldots \\
g_{1 w} & g_{2 w} & \ldots & g_{n w}
\end{array}\right] \quad C=\left[\begin{array}{c}
c_{1} \\
c_{2} \\
\ldots \\
c_{n}
\end{array}\right] \quad U=\left[\begin{array}{c}
u_{1} \\
u_{2} \\
\ldots \\
u_{w}
\end{array}\right]
$$

Para que pueda resolverse la matriz de los factores multiplicadores, el número de longitudes de onda debe ser igual o mayor que el número de componentes $\mathrm{n}$. Si n=w, se tiene un sistema de $\mathrm{n}$ ecuaciones con $\mathrm{n}$ incógnitas que puede resolverse haciendo:

$$
C=G^{-1} \cdot A
$$

Debido a que los espectros experimentales reales están sujetos a ruido aleatorio (como el ruido fotónico manifestado como variaciones de flujo inherentes a las propiedades estadísticas de los fotones, o el ruido del detector), la solución será más precisa si se utilizan las respuestas obtenidas en un mayor número de longitudes de onda, es decir, si $w>n$ como ocurre en las medidas aquí presentadas, siempre que los datos sean significativos (los restringidos a las longitudes de onda donde se encuentran las características propias de cada uno de los hidrocarburos estudiados -400 a $650 \mathrm{~nm}-)$. En este caso la ecuación no puede ser resuelta por inversión de la matriz G, dado que ésta no es una matriz cuadrada. Tal y como se explicó anteriormente, si se multiplican ambos lados por la expresión $\left(G^{\prime} G\right)^{-1} G^{\prime}$, entonces:

$$
\left(G^{\prime} G\right)^{-1} G^{\prime} A=\left(G^{\prime} G\right)^{-1} G^{\prime} G C=\left(G^{\prime} G\right)^{-1}\left(G^{\prime} G\right) C
$$

Como $\left(G^{\prime} G\right)^{-1}\left(G^{\prime} G\right)$ es la unidad, entonces:

$$
C=\left(G^{\prime} G\right)^{-1} G^{\prime} A
$$

Que se corresponde con el razonamiento anterior donde (Ec. 5). En esta expresión, es una matriz cuadrada de orden $\mathrm{n}$ (el número de gaussianas en el que se descompone el espectro), que para el caso de las gaussianas definidas varía entre 3 y 8 normalmente, tal y como se verá más adelante. En general, cuantas más longitudes de onda sean utilizadas, más eficazmente se promediará el 
ruido de forma efectiva, siempre que se estudie el espectro que presente valores de utilidad. La determinación de la región de longitudes de onda óptima por lo general es determinada empíricamente.

\subsubsection{Método con gaussianas predefinidas}

En este método se fija el número de componentes, la posición y la anchura en el espectro de cada una de las gaussianas. Al fijar las componentes, resulta un método sencillo y rápido que no requiere mucha computación cuando se quieren hacer comparativas. Cabe resaltar también que el ajuste de espectros a funciones gaussianas es también particularmente útil para desarrollo de otros sistemas de detección basados en, por ejemplo, fotodetectores, ya que la respuesta de éstos se puede asimilar a una función gaussiana y por tanto bastaría obtener el factor multiplicador de cada uno de los fotodetectores en las distintas longitudes de onda, para realizar la comparación con los patrones almacenados. El problema puede surgir al intentar hacer converger las frecuencias de los fotodetectores que se encuentren en el mercado con los espectros que se quieren estudiar, ya que pueden no ser suficientes como para encontrar la matriz de coeficientes que haga el error lo suficientemente pequeño. La obtención de las funciones gaussianas resulta más compleja con los espectros de fluorescencia, tal y como se explica a continuación.

En el caso aquí desarrollado, como se pretende asociar la potencia emitida por el LED con la calidad del espectro obtenido y su correcta identificación, se realizó un ajuste manual de las variables, de forma que se minimizó el error en cada compuesto, tomando como referencia el espectro obtenido cuando se emite con la corriente nominal del LED.

Por medio de una hoja de cálculo es posible obtener los coeficientes con las ecuaciones anteriores, previa introducción de los valores obtenidos con el espectrómetro, tal y como el Prof. Tom O'Haver del departamento de química y bioquímica de la Universidad de Maryland muestra en su página web [OTw], mediante la función ESTIMACION. LINEAL extendida a toda la matriz de datos. A modo de ejemplo se ha realizado el cálculo para la muestra de dieselA@0.65A, hasta conseguir el ajuste óptimo. 


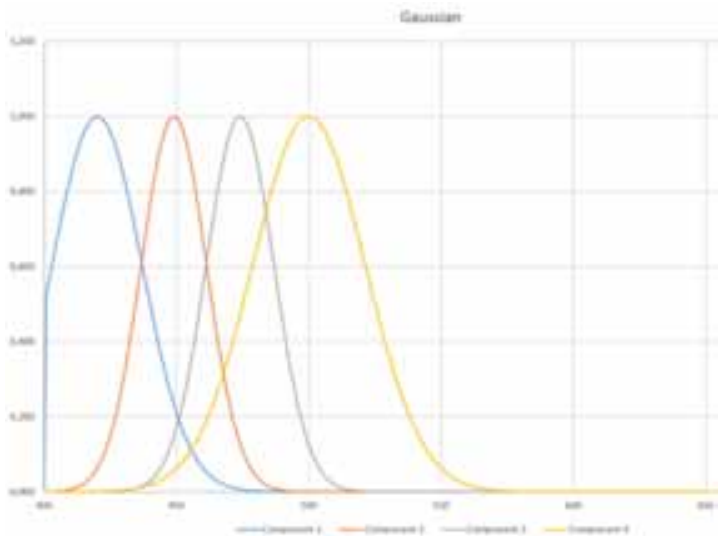

Figura 5-11: Gaussianas a prueba para modelar la respuesta del gasóleo A con 0.65A.

Para ello se toman por ser representativos 420, 449, 474 y $500 \mathrm{~nm}$. La asignación del ancho de cada una de las componentes se realiza en función de la separación de las frecuencias centrales. La segunda y tercera componentes deberán ser más estrechas, ya que se encuentran más próximas y su influencia con el resto debe ser menor puesto que se suman (Figura 5-12).

Los resultados finales son bastante aproximados (Figura 5-13), presentando errores reducidos y siendo suficiente la aproximación con 4 gaussianas.
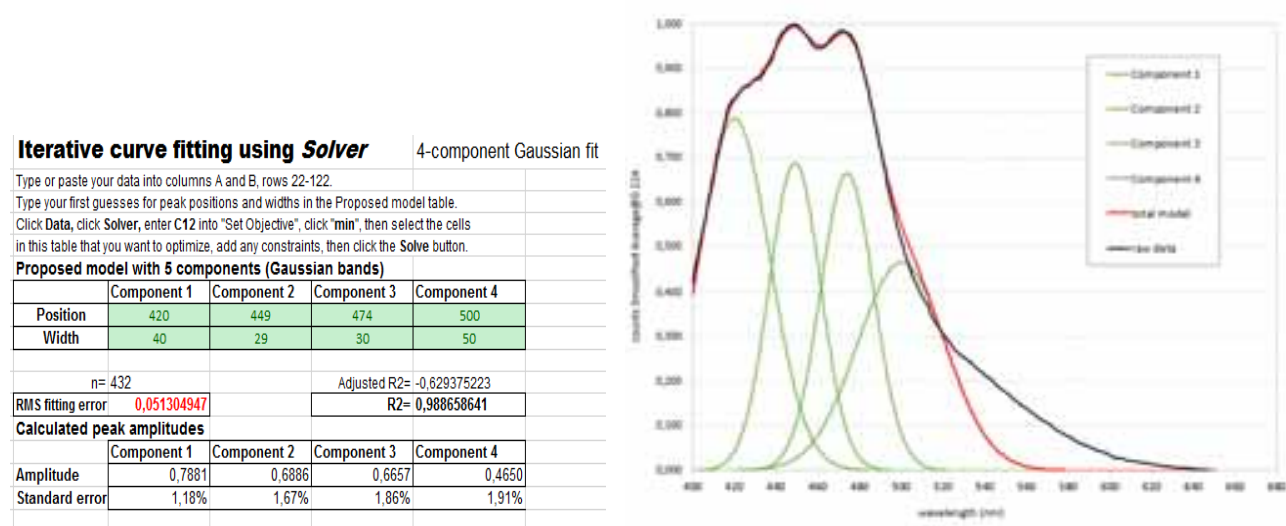

Figura 5-12: Ajuste manual a 4 componentes para gasoil A@0.65A.

Similares resultados pueden obtenerse con MatLab ${ }^{\mathrm{TM}}$ mediante un sencillo programa que también se ilustra en la misma fuente con un script que muestra el procedimiento de mínimos cuadrados clásico para un espectro con 4 componentes.

Sin embargo, con ambos métodos resulta muy difícil el ajuste, ya que las longitudes de onda en principio son fijas, y en el caso de realizar un ajuste que minimice el error, es necesario cambiar tanto este parámetro como el ancho de cada una de las gaussianas, por lo que 
no resulta un método útil para el fin buscado. Por el contrario, resultará bastante útil en la comparativa de medidas de campo una vez determinadas las funciones gaussianas, como elemento de identificación, tomando de una base de datos los parámetros de cada uno de los contaminantes almacenados, de forma que analizando el parámetro $\mathrm{R}^{2} \mathrm{y}$ otros se determine la presencia del mismo.

\subsubsection{Método de ajuste de gaussianas mediante iteraciones}

En este caso se pretende encontrar el número mínimo de gaussianas en las que se pueda descomponer el espectro de fluorescencia, con la ventaja de que en esta ocasión es posible variar tanto la longitud de onda central de cada una de ellas como evidentemente el coeficiente multiplicador.

Para el desarrollo de los cálculos se utilizarán diversas herramientas, de mayor a menor complejidad, hasta conseguir obtener unos valores adecuados. Dada la particularidad del uso que se da a la descomposición de los espectros en el presente trabajo, no existe una extensa bibliografía al respecto, por lo que a la luz de los resultados se pueden obtener interesantes conclusiones para establecer un método a utilizar en futuros análisis de otros contaminantes.

En primera instancia se utiliza el programa Origin ${ }^{\mathrm{TM}}$ de OriginLab, ya que se trata de una herramienta adaptada a la gestión de datos experimentales, especialmente en resultados obtenidos en ensayos químicos. Este programa presenta la ventaja de aprovechar la potencia de la computación por medio de la realización de iteraciones sucesivas (algoritmo de Levenberg Marquardt [F97]) hasta que se optimicen los datos. En el caso del ajuste a funciones gaussianas, operando tal y como se muestra en el apartado 5.3.2 para conseguir minimizar el error dado por la (Ec.5.16). Con los errores de cada uno de los puntos, junto con el coeficiente de determinación $\mathrm{R}^{2}$. Este parámetro es un estadístico para probar una hipótesis, determinando la calidad del modelo. Puede tomar valores comprendidos entre 0 y 1 , siendo este último el óptimo.

A partir de la señal filtrada mediante el filtro Savitzky-Golay, se obtiene la señal normalizada de la que se calculan los picos principales característicos del compuesto a partir de los cuales se puedan desarrollar las iteraciones con las que conseguir el ajuste. Al objeto de simplificar el procesado, se fija un umbral de un 70\%, de forma que se calculen los máximos de la parte superior de la curva únicamente, dado que para todos los compuestos estudiados es donde se encuentra la caracterización particular.

Existen diversos métodos de cálculo para encontrar los picos del espectro, a partir de los cuales realizar el cálculo de las gaussianas: máximos locales y primera o segunda derivada. A continuación se ilustran los procedimientos seguidos utilizando como herramienta de cálculo el programa Origin: 
- El método de los máximos locales es particularmente útil en respuestas suaves, pero en los espectros en estudio el nivel de ruido de los espectros con bajas corrientes es significativo con respecto a la señal, obteniéndose falsos positivos. Además dependiendo del tamaño de la ventana el resultado evidentemente varía de forma significativa, debiéndose ajustar a cada espectro obtenido con cada una de las corrientes con la que se alimenta el LED, y el objetivo es obtener un ajuste único para cada sustancia. Analizando el resultado para la corriente nominal, con una ventana de 2 puntos locales, se obtienen 3 picos Figura 5-13(a) a partir de los cuales se obtienen las gaussianas que el programa tomará como punto de partida para realizar las iteraciones. Dado que este espectro presenta poco ruido en comparación con el nivel de señal, se obtienen pocos picos, lo que puede resultar insuficiente a la hora de analizar las fluorescencias producidas con corrientes menores.

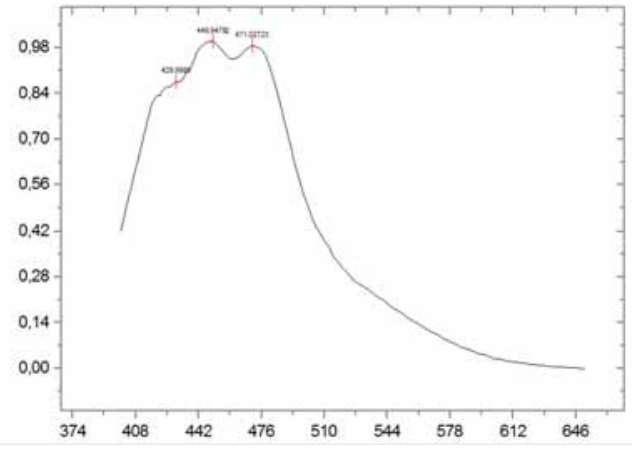

(a)

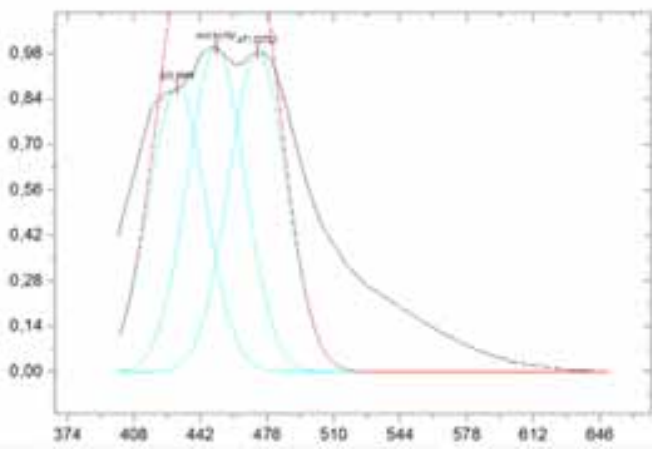

(b)

Figura 5-13: Picos obtenidos por el método de máximos locales (ventana de 2 puntos) para gasoil A@0.65A.

En la Figura 5-14 se observa el resultado del ajuste con gaussianas del espectro del gasóleo_A a partir de la búsqueda de picos por medio de máximos locales para una ventana de 2 muestras. Tal y como se puede observar en la tabla de resultados, tras 145 iteraciones el resultado converge, con una $\mathrm{R}^{2}$ elevada (0.9982). Sin embargo el resultado no es satisfactorio, debido a que el error ponderado se basa en todo el espectro, pero presenta mayor error precisamente en la zona de interés. 


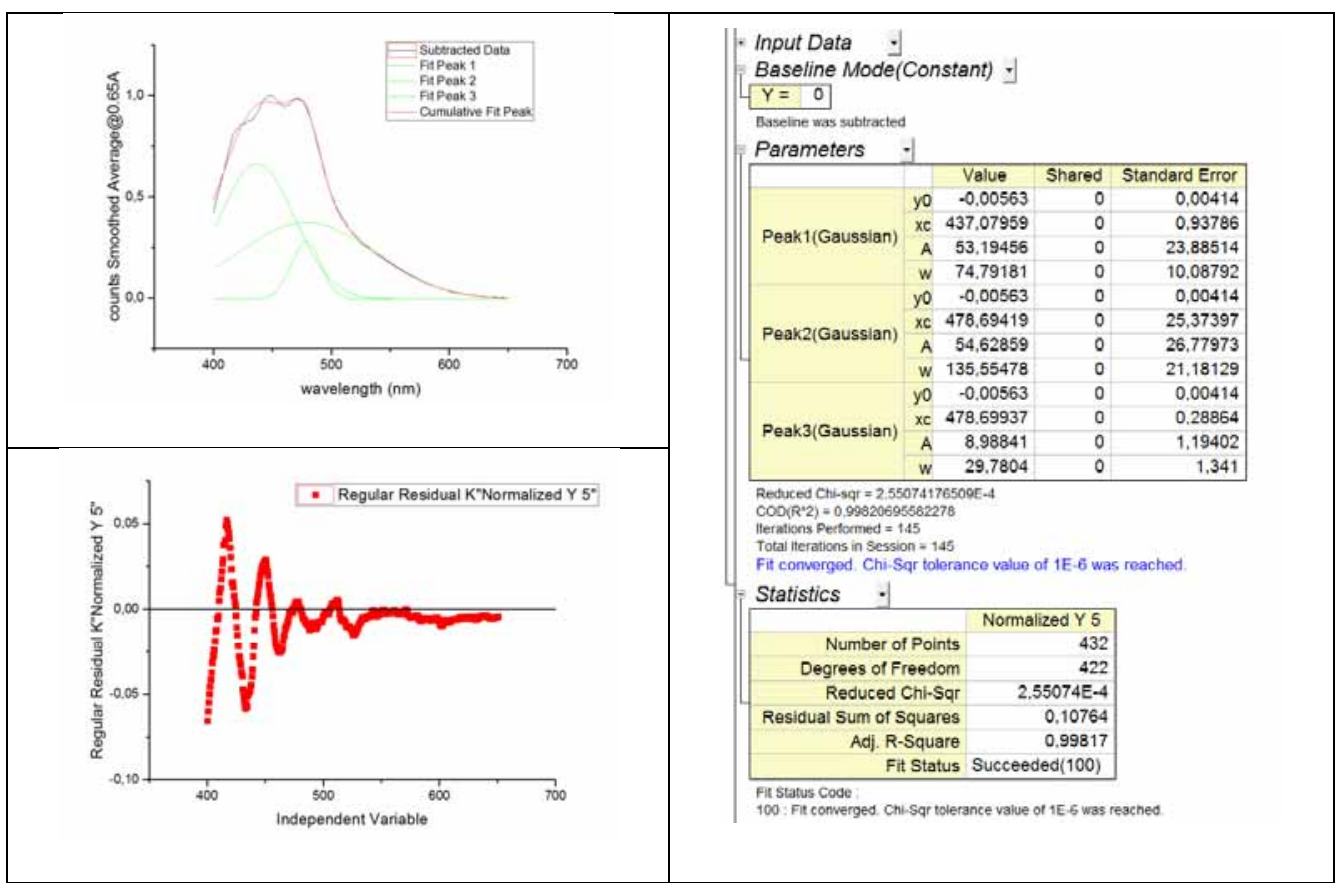

Figura 5-14: Cálculo de máximos gasoil A.

Si se realiza un estudio en el que se reduzca el ancho de banda entre los 400 hasta los $500 \mathrm{~nm}$, se mantienen las longitudes de onda de los picos, pero el ajuste de las gaussianas resulta más aproximado
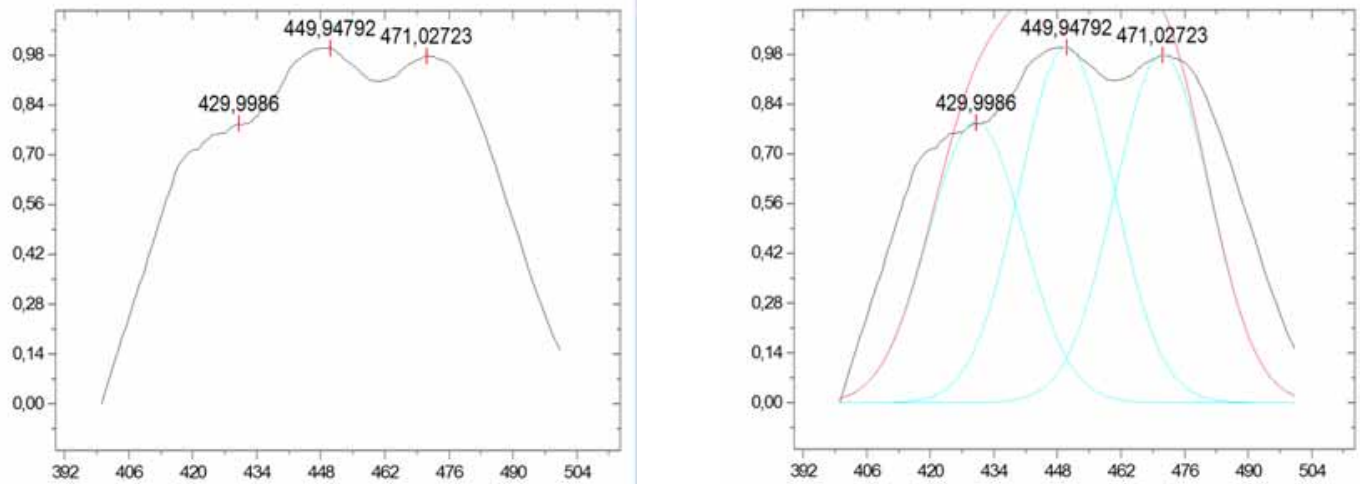

Figura 5-15: Cálculo de máximos gasoil $\mathrm{A} @ 0.65 \mathrm{~A}$.

Tal y como se puede observar en la Figura 5-16 con 17 iteraciones es suficiente para que converja, así como una $\mathrm{R}^{2}$ más óptima (0.9992), de manera que en principio el método podría ser suficiente para el estudio de los hidrocarburos a distintas potencias ópticas. 


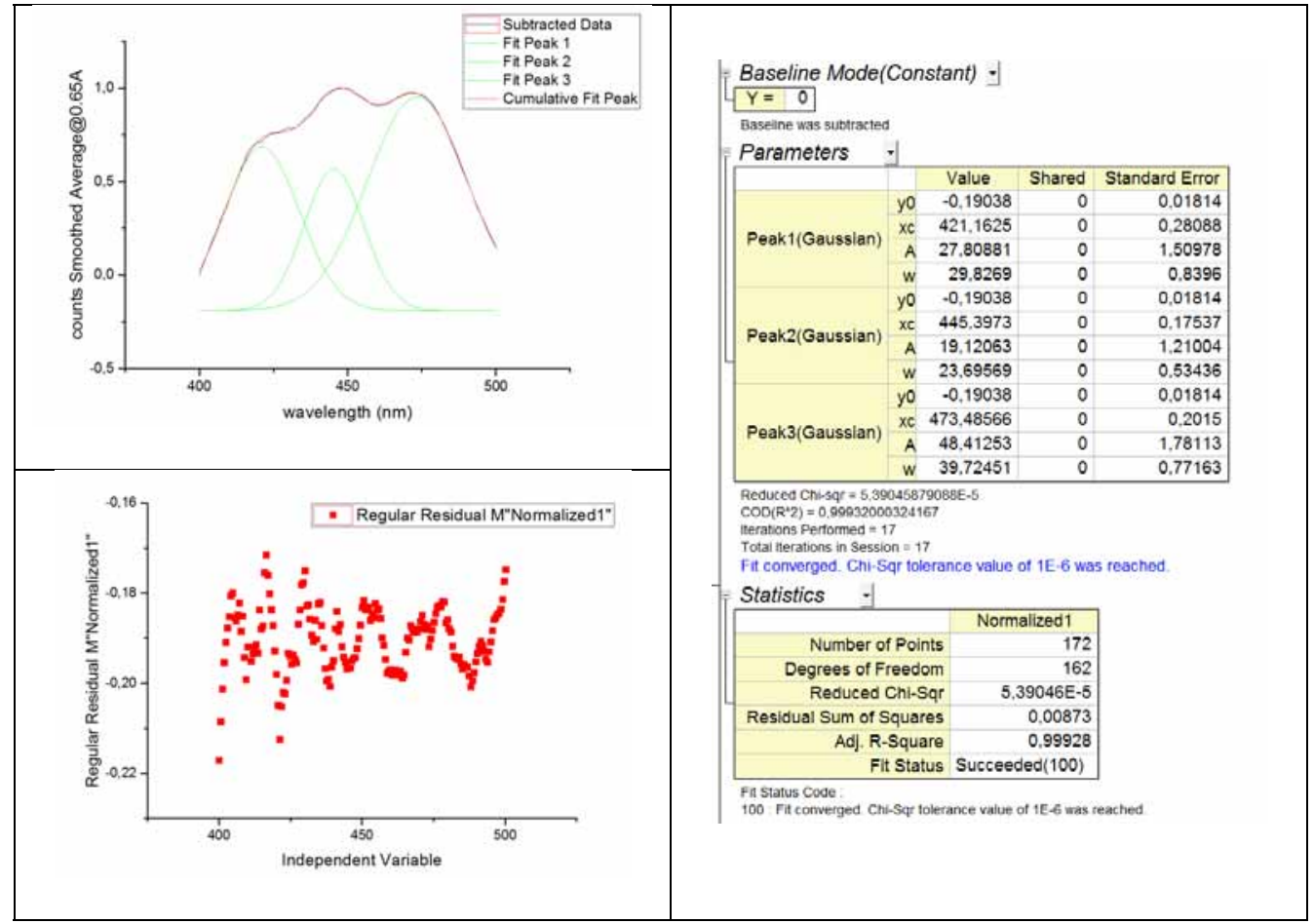

Figura 5-16: Cálculo de máximos gasoil A.

Teniendo en cuenta los resultados anteriores, se analiza a continuación un hidrocarburo que presenta menor fluorescencia, como es la gasolina 98. Se procede de igual forma que en caso anterior de éxito, limitando el cálculo entre los 400 y 500 nm., resultando en esta ocasión un mayor número de picos (Figura 5-17).
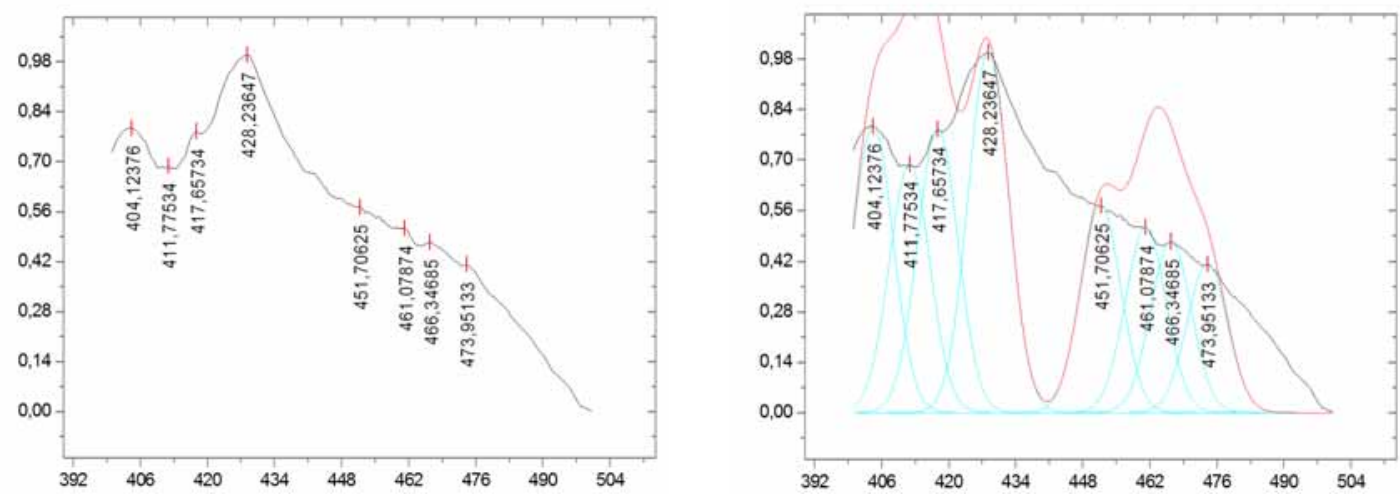

Figura 5-17: Cálculo de máximos gasolina98@0.65A.

Sin embargo no es suficiente como para que converja, y tras las 200 iteraciones muestra el resultado con las 8 gaussianas. Dado que el método debe ser válido para todos los compuestos, y que los máximo locales resulta insuficiente, se estudia a continuación el método de las derivadas. 


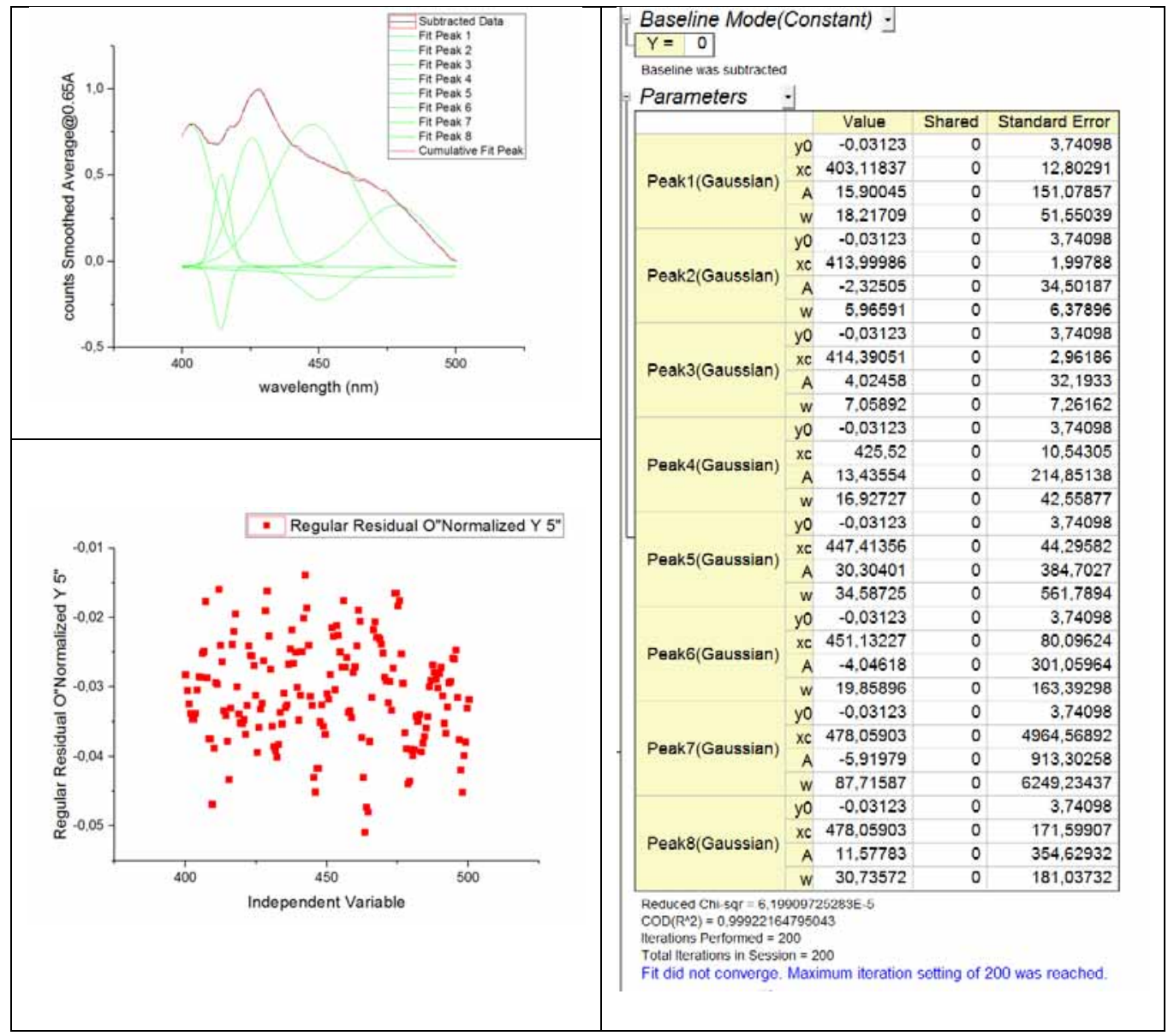

Figura 5-18: Cálculo de máximos gasolina 98.

- Mediante la primera derivada se realiza una búsqueda más exhaustiva, obteniéndose más picos, estando éstos muy próximos, lo que daría como resultado un número elevado de gaussianas que no sería el más conveniente dado que se desvirtúa el método, que pretende por medio de un número limitado y reducido de gaussianas realizar el análisis. Para optimizar el resultado se propone un post-filtrado, pero sólo es posible realizar otro filtrado SavitzkyGolay, lo cual no resulta muy apropiado ya que es redundante con el proceso anterior.

- La derivada segunda resulta un método más flexible, ya que aunque se encuentran también bastantes picos, incluidos los denominados ocultos ("Hidden Peaks") debido a que por definición se halla la tendencia, son en principio excesivos, pero a su vez permite entre otros un post filtrado mediante FFT teniendo más grados de libertad y siendo un proceso rápido fácil de implementar con otros lenguajes de programación. Para ilustrar este método, en la Figura 5-19 se muestra el resultado de la localización de picos en el gasóleo 
A sin realizar un post-filtrado. Como puede verse en la figura, se localiza un número excesivo de picos. La solución de compromiso entre el suavizado anterior del espectro hace que sea necesario un post-filtrado.
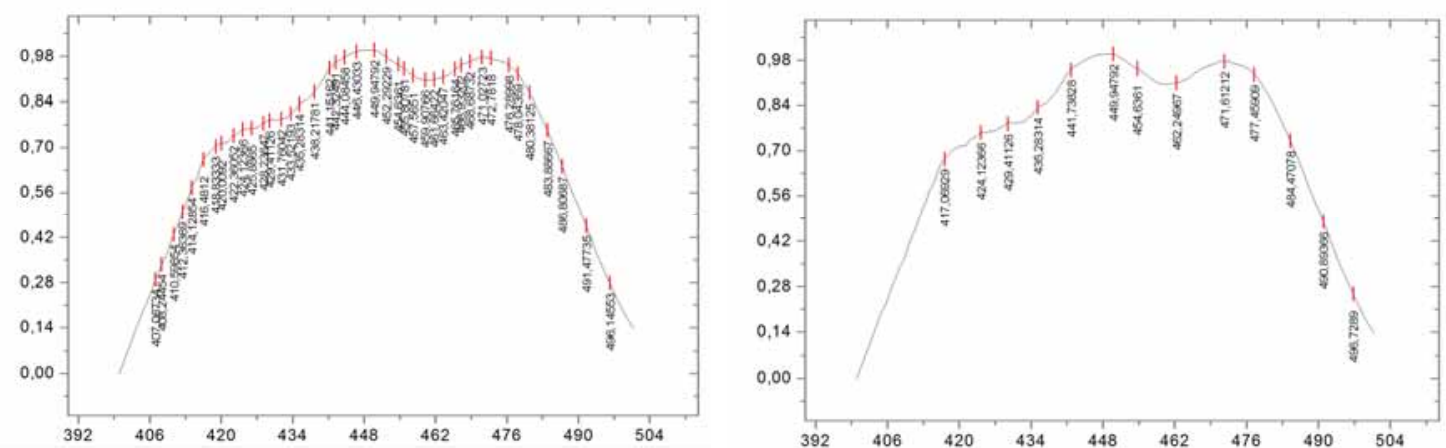

Figura 5-19: Cálculo de máximos gasoil A por el método de la derivada segunda sin postfiltrado (a) y con post-filtrado (b).

Con un máximo de iteraciones de 200 y una tolerancia de 0.02 , se consigue una convergencia con solamente 12 iteraciones. Puede observarse que el mayor de los errores se produce en el entorno de los $500 \mathrm{~nm}$, pero que se encuentra dentro de la tolerancia admisible. Asimismo el factor $\mathrm{R}^{2}$ presenta un valor de 0.9993 . A la vista de los resultados obtenidos parece que se puede tomar como método de referencia para ajustar los espectros de fluorescencia con gaussianas.

Con el fin de corroborar los resultados se repite el proceso con los mismos parámetros para el hidrocarburo que presenta menos fluorescencia entendida como potencia lumínica en el espectro visible, como es la gasolina 95. Los agentes añadidos a las gasolinas para proporcionar el octanaje correcto (antiguamente plomo y otros), actúan de forma negativa en la fluorescencia, particularmente en la de esta gasolina.
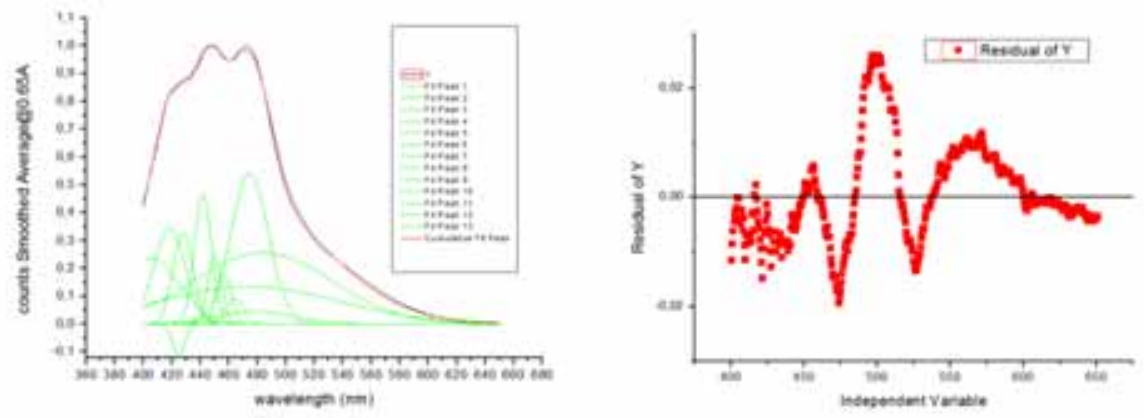

Figura 5-20: Cálculo de máximos por el método de la derivada segunda para el gasoil tipo A. 
Siguiendo el proceso descrito, se obtienen los resultados mostrados en la Figura 5-21, donde se puede observar que se consigue un buen ajuste con menos gaussianas. Esto es debido a que el espectro de este hidrocarburo presenta máximos más marcados quedando más definida la forma.
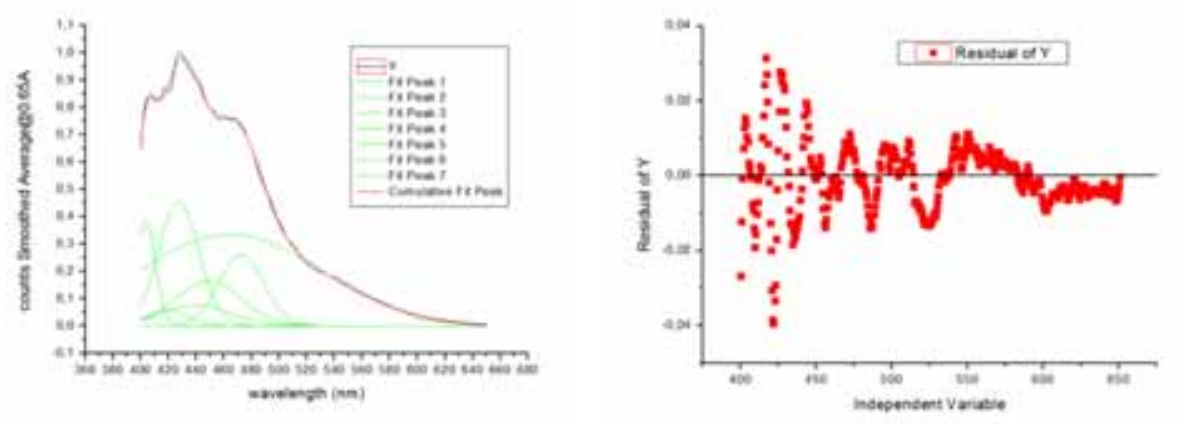

Figura 5-21: Cálculo de máximos por el método de la derivada segunda para el gasolina 95.

Se concluye por tanto que en principio, que se puede desarrollar un método mediante el cálculo de picos por medio de la segunda derivada y con un post-filtrado, con el que ajustar en gaussianas los espectros de los hidrocarburos obtenidos.

No obstante, con el fin de cubrir más posibilidades acerca del ajuste con gaussianas $\mathrm{MatLab}^{\mathrm{TM}}$ dispone de herramientas con las que programar un ajuste por iteraciones, e incluso un entorno ya desarrollado con el que ejecutarlo por medio de la llamada a cftool. Dentro de esta herramienta, se puede realizar el ajuste del espectro por medio de gaussianas. En particular, MatLab" ${ }^{\mathrm{TM}}$, tal y como explica en su manual de "Curve Fitting Toolbox" se basa en la ecuación genérica dada por:

$$
y=\sum_{i=1}^{n} a_{i} e^{\left[-\left(\frac{x-b_{i}}{c_{i}}\right)^{2}\right]}
$$

Donde $a$ es la amplitud, $b$ es el centroide, $c$ se refiere al ancho de la gaussiana y $n$ es

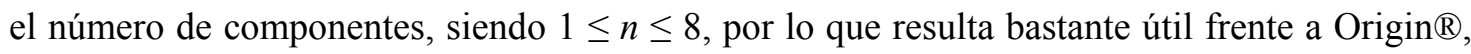
dado que se pretende utilizar pocas gaussianas.

Previamente es necesario cargar los datos. Gracias a la facilidad con la que se pueden cargar los datos desde ficheros Excel, para ilustrar este desarrollo se han preparado los datos con los que se ha trabajado anteriormente para poder comparar resultados: 
datos $x=x$ lsread $($ 'dieselA(3.82_0.65)none_cftool.xls', 'Measures', 'A2:A433');

datosy $=x l s r e a d\left(' d i e s e l A\left(3.82 \_0.65\right)\right.$ none_cftool.xls', 'Measures', 'B2:B433');

Al llamar a cftool se accede a la pantalla del programa donde se eligen los datos cargados anteriormente, el método de ajuste y el número de términos. Este último parámetro es donde difiere del método anterior, ya que ahora se puede ir aumentando el número de funciones hasta conseguir el número menor con el que converge. En la Figura 5-22 se muestra como para dos términos gaussianos realiza una aproximación que no tendría mucho sentido en el caso de un ajuste. $\mathrm{Al}$ ir aumentando el número de términos, el programa trata de realizar el ajuste

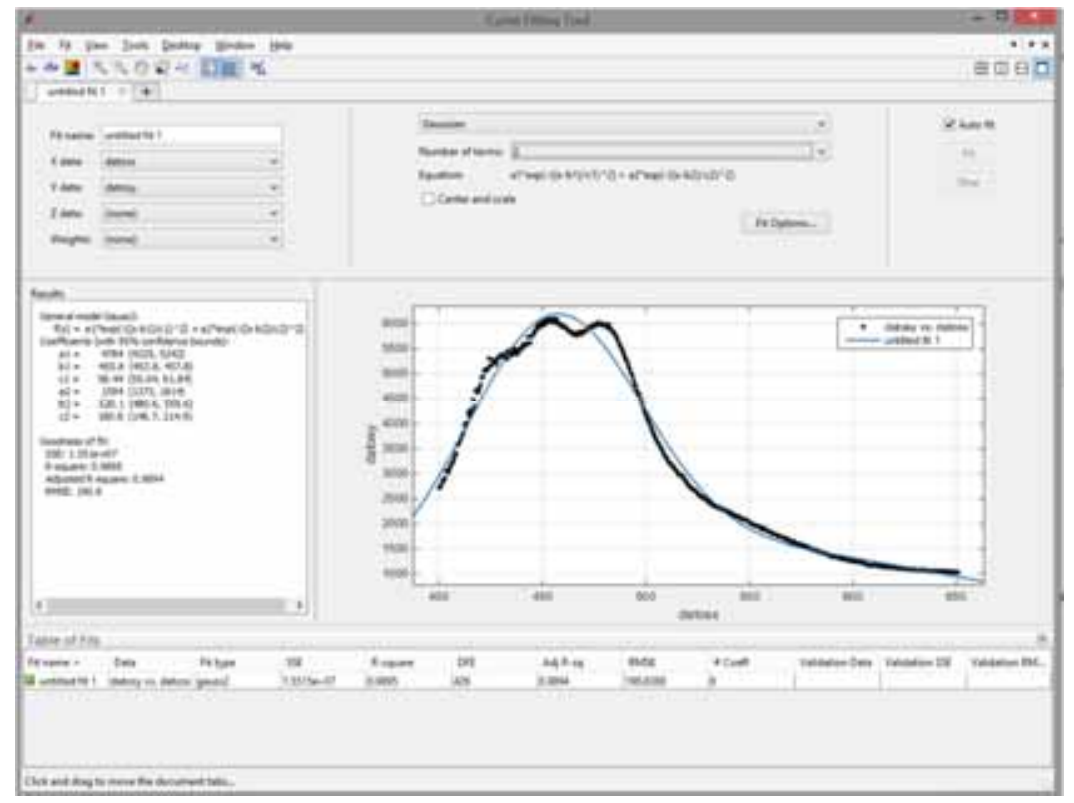

Figura 5-22: Ajuste con gaussianas del espectro de gasoil A con cftool de Matlab.

A medida que se aumenta el número de gaussianas se optimiza el resultado. En la se muestran los resultados a modo de comparativa para una variación de entre 1 y 8 gaussianas, de manera que pueda establecerse un criterio de mínimos componentes. Para establecer el criterio, se pueden comparar, además de $\mathrm{R}^{2}$, otros parámetros como SSE y RMSE, indicados en el programa como criterios para evaluar la bondad del modelo resultante.

SSE (Sum of Squares Due to Error): Este valor estadístico mide la desviación total de los valores de respuesta a partir del ajuste éstos. También se conoce como la suma de los cuadrados de los residuos.

$$
S S E=\sum_{i=1}^{n} w_{i}\left(y_{i}-\hat{y}_{i}\right)^{2}
$$


De la misma forma, la función de mérito es la suma ponderada de los residuos al cuadrado (WSSR), también llamados de chi-cuadrado:

$$
\chi^{2}(a)=\sum_{i=1}^{N}\left[\frac{y_{i}-y\left(x_{i} ; a\right)}{\sigma_{i}}\right]^{2}=\sum_{i=1}^{N} \omega_{i}\left[y_{i}-y\left(x_{i} ; a\right)\right]^{2}
$$

$\mathrm{R}^{2}$ mide el éxito del ajuste en la variación de los datos. Dicho de otra manera, $\mathrm{R}^{2}$ es el cuadrado de la correlación entre los valores de respuesta y los valores de respuesta previstos. También se conoce como el cuadrado del coeficiente de correlación múltiple y el coeficiente de determinación múltiple. Se define como la relación de la suma de los cuadrados de la regresión (SSR) y la suma total de cuadrados (SST). SSR se define como:

$$
\operatorname{SSR}=\sum_{i=1}^{n} w_{i}\left(\hat{y}_{i}-\bar{y}\right)^{2}
$$

SST también es conocido como la suma de los cuadrados en torno a la media, y se define como:

$$
S S T=\sum_{i=1}^{n} w_{i}\left(y_{i}-\bar{y}\right)^{2}
$$

Por tanto, $\mathrm{R}^{2}$ puede definirse como:

$$
R^{2}=\frac{S S R}{S S T}=1-\frac{S S E}{S S T}
$$

RMSE (Root Mean Squared Error): Este valor estadístico también se conoce como error estándar de forma o error estándar de la regresión. Es una estimación de la desviación estándar de la componente aleatoria en los datos, y se define como:

$$
R M S E=s=\sqrt{M S E}
$$

Siendo:

$$
M S E=s=\frac{S S E}{v}
$$

Donde:

$$
v=n-m
$$


Que indica los grados de libertad del parámetro $\mathrm{R}^{2}$, ya que $\mathrm{n}$ es el número de valores de la respuesta y m es el número de coeficientes ajustados a partir de los valores de la respuesta.

A la vista de la definición, interesa que SSE y RMSE sean lo menor posible y que $\mathrm{R}^{2}$ se aproxime lo máximo posible a 1 .

Aplicando para los espectros obtenidos con corriente nominal a los distintos compuestos, se obtienen los resultados que se muestran en las siguientes tablas, donde se resalta la opción que se considera más óptima, donde se toma el valor de compromiso con menor número de gaussianas y menor error.

\begin{tabular}{|c|c|c|c|}
\hline \multicolumn{4}{|c|}{ Gasoil A } \\
\hline Componentes & SSE & $\mathrm{R}^{2}$ & RMSE \\
\hline 1 & 0.9389 & 0.9844 & 0.04678 \\
\hline 2 & 0.3042 & 0.9949 & 0.02672 \\
\hline 3 & 0.8498 & 0.9858 & 0.04482 \\
\hline 4 & 0.006526 & 0.9999 & 0.003942 \\
\hline 5 & 0.8754 & 0.9854 & 0.04582 \\
\hline 6 & 0.2268 & 0.9962 & 0.0234 \\
\hline 7 & 0.02189 & 0.9996 & 0.007299 \\
\hline 8 & 0.005957 & 0.9999 & 0.003821 \\
\hline
\end{tabular}

Tabla II Resultados de ajuste con gaussianas del espectro de Gasoil A por medio de cftool de Matlab.

Los resultados reflejados en Tabla II muestran que una buena solución sería la opción de 4 u 8 gaussianas. No siempre más gaussianas se refleja como un resultado más ajustado, teniendo en cuenta además que más funciones implican más procesado. Esto se pone de manifiesto al comparar a modo de ejemplo el procesado con 4 y con 6 componentes (Figura $5-23_{\text {¡Error! }}$ No se encuentra el origen de la referencia.).

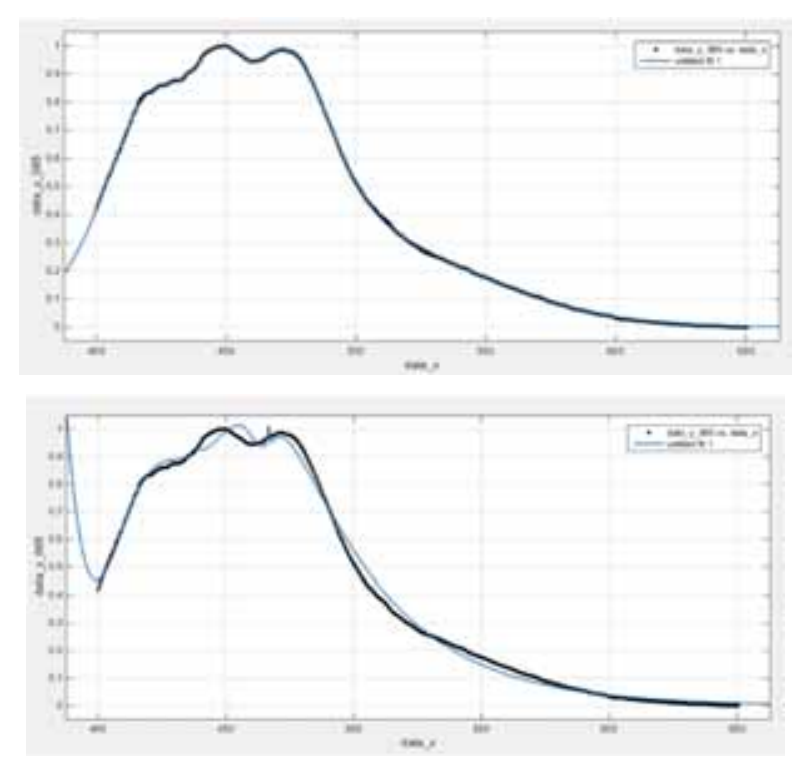

Figura 5-23: Comparativa de ajuste con 4 y 6 gaussianas del espectro de gasoil A con cftool de Matlab. 
De la misma forma se puede observar que el error acumulado depende de la longitud de onda donde se encuentre, y dado que el cálculo se extiende en todo el espectro representado, resulta interesante su observación, tal y como se aprecia en Figura 5-24, el error resulta muy similar en la zona de interés.
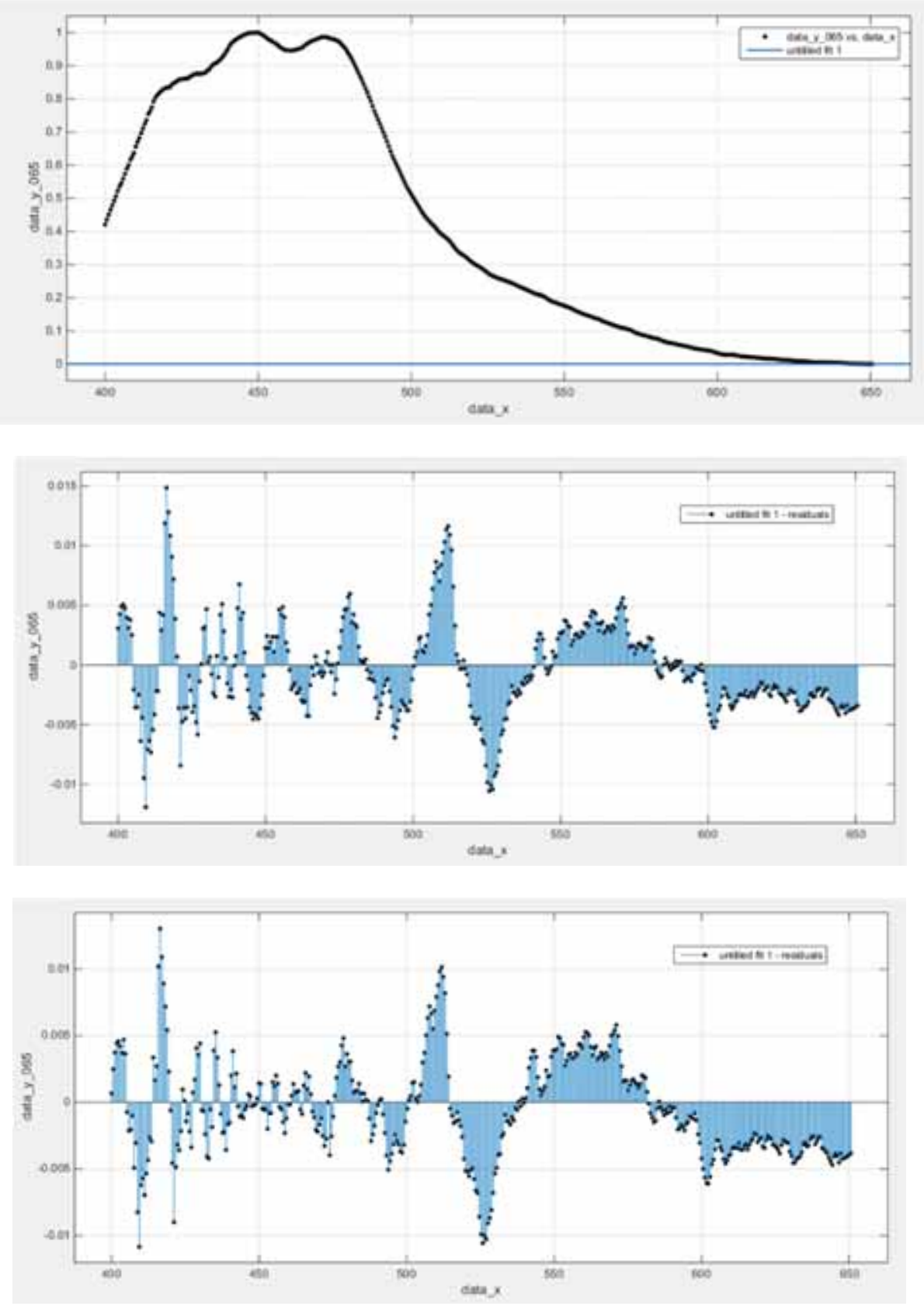

Figura 5-24: Comparativa del error del ajuste con 4 y 8 gaussianas del espectro de gasoil A con cftool de Matlab. 
Así pues, repitiendo el proceso para el resto de compuestos, se completan las tablas correspondientes.

\begin{tabular}{|c|c|c|c|}
\hline \multicolumn{4}{|c|}{ Gasoil A con aditivos } \\
\hline Componentes & SSE & $\mathbf{R}^{\mathbf{2}}$ & RMSE \\
\hline $\mathbf{1}$ & 0.7938 & 0.9871 & 0.04302 \\
\hline $\mathbf{2}$ & 0.6853 & 0.9889 & 0.04011 \\
\hline $\mathbf{3}$ & 0.6825 & 0.9889 & 0.04017 \\
\hline $\mathbf{4}$ & 0.00865 & 0.9999 & 0.004538 \\
\hline $\mathbf{5}$ & 0.2795 & 0.9955 & 0.02589 \\
\hline $\mathbf{6}$ & 0.005382 & 0.9999 & 0.003606 \\
\hline $\mathbf{7}$ & 0.005294 & 0.9999 & 0.003589 \\
\hline $\mathbf{8}$ & 0.003622 & 0.9999 & 0.00298 \\
\hline
\end{tabular}

Tabla III Resultados de ajuste con gaussianas del espectro de Gasoil A+ por medio de cftool de Matlab.

\begin{tabular}{|c|c|c|c|}
\hline \multicolumn{5}{|c|}{ Gasoil B } \\
\hline Componentes & SSE & $\mathbf{R}^{\mathbf{2}}$ & RMSE \\
\hline $\mathbf{1}$ & 0.7605 & 0.9857 & 0.0421 \\
\hline $\mathbf{2}$ & 0.353 & 0.9934 & 0.02879 \\
\hline $\mathbf{3}$ & 0.3228 & 0.9939 & 0.02762 \\
\hline $\mathbf{4}$ & 0.003401 & 0.9999 & 0.002846 \\
\hline $\mathbf{5}$ & 0.001905 & 1 & 0.002138 \\
\hline $\mathbf{6}$ & 0.001422 & 1 & 0.001853 \\
\hline $\mathbf{7}$ & 0.001818 & 1 & 0.002103 \\
\hline $\mathbf{8}$ & 0.001569 & 1 & 0.001961 \\
\hline
\end{tabular}

Tabla IV Resultados de ajuste con gaussianas del espectro de Gasoil B por medio de cftool de Matlab.

\begin{tabular}{|c|c|c|c|}
\hline \multicolumn{5}{|c|}{ Gasoil C } \\
\hline Componentes & SSE & $\mathbf{R}^{\mathbf{2}}$ & RMSE \\
\hline $\mathbf{1}$ & 0.7897 & 0.9868 & 0.04291 \\
\hline $\mathbf{2}$ & 0.5853 & 0.9902 & 0.03707 \\
\hline $\mathbf{3}$ & 0.5637 & 0.9906 & 0.0365 \\
\hline $\mathbf{4}$ & 0.01856 & 0.9997 & 0.006648 \\
\hline $\mathbf{5}$ & 0.09415 & 0.9984 & 0.01503 \\
\hline $\mathbf{6}$ & 0.1625 & 0.9973 & 0.01981 \\
\hline $\mathbf{7}$ & 0.005037 & 0.9999 & 0.003501 \\
\hline $\mathbf{8}$ & 0.005172 & 0.9999 & 0.00356 \\
\hline
\end{tabular}

Tabla V Resultados de ajuste con gaussianas del espectro de Gasoil C por medio de cftool de Matlab. 


\begin{tabular}{|c|c|c|c|}
\hline \multicolumn{4}{|c|}{ Gasolina 95 } \\
\hline Componentes & SSE & R2 & RMSE \\
\hline $\mathbf{1}$ & 0.6103 & 0.988 & 0.03772 \\
\hline $\mathbf{2}$ & 0.3239 & 0.9936 & 0.02757 \\
\hline $\mathbf{3}$ & 0.4449 & 0.9912 & 0.03243 \\
\hline $\mathbf{4}$ & 0.3167 & 0.9938 & 0.02746 \\
\hline $\mathbf{5}$ & 0.01679 & 0.9997 & 0.006346 \\
\hline $\mathbf{6}$ & 0.09817 & 0.9981 & 0.0154 \\
\hline $\mathbf{7}$ & 0.1942 & 0.9962 & 0.02174 \\
\hline $\mathbf{8}$ & 0.02915 & 0.9994 & 0.008453 \\
\hline
\end{tabular}

Tabla VI Resultados de ajuste con gaussianas del espectro de Gasolina 95 por medio de cftool de Matlab.

\begin{tabular}{|c|c|c|c|}
\hline \multicolumn{4}{|c|}{ Gasolina 98 } \\
\hline Componentes & SSE & R2 & RMSE \\
\hline $\mathbf{1}$ & 0.6199 & 0.9861 & 0.03801 \\
\hline $\mathbf{2}$ & 0.4171 & 0.9906 & 0.03129 \\
\hline $\mathbf{3}$ & 0.2529 & 0.9943 & 0.02445 \\
\hline $\mathbf{4}$ & 0.2529 & 0.9943 & 0.02454 \\
\hline $\mathbf{5}$ & 0.02566 & 0.9994 & 0.007844 \\
\hline $\mathbf{6}$ & 0.02897 & 0.9993 & 0.008365 \\
\hline $\mathbf{7}$ & 0.01333 & 0.9997 & 0.005695 \\
\hline $\mathbf{8}$ & 0.6199 & 0.9861 & 0.03801 \\
\hline
\end{tabular}

Tabla VII Resultados de ajuste con gaussianas del espectro de Gasolina 98 por medio de cftool de Matlab.

Con el programa Fityk [W10] también es posible establecer un ajuste por gaussianas de los hidrocarburos en estudio. Se trata de un programa desarrollado para el análisis de datos y ajuste de curvas analíticas, por lo que resulta muy útil en este propósito. Con los parámetros por defectos presenta un ajuste con mucha precisión, obteniendo de forma rápida el mínimo de funciones gaussianas para cada uno de los hidrocarburos. Mediante esta herramienta es posible calcular paso a paso cada una de las componentes (gaussianas) que se van añadiendo para ir conformando el espectro resultante más ajustado. Cada uno de los parámetros como longitud de onda y ancho pueden fijarse individualmente, de forma que tal y como se verá posteriormente, es posible la obtención de plantillas de cada uno de los compuestos.

A continuación se muestra el resultado de ir introduciendo componente a componente, hasta conseguir un error lo suficientemente pequeño, tomando como máximo 6 , ya que se pretende conseguir un sistema en el que se almacene el menor número variables posible.. 


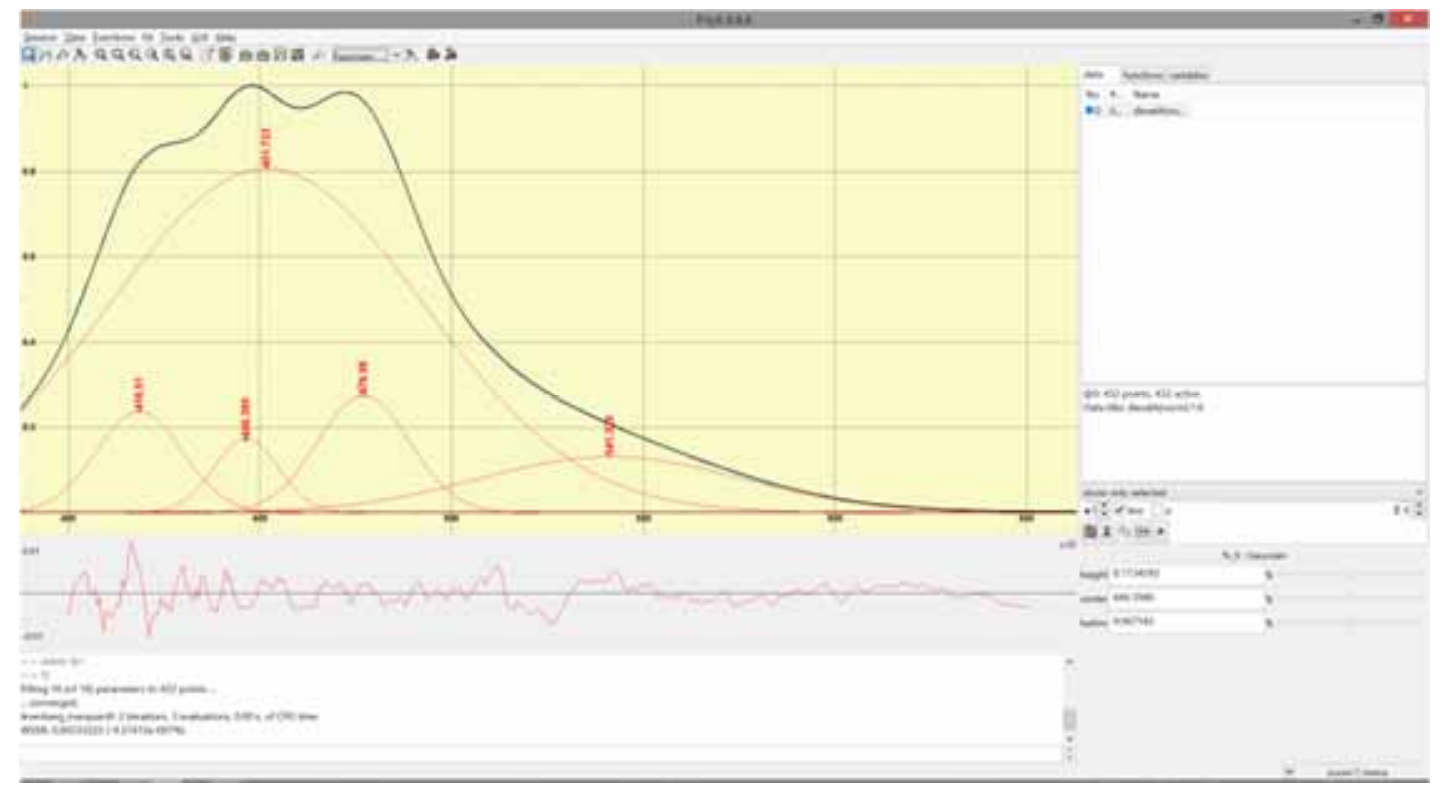

Figura 5-25: Ajuste mediante gaussianas con el programa Fityk

\begin{tabular}{|c|c|c|c|}
\hline \multicolumn{4}{|c|}{ Gasoil A } \\
\hline Componentes & Center & Height & FWHM \\
\hline Gaussian 1 & 451.723 & 0.806742 & 48.17036 \\
\hline Gaussian 2 & 476.9802 & 0.2736061 & 14.16332 \\
\hline Gaussian 3 & 418.5094 & 0.236756 & 13.26072 \\
\hline Gaussian 4 & 541.3284 & 0.1308588 & 40.41551 \\
\hline Gaussian 5 & 446.3946 & 0.1734479 & 9.96752 \\
\hline Gaussian 6 & - & - & - \\
\hline \multicolumn{4}{|c|}{$\chi^{2}=0.00331$} \\
\hline
\end{tabular}

Tabla VIII Resultados de ajuste con gaussianas del espectro de Gasoil A con Tifyk.

\begin{tabular}{|c|c|c|c|}
\hline \multicolumn{4}{|c|}{ Gasoil A con aditivos } \\
\hline Componentes & Center & Height & FWHM \\
\hline Gaussian 1 & 448.36306 & 0.8321257 & 95.3861 \\
\hline Gaussian 2 & 477.3335 & 0.232673 & 0.232673 \\
\hline Gaussian 3 & 417.8765 & 0.2436139 & 15.3202 \\
\hline Gaussian 4 & 539.4 & 0.1258832 & 40.71244 \\
\hline Gaussian 5 & 446.8424 & 0.1282176 & 9.755384 \\
\hline Gaussian 6 & 417.4499 & 0.0266164 & 2.614494 \\
\hline \multicolumn{4}{|c|}{$\chi^{2}=0.00452$} \\
\hline
\end{tabular}

Tabla IX Resultados de ajuste con gaussianas del espectro de Gasoil A+ por medio de Tifyk. 


\begin{tabular}{|c|c|c|c|}
\hline \multicolumn{5}{|c|}{ Gasoil B } \\
\hline Componentes & Center & Height & FWHM \\
\hline Gaussian 1 & 444.0779 & 0.121622 & 21.9465 \\
\hline Gaussian 2 & 468.0874 & 0.454582 & 45.4367 \\
\hline Gaussian 3 & 485.6923 & 0.203597 & 135.816 \\
\hline Gaussian 4 & 419.6365 & 0.863499 & 45.7107 \\
\hline Gaussian 5 & - & - & - \\
\hline Gaussian 6 & - & - & - \\
\hline \multicolumn{5}{|c|}{$\chi^{2}=0.0021$} & \\
\hline
\end{tabular}

Tabla X Resultados de ajuste con gaussianas del espectro de Gasoil B por medio de Tifyk.

\begin{tabular}{|c|c|c|c|}
\hline \multicolumn{5}{|c|}{ Gasoil C } \\
\hline Componentes & Center & Height & FWHM \\
\hline Gaussian 1 & 442.7477 & 0.47019 & 170.892 \\
\hline Gaussian 2 & 422.7973 & 0.530115 & 35.5272 \\
\hline Gaussian 3 & 470.8573 & 0.434289 & 40.3496 \\
\hline Gaussian 4 & 445.8732 & 0.195221 & 19.7989 \\
\hline Gaussian 5 & - & - & - \\
\hline Gaussian 6 & - & - & - \\
\hline \multicolumn{5}{|c|}{$\chi^{2}=0.00755$} \\
\hline
\end{tabular}

Tabla XI Resultados de ajuste con gaussianas del espectro de Gasoil C por medio de Tifyk.

\begin{tabular}{|c|c|c|c|}
\hline \multicolumn{5}{|c|}{ Gasolina 95 } \\
\hline Componentes & Center & Height & FWHM \\
\hline Gaussian 1 & 510.6492 & 0.208072 & 111.796 \\
\hline Gaussian 2 & 435.8408 & 0.496913 & 23.0147 \\
\hline Gaussian 3 & 463.3119 & 0.627214 & 53.9497 \\
\hline Gaussian 4 & 405.4065 & 0.792152 & 18.6309 \\
\hline Gaussian 5 & 416.5175 & 0.284127 & 9.05019 \\
\hline Gaussian 6 & 425.5580 & 0.430536 & 12.643 \\
\hline \multicolumn{4}{|c}{$\chi^{2}=0.00747$} \\
\hline
\end{tabular}

Tabla XII Resultados de ajuste con gaussianas del espectro de Gasolina 95 por medio de Tifyk. 


\begin{tabular}{|c|c|c|c|}
\hline \multicolumn{5}{|c|}{ Gasolina 98 } \\
\hline Componentes & Center & Height & FWHM \\
\hline Gaussian 1 & 511.0881 & 0.157776 & 113.356 \\
\hline Gaussian 2 & 421.1844 & 0.7713978 & 24.04562 \\
\hline Gaussian 3 & 466.6003 & 0.4589074 & 25.90158 \\
\hline Gaussian 4 & 401.1660 & 0.3391433 & 6.190977 \\
\hline Gaussian 5 & 427.9798 & 0.1312385 & 4.669462 \\
\hline Gaussian 6 & - & - & - \\
\hline \multicolumn{5}{|c|}{$\chi^{2}=0.01249$} \\
\hline
\end{tabular}

Tabla XIII Resultados de ajuste con gaussianas del espectro de Gasolina 98 por medio de Tifyk.

Donde se observa que en este caso, coincide prácticamente en el número de gaussianas. Existe una diferencia fundamental a la hora de evaluar el método, ya que Fityk resuelve tras 43 iteraciones con un resultado de 5 gaussinas. Con el método LevenbergMarquardt (LM), la herramienta cftool de Matlab no lo hace así aunque se indique, debido a que requiere más ajustes en el dominio de la frecuencia. Se pueden utilizar otros métodos de optimización de uso general, pero son más lentos incluso algunos de ellos son varios órdenes de magnitud más lentas. A veces pueden utilizarse otros métodos alternativos para encontrar el mínimo cuando el algoritmo LM se ha quedado atascado en un mínimo local, pero en la mayoría de los casos el método LM predeterminado es mejor.

En resumen, con los tres métodos utilizados, con el fin de obtener el mínimo número de componentes gaussianas, Fityk resulta una herramienta más eficaz. A partir de los resultados anteriores se establece el número de gaussianas y su posición para poder establecer la comparación en función de las corrientes de LED.

\subsection{Estudio de la fluorescencia en función de la corriente LED.}

Con el objeto de verificar una concordancia en la fluorescencia, y dada la utilidad que tiene la detección de hidrocarburos. A continuación se muestran los resultados de las medidas realizadas en laboratorio. Las medidas se muestran con un filtrado Savitzky-Golay para una ventana de 10 puntos. Se toman siete espectros producidos con las respectivas intensidades de corriente (a la intensidad nominal, dos intensidades mayores y cuatro menores), que se traducen en una potencia lumínica variable. Con los datos obtenidos es posible entonces establecer a partir de qué potencia lumínica, bien por desgaste del LED o bien por poca concentración del contaminante, la lectura no sería correcta. 


\section{Diésel A}

A la vista de los espectros representados en la Figura 5-26, el espectro de fluorescencia es proporcional a la potencia luminosa. Para corrientes bajas, el espectro emitido es muy tenue, y aparentemente no son muy reconocibles los picos destacados, así como su diferencia de amplitud.

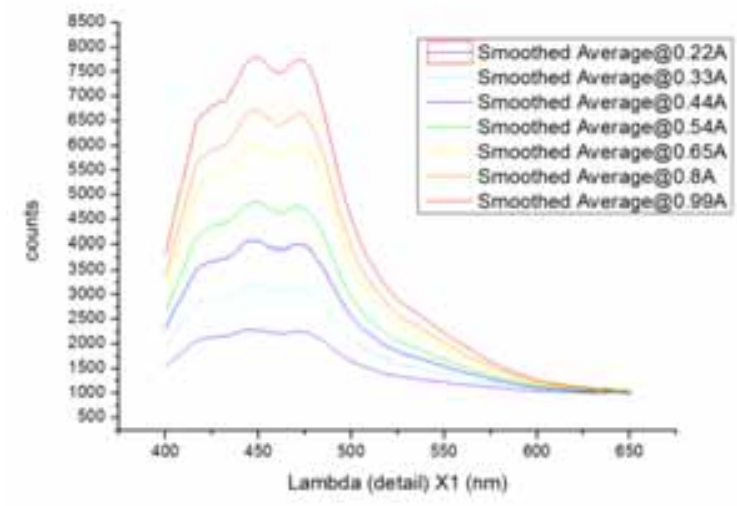

Figura 5-26: Espectros emitidos por gasóleo A con iluminación de LED de 365nm con distintas corrientes.

En la figura Figura 5-26 se aprecia claramente que a partir de la corriente nominal, el incremento de la fluorescencia no sigue la misma pendiente, debido a que por encima de esta corriente el LED no ofrece evidentemente un rendimiento igual. El fabricante sin embargo, indica en las hojas de características, que este dispositivo puede trabajar durante cortos intervalos de tiempo a corrientes superiores, aumentando su potencia lumínica, aunque no detalla la proporcionalidad. El gasóleo A presenta una mayor fluorescencia en comparación a los demás hidrocarburos estudiados (ver escalas), y al ser esta proporcional al contenido del elemento fluorescente y a la potencia lumínica, en este caso se debe al segundo factor, al coincidir éste en un cambio de pendiente justo en la corriente nominal. Se ha dejado las respuestas obtenidas sin normalizar con el fin de poder observar las diferencias entre las potencias lumínicas de las respuestas fluorométricas de los distintos compuestos. 


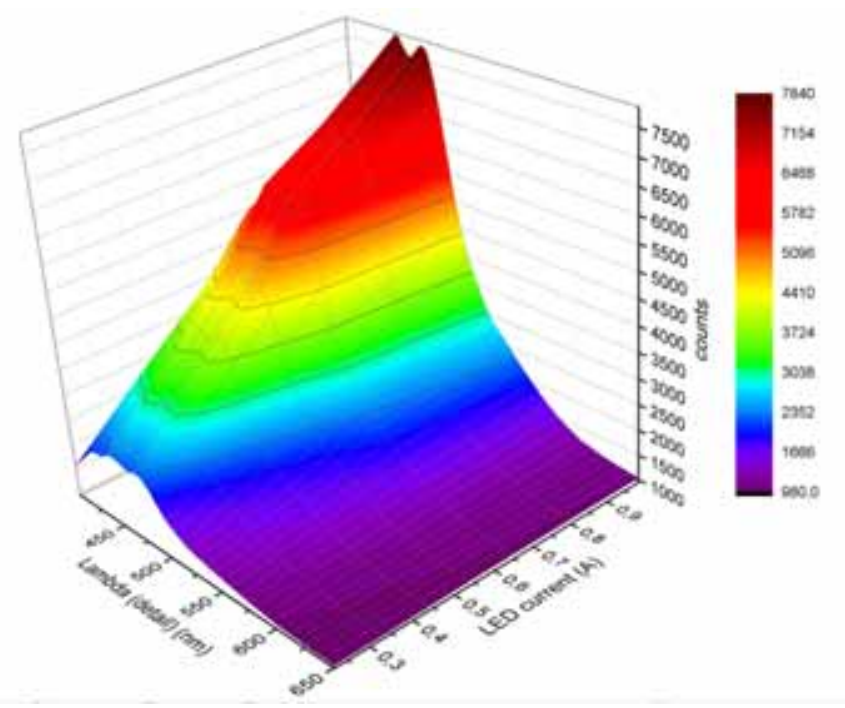

Figura 5-27: Espectros emitidos por gasóleo A con iluminación de LED de 365nm con distintas corrientes en representación 3D.

Para la corriente nominal de $650 \mathrm{~mA}$, a modo de referencia, se obtuvieron los siguientes resultados (Figura 5-28):

La función suavizada con el filtro Savitzky-Golay se descompone en 13 gaussianas de diferente altura y anchura. La función resultante obtenida como la suma de las gaussianas se encuentra representada en color rojo, y la comparación con la función original (en color negro). Resulta un número elevado de componentes, y en uno de los picos de la resultante-suma presenta un error apreciable a simple vista.

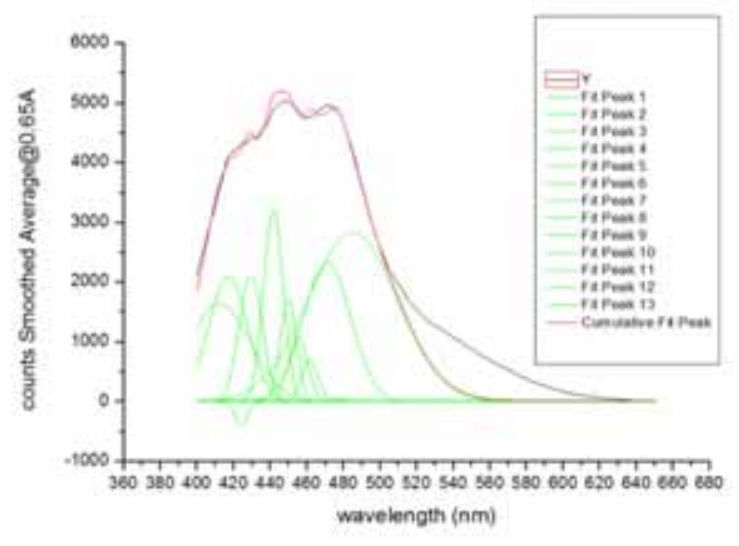

Figura 5-28: Descomposición en gaussianas del espectro emitido por gasóleo A con 650 $\mathrm{mA}$

Diesel A con aditivos

A la vista de los espectros representados en la Figura 5-29, el espectro de fluorescencia es como en el caso del hidrocarburo anterior, proporcional a la potencia luminosa y presenta 
muchas similitudes con éste. Para corrientes bajas, el espectro emitido también es muy tenue, y aparentemente es menos reconocibles los picos destacados, así como su diferencia de amplitud.

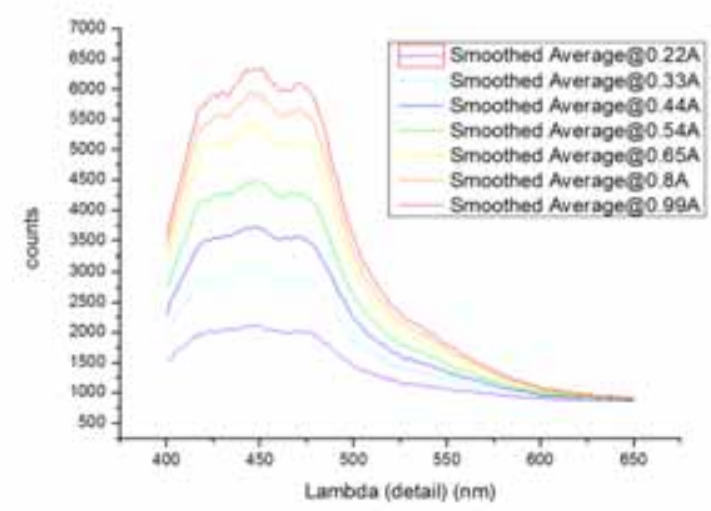

Figura 5-29: Espectros emitidos por gasóleo A plus con iluminación de LED de 365nm con distintas corrientes.

Este hidrocarburo tiene en las longitudes de onda más cortas (entre 400 y $425 \mathrm{~nm}$ ) una zona plana que puede servir como elemento diferenciador del gasóleo A a la hora de distinguir los patrones. Este resultado se mantiene para todas las corrientes de LED. Este factor es muy importante, dado que presenta menor fluorescencia que el gasóleo A convencional.

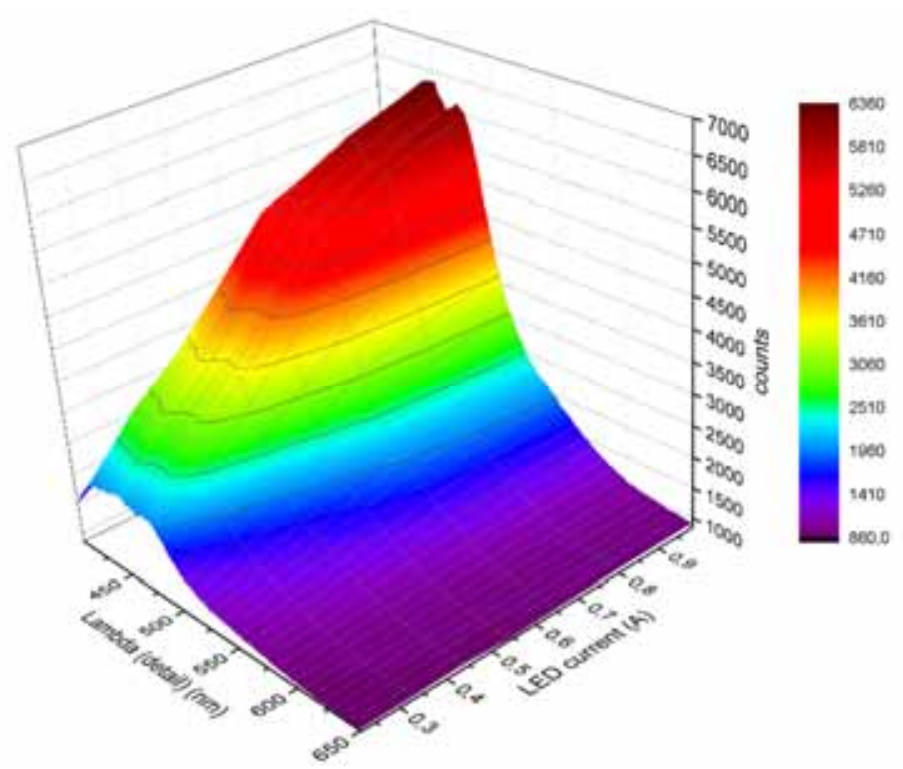

Figura 5-30: Espectros emitidos por gasóleo A+ con iluminación de LED de 365nm con distintas corrientes en representación 3D. 
Asimismo se aprecia con mayor claridad la caída de la pendiente en el aumento de la fluorescencia (Figura 5-30) a partir de la corriente nominal. Para la corriente nominal de 650 $\mathrm{mA}$, a modo de referencia, se obtuvieron los siguientes resultados (Figura 5-31):

La función suavizada con el filtro Savitzky-Golay se descompone al igual que el anterior en 13 gaussianas de diferente altura y anchura.

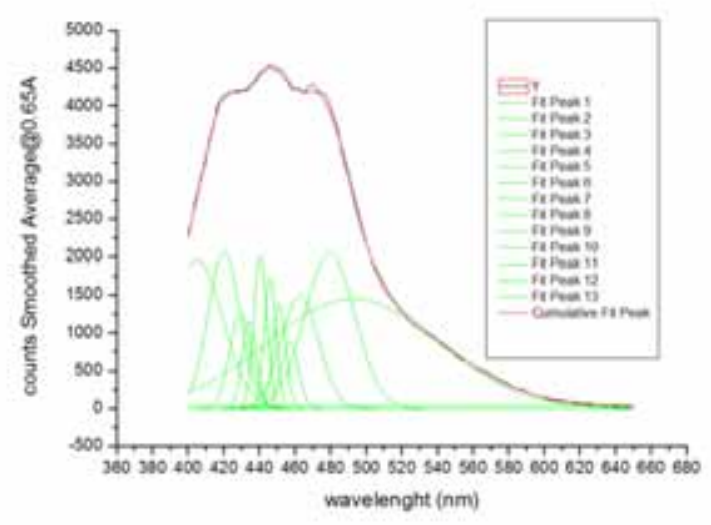

Figura 5-31: Descomposición en gaussianas para el espectro emitido con $650 \mathrm{~mA}$ para gasóleo A plus.

Diesel B

Para este hidrocarburo, tal y como se aprecian en los espectros representados en la Figura 5-32, también la potencia lumínica emitida es proporcional a la potencia luminosa. El espectro resulta más sencillo ya que no presenta picos muy marcados, lo que puede suponer algún problema a la hora del reconocimiento.

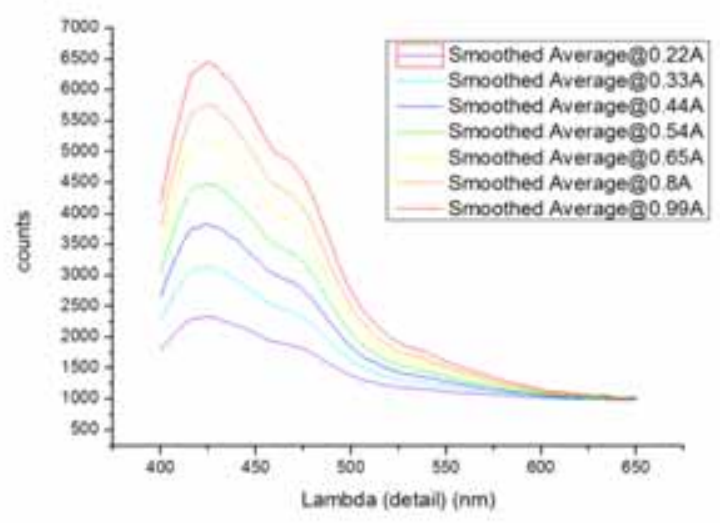

Figura 5-32: Espectros emitidos por gasóleo B con iluminación de LED de 365nm con distintas corrientes. 


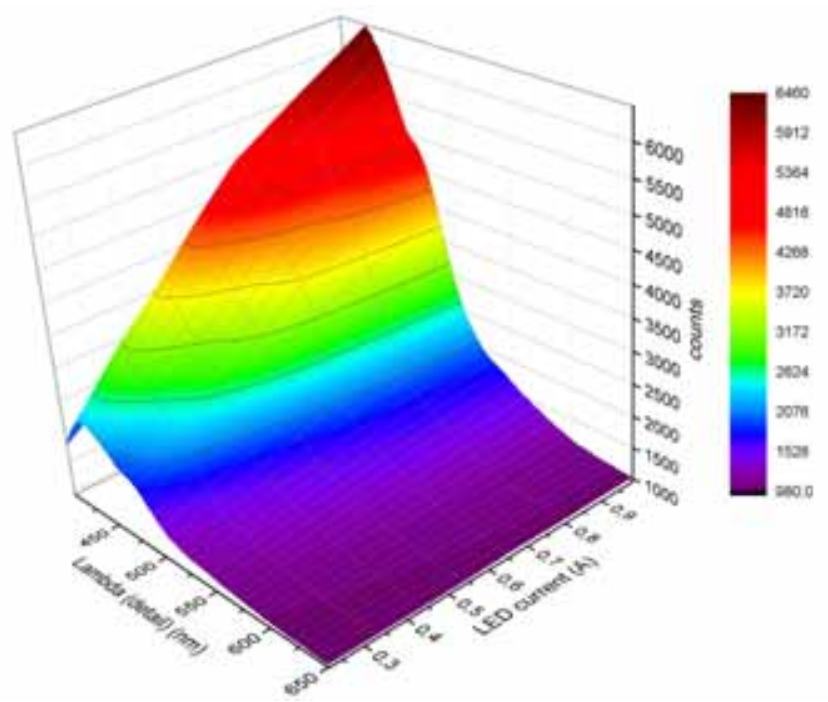

Figura 5-33: Espectros emitidos por gasóleo B con iluminación de LED de 365nm con distintas corrientes en representación 3D.

Para la corriente nominal de $650 \mathrm{~mA}$, a modo de referencia, se obtuvieron los siguientes resultados (Figura 5-34):

La función suavizada con el filtro Savitzky-Golay se descompone en 8 gaussianas de diferente altura y anchura: el "suelo" de la gráfica está basado en tres componentes de gran anchura.

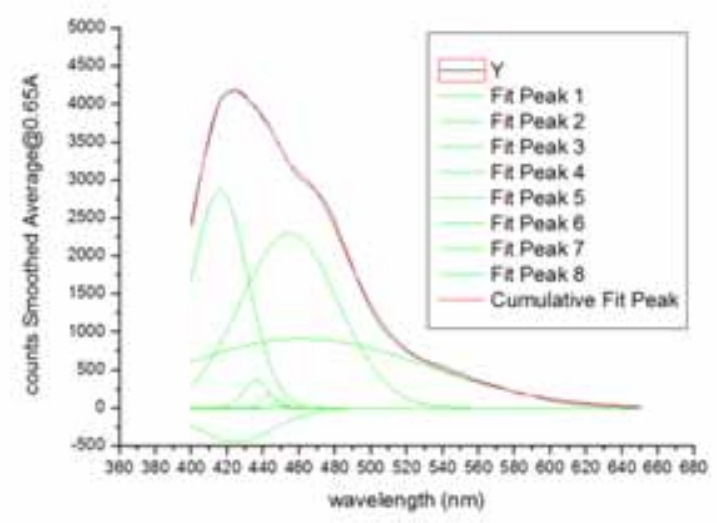

Figura 5-34: Descomposición en gaussianas para el espectro emitido con 650 mA para gasóleo B.

\section{Diesel C}

Para el diésel C en la Figura 5-35 se observan los espectros de fluorescencia para distintas corrientes. Al igual que en el caso del diésel B, aparentemente no presenta picos muy remarcados. Para corrientes altas, muestra unos pequeños picos a pesar de haber sido filtrado, 
que a la hora de descomponer el espectro, pueden dar como resultado la necesidad de incorporar más componentes.

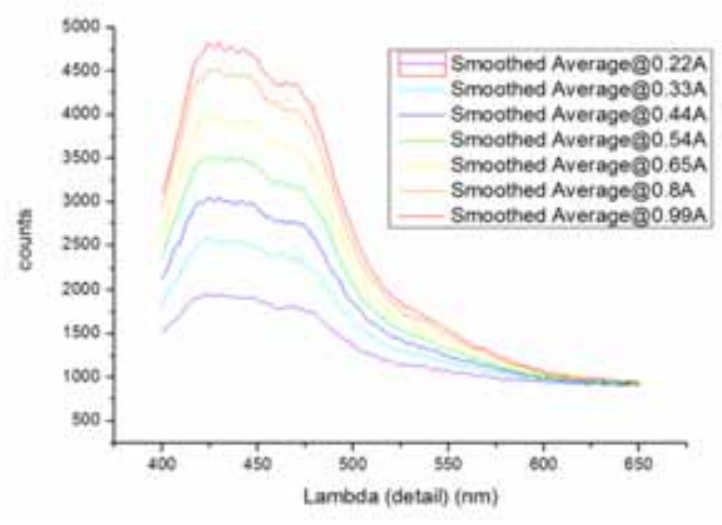

Figura 5-35: Espectros emitidos por gasóleo C con iluminación de LED de 365nm con distintas corrientes.

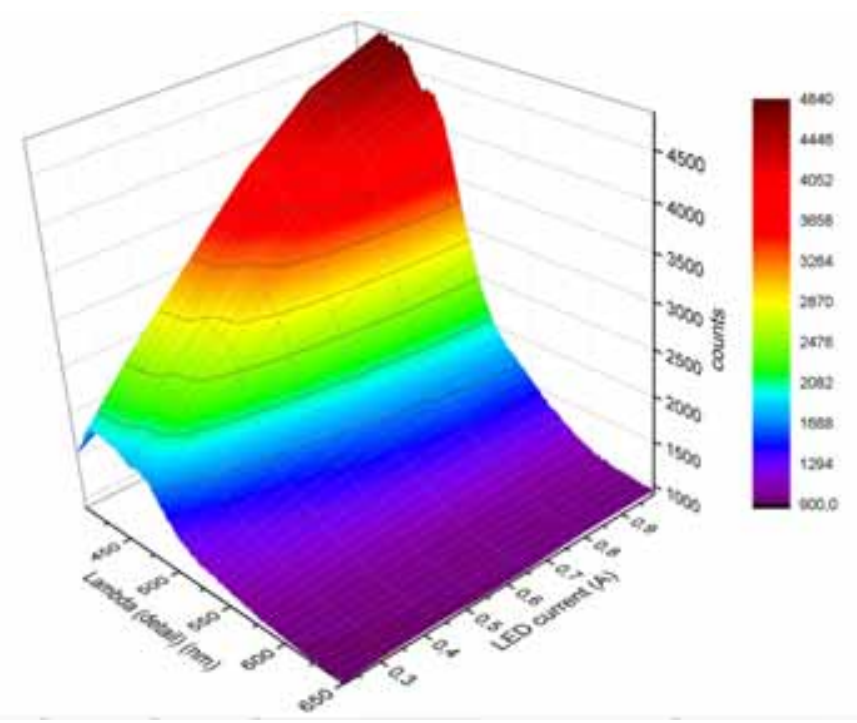

Figura 5-36: Espectros emitidos por gasóleo C con iluminación de LED de 365nm con distintas corrientes en representación 3D.

Para la corriente nominal de $650 \mathrm{~mA}$, a modo de referencia, se obtuvieron los siguientes resultados (Figura 5-37):

La función suavizada con el filtro Savitzky-Golay se descompone en 14 gaussianas de diferente altura y anchura con el procedimiento automático realizado con el programa Origin. 


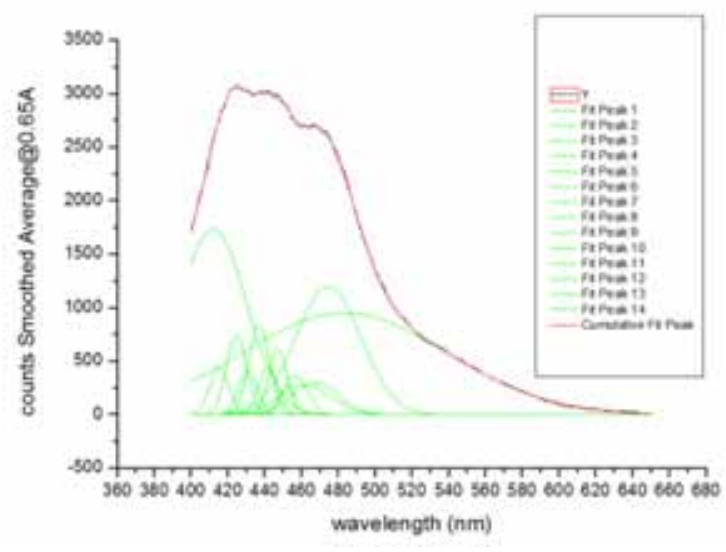

Figura 5-37: Descomposición en gaussianas para el espectro emitido con $650 \mathrm{~mA}$ para gasóleo C.

\section{Gasolina 95}

Este hidrocarburo, tal y como se observa en la Figura 5-38 presenta notables diferencias. Esto resulta muy conveniente para distinguir gasóleos de gasolinas. La parte del espectro que presenta picos se encentra en la zona de bajas longitudes de onda, pero sigue siendo efectivo el acotamiento entre los 400 y $650 \mathrm{~nm}$.

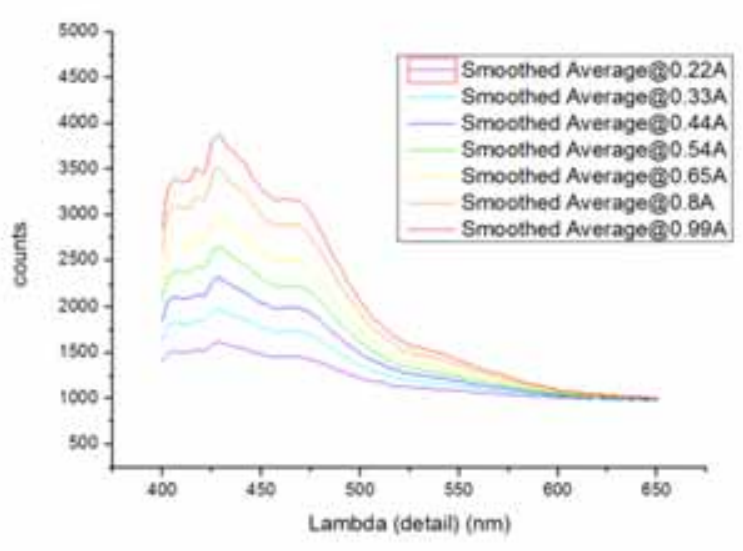

Figura 5-38: Espectros emitidos por gasolina 95 con iluminación de LED de 365nm con distintas corrientes. 


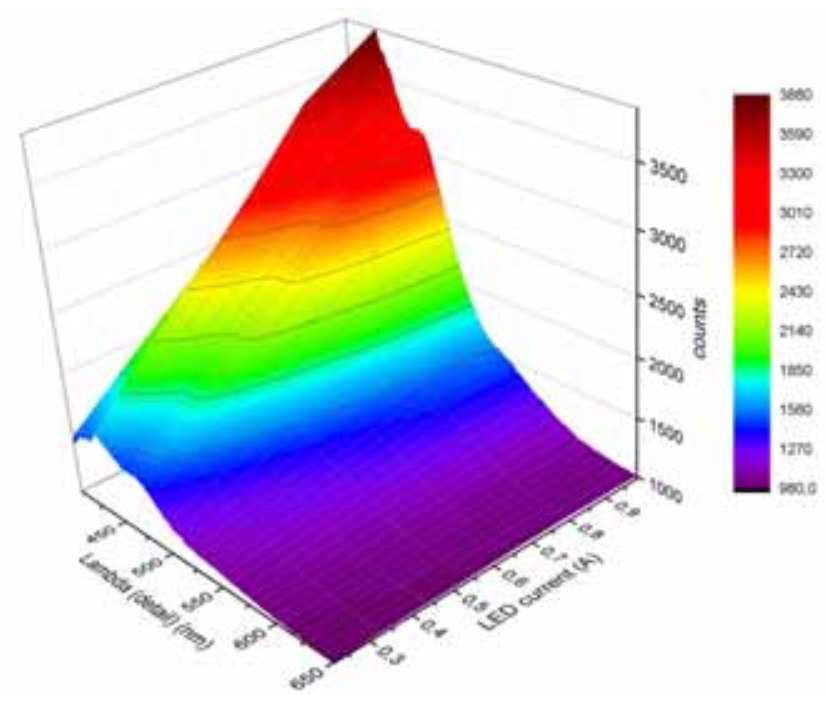

Figura 5-39: Espectros emitidos por gasolina 95 con iluminación de LED de 365nm con distintas corrientes en representación 3D.

Para la corriente nominal de $650 \mathrm{~mA}$, a modo de referencia, se obtuvieron los siguientes resultados (Figura 5-40):

La función suavizada con el filtro Savitzky-Golay se descompone en 7 gaussianas de diferente altura y anchura,

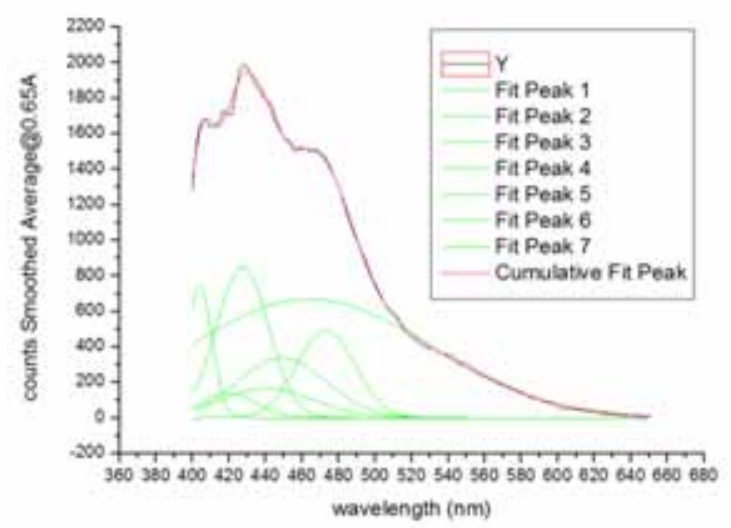

Figura 5-40: Descomposición en gaussianas para el espectro emitido con 650 mA para gasolina 95.

\section{Gasolina 98}

A la vista de los espectros representados en la Figura 5-41, el espectro de fluorescencia es proporcional a la potencia luminosa. Para corrientes bajas, el espectro emitido es muy tenue, y aparentemente no son muy reconocibles los picos destacados, así como su diferencia de amplitud. 


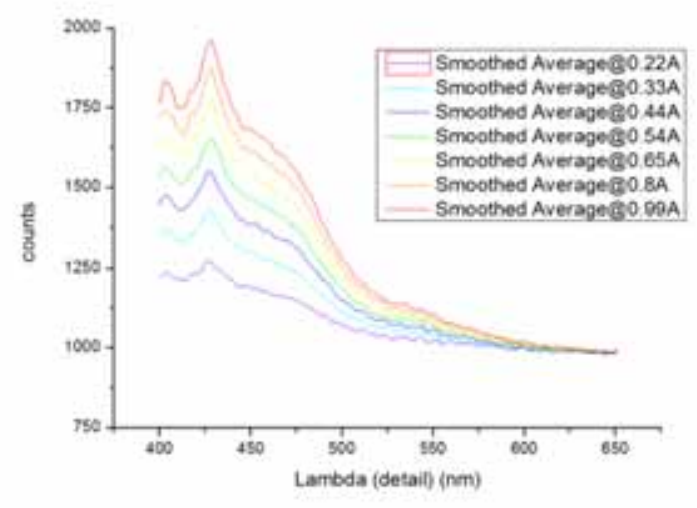

Figura 5-41: Espectros emitidos por gasolina 98 con iluminación de LED de 365nm con distintas corrientes.

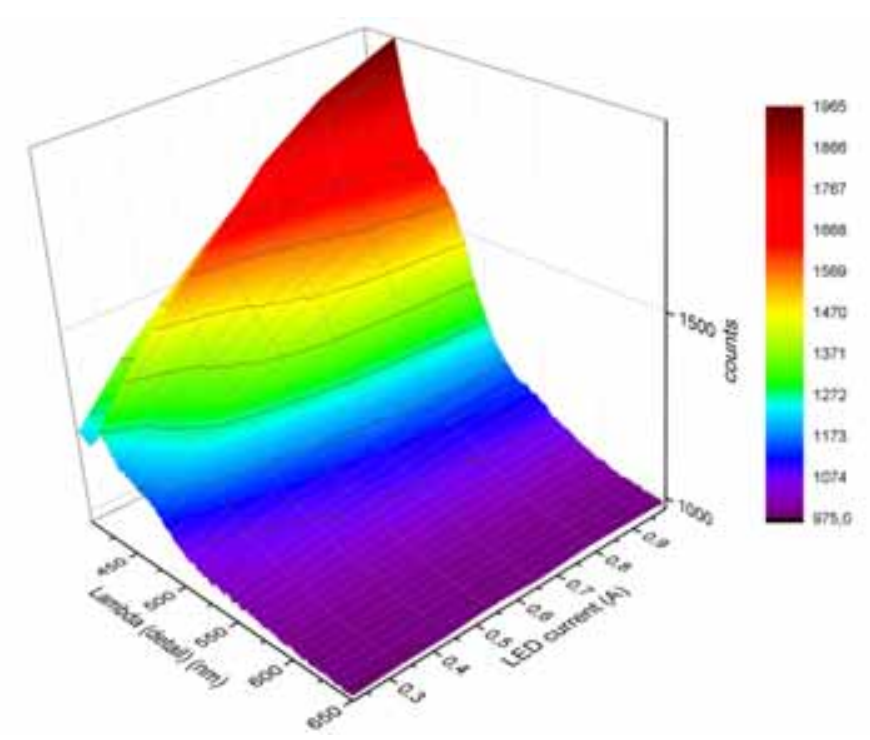

Figura 5-42: Espectros emitidos por gasolina 98 con iluminación de LED de 365nm con distintas corrientes en representación 3D.

Para la corriente nominal de $650 \mathrm{~mA}$, a modo de referencia, se obtuvieron los siguientes resultados (Figura 5-43):

La función suavizada con el filtro Savitzky-Golay se descompone en 8 gaussianas de diferente altura y anchura. Dado que la respuesta espectral tiene una notable menor potencia lumínica, el ruido presenta un rizado apreciable. A la hora de fijar los parámetros para realizar el procesado este factor hay que tenerlo muy en cuenta para que no sea considerado señal. En el resultado es también remarcable las dos componentes gaussianas de mayor longitud de onda, que cubren más del 90\% del área total. 


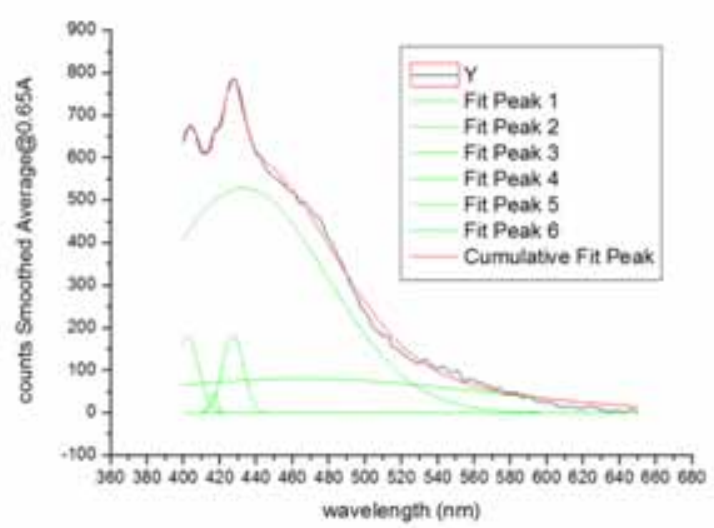

Figura 5-43: Descomposición en gaussianas para el espectro emitido con $650 \mathrm{~mA}$ para gasolina 98.

\subsection{Obtención de plantillas de los hidrocarburos}

En este apartado, tomando las referencias apuntadas anteriormente, se propone la obtención de un método que identifique mediante una plantilla cada uno de los compuestos en estudio, de manera que sea distinguible de los demás. Gracias a ello, se pueden obtener dos resultados principales: a partir de los datos anteriores en los que se reflejan los espectros obtenidos a varias corrientes, poder saber a partir de qué potencia óptica emitida por el LED ya no es posible obtener fluorescencia, y por otro lado, profundizar en el software de identificación de determinados compuestos (en este caso hidrocarburos) a partir de las huellas almacenadas. El manejo de algoritmos que implementen estos objetivos es estudiado principalmente en base a la procedencia de los datos [BWK97], pero principalmente se basan en la comparación de las longitudes de onda y el ancho de la función cuando ésta adquiere $1 / 2$ de su valor de pico. Existen más variables que se pueden tener en cuenta, como por ejemplo el área, pero la bondad del método se basa en el manejo del menor número de datos.

A continuación se muestran dos métodos diferenciados en su concepto. En uno de ellos se comparan los valores de las funciones obtenidas con el obtenido realizando un ajuste de la función desconocida. El otro sistema consiste en tomar una plantilla de longitudes de onda fijas con las que se realiza el ajuste de los compuestos y compararlo con el ajuste que se realiza con el de la función desconocida.

A continuación se describen ambos métodos y se muestran los resultados mediante diagramas de caja-bigotes. 


\subsubsection{Método de obtención de huellas particulares de cada compuesto}

En este método, tal y como se vio en el apartado 5.3.2.2, se procede mediante el programa Fityk a obtener una plantilla de cada uno de los compuestos a comparar: tomando como referencia el espectro de fluorescencia obtenido con la corriente nominal, se ajusta éste obteniéndose un número de gaussianas con determinados anchos y alturas que serán almacenados. Fijando la longitud de onda de cada componente, se realiza un nuevo ajuste con los espectros normalizados obtenidos con las corrientes de $0.33,0.41,0.54$ y 0.80 . De esta forma se tiene el margen de variación a determinadas longitudes de onda para dicho compuesto. Con estas variaciones se puede construir el diagrama de caja-bigotes. A modo de ejemplo se toma el gasóleo A donde se representan para cada una de las longitudes de onda resultantes, las componentes gaussianas en altura $(\mathrm{H})$ y anchura (FWHM) (Figura 5-44).

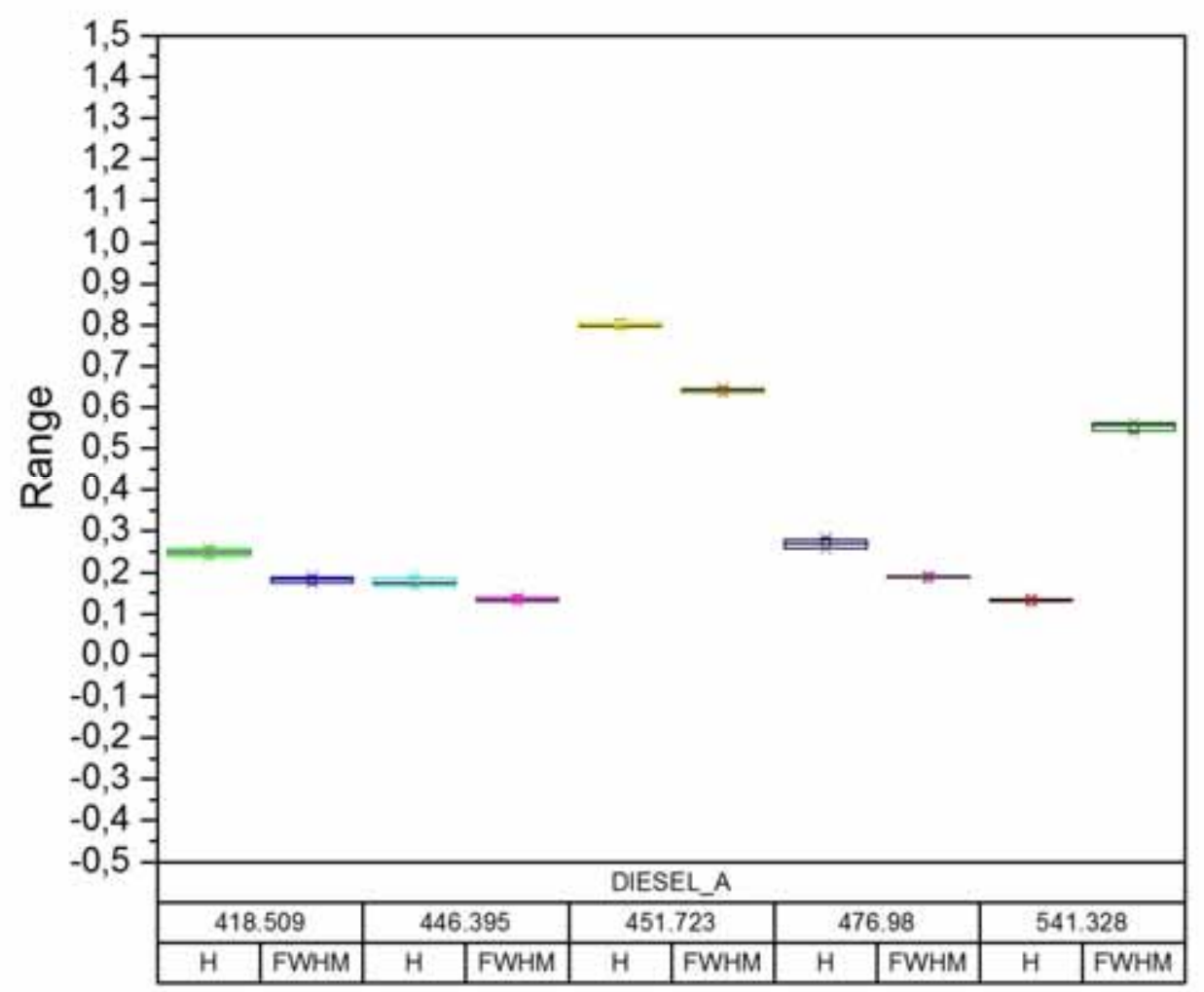

Figura 5-44: Plantilla de diagrama caja-bigotes obtenida para identificación de Diésel A.

Cabe destacar de la plantilla obtenida el estrecho margen que se observa para cad una de las alturas y anchuras. Esto es debido a la gran similitud existente entre las respuestas espectrales obtenidas para cada corriente. Tal y como se discute en el apartado 5.4, las diferencias cuantitativas son apreciables, pero al normalizar se conserva la información de cada uno de los compuestos, aportando robustez al procedimiento. A continuación, se realiza el ajuste de las 
sustancias con las que se pretende comparar, tomando como base las longitudes de onda obtenidas, en este caso las del gasóleo A. Es de esperar que solamente coincidan dentro del margen de caja la sustancia coincidente, quedando fuera las demás. Por ello se realiza este ajuste con todas las demás sustancias a estudio, para corrientes de $0.41,0.54$ y 0.65 , ya que son suficientemente representativas. Con el fin de que el resultado sea legible, se identificará cada una de las sustancias con un número, de manera que se sitúen sobre la plantilla de la Figura 5-44, para lo cual se tomará la siguiente numeración: Gasóleo A (1), gasóleo A con aditivos (2), gasóleo B (3), gasóleo C (4), gasolina 95 (5) y gasolina 98 (6).

Los resultados se muestran en la Figura 5-45, donde puede observarse que el diésel A parece distinguible del resto gracias a H y FWHM de la primera longitud de onda, y el $\mathrm{H}$ de la segunda.

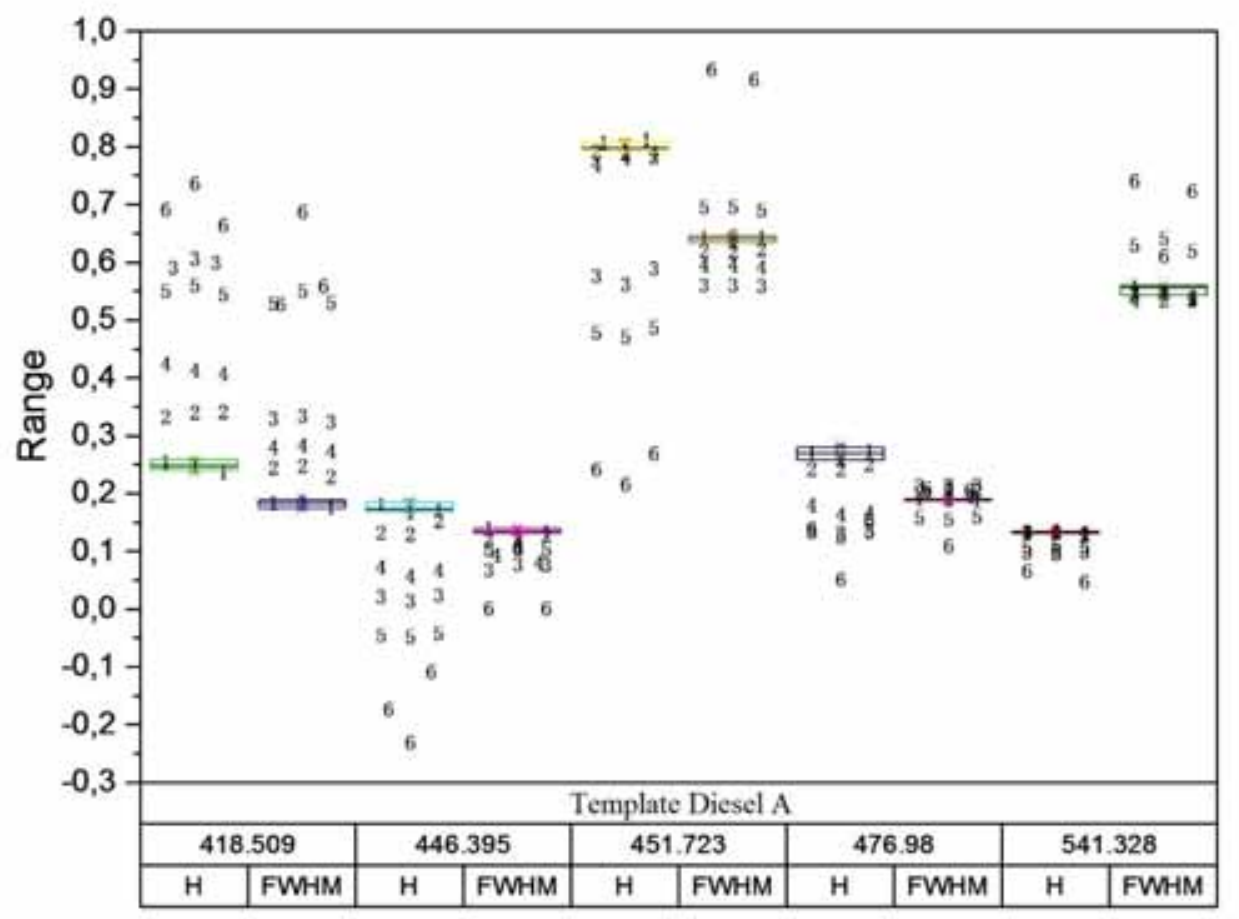

Figura 5-45: Plantilla de diagrama caja-bigotes obtenida para identificación de Diésel A con los demás hidrocarburos superpuestos

El desarrollo de algoritmos con mínimas iteraciones es discutido en [BWK97], y no es el objeto de este estudio, pero en principio parece bastante factible su realización. Para corroborar el método, se repite el proceso con un hidrocarburo diferente, tomándose una gasolina (gasolina 95 octanos), identificada con el número 5, obteniéndose los resultados mostrados en la Figura 5-46. La gráfica muestra una diferencia más notable que en caso anterior, estando los puntos de las distintas sustancias más separados, siendo más factible su identificación. 


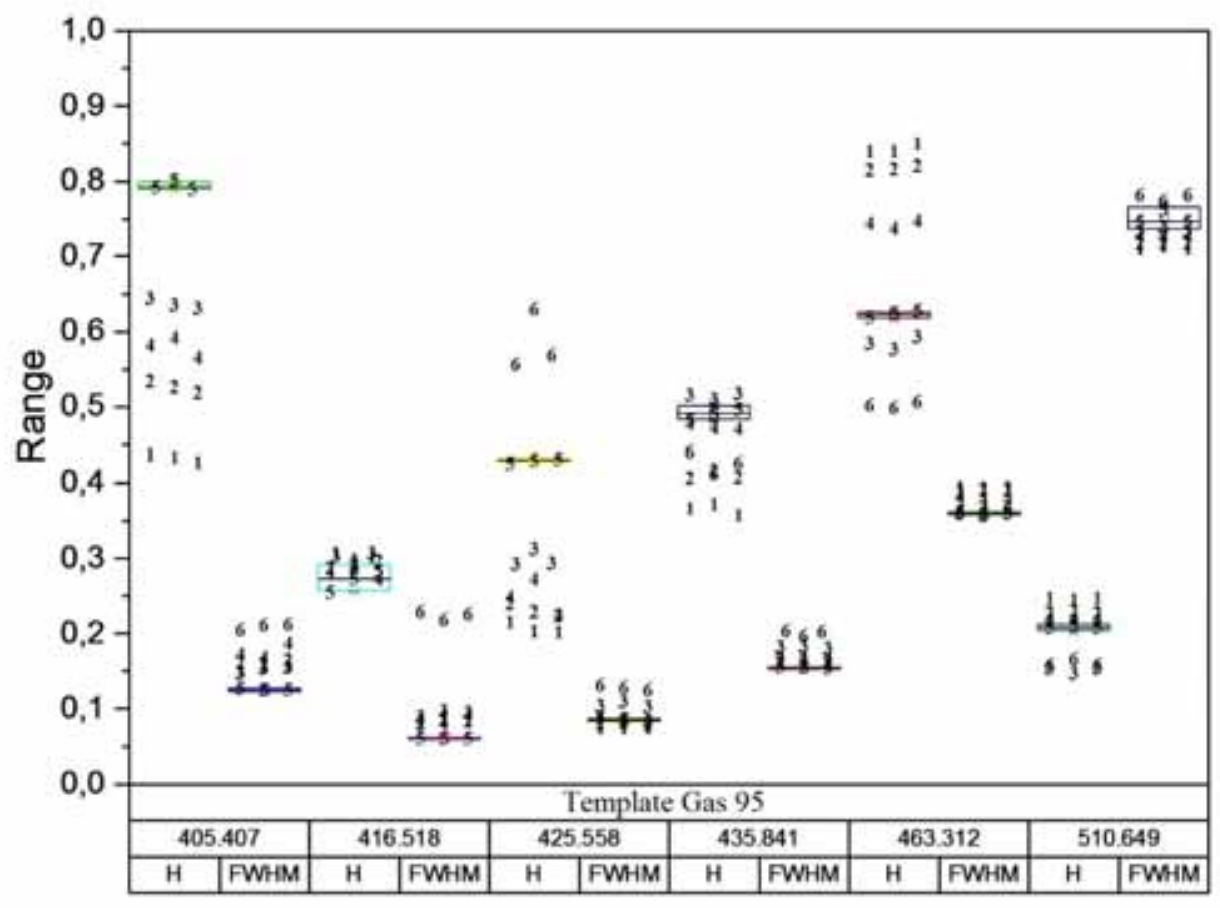

Figura 5-46: Plantilla de diagrama caja-bigotes obtenida para identificación de gasolina 95 con los demás hidrocarburos superpuestos

\subsubsection{Método de obtención de huellas común para todos los compuestos.}

En este caso, con el fin de reducir el procesado necesario, se busca una plantilla donde se reflejen los máximos de todos los compuestos, de forma que se manifiesten o no dependiendo de la sustancia estudiada. Este procedimiento requiere un mayor tiempo inicial en la obtención de la plantilla. Siguiendo el procedimiento mostrado en los apartados anteriores, se obtiene por medio de Fityk una plantilla "universal" (Figura 5-47) que se espera sea válida para los seis hidrocarburos.

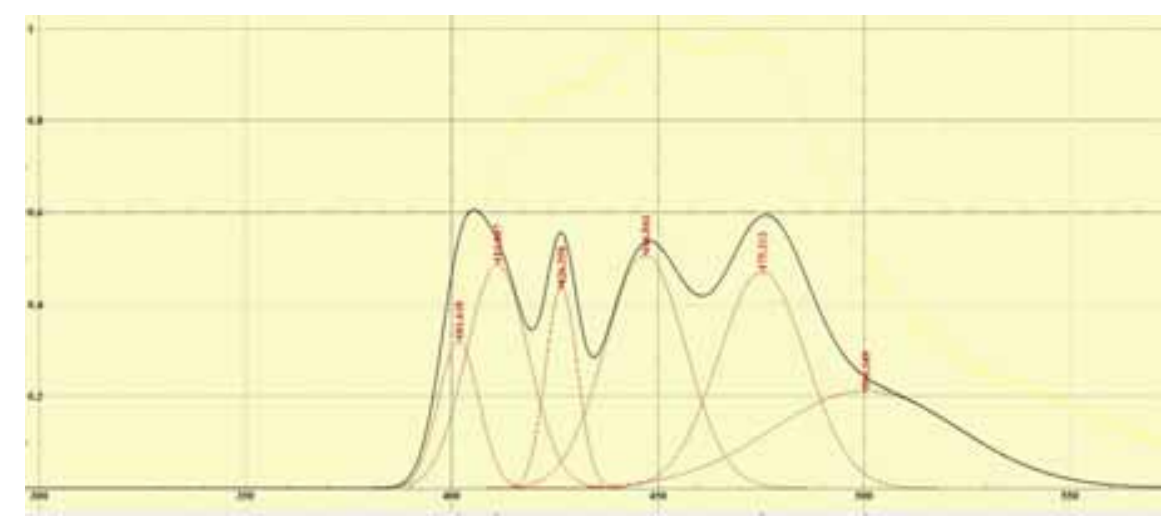

Figura 5-47: Plantilla a partir de la cual se obtienen los ajustes con gaussianas con los demás compuestos 
En este caso se hace necesario fijar además de las longitudes de onda, el ancho de la primera de las gaussianas. Esto es debido a que de otra manera no se consigue mantener confinado el resultado dentro de los márgenes de longitudes de onda. Por ello en la Figura 5-48 se observan los datos de FWHM de la longitud de onda de $401.618 \mathrm{~nm}$ superpuestos. A partir de ésta, se procede como en el apartado anterior, realizando el ajuste para el resto de hidrocarburos con las diferentes corrientes. En el caso del gasóleo A, el diagrama de caja-bigotes de la Figura 5-48 muestra el resultado donde destaca la similitud de los resultados del gasóleo A y el A con aditivos. El resto de resultados mantienen las diferencias entre los hidrocarburos, pudiéndose obtener un algoritmo de identificación.

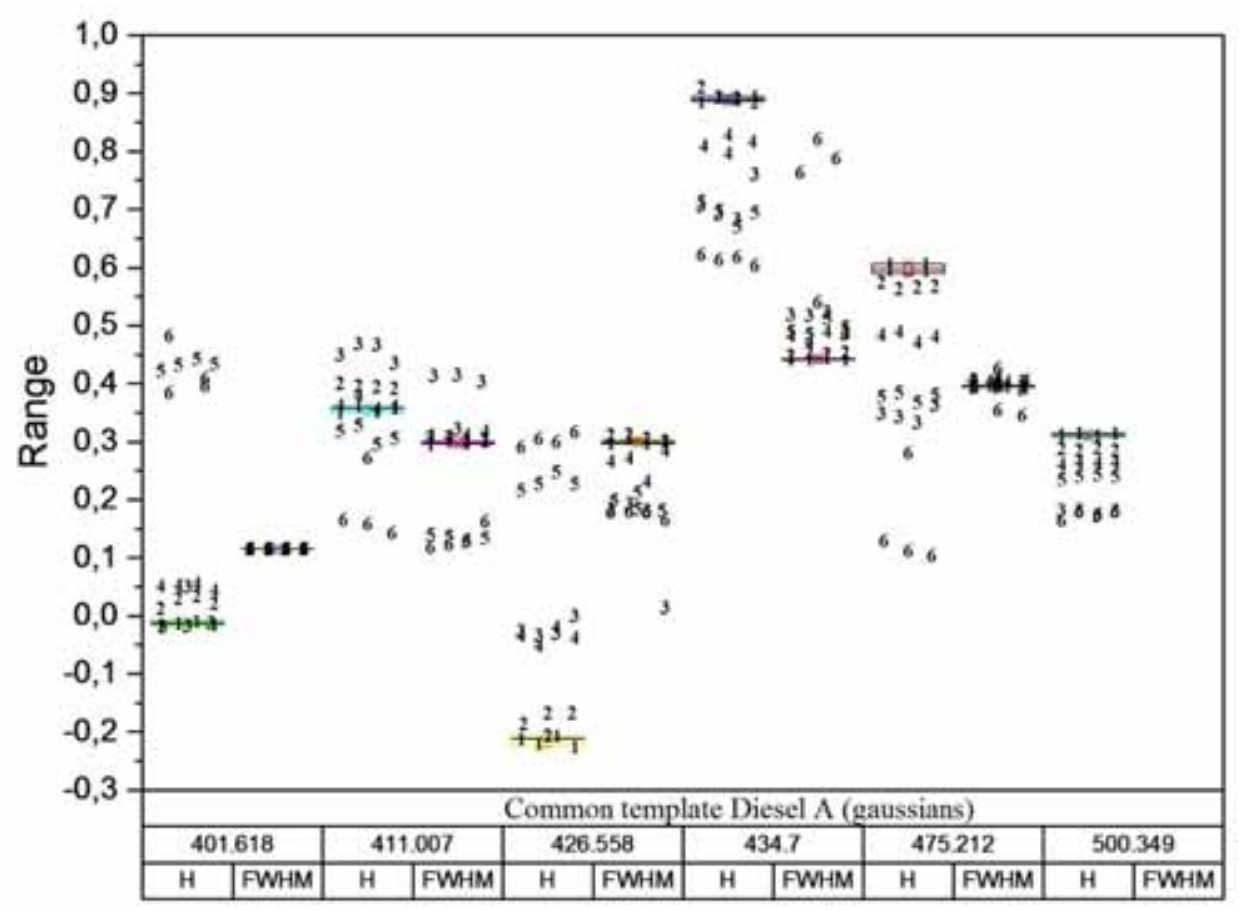

Figura 5-48: Plantilla de diagrama caja-bigotes obtenida para identificación de Gasóleo A con los demás hidrocarburos superpuestos

Se procede de igual manera como en el apartado anterior, es decir, con la gasolina 95. Al ser la plantilla común, los números permanecen en la misma ubicación, y simplemente se modifican los datos a partir de los cuales se obtienen las cajas, obteniéndose los resultados mostrado en la Figura 5-49. 


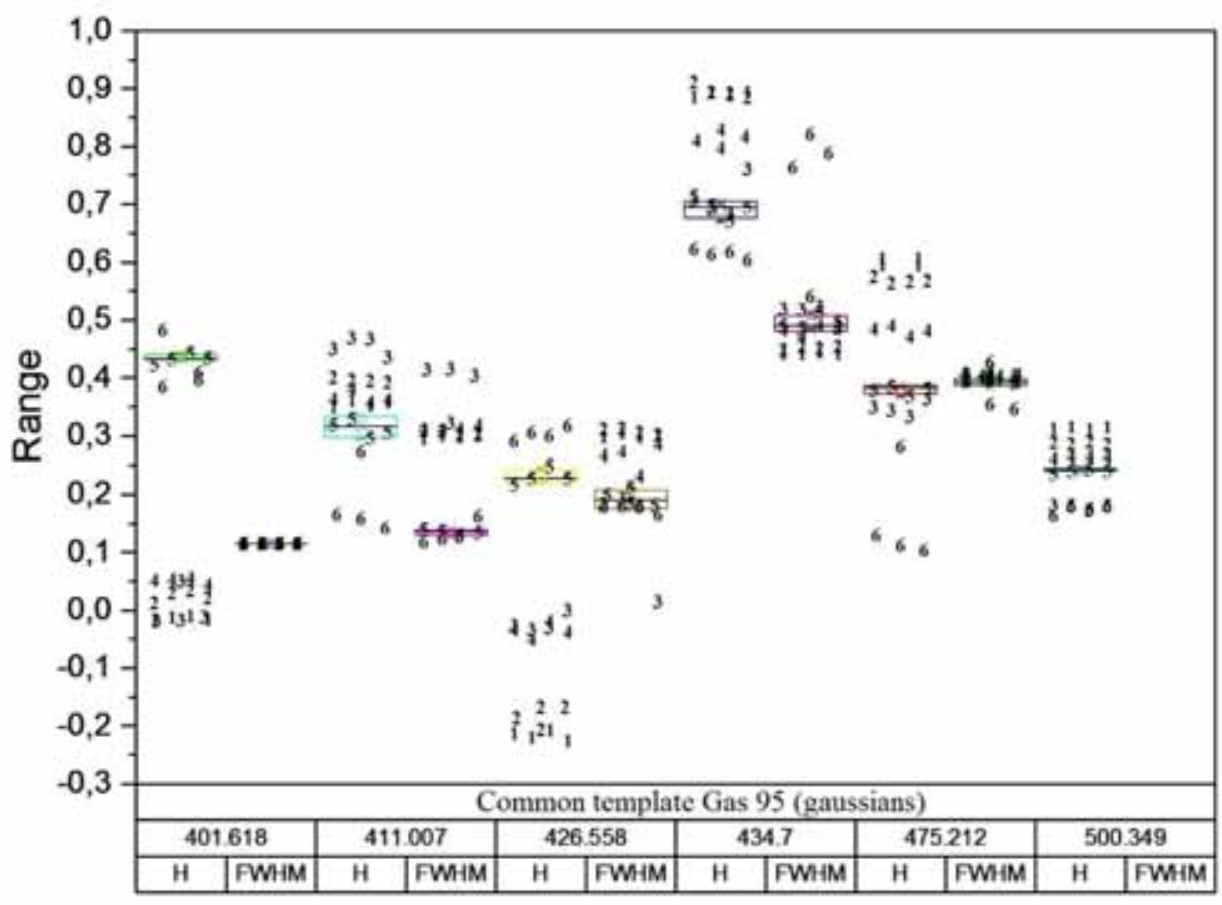

Figura 5-49: Plantilla de diagrama caja-bigotes obtenida para identificación de Gasolina 95 con los demás hidrocarburos superpuestos

\subsubsection{Método de obtención de huellas con lorentzianas}

La función lorentziana presenta una solución alternativa en el ajuste de espectros con funciones conocidas a las funciones gaussianas. La función lorentziana tiene un "suelo" que contiene un porcentaje mayor del área total que las funciones gaussianas. Esto presenta una ventaja en los espectros estudiados, ya que tal y como se ha comentado, la información de éstos se encuentra en aproximadamente en el 30\% superior de la respuesta espectrométrica, y no en picos muy marcados como en el caso de otras respuestas espectrométricas. Además, y dado que la finalidad del estudio presentado no se refiere a implementaciones con elementos concretos como fotodetectores, cuya respuesta obliga en parte a la utilización de gaussinas dado que su respuesta es similar a esta función, se realiza a modo de estudio complementario.

En la Figura 5-50 se muestra una comparativa de la función gaussina y lorentziana, ambas para una FWHM de 1, donde pueden observarse las diferencias antes comentadas. 


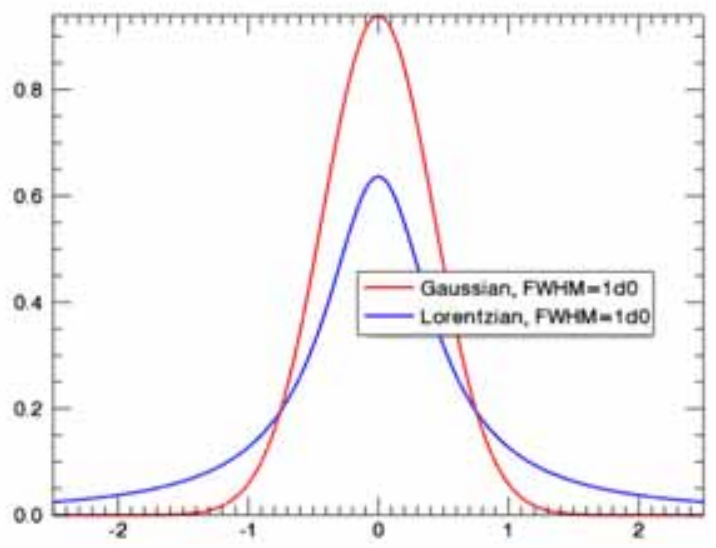

Figura 5-50: Comparativa de las funciones gaussiana y lorentziana. Fuente: http://ppenteado.net/idl/pp_lib/doc/pp_lorentz_from_fwhm.html

Generando una plantilla común para todos los hidrocarburos, y tomando como referencia el diésel A, se obtienen los resultados que pueden observarse en la Figura 5-51. En apariencia, los números que representan los compuestos estudiados a distintas corrientes, se encuentran bastante más diferenciados que en el caso de las gaussianas, por lo que pueden resultar más distinguibles. De la misma forma, las cajas que representan los márgenes de variación, son aún más estrechos.

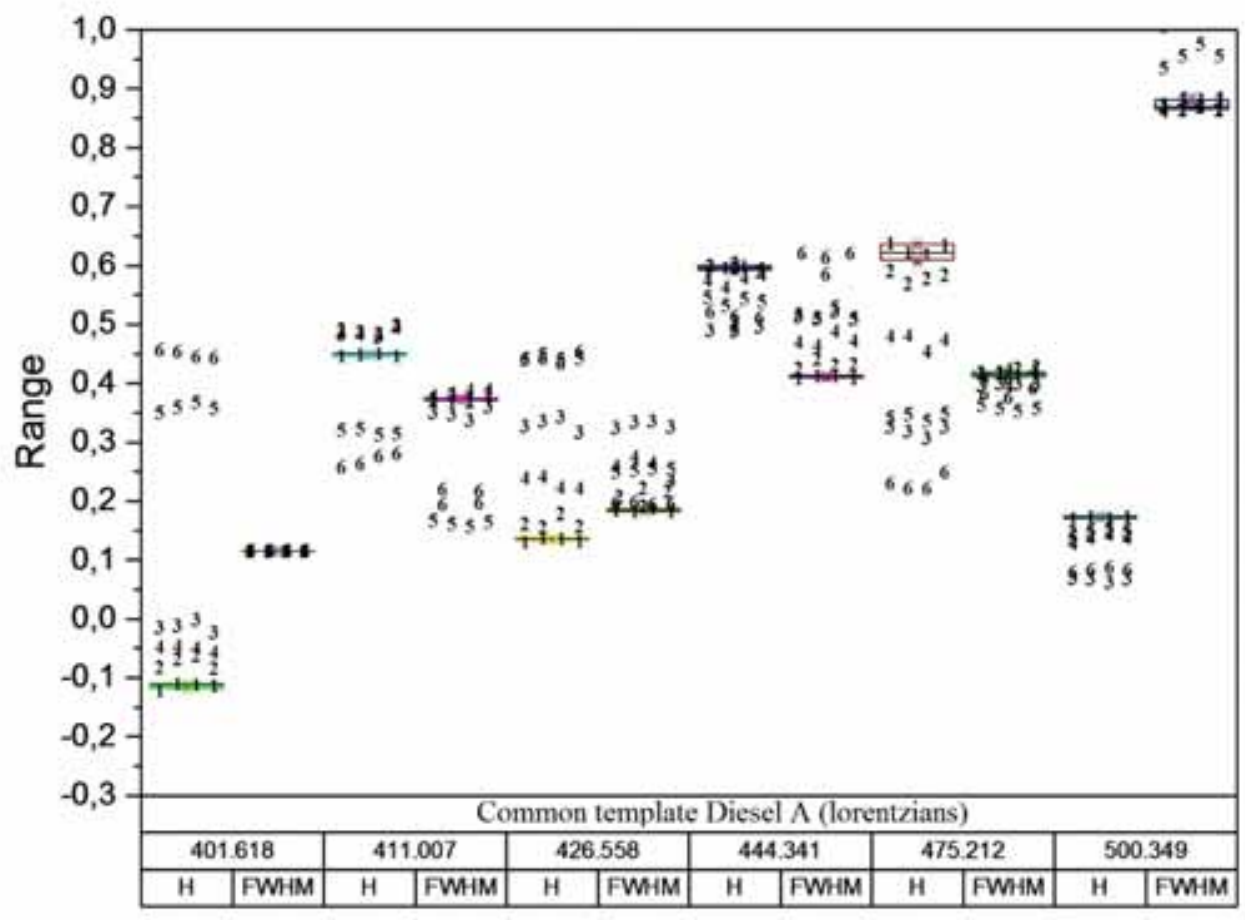

Figura 5-51: Plantilla de diagrama caja-bigotes con plantilla común para identificación de Gasóleo A con los demás hidrocarburos superpuestos 
Al repetir el proceso para el caso de la gasolina 95, los resultados son similares y confirman los anteriores. En el caso de la longitud de onda mayor, no se representa el FWHM porque se encuentra en la parte superior a aproximadamente 1.3, y se perdería precisión en el resto de representaciones.

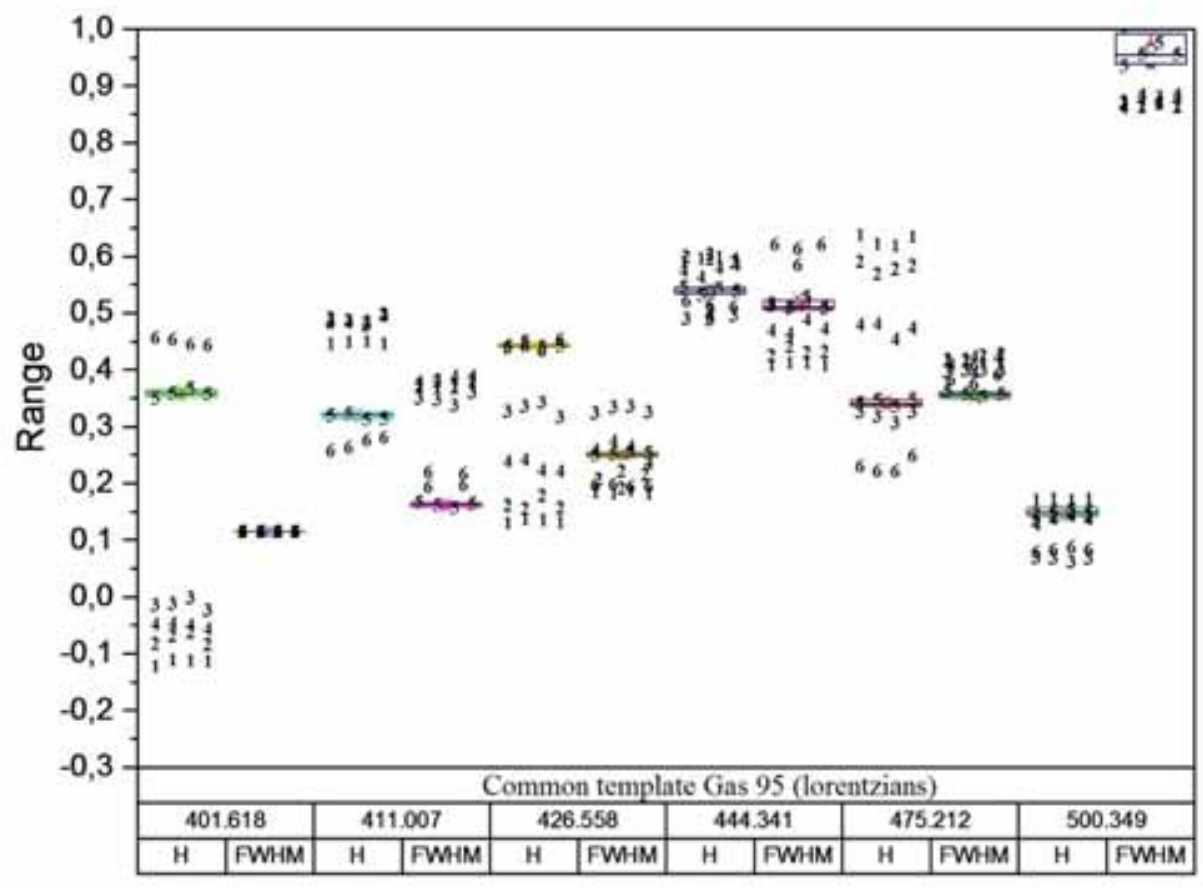

Figura 5-52: Plantilla de diagrama caja-bigotes con plantilla común para identificación de Gasolina 95 con los demás hidrocarburos superpuestos

\subsection{Conclusiones.}

Se presentan dos métodos de identificación obteniendo plantillas mediante procesamiento de los datos obtenidos. El primero de ellos resulta flexible y preciso, pero en una implementación real conlleva un procesado mayor, dado que se debe hacer la descomposición de acuerdo a cada una de las plantillas, donde no coincide ni el número de componentes, ni las longitudes de onda para así poder ser comparada.

En el segundo caso se toma una plantilla común que se aplica a todos los compuestos en estudio. Para comparar un espectro, es necesario realizar el filtrado, la normalización y la posterior descomposición. La comparación se hace contra una plantilla común donde coinciden las longitudes de onda, requiriendo por tanto este método menos procesado. Sin embargo este método ha resultado en algunos casos inexacto, siempre utilizando el programa Fityk. El desarrollo de un programa con Matlab que utilice los mismos procedimientos, pero con un ajuste de las variables que mejore los resultados, es posible. Sin embargo, el ajuste con funciones 
lorentzianas se muestra como una alternativa que puede requerir menos ajustes, a la vista de los resultados obtenidos.

La elección del método adecuado depende en definitiva de la potencia de procesado de la que se disponga. Es necesario tener en cuenta que dado que en la práctica el número de plantillas irá en aumento, el procesado toma cada vez mayor peso. Por otro lado, los procesadores monoplaca en los que se implementa el sistema cada vez tienen mayor potencia de cálculo, y que la medición en tiempo real de los procesos que se dan en la naturaleza no requieren velocidades muy altas, tal y como se ha explicado en el capítulo 2. En definitiva, los datos a analizar, las condiciones de contorno, el estado de la técnica y posteriores estudios de laboratorio y de campo de obligada realización son los que se deben tener en cuenta para implementar el programa del decisor. 



\section{Análisis funcional a largo plazo de los LEDs}

En este capítulo se estudia la viabilidad de los LED ultravioleta de alta potencia (HP-LED) como fuente luminosa en un sistema de detección-identificación en continuo. Más allá de lo mencionado anteriormente, donde se comenta el futuro de los UV-LED como sustitutos de las lámparas ultravioleta convencionales (Semiconductor Science and Technology 29-2014), los sistemas que trabajan en continuo someten a sus componentes a estrés térmico y eléctrico, lo que implica una mayor degradación que para un sistema en continuo hay que estudiar a largo plazo. Esto se realizará mediante ensayos de vida acelerado en diferentes condiciones de trabajo y para los dos tipos de LEDs que se muestran en este capítulo. Se plantearon dos condiciones de trabajo; el encendido constante del LED (funcionamiento continuo), y un ciclo de trabajo de un minuto (funcionamiento cíclico), donde una parte del tiempo el LED está encendido que es cuando se realiza la medida, y el resto del tiempo está apagado, para reducir su temperatura y su periodo de trabajo. El resultado no afecta a la firma de la fluorescencia del hidrocarburo pero si a su valor absoluto, en funcionamiento cíclico el LED ofrece más irradiancia y por tanto mayor nivel de fluorescencia. El análisis de todo ello se realizará en la parte de análisis funcional a largo plazo.

En las siguientes secciones se presenta el procedimiento de medida de los hidrocarburos, la instrumentación empleada en las medidas, y el análisis de los hidrocarburos en diferentes condiciones de contorno. Finalmente se presenta un método de análisis de la firma del LED de alta potencia ultravioleta que permita cuantificar cuando una firma pierde calidad para poder identificarla, esto está relacionado con la degradación a largo plazo de los LEDs, y con la necesidad de diferenciar a firma de un hidrocarburo de otra cualitativa y cuantitativamente.

\subsection{Introducción y estado del arte}

Los nuevos LEDs ultravioleta están creando nuevas oportunidades tecnológicas, especialmente en el área de la espectroscopia pero también en otros campos [Ven15], [MR13], [LaserF14], [KK095]. Sin embargo, son una tecnología que aún está en proceso de maduración con eficiencias 
por debajo de los LEDs comerciales blancos [SG10], cuanto menores longitudes de onda menores eficiencias [RKLW+15] [SGGW+06] y procesos tecnológicos y materiales que hacen más compleja alcanzar buenos periodos de vida [Meneg08]. A $365 \mathrm{~nm}$ el rendimiento está alrededor del 30\% con una potencia por chip de $3 \mathrm{~W}$ como máximo (el tipo de LED elegido para los ensayos) con tecnologías entre los LEDs convencionales y los LEDs del ultravioleta profundo, donde el rendimiento es aún menor y la potencia es del orden de mW [RoitL15]. Uno de los problemas de los LEDs ultravioleta es que se produce un salto en tecnología y complejidad, siendo habitual como material base el zafiro con una mala o al menos limitada calidad cristalina a largo plazo [KHLA+09].

Esta división también se refleja en los fabricantes, las marcas de gran consumo (aunque no todas) comienzan su producción en $365 \mathrm{~nm}$ (Nichia, LedEngin, LG, Lumileds y TSLC a partir de $380 \mathrm{~nm}$ ), mientras que por debajo de ella suele haber empresas de fotónica para aplicaciones científicas (Nichia, Crystal, Roithner Lasertechnik, Qphotonics, y LG que introdujo el LED de 285 nm el año pasado).

Recientemente se encuentran a la venta para gran consumo los LEDs de y alta potencia a 365 $\mathrm{nm}$. Sin embargo, éstos presentan alta energía de la radiación emitida, que hace difícil conseguir un material que no se degrade excesivamente con dicha energía, y menor rendimiento óptico que hace que se trabaje con potencias de disipación mayores a la del resto de LEDs para la misma potencia óptica, es decir, unos niveles de estrés mayores [CDVP12] [LYLTS10] [Meneg08].

Mientras las tecnologías más maduras de LEDs de alta potencia tienen esperanzas de vida muy largas, la esperanza de vida de los LEDs ultravioleta son menores, aunque la introducción de nuevos sustratos a nivel de investigación en lugar del zafiro [KABR+13] [GCGM+13], están mejorando su fiabilidad. Aunque después se trate en detalle la esperanza de vida (el Tiempo Medio entre Fallos, MTTF) obtenido en ensayos con LEDs ultravioleta, baste como ejemplo diferenciador que la esperanza de vida de los LEDs blancos esta entre 50.000 horas [USDep09] y 100.000 horas [FYP12, Lumil06] para una degradación óptica límite del 30\%, $280 \mathrm{~nm}$ entre 400 y 3000 horas [KHLA+09], y en $365 \mathrm{~nm}$ donde aún hay menos estudios Nichia publica que con el modelo de fabricación estándar de $365 \mathrm{~nm}$ y para una potencia de $120 \mathrm{~mW}$ una esperanza de vida de 17600 horas [MMYA+06]. Aunque no se han encontrado otras evaluaciones de vida para LEDs de $365 \mathrm{~nm}$ y alta potencia, si lo se puede relacionar con la vida de otros LEDs de baja potencia basados en $\mathrm{GaN}$ a diferentes longitudes de onda ultravioleta, que están sobre $2000 \mathrm{~h}$ trabajando en de forma continua. En las conclusiones del presente capítulo se trata de este aspecto.

En definitiva el área de los LEDs ultravioleta está aún de desarrollo, y se está encontrando en la fiabilidad uno de sus principales problemas [KBK08] [MBBS+10]. De ahí la necesidad de estimar 
la esperanza de vida de LEDs ultravioleta de $365 \mathrm{~nm}$ y alta potencia, para sistemas de detección continua de contaminantes $24 \mathrm{~h} / 7 \mathrm{~d}$.

Este capítulo comienza con una breve introducción de fiabilidad orientada a nuestra aplicación, con el objetivo de explicar el procedimiento de estimación de la esperanza de vida extrapolada a condiciones reales de los dos tipos de LED, ambos de $365 \mathrm{~nm}$ y $3 \mathrm{~W}$, a partir de ensayos acelerados en temperatura. Después se expondrá la metodología, planificación e instrumentación de los ensayos. En las siguientes secciones se presentan las medidas realizadas para dos tipos de LEDs en dos modos de trabajo, la caracterización de los LEDs en cada modo de trabajo, los resultados de los ensayos, la evaluación de la esperanza de vida en cada caso, y finalmente el análisis de fallos.

\subsection{Bases teóricas de la fiabilidad y los ensayos de vida acelerada}

Esta sección trata de sintetizar las bases teóricas que sustentan la planificación de los ensayos de vida acelerada realizados y la exposición de los resultados, basándonos en los gráficos de probabilidad de fallo en función del tiempo con la ecuación de Weibull [Wei51], y en la extrapolación a condiciones nominales de trabajo realizadas mediante el modelo de Arrhenius [Arrhe1889], y la combinación de ambos procedimientos e fiabilidad. En algunos de las explicaciones se simplificará dejando una referencia más completa en libros clásicos de fiabilidad [MHDBK98] [O'Con12][Yan07].

Según el manual ampliamente utilizado MIL-HDBK-338B (Military Handbook Electronic Reliability Design Handbook) [MHDBK98], la definición de fiabilidad es:

La fiabilidad es la probabilidad de que un elemento pueda desarrollar la función deseada durante un intervalo específico de tiempo bajo unas condiciones ambientales y de funcionamiento determinadas. La fiabilidad se representa por $\mathrm{R}(\mathrm{t})$, y está acotada entre 0 y 1 , todos los dispositivos comienzan funcionando $(R(t)=1)$, en $t=0$ y terminan fallando en $t=\infty(R(t)=0)$. La defiabilidad es $F(t)$, igualmente acotada entre 0 y 1 , siendo:

$$
F(t)=1-R(t)
$$

La fiabilidad $(\mathrm{R}(\mathrm{t}))$ es la probabilidad de que el LED ultravioleta funcione hasta el instante $\mathrm{t}$. Considerando una población de dispositivos, función densidad de probabilidad de fallos, $\mathrm{f}(\mathrm{t})$, es la probabilidad de que un dispositivo de la población tenga un fallo entre los instantes $\mathrm{t} y \mathrm{t}+\mathrm{dt}$. De modo que si como se ha explicado anteriormente, todos los elementos de un sistema fallan entre $t=0$ $\mathrm{y} t=\infty$ de donde se obtiene la igualdad: 


$$
\int_{0}^{\infty} f(t) d t=1
$$

A partir de la función densidad de probabilidad se puede calcular la función de distribución acumulativa (CDF - Cumulative Distribution Function), o sólo función distribución, $R(t)$ o $F(t)$. En función de $\mathrm{f}(\mathrm{t})$, se obtienen las ecuaciones que resuelven la probabilidad de que un elemento de que falle antes del instante $t(F(t))$, o que funcione hasta el instante $(R(t))$.

$$
\begin{gathered}
R(t)=1-F(t)=1-\int_{0}^{t} f(t) d t=\int_{t}^{\infty} f(t) d t, \\
R(0)=1, \quad R(\infty)=0 \\
F(t)=\int_{0}^{t} f(t) d t \\
F(0)=0, \quad F(\infty)=1
\end{gathered}
$$

La tasa de fallos o velocidad de fallos de un dispositivo se expresa en fallos/hora, o FIT (Failure in time); 1 FIT $=1 \cdot 10^{-9}$ fallos/hora o un fallo cada $10^{9}$ horas, que es una unidad más apropiada para dispositivos semiconductores. Su ecuación es:

$$
\lambda(t)=\frac{f(t)}{R(t)}
$$

La tasa de fallos $\lambda(t)$ es una función fundamental en el análisis de la fiabilidad, es la densidad de probabilidad de fallo en $t$ condicionado a no haber fallado antes de $t$, como expresa la (Ec.6.5). La Figura 6-1 es la curva de bañera, la representación de la $\lambda(\mathrm{t})$ típica para dispositivos semiconductores y electrónicos. Se observan 3 etapas:

Una primera etapa con tasa de fallos decreciente se corresponde con un periodo de vida infantil, en el que los fallos son debidos a problemas de calidad y por tanto a debilidades que lleva el dispositivo o equipo al salir de la fábrica, el porcentaje de fallos de este tipo se reduce según mejora la fabricación y madura la tecnología.

La segunda etapa comienza cuando no quedan componentes con debilidades o defectos de fabricación, a partir de ese momento los fallos son aleatorios y se mantiene una velocidad de fallos 
constante, por lo que se denomina periodo de vida útil. Agentes externos pueden hacer que la tasa aumente, por ejemplo aumento de humedad o temperatura de trabajo habitual.

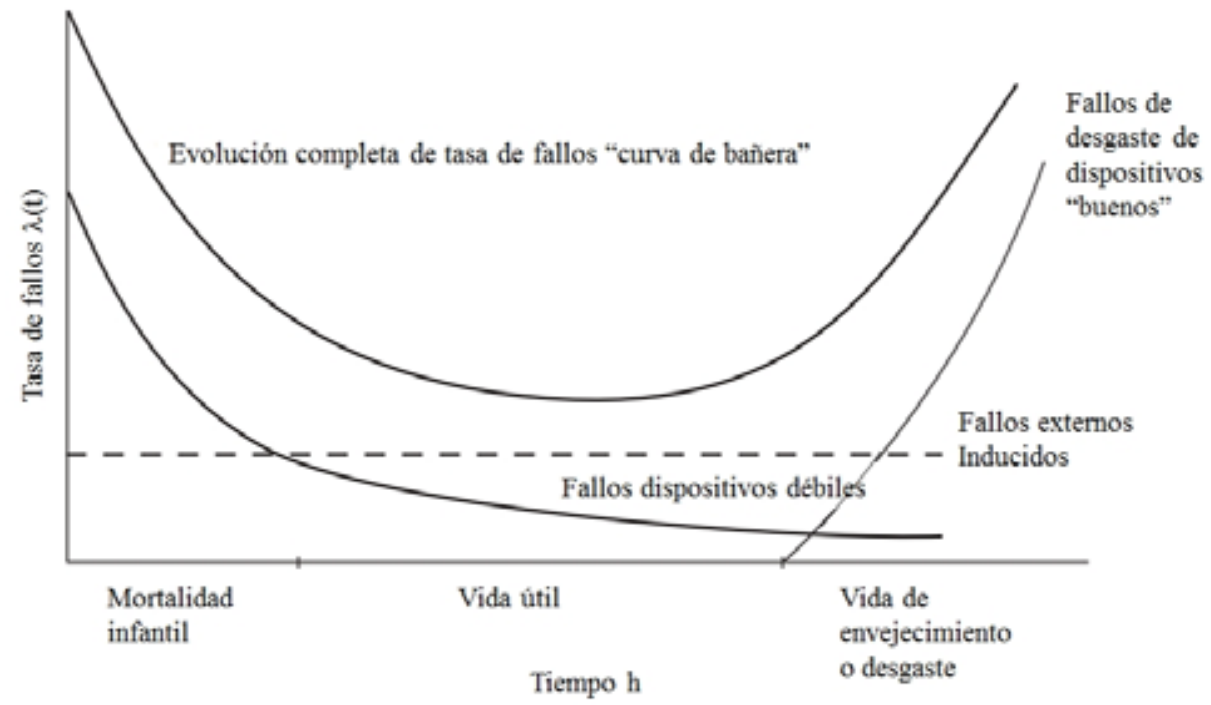

Figura 6-1: Evolución de la tasa de fallos de los dispositivos semiconductores. Tomada y traducida de [O'Con12].

En la tercera y última etapa la tasa de fallos aumenta con el tiempo y corresponde con el periodo de envejecimiento o desgaste. En esta etapa el dispositivo ha sufrido una acumulación de esfuerzo en los materiales que le lleva que comience el desgaste y con ello los fallos. La tasa de fallos es creciente. Para dispositivos de silicio poco estresados es habitual considerar que trabajan en periodo de vida útil, y que se retiran del mercado antes de llegar a la fase de desgaste, pero en componentes con alta estrés eléctrico o ambiental, la vida útil (con tasa de fallos constante) es mínima y aparece inmediatamente una tasa de fallos creciente, si el dispositivo es crítico hay que evaluar su probabilidad de fallo y cambiarlo por uno nuevo antes de que tenga una probabilidad de fallo excesiva. El caso de los LEDs de muy alta potencia se corresponde con dispositivos semiconductores fuertemente estresados en temperatura (alta temperatura en la unión) y densidad de corriente elevadas (entre $50 \mathrm{~A} / \mathrm{cm}^{2}$ y $100 \mathrm{~A} / \mathrm{cm}^{2}$ ).

En muchas aplicaciones, como en mantenimiento (mirar el anexo de mantenimiento de sensores), puede ser más relevante la función de la tasa de fallos $(\lambda(t))$ que la función fiabilidad $(\mathrm{R}(\mathrm{t}))$, ya que la primera nos muestra la evolución de la probabilidad de fallo de los elementos supervivientes en cada instante de tiempo, y nos evidencia la necesidad de reposiciones o calibraciones preventivas. 
Además de las definiciones de las funciones de fiabilidad, $f(t), Q(t), R(t)$ y $\lambda(t)$, es necesario definir otros parámetros básicos de fiabilidad. Estos son el MTTF (Tiempo Medio Hasta el Fallo Mean Time to Failure) y el MTBF (Tiempo Medio Entre Fallos - Mean Time Between Failure). Ambos parámetros son la vida media $(\theta)$ del elemento a estudiar, pero en el caso del MTTF para elementos no reparables, y el MTBF para elementos reparables. Sus unidades son horas hasta el fallo, ciclos, $\mathrm{Km}$, etc.

La vida media, $\theta$, o el MTTF, tiempo medio hasta el fallo se puede calcular a partir de la función densidad de fallos acumulada, como la esperanza matemática del tiempo hasta el fallo:

$$
M T T F=\int_{0}^{\infty} R(t) d t
$$

La esperanza de vida de un dispositivo es el tiempo más probable hasta el fallo, eso quiere decir que en una población la mitad de los elementos falla antes de ese instante y el resto después. En LEDs como en otros dispositivos, el MTTF es el parámetro que más se emplea comercialmente, y aunque no es exactamente así, su valor se considera el periodo de vida "típico" de un determinado tipo de LED.

El LED puede fallar de dos modos: de forma catastrófica (cortocircuito o circuito abierto) o de forma gradual por degradación excesiva de la funcionalidad, en este caso su potencia luminosa. Por tanto es necesario definir con qué porcentaje de degradación se considera que existe fallo, el valor más típico es el $70 \%$ de mantenimiento de la potencia luminosa inicial ya que ha sido el aprobado por organismos internacionales [Tay05] [Lumil06].

Desde el punto de vista teórico:

- El fallo es el evento o estado no operativo, en el cual el elemento no puede desarrollar la función previamente especificada.

- El modo de fallo es la consecuencia del mecanismo por el cual se produce el fallo, por ejemplo, cortocircuito, circuito abierto, o excesiva degradación.

- El mecanismo de fallo es el proceso físico-mecánico, químico, eléctrico, etc. que causa el fallo.

Suponiendo que se dispone de resultados reales del funcionamiento de una población de dispositivos, o que se han realizado ensayos de vida acelerada y extrapolado el resultado a condiciones nominales de funcionamiento, ahora es necesario trasladar en ecuaciones la evolución 
de todos los parámetros de fiabilidad. Se han propuesto varias funciones estadísticas para ello: la exponencial, normal, log-normal, Weibull, Gamma, etc. De ellas Weibull es la más utilizada en ensayos de vida acelerada, ya que tiene una representación más flexible, y a simple vista aporta información básica sobre la evolución de la vida del dispositivo [Wei51]. Además demostró que permitía representar muy bien la vida de futura de una población de muestras, aunque en el ensayo se empleasen muy pocas.

En la Figura 6-2 se refleja el comportamiento de las funciones de fiabilidad, $f(t), R(t), y \lambda(t)$ (denominada en dicha figura $\mathrm{h}(\mathrm{t})$ ), de las funciones de distribución más empleadas en fiabilidad.

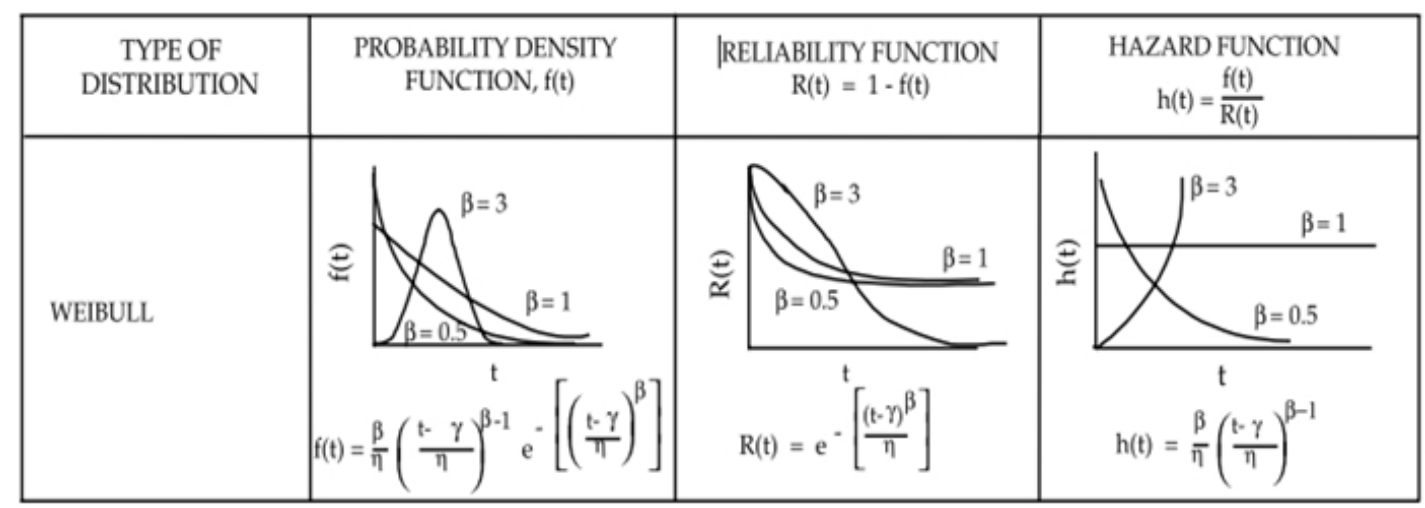

Figura 6-2: Gráficas de la función densidad, fiabilidad, y tasa instantánea de fallos de la función de Weibull. Tomada de la Figura 5.3.1 del [MHDBK98].

La función distribución de Weibull es la gráfica en la que representan los instantes de fallo de los ensayos acelerados, obteniendo los parámetros de fiabilidad (R(t), MTTF, etc.) en cada ensayo, y a partir de los cuales se aplica Arrhenius para poder extrapolar la función de fiabilidad $R(t)$ a la temperatura nominal de trabajo. La función de Weibull se define con tres parámetros, de los cuales el parámetro de origen se hace cero, quedándose sólo con dos parámetros:

$\beta$, parámetro de forma que muestra en qué periodo de vida de la curva de bañera se encuentra el elemento.

$\eta$, parámetro de escala.

$\gamma$, parámetro de origen (sólo se considera $\mathrm{t} \geq \gamma$ ) que muestra a partir de que tiempo, origen, empiezan a fallar los elementos. Pero esta variable no suele emplearse ya que en la práctica sólo es diferente de cero con ensayos muy singulares, por esta razón se utilizarán las ecuaciones simplificadas que son las más utilizadas. 
Las funciones de densidad de probabilidad de fallos, distribución de fallos acumulada (defiabilidad) y fiabilidad según la función de Weibull son:

$$
\begin{gathered}
f(t)=\frac{\beta}{\eta^{\beta}} t^{\beta-1} e^{-\left(\frac{t}{\eta}\right)^{\beta}} \\
F(t)=1-e^{-\left(\frac{t}{\eta}\right)^{\beta}} \\
R(t)=e^{-\left(\frac{t}{\eta}\right)^{\beta}}
\end{gathered}
$$

La vida media o esperanza matemática, es decir el MTTF para elementos no reparables, es:

$$
\theta=E(\tau)=\eta \Gamma\left(1+\frac{1}{\beta}\right)
$$

Donde $\Gamma\left(1+\frac{1}{\beta}\right)$ es el valor de la función gamma, $\Gamma(\mathrm{x})$, para $\mathrm{x}=1+1 / \beta$.

La función de tasa de fallo de la función de Weibull es:

$$
\lambda(t)=\frac{\beta}{\eta^{\beta}}(t)^{\beta-1}
$$

Para analizar si una serie de datos de fallo siguen una distribución de Weibull y obtener los parámetros que los caracterice es necesario linealizar la función de Weibull y evaluar la correlación de los instantes de fallo de las muestras con dicha línea. En el eje vertical aparece la probabilidad de fallo, y en el horizontal el tiempo en escala logarítmica. En esta tesis se empleará la aplicación ALTA (Acelerated Life Test Analysis) y Weibull++ de la empresa Reliasoft ${ }^{\circledR}$ para obtener los valores de los parámetros y dibujar las funciones:

$\eta$ es el instante en que la defiabilidad $\mathrm{F}(\mathrm{t}=\eta)=1-\mathrm{e}^{-1}=0,63212$ (Ec.6.8).

$\beta$ o parámetro de forma, es la pendiente de la recta, e indica como es la tasa de fallos. 
Si $\beta<1$ la tasa de fallos es decreciente con el tiempo, la tasa de fallos disminuye con el tiempo transcurrido, lo que se corresponde habitualmente en la curva de bañera con un comportamiento de mortalidad infantil, lado izquierdo de la curva de bañera, Figura 6-1.

Si $\beta=1$ la tasa de fallos es constante, no depende del tiempo. Esto se corresponde con la vida útil de la curva de bañera, se producen fallos de forma aleatorios a lo largo del tiempo. La función de Weibull para este caso es la función exponencial $\mathrm{R}(\mathrm{t})=\mathrm{e}-(\mathrm{t} / \eta), \theta=\eta=\mathrm{MTTF}=1 / \lambda$.

Si $\beta>1$ la tasa de fallos es creciente. Esto se corresponde con la zona de envejecimiento o desgaste que es la zona derecha de la curva de bañera Figura 6-1.

Hasta ahora se ha hablado de los ensayos y fallos a ser analizados sin considerar sus condiciones, pero una buena planificación de ensayos permite extrapolar los resultados a condiciones de trabajo diferentes, pero relacionadas con la condiciones de ensayo. Toda la teoría de análisis de ensayos de vida acelerada se basa en esta probada presunción [O'Con12] [Yan07] [Ne190].

Un ensayo acelerado es un ensayo que acelera la vida de un dispositivo en algún aspecto, dicho ensayo tiene al dispositivo funcionando de forma nominal en todos los parámetros menos en uno que es el que va a ser estresado. Es imprescindible para poder extrapolar los resultados que el parámetro a estresar no produzca modos y mecanismos de fallo diferentes a los que han aparecido en funcionamiento real, ya que de otra forma el ensayo no es útil. Para no tratar todos los tipos de ensayos acelerados y sus modelos matemáticos a aplicar para extrapolar a condiciones nominales de trabajo (tensión, corriente, temperatura, etc.) se explicará el tipo de ensayo que se ha realizado.

Los ensayos se han realizado con LEDs UV con alimentación nominal pero a temperaturas ambiente por encima de la temperatura habitual de trabajo $\left(25^{\circ} \mathrm{C}\right)$. Las tres temperaturas ambiente de los tres ensayos acelerados realizados han sido $60^{\circ} \mathrm{C}, 75^{\circ} \mathrm{C}$ y $90^{\circ} \mathrm{C}$. Estas temperaturas son muy conservadoras, son bajas comparadas con ensayos acelerados térmicos de otros dispositivos optoelectrónicos, que llegan a $150^{\circ} \mathrm{C}$ o más [GVNA+09] [VNNB10] [EAGN+10] [NGVAE13] [EANO+15]. Por tanto, dada la similitud entre la temperatura menor de ensayo acelerado y la nominal es de esperar que no se produzcan modos de fallo diferentes a los del funcionamiento real.

Los modelos de aceleración para estrés en temperatura están ampliamente contrastados en numerosos dispositivos y equipos [O'Con12] [Ne190]. Dentro de estos modelos el de Arrhenius es ampliamente utilizado ya que se cumple en la mayoría de los casos, aunque existen otros modelos alternativos como el Eyring [Nel90] que se deriva del modelo Arrhenius. Debido a que nuestro experimento a los tres ensayos se les ha aplicado el modelo de Arrhenius para extrapolar las condiciones nominales de trabajo, será el que se explica a continuación. 
La ley o modelo de Arrhenius [Arrhe1889] fue desarrollado por Svante August Arrhenius, que obtuvo el premio Nobel en 1903. Esta ley se desarrolló para interpretar resultados experimentales concretos, tales como la influencia de la temperatura en la velocidad de una reacción química, pero su uso se ha extendido a otras áreas [DM84], y especialmente a los análisis de ensayos acelerados de fiabilidad en temperatura, para a partir de varios ensayos de tiempo corto con temperaturas por encima de la nominal, extrapolar el comportamiento en vida del equipo a temperatura nominal [O'Con12] [Ne190].

El modelo de Arrhenius se basa en la idea de que la velocidad de la reacción química es proporcional al número de moléculas con energía térmica suficiente para superar la barrera energética que produce la reacción, cuya energía depende del proceso y se le denomina Energía de Activación del proceso. La velocidad de la reacción depende de la temperatura de la siguiente forma:

$$
v(T)=v_{0} e^{\frac{-E_{A}}{k T}}
$$

Donde $T$ es la temperatura en Kelvin, $k$ es la constante de Boltzman y $\mathrm{E}_{\mathrm{A}}$ es la energía de activación de la reacción.

Para los modelos de aceleración en fiabilidad se tiene en cuenta que existe una relación inversa entre la velocidad de la reacción física-química que produce el fallo y el tiempo en el que se produce. De esta forma, cuando se aplica esta ley a parámetros temporales de dispositivos sometidos a ensayos de vida acelerada se obtiene la relación vida-estrés de Arrhenius (Arrhenius life-stress model), que se expresa del siguiente modo:

$$
L(T)=A e^{\frac{E_{A}}{k T}}
$$

$\mathrm{L}(\mathrm{T})$ indica una característica temporal cuantificable de la vida del componente y que es dependiente de T (temperatura), por ejemplo; el MTTF, o el instante de tiempo en que un parámetro eléctrico del componente se ha degradado durante el ensayo un \% definido. $k$ es la constante de Boltzmann $\left(k=8,617343 \times 10^{-5} \mathrm{eV} /{ }^{\circ} \mathrm{K}\right)$, y Ea es la energía de activación del mecanismo que causa el fallo o la degradación. A es un parámetro de Arrhenius que depende del valor seleccionado de L(T), y que no es necesario para obtener el Factor de Aceleración.

El Factor de Aceleración (FA) en tiempo, del mecanismo de degradación que ha causado los fallos entre dos temperaturas, T1 y T2, se puede obtener a partir de la ecuación (Ec.6.13) como: 


$$
F A=\frac{L\left(T_{1}\right)}{L\left(T_{2}\right)}=\exp \left[\frac{E_{A}}{k}\left(\frac{1}{T_{1}}-\frac{1}{T_{2}}\right)\right]
$$

De esta forma si se conoce $\mathrm{L}(\mathrm{T})$ en un ensayo acelerado (por ejemplo, el MTTF a temperatura alta) se podría extrapolar dicho valor a la temperatura del componente en condiciones normales de funcionamiento utilizando la ecuación (Ec.6.3). Sin embargo, el principal problema para utilizar esta ecuación es que, en muchos casos, la energía de activación es desconocida, de hecho uno de los motivos habituales de los ensayos acelerados es obtener el valor de la energía de activación del mecanismo de fallo predominante.

La $E_{\mathrm{A}}$ del mecanismo de fallo que determina los resultados del ensayo, se puede evaluar a partir de dos o más ensayos, lo recomendable es al menos tres. El rango de valores de $\mathrm{E}_{\mathrm{A}}$ para los diferentes mecanismos de fallo de los dispositivos semiconductores tiene aproximadamente valores entre $0,3 \mathrm{eV}$ y $1,4 \mathrm{eV}$ [MHDBK98], pero puesto que Ea está en la exponencial de la ecuación (Ec.6.13) del Factor de Aceleración pequeñas variaciones de Ea afectan de forma importante a los Factores de Aceleración. Un decremento de $35^{\circ} \mathrm{C}$ en la temperatura de funcionamiento respecto a un experimento, por ejemplo del resultado a $60{ }^{\circ} \mathrm{C}$ a lo esperado a $25^{\circ} \mathrm{C}$, con $\mathrm{E}_{\mathrm{A}}=0.3$ significaría multiplicar el MTTF por 3.4 y si la $\mathrm{E}_{\mathrm{A}}=0,6$ el MTTF a $60^{\circ} \mathrm{C}$ se multiplicaría por 11.6.

Antes de las herramientas informáticas estos cálculos se realizaban gráficamente, y se obtenían los valores en temperatura nominal de trabajo del MTTF y del parámetro $\eta$ de la función de Weibull. Si los tres ensayos siguen la ley de Arrhenius sus gráficas de Weibull deben ser aproximadamente paralelas, ya que se corresponden al mismo mecanismo de fallo, con similar tasa de fallos $\lambda(t)$. Actualmente las herramientas profesionales de fiabilidad como ALTA nos permiten obtener el valor más probable de la energía de activación $\left(\mathrm{E}_{\mathrm{A}}\right)$ y a partir de ella los parámetros de Weibull $\beta, \eta$ y el MTTF en otra condición del estrés empleado en los ensayos. Con ello se obtiene como respondería un ensayo en condiciones nominales de trabajo que podría durar 20 años a partir de tres ensayos a temperaturas mayores que han durado meses o semanas, cuanto más alta es la temperatura mayor es la aceleración en tiempo que se produce.

En este trabajo se ha optado por ser conservadores tomando temperaturas cercanas a la nominal, lo que ha provocado que los ensayos hayan sido necesariamente largos, finalizando tras 4020 horas. 


\subsection{Metodología, planificación e instrumentación de ensayos}

El objetivo de los ensayos es evaluar la funcionalidad a largo plazo de LEDs UV de alta potencia, aplicados a la detección de contaminantes mediante fluorescencia.

La metodología y planificación se basan en las recomendaciones prácticas para realizar un ensayo acelerado tanto de investigadores [O'Con12] [Yan07] [Nel90], como de fabricantes de LEDs [LuxR08], esta información ha sido tamizada y completada con la experiencia del Grupo de Investigación Semiconductores III-V de la Universidad Politécnica de Madrid en la metodología, planificación e instrumentación de ensayos acelerados en temperatura [GVNA+09] [Nuñ12] [VNNB10] [EAGN+10] [NGVAE13] [EANO+15].

\subsubsection{Metodología}

Tras varias pruebas con diversos tipos de LEDs UV, se decidió ensayar con dos tipos de LEDs ultravioleta de $365 \mathrm{~nm}$ y $3 \mathrm{~W}$, con una corriente máxima en funcionamiento continuo de $700 \mathrm{~mA}$, y una corriente máxima pulsada de $1000 \mathrm{~mA}$. Los LEDs UV tienen una tecnología que no se puede considerar madura, con una eficiencia de aproximadamente un 30\% [MKN14], pero lejos de las eficiencias de los LEDs blancos sobre el 50\%, además se han reportado ciertos problemas de fiabilidad [MPTG+08] [MBBS+10] [MKN14], lo que sumado al estrés en temperatura por la potencia disipar $2.1 \mathrm{~W}$, y la elevada densidad de corriente del orden de $60 \mathrm{~A} / \mathrm{cm}^{2}$ hacen que sea obligado un estudio de funcionalidad a largo plazo, si se quieren integrar con los actuales sistemas de control de calidad de agua de las estaciones automáticas.

Una vez elegidos los dos tipos de LEDs a emplear, consideramos el modo de trabajo. Debido a que el objetivo del LED es dar una luz fuerte, se someten a altas corrientes, y en el caso de los LEDs de señalización de media potencia, se ha evidenciado que con pulsos cortos de alta corriente se obtiene mayor fiabilidad y mayor señalización que con corriente continua [HP-I-004], esta consideración en cuanto a nivel de radiación emitida también está evidenciada en LEDs ultravioleta [BLHD+05], en el caso de LEDs azules de baja potencia si se ha reportado que la vida aumenta de 2 a 4 veces entre funcionamiento continuo y pulsado al mismo nivel de corriente [YK03]. Estos trabajos no son directamente aplicables a LEDs UV de alta potencia, pero suponían plantearse la posibilidad de emplear ambos modos de trabajo el continuo y el cíclico, en nuestro caso un cíclico muy lento, ya que era necesario estabilizar la luz emitida para realizar la medida de contaminantes y luego dejar el LED en reposo. 
Por tanto en nuestros ensayos para cada tipo de LED UV denominados tipo A y tipo B, cuya diferencia más visual es que el A tienen una metalización superior con conductores paralelos, y el tipo $\mathrm{B}$ tiene una metalización en cuadrícula, se emplearon dos condiciones de trabajo diferente:

- Funcionamiento continuo. Constantemente se inyecta una corriente de $600 \mathrm{~mA}$, un $85 \%$ de la corriente máxima para funcionamiento continuo. La elección de esta corriente en lugar de la máxima indicada por el fabricante es arbitraria, está basada en no sobre-estresar al LED, y a la vez mantener un nivel de irradiancia fuerte.

- Funcionamiento cíclico. Se inyecta una corriente de $600 \mathrm{~mA}$ durante $30 \mathrm{~s}$, y se dejan los LEDs en reposo otros $30 \mathrm{~s}$, , como punto de origen se planteó un ciclo de 1 minuto al $50 \%$ de funcionamiento, aunque a nivel de caracterización eléctrica se han empleado otro tipo de ciclos.

Puesto que el ensayo acelerado en temperatura es el más común en esta área tecnológica, por ser el más resolutivo [LuxR08] [O'Con12] [Yan07] [Ne190], se decidió hacer simultáneamente tres ensayos acelerados en alta temperatura. En cada una de las tres estufas se introdujeron 8 LEDs, 4 de tipo A y 4 de tipo B, de los cuales 2 tenían inyección de corriente para funcionamiento continuo y 2 inyección para funcionamiento cíclico.

En total el ensayo debería tener 8x3, 24 LEDs, sin embargo al final se optó por poner un LED sin corriente en la cámara de alta temperatura para comprobar si sólo la alta temperatura afectaba a la degradación del LED, lo que unido a que se guardaron varios LEDs nuevos para medidas térmicas y ópticas, que después se detallará, obligaron a quitar un LED de cada tipo, con funcionamiento cíclico en la cámara de $90^{\circ} \mathrm{C}$.

Puesto que los LEDs comprados venían en un circuito disipador de aluminio denominado LED star de $20 \mathrm{~mm}$ de diámetro [BERQ15], dicho circuito incluía un zener en antiparalelo que actuaba como dispositivo de protección contra las descargas eléctricas. A dicho circuito de aluminio era necesario añadirle un disipador específico para que junto con LED no superase la conductividad térmica que nos ponían como límite en las curvas current-derating \& Tra incluidas en los datasheet de los fabricantes. El circuito disipador elegido fue el de un BGA (Ball Grid Array) de alta densidad de aletas, optimizado para convección natural.

Debido a que las tres cámaras empleadas eran diferentes, con ventiladores diferentes, se consideró más adecuado como condición de trabajo la convección natural dentro de la cámara, se introdujeron los LEDs en cajas de metal con pequeñas aperturas que evitasen el efecto del ventilador de cada cámara, y se introdujo un sensor en dicha caja, para medir la temperatura con los LEDs 
funcionando. En estas condiciones de contorno se programaron las cámaras para que los LEDs tuviesen condiciones de convección natural, y una temperatura ambiente de $60^{\circ} \mathrm{C}, 75^{\circ} \mathrm{C}$ y $90^{\circ} \mathrm{C}$. Por tanto los resultados de funcionalidad a largo plazo tendrán como referencia la temperatura ambiente de las condiciones nominales de trabajo, que en el caso de una estación automática acondicionada con aire acondicionado estarán sobre $25^{\circ} \mathrm{C}$.

\subsubsection{Planificación}

Durante el proceso de ensayo se realizaban dos tipos de medida; medidas de tensión con inyección de $600 \mathrm{~mA}$ y se medían 10 puntos de la curva I-V en directa entre $1 \mathrm{~mA}$ y $600 \mathrm{~mA}$, al principio del ensayo cada 2 horas para evaluar el comportamiento de la instrumentación y los LEDs, y después cada 8 horas, esto nos permitía detectar de forma prematura fallos catastróficos o cambios relevantes en la curva I-V que nunca ocurrieron.

Cada cierto número de horas se extraían los LEDs de las cámaras para hacer medidas más exhaustivas, inicialmente en torno a $48 \mathrm{~h}$ y después aproximadamente cada semana (168 horas) o más, cuando se observó que la degradación en los LEDs era progresiva, y en el caso de los LEDs a $60^{\circ} \mathrm{C}$ lenta. En la Figura 6-3 se refleja el flujograma de esta planificación.

En cada parada del ensayo se sacaban los LEDs y se les realizaba un conjunto completo de medidas, que consistían en medida precisa de curva I-V a cuatro hilos en directa, captura de espectrometría a $600 \mathrm{~mA}$ en continua con un miniespectrómetro USB MIGHTEX ${ }^{\mathrm{TM}}$ con un array CCD Toshiba de 3648 elementos y una resolución de $9 \mathrm{~nm}$, y tras comprar un equipo de potencia óptica también dicha medida con el sensor 3A (una termopila con un rango desde los $60 \mu \mathrm{W}$ a los $3 \mathrm{~W}$, y cinco rangos de medida) y el medidor USB Juno ambos de Ophir ${ }^{\mathrm{TM}}$. No se realizaba la curva I-V en inversa, porque no sería necesario desoldar el zener anti-descargas del circuito durante los ensayos, pero si al finalizar el ensayo se desmontó el zener y se hicieron medidas I-V tanto en directa como en inversa.

Con la evolución de la degradación obtenida en cada uno de los tres ensayos se pueden obtener los instantes de ensayo en los que se ha producido el fallo de cada LED. Ahora bien la degradación que se considera fallo es un elemento arbitrario, en iluminación y señalización se considera fallo una degradación superior al 30\% respecto al valor inicial emitido por el LED, apoyándose en [Tay05]. Pero algunos autores que han realizado ensayos a LEDs de ultravioleta profundo han considerado degradaciones mayores para estimar en fallo, en concreto el 50\% de degradación [CAFB +04 ] [SGGW+06] [MGCK+14] [SJDB+15], esto da idea de que los ensayos acelerados no dieron esperanzas de vida altas a la degradación del $30 \%$ 


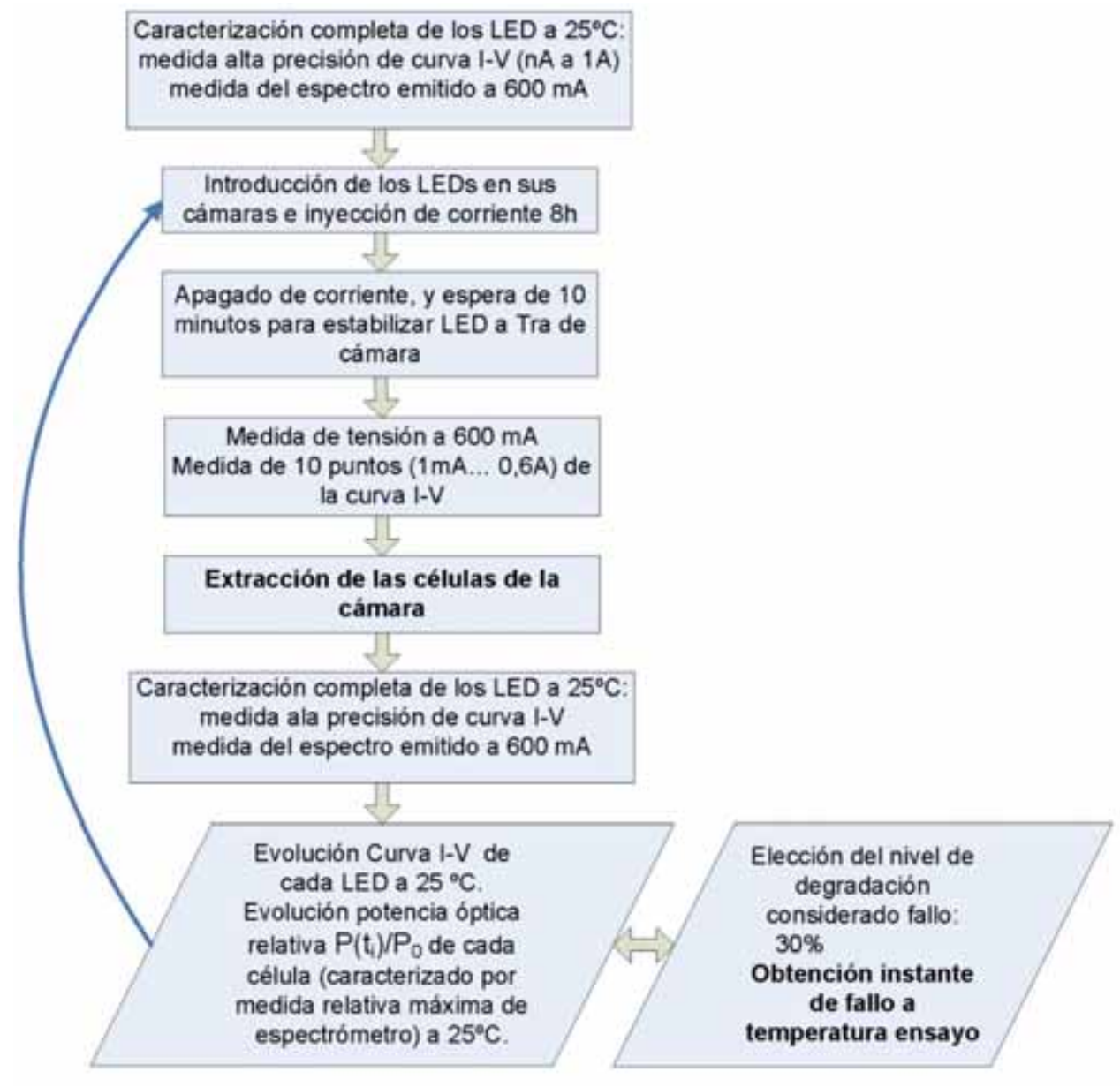

Figura 6-3: Flujograma del plan de ensayos acelerados en temperatura.

Una vez se obtengan todos los resultados para cada una de las temperaturas, con la salvedad de que dichos resultados variarán según el nivel de degradación que se consideren fallo, se aplicará el modelo de Arrhenius a los resultados. Para ello se empleará la herramienta ALTA (Accelerated Life Test Analysis) de Reliasoft que ofrecerá los valores más probables de cada parámetro de la fiabilidad y esperanza de vida para la temperatura nominal de trabajo, indicando si los ensayos siguen el modelo de Arrhenius.

El proceso a realizar para obtener la vida del LED en condiciones de trabajo nominales, se refleja en la Figura 6-4. 


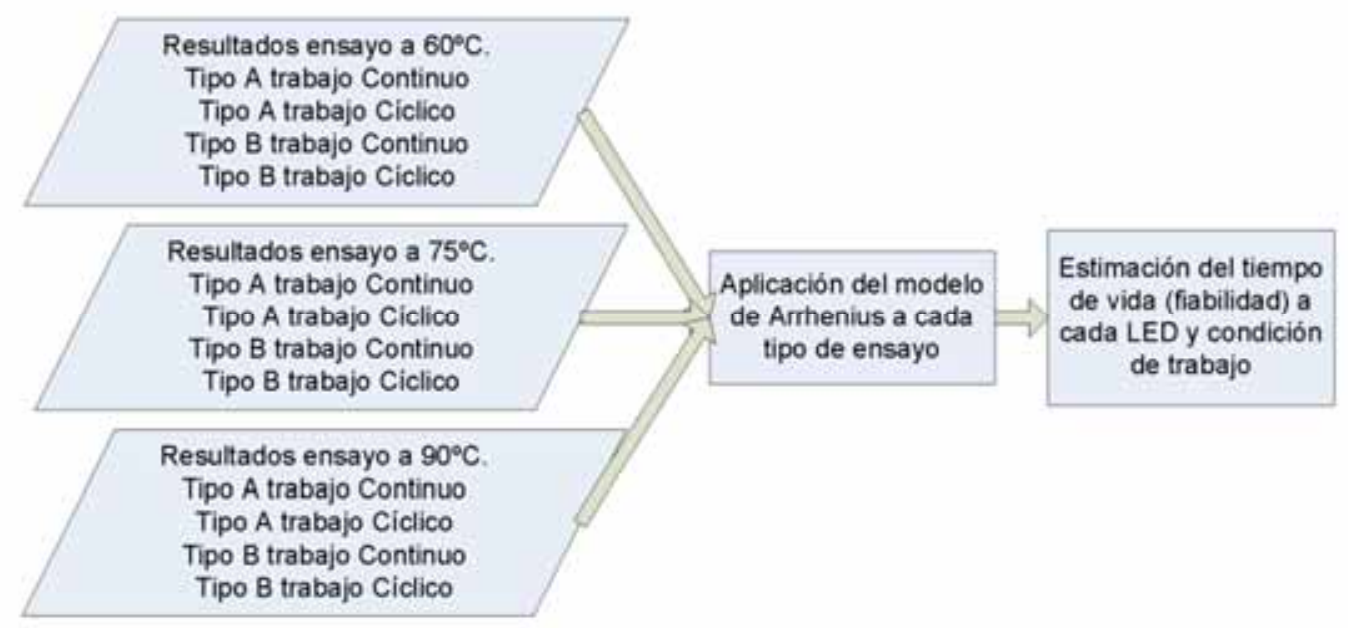

Figura 6-4: Flujograma del análisis de resultados de los ensayos acelerados.

\subsubsection{Instrumentación}

Los ensayos acelerados han requerido de dos sistemas de instrumentación. Cada uno de ellos está formado por subsistemas de medida, alimentación, control y conmutación, para controlar el conjunto se ha desarrollado en PC-Windows un instrumento virtual (VI es el Virtual Instrument del LabVIEW) mediante el lenguaje de programación labview LabVIEW (acrónimo de Laboratory Virtual Instrumentation Engineering Workbench).

El LabVIEW es un lenguaje de programación visual gráfico, desarrollado por National Instruments inicialmente para instrumentación, pero se ha extendido a diseño firmware, sistemas reales, simulados, embebido y pruebas hardware y software. El lenguaje es compatible con plataformas Windows, UNIX, MAC y GNU/Linux, tiene implementados drivers para cualquier tipo y marca de instrumentación, y para la mayoría de los interfaces de comunicaciones disponibles.

Ambos instrumentos diseñados constan de dos partes, la programación visual mediante un Diagrama de Bloques, los bloques van desde el control completo de un equipo a simples comandos de programación, la segunda parte es el interfaz con el usuario, formado por un Panel Frontal para programar cualquier parámetro de las medidas, o control del ensayo acelerado, el panel se subdivide en sub-paneles para funciones específicas como el control de temporización, de rangos de medidas o controles del sistema de conmutación. En esta sección se presentarán ambos sistemas de instrumentación, pero no se va a entrar en el detalle, por una parte porque no es objeto de esta tesis, y por otro lado porque son en gran parte consecuencia del desarrollos previos realizados en la 
ETSIST-UPM, que han tenido que actualizarse para su adaptación a este ensayo concreto; con 8 LEDs en cada cámara, alta potencia, y con unos objetivos específicos de medida. Para un detalle más profundo se referencia el trabajo previo sobre el que se basa este sistema [RG13], pero no es sino que la evolución de trabajos anteriores [NVGA+09] [NVGJ+11], más la fuerte ampliación de capacidades realizada para la tesis, que están comentadas en [ANVN+14] [Seg14].

El primer sistema que se presenta es el sistema de ensayos acelerados. Dicho sistema tiene como objetivo caracterizar los LEDs dentro de tres estufas simultáneamente, a $60^{\circ} \mathrm{C}, 75^{\circ} \mathrm{C}$ y $90^{\circ} \mathrm{C}$ de temperatura ambiente, y emular las condiciones de trabajo definidas, por un lado la corriente en continua de $600 \mathrm{~mA}$, y por otro el modo de trabajo cíclico con $30 \mathrm{~s}$ en funcionamiento con $600 \mathrm{~mA}$ de inyección de corriente y $30 \mathrm{~s}$ apagados. Cada uno de los ensayos han tenido una duración de unas 4000 horas, con lo que el número de conmutaciones de los LEDs en modo cíclico ha sido de $14,4 \cdot 10^{6}$ conmutaciones de encendido y otras tantas de apagado.

Para emular las condiciones de convección natural que tendrán los LEDs en las condiciones reales planteadas, se han introducido los LEDs a probar en cada estufa dentro de una caja de aluminio con pequeños agujeros Figura 6-5, que emulaba las condiciones de convección natural, y aislaba los LEDS de la convección forzada dentro de la estufa, además se ha controlado su temperatura interior de la caja para obtener las condiciones de ensayo definidas.

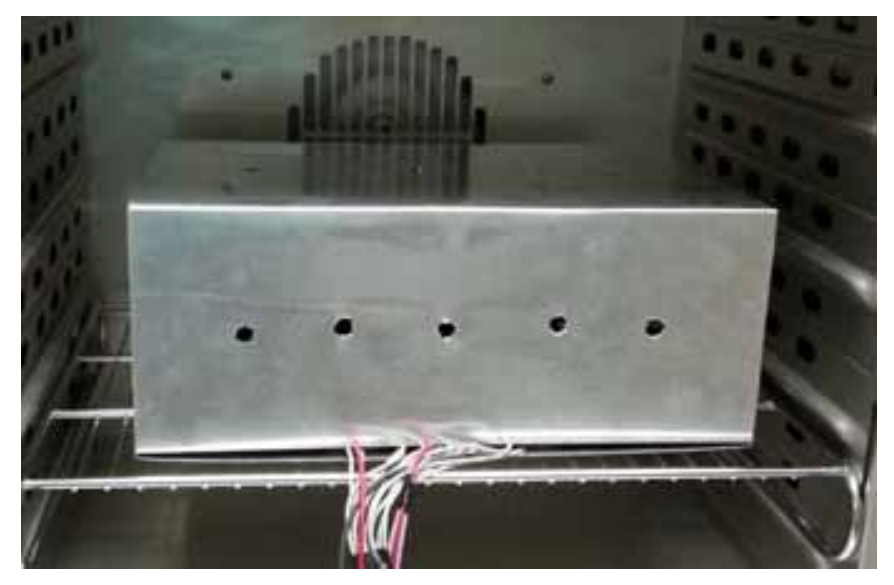

Figura 6-5: LEDs dentro de la caja preparados para el ensayo.

En la Figura 6-6 pueden verse los 8 LEDs ensayados encendidos hacia abajo, y sobre ellos su disipador de aletas. A los LEDs conectados en serie se les inyecta una corriente de $600 \mathrm{~mA}$, cada 30s se conmutaba la corriente de los LEDs en modo de trabajo cíclico a una resistencia de potencia (en color gris, en el centro del conector blanco) conectada en serie con los LEDs en funcionamiento continuo, y que ofrece una carga eléctrica equivalente a los LEDs hacia la fuente. El objetivo del 
sencillo circuito era evitar los picos de corriente en las conmutaciones, ya que habrían afectado de forma negativa a la vida de estos LEDs, por lo que fue comprobado con un osciloscopio que las fuentes no presentaban oscilaciones en las conmutaciones. El conector blanco de tornillo permitía desconectar los LEDs y llevarlos a la instrumentación que media la curva I-V completa, y la espectrometría. Al final se realizaron también en estos LEDs una vez degradados

Los LEDs que hay en cada cámara son:

- 2 LEDs tipo A con modo de trabajo continuo.

- 2 LEDs tipo A con modo de trabajo cíclico.

- 2 LEDs tipo B con modo de trabajo continuo.

- 2 LEDs tipo B con modo de trabajo cíclico.

Ya se ha indicado previamente que en la cámara de $90^{\circ} \mathrm{C}$ sólo se ensayaron 7 con corriente, se incluyó uno sin corriente para comprobar que la temperatura por sí sola no degradaba el LED, como así ocurrió.

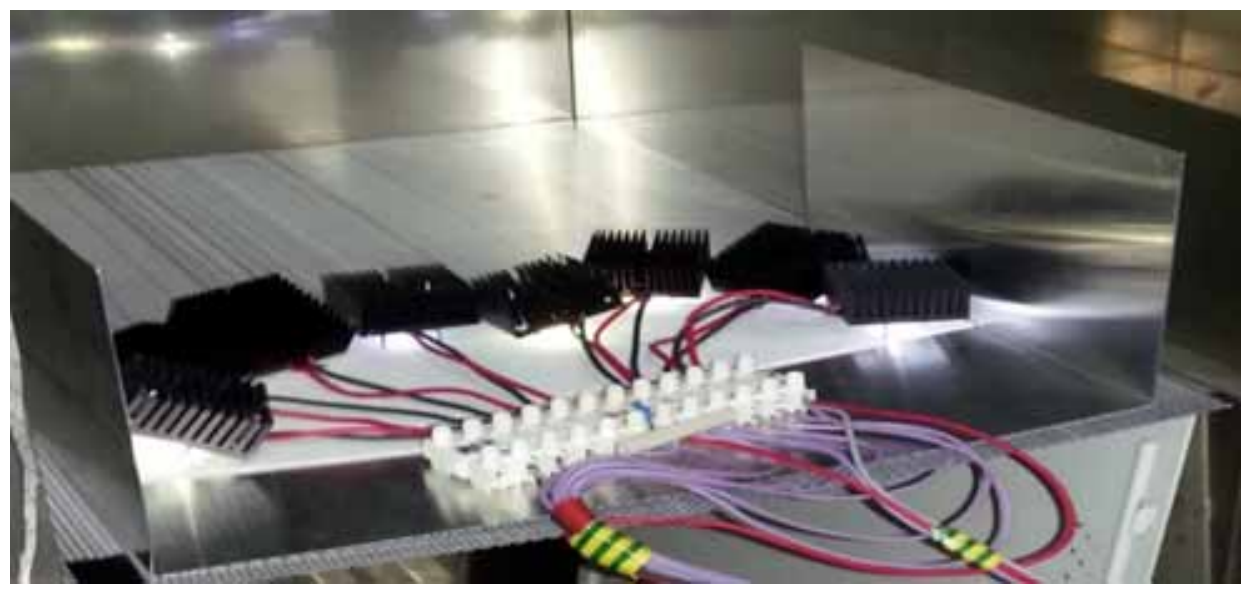

Figura 6-6: Circuito de 8 LEDs ensayados en una de las estufas antes de cerrar la caja.

En la Figura 6-7 se muestra la instrumentación y su conexión a dos de las estufas, una a cada lado del sistema de instrumentación, en la parte inferior aparece una esquina de la tercera estufa que está en el suelo. 


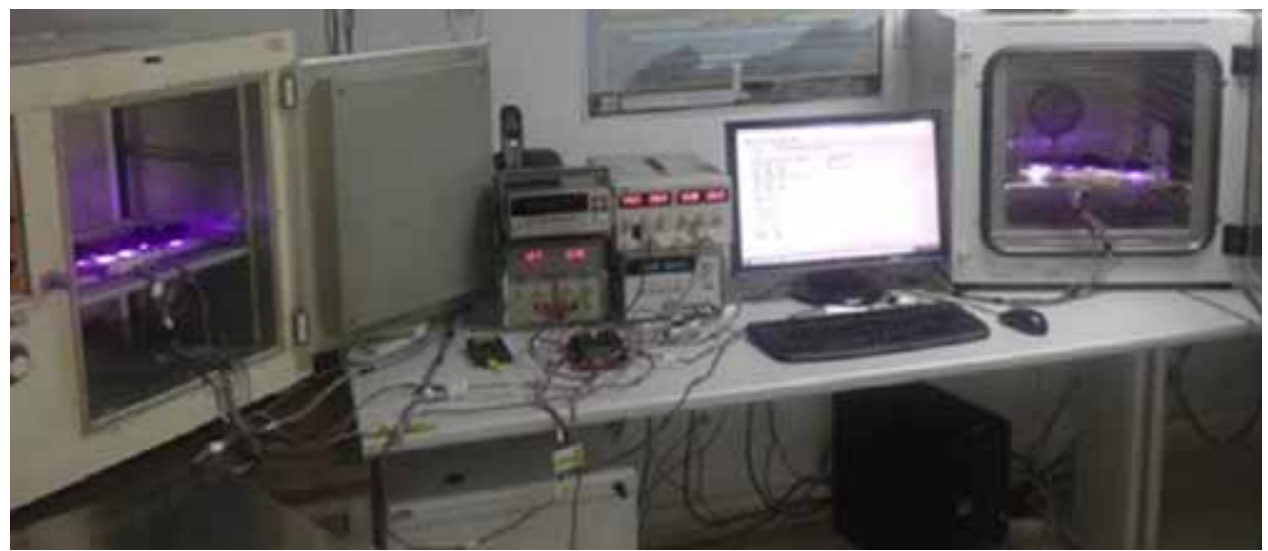

Figura 6-7: Instrumentación de ensayos acelerados en el centro, dos estufas a ambos lados, y una tercera estufa en la parte inferior izquierda.

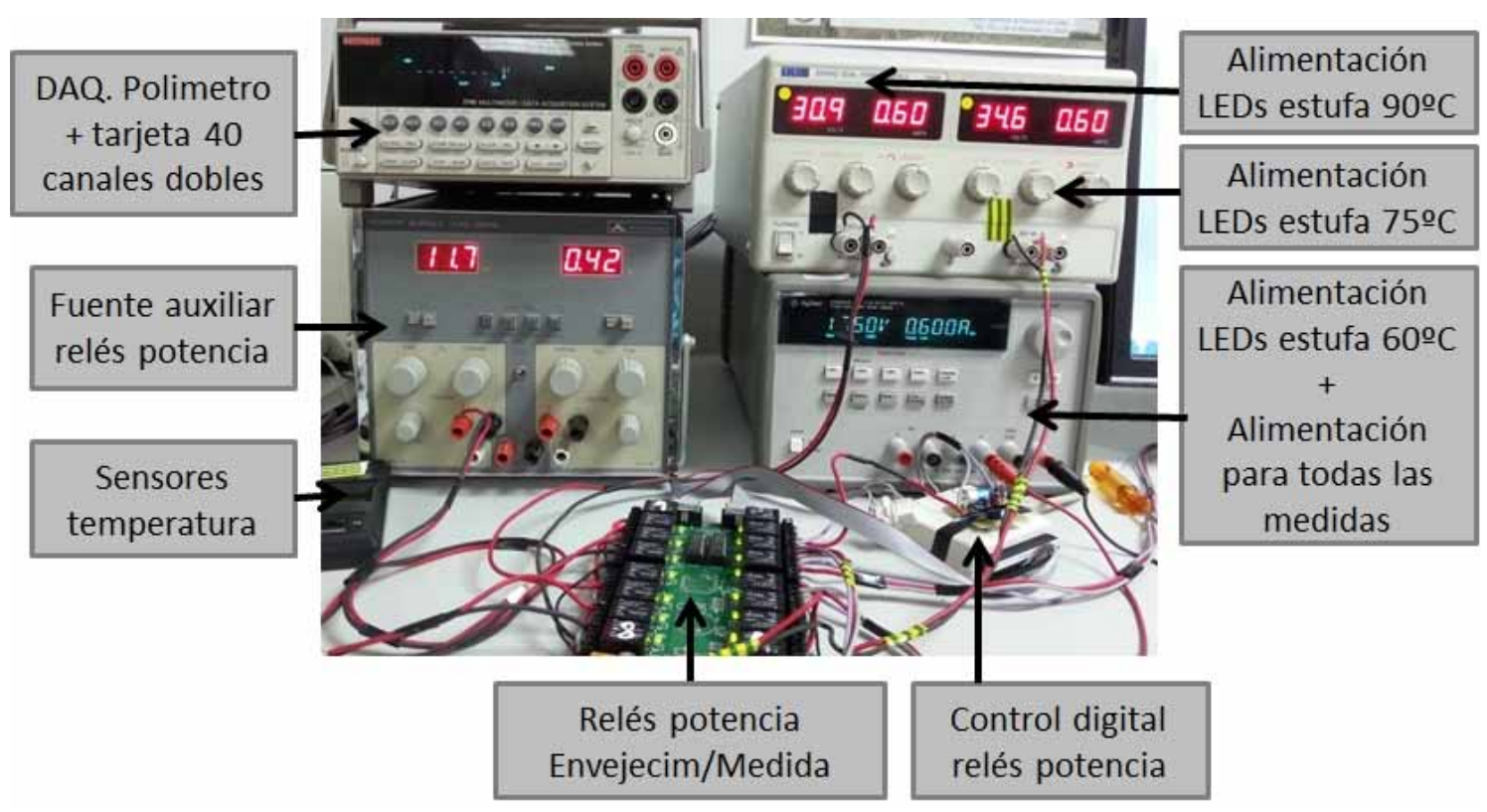

Figura 6-8: Estructura de la instrumentación.

En la Figura 6-8 se observa la estructura de la instrumentación, con tres fuentes para la inyección de corriente en cada una de las tres estufas, la fuente programable Agilent E3631A inyectaba la corriente de una de las estufas durante el envejecimiento y se programa para inyectar diferentes corrientes en cada uno de las tres estufas durante el ciclo de medida, la medida de los LEDs con dichas corriente lo realiza el Multimeter/Data Acquisition System (DAQ) 2700 de 
Keithley, que tenía una tarjeta 7702 con capacidad para medir 40 canales dobles, de los que son utilizados 24 canales. El multímetro de este equipo es de 6 1⁄2 dígitos (22-bit).

El segundo sistema de media permite medir las curvas I-V a cuatro hilos, para esta función podrían haberse empleado sistemas mucho más sencillos, pero la función diferenciadora de este sistema es que permite "medir" la temperatura en la unión del LED en los estados transitorios y en funcionamiento estático, es decir, durante el proceso de encendido y cuando el LEDs funcionan de forma estática al haberse llegado al equilibrio de temperatura entre la convección natural a temperatura ambiente, y la potencia emitida por el LED. El procedimiento se basa en que a bajas corriente el LED no se autocaliente, sabiendo que la tensión en el LED depende de la temperatura. De modo que si se calibra la tensión a baja corriente del LED en la estufa en un rango de temperaturas, suponiendo que de 25 a $115^{\circ} \mathrm{C}$ con intervalos de $15^{\circ} \mathrm{C}$, y cuando el LED funciona en condiciones reales (convección natural, $25^{\circ} \mathrm{C}$ y $600 \mathrm{~mA}$ ) al interrumpir la corriente de alimentación durante unos milisegundos para introducir la corriente de calibrado y medir la tensión, se puede extrapolar la temperatura de la unión a partir de la curva previamente calibrada [RHCNP05] [KRDH08] [VNNB10] [ANVG14] [ANVN+14] [ANVSG15]. Este es un proceso que solo sirve si se calibra de forma independiente cada tipo de LED. En la sección de caracterización del LED y sus modos de trabajo se detallarán los resultados de estas medidas. Como información adicional, este proceso era grabado desde la pantalla del PC, teniendo así la espectrometría del LED durante el proceso de arranque y en funcionamiento estático, de modo que se pueda relacionar la temperatura con la irradiancia emitida.

Esta caracterización se realizó para los dos tipos de LEDs nuevos, caracterizando posteriormente un LED envejecido con objeto de observar si se producía durante el ensayo acelerado además de degradación óptica, degradación térmica. Los equipos para la caracterización térmica pueden observarse en la Figura 6-9. Sus principales componentes son un espectrómetro de amplio espectro

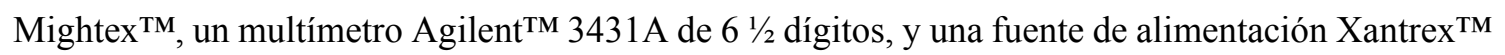
XDL 35-5TP programable con tres rangos de tensión y sensado de voltaje remoto para controlar con precisión las "medidas" de temperatura, y la realización de las curvas I-V. La instrumentación estaba al lado de la estufa Binder ${ }^{\mathrm{TM}}$, para poder realizar el calibrado de las características I-V a cada temperatura. 


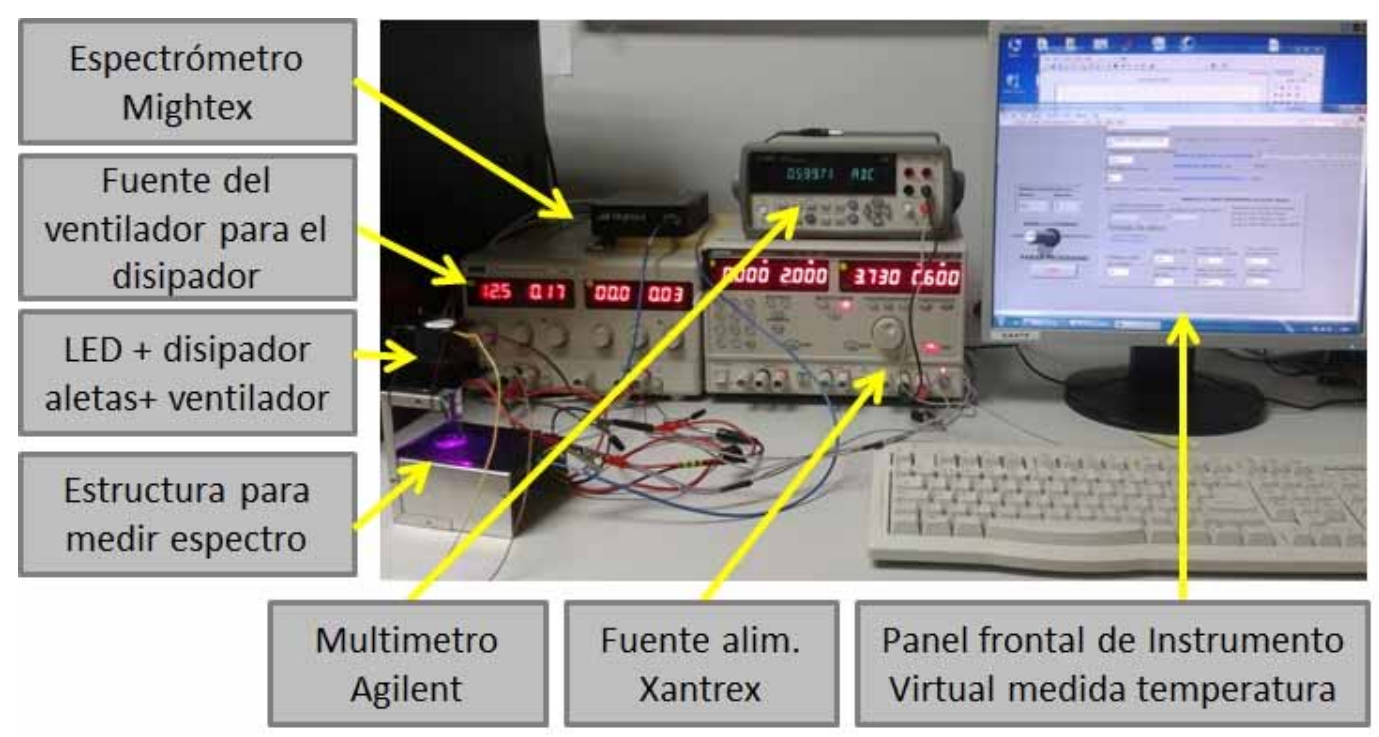

Figura 6-9: Estructura de la instrumentación para la medida de la temperatura de la unión del LED durante los dos modos de trabajo, y para caracterización de curva I-V.

En el caso de la Figura 6-9 se observa el ensayo concreto del LED con un ventilador de aire forzado sobre sus aletas de aluminio, esta fue una de las medidas realizadas, pero la mayoría se centraron en el modo de trabajo normal, con convección natural (sin ventilador) y diferentes modos de trabajo; el modo continuo y tres modos de trabajo cíclicos.

En la Figura 6-10 se muestra el sistema tomando una curva I-V de los LEDs. El programa VI de LabVIEW tiene un panel frontal específico para esta medida. La estructura metálica en la parte frontal es empleada para la medir la espectroscopia emitido por los LEDs. Del LED sólo se aprecian sus cables de medida y las aletas de disipación. En la zona inferior se encuentra la abertura de una esfera de integración que recoge parte de la luz emitida por el LED y la dirige a la fibra óptica de medida (azul) que es conducida al espectrómetro. Se taparon en negro todas las superficies que pudiesen reflejar la luz para tener una medida estable. El espectro medido evidentemente no muestra la potencia óptica total que emite el LED, sino que se mide la parte proporcional que incide sobre el detector de forma que se mide para cada LED su irradiancia relativa inicial y su evolución, obteniendo los datos de cómo se degrada durante el experimento, quedando reflejado en el número de cuentas del pico máximo del espectro a $365 \mathrm{~nm}$ [ANVSG15]. 


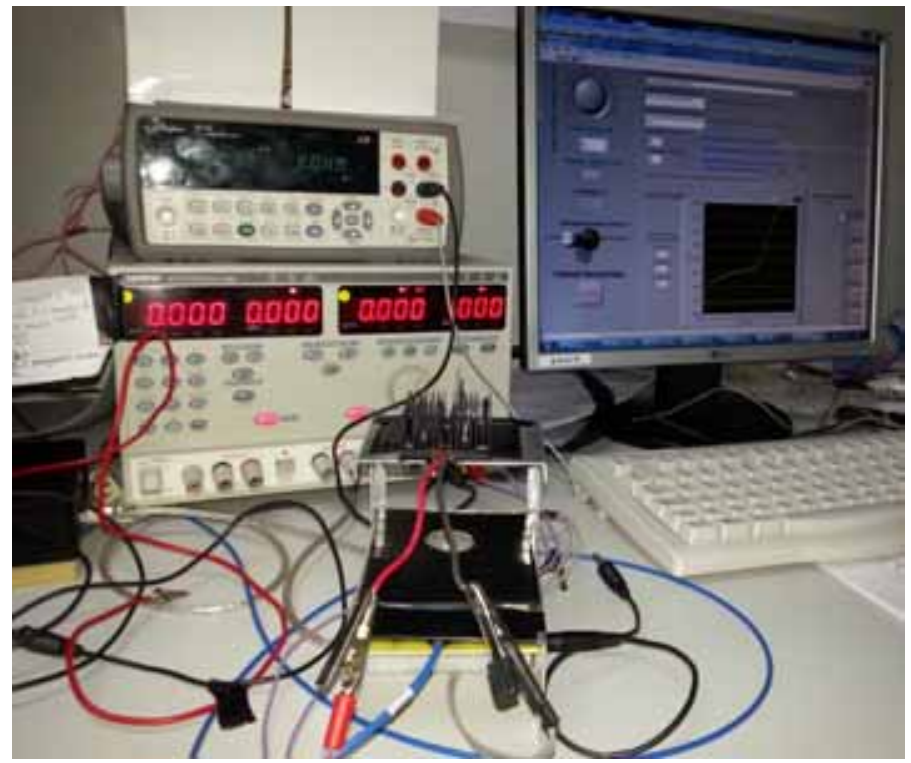

Figura 6-10: Sistema de instrumentación segundo midiendo la curva I-V de un LED, también era el empleado para medir la espectrometría.

En la Figura 6-11 se observa la caracterización de la irradiancia relativa del LED, a $8 \mathrm{~cm}$ de distancia, que son las condiciones reales de funcionamiento, mediante el equipo de medida JUNO de Ophir y su cabeza de sensado óptico por termopila 3A, de espectro amplio y con un rango de medida entre $60 \mu \mathrm{W}$ y $3 \mathrm{~W}$.

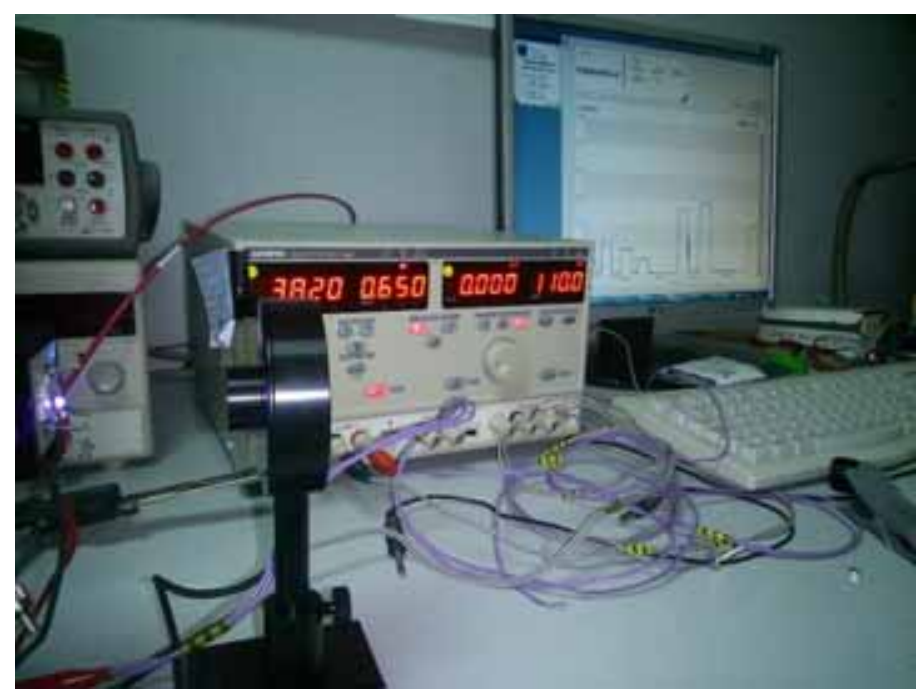

Figura 6-11: Sistema de medida de potencia óptica del LED, a la distancia real de uso, 8 $\mathrm{cm}$. 


\subsection{Caracterización de LEDs y modos de trabajo}

Esta sección está dedicada a la caracterización de los dos tipos de LEDs ultravioletas que se han empleado en los ensayos, y después se verá cómo evolucionan estas características durante el ensayo.

\subsubsection{Caracterización del LED}

Aunque algunas de las características ya fueron mencionadas anteriormente a continuación se exponen todas las relevantes para los estudios realizados:

- Se prueban dos tipos de LEDs ultravioleta de similares características eléctricas y de encapsulado, no necesariamente tecnológicas sobre las que se pidió información a los fabricantes y no se obtuvo respuesta. Estos LEDs serán denominados A y B. El LED tipo A tiene metalización mediante líneas paralelas, y el LED tipo B tiene una metalización en forma de cuadrícula, tal y como puede apreciarse en la Figura 4-10.

- La potencia máxima de alimentación para funcionamiento continuo es de aproximadamente $3 \mathrm{~W}$ en ambos casos, el tipo A emite ligeramente menos potencia óptica que el tipo B, pero ambos tienen una corriente nominal de $700 \mathrm{~mA}$. En funcionamiento cíclico las corrientes máximas indicadas son de $850 \mathrm{~mA}$ para el LED tipo A y de $1000 \mathrm{~mA}$ para el LED tipo B.

- La longitud de onda nominal es de $365 \mathrm{~nm}$, en un rango de valor mínimo $365 \mathrm{~nm}$ y máximo $370 \mathrm{~nm}$.

- El máximo flujo radiante es de $800 \mathrm{~mW}$ para el LED tipo A y $1000 \mathrm{~mW}$ para el B.

- La temperatura de la unión máxima es $100^{\circ} \mathrm{C}$ para el tipo A y $115^{\circ} \mathrm{C}$ para el $\mathrm{B}$.

En la figura Figura 6-12 se observan superpuestas las curvas I-V ambos tipos de LED. 


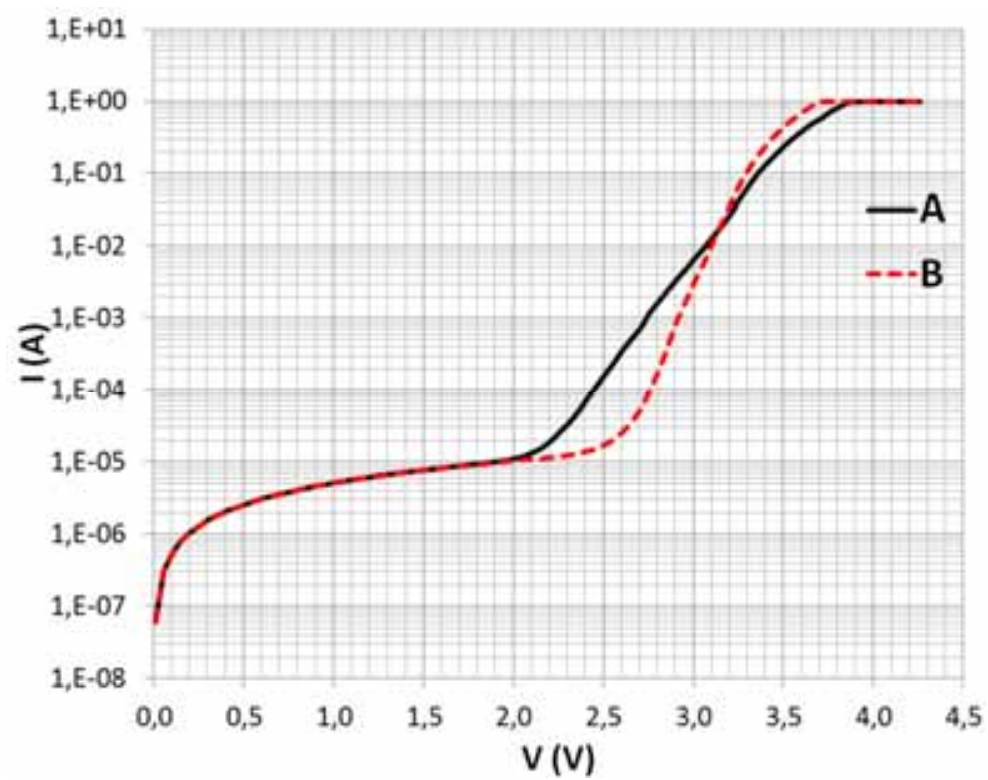

Figura 6-12: Curvas I-V de los LEDs tipo A y B.

En la Figura 6-13 se observan las espectrometrías de ambos tipos de LED. Un parámetro importante es observar que para $600 \mathrm{~mA}$ el LED A tiene una tensión de $3.72 \mathrm{~V}$ y el LED tipo B 3.58 $\mathrm{V}$, por tanto el tipo A consume más potencia que el tipo B aunque emite menor potencia luminosa. Relacionando estos parámetros el rendimiento óptico del B es mayor que el del LED tipo A.

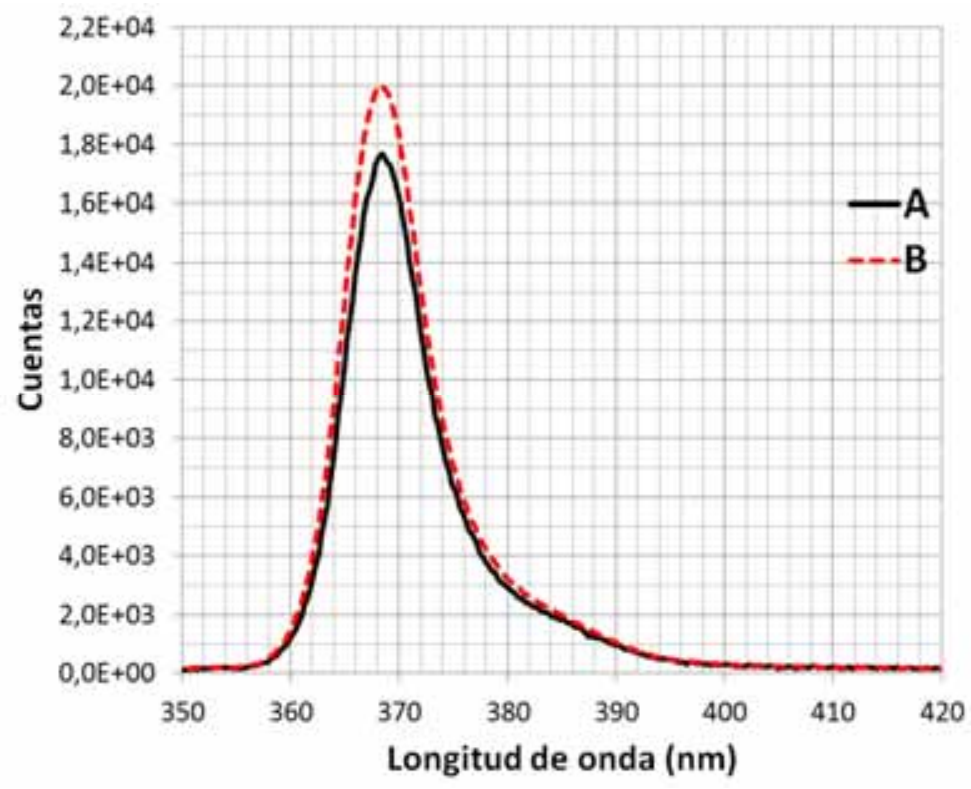

Figura 6-13: Espectrometrías de los LEDs tipo A y B. 
El LED tipo A tiene el pico $368.36 \pm 0,26 \mathrm{~nm}$ con 17661 cuentas y el B en $368,36 \pm 0,26 \mathrm{~nm}$ con 20030 cuentas. Las cuentas son unidades arbitrarias, e indican la medida relativa de la potencia medida por el CCD (charge-coupled device) del espectrómetro.

En las siguientes figuras se puede observar el encapsulado del LED, su circuito metálico con el que fue adquirido, y el disipador elegido para la convección forzada, debajo del LED se encuentra el zéner en antiparalelo. El chip del LED está ensamblado sobre un encapsulado cerámico de 4,5 $\mathrm{mm}$ $\mathrm{x} 4,5 \mathrm{~mm}$, la lente del chip es de cristal, y el espacio entre el chip y la lente esta relleno con silicona (material identificado por el fabricante, y el que menos se degrada con la luz ultravioleta [LYLTS10]. El chip está soldado sobre un MCPCB (Metal Core Printed Circuit Board), también conocido como, IMS (Insulated Metal Substrate) tipo [Ber15] con forma de "estrella" (star shape) de 19,9 mm de diámetro y núcleo de aluminio, (Figura 6-14 izquierda). En la estructura de disipación elegida (Figura 6-14 derecha) el LED se montaría hacia abajo para iluminar el agua con el posible contaminante, cuya fluorescencia emitida mediría el espectrómetro. Sobre el circuito del LED se montaría un disipador de aletas de aluminio 40x40x18 mm (ALDTM, heat sink BGA-STD-115) al que se unirá con una cinta térmica y tres tornillos que sujetan el circuito en forma de "estrella". La posición de las aletas sería hacia arriba para como es lógico en una convección natural. En la figura Figura 6-15 se detalla la estructura del encapsulado empleado, pero con el LED hacia arriba.

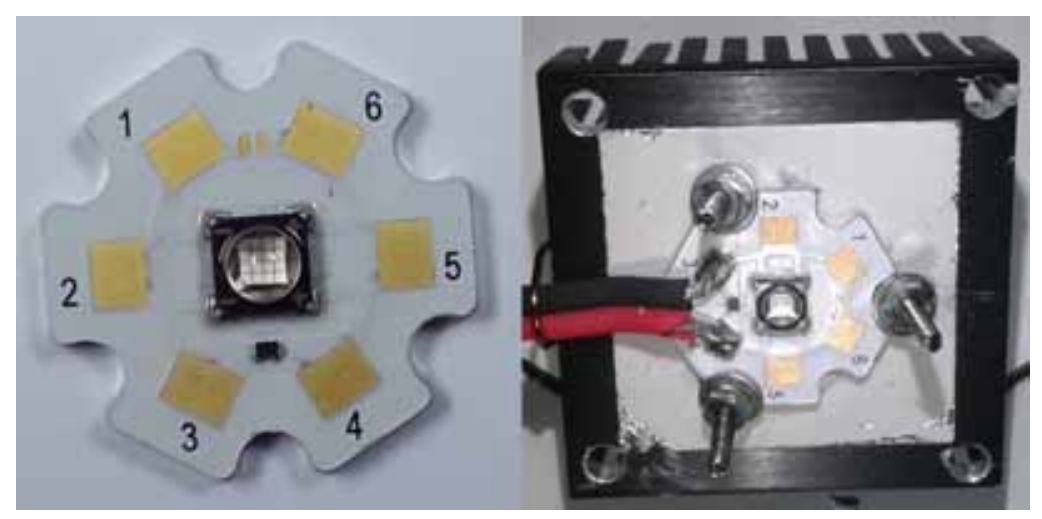

Figura 6-14: Foto real del LED, incluye circuito MCPCB, y el LED montado sobre el disipador y cableado [ANVSG15]. 


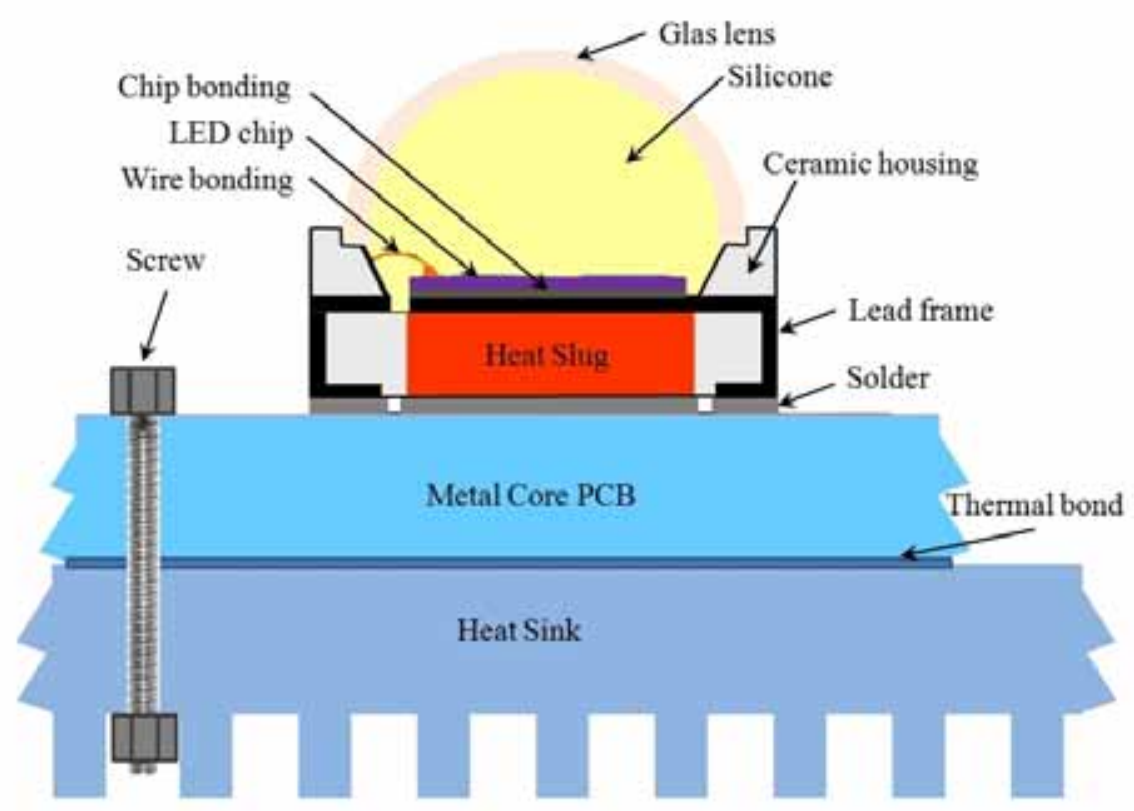

Figura 6-15: Encapsulado del LED con circuito MCPCB y disipador [ANVSG15].

Al plantear las condiciones de trabajo nominales de los dos tipos de LEDs a ensayar, se ha tenido en cuenta la experiencia previa en análisis de fiabilidad de los LEDs de alta potencia [CDVP12] [GKZT06] [FYP12] [YK03]. La densidad de corriente y la temperatura son los principales elementos que definen la vida de los LEDs de alta potencia, debido a que la emisión luminosa del LED se incrementa con la corriente, y ésta es su razón de ser, estos LEDs trabajan a altas densidades de corriente y temperatura, ambas interrelacionadas y además relacionadas directamente con la degradación y la fiabilidad [YK03] [SRS08] [SC12] [RHCNP05] [VNNB10] [NVN09] [NVGAE10]. Por tanto es necesario conseguir un equilibrio entre la funcionalidad buscada, una alta iluminación que requiere alta densidad de corriente y el mantenimiento de un periodo de vida estable y prolongado. La temperatura se puede reducir con unas buenas condiciones de disipación, y para reducir el efecto de la degradación de la corriente, existen dos caminos, no llevar al LED al máximo de corriente nominal (por ello se hará funcionar al LED al $85 \%$ de su corriente máxima en continua) y trabajar en modo cíclico, por tanto a la hora de plantear los ensayos de vida acelerada se considerarán todos estos elementos.

En los ensayos de vida acelerada que se han desarrollado, se han ensayado 12 LEDs de cada uno de los tipos A y B, de ellos uno se introdujo en la cámara de mayor temperatura sin inyección 
de corriente. Los 8 LEDs (4 de cada tipo) de cada una de las tres cámaras han estado dos en modo de trabajo continuo y dos en modo de trabajo cíclico, definidos de esta forma:

- Modo de trabajo continuo, se inyectaban de forma constante $600 \mathrm{~mA}$, que sólo se interrumpían durante unos minutos cada 8 horas para hacer las medidas dentro de la cámara, y las medidas semanales fuera de ella.

- El modo de trabajo cíclico. En este modo se ha ensayado el LED con un ciclo de 60 segundos, 30s encendido (ON) y 30s apagado (OFF), el uso de esta baja frecuencia en lugar de las frecuencias altas, por ejemplo 1 o $10 \mathrm{KHz}$ empleados en flashes de luz, es debido a que durante los 30 s de estado ON debe dar tiempo a que se estabilice de forma suficiente la iluminación del LED para realizar una medida del espectro de la fluorescencia del contaminante fiable y estable. Los $30 \mathrm{~s}$ apagado permiten bajar la temperatura del LED, relajar su estrés, y reducen a la mitad el tiempo de operación real para la misma función de medida en tiempo real. Se han probado otros dos ciclos de trabajo con 60 segundos de periodo, el ciclo 10s ON\&50s OFF y el contrario 50s ON\&10s OFF, para obtener su caracterización, pero no se ha realizado sobre ellos el ensayo acelerado.

Los tres ciclos planteados para su análisis tienen de partida que envejecen menos, en 10s ON\&50s OFF el funcionamiento se reduce a 1/5 del tiempo que trabaja el LED en continuo, y 1/2 y $4 / 5$ para los otros dos ciclos. Se introduce un estrés adicional en cada conmutación, que ha sido reducida de forma sustancial, al realizar la conmutación entre la carga que ofrecen los 4 LEDs en trabajo cíclico de cada cámara y la carga de una resistencia equivalente, a costa de alimentar una carga "innecesaria" durante el ciclo apagado del LED, pero elimina los picos de la conmutación, lo cual es fundamental para obtener los resultados de fiabilidad que se han obtenido. Aparece un problema secundario debido a que mientras el LED se enciende en cada ciclo, la potencia óptica emitida y su temperatura varían de forma dinámica. Para analizar este problema se planteó el segundo sistema de instrumentación (Figura 6-10), y se siguió el procedimiento de medida indirecta de la temperatura a partir de la tensión del LED a baja corriente, cuya operación ha sido demostrada en trabajos previos [RHCNP05] [KRDH08] [VNNB10].

Mientras el LED era encendido, sistema de instrumentación media en tiempo-real los valores I-V para analizar la temperatura, en la pantalla del PC se tenía funcionando el espectrómetro caracterizando la emisión óptica del LED, el proceso de evolución óptica se gravaba en el PC y luego se relacionaban las medidas I-V a baja corriente (10 mA, extrapolando la temperatura en la unión) con el espectro del LED, y en concreto con su pico máximo. La caracterización de estos modos de 
funcionamiento a nivel de emisión de luz ultravioleta y temperatura son fundamentales para evidenciar la funcionalidad que se puede obtener en cada caso, y las diferencias de fiabilidad y modos de fallo que pudiesen aparecer en los ensayos de vida acelerada. Por tanto, se han analizado todos los casos para convección natural, que es el modo en que se plantea la instalación en los sistemas automáticos de medida, y además se decidió comparar la convección natural con la forzada, integrando sobre nuestro disipador de aletas un ventilador superior, tal como se encuentran en las CPUs de los PCs.

La tensión de ambos tipos de LEDs a baja corriente $10 \mathrm{~mA}$ y temperatura ambiente $\left(25^{\circ} \mathrm{C}\right)$ es aproximadamente $3 \mathrm{~V}$, es decir esta corriente genera una potencia de $30 \mathrm{~mW}$, muy pequeña comparada con la potencia de trabaja del LED aproximadamente $3 \mathrm{~W}$. Una vez identificadas las tensiones a $10 \mathrm{~mA}$ para distintos niveles de temperatura, entre $25^{\circ} \mathrm{C} \mathrm{y} 70^{\circ} \mathrm{C}$, se ha obtenido un decremento de tensión prácticamente lineal con la temperatura. Para $10 \mathrm{~mA}$ el coeficiente de tensión a partir de $25^{\circ} \mathrm{C}$ es:

LED tipo A:

$$
\frac{\Delta V}{\Delta T}=-0.003521 \mathrm{~V} /{ }^{\circ} \mathrm{C}
$$

\section{LED tipo B:}

$$
\begin{aligned}
& \frac{\Delta V}{\Delta T}=-0.0021339 \mathrm{~V}^{\circ} \mathrm{C} \\
& \mathrm{La} \text { diferencia de ambos coeficientes deja clara las diferencias de tecnologías }
\end{aligned}
$$
semiconductoras de ambos tipos de LEDs. Estos valores se aproximan a los indicados por el datasheet de los fabricantes para la corriente nominal máxima $700 \mathrm{~mA}$.

Los resultados de temperatura del ensayo cíclico 50s ON\&10s OFF son muy similares a los de funcionamiento continuo (Figura 6-16), por lo que se presenta uno de los resultados obtenidos, donde se observa que no se reduce la temperatura, la potencia óptica emitida mejora poco, y se introduce la conmutación, sin obtener en lo medido una gran ventaja a cambio. 


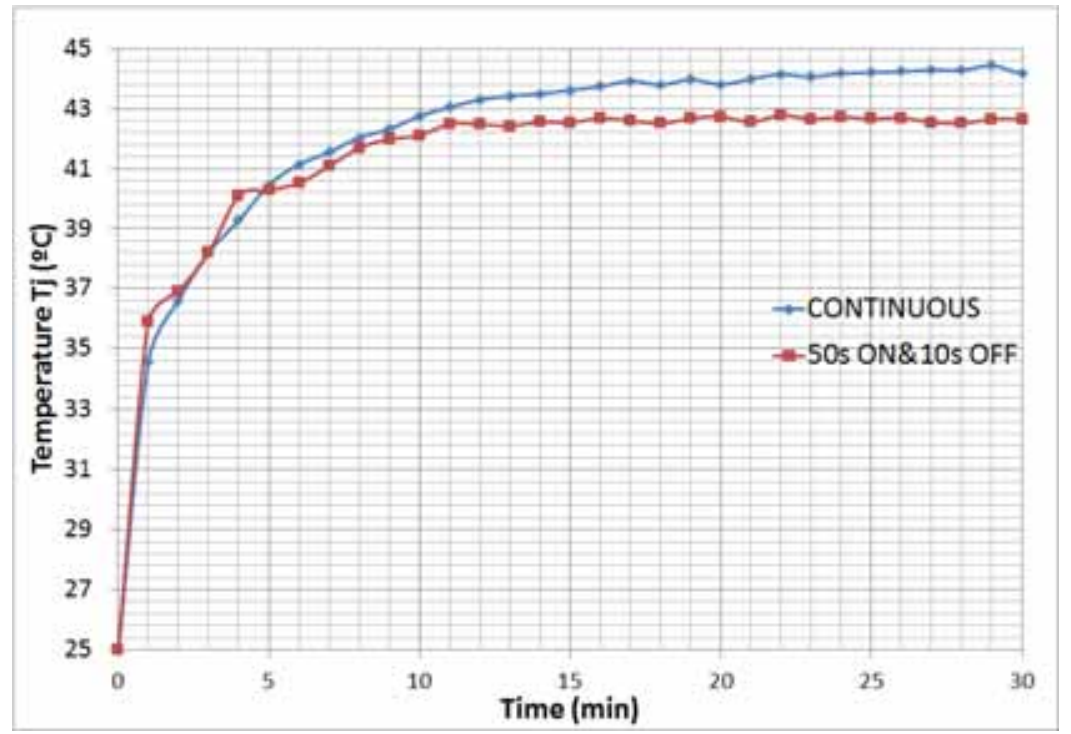

Figura 6-16: Evolución desde el encendido de la temperatura del LED tipo B en continua, y en ciclo 50s ON\&10s OFF.

En la siguientes figuras se observa la evolución de la temperatura en continua y con ciclos 30s ON\&30s OFF y 10 s ON\&50s OFF para el LED tipo A y tipo B. El mismo proceso para la potencia óptica emitida, y por último un detalle de esta última relacionada con que en el periodo de encendido debe realizarse la medida o sucesivas medidas, que durarían menos de un segundo.

\subsubsection{Caracterización del LED en convección natural: temperatura}

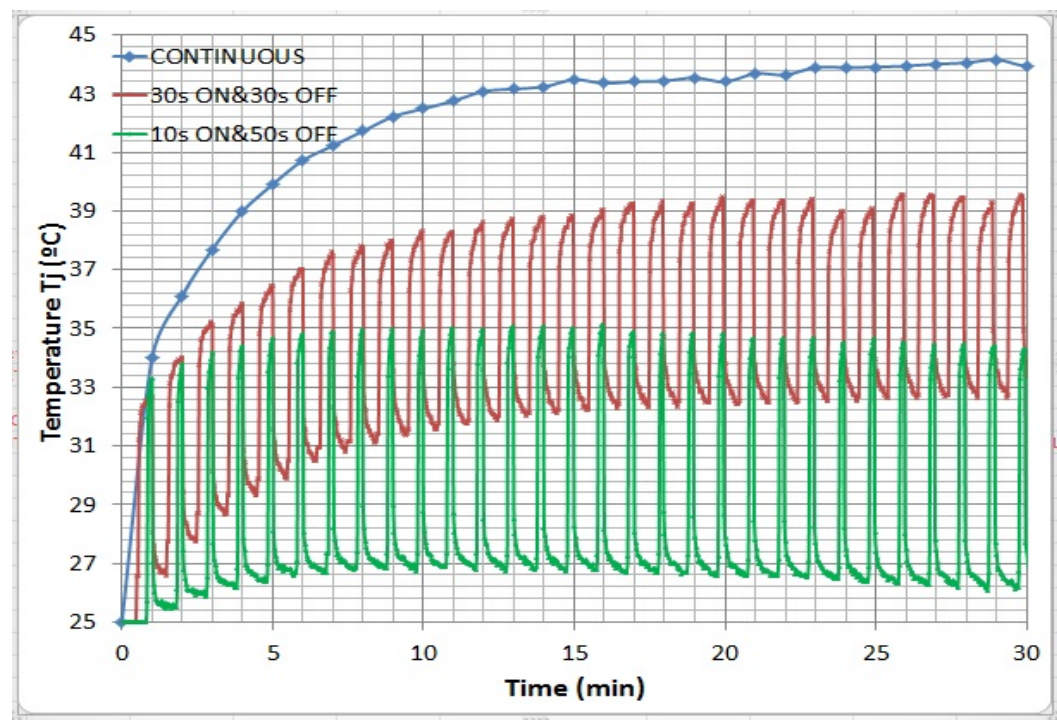

Figura 6-17: Evolución desde el encendido de la temperatura del LED tipo A en continua, y de los ciclos 30s ON\&30s OFF y 10s ON\&50s OFF. 


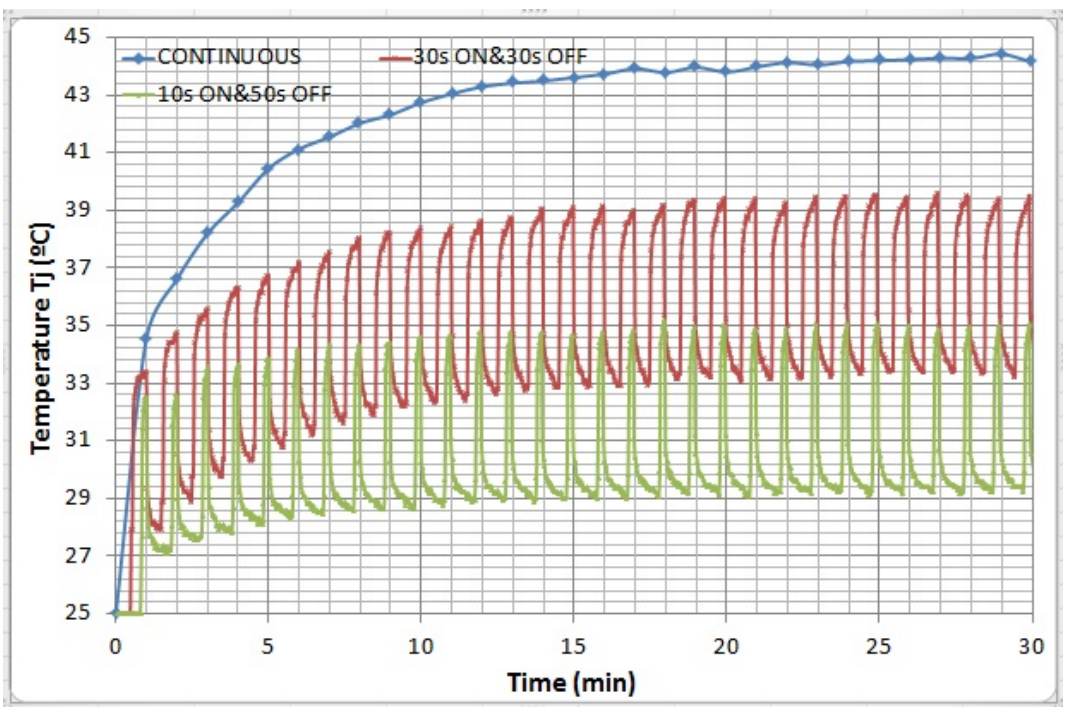

Figura 6-18: Evolución desde el encendido de la temperatura del LED tipo A en continua, y de los ciclos 30s ON\&30s OFF y 10s ON\&50s OFF. [ANVSG15]

\subsubsection{Caracterización del LED en convección natural: potencia óptica}

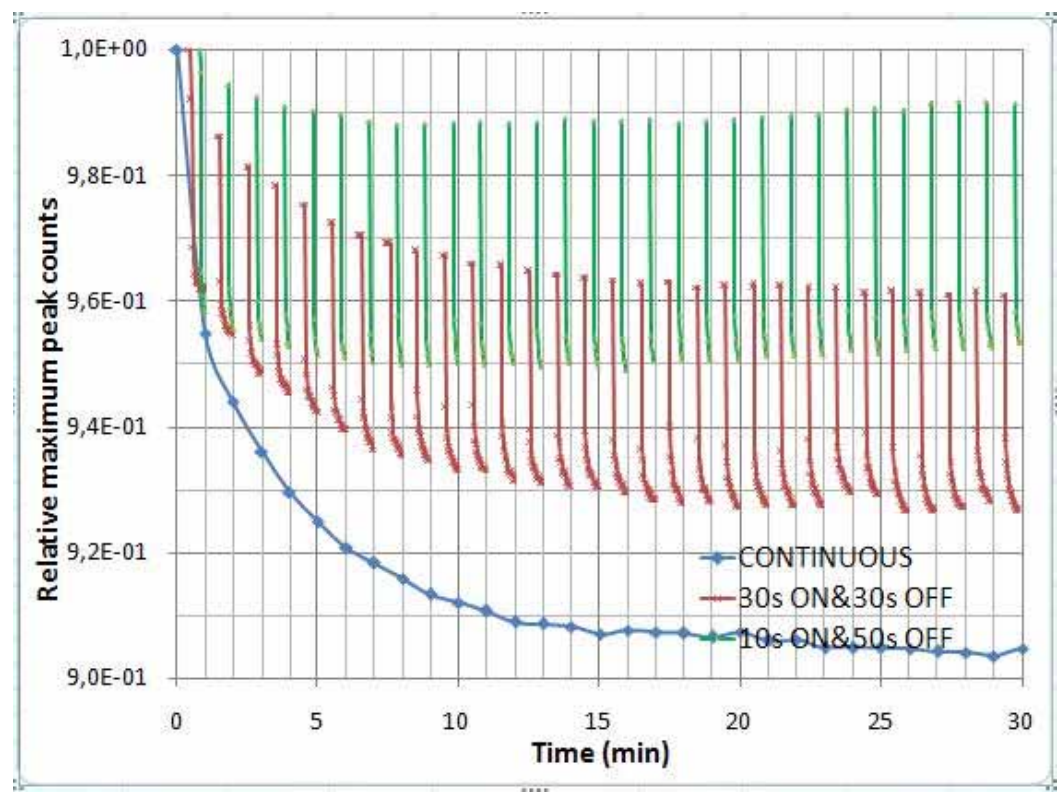

Figura 6-19: Evolución desde el encendido de la potencia óptica emitida del LED tipo A en continua, y de los ciclos 30s ON\&30s OFF y 10 s ON\&50s OFF. 


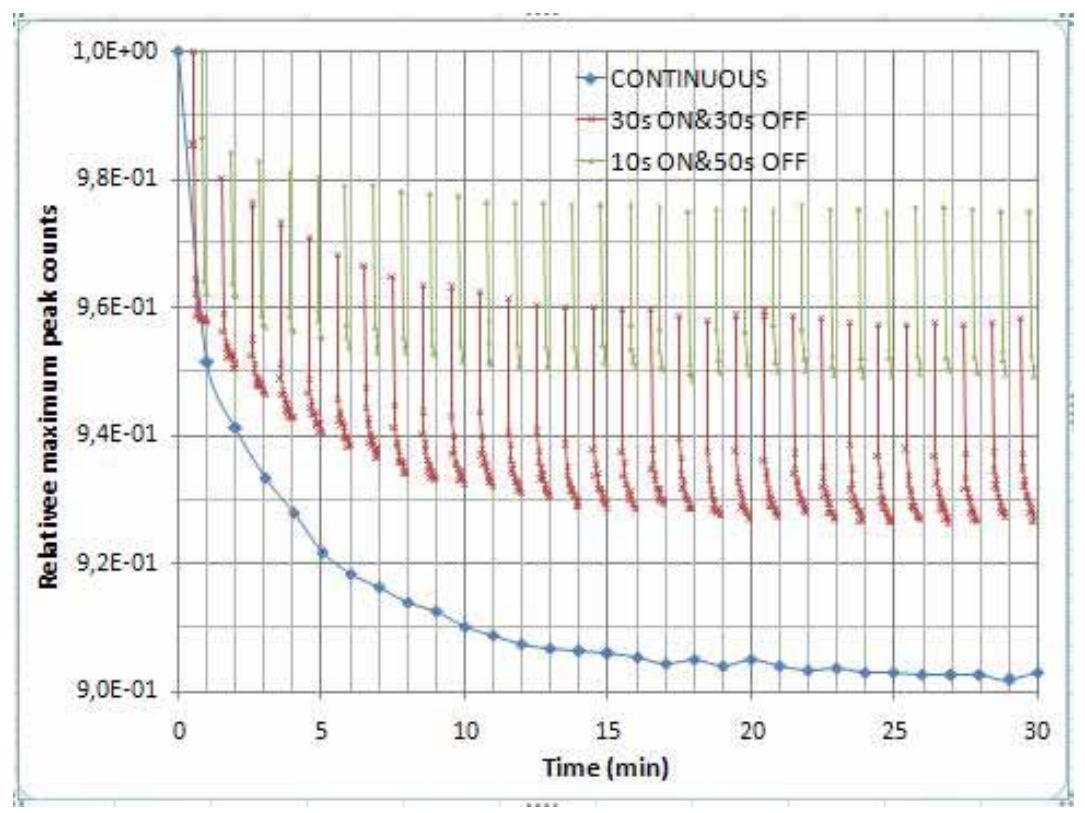

Figura 6-20: Evolución desde el encendido de la potencia óptica emitida del LED tipo B en continua, y de los ciclos 30s ON\&30s OFF y 10s ON\&50s OFF. [ANVSG15]

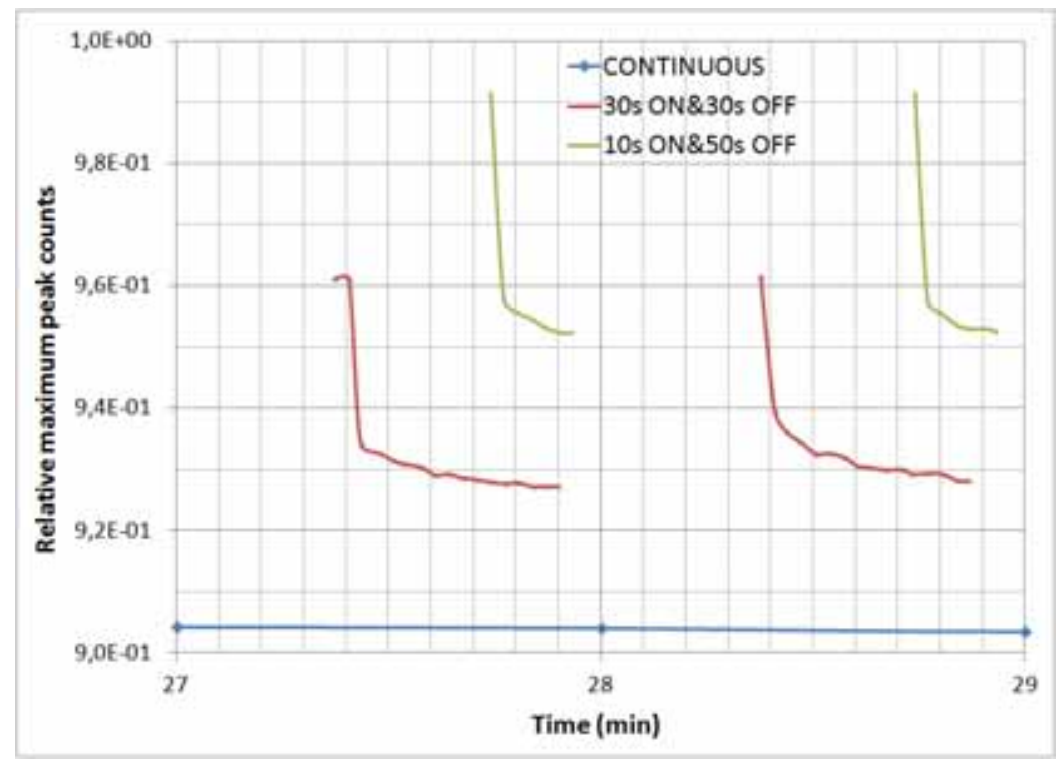

Figura 6-21: Detalle de evolución en funcionamiento estable de la potencia óptica emitida del LED tipo A en continua, y de los ciclos 30s ON\&30s OFF y 10s ON\&50s OFF. 


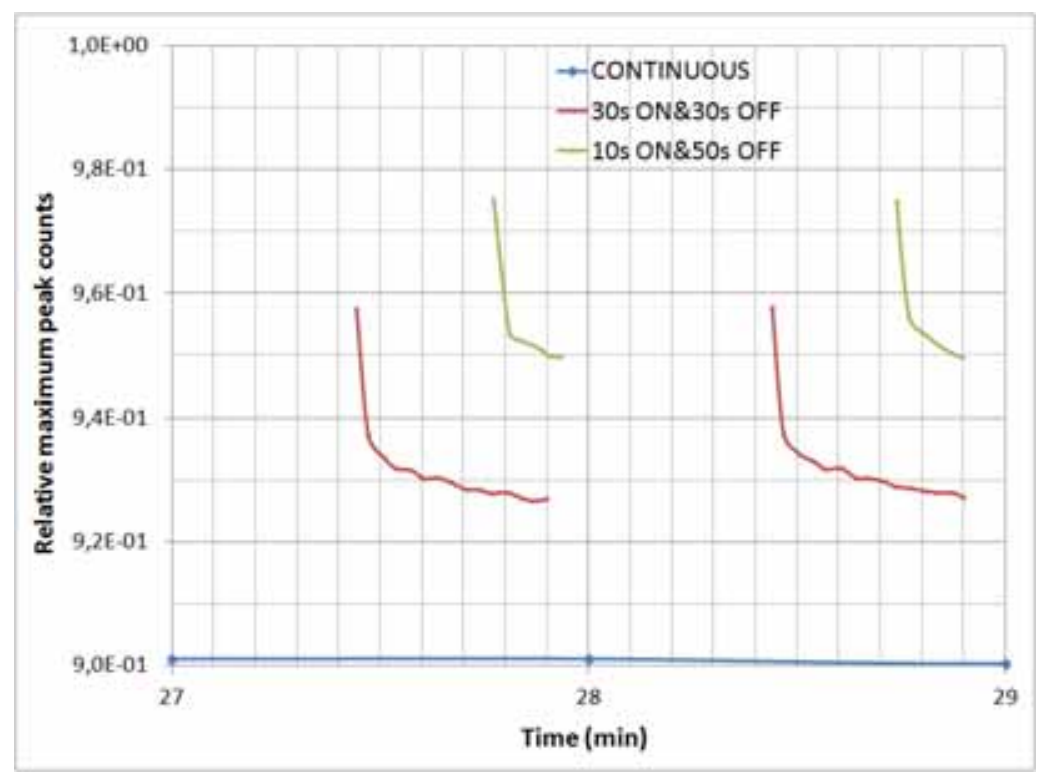

Figura 6-22: Detalle de evolución en funcionamiento estable de la potencia óptica emitida del LED tipo B en continua, y de los ciclos 30s ON\&30s OFF y 10s ON\&50s OFF. [ANVSG15]

De las gráficas anteriores se obtienen como conclusiones:

- El tiempo hasta que las temperaturas y emisiones ópticas son repetitivas son de unos 20 minutos. Siendo el incremento de temperatura inversamente proporcional a la emisión óptica.

- Los incrementos de temperatura en valores absolutos de los dos tipos de LEDs son muy similares. Para trabajo continuo es de unos $19^{\circ} \mathrm{C}$, para cíclica $30 \mathrm{~s}$ ON\&30s OFF es de $14,5^{\circ} \mathrm{C}$ y para 10 s ON\&50s OFF de $10^{\circ} \mathrm{C}$.

- Los decrementos de emisión óptica emitida (que se relacionan directamente con el pico del espectro) son muy similares en ambos LEDs en valores relativos, respecto al instante de arranque en frio donde existe una emisión máxima, se decrementa en un $10 \%$ para continua, en un 7,5\% para cíclica 30s ON\&30s OFF y en un 5\% para $10 \mathrm{~s}$ ON\&50s OFF. Hay que tener en cuenta que en valores absolutos, la emisión del LED tipo B es entre un 15-25\% mayor que la del tipo A.

- Las gráficas en detalle de la evolución instantánea de la emisión óptica cuando los LEDs están en funcionamiento estable indican que se produce un fuerte decremento en la emisión al encender el LED durante 4 a $6 \mathrm{~s}$, cuando se comienza a estabilizar la temperatura aparece una estabilización relativa de la emisión óptica, pero no 
definitiva. Como se observa el periodo de pseudo-estabilización es de 14 segundos en el ciclo 30s ON\&30s OFF y de 4 s en el ciclo 10s ON\&50s OFF. Por lo que en ambos casos sería necesario una señal de reloj entre el encendido y el periodo de medida del espectrómetro, dicho periodo es menor y con menos estabilidad para 10s ON, desde el punto de vista del laboratorio sería suficiente, pero en condiciones reales hay más variaciones en las condiciones, por lo que habría que comprobarlo en la aplicación. El ciclo de $30 \mathrm{~s}$ si que es claramente operativo para realizar la medida.

\subsubsection{Caracterización del LED en convección natural: circuito térmico}

Como se puede observar la potencia óptica en condiciones de ciclo tiene dos pendientes diferenciadas, la primera que es casi vertical que se corresponde con un incremento de temperatura $\mathrm{Tj}$ de la misma pendiente, que es debida a la baja resistencia térmica del chip más su encapsulado cerámico, y la segunda pendiente térmica de $\mathrm{Tj}$ menos pronunciada que será debida al circuito de aluminio y al disipador de aletas, una análisis de los elementos que influyen en el sistema térmico nos puede permitir generalizar resultados, para la elección de otro tipo de LED o disipador.

Aplicando la analogía entre circuitos RC eléctricos y térmicos, y el procedimiento de análisis térmico dinámico de [YHS08], se ha modelado el circuito térmico como un circuito eléctrico equivalente con dos redes RC en serie (R1C1 para el chip y encapsulado del LED y R2C2 para la disipación de aluminio) (Figura 6-23). La suma de la resistencia térmica puede ser obtenida de la potencia disipada durante el estado de encendido (ON), siendo 1,49W (2,14 W del LED menos $0,65 \mathrm{~W}$ de la luz emitida) y el incremento medio de temperatura durante el periodo estable $(11,32$ ${ }^{\circ} \mathrm{C}$ ). Esto tiene como resultado una $\mathrm{Rth}_{\mathrm{j}-\mathrm{a}}=15,2{ }^{\circ} \mathrm{C} / \mathrm{W}$ (unión-ambiente, junction-ambient) (R1+R2 $=15,2 \Omega$ en el circuito eléctrico). Ajustando el decremento de temperatura medido a la suma de la descarga de dos circuitos $\mathrm{RC}(\mathrm{V}(\mathrm{R} 1)+\mathrm{V}(\mathrm{R} 2)+25 \mathrm{~V})$, siendo $25 \mathrm{~V}$ equivalente a $25^{\circ} \mathrm{C}$, las constante $\mathrm{s}$ de tiempo obtenidas son $\tau_{1}=\mathrm{R} 1 \cdot \mathrm{C} 1=0,1 \mathrm{~s}$ y $\tau_{2}=\mathrm{R} 2 \cdot \mathrm{C} 2=155,6 \mathrm{~s}$. Finalmente identificando el valor de todos los parámetros, la resistencia térmica para la j-s (unión-disipador, junction-sink) y la s-a (disipador-ambiente, sink-ambient) son $\mathrm{R} 1 \equiv \mathrm{R} t \mathrm{j}_{\mathrm{j}-\mathrm{s}}=3^{\circ} \mathrm{C} / \mathrm{W}$ y R2 $\equiv \mathrm{Rth} \mathrm{s}_{\mathrm{-a}}=12,2^{\circ} \mathrm{C} / \mathrm{W}$. Como $\tau=\mathrm{R} \cdot \mathrm{C}$, la capacitancias térmicas son: $\mathrm{C} 1 \equiv \mathrm{Cth}_{\mathrm{j}-\mathrm{s}}=0,3 \mathrm{Ws} /{ }^{\circ} \mathrm{C}$ y $\mathrm{C} 2 \equiv \mathrm{Cth}_{\mathrm{s}-\mathrm{a}}=12,8 \mathrm{Ws} /{ }^{\circ} \mathrm{C}$.

Simulando con SPICETM el circuito eléctrico con un voltaje de $25 \mathrm{~V}$ (equivalente a Ta) y un ciclo de corriente de 1.49A (equivalente a la potencia disipada), se obtiene el análisis térmico dinámico en la condición de trabajo 30s ON\&30s OFF que se ajusta con la temperatura de la unión experimentalmente medida en Figura 6-23. Este modelo simula e identifica la respuesta térmico- 
dinámica para las condiciones de potencia y ciclos especificados, permitiendo una extrapolación a otras condiciones.

Los actuales resultados facilitan el desarrollo de nuevos sistemas ópticos con diferentes LEDs o disipadores, lo cual facilita su elección, y extrapolar la respuesta en dinámica de los dispositivos para conseguir un funcionamiento desde el punto de vista térmico lo más adecuado posible [YHS09].

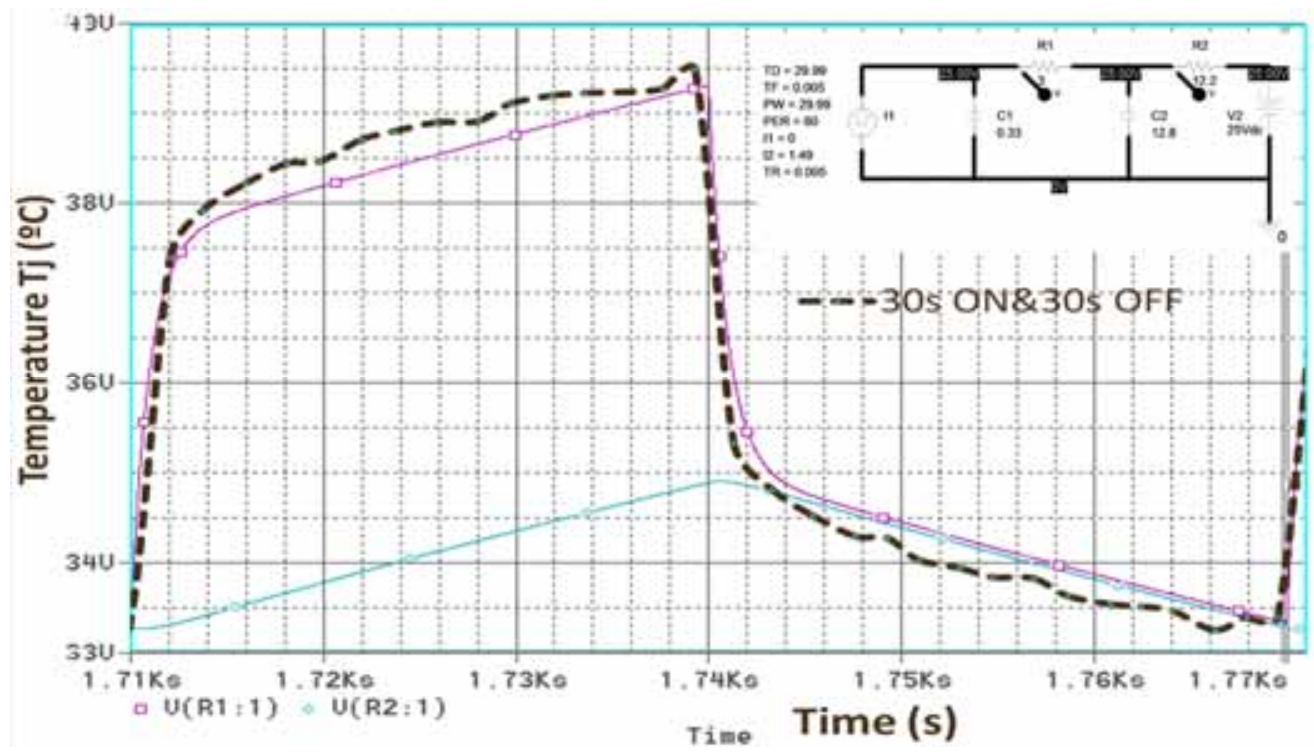

Figura 6-23: Temperatura en la unión experimental (línea discontinua) y simulación PSPICE (línea continua) para la condición de trabajo 30s ON\& 30s OFF en LED tipo B. [ANVSG15]

\subsubsection{Caracterización del LED en convección forzada: temperatura y potencia óptica}

En los siguientes párrafos se presentan los resultados de las medidas realizadas montando un ventilador de gama profesional para montar sobre el integrado del procesador de PCs o tarjetas gráficas, que irá atornillado sobre el disipador de aletas del LED. El ventilador usado tiene un rango de alimentación de 10,8 y 13,2 voltios, con unos niveles de funcionalidad según el fabricante en temperatura de $-10{ }^{\circ} \mathrm{C}$ y $70{ }^{\circ} \mathrm{C}$, y una vida de aproximadamente 40000 horas. La velocidad de funcionamiento puede variar entre 4500 y $18000 \mathrm{rpm}$, se ha configurado para una situación intermedia. Se han probado las mismas condiciones de funcionamiento que en convección natural. 
A continuación se presentan los resultados de uno de los tipos de LEDs (el A), ya que los resultados de ambos muy similares.

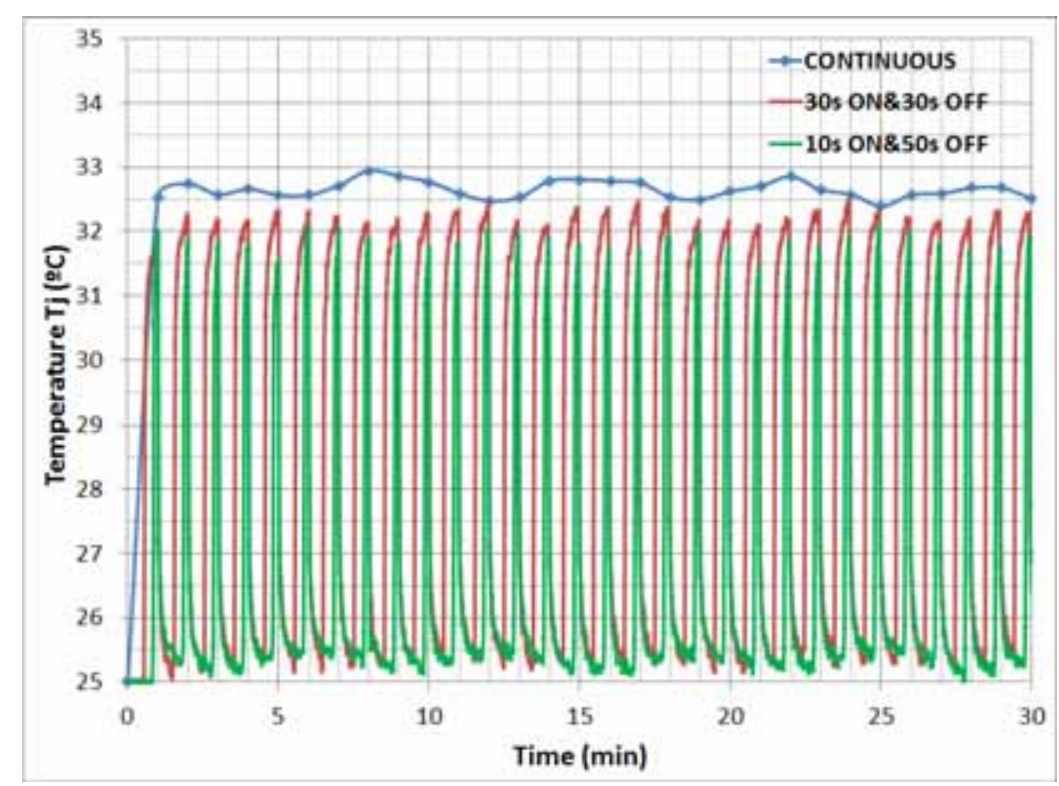

Figura 6-24: Evolución de la temperatura del LED tipo A en continua, y de los ciclos 30s ON\&30s OFF y 10 s ON\&50s OFF. C. forzada.

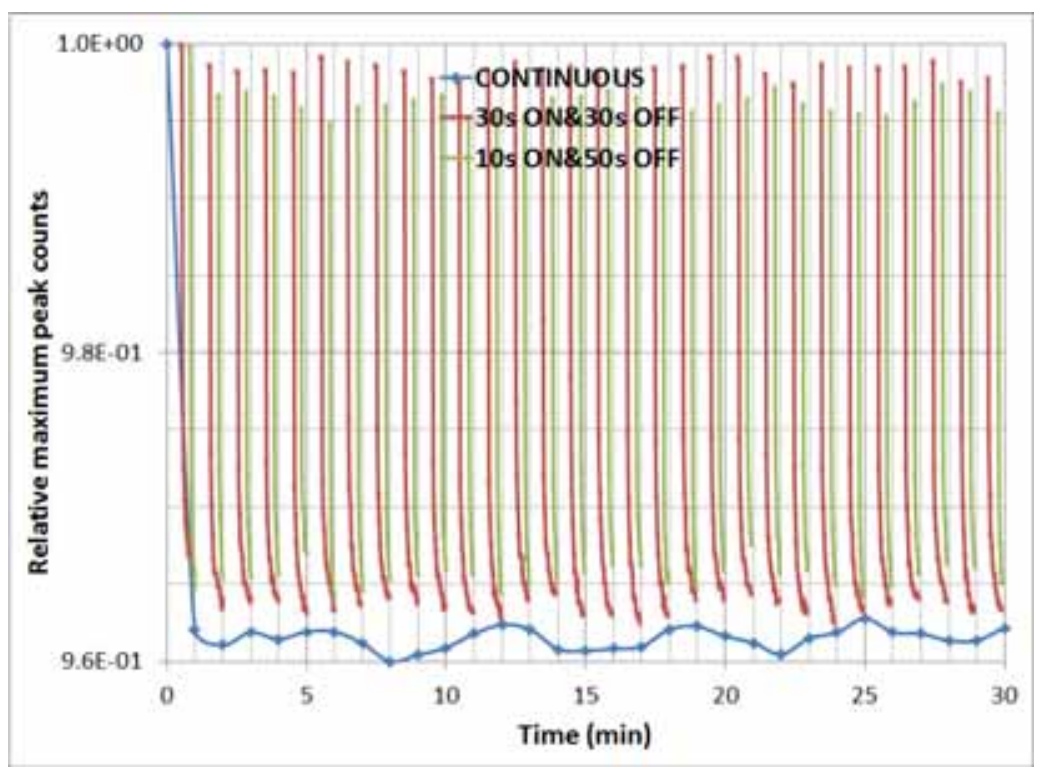

Figura 6-25: Evolución de la potencia óptica emitida del LED tipo A en continua, y de los ciclos 30s ON\&30s OFF y 10 s ON\&50s OFF. C. forzada. 


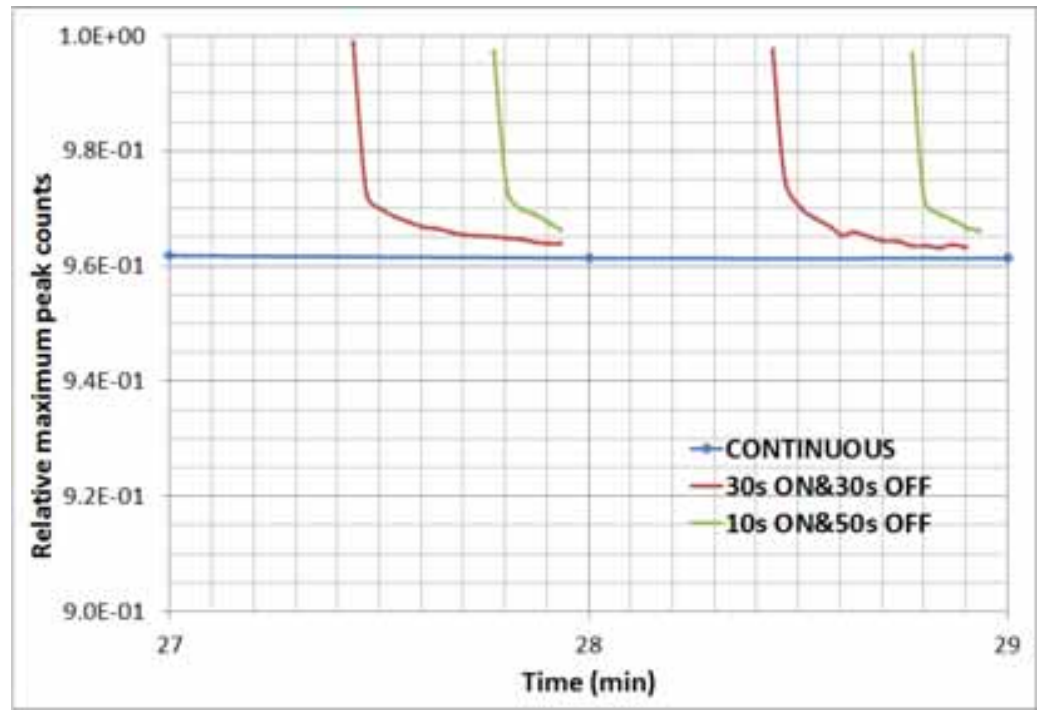

Figura 6-26: Detalle de evolución en funcionamiento estable de la potencia óptica emitida del LED tipo A en continua, y de los ciclos 30s ON\&30s OFF y 10s ON\&50s OFF.C. forzada.

Como se puede observar, al incluir un ventilador las temperaturas entre los tres tipos de funcionamiento caracterizados se aproximan y bajan considerablemente, siendo el incremento entre $13.5^{\circ} \mathrm{C}$ para funcionamiento continuo de $12,5{ }^{\mathrm{a}} \mathrm{C}$ para $30 \mathrm{~s}$ ON\&30s OFF y $12{ }^{\circ} \mathrm{C}$ para el ciclo $10 \mathrm{~s}$ ON\&50s OFF. La potencia óptica emitida también es muy similar, como consecuencia de la similitud de temperaturas. Es destacable que el periodo de estabilización es muy corto de 3 minutos en lugar de los aproximadamente 20 minutos anteriores, aunque, esto realmente no es importante, ya que se asume que el LED una vez encendido nunca debe apagarse. Es más importante que la potencia óptica emitida es mayor y se estabiliza en menos tiempo que en el caso con convección natural, lo que podría dar lugar a que funcionase con un ciclo de trabajo menor.

Por tanto, este modo de trabajo es más óptimo desde el punto de vista de la temperatura y de la potencia óptica, desde una visión de fiabilidad y considerando reales las 40.000 horas de vida definidas por el fabricante en funcionamiento continuo, serian una buena alternativa al sistema de convección natural propuesto. El único hándicap del sistema de ventilador es que en el ambiente de una estación automática, donde las condiciones de trabajo implican suciedad y bastante polvo, el ventilador podría degradar su funcionamiento rápidamente. Pero es una buena alternativa para tener en cuenta en otro tipo de equipos situados en laboratorio u otros sistemas con un buen filtrado de polvo. 


\subsection{Resultados de los ensayos acelerados}

La temperatura es un parámetro que acelera la vida en los dispositivos electrónicos, ésta característica ha sido empleada desde el comienzo del desarrollo teórico y práctico de la fiabilidad [MHDBK91][MHDBK98], para obtener predicciones de funcionamiento de los dispositivos en función de la temperatura o de parámetros funcionales como tensión y corriente acompañados de altas temperaturas para acortar la duración de los ensayos.

Por tanto, un dispositivo en funcionamiento nominal pero a alta temperatura acelera su vida, de modo que en un relativamente corto periodo de tiempo puede analizarse su comportamiento [SRS08] [YHS09] [SC12] [VNNB10] [NVGA+10], como podría ser en este caso, la degradación de la potencia luminosa emitida o la identificación de las debilidades del dispositivo desde el punto de vista de la fiabilidad [CDVP12].

En estos ensayos de vida acelerada (ALT Accelerated Life Test) se han ensayado 12 LEDs de cada tipo (dos para cada temperatura $\left(60^{\circ} \mathrm{C}, 75^{\circ} \mathrm{C}\right.$ y $90^{\circ} \mathrm{C}$ ambiente) y condición de trabajo (continua y cíclica $30 \mathrm{~s}$ ON\&30s OFF), excepto para $90^{\circ} \mathrm{C}$ donde sólo se tenía un LED de cada tipo con inyección cíclica y otro sin alimentar dentro de la cámara). La duración de los ensayos ha sido prolongada, 4020 horas para los ensayos de $60{ }^{\circ} \mathrm{C}$ y $90^{\circ} \mathrm{C}$, y de 3600 horas para el ensayo de $75^{\circ} \mathrm{C}$. El pequeño tamaño de la muestra empleada en los ensayos (dos LEDs de cada tipo para cada temperatura y mono de trabajo) no nos permite obtener unos valores de los parámetros de vida y fiabilidad con un alto nivel de confianza, de todos modos, el objetivo principal del ensayo es analizar la influencia de ambas condiciones de trabajo en la funcional de los LEDs e identificar si ambos LEDs pueden operar en las condiciones de trabajo definidas durante un periodo largo de tiempo (años) y si un tipo de LED es mejor que el otro.

En estos ensayos se han considerado dos tipos de fallos:

- Fallos catastróficos en los cuales se pierde de forma abrupta la potencia lumínica emitida por el LED, ya sea por un fallo parcial pero grave, por un circuito abierto o un cortocircuito.

- Fallos por degradación, son fallos debidos a una degradación progresiva de la potencia luminosa emitida hasta cierto límite. En este caso, se ha definido el fallo por degradación de la forma en que lo hace la Solid-State Illumination Systems and Technologies (ASSIST) para aplicaciones de iluminación, considerando que el fallo se produce cuando la potencia lumínica emitida cae por debajo de $70 \%$ de la potencia luminosa inicial [Tay05], al comienzo de la vida de cada LED. 
En los ensayos de vida acelerada no se ha observado ningún fallo catastrófico, pero bastantes LEDs han fallado por degradación de la potencia luminosa, superando el límite del fallo.

Los espectros de los LEDs se ha medido periódicamente durante el ALT fuera de las estufas a una $\mathrm{Ta}=25 \pm 0.5^{\circ} \mathrm{C}$ con convección natural. Puesto que el equipo de medida de potencia por unidad de área no se consiguió hasta el final del ensayo, casi todas las medidas se basan en la medida del espectro del LED, que consistía en único pico a $368 \mathrm{~nm} \pm 0.3 \mathrm{~nm}$ con una anchura total del pico máximo (full width high maximum - FWHM) de aproximadamente $9 \mathrm{~nm}$. Durante los ensayos se ha observado un ligero desplazamiento del pico a longitudes de onda mayores en $1.5 \mathrm{~nm}$, pero no se observa un ensanchamiento anormal del espectro. Estos valores están dentro de las especificaciones del fabricante, que identifica el pico entre 365 y $370 \mathrm{~nm}$. Por tanto, el valor en cuentas (la unidad de medida del espectrómetro concreto) del pico ha sido considerado como una medida fiable de la potencia óptica medida por el LED [SRS08].

Todos los LEDs han sido caracterizados con esta técnica en su estado inicial a diferentes niveles de corriente, aunque la referencia son 0.6 A, y en diferentes estados intermedios a una corriente de 0.6 A, dejando que la tensión de la fuente se adapte a la curva del LED. El resultado es que se observa un comportamiento similar para la posición del pico y el FWHM como puede observarse en la figura Figura 6-27.

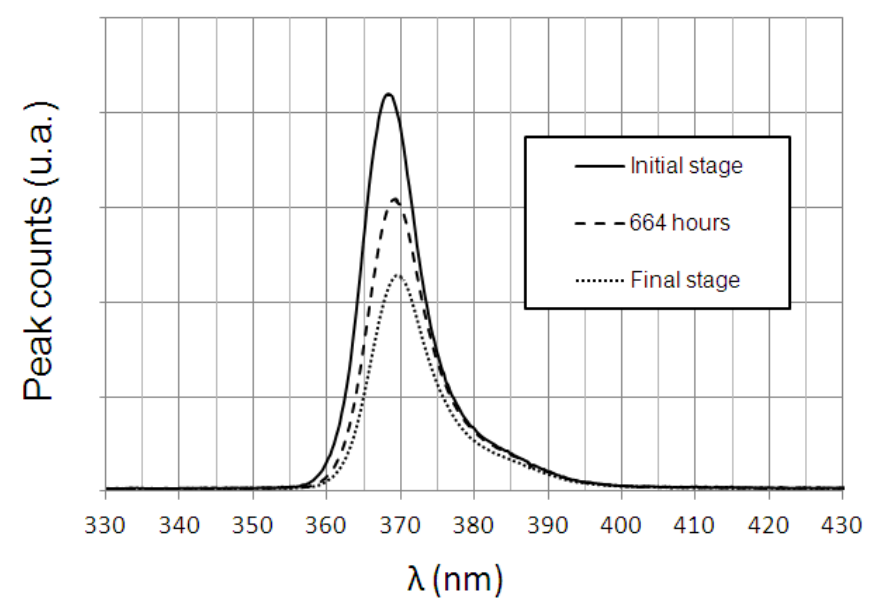

Figura 6-27: Espectro de un LED funcionando en modo cíclico en diferentes estados del ensayo de vida acelerado a $90^{\circ} \mathrm{C}$.

Las medidas realizadas posteriormente con el equipo óptico de medida en potencia (Figura 6-11), corroboran la hipótesis planteada y que es asumida en numerosos artículos por razones prácticas, debido a que el espectroscopio permite medir la evolución en potencia y espectro de la señal, mientras que el sistema de potencia óptica es caro y sólo permitiría obtener una evolución de 
potencia. Los resultados obtenidos midiendo dos LEDs sin degradar con nuestro espectrómetro, y posteriormente a la misma corriente con el equipo óptico son:

\begin{tabular}{|c|c|c|}
\hline & $\begin{array}{c}\text { Altura del pico } \\
\text { (cuentas) }\end{array}$ & $\begin{array}{c}\text { Potencia óptica } \\
\left(\mathrm{mW} / \mathrm{cm}^{2}\right)\end{array}$ \\
\hline LED tipo A & 17661 & 9,11 \\
\hline LEd tipo B & 20030 & 10,40 \\
\hline
\end{tabular}

Tabla XIV Relación entre medida de cuentas del espectrómetro y potencia óptica del LED a $8 \mathrm{~cm}$ de distancia.

La potencia óptica se ha medido a $8 \mathrm{~cm}$ del LED, la distancia de trabajo real planteada en la estación de medida, mientras dicha potencia sirve como referencia para conocer la luz con la que se han realizado las fluorescencia y todos los experimentos ópticos de reconocimiento de hidrocarburos de los ensayos, la medida de cuentas es totalmente relativa, con otro espectrómetro (otro CCD) u otra fibra óptica o sistema de captación de luz con otra distancia al LED, las cuentas serían proporcionales, pero con valores distintos.

Para evaluar la evolución durante los tres ensayos acelerados de las características eléctricas de los LEDs, se han realizado periódicamente las medidas de la curva I-V fuera de la cámara a $\mathrm{Ta}=25 \pm 0,5{ }^{\circ} \mathrm{C}$ con un límite de corriente de 1 A (Figura 6-12), y la captura de la lectura espectrométrica en dichas condiciones (Figura 6-13 y Figura 6-27), considerando como ya se ha comentado, el número de cuentas del pico proporcional a la potencia óptica emitida, y por tanto el valor inicial como la potencia óptica de referencia para cada LED. Además se ha realizado un análisis óptico del encapsulado mediante microscopio óptico.

Dos resultados fundamentales y evidentes de los ensayos han sido:

- Los LEDs introducidos sin alimentar en la cámara de $90{ }^{\circ} \mathrm{C}$, no sufrieron desde el punto de vista exterior la degradación de la silicona bajo la lente (Figura 6-14 y Figura 6-15). Además, las medidas de la curva I-V se mantuvieron estables, y la degradación óptica evidenciada mediante la espectroscopia fue casi inapreciable, por lo que la conclusión, es que las degradaciones y otros defectos observados en el resto de LEDs sometidos a ensayo han sido debidos a la combinación de corriente y temperatura. 
- Todos los fallos observados en ambos tipos de LEDs han sido debido a degradación de potencia óptica emitida, generando una potencia luminosa por debajo del $70 \%$ de la inicial, no se produjeron fallos catastróficos.

Los resultados que se presenta a presentar son particulares en cada cámara de dos tipos de LEDs A y B, y dos condiciones de trabajo continua y cíclica 30s ON\&30s OFF. Una vez analizados los resultados cualitativos y cuantitativos, se puede apreciar como es lógico que los LEDs sometidos a menor temperatura de ensayo $60{ }^{\circ} \mathrm{C}$ (temperatura ambiente en la estufa) tienen degradaciones con pendientes menos fuertes y mayor progresividad, por lo que son el mejor punto de partida para diferenciar entre los resultados de ambos tipos de LEDs. Pero hay que destacar que las diferencias cuantitativas y cualitativas importantes a nivel de duración del LED se dan entre los dos modos de trabajo, no entre los dos tipos de LEDs, no así a nivel de análisis de mecanismo de fallo donde si existen particularidades entre los tipos de LEDs A y B. Por tanto, en esta parte de representación de degradación de potencia luminosa, se representa para cada parámetro caracterizado primero los LEDs tipo A y luego los B.

En las figuras (Figura 6-28 y Figura 6-29) se puede observar la evolución de la potencia óptica relativa (respecto al valor inicial de cada LED) de los 4 LEDs en la cámara de $60^{\circ} \mathrm{C}$, tanto para los LEDs tipo A como para los B. En esta cámara la temperatura ambiente es sólo $35^{\circ} \mathrm{C}$ mayor que la temperatura ambiente.

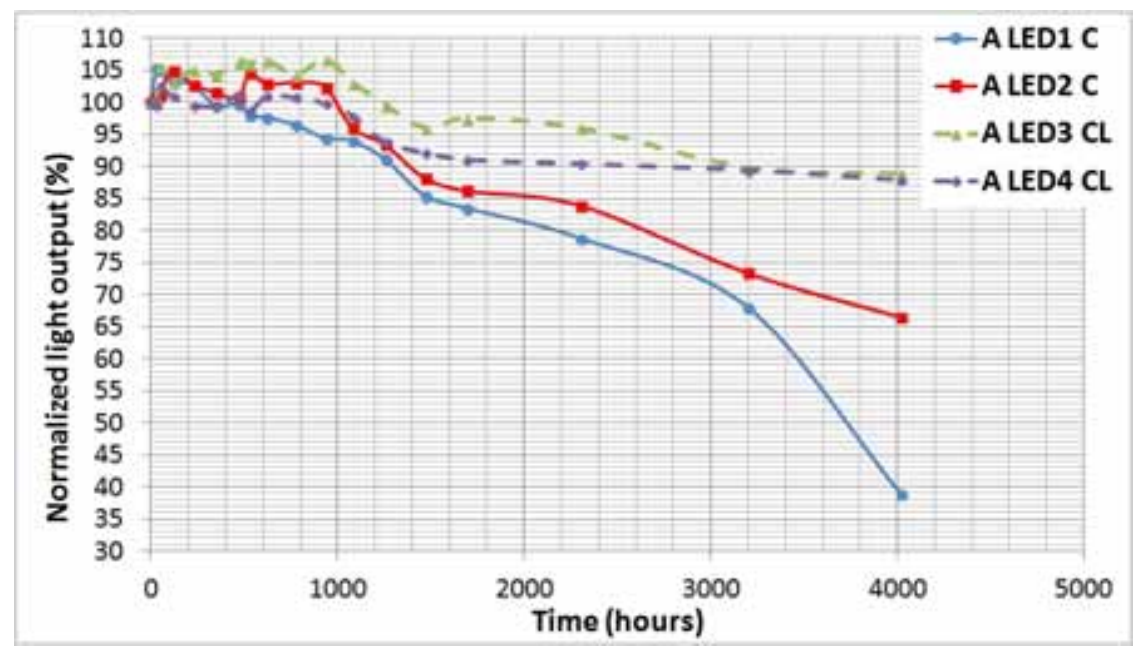

Figura 6-28: Evolución de la potencia óptica relativa de los LEDs tipo A sometidos a ensayo de vida acelerada a $60^{\circ} \mathrm{C}$. La letra final de la caja de títulos es $\mathrm{C}$ para la condición de trabajo continuo y CL para la condición de trabajo cíclico. 


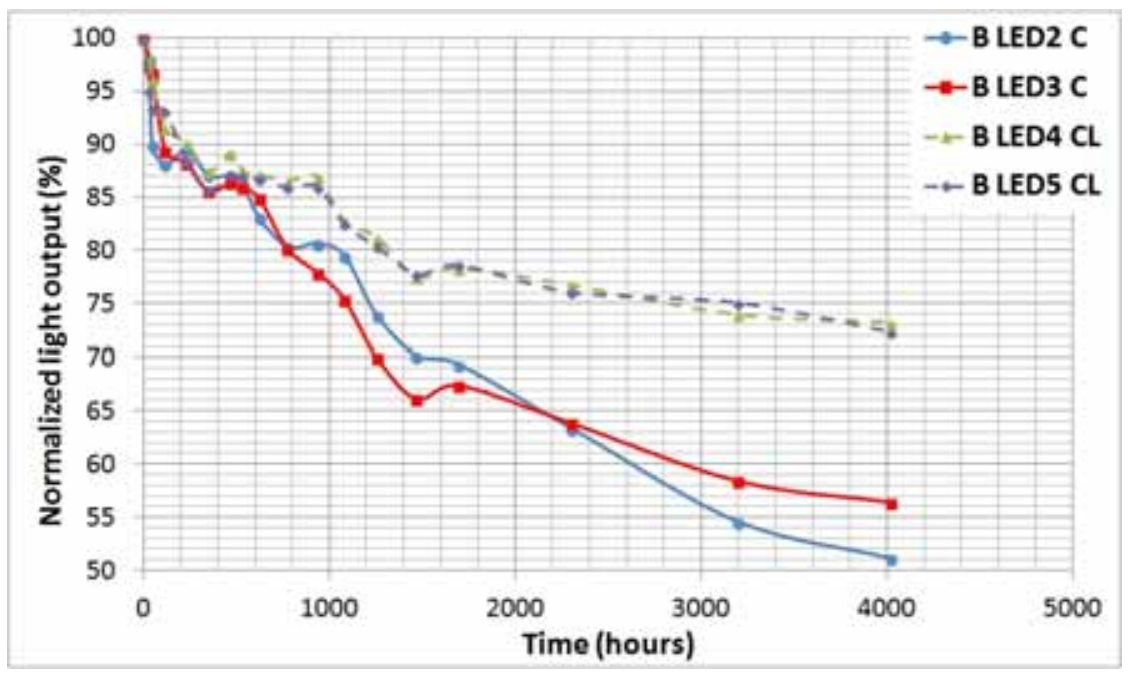

Figura 6-29: Evolución de la potencia óptica relativa de los LEDs tipo B sometidos a ensayo de vida acelerada a $60^{\circ} \mathrm{C}$. La letra final de la caja de títulos es $\mathrm{C}$ para la condición de trabajo continuo y CL para la condición de trabajo cíclico.

Como se puede observar la degradación de los LEDs una vez avanzado el ensayo es en condiciones de trabajo cíclicas (en línea discontinua) menor que la de los LEDs en funcionamiento continuo, también se observa que los LEDs tipo A tienen en esta condición más degradación que los tipo B. Esta situación se repite a todas las temperaturas de ensayo y tipos de LEDs. Más importante que esto es destacar que la pendiente de las degradaciones en ambos casos son muy diferentes, por lo que el corte con el límite de fallo por degradación ya se ha producido en todos los casos para funcionamiento continuo y sólo en algunos casos para funcionamiento cíclico, y si se prolongase la degradación del último periodo de ensayo en los LEDs cíclicos se obtendrían periodos de funcionamiento hasta el fallo varias veces mayor que en los LEDs en funcionamiento continuo.

Otra característica importante que se observa es que en los LEDs tipo A se produce una mejora de la potencia óptica al comienzo del ensayo, mientras que en los LEDs tipo B dicha mejora inicial no se produce, esta diferencia puede ser debida a la diferente tecnología de cada tipo de LEDs, aunque no se pudo conseguir que los fabricantes nos proporcionasen información sobre ellas. El comportamiento del tipo A con una mejora inicial ha sido explicada en varios trabajos de ensayos de vida acelerada sobre LEDs [VNNB10] [NVN09], y es debida a que el calentamiento inicial del LED produce una reordenación del cristal semiconductor que reduce el número de defectos, lo que produce una mejora de la eficiencia lumínica, tras este proceso inicial el LED sigue con un envejecimiento normal en semiconductores de potencia, observándose una degradación de sus 
características eléctricas y ópticas a menor o mayor plazo temporal. En los LEDs tipo B, la degradación se produce desde el instante inicial, es una respuesta que ha sido observada en ensayos de LEDs ultravioletas de $300 \mathrm{~nm}$ [MK09].

Comparando ambas evoluciones se puede observar que mientras que el LED tipo A tiene una evolución poco progresiva, con caídas fuertes de potencia óptica en varios instantes de la vida de cada LED, en los LEDs tipo B la degradación es más progresiva, aunque se puede apreciar en algún caso una caída brusca de la potencia entre dos medidas. Esta evolución será explicada en el análisis de fallos.

En las siguientes figuras se presenta la evolución media de la potencia óptica de salida (para los dos tipos de LEDs) de cada uno de los ensayos y condiciones de trabajo.

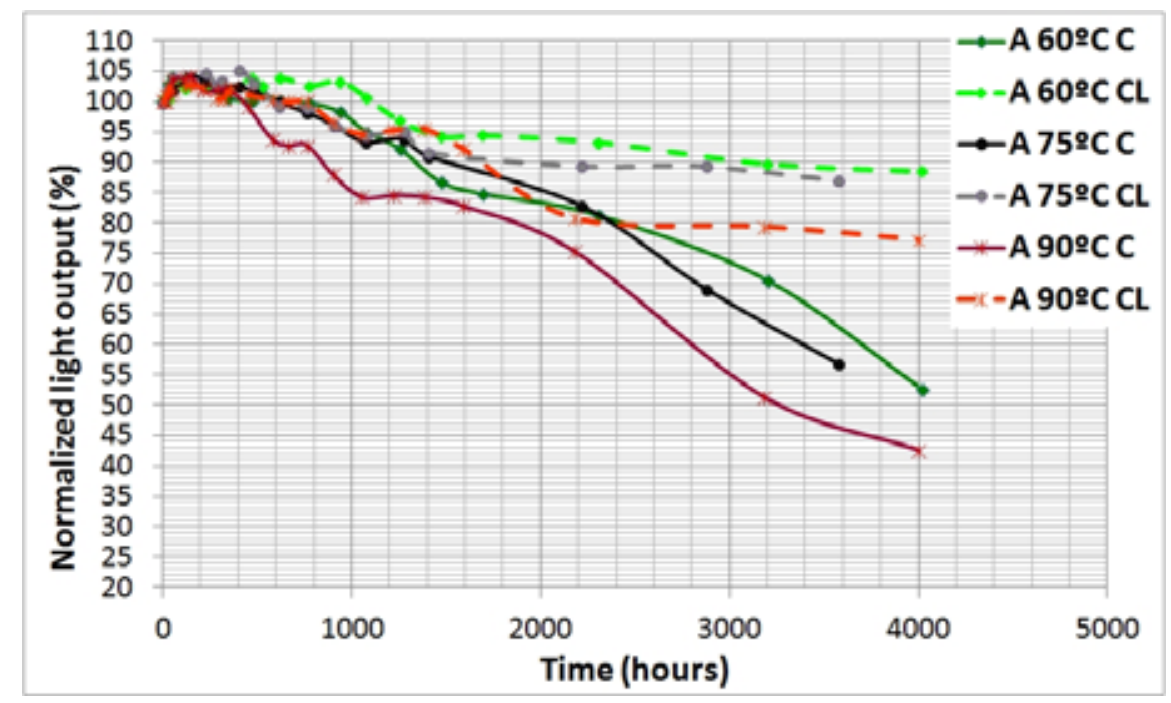

Figura 6-30: Evolución de la potencia óptica relativa media de los LEDs tipo A sometidos a ensayos de vida acelerada. La letra final de la caja de títulos es $\mathrm{C}$ para la condición de trabajo continuo y CL para la condición de trabajo cíclico. 


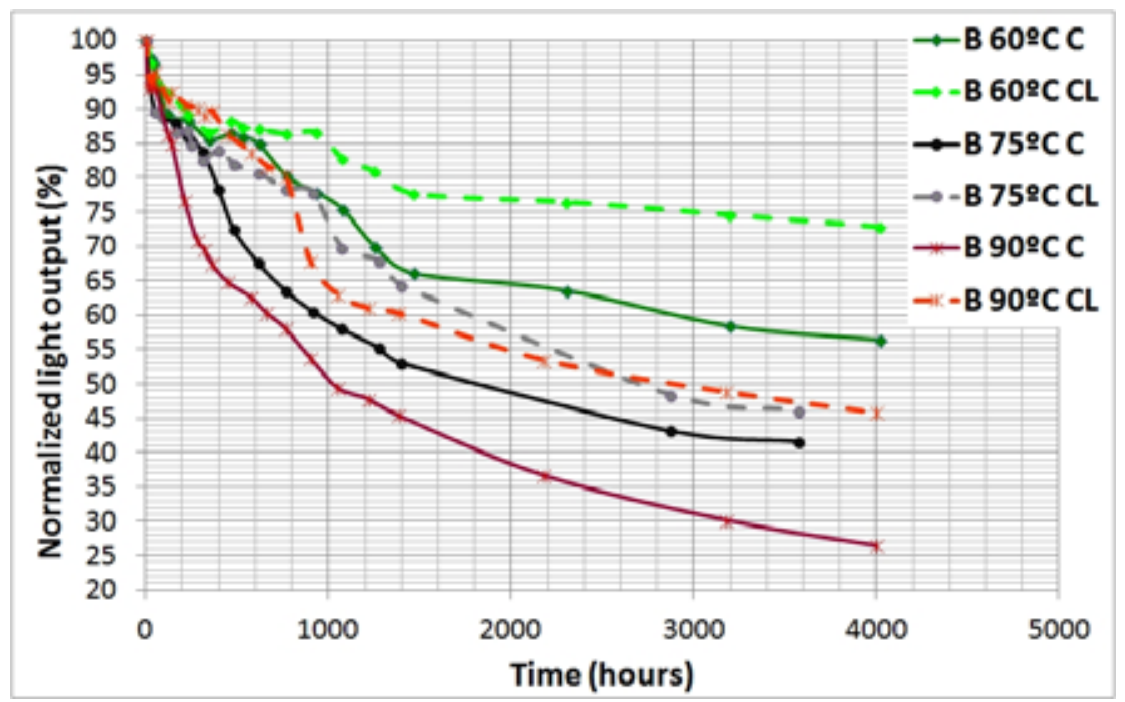

Figura 6-31: Evolución de la potencia óptica relativa media de los LEDs tipo B sometidos a ensayos de vida acelerada.

Como se puede observar en las figuras Figura 6-30 y Figura 6-31, existen una serie de conclusiones que se pueden generalizar para los dos tipos de LEDs, en el funcionamiento cíclico la degradación es mucho menor que el funcionamiento continuo, también se aprecia que la pendiente que define la futura degradación es más pronunciada en funcionamiento continuo que en cíclico. Además como es coherente según el modelo de Arrhenius en temperatura para los ensayos acelerados, la degradación es mayor a mayor temperatura, lo que implica a la temperatura de trabajo $25{ }^{\circ} \mathrm{C}$ los resultados de vida extrapolada serán mejores que los que observamos aquí, a alta temperatura.

Si se comparan los periodos de vida medio de cada condición del ensayo acelerado, se observa que en los LEDs tipo A, que los periodos de vida hasta el $70 \%$ de degradación son similares a cada temperatura, lo que quiere decir que la temperatura no influye mucho en los fallos, por lo que reducir la temperatura no supondrá una mejora en un factor grande. Mientas que en los LEDs tipo B, aunque los fallos a alta temperatura son más rápidos que en el tipo A, la distancia temporal respecto a los fallos a baja temperatura es mucho mayor, es decir, la diferencia de comportamiento al decrementar la temperatura es relevante, por tanto cuando se baje a la temperatura nominal de $25^{\circ} \mathrm{C}$, se pondrá de manifiesto un comportamiento sustancialmente mejor que a $60^{\circ} \mathrm{C}$. 


\subsection{Evaluación de parámetros de fiabilidad a $25^{\circ} \mathrm{C}$ : esperanza de vida (MTTF)}

Para analizar le factor de aceleración entre los resultados a cada una de las temperaturas, ha sido necesario cuantificar el instante de fallo de cada LED y cada condición de trabajo. En la mayoría de los casos de trabajo continuo los LEDs han fallo dentro del periodo de ensayo, y para estimar el instante de fallo "exacto" se ha interpolado linealmente entre el instante anterior a $70 \%$ de degradación y el posterior. En algunos casos de ensayo cíclico el LED no ha fallado durante el ensayo, por lo que para estimar el instante de fallo ha sido necesario extrapolar la evolución de degradación durante la última parte del ensayo hasta que llegase a una potencia óptica de salida del $70 \%$, en estos pocos casos, se han tomado los tres últimos puntos de la evolución de la vida caracterizada y se ha extrapolado con una línea recta la estimación del instante de fallo (Tabla XV y Tabla XVI).

\begin{tabular}{|c|c|c|}
\hline LEDS TIPO A & $\begin{array}{c}\text { Degradación del } \\
70 \% \text { (horas) }\end{array}$ & $\begin{array}{c}\text { Degradación del 70\% } \\
\text { (horas) }\end{array}$ \\
\hline $\begin{array}{c}\text { Condición de } \\
\text { trabajo }\end{array}$ & CONTINUO & $\begin{array}{c}\text { CíCLICO } \\
\text { 30s ON\&30s OFF }\end{array}$ \\
\hline LED 60 & \\
\hline LED $60^{\circ}$ & 2868 & 8662 \\
\hline LED 75 & 3602 & 16012 \\
\hline LED 75 & 2774 & 5702 \\
\hline LED 90 & 2927 & 14800 \\
\hline${\text { LED } 90^{\circ}}^{\circ}$ & 2482 & 6732 \\
\hline
\end{tabular}

Tabla XV Instante estimado de fallo a cada temperatura durante el ensayo para los LEDs ensayados de tipo A. 


\begin{tabular}{|c|c|c|}
\hline LEDS TIPO B & $\begin{array}{c}\text { Degradación del } \\
70 \% \text { (horas) }\end{array}$ & $\begin{array}{c}\text { Degradación del 70\% } \\
\text { (horas) }\end{array}$ \\
\hline $\begin{array}{c}\text { Condición de } \\
\text { trabajo }\end{array}$ & CONTINUO & 30s ON\&30s OFF \\
\hline LED $60^{\circ} \mathrm{C}$ & 1511 & 5606 \\
\hline LED $60^{\circ} \mathrm{C}$ & 1254 & 5093 \\
\hline LED $75^{\circ} \mathrm{C}$ & 500 & 1046 \\
\hline LED $75^{\circ} \mathrm{C}$ & 635 & 876 \\
\hline LED $90^{\circ} \mathrm{C}$ & 513 & \\
\hline LED $90^{\circ} \mathrm{C}$ & 270 & \\
\hline
\end{tabular}

Tabla XVI Instante estimado de fallo a cada temperatura durante el ensayo para los LEDs ensayados de tipo B.

En Tabla XV y Tabla XVI se incluyen los instantes de fallo estimado para cada LED, en cada línea de la tabla se encuentra el dato de un LED en continua y otro en cíclica. Como puede verse los resultados son coherentes con lo antes indicado, los fallos son antes si el LED funciona en trabajo continuo respecto al cíclico a la misma temperatura, y falla más rápido cuanto mayor es la temperatura. Es destacable que los instantes de fallo en los LEDs tipo A son más dispersos que en los LEDs tipo B, estos últimos parecen más uniformes.

Una vez obtenidos los instantes estimados de fallo de todos los LEDs, se ha realizado un análisis de fiabilidad mediante la integración de dos metodologías:

- Las gráficas de Weibull para identificar los parámetros de vida de los LEDs durante cada uno de los ensayos, de los cuales el más importante es el valor de $\beta$ para identificar si la tasa de fallos es decreciente $(\beta<1)$, constante $(\beta=1)$ o creciente $(\beta>1)$.

- La aplicación del modelo de Arrhenius a cada tipo de LED en sus tres ensayos acelerados. 
Para evaluar los resultados con la integración de ambos métodos Arrhenius-Weibull [O'Con12] [Ne190], se ha empleado una familia de herramientas de análisis de fiabilidad de Reliasoft ${ }^{\circledR}$, las dos aplicaciones que se han empleado son Weibul+ (herramienta para evaluar los parámetros de Weibull de cualquier ensayo) y ALTA (Accelerated Life Test Analysis) una herramienta que integra los resultados obtenidos en Weibull con los modelos utilizados en ensayos acelerados, en nuestro caso se ha empleado Arrhenius-Weibull por ser un ensayo acelerado en temperatura, obteniendo un buen ajuste de los instantes de fallo de los ensayos con el modelo propuesto.

Si se comparan ambos LEDs se observa que los fallos del LED B son prematuros, sin embargo, desde el punto de vista del modelo térmico de Arrhenius es más importante que entre saltos de $15{ }^{\circ} \mathrm{C}$ (incremento entre temperaturas de ensayo), las separaciones en tiempo son mayores que lo que se observa en los LEDs de tipo A. Centrándonos en el funcionamiento cíclico, que a la postre será el más importante, el salto entre el fallo a $60^{\circ} \mathrm{C}$ y $90^{\circ} \mathrm{C}$ del LED B es de 6 veces (de 876 a aprox. 5300), mientras que en el LED A es de 2 veces ( de 6732 a aprox. 12337), esto implica que el salto entre el funcionamiento a $60^{\circ} \mathrm{C}$ y la temperatura nominal de trabajo $25^{\circ} \mathrm{C}$ será varias veces mayor en el LED B que en el tipo A. La evaluación del parámetro de Arrhenius Ea (Energia de Activación) indicará en qué orden de deceleración se retrasarán los fallos al extrapolar a la temperatura de trabajo de $25^{\circ} \mathrm{C}(298 \mathrm{~K})$.

Una vez introducidos los datos de instantes de fallo y condición de trabajo térmica la herramienta ALTA proporciona la $\mathrm{E}_{\mathrm{A}}$ estimada para cada ensayo, y la herramienta Weibull++ presenta dicha solución en una gráfica de Weibull. Estas herramientas además trasladan los fallos de cada uno de los ensayos, mediante la ecuación de Arrhenius calculada (Ec.6.14) a la gráfica de Weibull a $25^{\circ} \mathrm{C}(298 \mathrm{~K})$ de modo que se puede apreciar el ajuste entre la predicción: las líneas rectas de la Figura 6-32 y los valores de sus parámetros de la Tabla XVII y finalmente los fallos a cada temperatura (Tabla XV). 6 LEDs en condiciones de trabajo continuo (C) a la izquierda de la gráfica y 5 LEDs en condiciones de trabajo cíclico (CL) en el lado derecho.

Antes de presentar los resultados, es necesario recordar que la función de fiabilidad con la ecuación de Weibull y sus parámetros vienen definidos por la (Ec.6.8. Donde $\eta$ es el parámetro de escala, y se corresponde con $\mathrm{F}(\mathrm{t}=\eta)=1-\mathrm{e}^{-1}=0.63212$ ((Ec.6.8) (cuya interpretación es que la probabilidad de fallo hasta el instante $t=\eta$ es del $63,212 \%$ ). $\beta$ es el parámetro de forma, que viene definido por la pendiente de la recta: para $\beta>1$ la tasa de fallos es creciente, siendo esto observable típicamente en dispositivos semiconductores con elevado estrés. El tiempo medio entre fallos o esperanza matemática de la vida se obtiene a través de la (Ec.6.10. 


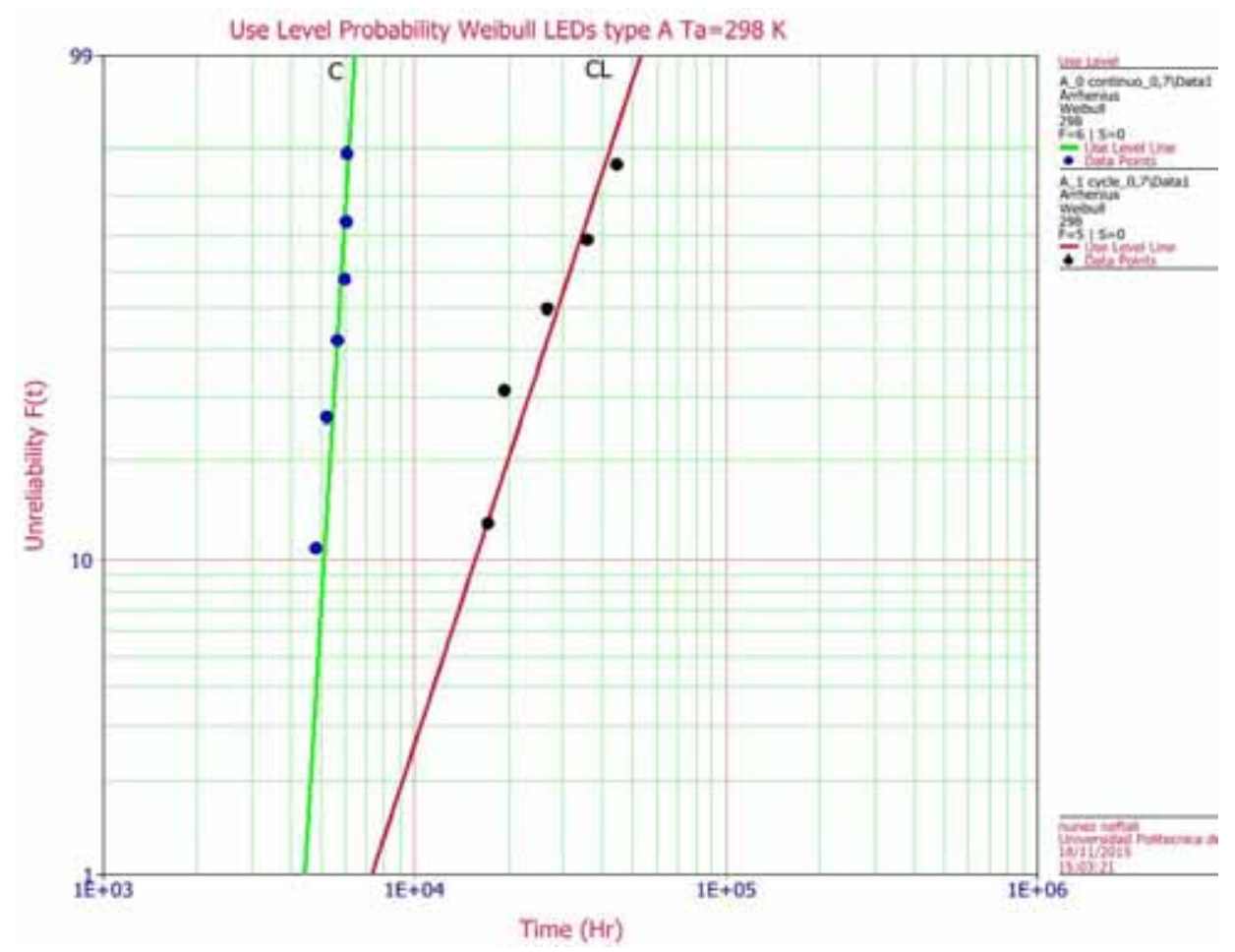

Figura 6-32: Gráfica de Weibull $\mathrm{F}(\mathrm{t})$ a $25^{\circ} \mathrm{C}$, probabilidad de fallo en función del tiempo de LEDs A. A la izquierda modo de trabajo continuo y a la derecha modo de trabajo cíclico. Los puntos son los instantes de fallo en cada temperatura de ensayo extrapolado mediante Arrhenius. (C significa funcionamiento continuo y CL funcionamiento cíclico).

Los resultados obtenidos para los parámetros de Weibull de la función $\mathrm{F}(\mathrm{t})$ a temperatura nominal de $25^{\circ} \mathrm{C}$, se reflejan en la Tabla XVII.

$F(t)=1-e^{-\left(\frac{t}{\eta}\right)^{\beta}} ;$ siendo $R(t)=e^{-\left(\frac{t}{\eta}\right)^{\beta}}$ 


\begin{tabular}{|c|c|c|}
\hline LEDs TIPO A & $\begin{array}{c}\text { Degradación del } \\
70 \% \text { (horas) }\end{array}$ & $\begin{array}{c}\text { Degradación del 70\% } \\
\text { (horas) }\end{array}$ \\
\hline $\begin{array}{c}\text { Condición de trabajo } \\
\text { LEDs tipo A }\end{array}$ & CONTINUO & CICLICO \\
\hline$\beta$ & 16,6 & 3,1 \\
\hline$\eta$ (horas) & 5848 & 32391 \\
\hline MTTF (horas) & 5664 & 28960 \\
\hline Ea & 0,13 & 0,20 \\
\hline
\end{tabular}

Tabla XVII Parámetros de la función defiabilidad F(t) para LEDs tipo A a temperatura ambiente de $25^{\circ} \mathrm{C}(298 \mathrm{k})$.

Lo primero que se observa en la Figura 6-32 para LEDs tipo A es que el ajuste de los puntos de fallo de cada ensayo a la función de vida extrapolada es bastante bueno, y que la vida en trabajo continuo a $25^{\circ} \mathrm{C}$, a la izquierda, es bastante menor que la vida con modo de trabajo cíclico, a la derecha.

Como se puede observar el MTTF (Mean Time to Failure) o esperanza media de vida para funcionamiento continuo del LED tipo A es excesivamente corto, $5664 \mathrm{~h}$, menor a un año de encendido ininterrumpido. Otro factor que se observa es que el parámetro $\beta$ es muy elevado (claramente el dispositivo tiene los fallos en periodo de desgaste o envejecimiento), desde el punto de vista gráfico aparece como una línea vertical lo que supone que los fallos se producen de forma consecutiva en muy corto periodo de tiempo, como puede apreciarse en la Figura 6-32. Este acumulación de fallos en la población de LEDs en el poco periodo de tiempo, se puede apreciar muy bien en la Figura 6-33 que refleja para ambos tipos de modo de trabajo, la línea que une el parámetro $\eta$ (un poco mayor que el MTTF) para cada temperatura de trabajo, y la función densidad de probabilidad de fallos $\mathrm{f}(\mathrm{t})$ en vertical y sombreada para cada temperatura y tipo de trabajo. En el eje vertical izquierdo $298 \mathrm{~K}\left(25^{\circ} \mathrm{C}\right)$, se puede ver prolongado la línea de los tres ensayos, y para cada tipo de funcionamiento, el valor de $\eta$, que es un poco mayor que el MTTF. En la parte inferior de la figura se encuentran los ensayos de modo de trabajo continuo ( C ) y en la parte superior el modo de trabajo cíclico $(\mathrm{CL})$. 
Para el modo de vida cíclico el MTTF es mucho mayor (28960 h) unos tres años y medio de funcionamiento ininterrumpido antes de llegar a una reducción de su potencia luminosa del $70 \%$. Aunque este resultado podría parecer insuficiente comparado con las vidas que ofrecen los LEDs blancos comerciales, hay que considerar que algunas de las lámparas empleadas en fluorescencia tienen esperanzas de vida de 1000 horas, y otras de unas 10000 horas, en cualquier caso bastante inferirores a lo que ofrece el LED tipo A, por lo que podemos considerar este resultado muy positivo.

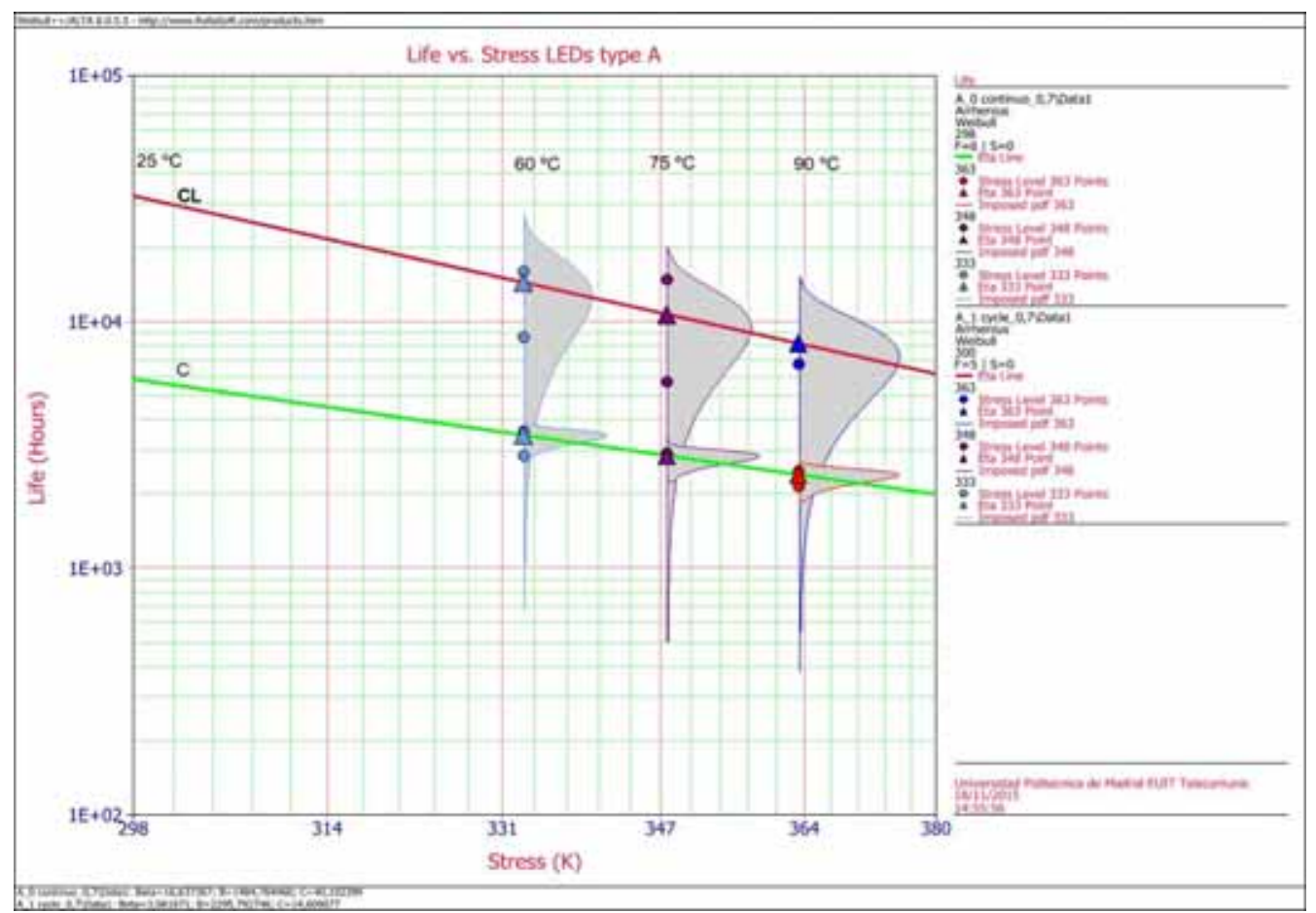

Figura 6-33: Función de vida respecto al estrés en temperatura, para LEDs tipo A

En las siguientes figuras y tabla se calcula la función defiabilidad para el LED tipo B, considerando los tres ensayos y su extrapolación a condiciones de trabajo nominales, temperatura ambiente $298 \mathrm{~K}\left(25^{\circ} \mathrm{C}\right)$ (C significa funconamiento continuo y CL funcionamiento cíclico). 


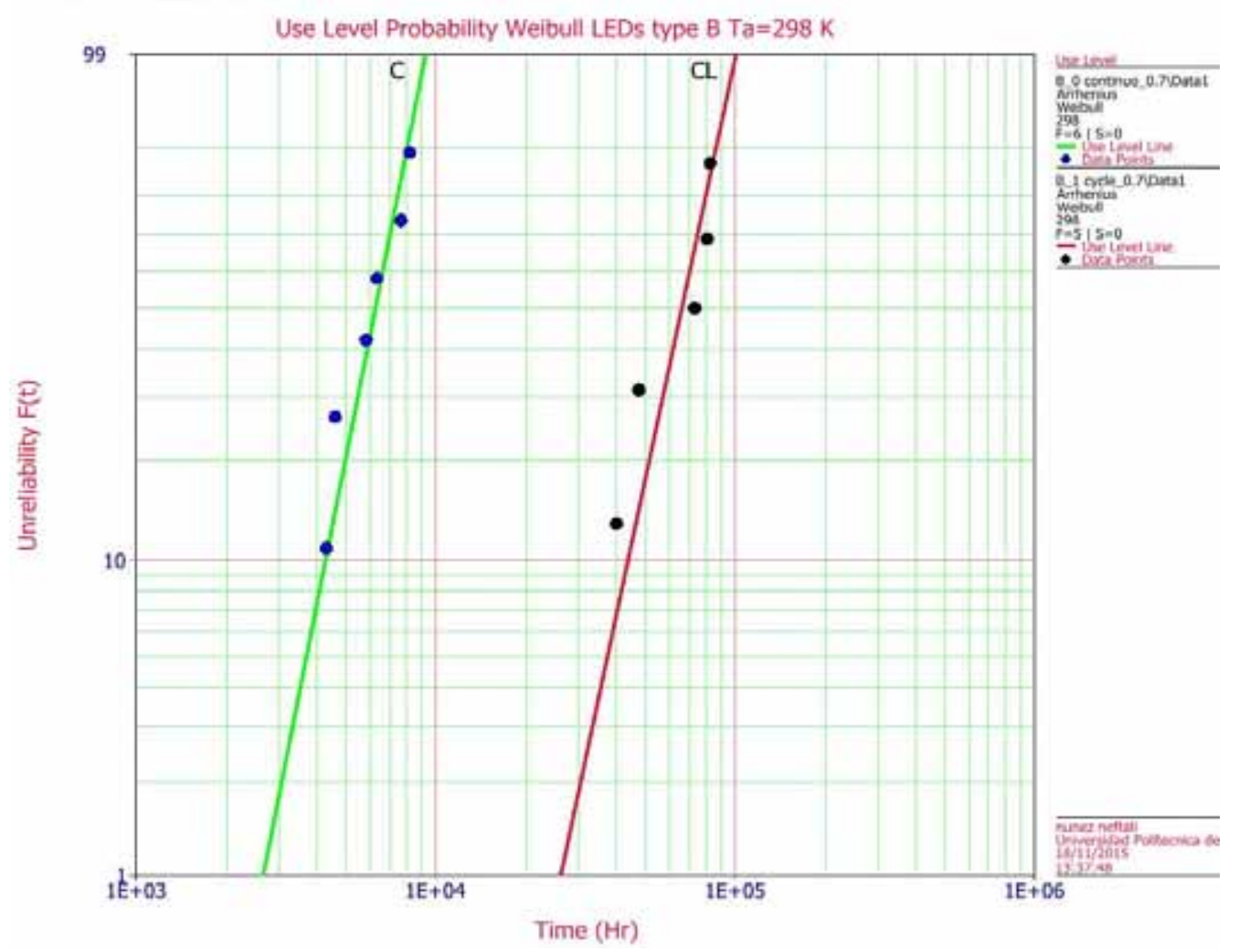

Figura 6-34: Gráfica de Weibull $\mathrm{F}(\mathrm{t})$ a $25^{\circ} \mathrm{C}$, probabilidad de fallo en función del tiempo de LEDs B. A la izquierda modo de trabajo continuo y a la derecha modo de trabajo cíclico. Los puntos son los instantes de fallo en cada temperatura de ensayo extrapolado mediante Arrhenius. (C significa funconamiento continuo y CL funcionamiento cíclico).

Los parámetros obtenidos para $\mathrm{Ta}=25^{\circ} \mathrm{C}$ de la función $\mathrm{F}(\mathrm{t})$ según Weibull se reflejan en la siguiente tabla.

\begin{tabular}{|l|c|c|}
\hline LEDs TIPO B & $\begin{array}{c}\text { Degradación del } \\
70 \% \text { (horas) }\end{array}$ & $\begin{array}{c}\text { Degradación del 70\% } \\
\text { (horas) }\end{array}$ \\
\hline $\begin{array}{l}\text { Condición de } \\
\text { trabajo LEDs tipo } \\
\text { A }\end{array}$ & CONTINUO & CICLIC \\
30s ON\&30s OFF \\
\hline$\beta$ & 4,9 & 4,54 \\
\hline$\eta$ (horas) & 6764 & 71807 \\
\hline MTTF (horas) & 6203 & 65568 \\
\hline Ea & 0,40 & 0,65 \\
\hline
\end{tabular}


Tabla XVIII Parámetros de la función defiabilidad $\mathrm{F}(\mathrm{t})$ para LEDs tipo $\mathrm{B}$ a temperatura ambiente de $25^{\circ} \mathrm{C}(298 \mathrm{k})$.

En los LEDs tipo B, Figura 6-34, el ajuste de los instantes de fallo es mejor que en los tipos A, lo cual es coherente con que los instantes de fallo del tipo A son menos homogéneos que los del tipo B. Los valores del factor de forma $\beta$ son similares para modo de trabajo continuo y cíclico, ambas líneas son paralelas, y la diferencia entre la vida esperada en continua y en funcionamiento cíclico es bastante mayor que en el caso A, eso se aprecia de forma más clara en los valores de los MTTF calculados (Tabla XVIII). La dispersión de los fallos de la población (gráfica de $\mathrm{f}(\mathrm{t})$ en vertical) en la Figura 6-35 es coherente con una $\beta$ de aproximadamente el mismo valor, la distribución de fallo de las poblaciones es similar, y se observa claramente que la vida en trabajo continuo es mucho más corta que en trabajo cíclico.

La Ea (Energía de Activación) del modelo de Arrhenius en temperatura, es mucho mayor en los LEDs tipo B que en los LEDs del tipo A, lo que implica un factor de aceleración respecto al mismo incremento de temperatura mucho mayor, ésta es la razón de que a pesar de tener a la menor temperatura $\left(60^{\circ} \mathrm{C}\right)$ fallos más prematuros que los LEDs tipo A, sin embargo tienen un MTTF estrapolado a $25^{\circ} \mathrm{C}$ mejor.

Como se puede observar el MTTF (Mean Time to Failure) o esperanza media de vida para funcionamiento continuo del LED tipo $\mathrm{B}$ es algo mejor que para el tipo A, pero también excesivamente corto, menor a un año de encendido ininterrumpido.

El valor de $\beta$ es de 4,54 por tanto se comporta como un dispositivo en periodo de vida de desgaste o envejecimiento, una vez que comienzan los fallos en la población, estos se acumulan en un corto periodo de tiempo. Como se verá en la siguiente figura la distribución de fallos de la población está más dispersa que en caso del LED tipo A en continua donde la $\beta$ es extraordinariamente alta con una dispersión de fallos muy estrecha. 


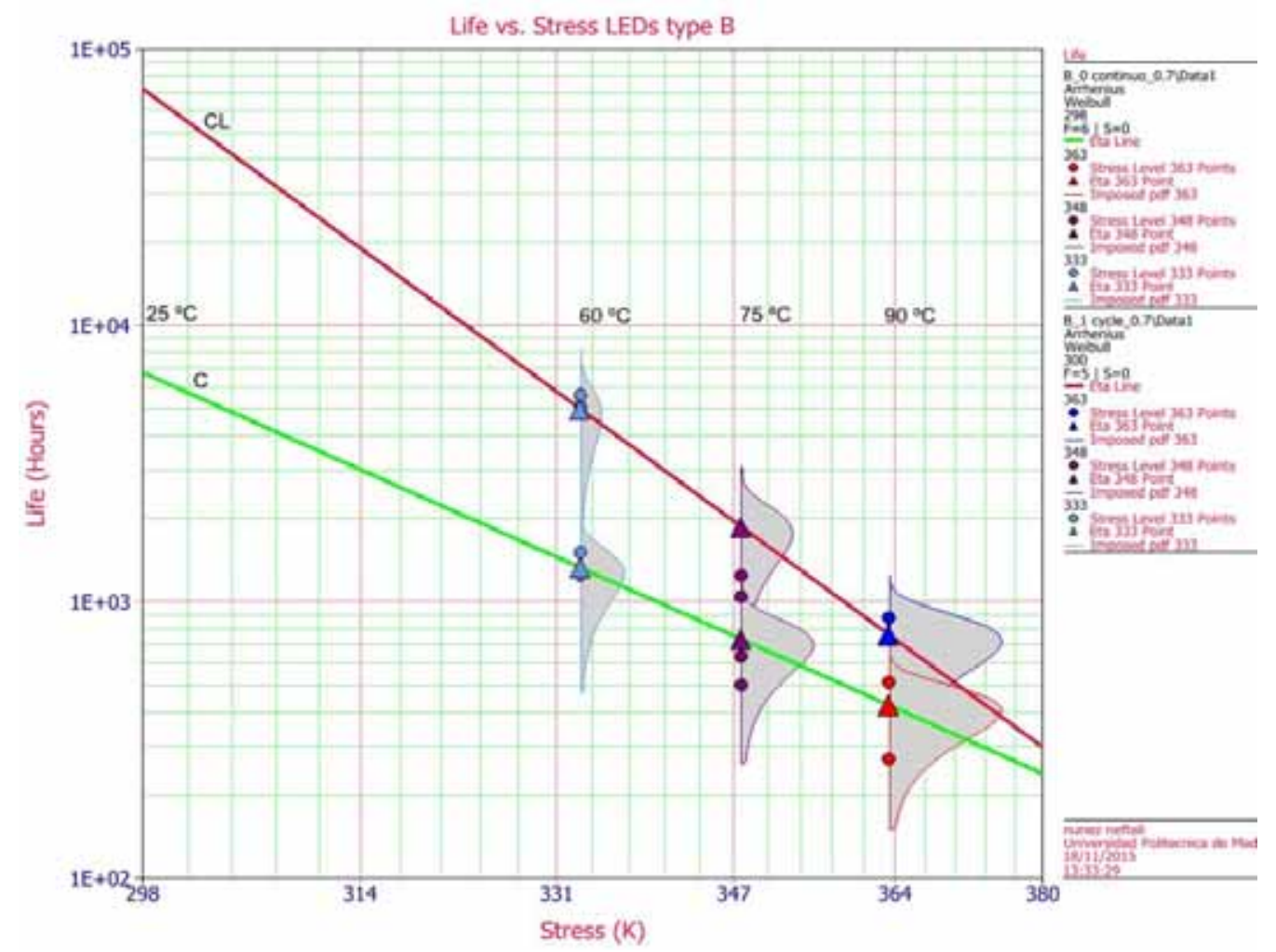

Figura 6-35: Función de vida respecto al estrés en temperatura, para LEDs tipo B. (C significa funcionamiento continuo y CL funcionamiento cíclico).

Para el modo de vida cíclico el MTTF de los LEDs tipo B es el doble (65558h) siete años y medio de funcionamiento que el que tienen los LEDs tipo A (28960), antes de llegar a una reducción de su potencia luminosa del $70 \%$. Estos resultados son buenos comparado con algunas de las lámparas empleadas en fluorescencia tienen esperanzas de vida de 1000 horas, y otras de unas 10000 horas. Hay que ser consciente de que el pequeño número de LEDs ensayado no puede ofrecer un valor exacto de la fiabilidad de estos tipos de LEDs, pero si un valor aproximado de la vida esperada, que como se aprecia es muy competitivo con las lámparas, y por otro lado también se ve que es mucho más rentable el modo de trabajo cíclico que el continuo.

En conclusión los resultados indican que la aplicación del LED ultravioleta en modo de trabajo cíclico 30s ON\&30s OFF para nuestro propósito es totalmente realista, especialmente en el caso de los LEDs tipo B. Incluso los LEDs tipo A que tienen la mitad de esperanza de vida y menor emisión óptica también serían una solución en el modo cíclico de trabaja, siempre que fuesen renovados cada dos o tres años de vida. 
Estas expectativas de vida mejorarían en condiciones de convección forzada, ya que se reduciría la temperatura en el LED en aproximadamente $7{ }^{\circ} \mathrm{C}$, lo que supondría que el MTTF aumentaría para el tipo de trabajo cíclico en un factor de aceleración, que se obtiene de la (Ec.6.14 aplicada para cada caso particular. En estos casos el MTTF se ha calculado para la temperatura ambiente $25^{\circ} \mathrm{C}$. S según la evaluación térmica se tendría la unión a unos $39,5^{\circ} \mathrm{C}(302,5 \mathrm{~K})$ en convección natural (los resultados obtenidos), y si se trabaja con el ventilador se reduce la temperatura a $32,5^{\circ} \mathrm{C}(295,5)$, por lo que esta información más la Ea de cada tipo de LED y su MTTF particular serían las entradas para la ecuación de Arrhenius. Obteneniendo los nuevos valores de MTTF (Mean Time to Failure) para convección forzada:

$$
\text { Para LEDs tipo A Ea=0.2;FA } \frac{28960}{\operatorname{MTTF}\left(T_{2}\right)}=\exp \left[\frac{0.2}{k}\left(\frac{1}{302,5}-\frac{1}{295,5}\right)\right]
$$

LEDs $\operatorname{A~MTTF}\left(T_{2}\right)=34732$ horas, equivalente a 4 años de vida.

$$
\text { Para LEDs tipo B Ea=0.65; FA }=\frac{65568}{M T T F\left(T_{2}\right)}=\exp \left[\frac{0.65}{k}\left(\frac{1}{302,5}-\frac{1}{295,5}\right)\right]
$$

LEDs B MTTF $\left(\mathrm{T}_{2}\right)=131808$ horas, equivalente a 15 años de vida.

Es necesario considerar que el fabricante del ventilador indica una vida esperada de 40.000 horas, por lo que el ventilador sería el primero en fallar en el caso de los LEDs tipo B, y pasaría a ser el eslabón débil del sistema.

Una vez obtenidos estos resultados el uso de un ventilador sería un opción a considerar ya que duplica la vida del LED B hasta el fallo, y durante la vida la degradación de potencia luminosa emitida es menor, aunque como coste tenemos la limitación del vida del ventilador, y que el sistema debería incluir filtros de polvo para evitar que el ventilador o el disipador pudieran perder sus características para disipar adecuadamente.

\subsection{Análisis del fallo}

Así como para evaluar la esperanza de vida del LED el parámetro fundamental era el modo de trabajo, en el análisis de fallos, se llega a la conclusión de que la división de comportamiento, es decir de mecanismos que contribuyen al fallo, depende del tipo de LED.

El objetivo del análisis de fallos es comprender la causa raíz del fallo para mejorar el diseño del LED y ampliar la vida esperada, y al no ser fabricantes de LEDs sólo se pretende informar a la 
comunidad científica de las evidencias que han sido encontradas sobre los fallos detectados, en este caso todos por degradación, y reflejar como se relacionan estas evidencias con la degradación del LED, identificando posibles mejoras en el diseño del LED o en el procedimiento de la medida de fluorescencia para alargar la vida del LED en las mejores condiciones posibles.

La información de la que se dispone con respecto a los LEDs afecta a los parámetros eléctricos y a algunos de los materiales del encapsulado, pero tal y como ya se ha mencionado, los fabricantes no han proporcionado información del tipo de semiconductor empleado ni de su material base, por tanto la degradación del semiconductor y su relación con la curva I-V es de muy difícil interpretación, sólo es posible basarnos en la bibliografía sobre diodos LEDs ultravioleta, que bien han evaluado la tecnología [Meneg08] o bien han realizado ensayos acelerados, que coinciden en indicar la complejidad de obtener buenos parámetros de fiabilidad con el material base típicamente empleado zafiro, y con el semiconductor para la unión p-n GaN, [KABR+13] de los LEDs.

Para evidenciar la degradación se realizó, como ya se ha comentado, una espectrometría periódica de cada LED, obteniendo la potencia luminosa relativa entre las cuentas (unidad arbitraria del espectrómetro) en el pico del espectro al instante inicial y la evolución a lo largo del ensayo.

Para observar la posible degradación del LED se emplearon dos métodos, por una parte una inspección microscopio óptico, que permite observar degradaciones del encapsulado a nivel "macroscópico", no necesariamente puede observarse una degradación de la pasivación del chip o delaminaciones, así como tampoco se puede identificar qué proporción de luz emitida por el LED llega al sensor, y si esta cambia debida a defectos no apreciables por el microscopio. El segundo método es eléctrico, la caracterización en directa de la curva I-V del LED, en cada uno de los periodos de control, y la caracterización en inversa al final de la vida, estos son unos métodos muy empleados, pero normalmente la bibliografía ofrece resultados cualitativos, pero no cuantitativos. La curva en inversa de cada LED al finalizar el ensayo, se comparará con la curva en inversa de un LED típico A o B, hay que tener en cuenta que la integración del zener en inversa, no permite quitarlo y reponerlo a su sitio, por lo que sólo se eliminó al final, y en uno de los LEDs dejado nuevo, se podría haber eliminado esta protección zener de los LEDs durante el ensayo, pero esto habría alterado el resultado, ya que el zener viene montado de fábrica.

Se parte con estas condiciones de contorno para la realización el análisis de la degradación del LED, pudiendo plantear hipótesis razonables respecto a los resultados, pero salvo que estos sean muy tangibles no se puede realizar afirmaciones categóricas sobre todos los factores que afectan a la degradación del LED, que pueden ser muchos y algunos de ellos a nivel interno del semiconductor [CDVP12] [Meneg08]. 
En ambos tipos de LEDs se observa una degradación del encapsulado del LED al ser sometido a alta temperatura y condiciones de trabajo nominales, esta degradación consiste fundamentalmente en la aparición de grietas en la silicona situada entre el chip y la lente de cristal (Figura 6-15), más tarde aparece una delaminación entre la silicona y la parte superior del chip, que en algunos fotos se ve concentrada o teniendo como origen la metalización superior del LED. Se asume que es silicona y no epoxi, debido a que es el material típico de LEDs ultravioleta, al ser el que mejor soporta la degradación producida por esta radiación de alta energía [LYLTS10], además desencapsulándo el LED se observa que parece silicona. Otro efecto secundario de esta degradación es que la disipación del LED hacia la parte superior se reduce, y la luz reflejada realimenta la temperatura del LED, lo que inducirá una pérdida de eficiencia y un ciclo continuo y acelerado de autocalentamiento-degradación.

Para simplificar el desarrollo de las hipótesis planteadas, se indicarán que los mecanismos que se han podido identificar, y que contribuyen al fallo son de dos tipos:

- Degradación del encapsulado. En concreto es visible la producida en la silicona situada entre el chip y la lente. En ambos LEDs se producen procesos similares; la generación paulatina de una o dos grietas que genralmente parten de los "wire bonding", estas grietas se ramifican y expanden en horizontal y vertical hasta llegar a la lente de cristal, y después la delaminación de la silicona respecto a la parte superior del LED. Este proceso es más visible en los LEDs tipo B que en los tipo A.

- Degradación de la curva I-V LED. Se observa que todos los LEDs A sufren una degradación de la curva I-V importante tanto en directa como en inversa. Mientras que la degradación en los LEDs tipo B observada es mínima, esto sugiere que el LED B tiene una estructura semiconductora más estable y fiable.

Estos mecanismos de fallo son más rápidos y más graves a mayor temperatura, también son más graves y rápidos para corriente continua que para corriente cíclica.

\subsubsection{Identificación de fallos por degradación del encapsulado}

Durante los ensayos no se han observado que el encapsulado torne el color hacia el amarillo, pero tras centenares de horas se observa en primer lugar un agrietamiento en la silicona y posteriormente una ramificación en las grietas junto con un aumento del tamaño. Además, la silicona se degrada sobre la superficie del chip. En la Figura 6-36 se observa un LED tipo A antes de 
agrietarse y al final del ensayo, y en la Figura 6-37 un LED tipo B antes de agrietarse y al final del ensayo. Es importante observar que las grietas comienzan en los "wire bonding", y que para este caso en el LED A la degradación no ha evolucionado excesivamente con el tiempo, mientras que en los LED B con grietas en forma de X originadas en línea con los dos "wire bonding”, la degradación si ha evolucionado de forma muy fuerte.

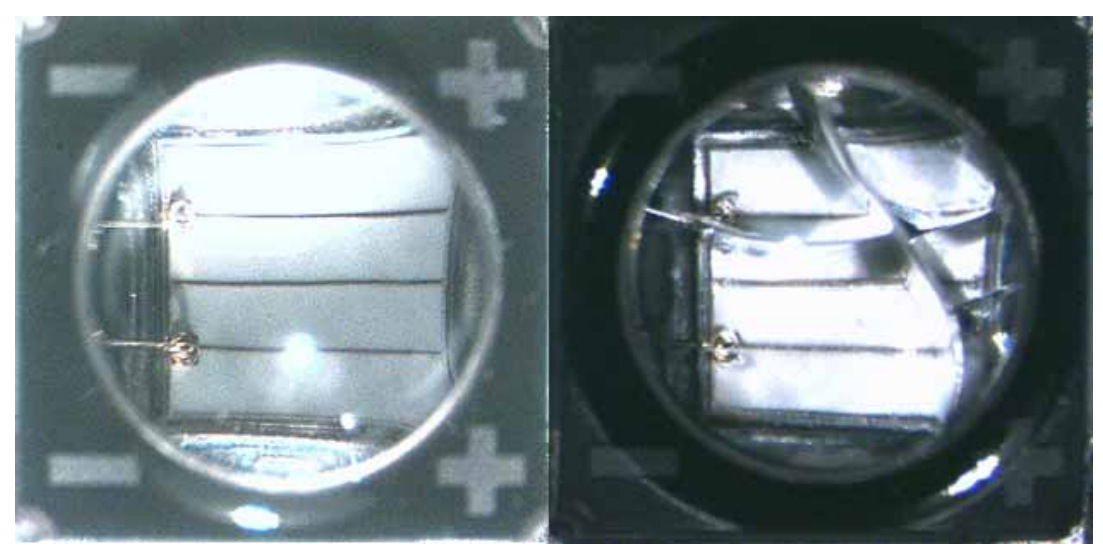

Figura 6-36: LED tipo A antes y al final del ensayo acelerado.

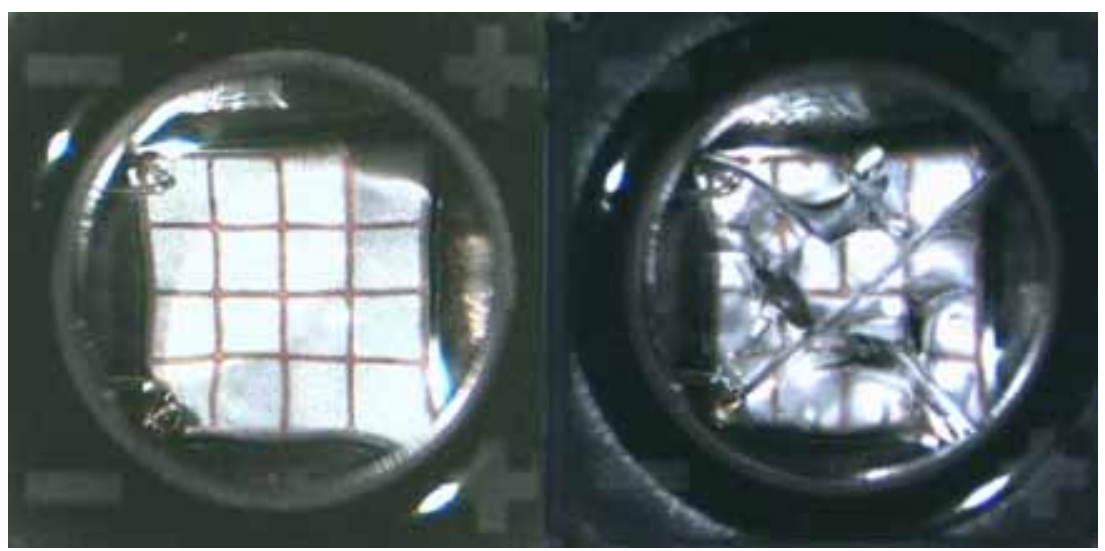

Figura 6-37: LED tipo B antes y al final del ensayo acelerado.

Para evaluar la influencia del agrietamiento en la degradación de potencia luminosa del LED, en la Figura 6-38 se observa la evolución de la potencia luminosa para los 4 LEDs tipo B en el ensayo de $60^{\circ} \mathrm{C}$, y el instante de medida en el que se detecta la grieta del LED, se puede observar que el LED 4 en funcionamiento cíclico no llega a sufrir la rotura de la silicona. Como se observa en la Figura 6-38 en cada comienzo de rotura hay un cambio de pendiente de degradación que en el caso de los LEDs en funcionamiento cíclico, ha supuesto que el LED 5 que tenía menor degradación supere al 4 al sufrir la rotura de la silicona. Un hecho que dificulta el análisis causa efecto, es que no 
todos los LEDs siguen la misma evolución una vez rota la silicona, en unos casos no se produce ramificación o es pequeña, y en otros, la mayoría, la degradación evoluciona hasta tener agrietada y delaminada gran parte de la silicona. Esta diferencia se debe a situaciones tras la grieta más o menos estables, desde el punto de vista dilatación contracción, se ha dado el caso en LEDs A de que aparece una grieta horizontal entre ambos wire bonding, y ésta se queda estabilizada durante todo el ensayo.

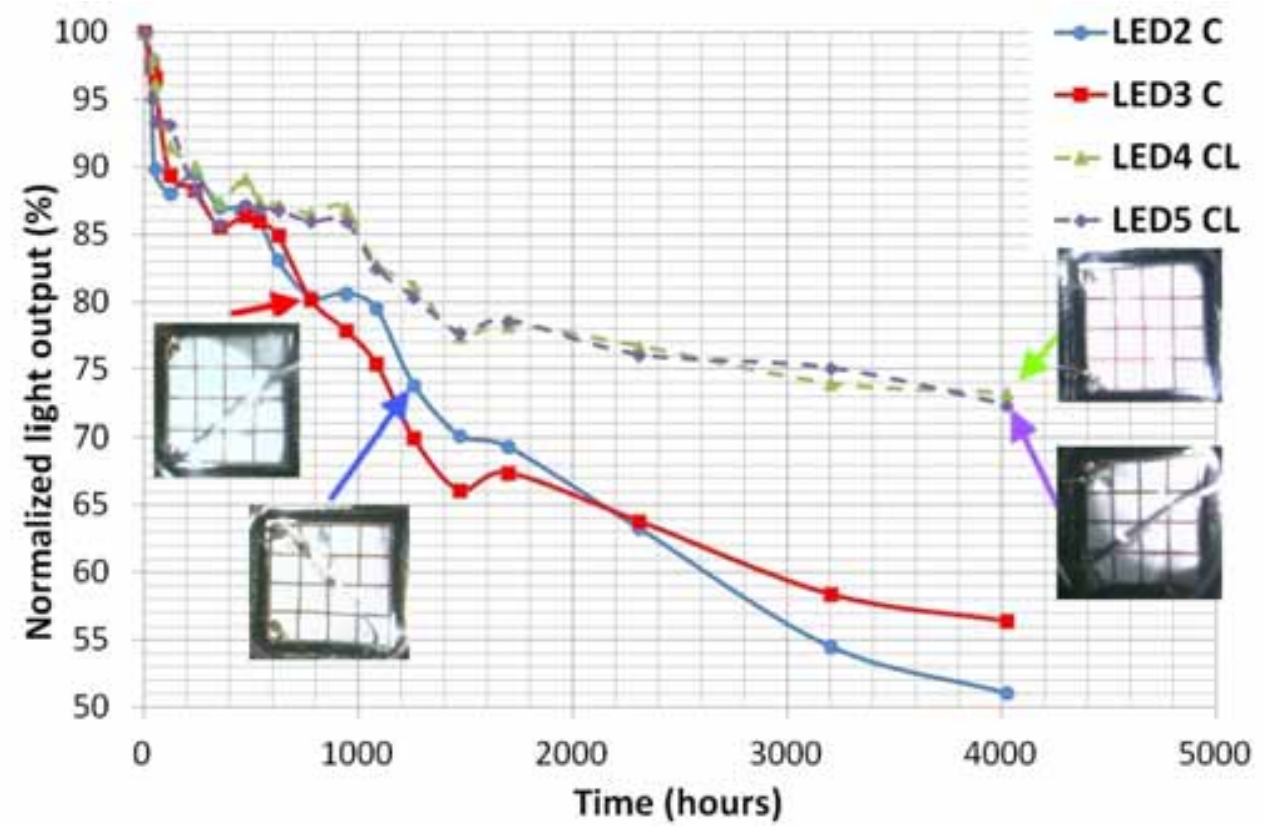

Figura 6-38: Potencia de salida normalizada para los LEDs tipo B a $60^{\circ} \mathrm{C}$, y el "instante" de detección de la grieta en la silicona. (C significa funcionamiento continuo y CL funcionamiento cíclico).

En la Figura 6-39 se ha representado el instante en que se detecta la primera grieta de la silicona en cada uno de los 11 LEDs sometidos a ensayo de vida acelerada. Para alta temperatura y la misma condición de trabajo, las grietas ocurren antes. Además los LEDs que funcionan en condición de trabajo continua para la misma temperatura tienen las grietas antes que los LEDs trabajando en condición cíclica. Sólo LEDs trabajando en las condiciones más benignas, menos aceleradas, acaban el ensayo sin grietas, en concreto dos LEDs del tipo A y el LED 4 antes mencionado del tipo B, todos ellos en modo de trabajo cíclico a $60{ }^{\circ} \mathrm{C}$. Si se comparan los instantes de detección de las grietas, éstas aparecen antes en los LEDs tipo B que en los LEDs tipo A. A partir de ese instante, se produce un agrietamiento en ramificación y una delaminación más importante en los LEDs B. La hipótesis que se plantea y que se desarrollará en el análisis de fallos, es que la 
delaminación más importante en los LEDs tipo B es debida a que en ellos la metalización tiene forma de cuadrícula y es más gruesa, mientras que en los tipo A son líneas horizontales más finas.

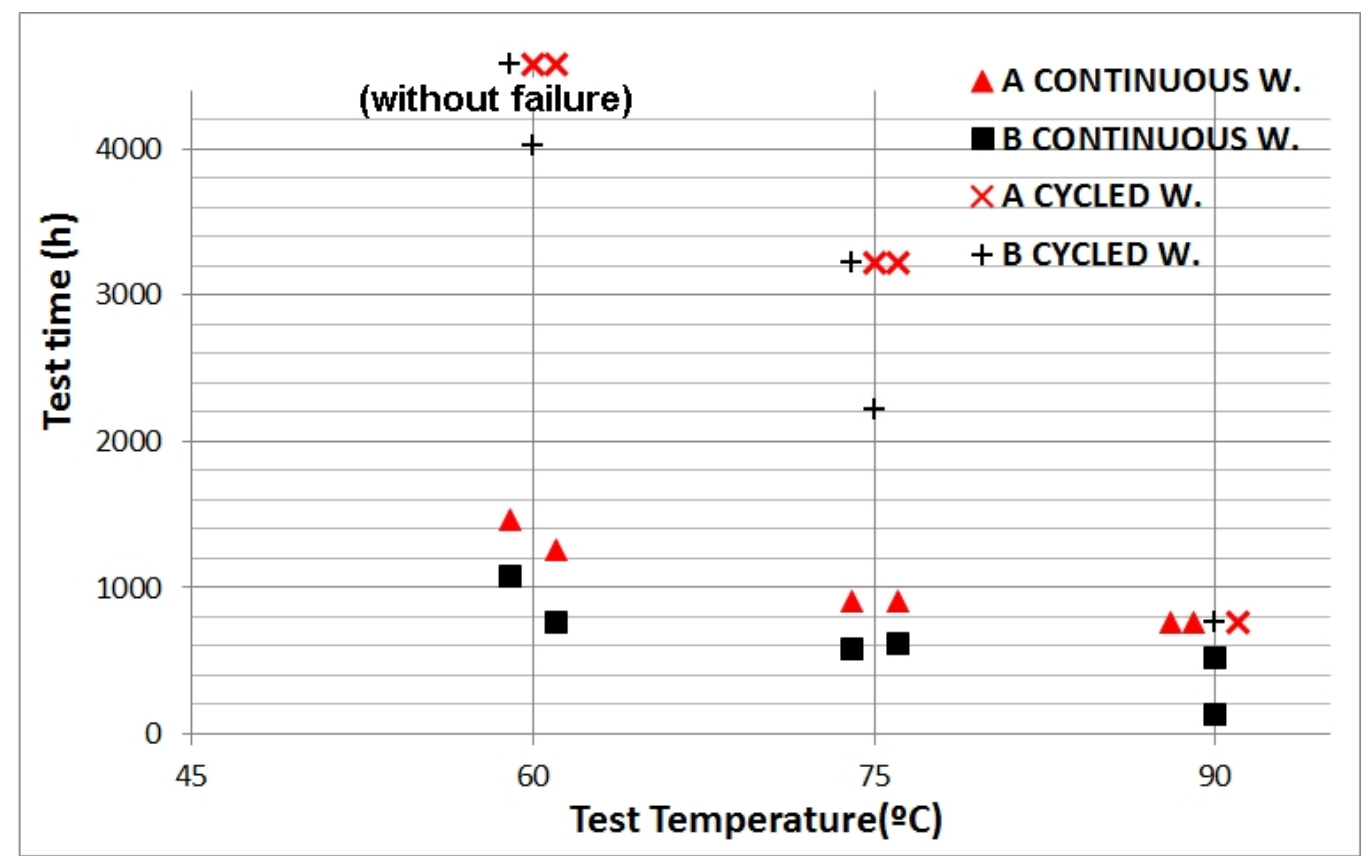

Figura 6-39: Detección del agrietamiento de la silicona para cada temperatura de ensayo, ambas condiciones de trabajo, y ambos tipos de LED.

Como se puede concluir de los resultados anteriores, existe una relación directa entre el agrietamiento de la silicona del encapsulado, y un importante incremento en la degradación de la potencia luminosa emitida.

El segundo mecanismo de fallo que contribuye a la degradación de los LEDs debe ser la degradación del semiconductor, esto se puede ver reflejado en la evolución de la curva I-V de los LEDs. En el caso de los tipos A esto es muy claro, hay más degradación y más rápida a mayor temperatura y modo de trabajo continuo.

Para analizar la influencia de ambos mecanismos de fallo en la degradación del LED, se analiza el ensayo a $60{ }^{\circ} \mathrm{C}$ (la temperatura con menor factor de aceleración) que es en el que la degradación óptica y de la curva I-V ha sido más lenta y progresiva.

En las Figuras siguientes y para facilitar su interpretación, se refleja la evolución de la degradación de los LEDs tipo A del ensayo a $60^{\circ} \mathrm{C}$ (antes presentada en la Figura 6-28), la evolución de la curva I-V de cada uno de ellos (Figura 6-40), tanto en inversa como en directa. Es necesario recordar que la curva en negra discontinua es un LED nuevo tipo A genérico, y que sólo se ha medido 
en inversa la última curva del LED al finalizar el ensayo, los valores de corriente en inversa son negativos, pero se han pasado a positivos para poder verlos en una escala logarítmica. Todos los LEDs tienen una fuerte degradación de la curva I-V tanto en directa como en inversa, en el caso de la corriente de inversa, los LEDs en cíclica tienen una degradación un orden de magnitud por debajo de los LEDs en continua. En la Figura 6-41 se reflejan las fotos del estado final de cada uno de los LEDs, los LEDs en continua sufren una importante degradación de la silicona y los de funcionamiento cíclico no tienen degradación. En los LEDs tipo A se identifican estos dos mecanismos de degradación que contribuyen al fallo. Una deducción obvia y quizá simplista es suponer que los LEDs en continua sufren la degradación de potencia óptica debido a la degradación del semiconductor (reflejado en la curva I-V, especialmente en la zona de inversa) y degradación del encapsulado, mientras que los LEDs funcionando en cíclica sólo tienen degradación debida a la del semiconductor. 


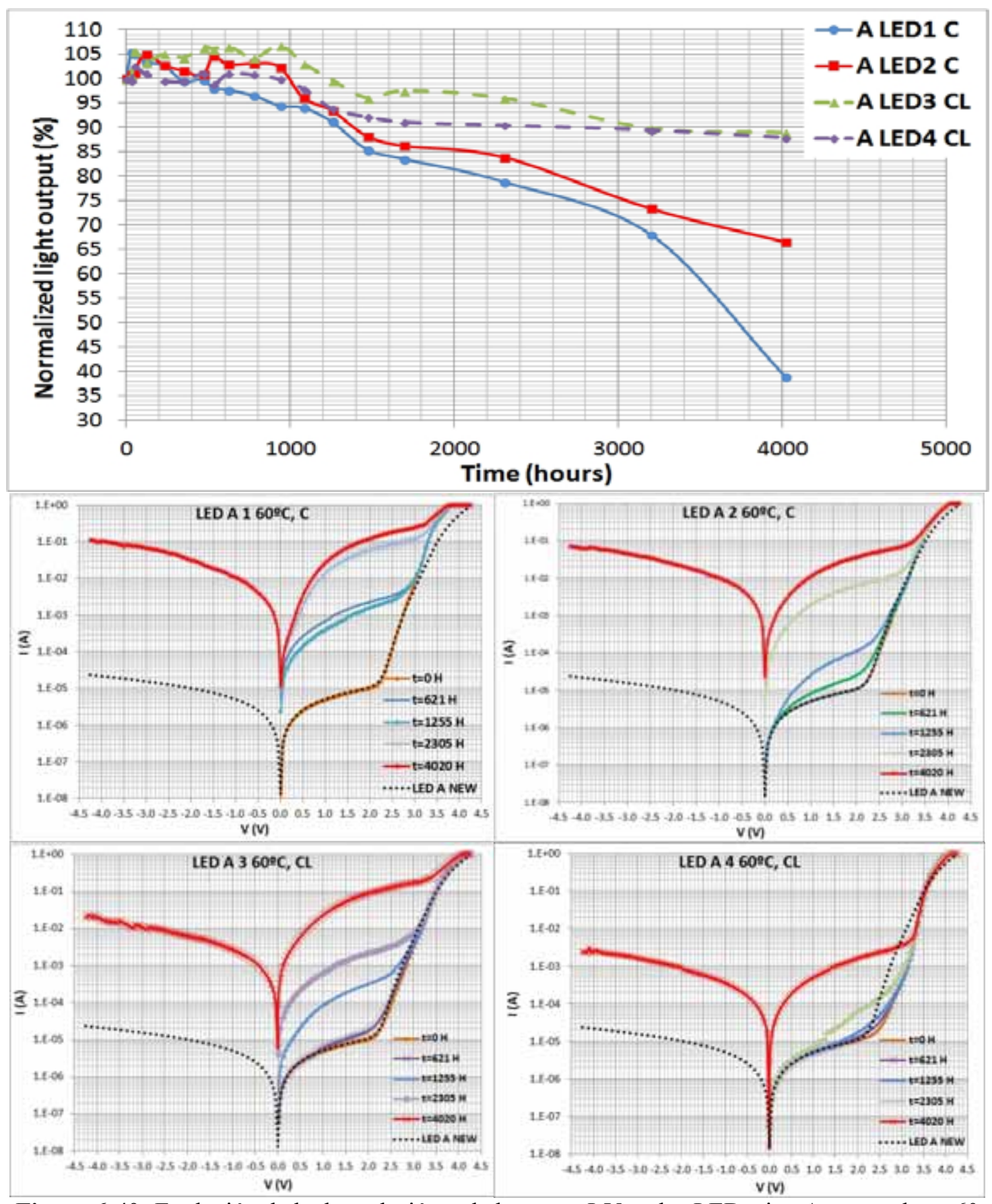

Figura 6-40: Evolución de la degradación y de la curva I-V en los LEDs tipo A ensayados a 60 ${ }^{\circ} \mathrm{C}$, la $\mathrm{C}$ final del título significa trabajo continuo, y la CL trabajo cíclico. 


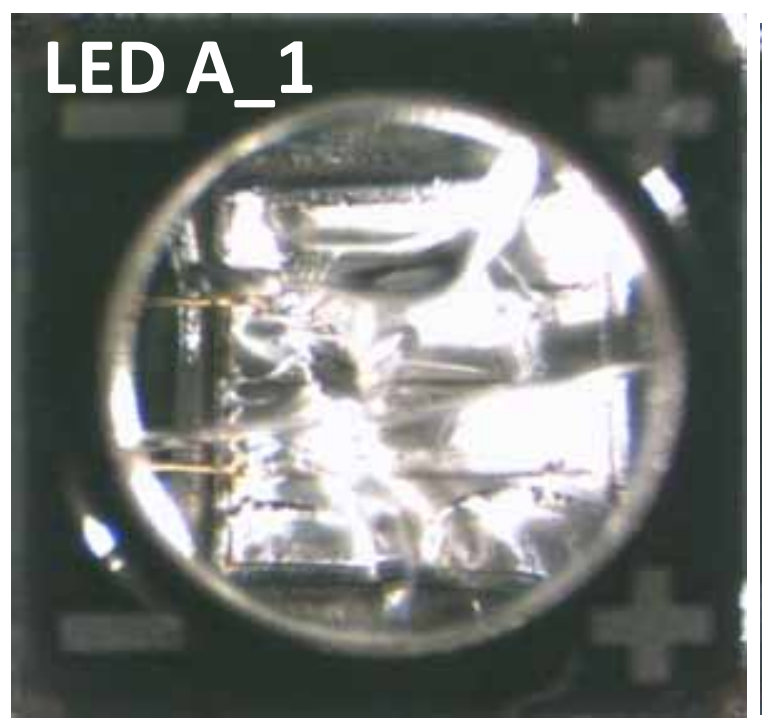

LED A_3

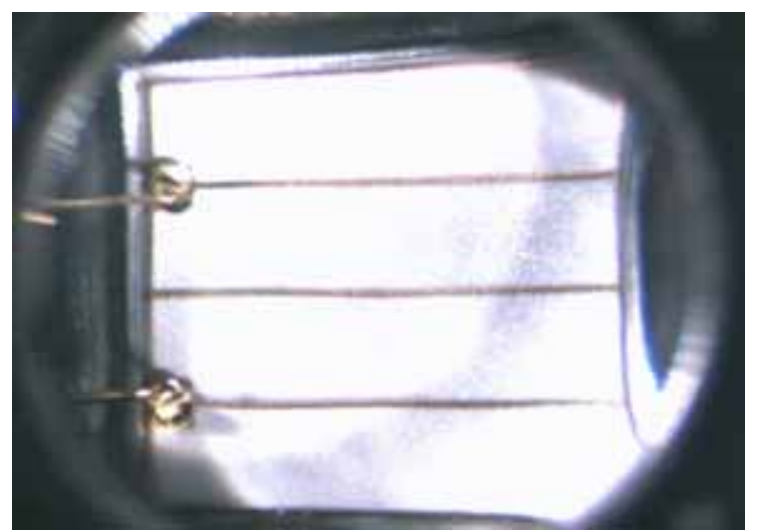

\section{LED A_4}

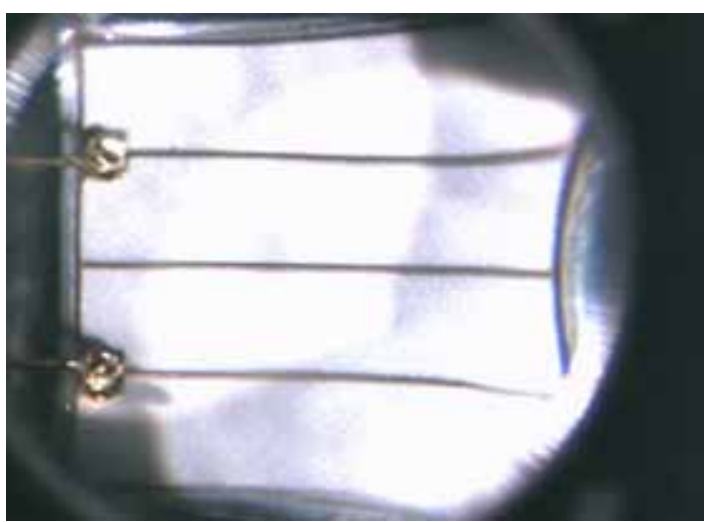

Figura 6-41: Situación del encapsulado de los LEDs tipo A ensayados a $60^{\circ} \mathrm{C}$, al finalizar el ensayo 4020 horas.

Los resultados para el resto de LEDs tipo A ensayados, es que se mantiene una degradación importante de la curva I-V, especialmente en inversa, y que la degradación de la silicona es similar o más importante, ya que lo que queda por mostrar son ensayos a mayor temperatura, en los que todos los LEDs tipo A han sufrido grietas y delaminaciones entre la silicona y la parte superior del chip.

A continuación se muestra la evolución de los LEDs tipo B.

En la Figura 6-42 se puede ver la evolución de los LEDs tipo B del ensayo a $60{ }^{\circ} \mathrm{C}$, (el 2 y 3 en continua, el 4 y 5 en trabajo cíclico). Cabe resaltar que los LEDs en continua se han degradado a nivel de potencia óptica antes y más que los LEDs en cíclica. 


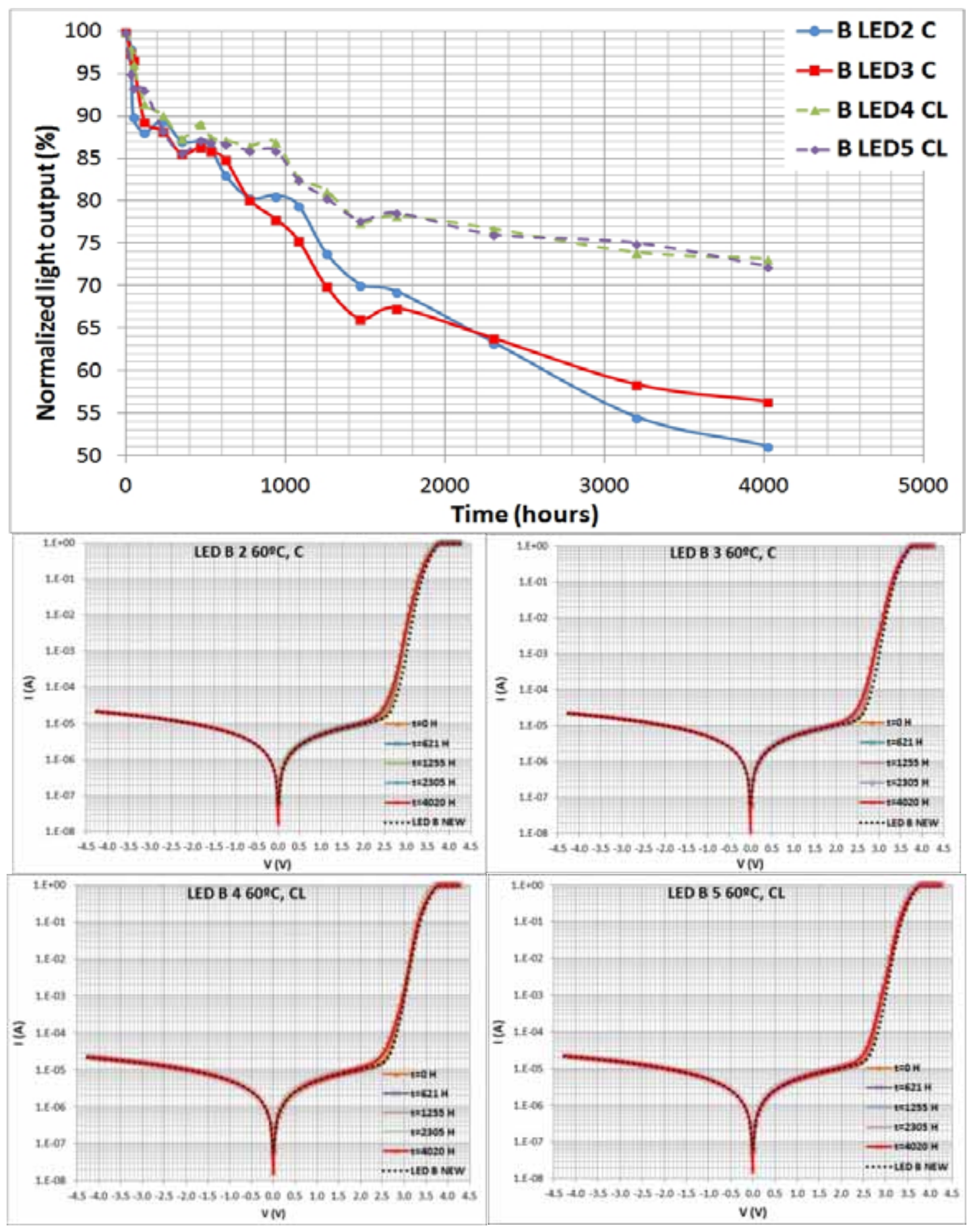

Figura 6-42: Evolución de la curva $\mathrm{I}-\mathrm{V}$ en los LEDs tipo $\mathrm{B}$ ensayados a $60^{\circ} \mathrm{C}$, donde la $\mathrm{C}$ final del título significa trabajo continuo, y la CL trabajo cíclico. 

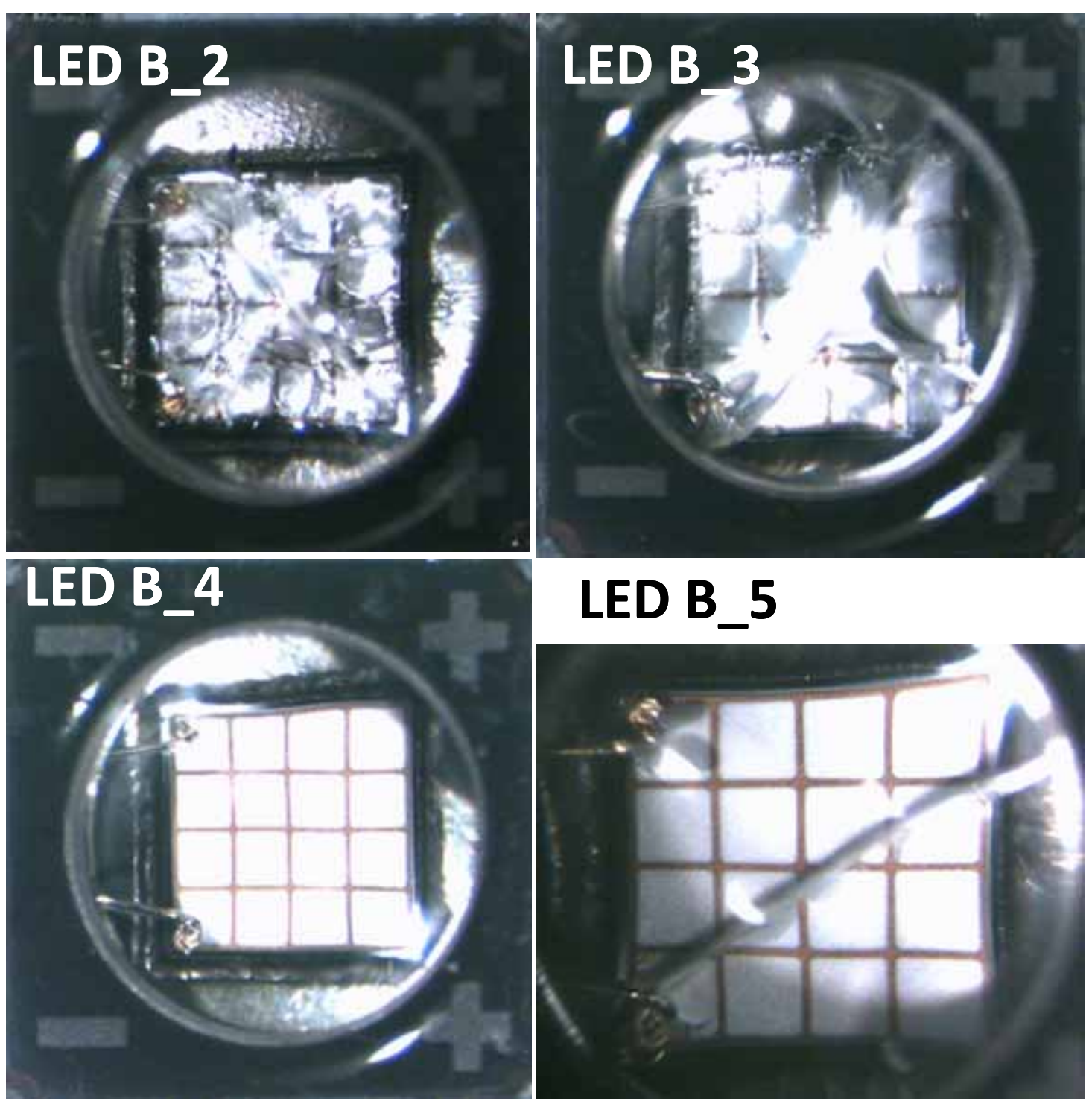

\section{LED B_5}

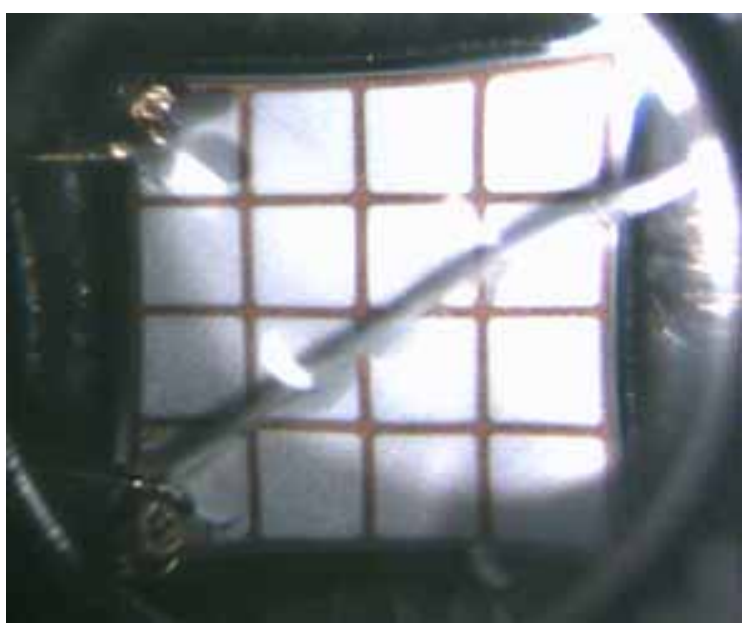

Figura 6-43: Situación del encapsulado de los LEDs tipo A ensayados a $60{ }^{\circ} \mathrm{C}$, al finalizar el ensayo 4020 horas.

UN análisis exhaustivo de la Figura 6-42 con degradaciones junto con las curvas I-V y la Figura 6-43 con las fotos finales de cada LED, resulta interesante observar que hasta las 600 horas todos los LEDs se degradan casi lo mismo, y no es debido a la silicona, pues en ese instante del ensayo aún ninguna de las siliconas se había degradado. En cuanto a curva I-V en inversa y directa, la evolución de todos los LEDs, es muy similar, independientemente de su modo de trabajo. Al respecto de las grietas en la silicona, los LEDs en continua tienen una agrietamiento y delaminación muy fuertes, el LED 5 en cíclica tiene un corte limpio que no puede reflejar demasiada luz, y el 4 no se ha roto. En este caso no hay una deducción obvia que refleje el comportamiento de todos los LEDs, si las curvas I-V no reflejan una degradación del semiconductor, y las pérdidas por 
degradación de la silicona en los LEDs 4 y 5 deben ser muy bajas, debe existir algún mecanismo de degradación que contribuye al fallo y que no se detecta mediante la curva I-V. Hay que considerar que interpretar las degradaciones de emisión óptica de un LED no son evidentes, siendo necesaria la utilización de técnicas complejas con instrumentación específica como caracterización capacidadtensión, caracterización en alta frecuencia, microscopía electrónica, desencapsulación, etc. [Mene09].

\subsubsection{Análisis de la degradación de la silicona}

De los dos mecanismos de degradación indicados (degradación de la silicona y del semiconductor) se puede obtener más información a partir de las grietas del encapsulado, ya que es un proceso visible y del que se ha realizado un seguimiento a lo largo del ensayo, mientras que sobre la degradación del semiconductor sólo se ha podido emplear la curva I-V como elemento de medida de dicha degradación, dado que no se tienen datos acerca de los materiales.

Al respecto del análisis del proceso de degradación de la silicona, tal y como se ha demostrado, el funcionamiento en continua y la temperatura causan mayor degradación y estrés termo-mecánico que la condición de trabajo cíclica y las temperaturas inferiores. El ensayo adicional de dos LEDs a $90{ }^{\circ} \mathrm{C}$ sin corriente, donde no se produjo rotura de la silicona, indican que por si la temperatura no produce la rotura de la silicona ni degradación sustancial de la potencia luminosa emitida. 


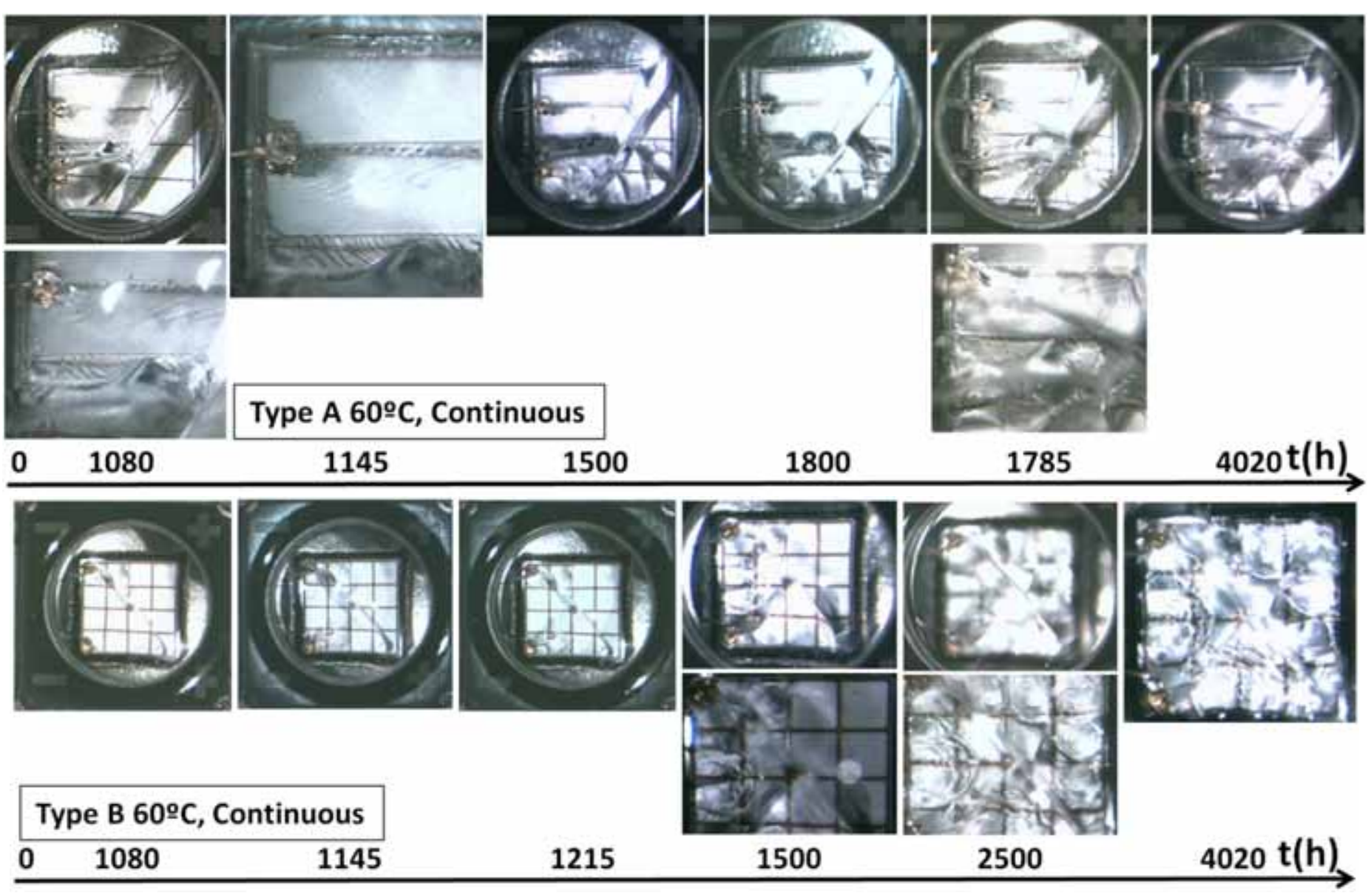

Figura 6-44: $60^{\circ} \mathrm{C}$ en continua, parte superior LED tipo A, parte inferior LED tipo B de [ANVSG15]. 

En la Figura 6-44 se puede observar la evolución de la degradación de la silicona para dos LEDs tipo A y B (A imágenes superiores, B inferiores) que se ensayaron en modo continuo a $60{ }^{\circ} \mathrm{C}$. Como se puede observar hay ciertas similitudes entre ambos procesos, y algunas diferencias.

A las 1080 horas se observa la grieta en ambos encapsulados. En el LED tipo A comienzan en el "wire bonding" inferior y luego se bifurca en diagonal cruzando todo el encapsulado, en el "wire bonding" superior se observan pequeñas fisuras que no evolucionaran a grietas hasta las 1785 horas, esto se puede observar en el detalle a las 1145 horas, donde además se observan grietas paralelas en diagonal que van desde la metalizalización del LED hacia la primera grieta creada en el encapsulado, esto al menos indica que el comportamiento en cuanto a dilataciones de la silicona diferencia entre las líneas de metalización y el resto de superficie del semiconductor (blanco). 3

A partir de 1785 horas se acelera el proceso, creándose una grieta del "wire bonding" superior hacia la grieta central, y empezando a producirse ramificaciones de las grietas más grandes, al finalizar el ensayo, se observa muy agrietada la parte inferior del LED, no así la parte superior que está relativamente bien.

En el LED tipo B se observa una grieta que comienza en línea con el "wire bonding" y cruza en diagonal todo el encapsulado, a las $1145 \mathrm{~h}$ se origina una segunda grieta en el otro "wire bonding" que evoluciona poco a las 1215 horas, pero a las 1500 ha generado una grieta que se ha cruzado con la primera. Tras las 1500 horas hay un número progresivo de grietas, y una delaminación que comienza en el lado izquierdo entre los dos "wire bonding", como se observa en la foto inferior a $1500 \mathrm{~h}$. A $2500 \mathrm{~h}$, la foto superior se ha enfocado a la lente de cristal del LED, se puede observar que no está rota, dicha lente cubre la silicona colocada sobre el chip, pero se ve la primera grieta que es la más grande llega de la superficie del chip a la parte inferior de la lente, es decir parte la silicona en dos. No se han observado problemas en la lente de cristal (el material ha sido indicado por el fabricante). En el detalle de la foto a $2500 \mathrm{~h}$, enfocada en el chip, se observan delaminaciones en forma de concha que están limitadas por la metalización en cuadrícula. A las $4020 \mathrm{~h}$ se observa en una foto enfocada sobre la superficie del chip, el estado final de ambos LEDs.

Otro resultado importante es que la rotura de la silicona produce un efecto de autocalentamiento debido a las reflexiones de luz en ella. Se han medido LEDs con la silicona muy agrietada, y se ha observado un incremento de la temperatura en la unión del chip de $1,5^{\circ} \mathrm{C}$ con respecto a los LEDs en su estado original. El procedimiento de medida ha sido el indicado previamente. 
Para poder analizar las causas del agrietamiento, donde se había observado que estas comenzaban entre las zonas metálicas ("wire bonding" y metalizaciones) y la silicona, era necesario realizar una simulación termo-mecánica del encapsulado en condiciones de funcionamiento.

Con este objetivo se han realizado simulaciones térmicas estáticas a una $\mathrm{Ta}=25^{\circ} \mathrm{C}$ y 600 $\mathrm{mA}$ de corriente continua, con su correspondiente potencia. Estas simulaciones se han realizado con un software de elementos finitos (FEM - finite element method), que es una herramienta eficaz para evaluar el comportamiento del encapsulado del dispositivo [YYYG+10] [LL11] [TWL09] [ZL14], y comparar problemas que han surgido con resultados experimentales.

En la Figura 6-45 se muestra la simulación completa del encapsulado (para convección natural y modo de trabajo continuo) desarrollada por la herramienta Autodesk Simulaton Multiphysics ${ }^{\circledR}$. Los resultados obtenidos están confirmados por las medidas de temperatura en la unión del chip.

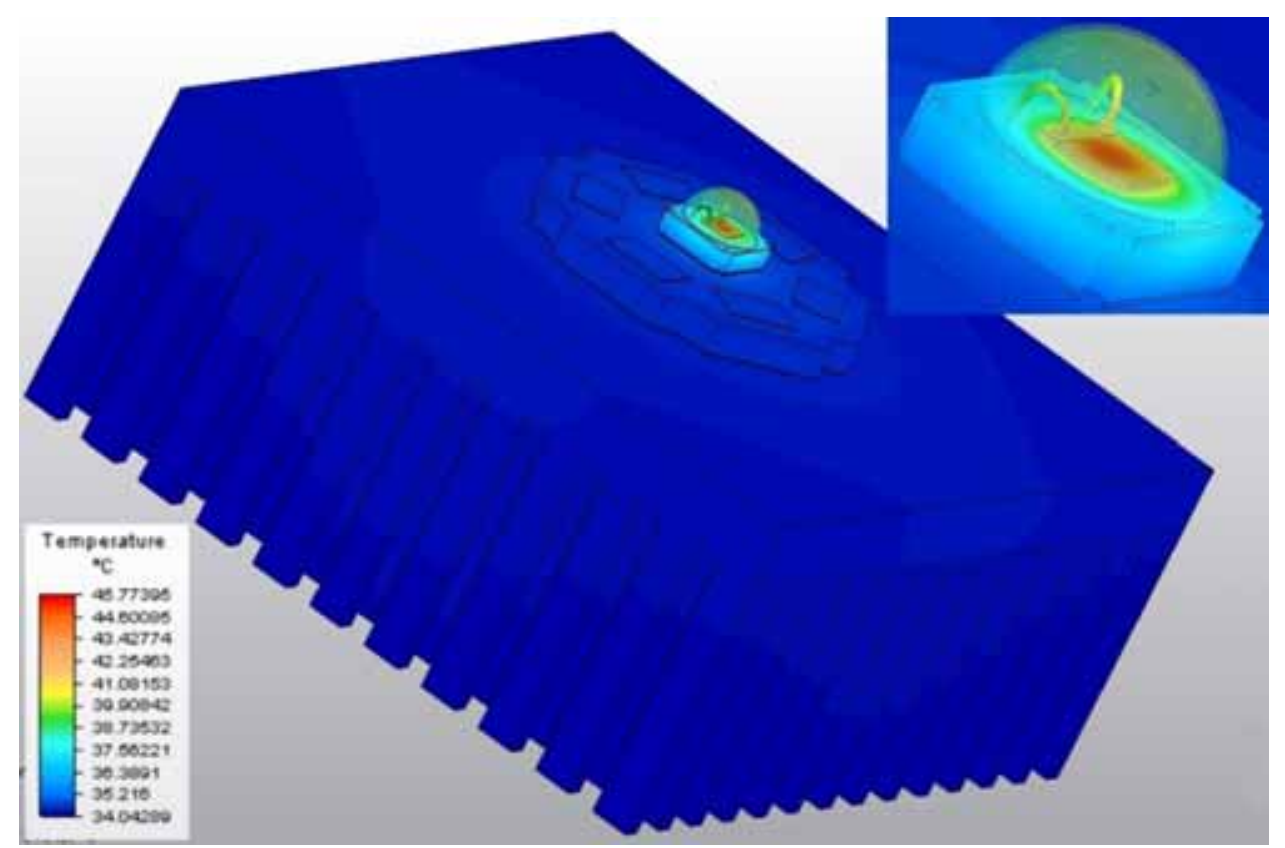

Figura 6-45: Análisis térmico estático mediante FEM del UV-LED a Ta $=25^{\circ} \mathrm{C}$, convección natural, y funcionamiento continuo a $600 \mathrm{~mA}$. [ANVSG15]

Un paso adicional para analizar el estrés termo-mecánico debido a la expansión y contracción de materiales con diferentes coeficientes de expansión (CTE Coefficient of Thermal Expansion) es introducir en el programa las temperaturas de cada elemento y las características mecánicas del material. Por tanto para realizar el análisis termo-mecánico se emplea como entrada los resultados del análisis térmico (Figura 6-45) y la Tabla XIX con los parámetros mecánicos de los materiales, donde hemos considerado el zafiro, por ser el más común, el 
material base de estos LEDs ultravioleta [MKN14] [Mene09], hemos limitado la simulación al encapsulado, que ha sido simulado mediante análisis de estrés mecánico estático (Figura 7.44).

\begin{tabular}{|c|c|c|c|c|}
\hline & Sapphire & $\mathrm{Au}$ "wire bonding" & Silicone & Glass lens \\
\hline $\begin{array}{c}\text { Elastic modulus } \\
(\mathrm{GPa})\end{array}$ & 400 & 78 & $6.1 \times 10^{-4}$ & 35 \\
\hline Poisson ratio & 0.22 & 0.42 & 0.34 & 0.4 \\
\hline Density $\left(\mathrm{Kg} / \mathrm{m}^{3}\right)$ & 3965 & 19320 & 1200 & 1300 \\
\hline $\mathrm{CTE}\left(\mathrm{ppm} /{ }^{\circ} \mathrm{C}\right)$ & 7.9 & 14.2 & 300 & 47 \\
\hline $\begin{array}{c}\text { Thermal } \\
\text { conductivity } \\
\left(\mathrm{W} / \mathrm{m}^{\circ} \mathrm{C}\right)\end{array}$ & 41.9 & 318 & $1(0.2-1.8)$ & 0.58 \\
\hline \multicolumn{2}{|l|}{} \\
\hline
\end{tabular}

Tabla XIX Parámetros térmicos y mecánicos de la zona superior del encapsulado. [ANVSG15]

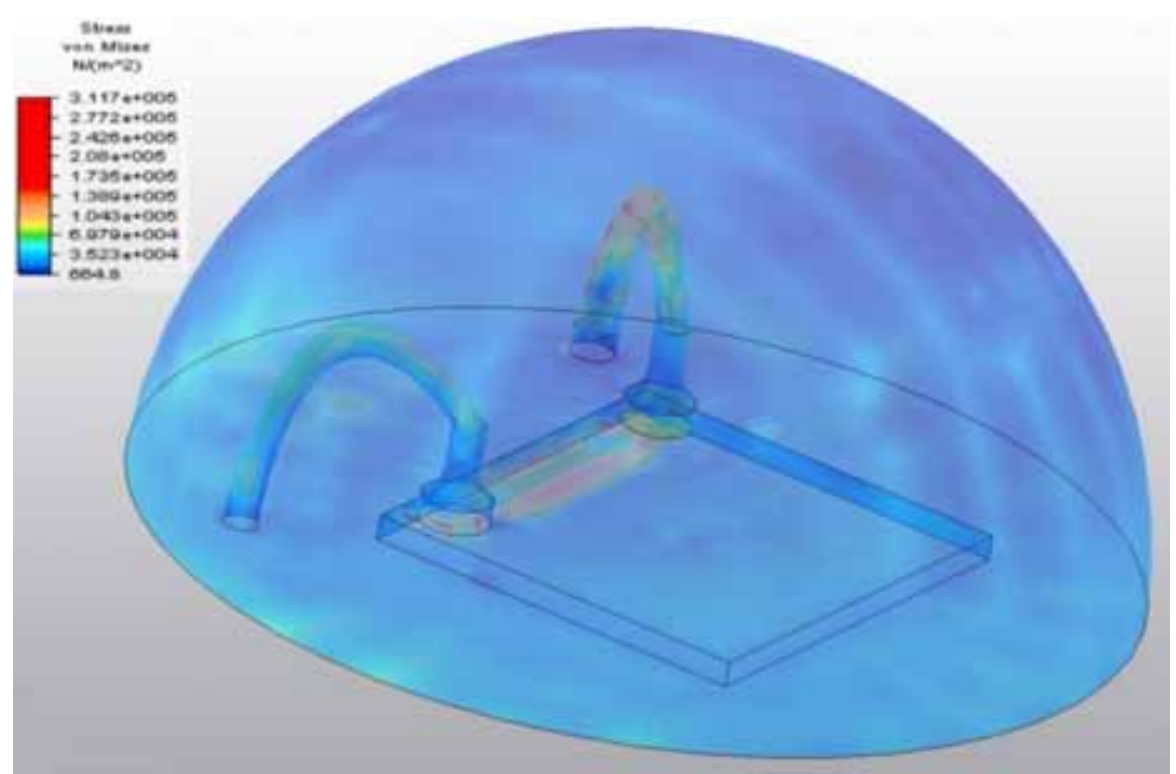

Figura 6-46: Resultado del análisis de estrés estático mediante von Misses, para la silicona que rellena la lente de cristal. [ANVSG15]

En coherencia con la experiencia obtenida, estas simulaciones muestran en la Figura 6-46 que el mayor estrés está presente en la zona entre los bonding, la unión del "ball bonding" con el chip y del encapsulado cerámico con el MCPCB (Metal Core PCB). Sin embargo no se han observado delaminaciones de los wirebonding respecto al chip o del chip respecto a su base cerámica, sólo se observan agrietamientos de la silicona que rellena el espacio entre el chip y la lente de cristal (como se puede ver en los detalles de la Figura 6-44).

En la Figura 6-46 se observa en detalle el von Mises análisis de estrés estático exclusivamente de la silicona que rellena el cristal de la lente [CGLL12]. De la simulación se extrae que el mayor estrés de la silicona se produce en la parte superior de ambos "wire bonding", en la silicona pegada a los "ball bonding" y también en la superficie del chip entre los dos "wire bonding". Estos resultados de simulaciones de estrés son coherentes con los resultado experiementales evidenciados con microscopio óptico (Figura 6-44), donde observa que las fisuras que originan las posteriores grietas comienzan en los "ball bondings" o en los "wire 
bonding”, y que la delaminación del LED tipo B comienza en la zona izquierda entre ambos "ball bonding". Una vez comenzada la degradación el proceso se realimenta, la luz reflejada calienta más en chip y este resulta menos eficiente en cuanto a iluminación disipando más calor, y produciendo mayores expansiones en los materiales. En la primera fase de degradación aparecen las grietas que deparan en ramificaciones, y en la segunda fase se producen delaminaciones de la silicona próximas a las metalizaciones. Las delaminaciones con forma de "marcas de playa" Figura 6-44, LED A 1145 h y las delaminaciones en forma de concha (conchoidal fracture) son debidas a la fatiga de la silicona y deviene del desajuste de la expansión térmica entre los materiales [LM06] [BTRL08], la silicona adherida al semiconductor del chip y la silicona adherida a la metalización superior (Figura 6-44).

Las propuestas que se pueden realizar para mitigar los problemas de degradación de la silicona se originan en diferentes áreas tecnológicas. Todas ellas se basan en reducir o eliminar el estrés termo-mecánico. Quedan por tanto resumidas en las siguientes soluciones:

- Sin realizar modificaciones de diseño en el LED. Es necesario buscar soluciones que produzcan menos estrés termo-mecánico y una distribución de la temperatura en el encapsulado más homogénea. Hay dos soluciones posibles: una reducir la potencia y por tanto la temperatura con un modo de trabajo cíclico, y otra reduciendo y homogeneizando la temperatura para ello la solución de convención forzada mediante un ventilador tipo "CPU" sobre el disipador sería una buena solución (Figura 6-24).

- Cambiando la silicona. La silicona óptica es por el momento el mejor material para los LEDs ultravioleta debido a su buen comportamiento y resistencia térmica a la radiación de alta energía [LYLTS10] [CDVP12]. Sin embargo, debido al alto CTE de la silicona, la interacción con los "wire bonding" y el chip tienen una solución compleja. Una alternativa, si fuera posible, sería buscar una silicona que mantuviese las buenas características ópticas, pero con menor CTE. Otra alternativa es prescindir de la silicona, algunos fabricantes de LEDs (Nichia para LEDs de menor potencia) dejan vacía la zona entre el chip y la lente de cristal, o la pueden rellenar con gases como el nitrógeno que no oxidan los materiales.

- Con modificaciones del encapsulado. Es necesario buscar un diseño del encapsulado que reduzca el estrés termo-mecánico entre la silicona, la metalización del chip, y los "wire bonding". Las soluciones que se pueden proponer son la mejora del diseño de la metalización del chip [HGE14] y la eliminación o modificación de las conexiones de "wire bonding" mediante tecnología Through Silicon Via (TVS) en el chip del LED [HGE14] [VLLM+11]. En cualquier caso, es necesario un análisis de costes y de fiabilidad antes de afrontar cambios radicales en la fabricación, ya que 
a pesar del defecto de las grietas en la silicona, la esperanza de vida de ambos LEDS, y especialmente el tipo B supera en varias veces la esperanza de vida de una lámpara equivalente para aplicaciones de fluorescencia.

\subsubsection{Análisis de la degradación del semiconductor}

Existen múltiples causas de la degradación de la potencia óptica del LED [CDVP12], no se pueden simplificar los métodos de fallo razonando que aquella potencia óptica que no es debida a la degradación de la silicona es debida a la degradación del semiconductor.

Respecto a la degradación el semiconductor; se ha observado para los LEDs tipo A una fuerte degradación de la curva I-V tanto en inversa como en directa, mientras que para los LEDs tipo B se ha observado una degradación baja de la curva I-V durante el ensayo acelerado.

En el caso de los LEDs A los factores que contribuyen a la degradación podrían ser exclusivamente la degradación de la silicona y la degradación del semiconductor, ya que en aquellos LEDs sin degradación de la silicona si se observa una degradación rápida e importante en la curva I-V, mientras que en los LEDs tipo A esta hipótesis no puede plantearse, al menos en base a la degradación de la curva I-V ya que se tienen LEDs (el 4 y 5 cíclicos a $60^{\circ} \mathrm{C}$ ) con la silicona nada o poco degradada, con la curva I-v muy poco degradada y sin embargo con una degradación de la potencia óptica de salida muy importante de aproximadamente un 25\% para los LEDs B mencionados.

Se ha evidenciado que los LEDs tipo A tienen una degradación de las curvas en inversa importantes, con unas corrientes de fugas muy altas, de $10^{-1}-10^{-2} \mathrm{~A}$ a una tensión de $1,5 \mathrm{~V}$, comparadas con la situación inicial de $10^{-5} \mathrm{~A}$. Este hecho, según los autores [KABR+13] refleja que el efecto de la densidad de dislocaciones o defectos en el semiconductor que producen recombinaciones no radiativas, y por tanto suponen una reducción de la potencia óptica emitida ha aumentado de forma importante. 


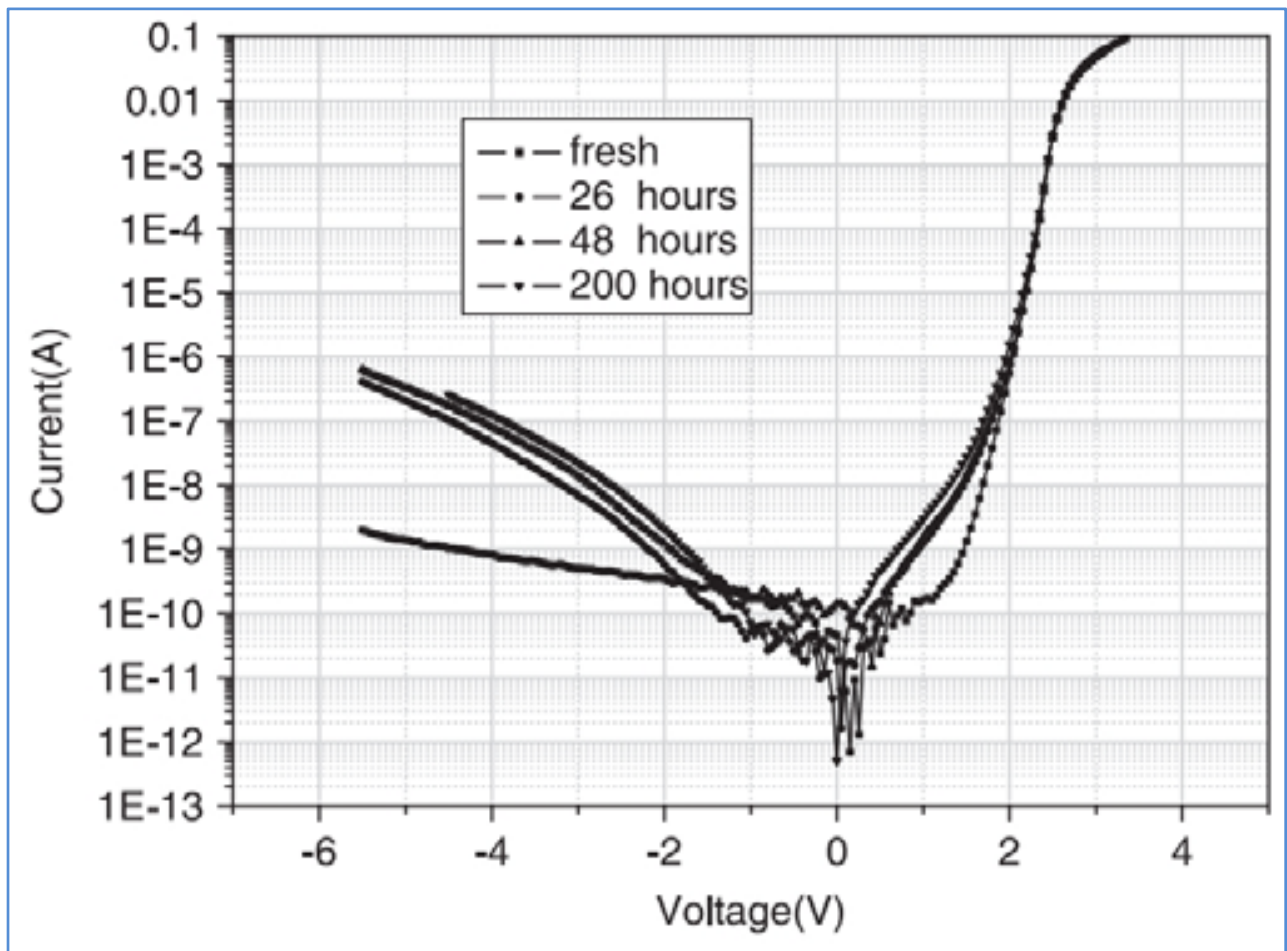

Fig. 2. $I-V$ curves of LED stressed by current density of $26.5 \mathrm{~A} / \mathrm{cm}^{2}$.

Figura 6-47: Tomada de [YSCQ+07], evolución de la curva I-V en un ensayo acelerado en temperatura de leds violeta $(\mathrm{InGaN} / \mathrm{GaN})$.

Nuestros resultados de evolución con el tiempo de la curva I-V durante el ensayo acelerado en temperatura con condiciones nominales de trabajo es coherente con múltiples resultados de ensayos sobre LEDs basados en GaN, entre ellas destacamos [YSCQ+07] (Figura 6-47) con unos resultados iguales a los de los LEDs tipo A, otras referencias sólidas de coherencia de resultados en esta área son [KABR+13] [QG13] [HYS08] [LOGH+06] [GCGS+05] [MLPR+02]. Algunos autores [MK09] y [MLPR+02], reflejan la correspondencia de las zonas de la curva I-V del LED con sus características y parámetros físicos. Tomando como base esta explicación, se tratará de identificar como estarán afectados los LEDs estudiados. 


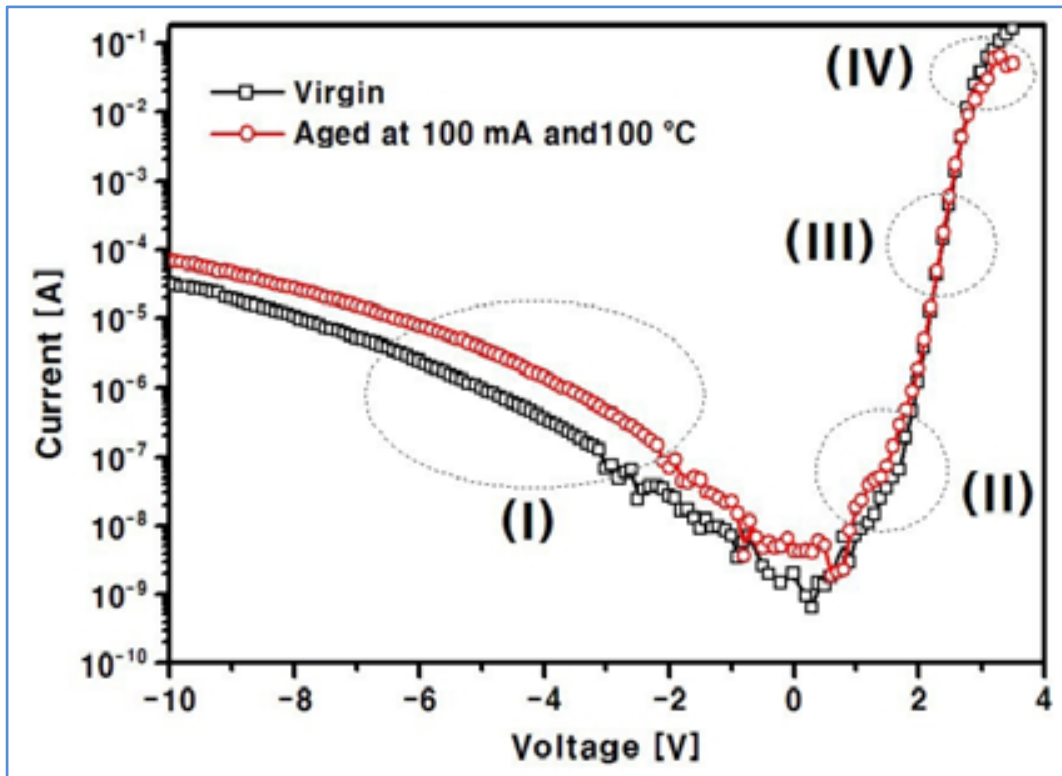

Fig. 2. I-V characteristics on a semilogarithmic scale measured in a virgin sample and in a device aged at $100 \mathrm{~mA}$ and $100{ }^{\circ} \mathrm{C}$

Figura 6-48: Tomada de [MK09], explicación de las zonas de la curva I-V, sobre los resultados de un ensayo acelerado.

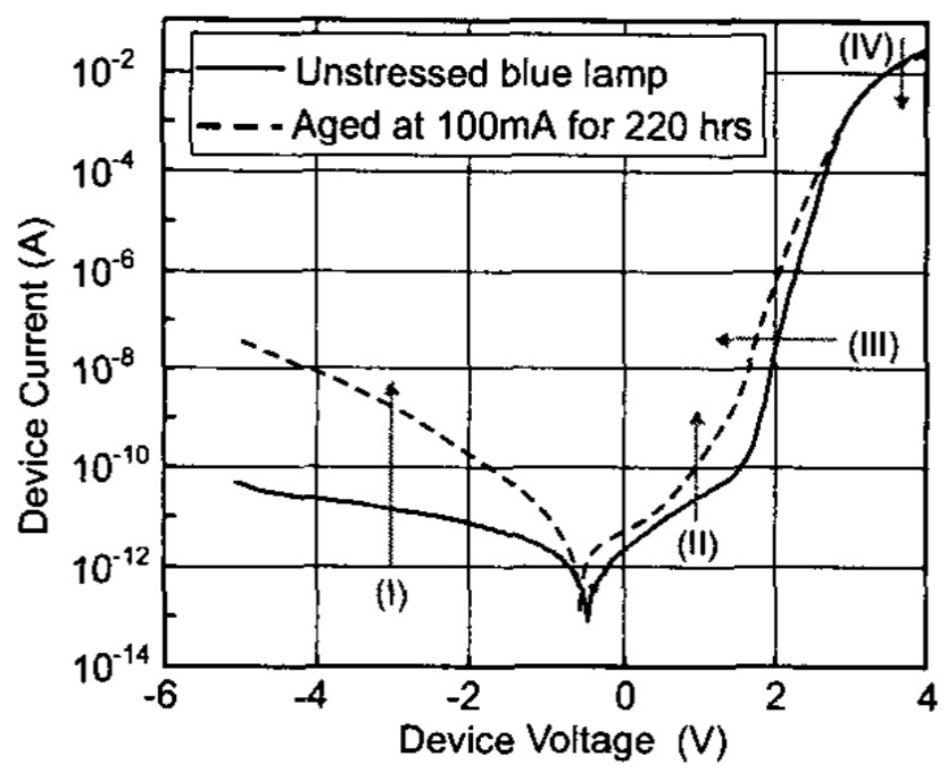

Fig.6: I-V characteristics of unstressed and aged blue LED lamps (stressed at $100 \mathrm{~mA} \mathrm{DC}$ for $220 \mathrm{hrs}$ ).

Figura 6-49: Tomada de [MLPR+02], explicación de las zonas de la curva I-V, sobre los resultados de un ensayo acelerado.

Como indican [MK09] y [MLPR+02], (Figura 6-47 y Figura 6-48). la zona (I) refleja un incremento de la corriente de fugas en inversa debido a la corriente de túnel relacionada con la formación de defectos o dislocaciones en la capa activa[LCYJ04]; (II) es la zona de bajas tensiones en directa $(<2.2 \mathrm{~V})$, un incremento de corriente refleja un cambio en la corriente generación-recombinación y por tanto una pérdida de potencia lumínica, (III) es la de medias tensiones antes de llegar al punto de trabajo, un aumento de corriente refleja un aumento en el 
factor de idealidad (n de la ecuación de corriente del LED); (IV) se refleja un aumento de la resistencia serie (Rs) que puede atribuirse a una degradación del contacto de metal, o un incremento en la densidad de dopado de la capa-P debido al estrés por corriente.

Como se puede observar en nuestros LEDs tipo A se observa en todos los casos una fuerte degradación de la curva I-V. En la zona I (tensión inversa) de la curva I-V se ve que la corriente de fugas ha aumentado en varios órdenes de magnitud para todos ellos, un orden de magnitud menos en los LEDs de funcionamiento cíclico que los de funcionamiento continuo, esto según la bibliografía supone una pérdida de potencia debido al aumento de defectos en el semiconductor que producen recombinación no radiativa, la degradación de la zona (II) y (III) también es visible en todos ellos, lo que según la bibliografía es otra fuente de recombinación no radiativa, mientras que la degradación de la zona (IV) es más visible en los LEDs de funcionamiento continuo que en los cíclicos, por lo que los LEDs de funcionamiento continuo al finalizar el ensayo tienen afectada también su resistencia serie.

En los LEDs tipo B no se observa una degradación en la zona (I) de la curva I-V y si una pequeña degradación en la zona (II) que es común a todos los LEDs, esta zona se corresponde con la corriente de generación-recombinación, por lo que esto afectaría a la emisión de luz, pero no se puede cuantificar en qué proporción. Si se comparan estas curvas con las de los LEDs tipo A, no parece sensato asumir que el efecto de degradación pueda ser similar cuantitativamente en ambos casos, por lo que sólo resta asumir que en los LEDs tipo B hay una degradación que contribuye al fallo y que no ha sido detectada con las herramientas disponibles. Entre los mecanismos de degradación que contribuyen al fallo, caben destacar los relacionados con la pasivación: en el trabajo [MTZA06] sobre GaN-based LEDs se puede observar en la figura 2 unas curvas de evolución de degradación debido a problemas con la pasivación similares a nuestros resultados. Otras fuentes de degradación han sido reportadas en trabajos de revisión de LEDs por [CDVP12], o en una revisión más concreta de GaN-based LEDs ultravioleta en [Meneg08].

\subsection{Discusión y conclusiones}

Con estos ensayos se ha evaluado la influencia de los modos de trabajo continuo y cíclico (30s ON\&30s OFF) sobre la vida del LED, estos modos de trabajo se han elegido porque permiten una detección de hidrocarburos contaminantes en tiempo real y de modo continuo 24/7. Se han considerado dos tipos de LEDs ultravioleta $(365 \mathrm{~nm})$ de alta potencia $(3 \mathrm{~W})$, con un chip de $1 \mathrm{~mm}^{2}$ aproximadamente, que trabaja con alta densidad de corriente de $60 \mathrm{~A} / \mathrm{cm}^{2}$ en nuestras condiciones de trabajo $600 \mathrm{~mA}$. Ofrecen una potencia óptica a $8 \mathrm{~cm}$ de $9,11 \mathrm{~W} / \mathrm{cm}^{2}$ para LED 
tipo A y 10,40 W/ $\mathrm{cm}^{2}$ para LED tipo B. Se ha considerado fallo cuando los LEDs bajan del $70 \%$ de la potencia lumínica emitida inicialmente.

Se han analizado los resultados de los ensayos mediante las ecuaciones básicas de fiabilidad descritas en la sección dos, tanto la función de Weibull como el modelo de Arrhenius para ensayos acelerados en temperatura.

Se ha planteado la metodología y planificación de los ensayos, consistentes en acelerar la vida en temperatura de LEDs en condiciones nominales de trabajo, mediante ensayos de vida acelerada a $60^{\circ} \mathrm{C}, 75^{\circ} \mathrm{C}$ y $90^{\circ} \mathrm{C}$ de temperatura ambiente. A partir de aquí y con los modelos previamente descritos se estimarán los parámetros de fiabilidad de ambos tipos de LEDs tipo A y B en las dos condiciones de trabajo.

Se ha descrito la instrumentación empleada tanto para la realización de los ensayos acelerados como los diversos sistemas de instrumentación para caracterizar el LED antes, durante y después de los ensayos acelerados. Gran parte de la instrumentación de basa en programación de LabVIEW y un conjunto de instrumentos cada uno con una aplicación específica, conmutación, medida, medida, alimentación, control, de modo que en conjunto nos han permitido hacer una evaluación dinámica y estática del comportamiento del LED en cuanto a temperatura y emisión de potencia lumínica y espectro óptico, en esta sección se han identificado los equipos utilizados.

Con la instrumentación previamente descrita se ha realizada una caracterización del LED, consistente en:

- Caracterización óptica y descripción de los encapsulados de los LEDs, el LED A tiene las metalizaciones horizontales, y el LED B en cuadrícula.

- Medida de la curva I-V de cada LED en directa durante todo el ensayo, y medida la curva en inversa al final del ensayo. Esta limitación se debe al zener en antiparalelo que lleva el circuito del LED para protegerlo de descargas electrostáticas, que no fue retirado hasta finalizar los ensayos. Sobre el circuito metálico en el que se adquirió el LED se puso un disipador de aletas que superaba las necesidades identificadas por los fabricantes.

- Relación del valor en cuentas del pico de la espectroscopia con la potencia óptica emitida, ya que la caracterización óptica de los ensayos se basó fundamentalmente en su emisión espectro.

- Se mide el coeficiente de tensión en temperatura para cada LED, paso previo para la caracterización térmico-óptica de los LEDs. Dicha caracterización se realiza para convección natural y convección forzada, y para condiciones dinámicas y estáticas. Además se ha realizado un modelo térmico del LED para condiciones de trabajo cíclico. 
Los resultados de las caracterizaciones termo-ópticas son que los LEDs en continua incrementan su temperatura de la unión $19^{\circ} \mathrm{C}$ sobre la temperatura ambiente, mientras que los cíclicos 30 s ON\&30s OFF lo hacen en $14,5^{\circ} \mathrm{C}$ y para $10 \mathrm{~s}$ ON\&50s OFF en $10^{\circ} \mathrm{C}$. En cuanto a la potencia lumínica los cíclicos incrementan su potencia sobre un 2,5-5 \% respecto a la condición de continua, por tanto no es una mejora muy relevante, la temperatura si es un hecho más crítico. En funcionamiento con convección forzada se consigue que todas las condiciones de trabajo sufran un incremento de temperatura mucho menor entre 8 y $7{ }^{\circ} \mathrm{C}$, y una mejora de potencia óptica de un 3\% aproximadamente. Las condiciones de trabajo con convección forzada son muy positivas, y vienen limitadas porque la esperanza de vida del LED es de 40000 horas, y precisa de un ambiente de trabajo muy limpio para que el ventilador no pueda verse afectado por el polvo, cosa que no se debe tener en la estación automática de medida donde se instalaría el equipo.

Después de presentar la evolución de la degradación de potencia óptica para el ensayo de $60^{\circ} \mathrm{C}$ y para la media de los tres ensayos, y de extrapolar los instantes de fallo en las tablas Tabla XV y Tabla XVI. Se ha aplicado la función y modelo Weibull-Arrhenius para mostrar desde la Figura 6-32 a la Figura 6-35 y en las Tabla XVII y Tabla XVIII los resultados de los ensayos de vida acelerada, tanto los parámetros de la ecuación de Weibull $(\mathrm{F}(\mathrm{t})$ defiabilidad)) para las condiciones nominales de trabajo $\left(25^{\circ} \mathrm{C}\right)$, como la energía de activación de la ecuación de Arrhenius para cada tipo de ensayo acelerado.

Las conclusiones más importantes de los resultados obtenidos son que el modo de trabajo cíclico es mucho más fiable que el modo de trabajo continuo, y que ambos tipos de LEDs tendrían una esperanza de vida varias veces mayor que las lámparas actualmente empleadas para espectroscopia.

En funcionamiento continuo ambos tipos de LEDs tienen un MTTF de unas 6000 horas, parte del problema es que su energía de activación es muy baja, $\mathrm{Ea}=0,13$ para tipo $\mathrm{A}$ y $\mathrm{Ea}=0,4$ para tipo B, es decir, la temperatura influye poco en la degradación, bajar la temperatura a $25^{\circ} \mathrm{C}$ no supone una mejora sustancial en la vida. El incremento del MTTF en funcionamiento cíclico respecto al continuo supone un factor de multiplicación de $5 \mathrm{o} 10$ veces mejores respectivamente para LEDs tipo A $(\mathrm{MTTF}=28960)$ y B $(\mathrm{MTTF}=65568)$. Las mejor respuesta de los LEDs tipo $\mathrm{B}$ en funcionamiento cíclico al trabajar a baja temperatura $\mathrm{Ta}=25^{\circ} \mathrm{C}$ se debe a que su energía de activación es $\mathrm{Ea}=0,65 \mathrm{eV}$, mucho mayor que la energía de activación de los tipo $\mathrm{A} \mathrm{Ea=0,2} \mathrm{eV}$.

El tiempo de vida esperado en funcionamiento continuo puede parecer bajo, pero está en línea con resultados obtenidos en otros ensayos, todos para potencias bajas o medias: En [KABR+13] son $1850 \mathrm{~h}$ para $30^{\circ} \mathrm{C}$ en LEDs de $365 \mathrm{~nm}$, en [GCGS+05] para LEDs de 250-300 $\mathrm{nm}$ crecidos sobre zafiro, se obtienen energías de activación para la degradación de $0,23 \mathrm{eV}$ y $0,27 \mathrm{eV}$ para $100 \mathrm{~A} / \mathrm{cm} 2$ (nuestros LEDs trabajan aprox. $60 \mathrm{~A} / \mathrm{cm} 2$ ) y $200 \mathrm{~A} / \mathrm{cm}^{2}$ respectivamente, 
muy similares a las obtenidas por nosotros en corriente continua, y también se observa una degradación de la curva I-V “idéntica” a la de los LEDs tipo A. En [RKLW+15] se reproduce la evolución de curva I-V delos LEDs tipo A, en LEDs de 380-220 nm, identificando una vida de 1000 horas para una degradación del 50\%, una vida muy inferior a la esperada para nuestros LEDS en condiciones de trabajo continuas. En [MMYA+06] Nichia publica para fabricación estandar de GaN-based LEDs a $365 \mathrm{~nm}$ y $120 \mathrm{~mW}$ de potencia (muy por debajo de los 800-1000 $\mathrm{mW}$ que obtienen nuestros LEDs) un MTTF de 17600 horas. Consultando la documentación de empresas que venden LEDs de $365 \mathrm{~nm}$ fundamentalmente para curado de pegamentos y esterilización, indican una esperanza de vida de entre 10000 a 20000 horas, en este último caso en funcionamiento pulsado. Como se observa, nuestros resultados están en línea con la bibliografía presentada para LEDs de $365 \mathrm{~nm}$, y son mejores que lo que ofrecen LEDs de menor longitud de onda. A pesar de estas limitaciones de vida tanto [RKLW+15] como [SGGW+06] reflejan la rápida mejora en eficiencia de los LEDs ultravioleta, que ya son competitivos con las lámparas ultravioleta y que además se espera un desarrollo en fiabilidad y eficiencia de modo acelerado.

En general los resultados son muy positivos teniendo en cuenta la aplicación que se planteaba, pero claramente es mejor el uso en condiciones de funcionamiento cíclico que en funcionamiento continuo. Siendo conservadores hay que plantear que los resultados obtenidos a nivel de valores (MTTF, Ea) pueden tener un error debido a que se han empleado pocos dispositivos en los ensayos, por lo que indicar que el LED tipo A no resulta válido y que el LED B presenta un tiempo de vida dos veces superior resulta muy drástico. Desde un punto de vista más objetivo, a la vista de los resultados y teniendo en cuenta un margen de error, se deduce que ambos LEDs pueden ser empleados para esta aplicación en condiciones de trabajo cíclico, y que el LED A habría que reponerlo antes que el B, pero no por ello debe ser desechado, ya que ambos tienen unas expectativas de vida muy positivas, y un costo bajo comparado con las lámparas ultravioleta. Otro factor importante es que un degradación óptica del 30\% es un valor muy conservador, la mayoría de las lámparas ultravioleta se degradan más antes de cambiarlas, además es importante destacar que durante los ensayos se ha demostrado la estabilidad del pico de longitud de onda del LED que sólo ha variado hacia valores mayores en 1,5 nm aproximadamente.

En definitiva estos prolongados ensayos demuestran la operatividad del LED ultravioleta de alta potencia, para la detección de hidrocarburos mediante fluorescencia, y la posibilidad de aplicar este equipo de medida en condiciones de funcionamiento continuo 24/7 y tiempo real. 



\section{Comunicación con Metamateriales}

En el caso de las estaciones fijas, se dispone de un sistema de comunicaciones VSAT. Se trata de una red privada de comunicaciones por satélite, muy conveniente para redes en las que los equipos se encuentran situados en puntos poco accesibles o con baja cobertura de otras alternativas, como es el caso de redes de medición de parámetros medioambientales como estaciones con pluviómetros, nivómetros, etc, normalmente ubicadas en cotas altas de difícil acceso. El coste de instalación de estas redes es elevado, y resultan más rentables cuantas más estaciones tenga la red. Al coste de instalación hay que añadir el coste del segmento satélite. Dado que no se requiere transmitir un gran volumen de datos ni es necesaria una alta velocidad, estos costes no son excesivos si se tiene en cuenta la competencia que existe actualmente en el mercado y que este tipo de redes son contratadas por servicios gubernamentales responsables de la vigilancia del medio ambiente, o de grandes compañías, que las utilizan para diversos usos como vigilancia de gaseoductos, estaciones de servicio, etc. Se puede concluir entonces, que la interpretación más libre del término VSAT puede incluir cualquier forma de sistema terminal pequeño, independientemente de si es parte de una red de datos dedicada o de una red de datos basada en la distribución de televisión terrestre, o si se refiere a aplicaciones civiles o militares.

En cualquier caso, este tipo de redes requiere como medida de seguridad un sistema redundante de comunicaciones., por lo que bien sea por este motivo, o bien por sistemas en los que no se pueda incluir un sistema satélite, se hace necesario profundizar en el desarrollo de un sistema que optimice el sistema de telefonía celular para garantizar las comunicaciones en entornos donde la cobertura no sea óptima.

\subsection{Utilización de metamateriales en comunicación dual}

Durante los últimos años, uno de los temas claves de investigación en electromagnetismo ha sido el estudio y aplicación de los metamateriales. En estos años iniciales de investigación la terminología ha sido muy variada, por lo que inicialmente se ha planteado uniformar dicha terminología con el fin de saber a qué nos estamos refiriendo en cada momento. Por ello, en este capítulo se va a introducir el concepto de metamaterial. Primero se definen dichas estructuras y se aclara la terminología dada al respecto. 
Los metamateriales electromagnéticos (MTMs) se definen como estructuras electromagnéticas homogéneas y artificiales que poseen propiedades que no se encuentran en la naturaleza $[\mathrm{XXX}]$. El hecho de que se consideren estructuras homogéneas implica que las células microscópicas que componen su estructura tienen un longitud p mucho menor que la longitud de onda guiada $\lambda \mathrm{g}$. Podría decirse que el límite superior para dicha distancia es un cuarto de la longitud de onda guiada, $\mathrm{p}<\lambda \mathrm{g} / 4$. La condición $\mathrm{p}=\lambda \mathrm{g} / 4$ se denomina "límite de homogeneidad efectiva" o "condición de homogeneidad efectiva". Dicha condición nos asegura que el fenómeno de refracción domina sobre los fenómenos de dispersión/difracción cuando una onda electromagnética se propaga a través del medio MTM. Cuando esta condición se cumple, la estructura es electromagnéticamente uniforme a lo largo de la dirección de propagación y queda determinada por sus parámetros constitutivos a nivel macroscópico, que dependen únicamente de la naturaleza de la célula unitaria.

Los parámetros constitutivos son la permitividad $\varepsilon$ y la permeabilidad $\mu$ del material. De este modo, el índice de refracción del material n queda definido por:

$$
n= \pm \sqrt{\varepsilon_{r} \cdot \mu_{r}}
$$

donde $\varepsilon_{\mathrm{r}}$ y $\mu_{\mathrm{r}}$ son la permitividad y permeabilidad relativas respecto a la del espacio libre. Las cuatro posibles combinaciones de los signos del par $(\varepsilon r, \mu r)$ dan lugar a los cuatro tipo de materiales de la Fig. 1. De este modo se puede denominar "materiales doblemente positivos" (DPS) a los que poseen $\varepsilon_{\mathrm{r}}$ y $\mu_{\mathrm{r}}>0$ y "materiales con epsilon negativa" (ENG) si $\varepsilon_{\mathrm{r}}<0$ y $\mu_{\mathrm{r}}>0$, "materiales con mu negativa" (MGN) poseen $\varepsilon_{\mathrm{r}}>0$ y $\mu_{\mathrm{r}}<0$ y finalmente aquellos con $\varepsilon \mathrm{r} \mathrm{y} \mu \mathrm{r}<$ 0 son los "materiales doblemente negativos" (DNG). Los DPS, ENG, MNG son los materiales convencionales, mientras que los DNG se denominan también "materiales a izquierdas" o "lefthanded" (LH). Los materiales LH poseen índice de refracción negativo (NRI) y se caracterizan por tener la velocidad de fase y grupo anti-paralelas, como se demostrará más adelante, mientras que los materiales DPS poseen velocidades de fase y grupo paralelas e índice de refracción positivo, por lo que también son denominados "materiales a derechas" o "right-handed" (RH). 


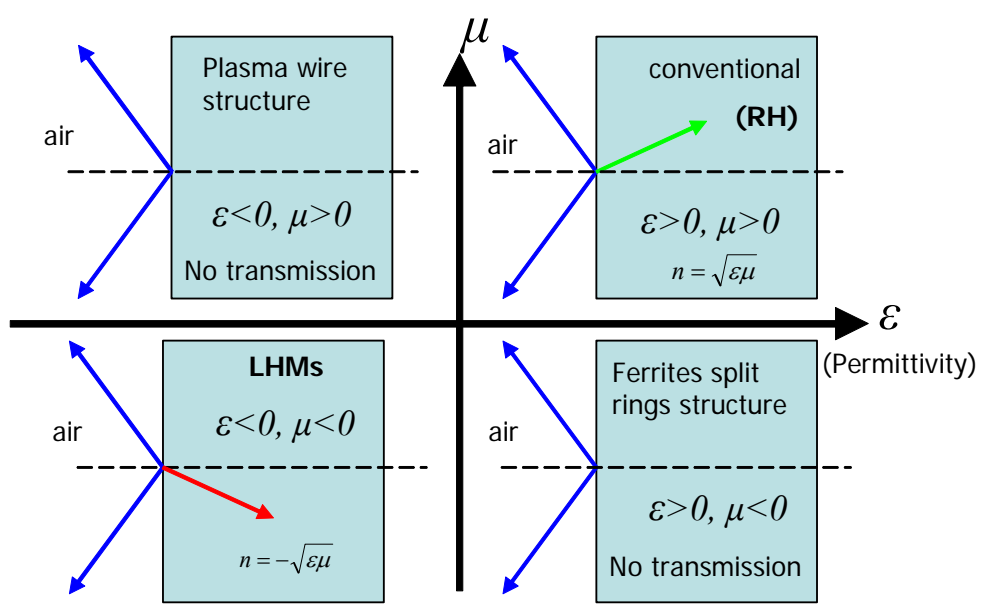

Figura 7-1: Clasificación de los distintos tipos de materiales de acuerdo con los valores de permitividad y permeabilidad

\subsection{Desarrollo diplexor y amplificadores para 380 y 960 MHz}

Los sistemas de telecomunicación inalámbricos tienen cada vez más demanda, lo que obliga a utilizar un espectro cada vez mayor, así como a un reparto en las frecuencias cada vez más eficiente, como es el caso de la telefonía móvil de tercera generación UMTS (uno de los servicios más populares de telecomunicación). En consecuencia, las frecuencias utilizadas cada vez son más altas. A estas frecuencias surgen dos problemas: primeramente las pérdidas en las líneas de transmisión aumentan significativamente y en segundo lugar, los dispositivos de estado sólido tienen limitaciones de potencia en radiofrecuencia (RF). Existen también algunos problemas en el diseño e implementación de sistemas de comunicación convencionales cuando se necesita gran cantidad de potencia en RF. Se podría pensar en combinar dispositivos RF para alcanzar el nivel de potencia deseado, sin embargo esta solución se hace ineficaz a frecuencias de microondas. Además en el receptor o en el emisor se manifiesta una alta figura de ruido como consecuencia de las pérdidas las líneas de interconexión. Otro problema añadido es la necesidad de transpondedores multifunción. Como consecuencia de todos estos inconvenientes se hace necesaria la utilización y desarrollo de amplificadores de alto rendimiento y multifrecuencia.

Las soluciones más convencionales para los problemas antes mencionados pasan por el uso de switches [1], elementos concentrados [2] o diplexores [3].

En este apartado se describen posibles soluciones a este problema y se ejemplifica sobre amplificadores en clase CE, modo de funcionamiento descrito por Raab [8], seleccionado por su facilidad de aplicación a dispositivos bipolares. Se proponen tres técnicas en el diseño e 
implementación de los amplificadores: la primera de las soluciones propuestas consiste en la utilización, en la adaptación de entrada, de líneas CRLH, y en la salida líneas convencionales (en cortocircuito o circuito abierto) para los armónicos, junto con líneas CRLH para sintetizar la impedancia las frecuencias de interés (Figura 7-2).

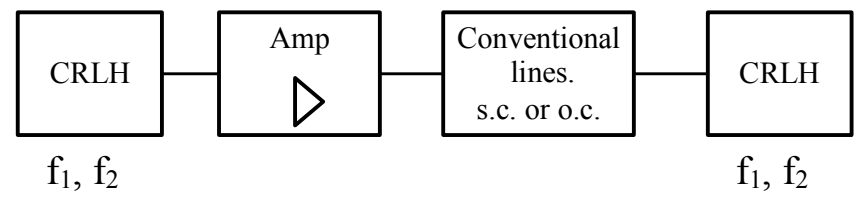

Figura 7-2: Propuesta 1 con líneas convencionales y CRLH

La segunda de las propuestas consiste en adaptar la entrada con líneas CRLH y la salida con líneas E-CRLH (Figura 7-3). En el apartado siguiente se desarrollan los conceptos de este tipo de líneas.

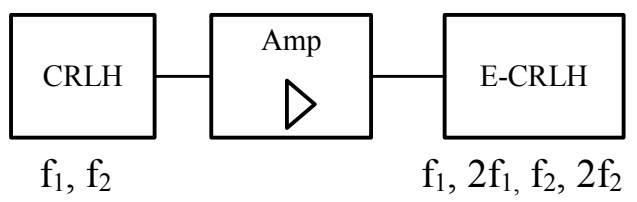

Figura 7-3: Propuesta 2 con CRLH y E-CRLH

Por último se ofrece una solución con diplexores realizados con metamateriales.

La aparición de líneas CRLH en los últimos años [4] ha abierto nuevas posibilidades en el diseño de amplificadores de doble banda. Aunque algún amplificador de doble banda han sido ya presentados anteriormente [5], éstos carecen de la terminación armónica suficiente como para alcanzar alto rendimiento. A este respecto parece una solución factible la planteada en la referencia [6], donde se utiliza una doble red para adaptar la impedancia a los fundamentales y armónicos. Es decir, existe la necesidad en las clases de alto rendimiento de al menos realizar una terminación armónica de las frecuencias que se desee amplificar.

En función de la clase en la que se desea que trabaje el amplificador, así tendrá que ser la impedancia que presente ante los distintos armónicos. Las clases más comunes están representadas en la Tabla XX, donde se describe la máxima eficiencia que puede tener, y las impedancias que deben presentar a la frecuencia fundamental y al primer armónico. 


\begin{tabular}{|c|c|c|c|}
\hline Class & $\begin{array}{c}\text { Max. } \\
\text { Output } \\
\text { Efficiency } \\
\eta_{\text {out }}\end{array}$ & $\begin{array}{c}\text { Fundamental } \\
\text { Impedance } \\
Z_{f o}\end{array}$ & $\begin{array}{c}\text { Even } \\
\text { Harmonic } \\
\text { Impedance } \\
Z_{\text {even harmonic }}\end{array}$ \\
\hline $\begin{array}{c}\text { A } \\
\text { saturated }\end{array}$ & $63.5 \%$ & Real & S.C. \\
\hline $\begin{array}{c}\text { A saturated and } \\
\text { overexcited }\end{array}$ & $80 \%$ & Real & S.C. \\
\hline B & $78.5 \%$ & Real & S.C. \\
\hline C & $100 \%$ & Real & S.C. \\
\hline C saturated & $100 \%$ & Real & S.C. \\
\hline C_E & $80 \%$ & Complex & O.C. \\
\hline D & $100 \%$ & Real & S.C. \\
\hline E & $100 \%$ & Complex & O.C. \\
\hline F & $88 \%$ & Real & S.C. \\
\hline-1 & $88 \%$ & Real & O.C. \\
\hline
\end{tabular}

Tabla XX.-Clases de amplificadores (S.C=Short Circuit, O.C.= Open Circuit).

Se proponen tres posibles soluciones en el diseño de amplificadores, basadas en las descritas anteriormente, tomando como ejemplo un amplificador clase $\mathrm{CE}$ de alto rendimiento.

Se procede al estudio de las líneas que se deben implementar a la entrada y a la salida para hacer trabajar al transistor en la clase deseada (CE). Los valores calculados se pueden observar en la Tabla XXI.

\begin{tabular}{|c|c|c|c|c|}
\hline $\begin{array}{c}\text { Line } \\
\text { Input }\end{array}$ & $\mathrm{f} 1=380$ & $2 \cdot \mathrm{f} 1=720$ & $\mathrm{f} 2=960$ & $2 \cdot \mathrm{f} 2=1290$ \\
\hline $\begin{array}{c}\text { Series } \\
\text { Line }\end{array}$ & $14.45^{\circ}$ & N.D. & $27.75^{\circ}$ & N.D. \\
\hline $\begin{array}{c}\text { Shunt } \\
\text { Line }\end{array}$ & $127.6^{\circ}$ & N.D. & $54.31^{\circ}$ & N.D. \\
\hline Output & \multicolumn{5}{|c|}{} \\
\hline $\begin{array}{c}\text { Series } \\
\text { Line }\end{array}$ & $57.5^{\circ}$ & $\pm 90^{\circ}$ & $54.82^{\circ}$ & $\pm 90^{\circ}$ \\
\hline $\begin{array}{c}\text { Shunt } \\
\text { Line }\end{array}$ & $45.41^{\circ}$ & $\pm 90^{\circ}$ & $39.3^{\circ}$ & $\pm 90^{\circ}$ \\
\hline
\end{tabular}

Tabla XXI Resumen de valores de la línea de transmisión.

El circuito a simular debe realizarse por tanto con las líneas que presenten las impedancias calculadas. 


\section{Diseño con líneas convencionales y metalíneas CRLH.}

Así pues, a la vista de los resultados obtenidos anteriormente, y siguiendo el diseño de la Figura 7-2, si se realiza el diseño con líneas convencionales, éstas deben satisfacer los valores mostrados en la Tabla XXI.

Las redes de entrada son sintetizadas con líneas de transmisión CRLH (solo se necesitan dos condiciones de fase), donde los valores obtenidos se muestran en la Tabla XXII (capacidades en $\mathrm{pF}$, inductancias en $\mathrm{nH}$, y longitudes referidas a grados eléctricos a $\mathrm{f} 1=380 \mathrm{MHz}$ ).

\begin{tabular}{|c|c|c|c|}
\hline & $\mathrm{C}_{\mathrm{L}}$ & $\mathrm{L}_{\mathrm{L}}$ & Length \\
\hline CRLH S & 8.46 & 21.16 & $41.26^{\circ}$ \\
\hline CRLH P & 13.5 & 33.69 & $53.26^{\circ}$ \\
\hline
\end{tabular}

Tabla XXII Resumen de valores de la línea de transmisión de entrada CRLH.

El circuito así realizado debe presentar un comportamiento dual, de forma que para cada una de las dos frecuencias de trabajo presente a la entrada y a la salida del transistor las impedancias características de la clase CE. Para el resto de frecuencias la transmisión debe ser mínima.

Se repite el estudio, esta vez para la otra frecuencia de trabajo, $960 \mathrm{MHz}$.

Los resultados obtenidos mediante simulación del circuito completo (Figura 7-4), se muestran en las figuras:

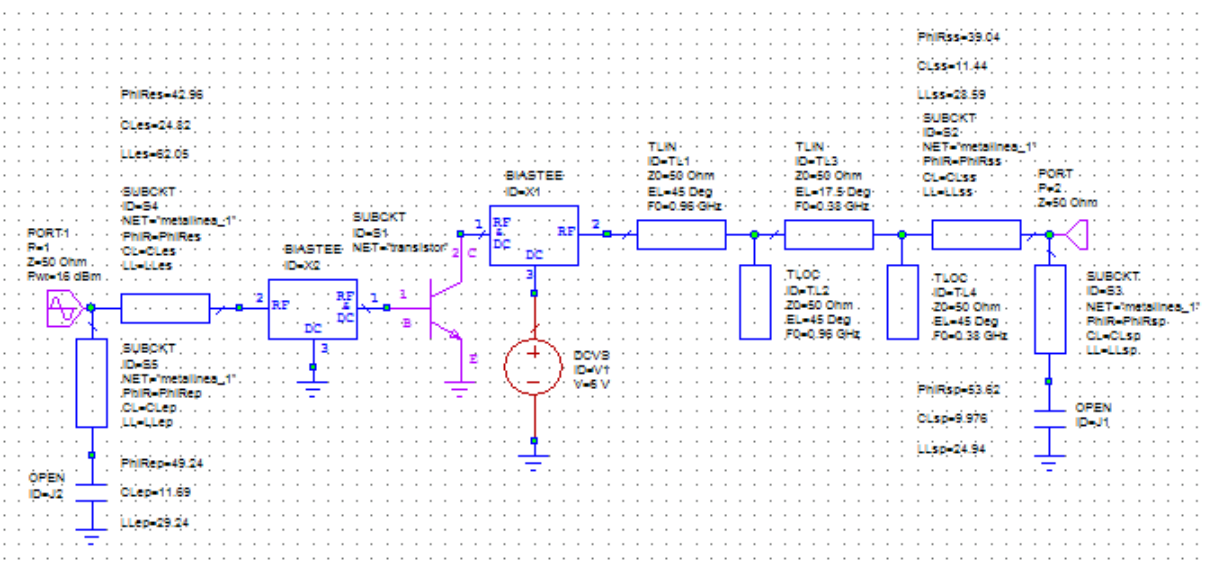

Figura 7-4: Circuito donde se introducen las líneas convencionales y las metalíneas. 


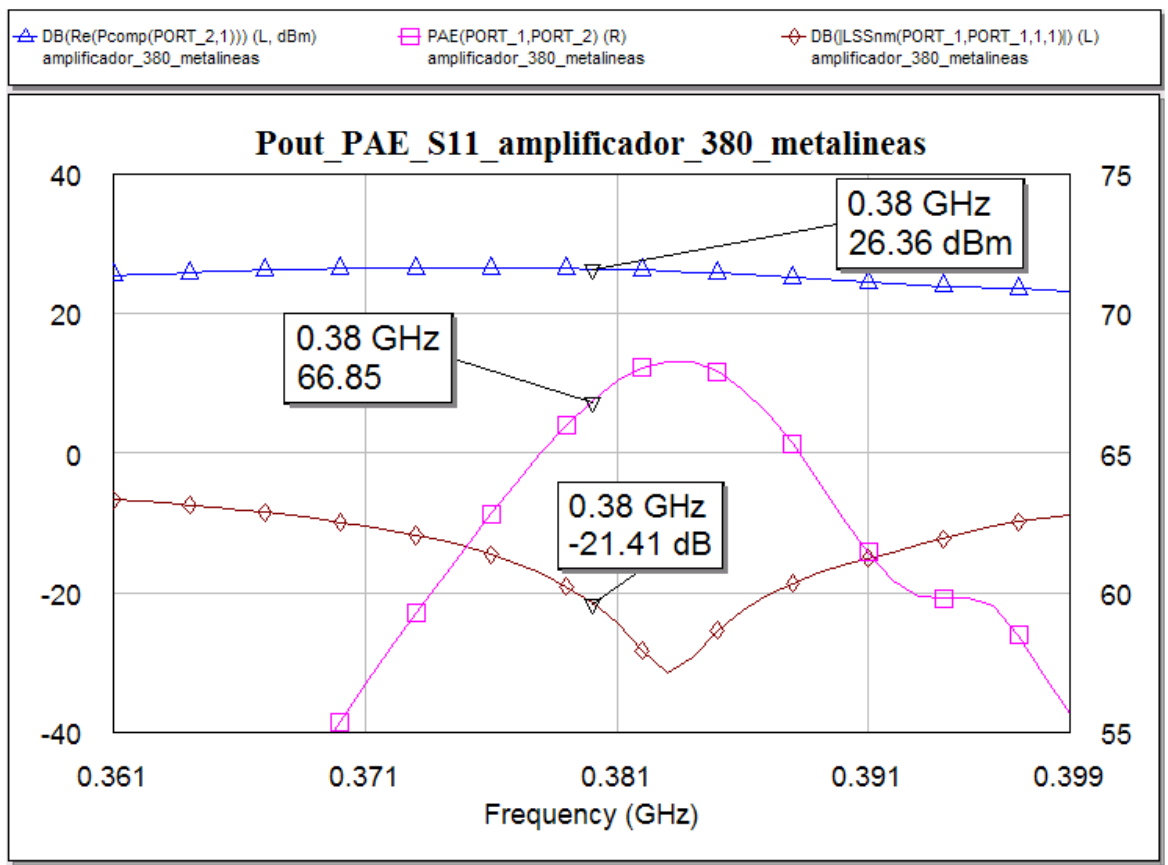

Figura 7-5: Resultados (potencia de salida, PAE y S11) del circuito optimizado implementado con líneas convencionales y metalíneas CRLH, a $380 \mathrm{MHz}$.

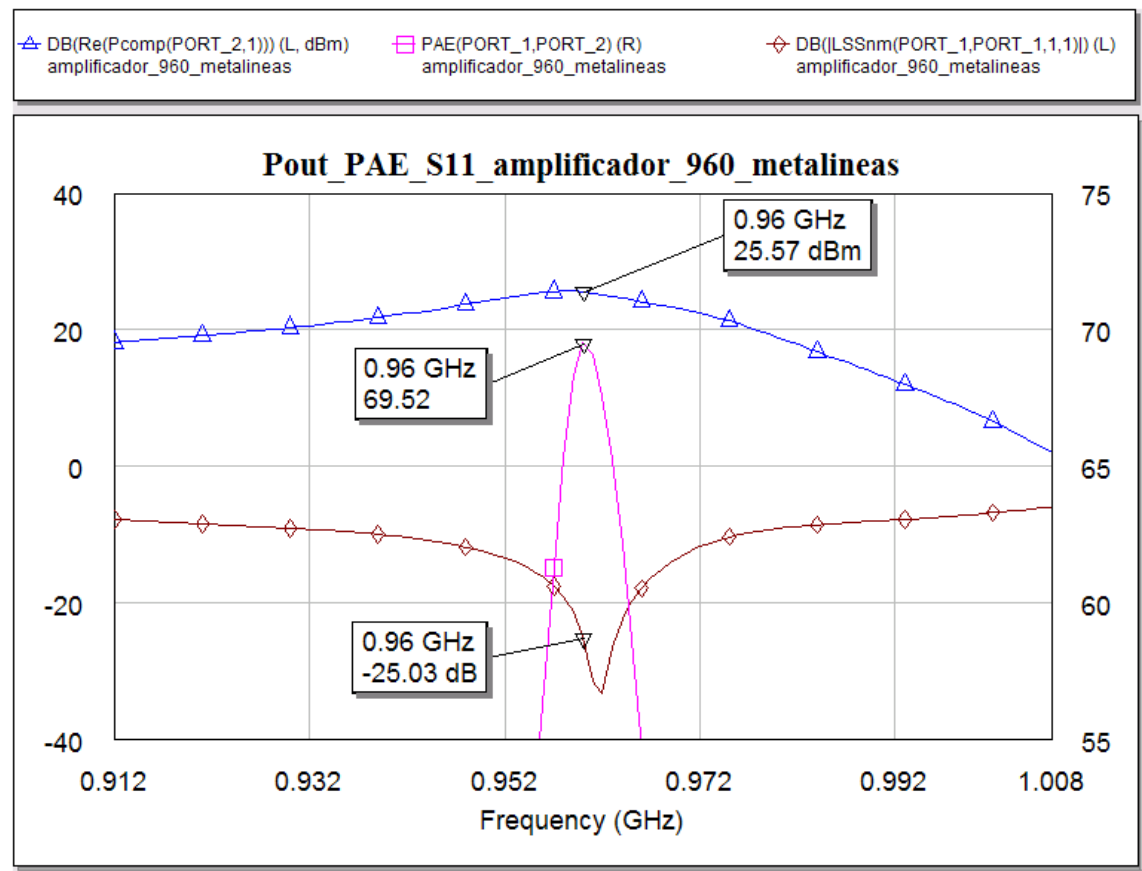

Figura 7-6: Resultados (potencia de salida, PAE y S11) del circuito optimizado implementado con líneas convencionales y metalíneas CRLH, a $960 \mathrm{MHz}$.

\section{Diseño con metalíneas CRLH y E-CRLH}

En este caso las redes de salida son sintetizadas con líneas ECRLH (donde son necesarias cuatro condiciones de fase a los dos fundamentales y sus respectivos armónicos), de forma que el 
conjunto amplificador-redes presente un comportamiento en clase $\mathrm{CE}$ en ambas frecuencias de funcionamiento.

En particular, una línea de transmisión de metamaterial E-CRLH, bajo una condición de equilibrio extendida, presenta dos frecuencias de propagación de longitud de onda infinita (polos). Además, la línea E-CRLH es intrínsecamente una estructura cuatri-banda (donde la cuaterna de frecuencias es arbitraria).

\begin{tabular}{|c|c|c|c|c|}
\hline $\begin{array}{c}\text { E-CRL } \\
\text { S }\end{array}$ & $\mathrm{C}_{\mathrm{R}} \mathrm{C}=1.34$ & $\mathrm{~L}_{\mathrm{R}} \mathrm{C}=3.35$ & $\mathrm{C}_{\mathrm{L}}^{\mathrm{C}}=10.25$ & $\mathrm{~L}_{\mathrm{L}}^{\mathrm{C}}=25.64$ \\
\hline & & & & $\mathrm{L}_{\mathrm{L}}^{\mathrm{D}}=$ \\
\hline \multirow[t]{2}{*}{$\begin{array}{c}\text { E-CRLH } \\
\text { P }\end{array}$} & ${ }_{\mathrm{R}}^{\mathrm{C}}=1.38$ & 5 & $\mathrm{C}_{\mathrm{L}}^{\mathrm{C}}=9.924$ & ${ }_{\mathrm{L}}^{\mathrm{C}}=24.81$ \\
\hline & $\mathrm{C}_{\mathrm{R}}^{\mathrm{D}}=0.99$ & $\mathrm{~L}_{\mathrm{R}}^{\mathrm{D}}=2.48$ & $C_{L}{ }^{D}=13.78$ & $\mathrm{LL}_{\mathrm{L}}^{\mathrm{D}}=$ \\
\hline
\end{tabular}

Tabla XXIII Resumen de valores de la línea de transmisión de salida E-CRLH.

El circuito resultante se implementa en bloques, de manera que se pueda controlar el orden que se quiere desarrollar, para su posterior simulación.

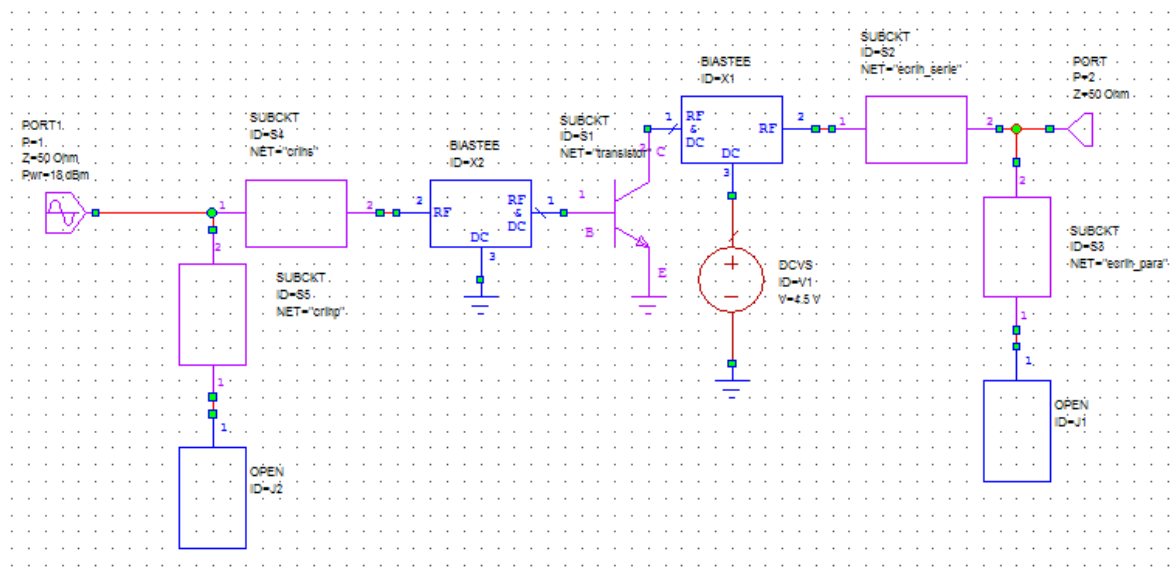

Figura 7-7: Circuito resultante implementado con líneas CRLH y E-CRLH .

En Figura 7-8 y Figura 7-9 se muestra que el comportamiento obtenido para la solución mostrada en la Figura 7-3. Su comportamiento como en el caso anterior es muy cercano al ideal (Potencia de salida y PAE elevadas a las frecuencias de funcionamiento y baja reflexión $\mathrm{S}_{11}$ ) y el pequeño desajuste se debe a una implementación no exacta de los valores de las líneas y las ligeras pérdidas que tienen las líneas CRLH y ECRLH principalmente a las frecuencias de los fundamentales. En ambas frecuencias la ganancia en potencia es mayor que $25 \mathrm{~dB}$, la PAE está cercana al $60 \%$ y la reflexión a la entrada por debajo de $-20 \mathrm{~dB}$. 


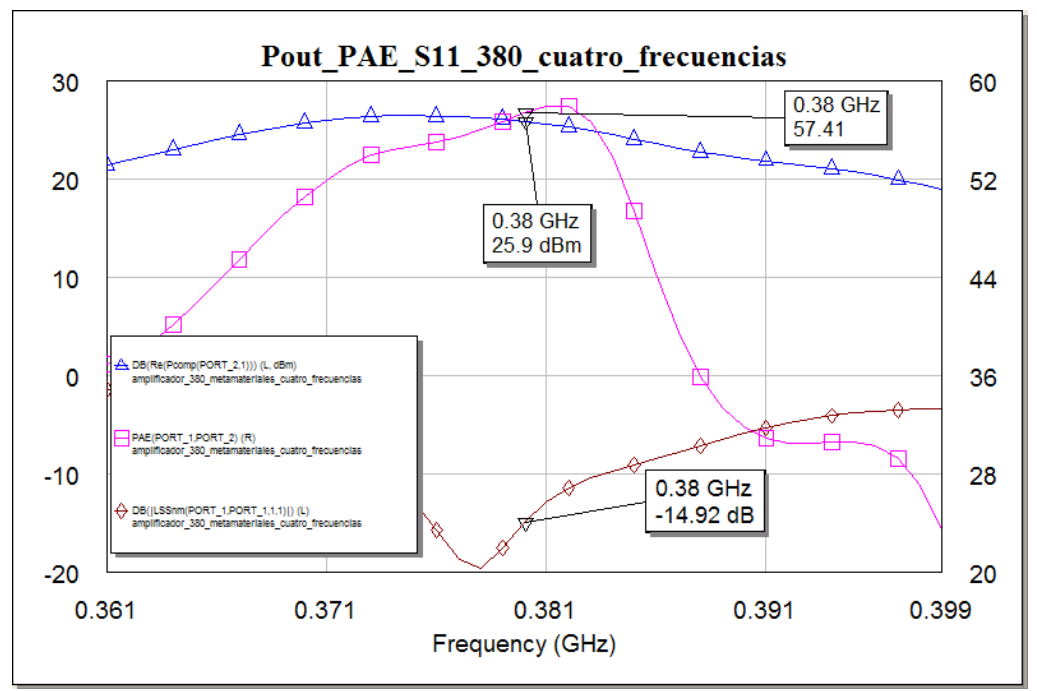

Figura 7-8: Potencia de salida, rendimiento y reflexión a 380 MHz.

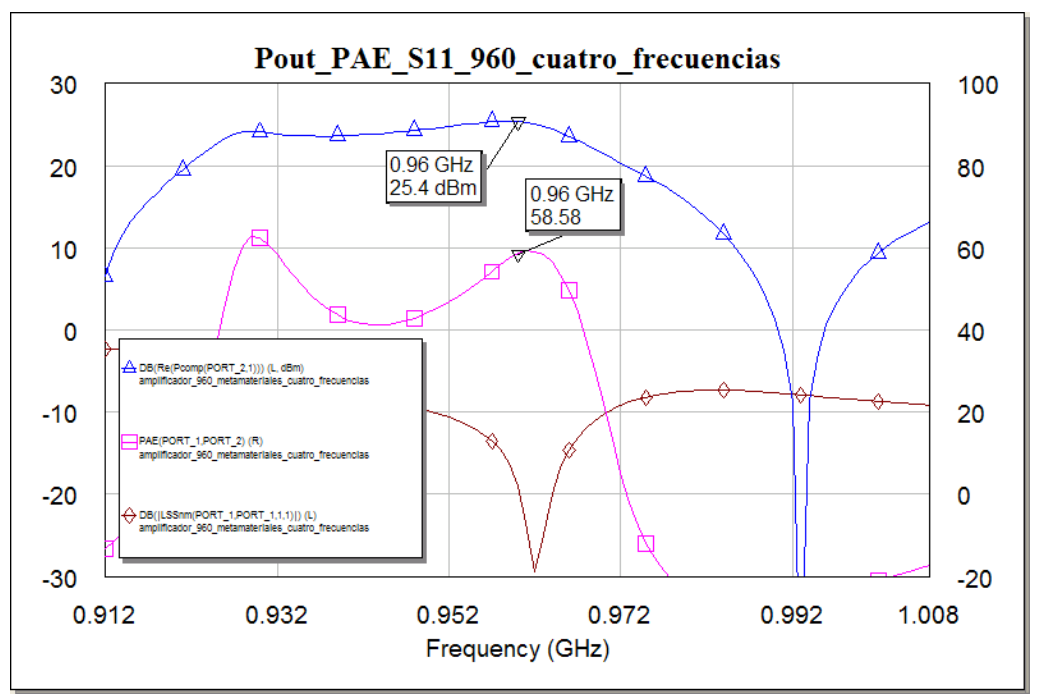

Figura 7-9: Potencia de salida, rendimiento y reflexión a 960 MHz.

\section{Diseño y realización de un amplificador con diplexores CRLH}

Se propone a continuación una solución alternativa a las anteriores, mediante el uso de metamateriales en diplexores, de forma que la señal se inyecta por un elemento común, siendo en este caso el diplexor el encargado de discriminar la señal a uno de los dos amplificadores sintonizados, en función de su frecuencia.

Se parte de un diseño de un diplexor para un amplificador bibanda a las frecuencias de trabajo descritas en los apartados anteriores, es decir, $380 \mathrm{MHz}$ y $960 \mathrm{MHz}$.

Tras los cálculos siguiendo el procedimiento para líneas implementadas con metamateriales, con la salvedad de que esta vez se pretende el control de dos frecuencias en cada rama, por lo que se emplearán líneas D-CRLH.

Se procede entonces al desarrollo de un circuito con líneas convencionales D-CRLH donde exista un puerto común de entrada, una rama Dual CRLH con banda eliminada a $960 \mathrm{MHz}$ 
donde se encontrará una de las salidas del diplexor, y otra rama Dual CRLH con banda eliminada a $380 \mathrm{MHz}$ donde se encontrará la otra salida del diplexor (Figura 7-10).

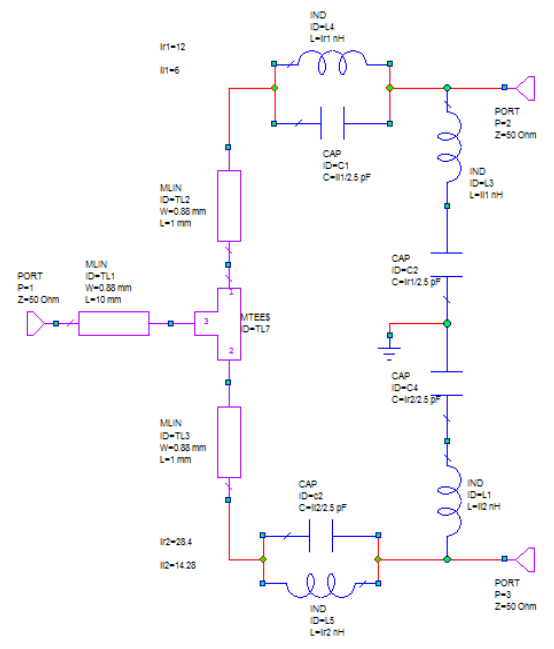

Figura 7-10: Diplexor con elementos ideales para 380 y $960 \mathrm{MHz}$.

Posteriormente se procede al diseño del mismo con componentes reales SMD, a fin de observar las variaciones con respecto al comportamiento del modelo original.
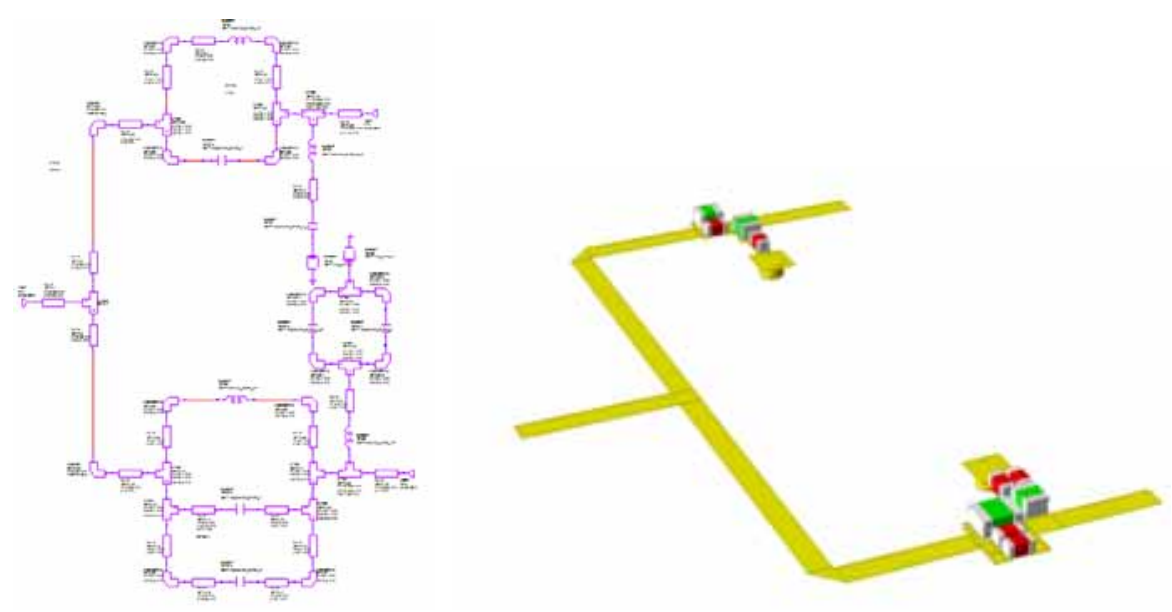

Figura 7-11: Diplexor con elementos reales.

Los resultados que presenta difieren de los del ideal, pero siguen teniendo unos valores aceptables (Figura 7-12). 


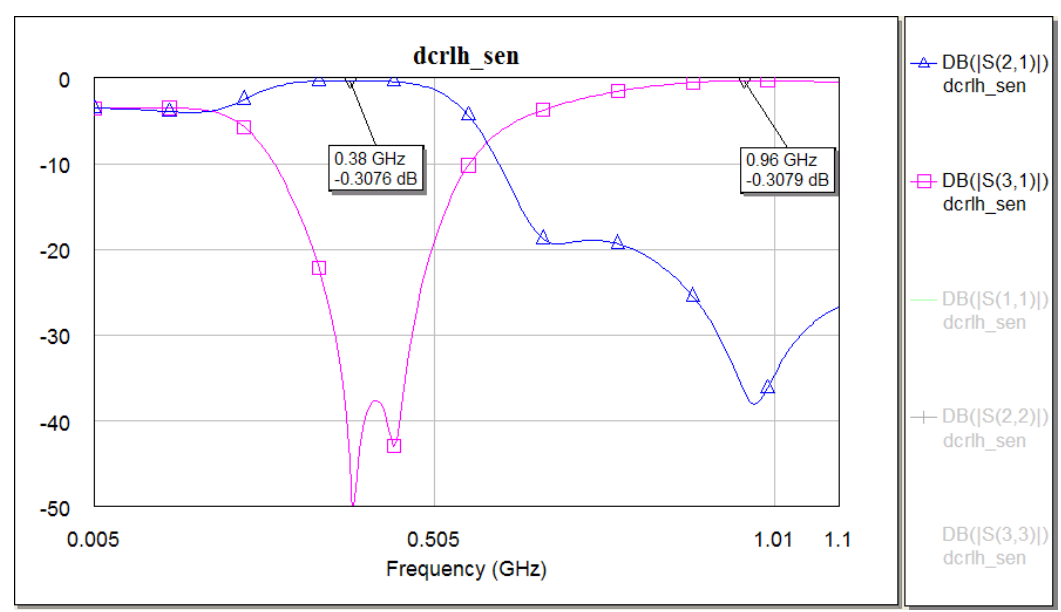

Figura 7-12: Resultados de la simulación del diplexor con elementos reales para 380 y $960 \mathrm{MHz}$.

Se procede por tanto a la realización de sendos amplificadores para cada una de las ramas del diplexor.

Al objeto de tener la suficiente potencia de salida, se realiza cada uno de los amplificadores con dos etapas, una de driver y otra de potencia.

A continuación se expone el desarrollo seguido para la implementación del amplificador de $380 \mathrm{MHz}$.

Partiendo de un amplificador teórico como el mostrado en Figura 7-13.

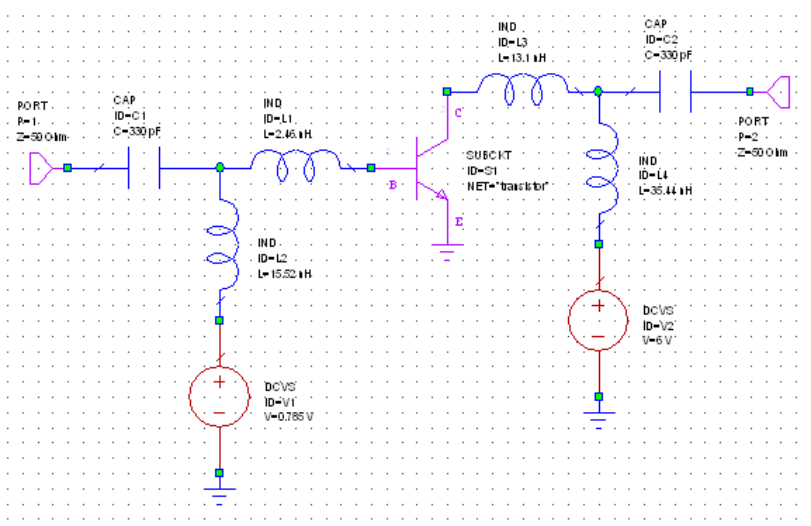

Figura 7-13: Circuito convencional a $380 \mathrm{MHz}$.

A partir de este circuito, se desarrolla el circuito con elementos reales, a fin de comprobar su correcto funcionamiento. El circuito resultante se muestra en la Figura 7-14. 

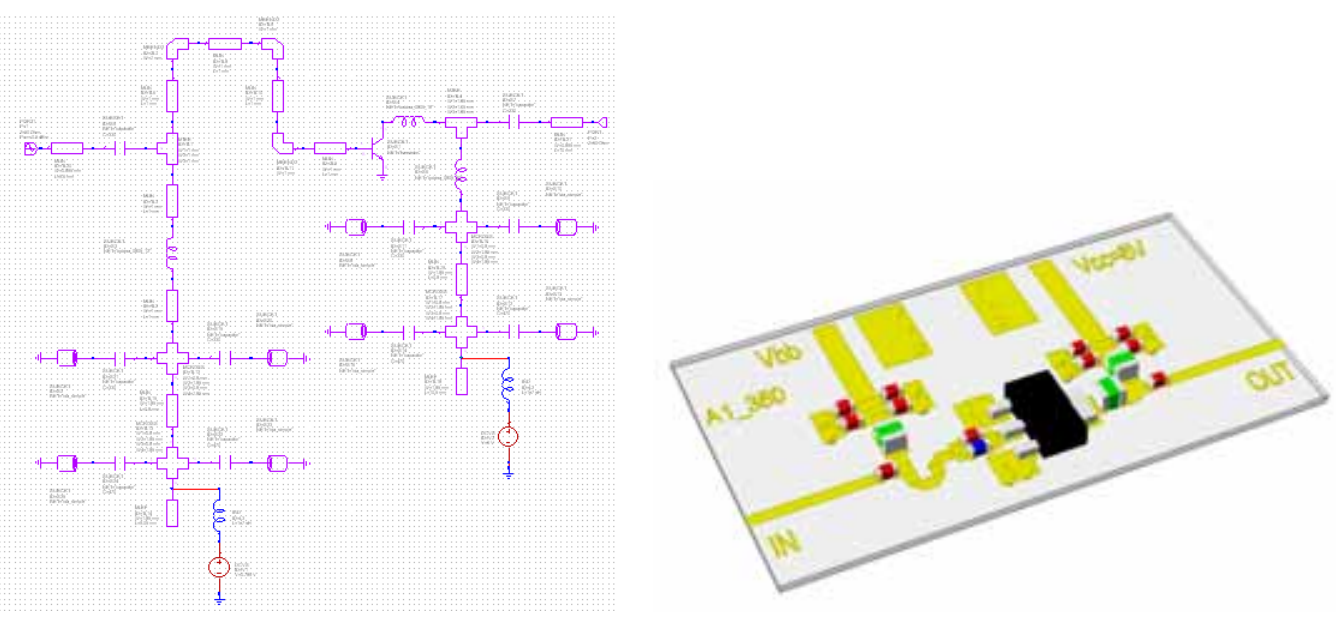

Figura 7-14: Circuito a $380 \mathrm{MHz}$ en vista 3D

Los resultados se presentan en de forma comparativa en la Figura 7-15, donde se observa que el valor que más difiere en el modelo real respecto del ideal es el $\mathrm{S}_{11}$, presentando no obstante un valor válido

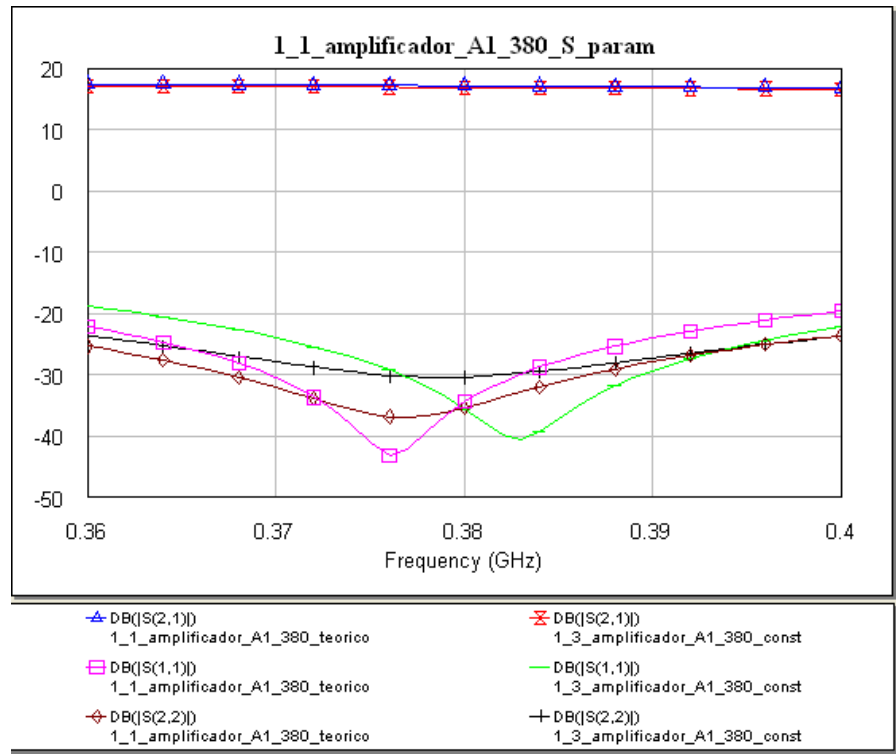

Figura 7-15: Resultados comparativos del amplificador de $380 \mathrm{MHz}$ ideal y real.

Es de resaltar, que si se hace un estudio de potencia del amplificador ideal (Figura 7-17), este presenta una respuesta muy similar, tanto en potencias entregadas como en consumo de corriente, a la del amplificador con elementos reales. 


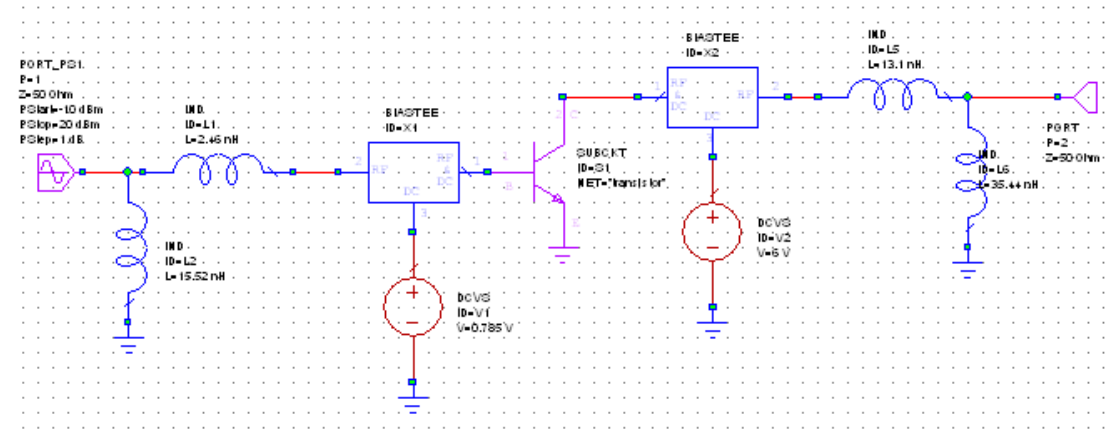

Figura 7-16: Circuito para el análisis de potencia del amplificador.

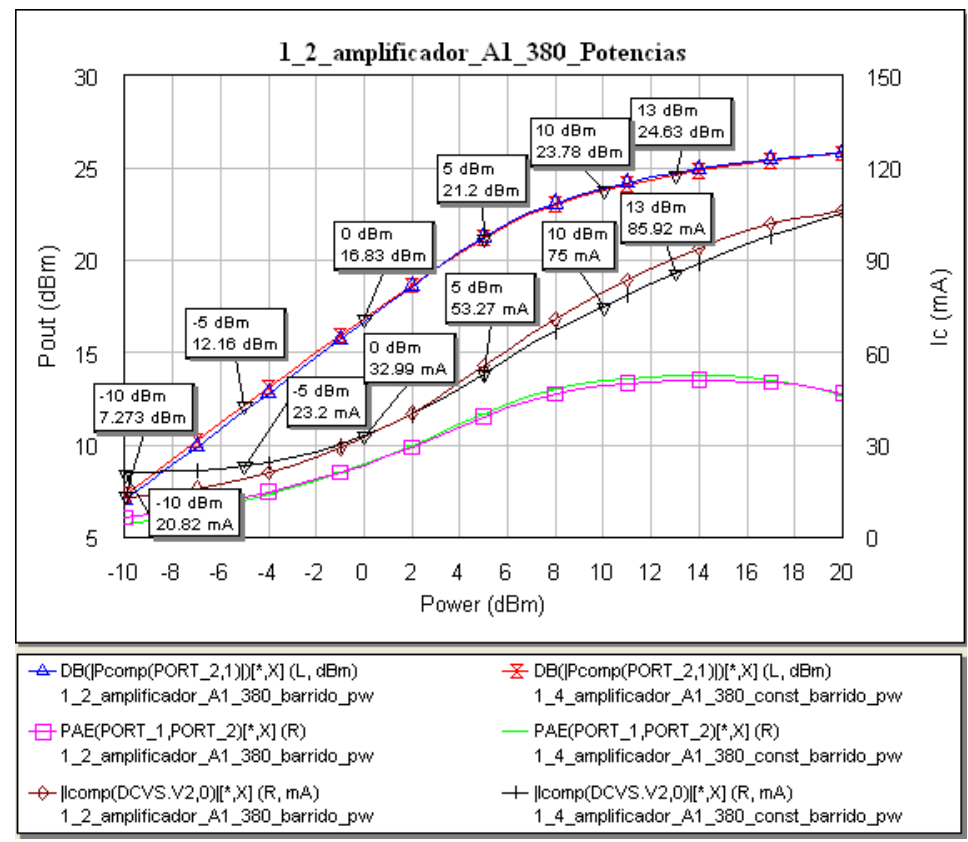

Figura 7-17: Estudio comparativo de potencias del circuito ideal y real a $380 \mathrm{MHz}$.

Siguiendo el mismo procedimiento, se realiza el estudio del amplificador a $960 \mathrm{MHz}$, presentando los resultados que se muestran en Figura 7-18, Figura 7-19 y Figura 7-20
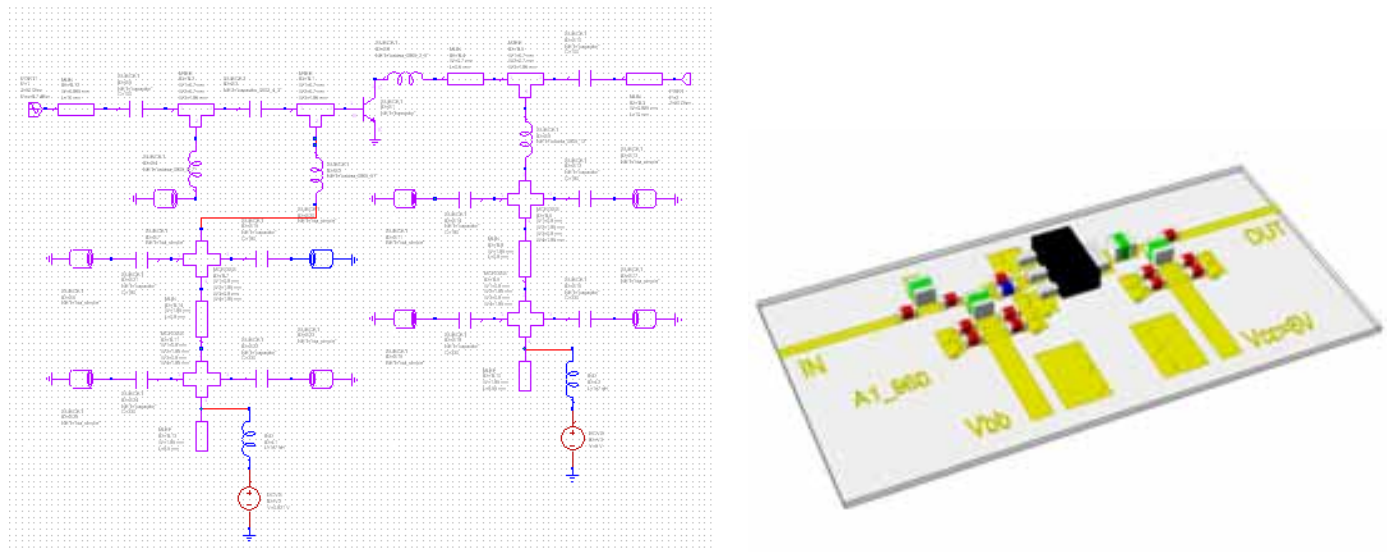

Figura 7-18: Circuito a $960 \mathrm{MHz}$ en 3D. 


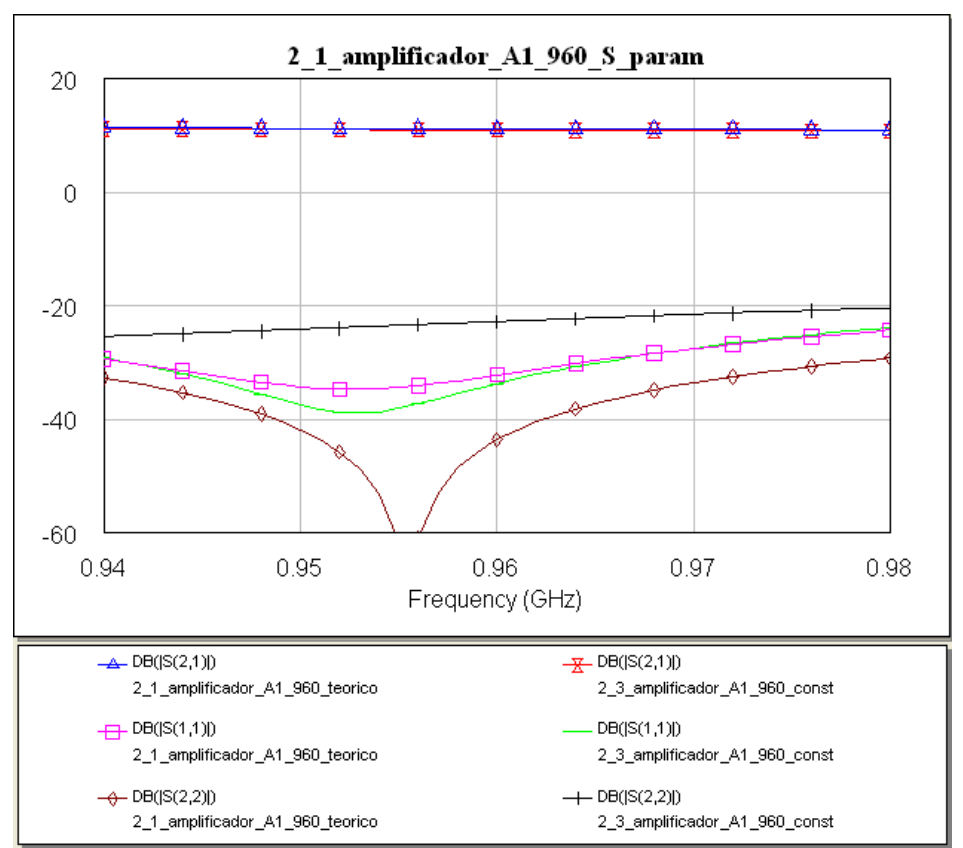

Figura 7-19: Resultados comparativos del amplificador de $960 \mathrm{Mhz}$ ideal y real.

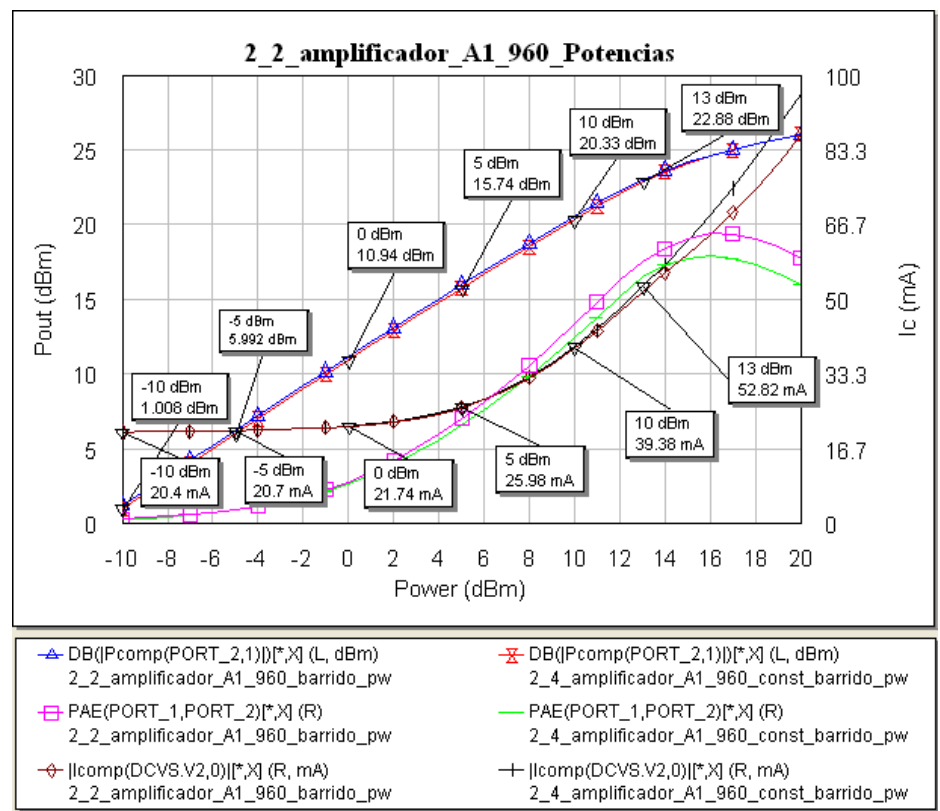

Figura 7-20: Estudio comparativo de potencias del circuito ideal y real a $960 \mathrm{MHz}$.

Una vez visto el correcto funcionamiento de los amplificadores, se procede a su construcción y a la realización de medidas, tanto del amplificador a 380MHz (Figura 7-21 y Figura 7-22), como del amplificador a $960 \mathrm{MHz}$ (Figura 7-23 y Figura 7-24), donde puede observarse un correcto funcionamiento en transmisión, y un desajuste en el parámetro $\mathrm{S}_{22}$, debido a la variación de los componentes reales con respecto a los simulados. 


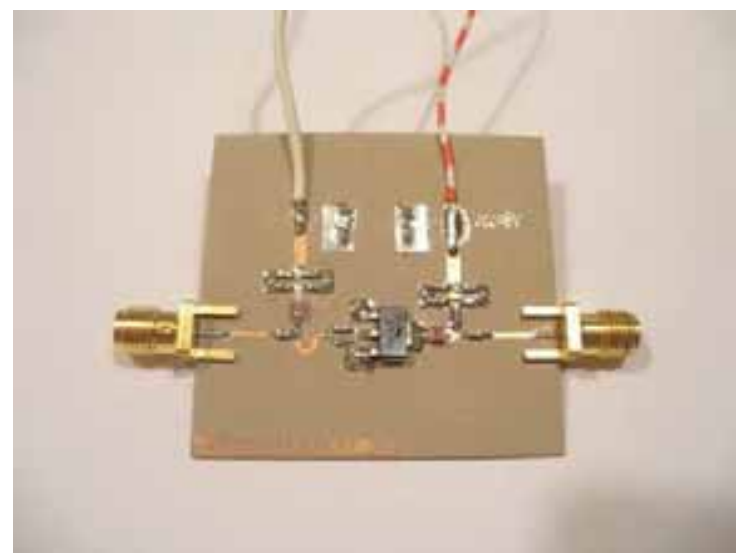

Figura 7-21: Amplificador "driver" a $380 \mathrm{MHz}$ construido.

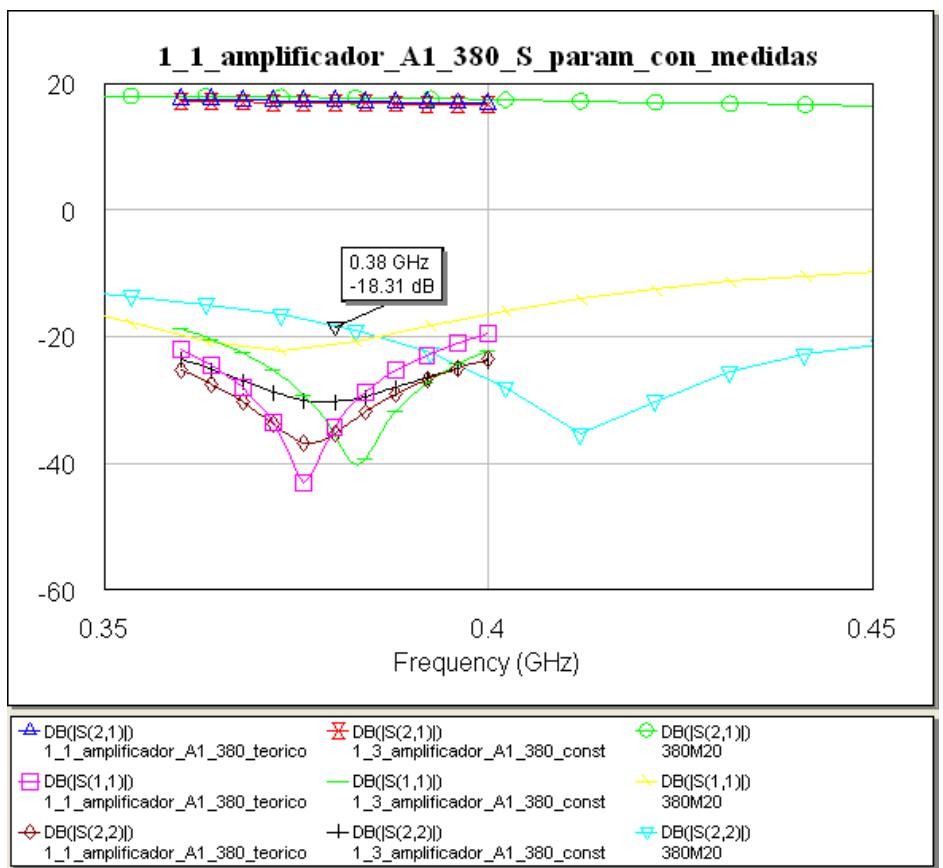

Figura 7-22: Resultados comparativos del amplificador “driver" a $380 \mathrm{MHz}$ construido.

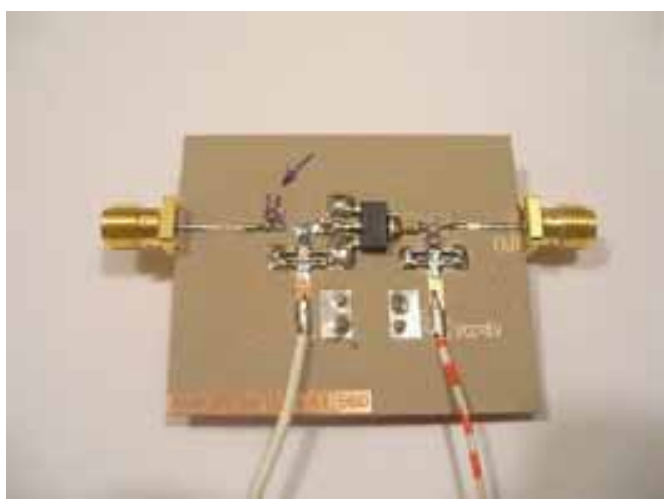

Figura 7-23: Amplificador “driver” a $960 \mathrm{MHz}$ construido. 


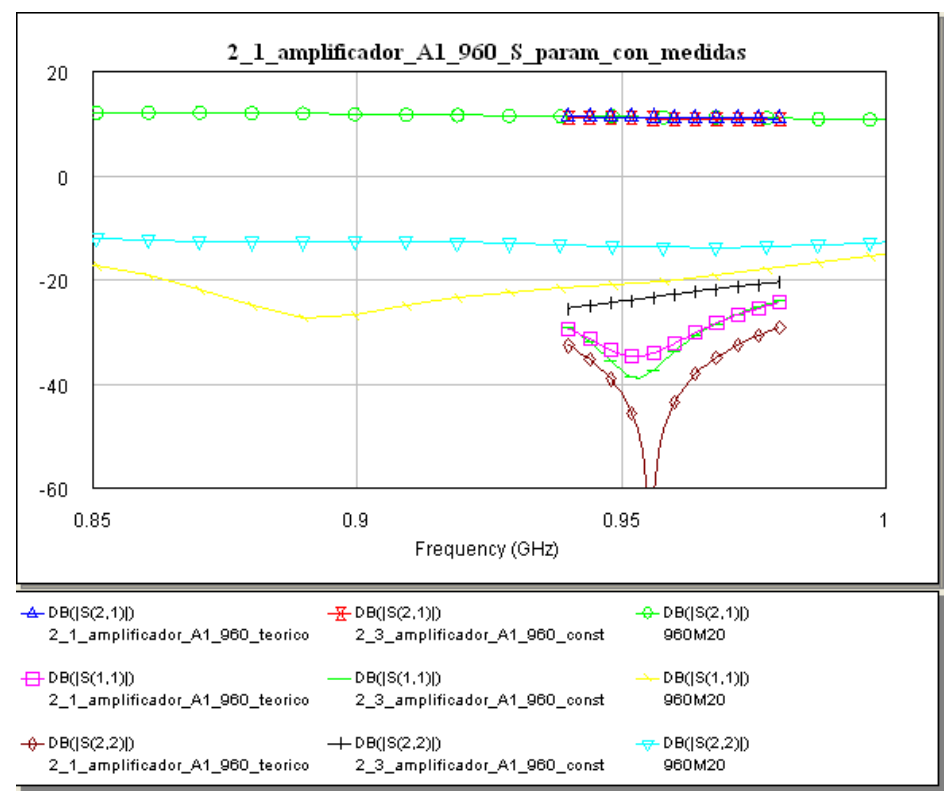

Figura 7-24: Resultados comparativos del amplificador "driver" a $960 \mathrm{MHz}$ construido.

El paso siguiente consiste en montar a continuación de la etapa driver la etapa de potencia, de forma que se procede al desarrollo del circuito en el simulador. En Figura 7-25 se muestra el diagrama de bloques utilizado para $380 \mathrm{MHz}$, donde el primer bloque representa el driver ya analizado, se detalla la etapa de potencia utilizada, y se muestra el aspecto de ambas etapas montadas.
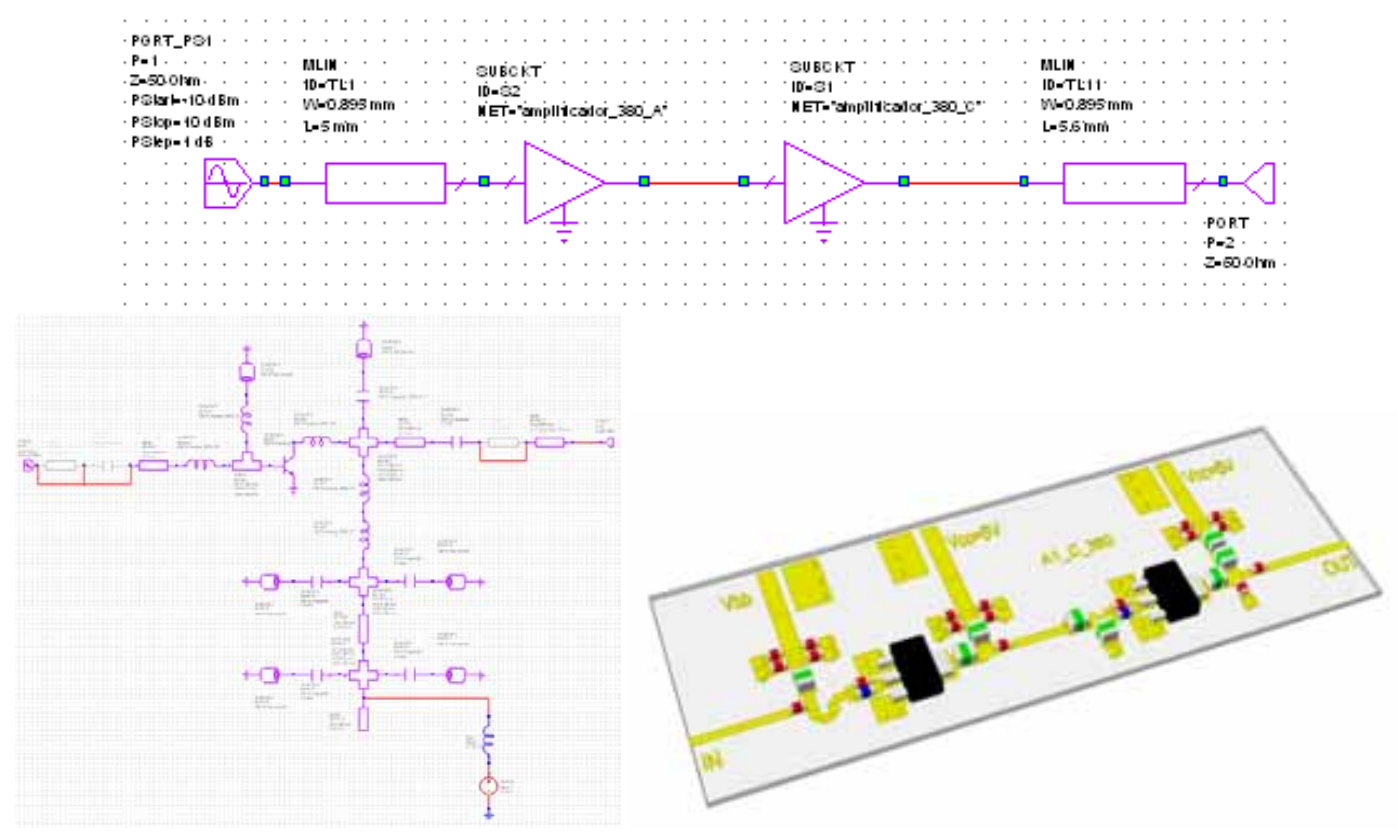

Figura 7-25: Diagrama de bloques driver+Potencia, detalle del circuito de potencia y circuito real a $380 \mathrm{MHz}$.

Los resultados simulados de este montaje se muestran en Figura 7-26. 


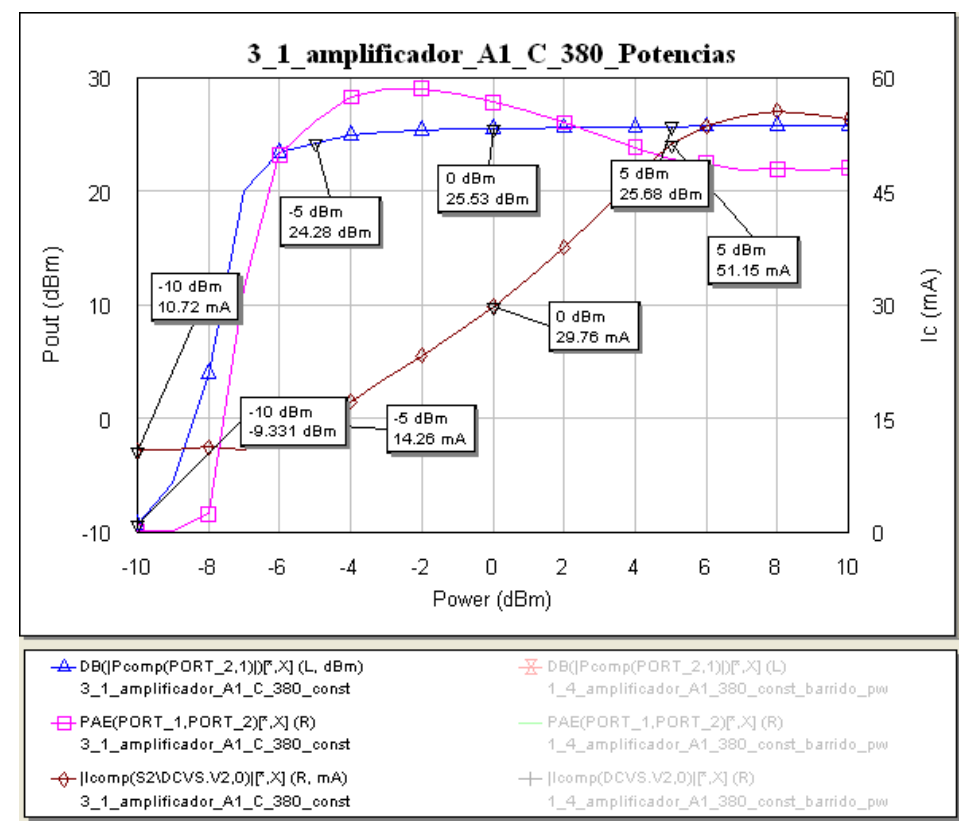

Figura 7-26: Resultados comparativos del amplificador driver+Potencia a $380 \mathrm{MHz}$.

Posteriormente se procede a su construcción física, tal y como se muestra en Figura 7-27. Las medidas realizadas sobre este montaje muestran resultados muy similares a los simulados respecto a potencias y PAE, si bien el consumo (Ic) es algo mayor que el simulado.

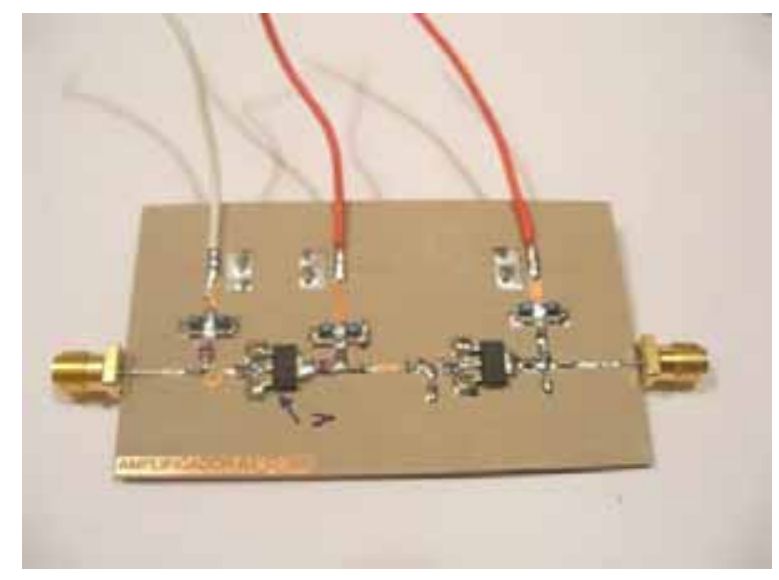

Figura 7-27: Amplificador driver+Potencia a $380 \mathrm{MHz}$ construido.

En Figura 7-28 se muestra el diagrama de bloques utilizado para $960 \mathrm{MHz}$, donde el primer bloque representa el driver ya analizado, se detalla la etapa de potencia utilizada, y se muestra el aspecto de ambas etapas montadas. 


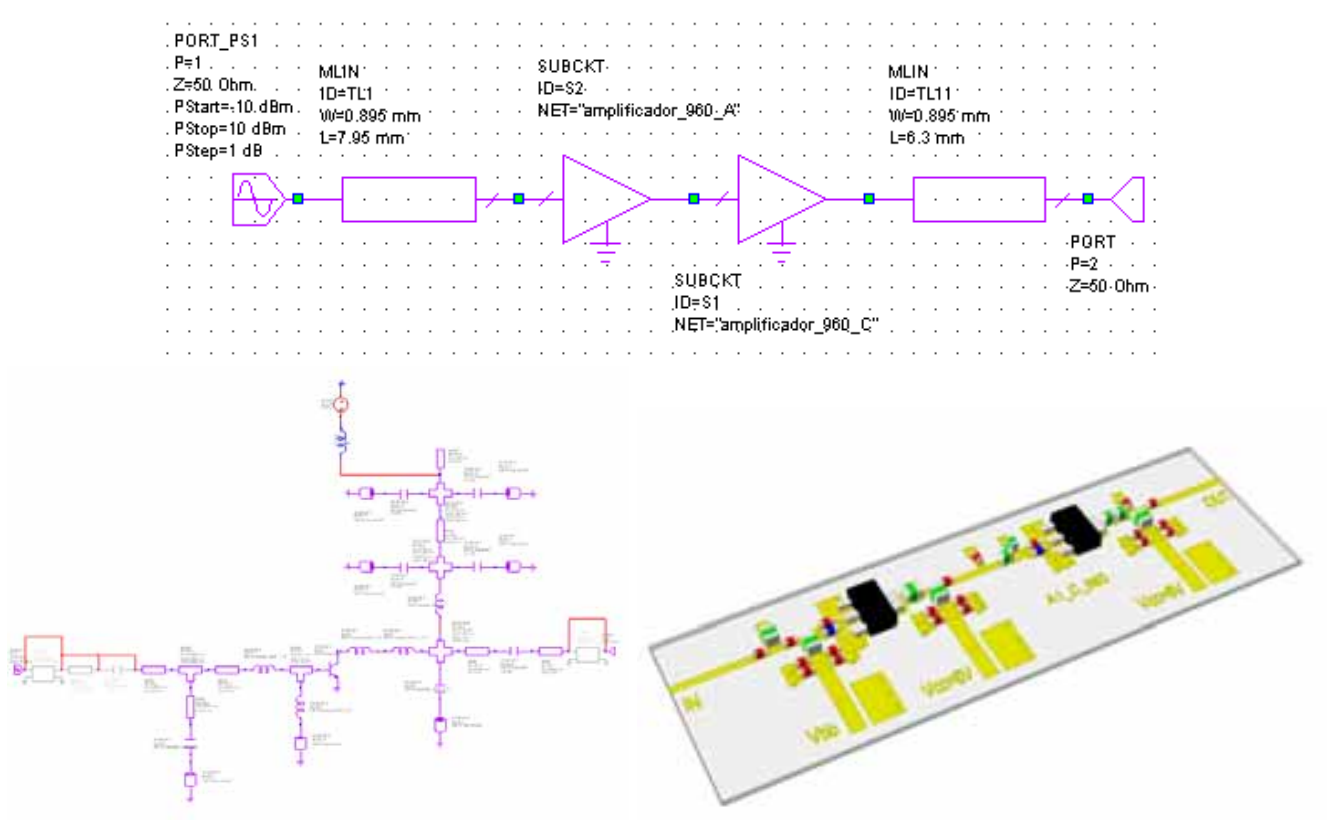

Figura 7-28: Diagrama de bloques driver+Potencia, detalle del circuito de potencia y circuito real a $960 \mathrm{MHz}$.

Los resultados simulados de este montaje se muestran en Figura 7-29.

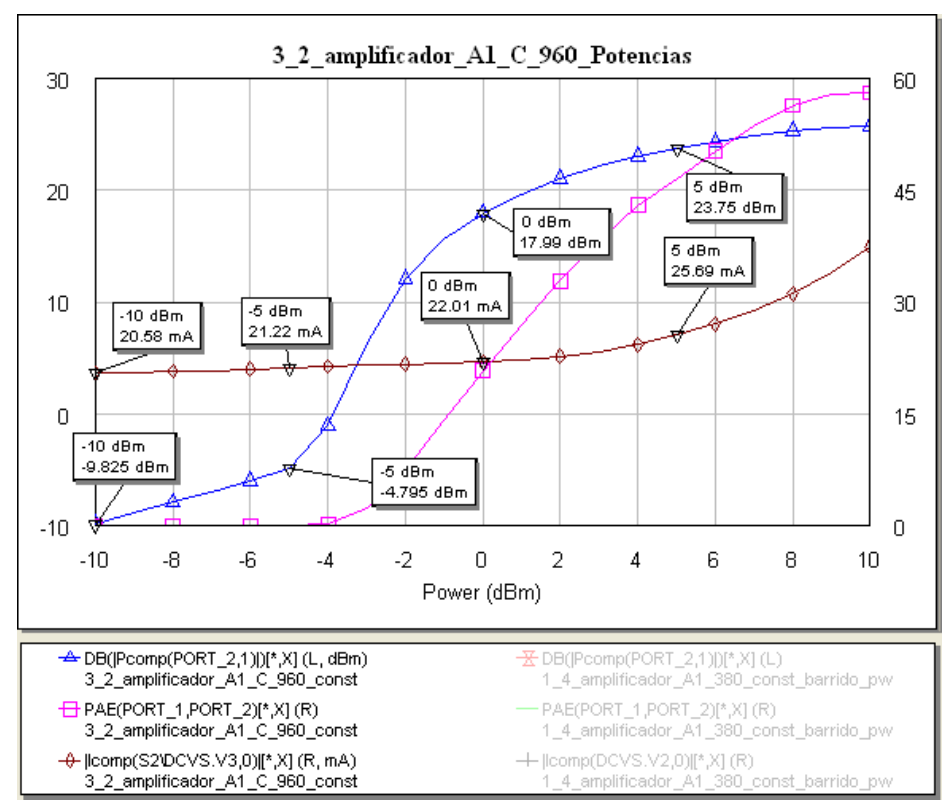

Figura 7-29: Resultados comparativos del amplificador driver+Potencia a $960 \mathrm{MHz}$.

Posteriormente se procede a su construcción física, tal y como se muestra en Figura 7-30, presentando las medidas realizadas sobre este segundo prototipo resultados similares a los comentados para el amplificador anterior (resultados muy similares a los simulados respecto a potencias y PAE, si bien el consumo (Ic) es algo mayor que el simulado). 


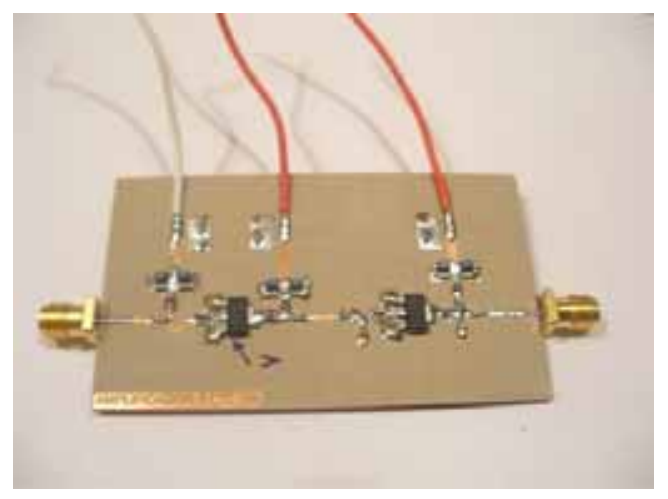

Figura 7-30: Amplificador driver+Potencia a $960 \mathrm{MHz}$ construido.

Por último, se montan los dos amplificadores junto con dos diplexores a fin de tener una única entrada y una única salida, tal y como muestra la Figura 7-31.
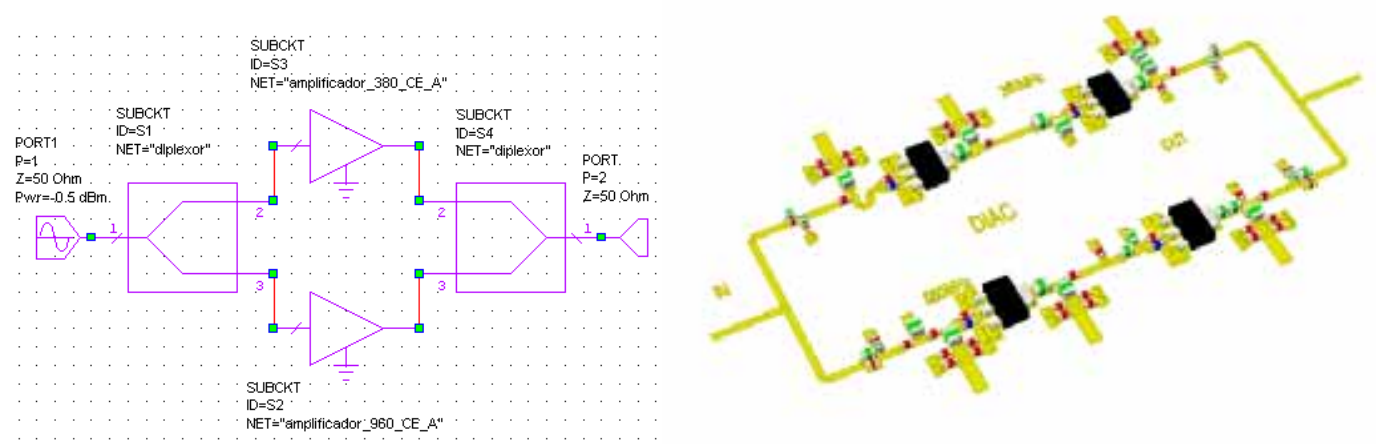

Figura 7-31: Diagrama de bloques y circuito físico con dos diplexores y dos amplificadores.

El posterior análisis de potencia y PAE a $380 \mathrm{MHz}$ se muestra en la Figura 7-32, donde no se aprecia pérdida de potencia comparativamente al circuito aislado (sin diplexores).

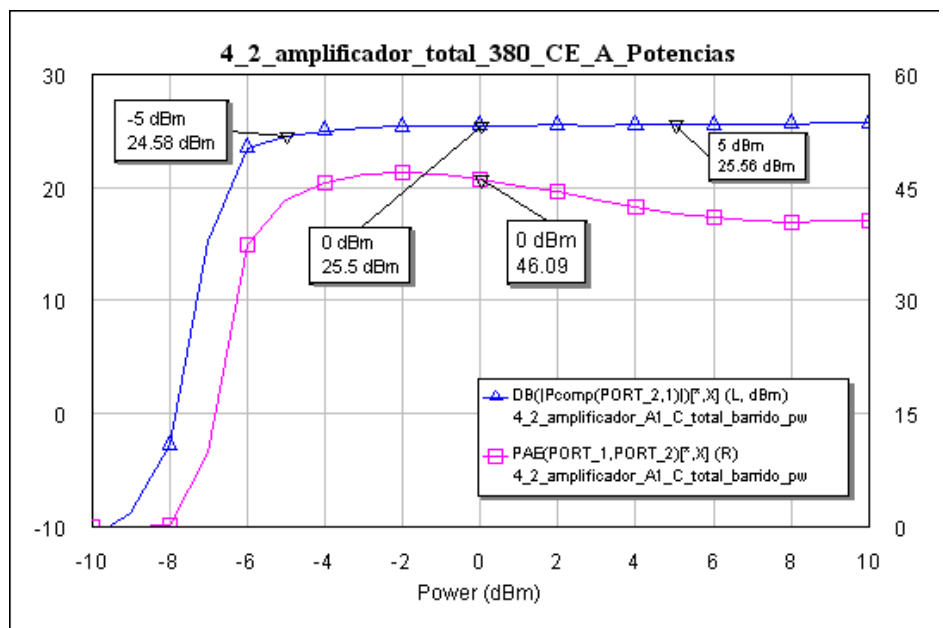

Figura 7-32: Resultados comparativos del amplificador dual completo para una frecuencia de $380 \mathrm{MHz}$. 
Para el caso de $960 \mathrm{MHz}$ el posterior análisis de potencia y PAE se muestra en la Figura 7-33, donde tampoco se aprecia pérdida de potencia comparativamente al circuito aislado (sin diplexores).

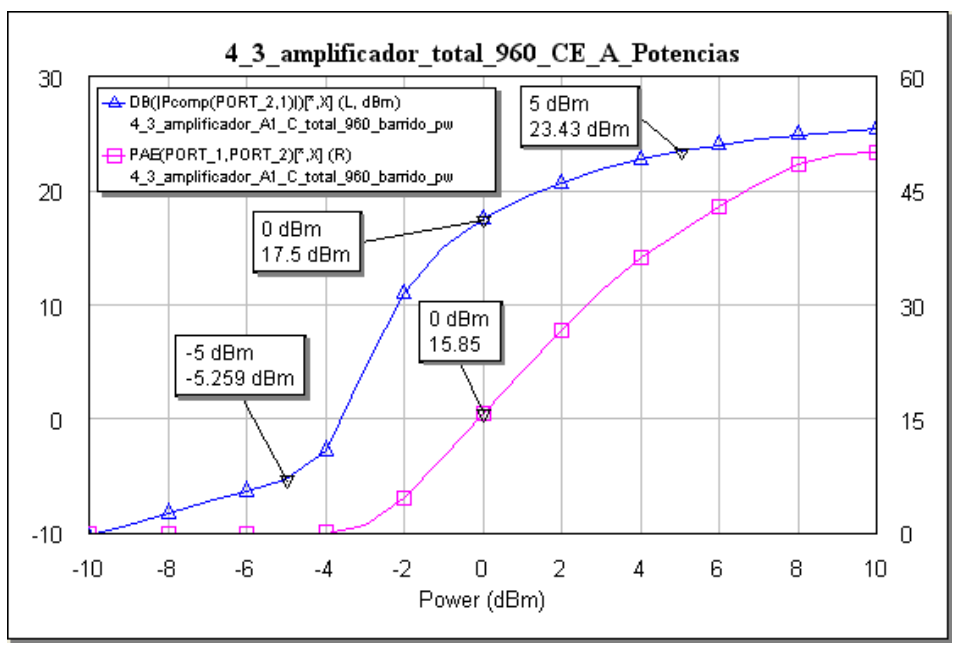

Figura 7-33: Resultados comparativos del amplificador dual completo para una frecuencia de $960 \mathrm{MHz}$.

\subsection{Conclusiones}

Las líneas de metamateriales presentan una alternativa a los circuitos clásicos, ofreciendo además nuevas posibilidades de desarrollo en el campo de estructuras activas.

Las posibilidades que ofrece la simulación hacen que cada vez se pueda predecir el comportamiento de montajes complejos de implementar. Además el hecho de trabajar con metamateriales no supone una carga adicional a la simulación, ya que éstas se realizan con componentes discretos convencionales.

Con estas simulaciones se describe la técnica de diseño para el amplificador en clase CE banda dual usando líneas de transmisión CRLH y ECRLH, que no requieren el uso de conmutadores o diplexores. Se propone un procedimiento basado en una sección de tipo L con líneas CRLH y ECRLH para encontrar los valores de las impedancias que satisfacen los requerimientos en el primer y segundo armónico. El amplificador resultante presenta alto rendimiento, bajas pérdidas y unos diseños compactos exigidos en los equipos de comunicaciones inalámbricos modernos.

Por último, se muestra otra posibilidad de diseño montando dos amplificadores con diplexores, con la ventaja de presentar un diseño sencillo tanto en los cálculos como en el desarrollo del circuito, presentando además unos resultados satisfactorios. 


\section{Conclusiones y trabajos futuros}

El objetivo fundamental de esta tesis es validar la aplicación del LED ultravioleta de alta potencia para la detección de contaminantes en aguas continentales mediante métodos de fluorescencia. El sistema se plantea para su implantación en estaciones automáticas de control de calidad de agua, para realizar un seguimiento en tiempo real y modo continuo de los posibles contaminantes, para identificarlos. Para realizar esta validación se ha realizado un exhaustivo análisis de los LEDs ultravioleta de alta potencia a $365 \mathrm{~nm}$, que ha incluido su caracterización completa, y su análisis de vida en diferentes modos de trabajo, además se ha desarrollado una metodología de identificación de contaminantes, basándonos en la huella espectrometría que dejan los hidrocarburos, y en su ajuste con Gaussianas o Lorentzianas.

El histórico de esta tesis tiene como objetivo la detección de contaminación por hidrocarburos, pero se comenzó en la línea de emplear metamateriales para la detección de contaminantes y posteriormente se pasó a los HP UV-LED (LEDs ultravioleta de alta potencia). En la línea de metamateriales en los que no se tenía experiencia se empezó por desarrollar sistemas de comunicaciones móviles que por una parte son un bloque fundamental de un sistema de alarma de contaminantes, y por otra nos permitía adquirir experiencia en metamateriales para pasar al sensado con este tipo de materiales. En paralelo con la posibilidad surgió la aparición de nuevos dispositivos (LEDs ultravioleta de alta potencia) y equipos (microespectrometros) que prometían ser una alternativa fiable y económicamente asequible para desarrollar sensores de fluorescencia para detectar contaminantes, hay que tener en cuenta que los hidrocarburos son fluidos que fluorecen fácilmente bajo luz ultravioleta, y esta última línea de investigación es en el que se ha desarrollado el resto de la tesis.

La tesis se ha iniciado con un análisis del estado del arte en control de calidad del agua y detección de contaminantes, haciendo hincapié en la aplicación de la fluorescencia para hidrocarburos, y cuáles son sus principales características. A partir de ahí se presenta el trabajo realizado que ha sido amplio y centrado en varias líneas:

- La pre-validación del LED como fuente de luz excitadora de fluorescencia en lugar de los sistemas tradicionales.

- La exposición de la metodología de medida y su instrumentación. 
- El análisis de la firma de los hidrocarburos bajo la luz del HP UV-LED. En este punto se analizar parámetros secundarios como la viscosidad y temperatura que resultan ser fundamentales para identificar al hidrocarburo. Se prueban diversos modos de filtrado de la señal medida, la firma del hidrocarburo, para reflejar una buena lectura, y se realiza un análisis con gaussianas y lorentzianas para descomponer la firma, y poder identificarla. Sus principales aplicaciones son cuantificar cuando una luz del LED degradada, puede ofrecer una firma espectrométrica claramente identificada y por otro lado identificar un hidrocarburo que ha contaminado el agua. Se demuestran el alcance de ambos desarrollos.

- El análisis funcional del HP UV-LED a largo plazo. Uno de las posibles ventajas del sistema de detección con LED para funcionamiento continuo, es que los sistemas de lámparas tradicionales no son operativos en esta área por razones de coste y sobre todo por razones de vida, son lámparas que se degradan mucho en funcionamiento continuo y su vida va de las 1000 a las 10000 horas. Una vida suficiente para un laboratorio, pero insuficiente para trabajo en campo de modo continuo, por ello era imprescindible analizar la vida del LED. Se realiza el análisis de los parámetros eléctricos y térmicos en dos tipos de LEDs de $3 \mathrm{~W}$, tipos A y B,. y se miden ambos en dos modos de trabajo continuo y cíclico (30s ON\&30s OFF), y dos modos de operación convección natural y forzada. El siguiente paso ha sido realizar ensayos de vida acelerada en temperatura $\left(60^{\circ} \mathrm{C}\right.$, $75^{\circ} \mathrm{C}$ y $90^{\circ} \mathrm{C}$ ) respecto a la condición nominal de trabajo $\mathrm{Ta}=25^{\circ} \mathrm{C}$, se han identificados las degradaciones y esperanzas de vida de los LEDs con un límite de fallo por degradación del 70\%, y posteriormente se extrapola mediante el modelo Weibull-Arrhenius la ecuación de la fiabilidad de ambos tipos de LEDs y condiciones de trabajo a la temperatura nominal. Además se realiza un análisis de fallos de ambos LEDs para identificar posibles mejoras en HP UV-LEDs, que son una tecnología aún inmadura y en proceso de desarrollo y mejora.

- Tras desarrollar la línea final de investigación de la tesis, se incluye su comienzo, la aproximación a los metamateriales, mediante el desarrollo de sistemas de comunicaciones móviles duales, que permitirían una comunicación segura y redundante de una alarma por contaminación. 


\subsection{Contribuciones}

A partir de los resultados obtenidos, a continuación se exponen las principales contribuciones al estado del arte en esta área tecnológica:

- Se realiza una pre-validación del HP UV-LED comparándolo con fuentes convencionales para fluorescencia (lámpara de mercurio y láser). Se identificaron las ventajas y limitaciones del LED respecto a sus "competidores" así como se desarrollaron medidas en todos los hidrocarburos típicos de consumo con estas fuentes de luz. Los resultados se publicaron en una conferencia [AGMGE13].

- Se ha desarrollado una instrumentación de medida mediante HP UV-LED y microespectrómetros que no difiere de la publicada por otros grupos de investigación que han trabajo en paralelo temporalmente con nosotros, en estos grupos han trabajado en la detección de contaminación por algas en lugar de hidrocarburos. Nosotros no hemos avanzado en un prototipo operativo de la instrumentación porque para nosotros será prioritario identificar hidrocarburos concretos, para ello hemos realizado análisis mediante gaussianas, y además, queremos operar en continua 24/7, para ello hemos realizado diversos ensayos de vida acelerada sobre los HP UV-LED, ambos objetivos que consideramos muy ambiciosos, nos diferencian de los grupos de investigación indicados

- Se ha analizado la respuesta del hidrocarburo a diversas condiciones de degradación del LED, y se ha demostrado que una pérdida de potencia lumínica del $30 \%$ es muy conservadora, se puede seguir identificando la firma del hidrocarburo con una degradación del $40 \%$ en cualquiera de los compuestos, incluido el de menor fluorescencia. No hemos visto ningún trabajo que aporte esta información en el área de LEDs aplicados a la espectrometría.

- Se ha empleado el análisis por gaussianas y lorentzianas para el objetivo antes descrito, pero también para desambiguar la identificación de la firma de los diferentes hidrocarburos con varios niveles de iluminación, del $70 \%$ al 108\% de la luz emitida inicialmente por el LED. La utilización del ajuste por ambos tipos de función de una firma espectrométrica es común en el área de la quimiometría, la aportación que hacemos es demostrar que con estos procedimiento se puede realizar la identificación de hidrocarburos por dos métodos, en los que mediante diagramas de bigotes se evidencian la altura y anchura de longitudes de onda que es necesario comparar para desambiguar la identificación de cualquiera de los hidrocarburos. 
- Se realiza una caracterización completa de los nuevos HP UV-LEDs de 365nm, demostrando que el modo de funcionamiento cíclico permite una duración entre 5 y 10 veces mayor que el modo de trabajo en continua. Analizando cómo afecta cada tipo de modo de trabajo a la degradación de la emisión de luz, y como afectan los mecanismos de degradación asociados a la degradación del encapsulado. Este trabajo tiene como principal novedad que cuantifica la diferencia de trabajar en modo continuo y en modo cíclico (de baja frecuencia), tanto en esperanza de vida como en degradación física del dispositivo. Este trabajo se ha publicado en [ANVSG15] [ANVN+14].

- Se han realizado tres ensayos acelerados en temperatura sobre dos tipos de HP UV LEDs y dos modos de trabajo, dada la novedad del dispositivo y de la aplicación planteada, los resultados preliminares de estos ensayos fueron publicados en [ANVG14]. En la tesis se completan los resultados con las gráficas de degradación en cada ensayo y tipo de trabajo, la caracterización de la degradación que sufre cada tipo de LEd y como ha ocurrido dicho proceso, y por último la identificación de la energía de activación y esperanza de vida de cada tipo de LED y modo de trabajo a temperatura nominal $25^{\circ} \mathrm{C}$. Esperamos que el esfuerzo realizado a lo largo de los ensayos acelerados, en caracterización, evaluación de fiabilidad y análisis de fallos de lugar a una publicación. Los resultados han sido totalmente concluyentes, ambos LEDs en funcionamiento continuo tienen una esperanza de vida de 6000 horas similar a la de algunas de las lámparas, pero en funcionamiento cíclico (30s ON\&30s OFF) tienen esperanzas de vida (MTTF - Mean Time to Failure - Tiempo Medio entre Fallos) de 28960 para el tipo A y 65568 para el tipo $\mathrm{B}$, con unas energías de activación de $\mathrm{E}_{\mathrm{A}}=0.2$ $\mathrm{eV}$ y $\mathrm{E}_{\mathrm{A}}=0.65 \mathrm{eV}$, y una variación en longitud de onda de $+1,5 \mathrm{~nm}$, unos resultados mucho mejores que los que ofrecen las lámparas convencionales de espectrometría, por lo que se evidencia que estos sistemas pueden ofrecer unas prestaciones que no están al alcance de los sistemas convencionales.

- Finalmente la principal aportación del trabajo en comunicaciones con metamateriales es el desarrollo de un amplificador dual cuya técnica puede ser adaptada a distintas frecuencias. Este amplificador, robusto, de pequeño tamaño y elevada ganancia contribuye en el desarrollo de sistemas compactos integrables en estaciones de monitorización donde las comunicaciones son muy importantes. Este trabajo ha dado lugar a dos publicaciones [JGAG+09] [JGGA09]. 


\subsection{Trabajos futuros}

Es necesario continuar el desarrollo de sistemas compactos de análisis de calidad y detección de contaminantes. Para ello, se propone trabajar en sistemas de campo de fácil instalación en estaciones fijas. Con la experiencia adquirida en estas estaciones, y dado el avance tecnológico tanto en sondas como en sistemas de procesadores, espectrómetros, junto con los sistemas de comunicaciones propuestos, es posible el desarrollo de un analizador-detector compacto de tipo boya, de forma que pueda instalarse en lugares donde se debe hacer un seguimiento. El ahorro en obra civil es muy remarcable, siendo además posible la sustitución de elementos completos para su reparación en el laboratorio, y no "in situ". Actualmente existen elementos similares para la recogida de muestras, sirviendo éstos como experiencia útil para la elección de materiales de fabricación, anclajes y métodos estancos.

Por otro lado, el movimiento en el mercado de LEDs hace que sean necesarios nuevos análisis de los dispositivos que salen al mercado, ya que cambian tanto en consumo como en potencia lumínica irradiada. Nichia ha proporcionado a nuestro grupo una serie de muestras de LEDs de última generación, donde la silicona es sustituida por gas, de forma que se evitan las fracturas, y el conexionado es mucho más robusto y repartido por la superficie. De esta misma serie nos han sido proporcionados LEDs compuestos por cuatro unidades en un solo dispositivo (Figura 8-1), al objeto de aumentar la potencia lumínica.

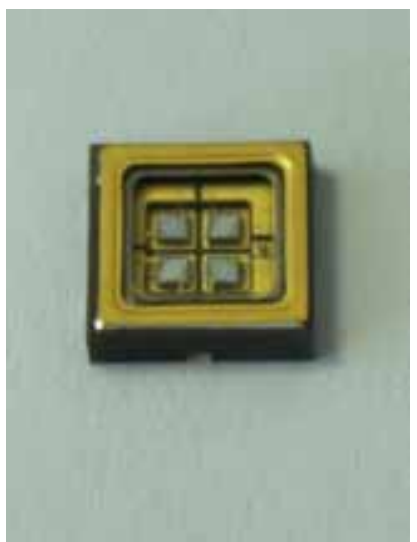

Figura 8-1: HP UV-LED de Nichia con cuatro unidades.

En este sentido, es de esperar que salgan al mercado LEDs con emisiones en longitudes de onda más cortas, siendo interesante investigar las respuestas de los distintos compuestos a este estímulo.

La ampliación de la base de datos para la identificación de nuevos compuestos, el estudio de muestras degradadas para identificar el tiempo que lleva el vertido en el agua, así como la 
influencia de factores de contorno que pueden alterar las medidas, como turbidez, algas etc. es otro de los puntos a desarrollar.

\subsection{Publicaciones y contribuciones a congresos}

\section{Lista de Publicaciones}

Arques-Orobon, F. J., Nuñez, N., Vazquez, M., Segura-Antunez, C., \& González-Posadas, V. (2015). High-power UV-LED degradation: Continuous and cycled working condition influence. Solid-State Electronics, 111, 111-117.

Arques-Orobon F.J., Nuñez N., Vazquez M., González-Posadas V. UV LEDs reliability tests for fluoro-sensing sensor application. Microelectronis Reliability 54 2154-2158.(2014). doi:10.1016/j.microrel.2014.07.059.

Jimenez-Martin, J.L., Gonzalez-Posadas V., Gonzalez-Garcia J. E. and F. J. Arques-Orobon. Dual Band High Efficiency Class CE Power Amplifier Based on CRLH Diplexer. Progress In Electromagnetics Research, PIER 97, 217-240, 2009

Jimenez Martin, J. L., Gonzalez-Posadas, V., Arques, F. J., Garcia-Muñoz, L. E., \& SegoviaVargas, D. (2009). Dual band high efficiency power amplifier based on CRLH lines. Radioengineering, 18(4), 567-578.

\section{Contribuciones a Congresos}

Arques-Orobon, F. J., Gonzalez-Posadas, V., Martin, J., Luis, J., Gutierrez Rios, J., \& Esteban Orobio, A. (2013, April). Fluoro-sensing applied to detection and identification of hydrocarbons in inland waters. In Networking, Sensing and Control (ICNSC), 2013 10th IEEE International Conference on (pp. 193-198). IEEE.

González Posadas, V., Jiménez Martín, J. L., Arqués Orobón, F. J., Herraiz Martínez, F. J., \& Segovia Vargas, D. "Estudio y Estrategias de diseño para amplificadores de doble banda de alto rendimiento. Estructuras con líneas CRLH y ECRLH”. XXIII Simposium Nacional de la Unión Científica Internacional de Radio (2008).

Jiménez Martín, J. L., González Posadas, V., Arqués Orobón, F. J., Herraiz Martínez, F. J., \& Segovia Vargas, D. "Amplificadores clase CE de doble banda con estructuras basadas en líneas CRLH y ECRLH” XXIII Simposium Nacional de la Unión Científica Internacional de Radio (2008). 
Francisco José Arques, V. González, J.L. Jiménez, F.J. Herraíz, D. Segovia. "Metamaterial dual band CE power amplifier" 2nd International Congress on Advanced Electromagnetic Materials in Microwaves and Optics, Pamplona, Spain, September 21-26, 2008.

Arques-Orobon F. J., Nuñez N., Vazquez M., Nogueira E., Montalvo F., Galgo H., GonzálezPosadas V.. XVI Congreso de Confiabilidad de la Asociación Española para la Calidad. San Sebastián, España.Dic 2014. 



\section{Bibliografía}

[AGMGE13] Arques-Orobon, F. J., Gonzalez-Posadas, V., Martin, J., Luis, J., Gutierrez Rios, J., \& Esteban Orobio, A. (2013, April). Fluoro-sensing applied to detection and identification of hydrocarbons in inland waters. In Networking, Sensing and Control (ICNSC), 2013 10th IEEE International Conference on (pp. 193-198). IEEE.

[ANVG14] Arques-Orobon F.J., Nuñez N., Vazquez M., González-Posadas V. UV LEDs reliability tests for fluoro-sensing sensor application. Microelectronis Reliability 54 2154-2158.(2014). doi:10.1016/j.microrel.2014.07.059.

[ANVN+14] Arques-Orobon F. J., Nuñez N., Vazquez M., Nogueira E., Montalvo F., Galgo H., González-Posadas V.. XVI Congreso de Confiabilidad de la Asociación Española para la Calidad. San Sebastián, España.Dic 2014.

[ANVSG15] Arques-Orobon, F. J., Nuñez, N., Vazquez, M., Segura-Antunez, C., \& González-Posadas, V. (2015). High-power UV-LED degradation: Continuous and cycled working condition influence. Solid-State Electronics, 111, 111-117.

[Arrhe1889] Arrhenius S, "On the Reaction Velocity of the Inversion of Cane Sugar by Acids" Zeitschrift für Physikalische Chemie 4, 226- (1889), traducido al inglés en. Selected Readings in Chemical Kinetics, edited by M. H. Back and K. J. Laidler, Oxford: Pergamon, NY, 1967, pp. 31-35.

[AVNM05] R. Alvarez, M. Vázquez, N. Núñez, F. Montalvo. "Plan de ensayos acelerados de fiabilidad para el nuevo producto: Célula solar fotovoltaica" Memoria interna IES-UPM. Febrero 2005.

[Ber15]

[BF03] Brown, Carl. E., Fingas, Mervin F. "Review of development of laser fluorosensors for oil spill application". Marine Pollution Bulletin 47 477-484 (2003).

[BICR03] Baker, A., Inverarity R., Charlton, M., Richmond, S. "Detecting river pollution using fluorescence spectrophotometry: case studies from the Ouseburn, NE England". Envionmental Pollution 124 57-70 (2003).

[BLHD+05] Bilenko, Y., Lunev, A., Hu, X., Deng, J., Katona, T. M., Zhang, J., ... \& Khan, A. (2005). 10 milliwatt pulse operation of $265 \mathrm{~nm} \mathrm{AlGaN} \mathrm{light} \mathrm{emitting}$ diodes.Japanese journal of applied physics, 44(1L), L98.

[BTRL08] Bailey, C., Tilford, T., Ridout, S., \& Lu, H. Optimizing the reliability of power electronics module isolation substrates. In Proceedings of the 2008 International Conference on Engineering Optimization, Rio de Janeiro, Brazil (pp. 1-5). (2008).

[BWK97] Alsberg, B. K., Winson, M. K., \& Kell, D. B. (1997). "Improving the interpretation of multivariate and rule induction models by using a peak 
[CAFB+04] Crawford, M. H., Allerman, A. A., Fischer, A. J., Bogart, K. H. A., Lee, S. R., Chow, W. W., ... \& Kurtz, S. R. (2004, January). Advances in AlGaN-based deep UV LEDs. In MRS Proceedings (Vol. 831, pp. E10-1). Cambridge University Press.

[CAG+14] Camerlingo, C., d'Apuzzo, F., Grassia, V., Perillo, L., \& Lepore, M. (2014). Micro-Raman Spectroscopy for Monitoring Changes in Periodontal Ligaments and Gingival Crevicular Fluid. Sensors, 14(12), 22552-22563.

[CAH13] Chong, S. S., Aziz, A. R., \& Harun, S. W.. "Fibre optic sensors for selected wastewater characteristics". Sensors 2013, 13(7), 8640-8668.

[CCK+88] Camagni, P., Colombo G., Koechler C., Pedrini A., Omenetto N., and Rossi G. "Diagnostic of Oil Pollution by Laser-Induced Fluorescence". IEE Transactions on Geoscience and Remote Sensing. Vol. GE-26 NO. 1 January 1988 pp 222-26.

[CDVP12] Chang, M. H., Das, D., Varde, P. V., \& Pecht, M. (2012). Light emitting diodes reliability review. Microelectronics Reliability, 52(5), 762-782.

[CGLL12] Chen, R., Gao, X., Liu, X., Li, C., \& Liu, S. (2012, August). An innovative way to improve the reliability of gold wire in lighting emitting diodes (LEDs). In Electronic Packaging Technology and High Density Packaging (ICEPTHDP), 2012 13th International Conference on (pp. 1266-1270). IEEE.

[CLM+01] Chang, C. W., Laird, D. A., Mausbach, M. J., \& Hurburgh, C. R. (2001). Nearinfrared reflectance spectroscopy-principal components regression analyses of soil properties. Soil Science Society of America Journal, 65(2), 480-490.

[Crys13] Single-chip UVC LED from Crystal IS Achieves $65 \mathrm{~mW}$ cw at $260 \mathrm{~nm}$

[CSH12]

Chee-Loon, Ng., Senft-Grupp, S., and Hemond, H.F. "A multi-platform optical sensor for in situ sensing of water chemistry." Limnology and Oceanography: Methods 10.12 (2012): 978-990.

[CSH12] Chen, Tao, Suyan Li, and Hui Sun. "Metamaterials application in sensing." Sensors 12.3 (2012): 2742-2765.

[DM84] A.M. Diego, J.M. Merino. "Carácter general de la ley de Ahrrenius", Enseñanza de las ciencias: revista de investigación y experiencias didácticas, ISSN 0212-4521, Vol. 2, Nº 1, 1984, págs. 29-32

[EAGNV10] Espinet, P., Algora, C., González, J. R., Núnez, N., \& Vázquez, M. (2010). Degradation mechanism analysis in temperature stress tests on III-V ultra-high concentrator solar cells using a 3D distributed model. Microelectronics Reliability, 50(9), 1875-1879.

[EANO+15] Espinet-González, P., Algora, C., Núñez, N., Orlando, V., Vázquez, M., Bautista, J., \& Araki, K. (2015). Temperature accelerated life test on commercial concentrator III-V triple-junction solar cells and reliability analysis as a function of the operating temperature. Progress in Photovoltaics: Research and Applications, 23(5), 559-569.

[EGV08] Estebanez B., Gutierrez-Rios .I., Vassal'lo-Saco .I., The Use of the Fluorescence to the Study of the Water Quality. Radioengineering, Vol. 17, No. 2, June 2008.

[EGV08] Estébanez B., Gutiérrez-Ríos J., Vassal'lo-Saco J., "The Use of the Fluorescence to the Study of the Water Quality". Radioengineering, Vol. 17, No. 2, June 2008.

[EWH97] Evans, J.G, Wass, P.D., Hodgson, P. "Integrated continuous water quality monitoring for the LOIS river syndromme." Science of the total environment 194 (1997): 111-118. 
[F97] de La-Fuente, J. L. (1997). "Técnicas de cálculo para sistemas de ecuaciones, programación lineal y programación entera”.

[FDCT+12] Fernandez-Jaramillo, A. A., Duarte-Galvan, C., Contreras-Medina, L. M., Torres-Pacheco, I., Romero-Troncoso, R. D. J., Guevara-Gonzalez, R. G., \& Millan-Almaraz, J. R. (2012). Instrumentation in developing chlorophyll fluorescence biosensing: A review. Sensors, 12(9), 11853-11869.

[FYP12] Fan, J., Yung, K. C., \& Pecht, M. (2012). Lifetime estimation of high-power white LED using degradation-data-driven method. Device and Materials Reliability, IEEE Transactions on, 12(2), 470-477.

[G91] Griffiths, Ian Martin. Automatic river quality monitoring. Diss. 1991.

[GCGM+13] Grandusky, J. R., Chen, J., Gibb, S. R., Mendrick, M. C., Moe, C. G., Rodak, L., \& Schowalter, L. J. (2013). $270 \mathrm{~nm}$ pseudomorphic ultraviolet lightemitting diodes with over $60 \mathrm{~mW}$ continuous wave output power. Applied Physics Express, 6(3), 032101.

[GCGS+05] Gong, Z., Chhajed, S., Gaevski, M., Sun, W., Advivarahan, V., Shatalov, M., $\&$ Khan, M. A. (2005, January). Reliability and degradation modes of $280 \mathrm{~nm}$ deep UV LEDs on sapphire. In MRS Proceedings (Vol. 892, pp. 0892-FF09). Cambridge University Press.

[GKZT06] Grillot PN, Krames MR, Zhao H, Teoh SH. "Sixty thousand hour light output reliability of AlGainP light emitting diodes". IEEE Trans Dev Mater Reliabvol 6252 (2006).

[GO94] Goshtasby, A. and O'Neill W. D., "Curve fitting by a sum of Gaussians" CVGIP Graphical Models and Image Processing Volume 56, Issue 4, July 1994, Pages 281-288

[Gut12] Julio Gutierrez et al. Boletin Oficial de la Propiedad Industrial. N 3664. April 2012. Page 8415. ISSN: 1889-1292.

[GVGM+06] Gutierrez-Rios 1., Vassal'lo-Saco 1., Sot, I., Gallego,E., Maraver, P., Esteba, A., Medrano, A., Vassal'lo-Sanz,.I. Tecnicas de teledetección inteligente de vertidos de hidrocarburos en medio marino (Report Fluorosensing). Final Report- Reference: TTIVHMM02_Final_2006 - Fundacion Arao - Xuntade Galicia. 2006.

[GVNA+09] Gonzalez JR, Vázquez M, Nunez N, Algora C, Rey-Stolle I, Galiana B. "Reliability analysis of temperature step-stress tests on III-V high concentrator solar cells". Microelectron Reliab 2009;49:673-80.

[GVS+06] Gutiérrez-Ríos J., Vassal'lo-Saco J., Sot, I., Gallego,E., Maraver, P., Esteba, A., Medrano, A., Vassal'lo-Sanz, J. "Técnicas de teledetección inteligente de vertidos de hidrocarburos en medio marino" (Report Fluorosensing). Final Report- Reference: TTIVHMM02_Final_2006 - Fundación Arao - Xunta de Galicia, 2006.

[H08w] Holand, S. M. (2008). Principal components analysis (PCA). http://strata. uga. edu/software/pdf/pcaTutorial. pdf. Last accessed, 12(27), 2011 ..

[HBM+09] Henderson, R. K., Baker, A., Murphy, K. R., Hambly, A., Stuetz, R. M., \& Khan, S. J. "Fluorescence as a potential monitoring tool for recycled water systems: A review". Water research 2009, 43(4), 863-881.

[HGE14] Hahn, B., Galler, B., \& Engl, K. (2014). Development of high-efficiency and high-power vertical light emitting diodes. Japanese Journal of Applied Physics, 53(10), 100208.

[HP-I-004] Hewlett Packard "Reliability of Precision optical Performance AlInGaP LED Lamps in Traffic Signals and Variable Message Signs". Application Brief I004 . 
[HYS08] Hu, J., Yang, L., \& Shin, M. W. (2008). Electrical, optical and thermal degradation of high power $\mathrm{GaN} / \mathrm{InGaN}$ light-emitting diodes. Journal of Physics D: Applied Physics, 41(3), 035107.

[IE11] Ibañez, G. A., \& Escandar, G. M. (2011). Luminescence Sensors Applied to Water Analysis of Organic Pollutants-An Update. Sensors, 11(12), 1108111102.

[IE11] Ibañez, G. A. and Escalar, G.M. "Luminescence Sensors Applied to Water Analysis of Organic Pollutants-An Update" Sensors 2011, 11(12), 1108111102 ;

[JGAG+09] Jimenez Martin, J. L., Gonzalez-Posadas, V., Arques, F. J., Garcia-Muñoz, L. E., \& Segovia-Vargas, D. (2009). Dual band high efficiency power amplifier based on CRLH lines. Radioengineering, 18(4), 567-578.

[JGGA09] Jimenez-Martin, J.L., Gonzalez-Posadas V., Gonzalez-Garcia J. E. and F. J. Arques-Orobon. Dual Band High Efficiency Class CE Power Amplifier Based on CRLH Diplexer. Progress In Electromagnetics Research, PIER 97, 217240, 2009

[JLG08] Jha, Maya N., Levy, Jason and Gao, Yang, “Advances in Remote Sensing for Oil Spill. Disaster Management: State-of-the-Art". Sensors Technology for Oil Spill Surveillance. Sensors 2008, 8(1) pp. 236-255.

[JN13] Jayawardena, A., Liu, Y. W., \& Narendran, N. Analysis of three different junction temperature estimation methods for AC LEDs. Solid-State Electronics, 86, 11-16. (2013).

[Jon42] Jones, R. N. (1942). The Spectrographic Analysis of Carcinogenic Hydrocarbons and Metabolites. III. Distribution of 1, 2, 5, 6-Dibenzanthracene in Rats Following Subcutaneous Injection in Olive Oil. Cancer Research, 2(4), 252-255.

[JXL10] Ji, J. W., Xu, M. H., \& Li, Z. M. (2010, December). Research and application on chlorophyll fluorescence on-line monitoring technology. In Advanced Materials Research (Vol. 139, pp. 2550-2555).

[KABR+13] Kurin, S., Antipov, A., Barash, I., Roenkov, A., Helava, H., Tarasov, S., ... \& Makarov, Y. (2013). CHVPE growth of AlGaNbased UV LEDs. Physica status solidi (C), 10(3), 289-293.

[KBK08] Khan, A., Balakrishnan, K., \& Katona, T. (2008). Ultraviolet light-emitting diodes based on group three nitrides. Nature photonics, 2(2), 77-84.

[KHLA+09] Khan, A., Hwang, S., Lowder, J., Adivarahan, V., \& Fareed, Q. (2009, April). Reliability issues in AlGaN based deep ultraviolet light emitting diodes. In Reliability Physics Symposium, 2009 IEEE International (pp. 89-93). IEEE.

[KK095] Karlsson, M., Kalberg, B., and Olsson, R. 1. O. Determinaton of Nitrate in Municipal Waste-Water by UV Spectroscopy, Analytica Chimica Acta, vol 312, no. 1 pp. 107-113, Aug 1995.

[KRDH08] Keppens, A., Ryckaert, W. R., Deconinck, G., \& Hanselaer, P. (2008). High power light-emitting diode junction temperature determination from currentvoltage characteristics. Journal of Applied Physics, 104(9), 093104.

[KW11] Kissinger, J., \& Wilson, D. (2011). Portable fluorescence lifetime detection for chlorophyll analysis in marine environments. Sensors Journal, IEEE, 11(2), 288-295.

[KW11] Kissinger, J. and Wilson D. "Portable fluorescence lifetime detection for chlorophyll analysis in marine environments." Sensors Journal, IEEE 11.2 (2011): 288-295. 
[L06] Lakowicz, J. R. "Fluorescence sensing. In Principles of fluorescence spectroscopy". 3rd edn Springer. New York. 2006; pp 623-673.

[Lak06] Lakowicz, J. R. Principles of Fluorescence Spectroscopy. Springer. 3rd ed. (2006).

[LASERF14] UV LEDs help detect hydrocarbon contaminants in water.Laser Focus World. http://www.laserfocusworld.com/articles/2014/02/uv-leds-help-detecthydrocarbon-contaminants-in-water.html.

[LBW13] Leeuw, T., Boss, E. S., \& Wright, D. L. (2013). In situ measurements of phytoplankton fluorescence using low cost electronics. Sensors, 13(6), 78727883

[LBW13] Leeuw, T., Boss E.S. and Wright, D. L. "In situ measurements of phytoplankton fluorescence using low cost electronics." Sensors 13.6 (2013): $7872-7883$.

[LCYJ04] Li, D. S., Chen, H., Yu, H. B., Jia, H. Q., Huang, Q., \& Zhou, J. M. (2004). Dependence of leakage current on dislocations in GaN-based light-emitting diodes. Journal of applied physics, 96, 1111-1114.

[Leo98] Leonard Nemerow, Nelson,. "Tratamiento de Vertidos Industriales" Ed. Díaz de Santos ISBN: 84-7978-337-0, pp 775-777, 1998.

[LFL05] Lemke, M., Fernández-Trujillo, R., \& Löhmannsröbenc, H. G. (2005). In-situ LIF analysis of biological and petroleum-based hydraulic oils on soil. Sensors, 5(1), 61-69..

[LFL05] Lemke, M., Fernández-Trujillo, R. and Löhmannsröben, H-G: In-situ LIF Analysis of Biological and Petroleum-based Hydraulic Oils on Soil. Sensors 2005, 5, 61-69.

[LJKN10] Liu, Y., A. Jayawardena, T.R. Klein, and N. Narendran. 2010. Estimating the junction temperature of AC LEDs. Tenth International Conference on Solid State Lighting, August 1-5, 2010, San Diego, CA, Proceedings of SPIE 7784: 778409.

[LL11] Liu, S., \& Liu, Y. (2011). Modeling and Simulation for Microelectronic Packaging Assembly: Manufacturing, Reliability and Testing. John Wiley \& Sons. doi:10.1002/9780470827826

[LM06] Lynch, S. P., \& Moutsos, S. A brief history of fractography. Journal of Failure Analysis and Prevention, 6(6), 54-69. (2006). +310.1361/154770206X156231

[LOGH+06] Lee, S. W., Oh, D. C., Goto, H., Ha, J. S., Lee, H. J., Hanada, T., ... \& Lee, J. S. (2006). Origin of forward leakage current in GaN-based light-emitting devices. Applied physics letters, 89(13), 132117.

[Lumil06] Lumileds. Luxeon reliability, Reliability Datasheet RD25, Philips Lumileds; (2006).

[LuxR08] Luxeon. Luxeon Reliability 2008. https://www.olino.org/wpcontent/uploads/2008/articles/thousand_lumen_led_Luxeon_RD25.pdf (consultado junio 2015).

[LYLTS10] Lin, Y. H., You, J. P., Lin, Y. C., Tran, N. T., \& Shi, F. G. Development of high-performance optical silicone for the packaging of high-power LEDs. Components and Packaging Technologies, IEEE Transactions on, 33(4), 761766. (2010). doi:10.1109/TCAPT.2010.2046488

[MBBS+10] Meneghini, M., Barbisan, D., Bilenko, Y., Shatalov, M., Yang, J., Gaska, R., ... \& Zanoni, E. (2010). Defect-related degradation of Deep-UV-LEDs. Microelectronics Reliability, 50(9), 1538-1542. 
[Meneg08] Meneghini, M. (2008). Analysis of the physical processes that limit the reliability of $\mathrm{GaN}$-based optoelectronic devices.

[MGCK+14] Moe, C. G., Grandusky, J. R., Chen, J., Kitamura, K., Mendrick, M. C., Jamil, M., ... \& Schowalter, L. J. (2014, March). High-power pseudomorphic midultraviolet light-emitting diodes with improved efficiency and lifetime. In SPIE OPTO (pp. 89861V-89861V). International Society for Optics and Photonics.

[MHDBK91] MIL-HDBK-217F: "Reliability Prediction of Electronic Equipment".

[MHDBK98] MIL-HDBK-338B: "Electronic Reliability Design Handbook".

[MK09] Moon, S. M., \& Kwak, J. S. (2009). High-current electro-optical degradation of InGaN/GaN light-emitting diodes fabricated with Ag-based reflectors. Journal of the Korean Physical Society, 55(3), 1128-1131.

[MKN14] Muramoto, Y., Kimura, M., \& Nouda, S. Development and future of ultraviolet light-emitting diodes: UV-LED will replace the UV lamp. Semiconductor Science and Technology, 29(8), 084004. (2014). doi:10.1088/02681242/29/8/084004

[MKN14] Muramoto, Y, Kimura, M., Nouda S. "Development and future of ultraviolet light-emitting diodes: UV LED will replace the UV lamp". Semiconductors Science and Technology. 29. (2014) Doi: 10.1088/0268-1242/29/8/084004.

[MLPR+02] Meneghesso, G., Levada, S., Pierobon, R., Rampazzo, F., Zanoni, E., Cavallini, A., ... \& Eliashevich, I. (2002). Degradation mechanisms of GaNbased LEDs after accelerated DC current aging. In IEDm: international electron devices meeting (pp. 103-106).

[MMYA+06] Mukai, T., Morita, D., Yamamoto, M., Akaishi, K., Matoba, K., Yasutomo, K., ... \& Nagahama, S. I. (2006). Investigation of optical output power degradation in $365 \mathrm{~nm}$ UV-LEDs. physica status solidi (c), 3(6), 2211-2214.

[MPTG+08] Meneghini, M., Pavesi, M., Trivellin, N., Gaska, R., Zanoni, E., \& Meneghesso, G. (2008). Reliability of deep-UV light-emitting diodes. Device and Materials Reliability, IEEE Transactions on, 8(2), 248-254.

[MR13] Mills, P., \& Raymont, J. (2013). The UV-LED. RadTech International. Chapter by Ed kiyoi: The State of UV-LED Curing:An Investigation of Chemistry and Applications, pg 62.

[MSYN+03] D. Morita, M. Sano, M. Yamamoto, M. Nonaka, K. Yasutomo, K. Akaishi, S. Nagahama, and T. Mukai, "Over $200 \mathrm{~mW}$ on $365 \mathrm{~nm}$ ultraviolet light emitting diode of GaN-free structure," Phys. Stats. Sol. A 200, pp. 114-117 (2003).

[MTOY+10] Meneghini, M., Trivellin, N., Orita, K., Yuri, M., Tanaka, T., Ueda, D., ... \& Meneghesso, G. (2010). Reliability evaluation for Blu-Ray laser diodes. Microelectronics Reliability, 50(4), 467-470.

[MTZZ+06] Meneghini, M., Trevisanello, L. R., Zehnder, U., Zahner, T., Strauss, U., Meneghesso, G., \& Zanoni, E. (2006). High-temperature degradation of GaN LEDs related to passivation. Electron Devices, IEEE Transactions on, 53(12), 2981-2987.

[Ne190] W. Nelson "Accelerated Testing. Statistical Models, Test Plans and Data Analyses." Editorial John Wiley\&Sons. 1990.

[NGVAE13] Núñez, N., González, J. R., Vázquez, M., Algora, C., \& Espinet, P. (2013). Evaluation of the reliability of high concentrator GaAs solar cells by means of temperature accelerated aging tests. Progress in Photovoltaics: Research and Applications, 21(5), 1104-1113. 
[NLG08] Nand M. Jha, Jason Levy J.J., Yang Gao: Advances in Remote Sensing for Oil Spill Disaster Management:State-of-the-Art Sensors Technology for Oil Spill Surveillance, Sensors 2008,8, 236-255.

[NS56] Northrop, D. C., \& Simpson, O. (1956, January). Electronic Properties of aromatic hydrocarbons. II. Fluorescence transfer in solid solutions. In Proceedings of the Royal Society of London A: Mathematical, Physical and Engineering Sciences (Vol. 234, No. 1196, pp. 136-149). The Royal Society.

[NSH12] Ng, C. L., Senft-Grupp, S., \& Hemond, H. F. A multi-platform optical sensor for in situ sensing of water chemistry. Limnology and Oceanographic: Methods, 2012; 10, 978-990.

[NTC+14] Ng, C. L., Teo, W. K., Cai, H. T., \& Hemond, H. F. Characterization and field test of an in situ multi-platform optical sensor. Limnology and Oceanography: Methods, 2014;12(7), 484-497.

[NTCH14] Ng, C. L., Teo, W. K., Cai, H. T., \& Hemond, H. F. Characterization and field test of an in situ multi-platform optical sensor. Limnology and Oceanography: Methods, 2014;12(7), 484-497. DOI: 10.4319/lom.2014.12.484.

[Nuñ12] Nuñez, N. (2012). Ensayos acelerados de fiabilidad de células solares de concentración (Doctoral dissertation, E_Telecomunicacion). Universidad Politécnica de Madrid.

[NVGA+09] N. Núñez, M. Vázquez, J. R. González, C. Algora and E.Perez. "Sistema de Instrumentación de Ensayos Acelerados para Evaluar la Fiabilidad de Dispositivos Semiconductores III-V a Partir de Datos de Degradación". II Jornadas Iberoamericanas de Asset Management y XI Congreso de Confiabilidad de la Asociación Española para la Calidad. Valencia, España. Jun 2009.

[NVGAE10] Núñez, N., Vázquez, M., González, J. R., Algora, C., \& Espinet, P. Novel accelerated testing method for III-V concentrator solar cells. Microelectronics Reliability, 50(9), 1880-1883. (2010). Novel accelerated testing method for III-V concentrator solar cells

[NVGJ+11] N. Núñez, M. Vázquez, J. R. González, F. J. Jiménez, J. Bautista. "Instrumentation for accelerated life tests of concentrator solar cells". Review of Scientific Instruments. 2011; Vol 82;2; 024703-024703-7.

[NVN09] Nogueira, E., Vázquez, M., \& Núñez, N. (2009). Evaluation of AlGaInP LEDs reliability based on accelerated tests. Microelectronics Reliability, 49(9), 12401243.

[O'Con12] P. O'Connor and and Andre Kleyner. Practical Reliability Engineering, Editorial John Wiley\&Sons. 5th edition. 2012.

[OTw] https://terpconnect.umd.edu/ toh/spectrum/CurveFittingB.html

[Paj12] Pajares, G. (2012). Sensors in collaboration increase individual potentialities. Sensors, 12(4), 4892-4896.

[PDC+06] Pistonesi, M. F., Di Nezio, M. S., Centurión, M. E., Palomeque, M. E., Lista, A. G., \& Band, B. S. F. (2006). Determination of phenol, resorcinol and hydroquinone in air samples by synchronous fluorescence using partial leastsquares (PLS). Talanta, 69(5), 1265-1268.

[Prin15] Measurement of Environmental Contaminant Hydrocarbons by Fluorescence Spectroscopy. Princenton Instrumets. http://www.princetoninstruments.com/Uploads/Princeton/Documents/Library /UpdatedLibrary/EEM_for_Environmental_contaminant_hydrocarbons.pdf (accessed on 17 2015) 
[QG13] Qian, K., \& Guo, Z. (2013, November). Study of defect density and aging properties of GaN LEDs. In Solid State Lighting (ChinaSSL), 2013 10th China International Forum on (pp. 27-30). IEEE.

[RBH+09] Rohde, P., Busch, J.A., Henkel, R.H., Voss, D., Zielinski, O. "Detection and identification of hyrocarbons in marine waters using time-resolved laserfluorescence: Set-up and first results of a new submersible sensor". IEEE Oceans Conference Puplications. 2009.

[RBHVZ09] Rohde, P., Busch, J., Henkel, R. H., Voss, D., \& Zielinski, O. (2009, May). Detection and identification of hydrocarbons in marine waters using timeresolved laser-fluorescence: set-up and first results of a new submersible sensor. In OCEANS 2009-EUROPE (pp. 1-5). IEEE.

[RG13] Ramírez García, J., \& García-Mochales Martínez, J. (2013). Instrumentación de referencia para realización automática de ensayos de fiabilidad.

[RHCNP05] Ryu, H. Y., Ha, K. H., Chae, J. H., Nam, O. H., \& Park, Y. J. (2005). Measurement of junction temperature in GaN-based laser diodes using voltage-temperature characteristics. Applied Physics Letters, 87(9), 093506.

[RKLW+15] Rass, J., Kolbe, T., Lobo-Ploch, N., Wernicke, T., Mehnke, F., Kuhn, C., ... \& Kneissl, M. (2015, March). High-power UV-B LEDs with long lifetime. In SPIE OPTO (pp. 93631K-93631K). International Society for Optics and Photonics.

[RLw] $\quad$ http://www.roithner-laser.com/pricelist.pdf (accessed on July 2015)]

[RoitL15] Roithner Lasertechnik GmbH pricelist. http://www.roithnerlaser.com/pricelist.pdf (accessed on 17 2015)

[RZN00] Riordon, J., Zubritsky, E, and Newman, A. "Top 10 Articles." Analytical chemistry 72.9 (2000): 324-A.

[S11] Schafer, Ronald W. "What is a Savitzky-Golay filter?[lecture notes]." Signal Processing Magazine, IEEE 28.4 (2011): 111-117.

[SC12] Sawant M, Christou A. Failure modes and effects criticality analysis and accelerated life testing of LEDs for medical applications. Solid-State Electron 2012;78:39-45.

[Sch11] Schafer, R. W. (2011). What is a Savitzky-Golay filter?[lecture notes]. Signal Processing Magazine, IEEE, 28(4), 111-117.

[Seg14] Segura Antúnez, C. (2014). Estudio de la fiabilidad mediante ensayos acelerados de diodos ultravioletas de alta potencia.

[SG10] Shur, M. S., \& Gaska, R. (2010). Deep-ultraviolet light-emitting diodes. Electron Devices, IEEE Transactions on, 57(1), 12-25.

[SG64] Savitzky, A., \& Golay, M. J. (1964). Smoothing and differentiation of data by simplified least squares procedures. Analytical chemistry, 36(8), 1627-1639.

[SG64] Savtitzky, A., Golay, M.J.E. "Smoothing and Differentiation of data by simplified least squares procedures"; Analytical Chemistry 36, 1627 (1964)

[SGGW+06] Shatalov, M., Gong, Z., Gaevski, M., Wu, S., Sun, W., Adivarahan, V., \& Khan, M. A. (2006, February). Reliability of AlGaN-based deep UV LEDs on sapphire. In Integrated Optoelectronic Devices 2006 (pp. 61340P-61340P). International Society for Optics and Photonics.

[SH12] Shin, M. W., \& Jang, S. H. Thermal analysis of high power LED packages under the alternating current operation. Solid-State Electronics, 68, 48-50. (2012). 
[SJDB+15] Shatalov, M., Jain, R., Dobrinsky, A., Sun, W., Bilenko, Y., Yang, J., ... \& Gaska, R. (2015, March). High-efficiency UV LEDs on sapphire. In SPIE OPTO (pp. 93631M-93631M). International Society for Optics and Photonics.

[SR08] Strobl, Robert O., and Paul D. Robillard. "Network design for water quality monitoring of surface freshwaters: A review." Journal of environmental management 87.4 (2008): 639-648.

[SRS08] Sawyer, S., Rumyantsev, S. L., \& Shur, M. S. Degradation of AlGaN-based ultraviolet light emitting diodes. Solid-State Electronics, 52(6), 968-972. (2008). doi:10.1016/j.sse.2008.01.027

[Tay05] J. Taylor. Industry alliance proposes standard definition for LED life LEDs Magazine, April 2005, pp. 9-11 (2005).

[Tka06] Tkachenko, Nikolai Y: Optical Spectroscopy, Methods and Instrumentations. Elsevier B. Y, First Edition, 2006.

[TWL09] Tan, L., Li, J., Wang, K., \& Liu, S. Effects of defects on the thermal and optical performance of high-brightness light-emitting diodes. Electronics Packaging Manufacturing, IEEE Transactions on, 32(4), 233-240. (2009). Doi: 10.1109/TEPM.2009.2027893

[USDep09] U.S. Department of Energy. Lifetime of White LEDs. http://apps1.eere.energy.gov/buildings/publications/pdfs/ssl/lifetime_white_le ds.pdf (2009).

[VB01] Valeur, B., \& Brochon, J. C. (Eds.). New Trends in Fluorescence Spectroscopy: Applications to Chemical and Life Sciences. (Vol. 1). Springer. (2001).

[VDur59] Van Duuren, B. L. (1958). Identification of some polynuclear aromatic hydrocarbons in cigarette-smoke condensate. Journal of the National Cancer Institute, 21(1), 1.

[Ven15] Venugopalan, H. (2015). UVC LEDs enable cost-effective spectroscopic instruments. LASER FOCUS WORLD, 51(1), 81-85.

[Ven15] Venugopalan, H. "Ultraviolet LEDs: UVC LEDs enable cost-effective spectroscopic instruments" Laser Focus Word 51(1), 81-85. (2015).

[VLLM+11] Van der Plas, G., Limaye, P., Loi, I., Mercha, A., Oprins, H., Torregiani, C., \& Marchal, P. Design issues and considerations for low-cost 3-D TSV IC technology. Solid-State Circuits, IEEE Journal of, 46(1), 293-307. (2011).

[VNNB10] Vázquez, M., Núñez, N., Nogueira, E., \& Borreguero, A. (2010). Degradation of AlInGaP red LEDs under drive current and temperature accelerated life tests. Microelectronics Reliability, 50(9), 1559-1562.

[VVG+10] Vassal Lo Sanz, J., Vassal Lo Saco, J., Gutiérrez Ríos, J., Soto Macía, I., Gallego García, E., Maraver Abad, P., \& Madrano Gil, A. "Detector for the remote detection of fluorescent substances". 2010. Int. Patent. $\mathrm{N}^{\mathrm{o}}$ WO2009141473 (A3)

[VVGS+10] Vassal Lo Sanz, J., Vassal Lo Saco, J., Gutiérrez Ríos, J., Soto Macía, I., Gallego García, E., Maraver Abad, P., \& Madrano Gil, A. Detector for the remote detection of fluorescent substances. 2010. Int. Patent. $\mathrm{N}^{\mathrm{o}}$ WO2009141473 (A3)

[W10] Wojdyr, Marcin. "Fityk: a general-purpose peak fitting program." Journal of Applied Crystallography 43.5 (2010): 1126-1128.

[War73] J. Warleta Carrillo. "Fiabilidad bases teóricas y prácticass". Editado por Instituto Nacional de Técnica Aeroespacial.1973. ISBN:84-500-5738-8 
[WAT+13] Wang, Y., Akiyama, H., Terakado, K., \& Nakatsu, T. (2013). Impact of sitedirected mutant luciferase on quantitative green and orange/red emission intensities in firefly bioluminescence. Scientific reports, 3 .

[Wei51] Waloddi Weibull. "A statistical Distribution Function of Wide Applicability". J. Appl. Mech.-Trans. ASME 18 (3): 293-297.

[Yan07] G. Yang. "Life Cycle Reliability Engineering" Chapter 7. .C:Wiley 2007. ISBN 9780471715290.

[YHS08] Yang, L., Hu, J., \& Shin, M. W. (2008). Dynamic thermal analysis of highpower LEDs at pulse conditions. Electron Device Letters, IEEE, 29(8), 863866.

[YHS09] Yang, L., Hu, J., \& Shin, M. W. Degradation of high power LEDs at dynamic working conditions. Solid-State Electronics, 53(6), 567-570. (2009). doi:10.1016/j.sse.2009.03.014

[YJD08] Yang, Wei, Jun Nan, and Dezhi Sun. "An online water quality monitoring and management system developed for the Liming River basin in Daqing, China." Journal of environmental management 88.2 (2008): 318-325.

[YK03] Yanagisawa, T., \& Kojima, T. (2003). Degradation of InGaN blue lightemitting diodes under continuous and low-speed pulse operations. Microelectronics Reliability, 43(6), 977-980.

[YSCQ+07] Yu, T., Shang, S., Chen, Z., Qin, Z., Lin, L., Yang, Z., \& Zhang, G. (2007). Luminescence degradation of $\mathrm{InGaN} / \mathrm{GaN}$ violet leds. Journal of luminescence, 122, 696-699.

[YYYG+10] Yin, L., Yang, L., Yang, W., Guo, Y., Ma, K., Li, S., \& Zhang, J. Thermal design and analysis of multi-chip LED module with ceramic substrate. SolidState Electronics, 54(12), 1520-1524. (2010).

[ZL14] Zhang, S. U., \& Lee, B. W. Fatigue life evaluation of wire bonds in LED packages using numerical analysis. Microelectronic Reliability (2014). 


\section{Anexo: Estudio de la fiabilidad de los datos en sistemas automáticos}

\subsection{Medidas realizadas cada 15 minutos}

Los datos obtenidos a partir de las medidas realizadas durante un período de doce días, tomando datos cada 15 minutos, se reflejan en la gráfica. Se corresponden con los cuatro sensores mencionados, cada uno de los cuales, según lo visto en el apartado anterior, estará afectado de posibles errores en las medidas en función de su tecnología, además de la propia de las tarjetas.

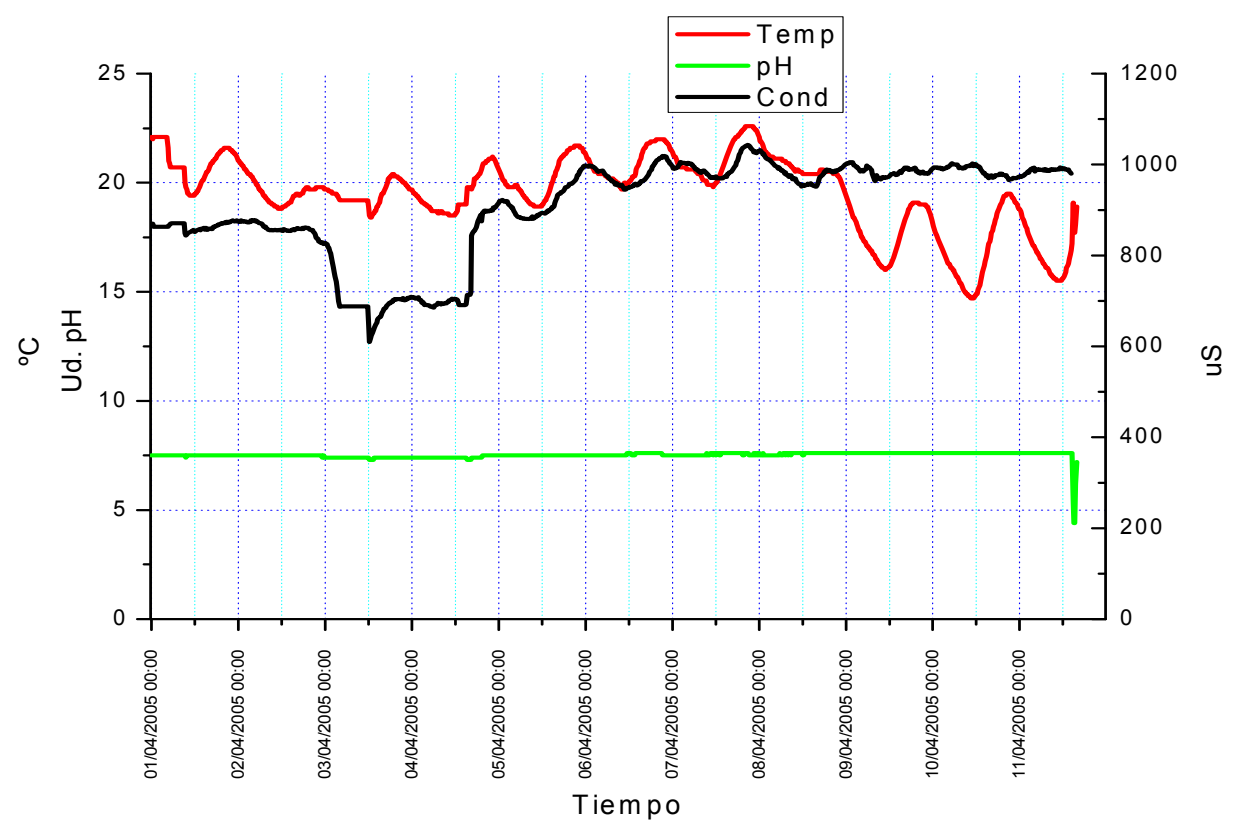

Figura 10-1: Evolución de los parámetros con medidas tomadas cada 15 minutos.

Según la evolución de las curvas se propone tomar dos parámetros que representen resultados diferenciados, para así poder obtener alguna conclusión. Por tanto se realizarán los análisis sobre la curva de temperatura, con una aparente continuidad en los datos, y una frecuencia más o menos constante y baja, y sobre la medida de $\mathrm{pH}$, que presenta un valor muy constante, excepto al final del muestreo, donde debido a una autocalibración, se aprecia una 
subida abrupta que se debería reflejar de alguna manera en los resultados. La medida de conductividad tiene cierta similitud a efectos prácticos con la medida de temperatura, si bien presenta un intervalo durante el día 3 y 4 en el que los datos parecen bastante erróneos por lo abrupto de los cambios reflejados, por lo que como medida óptima no sería significativo.

Se analizarán por tanto los resultados de estos dos sensores tomando como herramienta el programa Origin ${ }^{\circledR}$, ya que es bastante versátil a la hora de hacer el análisis espectral.

\subsubsection{Medida de temperatura: 1 muestra cada 15 minutos}

Se realiza la FFT de los datos, indicando correctamente el tiempo de muestreo, obteniendo:

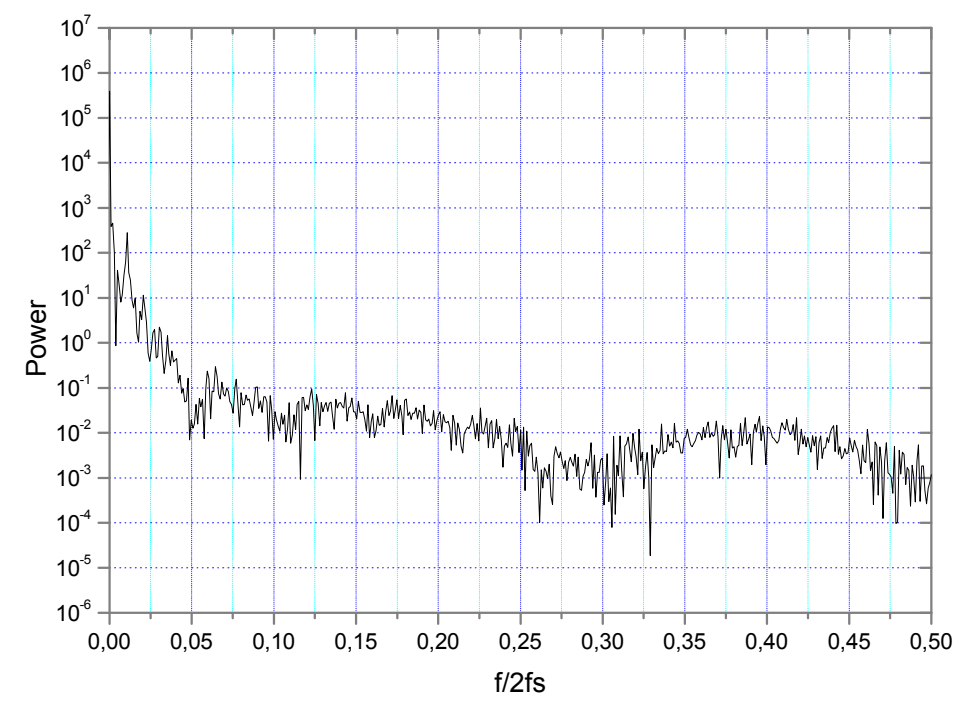

Figura 10-2: Datos de temperatura tomados cada 15 minutos en 12 días

En el comportamiento de la FFT se observa que tiene la forma de paso-bajo, con bastante rizado, por lo que existen componentes a muchas frecuencias.

En lo que se refiere al eje x, está normalizado para f/2fs, siendo la frecuencia mayor la marcada en este caso por el período de 15 minutos, es decir, $15 \times 60$ segundos.

En el eje de ordenadas, Origin ${ }^{\circledR}$ opera con el valor de los grados centígrados como si fuesen milivoltios, por lo que el nivel de continua de unos $20^{\circ} \mathrm{C}$ se representa en la tabla, como 19999,1 mV en la columna "Real(Y)":

\begin{tabular}{|c|c|c|c|c|c|c|}
\hline \multicolumn{7}{|c|}{ FFTTemp15min } \\
\hline & Freq $[X]$ & Real[Y] & $\operatorname{lmag}[\mathrm{Y}]$ & $r[Y]$ & Phi[Y] & Power[Y] \\
\hline 513 & 0 & 19999,1 & 0 & 19999,1 & -1260 & 390589,84454 \\
\hline 514 & $9,76563 \mathrm{E}-4$ & $-603,50463$ & $-178,69836$ & 629,40523 & $-1423,50592$ & 386,86615 \\
\hline
\end{tabular}


Figura 10-3: Detalle numérico

En esta misma gráfica, se observa a continuación un pico significativo en una frecuencia muy baja, tal y como puede apreciarse en el siguiente detalle:

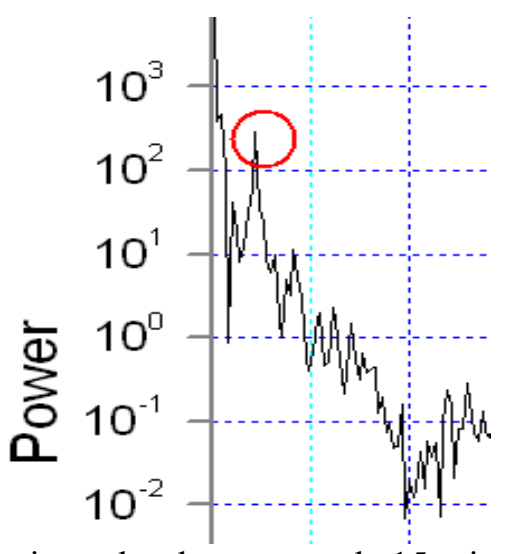

Figura 10-4: Detalle del pico sobre la muestra de 15 minutos de temperatura.

Observando la posición en la tabla de la que se ha servido para realizar la representación, observamos que se corresponde con la muestra 524, y la muestra de frecuencia cero es la 513. Por tanto, la diferencia son 11 muestras que nos indicarán el período del pico.

\begin{tabular}{|c|c|c|c|c|c|c|}
\hline \multicolumn{7}{|c|}{ FFTTemp15min } \\
\hline & Freq $[X]$ & Real[Y] & $\operatorname{Imag}[Y]$ & $r(Y)$ & Phi[Y] & Power[Y] \\
\hline 513 & 0 & 19999,1 & 0 & 19999,1 & -1260 & 390589,84454 \\
\hline 514 & $9,76563 \mathrm{E}-4$ & $-603,50463$ & $-178,69836$ & 629,40523 & $-1423,50592$ & 386,86615 \\
\hline 515 & 0,00195 & 190,23971 & $-655,76363$ & 682,80091 & $-1333,82234$ & 455,29012 \\
\hline 516 & 0,00293 & 236,61583 & $-217,59036$ & 321,45391 & $-1302,60144$ & 100,91076 \\
\hline 517 & 0,00391 & 10,27305 & $-28,04431$ & 29,86669 & $-1329,88147$ & 0,87111 \\
\hline 518 & 0,00488 & $-94,78245$ & $-180,98358$ & 204,30068 & $-1377,64138$ & 40,76052 \\
\hline 519 & 0,00586 & 7,70765 & $-140,33961$ & 140,55111 & $-1346,85639$ & 19,29161 \\
\hline 520 & 0,00684 & $-84,07702$ & 34,28706 & 90,79949 & $-1462,1859$ & 8,05132 \\
\hline 521 & 0,00781 & $-109,44858$ & $-9,01693$ & 109,81938 & $-1435,29032$ & 11,77763 \\
\hline 522 & 0,00879 & $-105,35935$ & $-146,15367$ & 180,17072 & $-1385,7871$ & 31,70067 \\
\hline 523 & 0,00977 & $-186,63112$ & $-169,97368$ & 252,43262 & $-1397,67441$ & 62,22874 \\
\hline 524 & 0,01074 & 442,31534 & $-308,11175$ & 539,05075 & $-1294,86062$ & 283,76535 \\
\hline 525 & 0,01172 & 138,05399 & $-134,73321$ & 192,90397 & $-1304,30254$ & 36,33979 \\
\hline
\end{tabular}

Figura 10-5: Detalle de la tabla de las medidas de temperaturas de 15 minutos donde se aprecia el valor numérico del pico observado.

Así, llamando $\mathrm{S}$ a la distancia desde el origen y $\mathrm{M}$ al número de muestras total:

$$
\frac{1}{\frac{S}{M} \times \frac{1}{T_{s}}}=\frac{1}{\frac{11}{1024} \times \frac{1}{15 \times 60}}=83781.8181 \text { segundos } \equiv 23.27 \text { horas }
$$

Efectivamente se verifica el ciclo de las temperaturas que se da con un intervalo aproximado de 24 horas, siendo la hora de mayor temperatura la del mediodía. Este ciclo no es 
exacto, porque en los 12 días del análisis, en el mes de abril, nos vamos aproximando al período caluroso y las horas de luz solar varían.

En lo que respecta al resto de frecuencias, estas se encuentran a una potencia mucho menor que esta, exceptuando las cercanas. Es interesante este apartado, a fin de establecer comparaciones con la gráfica con las medidas realizadas cada hora.

\subsubsection{Medida del pH: 1 muestra cada 15 minutos}

Se realiza la FFT de los datos, obteniéndose:

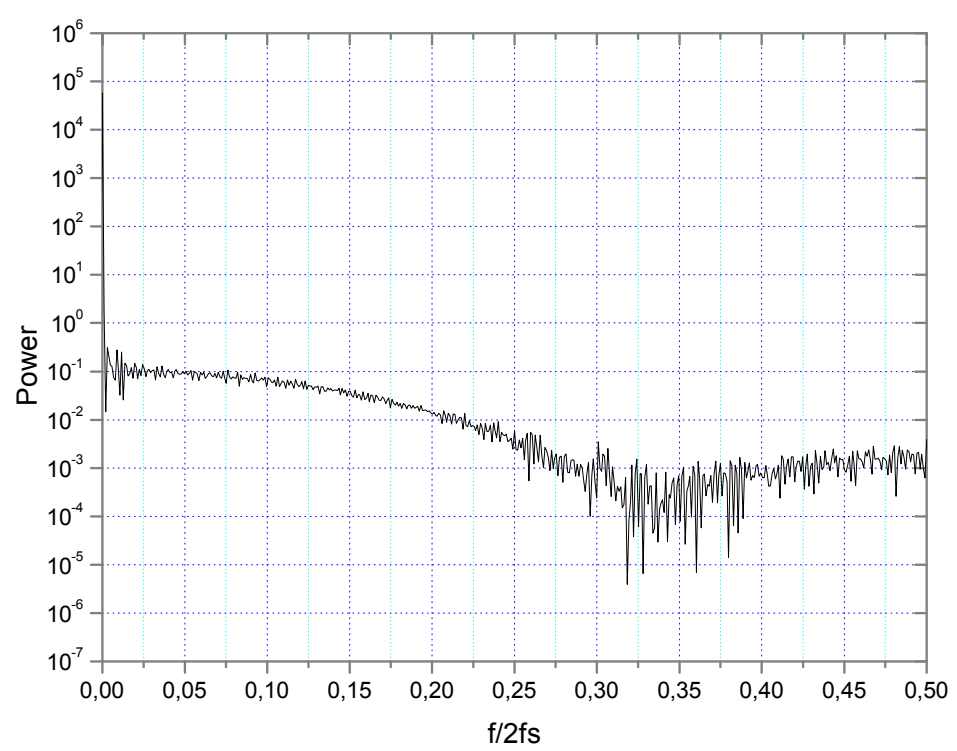

Figura 10-6: Datos de $\mathrm{pH}$ tomados cada 15 minutos en 12 días

A diferencia de la respuesta del sensor de temperatura, existe un ciclo en la medida del $\mathrm{pH}$ prácticamente inapreciable, ya que se trata de un parámetro, en principio, independiente de la luz solar. Al ser la respuesta mucho más constante, a frecuencias bajas-medias se manifiestan de una forma más localizada debido a un rizado de la señal mucho más constante que incluye menos componentes espectrales.

\subsubsection{Medidas realizadas cada hora}

Al igual que sucede con los datos quinceminutales, se toman 1024 muestras, pero esta vez espaciadas una hora, por lo que la toma de datos se debe prolongar hasta los 43 días aproximadamente. También se corresponden con los cuatro sensores mencionados. 


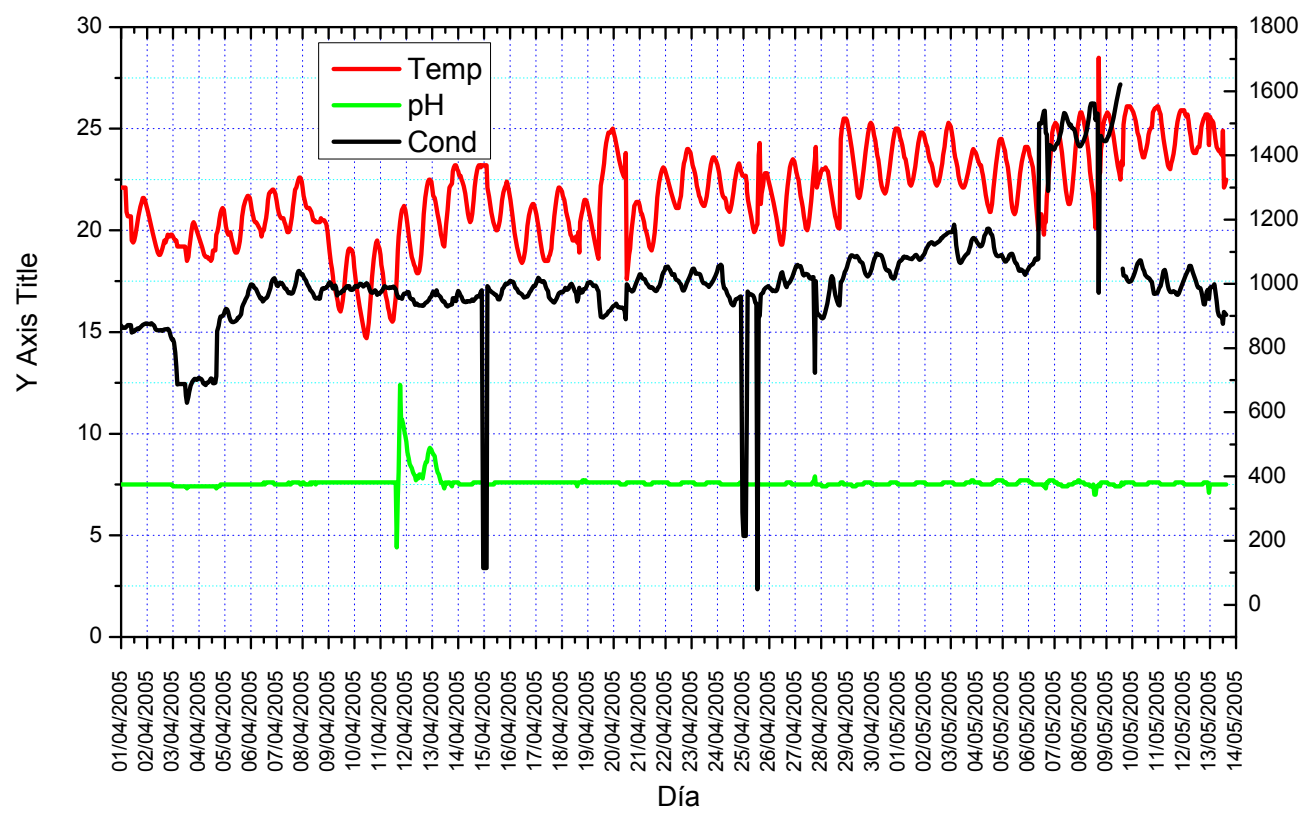

Figura 10-7: Evolución de los parámetros con medidas tomadas cada hora.

\subsubsection{Medida de temperatura: 1 muestra cada hora}

Al tomar una frecuencia de muestreo mucho menor, se aprecia que el rizado de la señal ahora queda oculto, como era de esperar, pero sin embargo la baja frecuencia continúa reflejándose, ya que el período de muestreo es mayor que el período de los ciclos de 12 horas de la luz solar. Con respecto a las medidas en alta frecuencia ya no continúan apareciendo, ya que ahora los saltos serán menos abruptos no siendo ahora comparables a la potencia en baja frecuencia. 


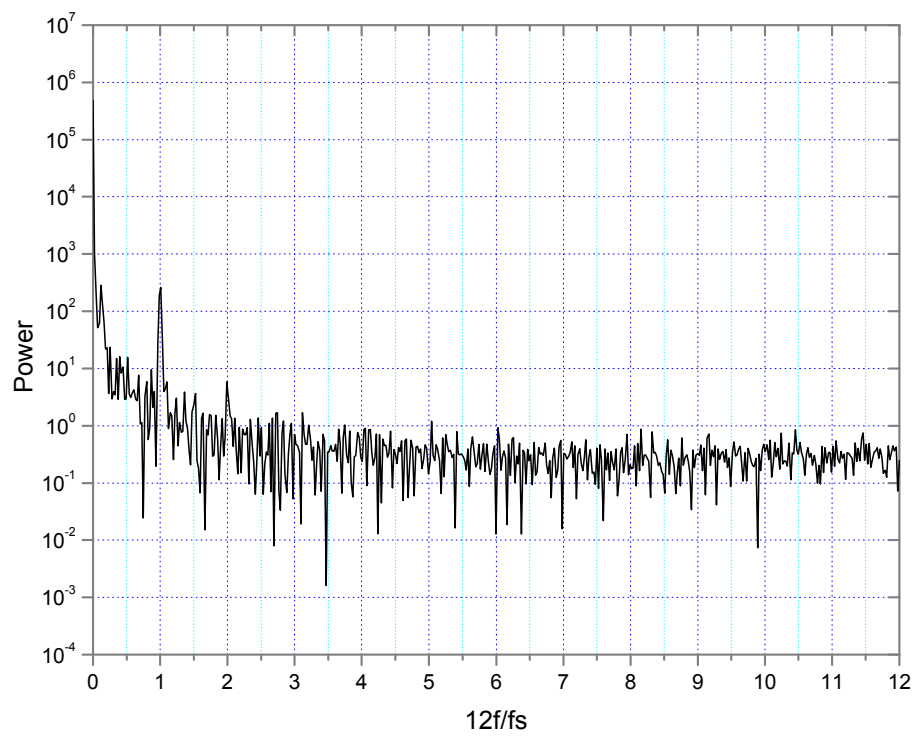

Figura 10-8: Datos de temperatura tomados cada hora en 42 días

Sin embargo, la potencia media del resto de potencias es sensiblemente más elevada que la detectada en las medidas quinceminutales; esto posiblemente sea debido a la elevación de la temperatura a medida que va pasando el tiempo, haciendo que el valor medio aumente.

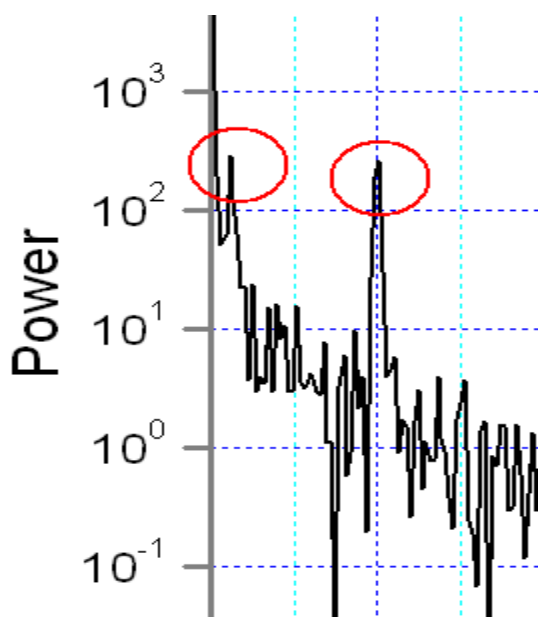

Figura 10-9: Detalle de la FFT de los datos de temperatura

Al observar la gráfica, se aprecia un pico significativo que, siguiendo el razonamiento antes explicado, presenta una separación con respecto al origen de 42 unidades. Operando:

$\frac{1}{\frac{S}{M} \times \frac{1}{T_{s}}}=\frac{1}{\frac{42}{1024} \times \frac{1}{60 \times 60}}=87771.428$ segundos $\equiv 24.38$ horas

Que pone de nuevo de manifiesto el ciclo diario de esta medida. Se aprecia asimismo un pico comparable al anterior, quizá menos notable debido a que las frecuencias del entorno son más elevadas, separado 5 unidades. El período al que corresponde será: 
$\frac{1}{\frac{S}{M} \times \frac{1}{T_{s}}}=\frac{1}{\frac{5}{1024} \times \frac{1}{60 \times 60}}=737280$ segundos $\equiv 204.8$ horas

Que son aproximadamente 8.5 días. Esto parece corroborar los mantenimientos preventivos que se realizaron en la estación durante el período de análisis. Se realizaron 6 mantenimientos (la mayoría cada 7-8 días) pero alguno de ellos se espació 10 días o más debido a las fiestas que hubo durante este período ( 1 y 2 de mayo), como parece que así se refleja, ya que cada vez que se realiza uno de estos mantenimientos, se recalibra la sonda, apareciendo un salto en la medida después de la calibración. La tendencia de esta sonda es de acumular un error que hace que la medida vaya en término medio creciendo, aunque la oscilación de la misma sea correcta. Por ello, al recalibrar la sonda con un patrón, la medida baja bruscamente.

\subsubsection{Medida del pH: 1 muestra hora}

Se realiza la FFT de los datos, indicando correctamente el tiempo de muestreo, obteniendo:

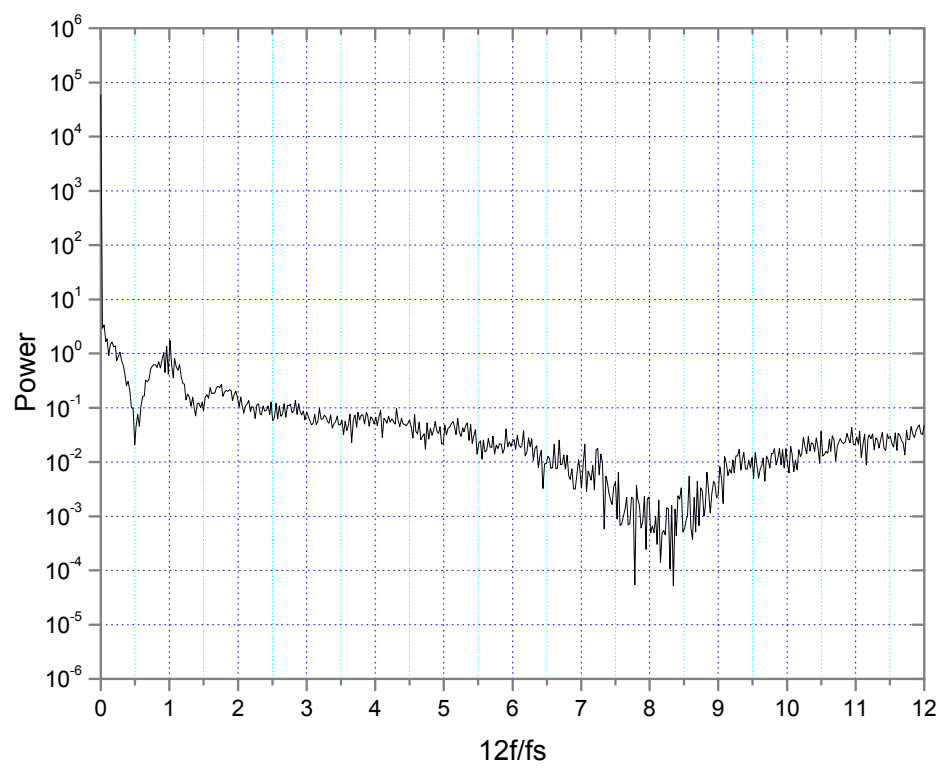

Figura 10-10: Datos de $\mathrm{pH}$ tomados cada hora en 42 días

Es interesante resaltar que el análisis de este parámetro pone de manifiesto un pico a la misma frecuencia de 8.5 días, inapreciable viendo la evolución de la gráfica, al contrario de lo que ocurría con la temperatura:

$\frac{1}{\frac{S}{M} \times \frac{1}{T_{s}}}=\frac{1}{\frac{5}{1024} \times \frac{1}{60 \times 60}}=737280$ segundos $\equiv 204.8$ horas

Que corrobora los resultados anteriores. 


\subsection{Obtención de las autocorrelaciones}

A continuación se muestran los resultados obtenidos a partir de las autocorrelaciones de la medidas quinceminutales de la temperatura y el $\mathrm{pH}$.

Se pretende detectar el grado de predicción existente en cada una de las medidas. En este caso se muestran dos variables para un tiempo determinado, y en la autocorrelación intervienen dos factores importantes: la frecuencia de la toma de la muestra y el intervalo de tiempo en el que se realiza la autocorrelación.

Al respecto de la temperatura, se observa que está muy correlado, por lo que en principio, la pauta de comportamiento de este parámetro es predecible para la serie analizada. Para cada valor, el valor siguiente no difiere mucho, y por tanto las variaciones son lentas. Este sistema se puede utilizar por tanto para detectar fallos en el sistema, ya que producirán transitorios abruptos que se manifestarán en la autocorrelación.

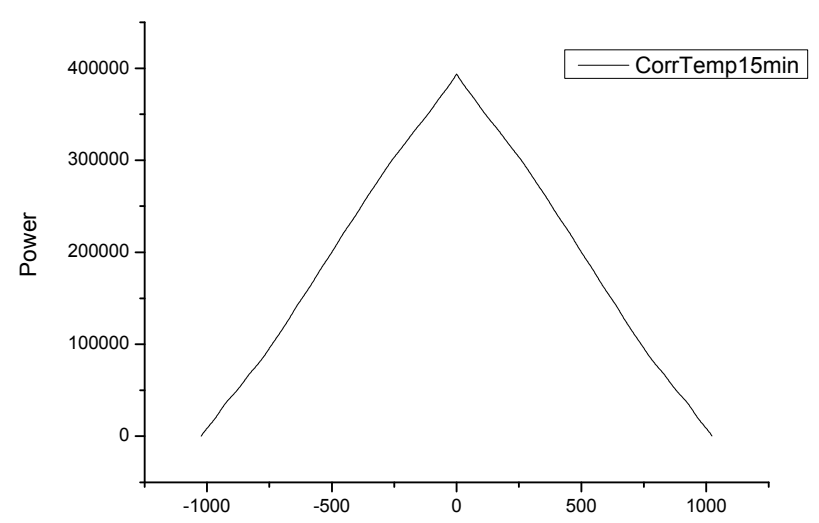

Figura 10-11: Autocorrelación de la temperatura para medidas quinceminutales

La medida de $\mathrm{pH}$ se muestra de manera similar, pero mucho menos correlada: obsérvese en el eje de ordenadas el valor del pico, con respecto al anterior. Esto significa que a pesar de ser una medida más constante, el salto al final del día 11 genera una incertidumbre en la medida que se manifiesta en la autocorrelación. 


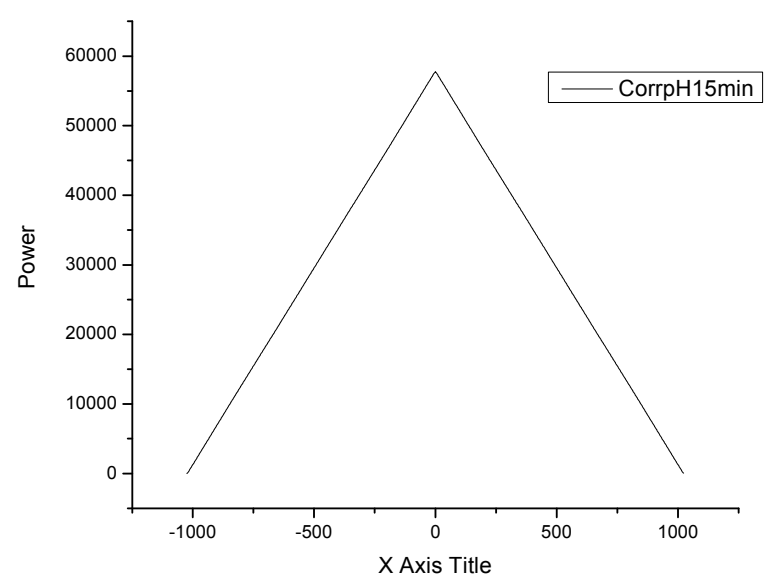

Figura 10-12: Autocorrelación del pH para medidas quinceminutales

En general se puede observar que ambas señales se encuentran bastante autocorreladas. Esto era predecible dado que se han tomado en este ensayo unos datos bastante constantes. 



\section{Anexo: Espectros de Fluorescencia obtenidos.}

A continuación se muestran los resultados obtenidos con el espectrómetro, con los tiempos de exposición y el número de medidas con las que se realiza el promedio para cada una de las corrientes indicadas en la leyenda.

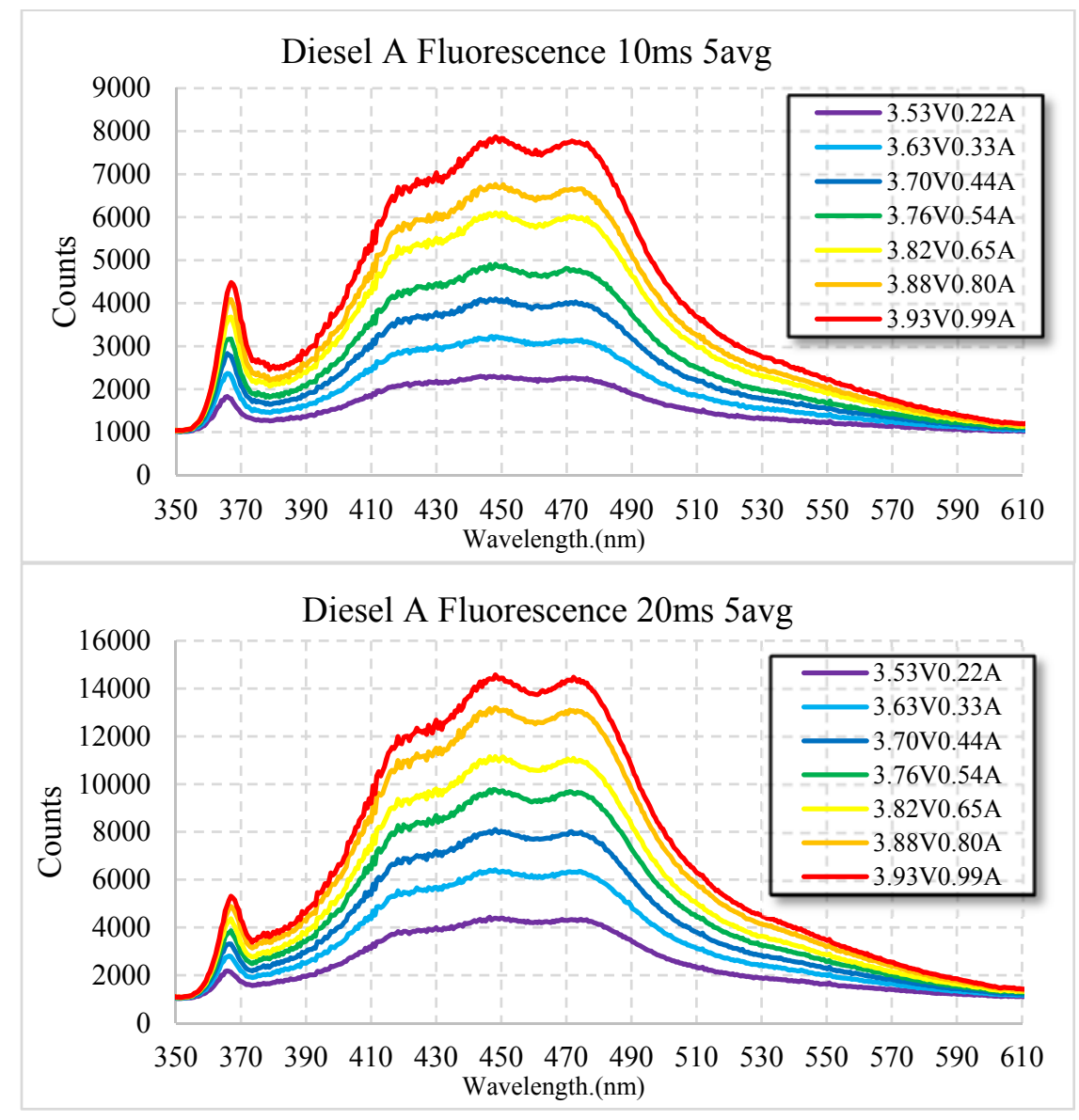



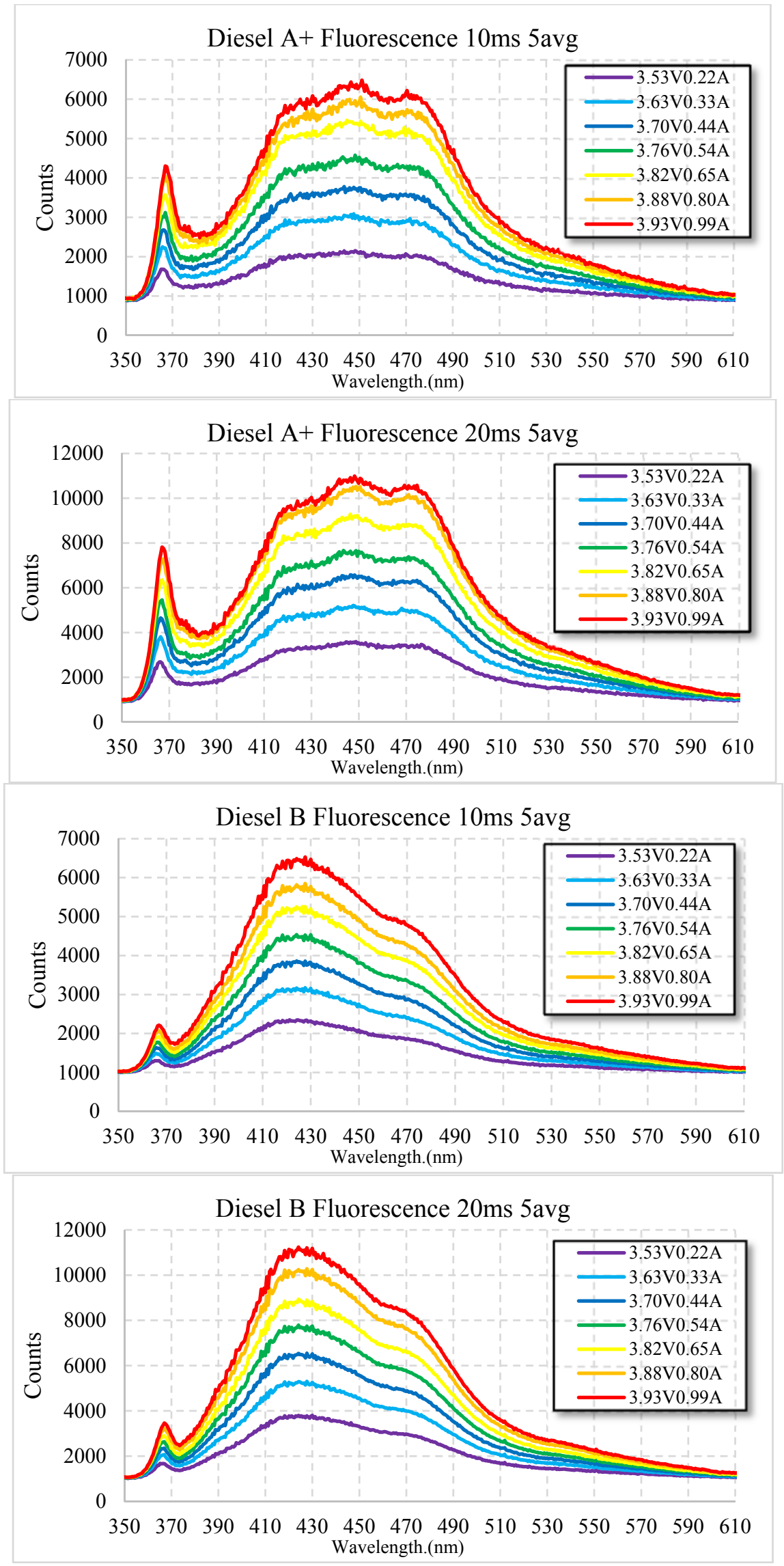

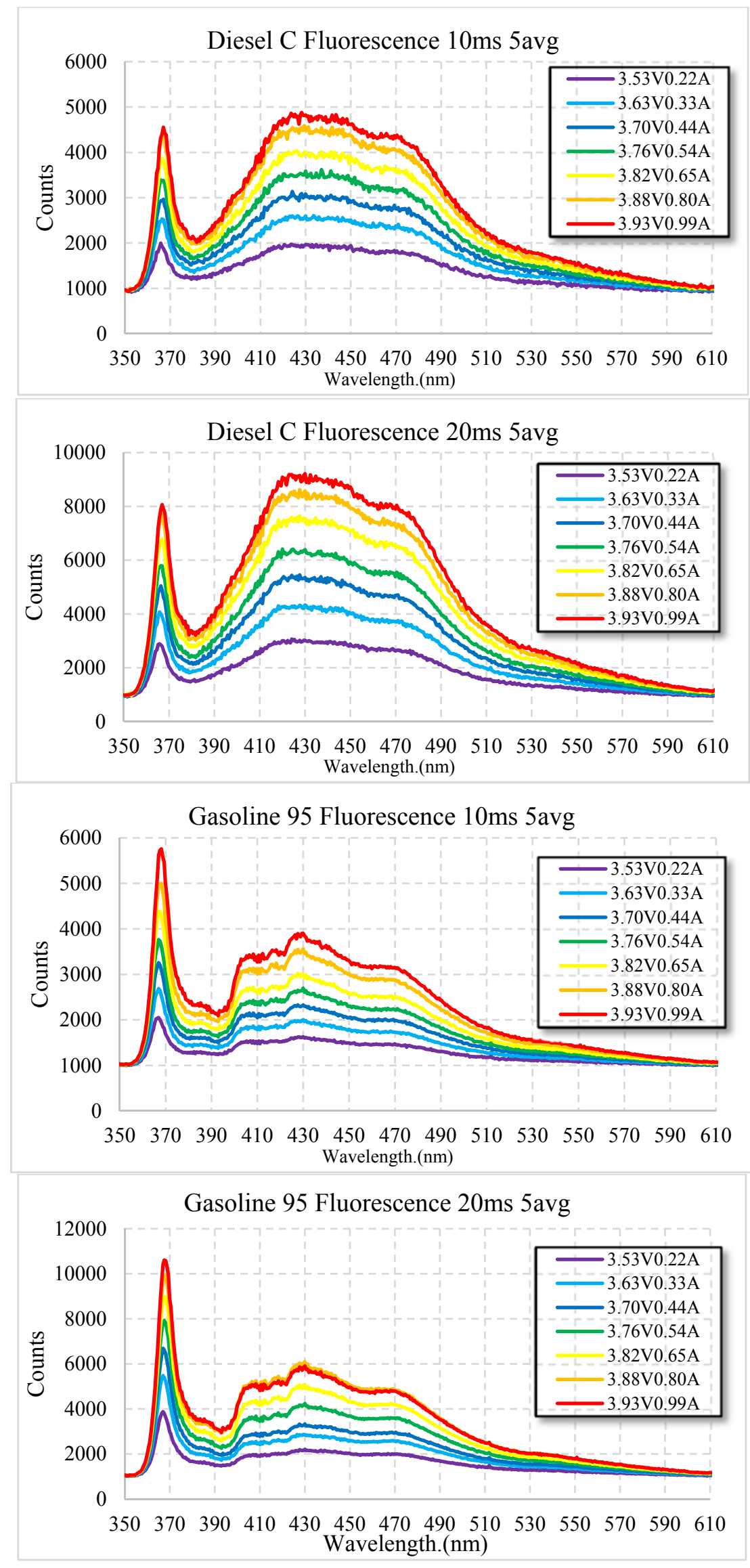

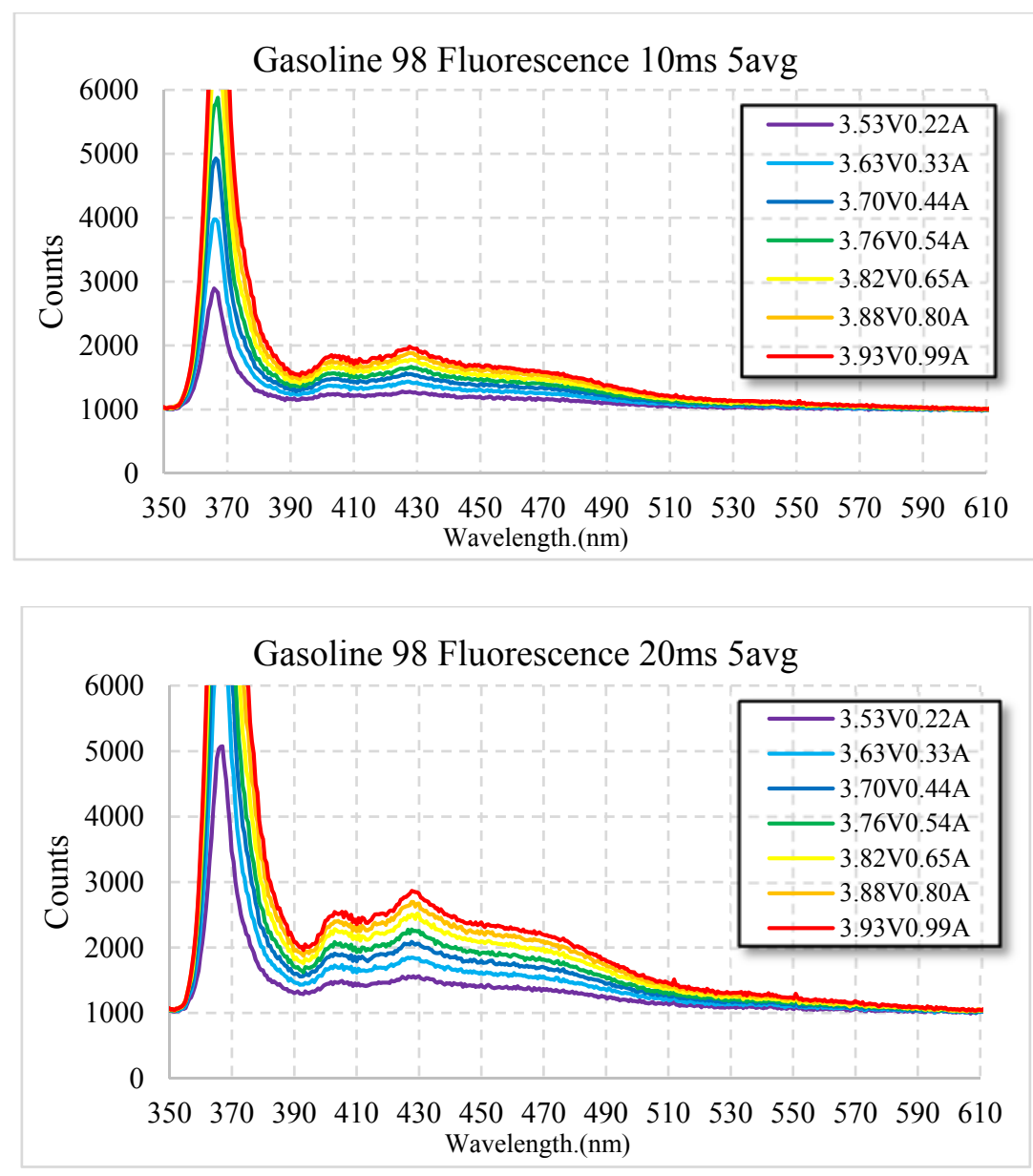


\section{Anexo: Ajuste de gaussianas obtenido con los programas Origin y Fytik}

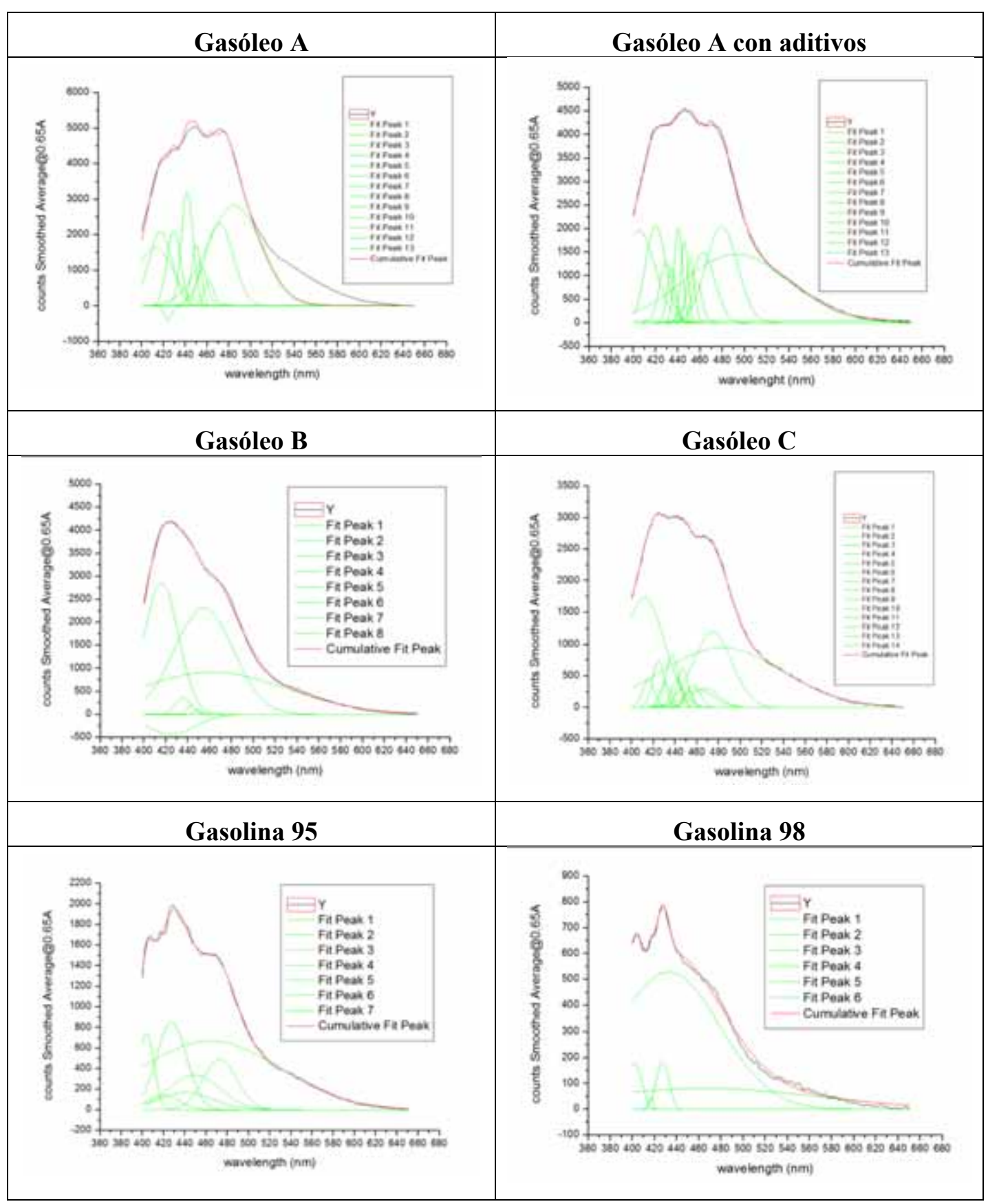




\section{Diésel A}

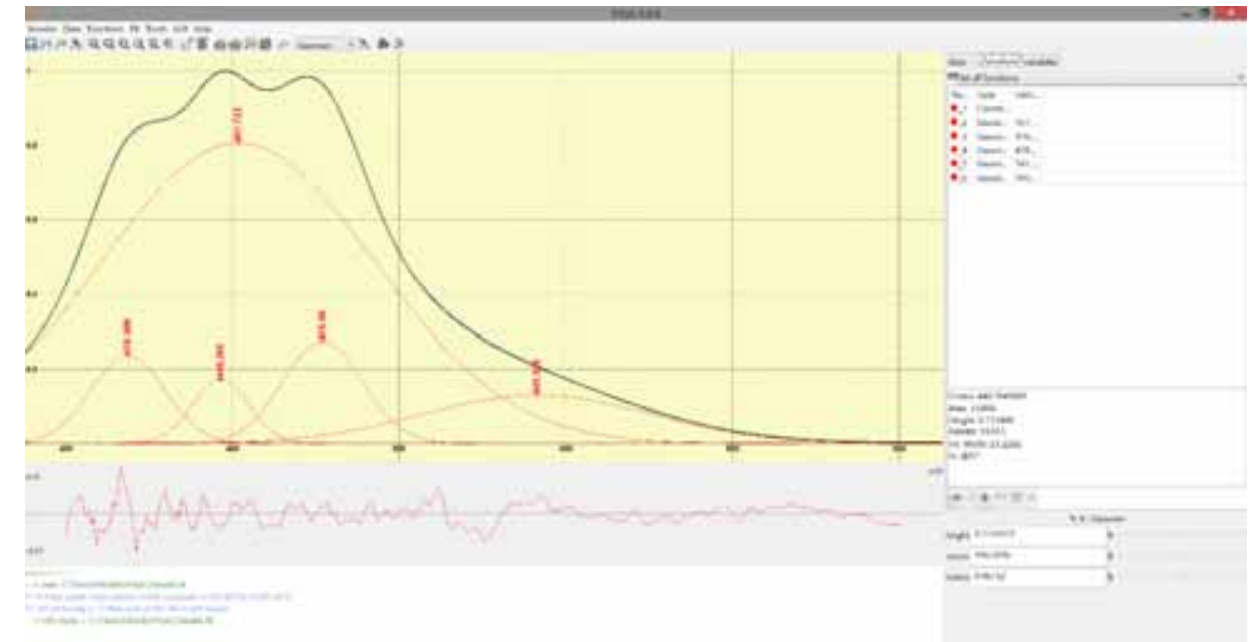

\section{Diésel A+}

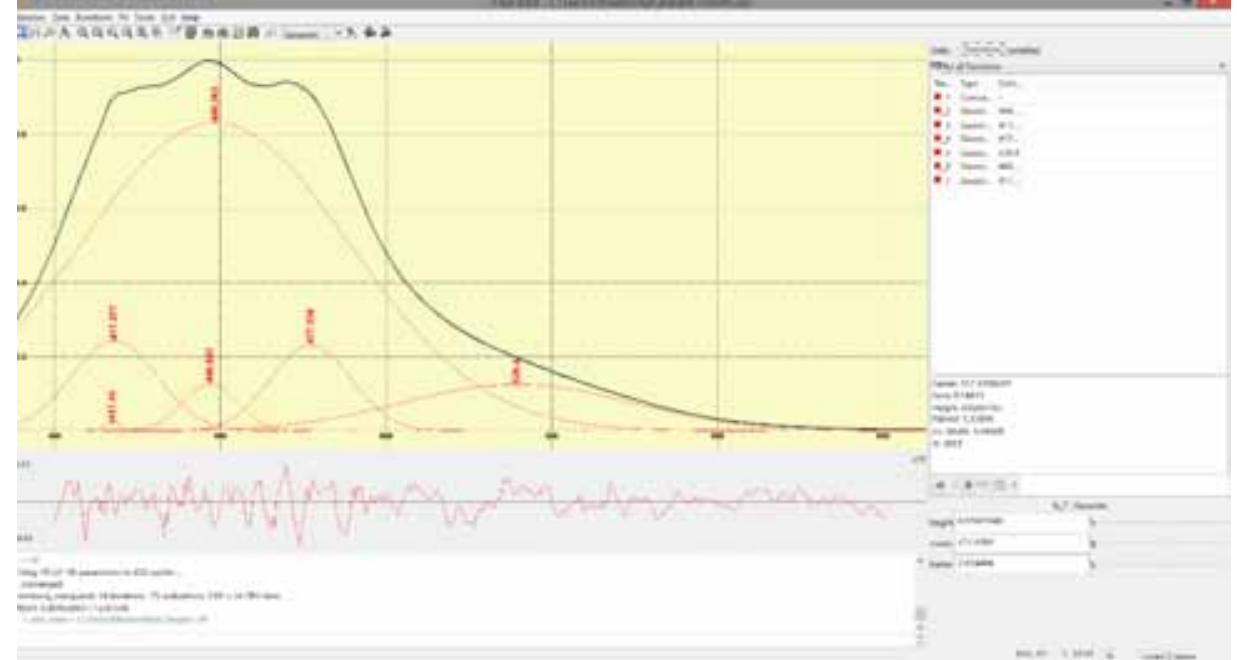

\section{Diésel B}

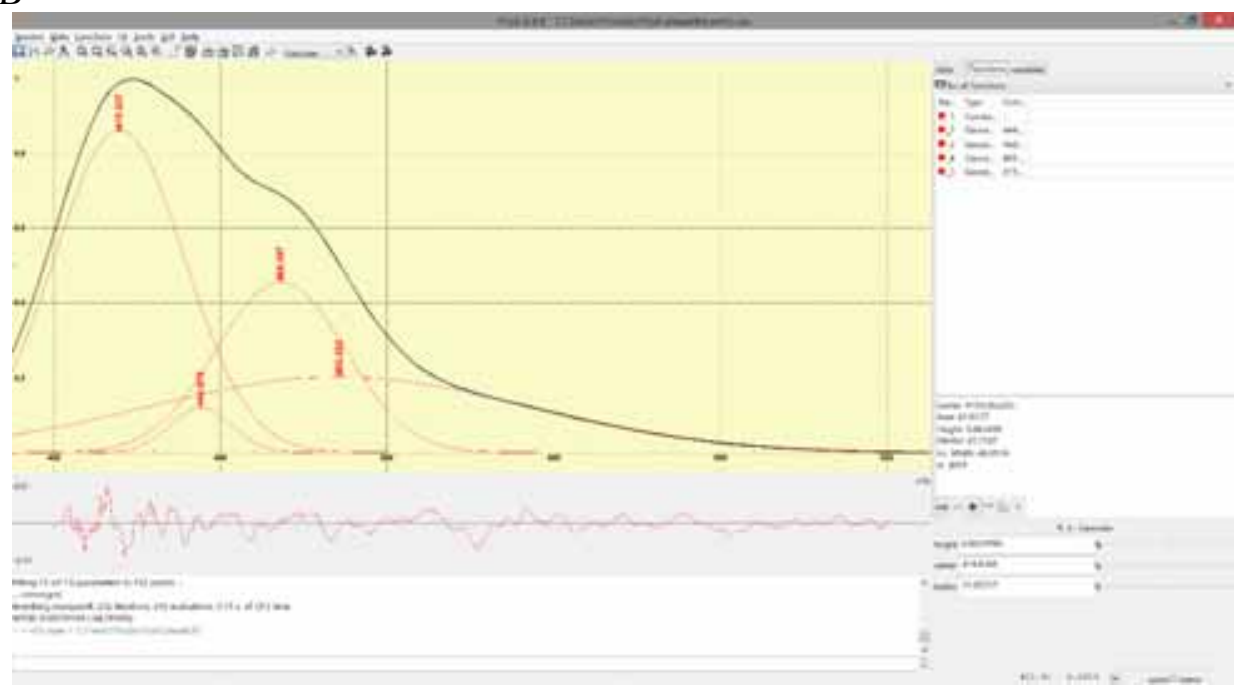

Diésel C 


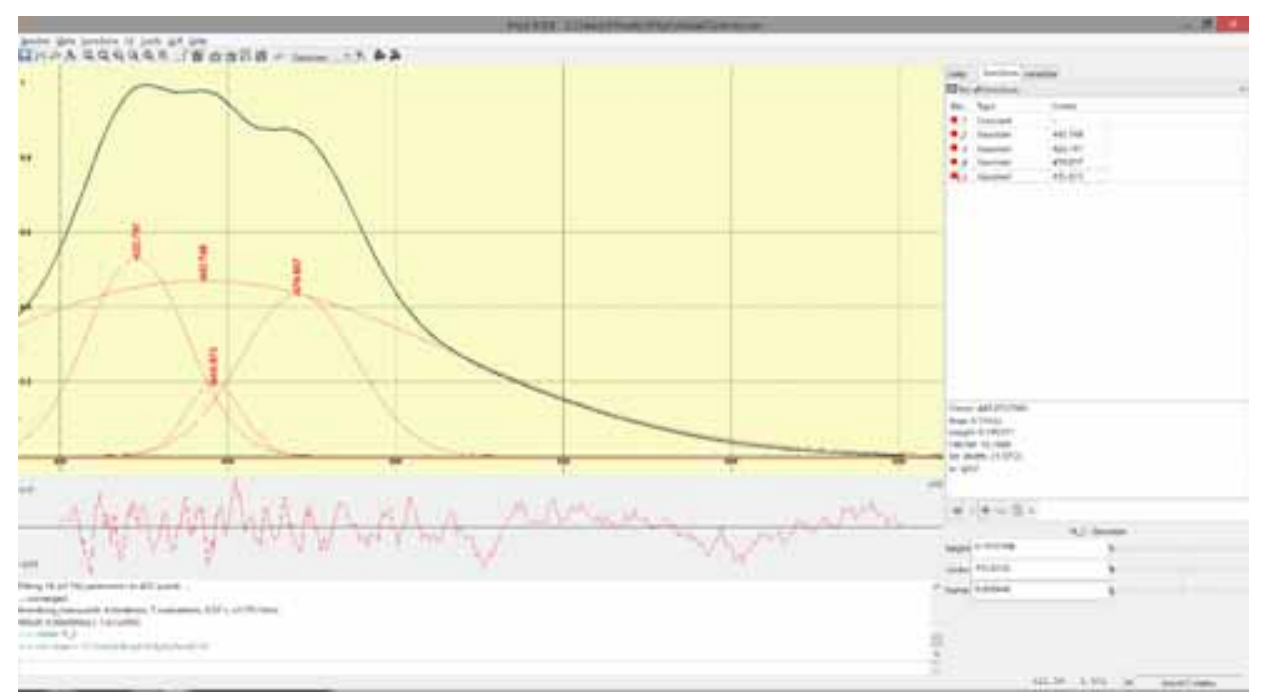

Gasolina 95

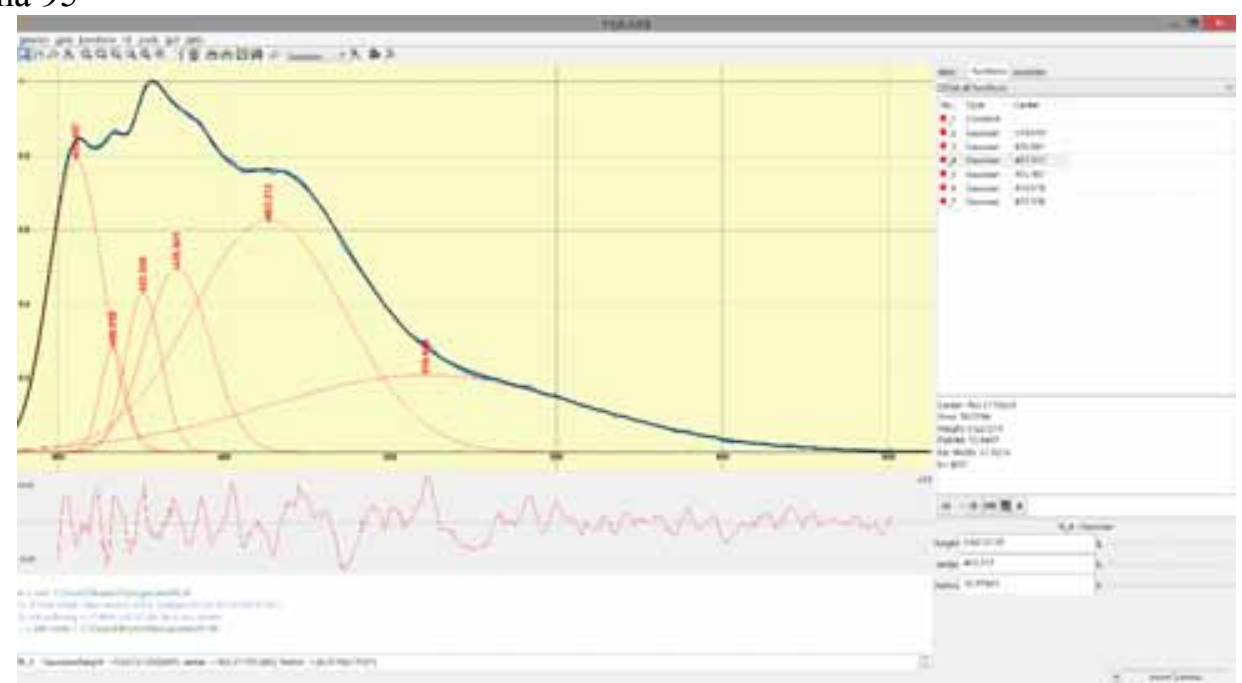

\section{Gasolina 98}

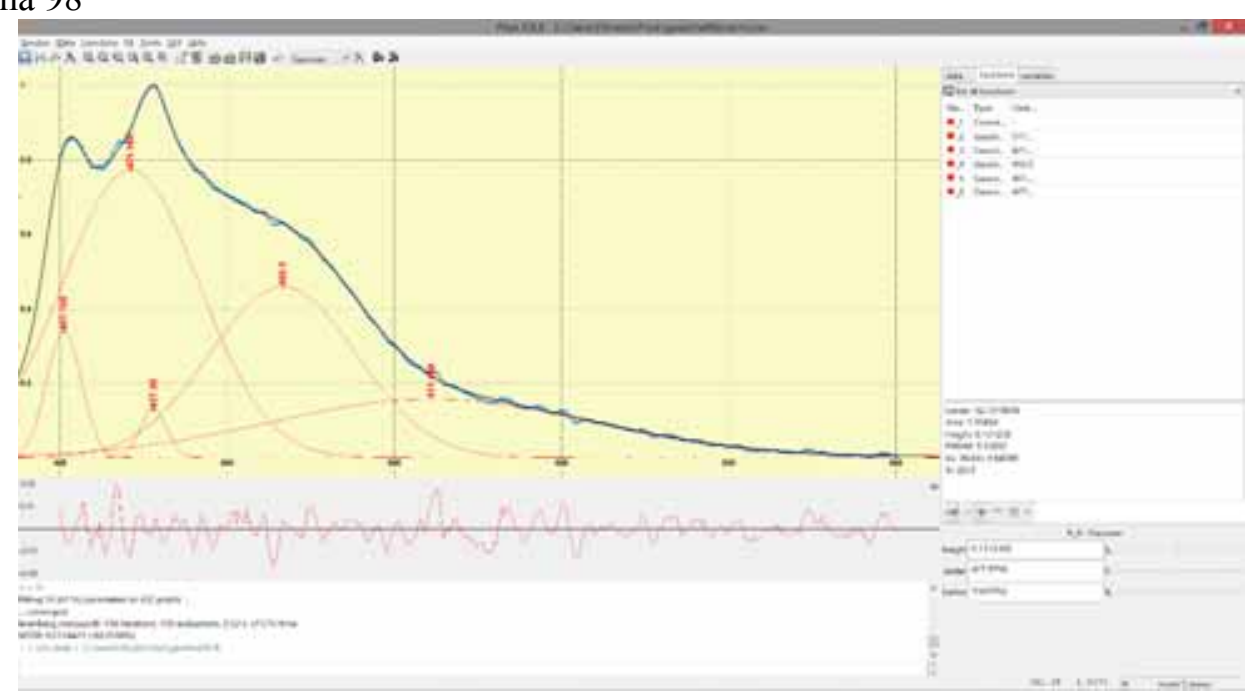

